
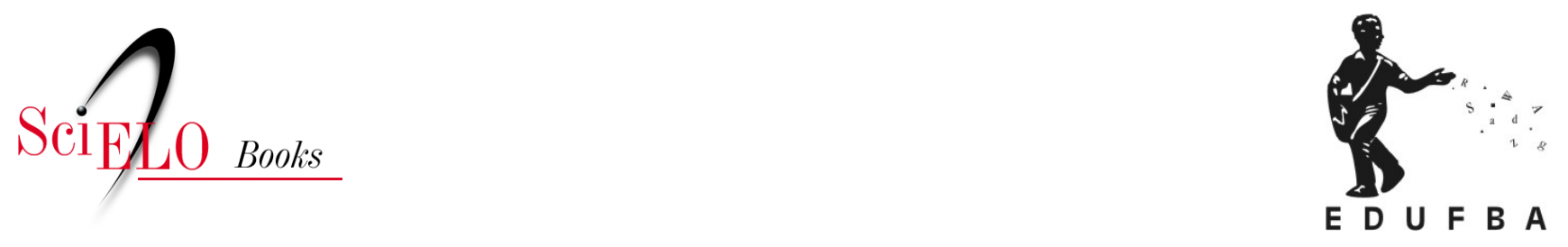

\title{
Observatório de análise política em saúde abordagens, objetos e investigações
}

\author{
Carmen Fontes Teixeira (org.)
}

TEIXEIRA, C.F., comp. Observatório de análise política em saúde: abordagens, objetos e investigações [online]. Salvador: EDUFBA, 2016, 510 p. ISBN 978-85-232-2021-1.

https://doi.org/10.7476/9788523220211.

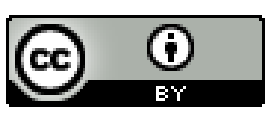

All the contents of this work, except where otherwise noted, is licensed under a Creative Commons Attribution 4.0 $\underline{\text { International license. }}$

Todo o conteúdo deste trabalho, exceto quando houver ressalva, é publicado sob a licença Creative Commons Atribição $\underline{4.0}$. 


\section{OBSERVATÓRIO DE ANÁLISE POLIITICA EM SAÚDE}

abordagens, objetos e investigações 


\section{UNIVERSIDADE FEDERAL DA BAHIA}

REITOR

João Carlos Salles Pires da Silva

VICE-REITOR

Paulo Cesar Miguez de Oliveira

ASSESSOR DO REITOR

Paulo Costa Lima

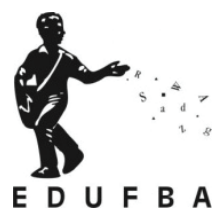

EDITORA DA UNIVERSIDADE FEDERAL DA BAHIA

DIRETORA

Flávia Goulart Mota Garcia Rosa

CONSELHO EDITORIAL

Alberto Brum Novaes

Angelo Szaniecki Perret Serpa

Caiuby Alves da Costa

Charbel Niño El Hani

Cleise Furtado Mendes

Dante Eustachio Lucchesi Ramacciotti

Evelina de Carvalho Sá Hoisel

José Teixeira Cavalcante Filho

Maria Vidal de Negreiros Camargo 
Carmen Fontes Teixeira ORGANIZADORA

\section{OBSERVATÓRIO DE ANÁLISE POLÍTICA EM SAÚDE abordagens, objetos e investigações}

Salvador

EDUFBA 
2016, Autores.

Direitos dessa edição cedidos à Edufba.

Feito o Depósito Legal.

Grafia atualizada conforme o Acordo Ortográfico da Língua Portuguesa de 1990, em vigor no Brasil desde 2009.

\section{CAPA E PROJETO GRÁFICO \\ Igor Almeida}

IMAGEM DA CAPA

Gilson Rabelo

REVISÃO

Paulo Bruno Ferreira da Silva

NORMALIZAÇÃO

Sandra Batista

Dados Internacionais de Catalogação-na-Publicação (CIP)

Elaboração: Fábio Andrade Gomes - CRB-5/1513

014 Observatório de análise política em saúde : abordagens, objetos e investigações / Carmen Fontes Teixeira, organização e apresentação. - Salvador : EDUFBA, 2016.

$510 \mathrm{p}$.

ISBN 978-85-232-1544-6

1. Política de saúde - Brasil. 2. Saúde pública - Brasil. I. Teixeira, Carmen Fontes, org. II. Título: Abordagens, objetos e investigações.

CDU: $614(81)$

\section{Editora afiliada à}

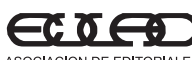

ASOCIAC UNIVERSITARIAS DE AMERICA
LATINAY YLL CARIBE
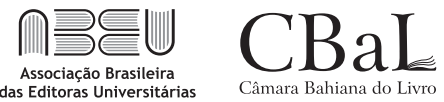

Editora da UFBA

Rua Barão de Jeremoabo

$\mathrm{s} / \mathrm{n}$ - Campus de Ondina

40170-115 - Salvador - Bahia

Tel.: +55 71 3283-6164

Fax: +55 71 3283-6160

www.edufba.ufba.br

edufba@ufba.br 


\section{SUMÁRIO}

\section{ApresentaçÃo}

09

ANÁlISE SÓCIO-HISTÓRICA DAS POLÍTICAS dE SAÚdE: ALGUMAS OQUESTÕES METODOLÓGICAS DA ABORDAGEM BOURDIEUSIANA

Ligia Maria Vieira-da-Silva, Sonia Cristina Lima Chaves, Monique Azevedo Esperidião, Sandra Garrido de Barros e Jamacy Costa Souza

Produção Científica SObRe Política de SAÚde No BRASIL (1988-2014): CONTRIBUição aO debate SObre a Reforma Sanitária Brasileira Jamilli Silva Santos e Carmen Fontes Teixeira

A SAÚde NA AGENDA POLÍTICA: ANÁlISE DAS CANDIDATURAS À PRESIDÊNCIA DA REPÚBLICA EM 2014 Liz Duque Magno e Jairnilson Silva Paim

SAÚde NO PODER LEGISLATIVO: OBJETO, INVESTIGAÇÃo E TENDÊNCIAS Ana Maria Costa, Raquel Abrantes Pêgo, Fabiana da Cunha Saddi, Daniel Adolpho D. Assis, Lidiane F. Goncalves e Alyne Alvarez Silva 
Problemas, objetos e inVestigações acerca da Judicialização da SAúde no Brasil: a contribuição do ObServatório de AnÁlise Política em Saúde Luis Eugênio Portela F. de Souza, Erik Asley F. Abade, Erick Soares Lisboa, Izamara Damasceno Catanheide, Josele R. Santa Bárbara e Kleize Araújo O. Souza

As ORGANizações do MOVimento Negro e O PROCESSO de IMPLEMENTAÇÃo dA Política Nacional de Saúde Integral da População Negra (2006-2014) Marcos Vinícius Ribeiro de Araújo e Carmen Fontes Teixeira

ATENÇÃo PRIMÁRIA À SAÚdE: REFLEXões SOBRE A POLÍTICA A PARTIR DA PRÁtICA dE PESOQUISA Maria Guadalupe Medina, Rosana Aquino, Ana Luiza Queiroz Vilasbôas, Cristiane Abdon Nunes e Nília Maria de Brito Lima Prado

ANÁ lise de políticas de SAÚde BUCAL NO BRASIL: ESTAdo dA ARTE E POSSÍVEIS CONTRIBUIÇõES TEÓRICO-METOdOLÓGICAS Sônia Cristina Lima Chaves, Paulo Frazão, Sandra Garrido de Barros, Denise Nogueira Cruz, Thais Regis Aranha Rossi e Ana Maria Freire de L. Almeida

A INFÂNCIA COMO OBJETO DE ANÁLISE POLÍTICA EM SAÚDE Monique Azevedo Esperidião, Carla Silva Soares, Carolina Rodrigues Araújo, Marta Caires de Souza, Raquel Malheiros, Andréa Montalvão e Laiana Behy Santos

Política nacional de CIÊNCIA, TECNOlogia E INOVAÇÃo em SAÚde no Brasil: IMPACTO NA AMPLIAÇÃO DO ACESSO E NA PRODUÇÃO DE TECNOLOGIAS VOLTADAS Às DEMANDAS do SISTEMA ÚNICO DE SAÚdE Maria Cristina de Camargo Fonseca, Erika Aragão, Jane Mary Guimarães, Bethania de Araújo Almeida e Sebastião Loureiro

MEDICAMENTO, ASSISTÊNCIA FARMACÊUTICA E VIGILÂNCIA SANITÁRIA NA ATENÇÃo INTEGRAL À SAÚdE Ediná Alves Costa, Gisélia Santana Souza, Patrícia Sodré Araújo, Tatiane de Oliveira Silva Alencar, Rafael Damasceno de Barros, Mariluce Karla Bonfim de Souza, Yara Oyram Ramos Lima 


\section{CONTORNOS DA ADMINISTRAÇÃo PÚBLICA E REPERCUSSÕES NO ÂMBITO}

DA GESTÃO HOSPITALAR: PROBLEMÁTICAS, OBJETOS E PERSPECTIVAS Thadeu Borges Souza Santos, Silvânia Sales de Oliveira, Silvana Lima Vieira e Isabela Cardoso de Matos Pinto

TRABALHO E EDUCAÇÃo NA SAÚdE: DIÁloGOS ENTRE A PROdUÇÃo CIENTÍFICA E AS POLÍTICAS NA SAÚdE

Catharina Leite Matos Soares, Ednir Assis Souza, Iracema Viterbo Silva, Liliana Santos, Soraya Almeida Belisário, Tania Cristina França da Silva, Vinício Oliveira da Silva e Isabela Cardoso de Matos Pinto

NARRATIVAS de PESOUUISAdORES SOBRE A MIDIATIZAÇÃo DAS POLÍTICAS DE SAÚdE NO BRASIL Maria Ligia Rangel-S, Gabriela Lamego, Antonio Marcos Pereira Brotas, Márcia Cristina Rocha Costa e Ana de Oliveira Barbosa 461

SOBRE OS AUTORES 


\section{APRESENTAÇÃO}

O Observatório de Análise Política em Saúde (OAPS) é o resultado e a expressão de um trabalho que começou em 2013, com a elaboração de um projeto voltado ao aprofundamento das análises políticas e desenvolvimento de análises de políticas públicas na área de saúde, apresentado e aprovado pelo Conselho Nacional de Desenvolvimento Científico e Tecnológico (CNPq), ${ }^{1}$ em 2014. A execução desse projeto contemplou a conformação de uma rede de pesquisadores vinculados a diversas instituições da área de saúde, responsáveis pela elaboração e execução de projetos de estudos e pesquisas articulados em 11 eixos temáticos, cujos produtos vêm sendo divulgados através da realização de oficinas de trabalho e principalmente através do site do OAPS, lançado oficialmente durante o $11^{\circ}$ Congresso da Associação Brasileira de Saúde Coletiva (Abrasco), em 2015. ${ }^{2}$

A criação do OAPS responde à necessidade de inserção dos pesquisadores da área de Política, Planejamento, Gestão e Avaliação em Saúde (PPGAS), nos espaços de debate público sobre temas

1 Chamada MCTI/CNPq/CT-Saúde/MS/SCTIE/Decit n. ${ }^{0}$ 41/2013. Rede Nacional de Pesquisas sobre Política de Saúde: Conhecimento para efetivação do Direito Universal à Saúde. Coordenação: prof. Jairnilson Silva Paim.

2VVerem: www.analisepoliticadesaúde@org.br. 
relevantes no campo da saúde, especialmente aqueles que têm se constituído em objeto de pesquisas científicas desenvolvidas pelos grupos que compõem os eixos temáticos. Nesse sentido, esses grupos reuniram e incorporaram a experiência anterior de pesquisa, em suas respectivas áreas e estão tratando de dar um salto de qualidade na organização do processo de produção de conhecimentos, com base nos princípios de cooperação, solidariedade, relevância social e qualidade dos produtos apresentados, quer seja sob a forma de dissertações, teses, artigos, capítulos e livros, quer seja sob a forma de textos para debate e contribuições aos posicionamentos políticos dos sujeitos, entidades e movimentos que compõem, atualmente, o arco de alianças em defesa da Reforma Sanitária Brasileira (RSB) e do Sistema Único de Saúde (SUS).

A implantação do OAPS evidencia o reconhecimento de que é necessário e urgente inovar as formas de produção e divulgação do conhecimento científico, de modo a acelerar o processo de "sensocomunização", isto é, de incorporação desses conhecimentos às práticas institucionais, sociais e políticas de um modo geral. $\mathrm{O}$ site do OAPS vem se configurando, portanto, como uma plataforma que reproduz e multiplica a difusão de análises críticas e posicionamentos políticos de pesquisadores da área de PPGAS e também de outras áreas, a exemplo das Ciências Sociais e Humanas, que contribuem para que a comunidade científica da Saúde Coletiva e da saúde em geral se aproprie de informações e conhecimentos que permitam a superação do senso comum que muitas vezes permeia o debate político no campo da saúde.

Além do funcionamento regular do site do OAPS, o coletivo de pesquisadores entende que é necessário registrar, sob a forma de publicações em artigos e livros, os produtos das pesquisas realizadas, de acordo com a tradição que ainda prevalece no âmbito da comunidade científica em geral e na Saúde Coletiva, em particular. Nesse sentido, o OAPS apresenta, nesta coletânea, parte do resultado do trabalho desenvolvido, até o momento, pelos pesquisadores dos diversos eixos temáticos, incluindo reflexões acerca de questões teórico-me- 
todológicas da pesquisa na área de PPGAS, bem como resultados de estudos e pesquisas já concluídas ou em andamento no âmbito dos diversos eixos temáticos, tendo em comum a preocupação com subsidiar o debate em torno dos problemas que vem sendo enfrentados no processo de formulação e implementação de políticas, bem como contribuir para a continuidade e aperfeiçoamento da RSB.

Trata-se, portanto, de um esforço coletivo, que se revela na multiplicidade de autores responsáveis pela elaboração de cada um dos capítulos, em sua maioria fruto do diálogo realizado entre orientadores e alunos de pós-graduação durante o desenvolvimento de suas dissertações de mestrado ou teses de doutorado, diálogos esses que extrapolaram, em grande medida, o colóquio singular entre orientador-aluno e reverberaram nas reflexões e debates em sessões temáticas conduzidas no âmbito do OAPS.

$\mathrm{O}$ primeiro capítulo evidencia, magistralmente, esse modus operandi, na medida em que traz a reflexão de um coletivo de pesquisadores liderados pela professora Ligia Maria Vieira da Silva, em torno de questões teórico-metodológicas suscitadas pela adoção da abordagem bourdiesiana na análise de políticas de saúde, problematizando noções e conceitos que vêm sendo utilizados nas pesquisas realizadas pelo grupo há cerca de uma década, quais sejam os conceitos de espaço social, campo, habitus, illusio e agentes, oriundos da sociologia reflexiva de Pierre Bourdieu, empregados na construção de diversos objetos de estudo, a exemplo da política de controle da aids, da política de alimentação do trabalhador ou da constituição do "espaço social da Saúde Coletiva”.

O capítulo 2 apresenta o mapeamento da produção científica sobre Política de Saúde, com base em um amplo levantamento dos artigos indexados na base Scientific Electronic Library Online (Scielo), no período de 1988 a 2014, apresentando uma tipologia dos estudos que permite a identificação das tendências que vêm se configurando nessa área, principalmente no que diz respeito às temáticas abordadas. Além disso, analisa o conteúdo os trabalhos que tomam como objeto o processo de RSB, identificando as perspectivas adotadas pelos autores, tanto em termos teóricos quanto políticos. 
Os capítulos seguintes trazem diferentes visões acerca do processo político em saúde, no âmbito dos poderes da República no momento atual. O capítulo elaborado por Liz Magno e Jairnilson Paim traz uma análise das propostas para a saúde contidas nos programas das candidaturas majoritárias à presidência da República, nas eleições de 2014, à luz das demandas apresentadas pelos movimentos sociais nas Jornadas de Junho de 2013, e das propostas que compõem a agenda estratégica das entidades que apostam na RSB.

Em seguida, Ana Costa e colaboradores apresentam a análise do debate político sobre saúde no âmbito do Poder Legislativo ao nível federal, objeto das investigações que vem sendo realizadas pelo grupo, sediado em Brasília. Nessa perspectiva, o capítulo delimita o objeto e apresenta uma revisão bibliográfica sobre o tema, avançando na análise da composição atual do Congresso nacional e suas implicações no debate em torno de temas polêmicos na área de saúde, como é o caso do aborto.

O capítulo de autoria de Luis Eugenio Souza e demais colabo12 radores do eixo temático "Acompanhamento das decisões judiciais relativas à saúde”, apresenta os objetos e métodos que vêm sendo utilizados na análise de processos de "judicialização" da saúde, agregando resultados de estudos concluídos que apontam as implicações políticas do debate sobre o tema.

Inaugurando a sequência de estudos que abordam políticas específicas, o capítulo elaborado por Marcos Vinicius Ribeiro e Carmen Teixeira analisa a participação das organizações do Movimento Negro no processo de implementação da Política de Saúde Integral da População Negra no período 2006-2014, problematizando as concepções e práticas dessas organizações em relação ao movimento pela RSB.

O capítulo elaborado sob a coordenação de Maria Guadalupe Medina traz uma sistematização dos problemas e objetos de investigação dos pesquisadores envolvidos no eixo temático "Atenção primária e promoção da Saúde", tendo como ponto de partida a identificação das diversas concepções sobre atenção primária à saúde presentes na literatura internacional. 
O capítulo seguinte, da autoria dos pesquisadores do eixo temático dedicado às políticas de saúde bucal, sob coordenação de Sônia Chaves, traz uma revisão do estado da arte nessa área, apresenta os estudos que vêm sendo desenvolvidos pelos pesquisadores do eixo e discute as perspectivas teórico-metodológicas que vêm sendo utilizadas para a compreensão dos processos de formulação e implementação dessas políticas.

No capítulo que segue, Monique Esperidião e demais pesquisadores do eixo temático "Políticas de saúde voltadas para a infância", analisam a emergência dessa problemática como objeto de políticas públicas e recuperam a trajetória das políticas desenvolvidas pelo Estado brasileiro em uma perspectiva histórica, que cobre o período compreendido entre a década de 1940 e os dias atuais, apresentando, em seguida, as reflexões do grupo sobre o conceito de infância, o estado da arte nessa área e os projetos que vêm sendo realizados.

O capítulo seguinte, por sua vez, traz a reflexão do grupo de pesquisadores que tem se debruçado sobre as Políticas de Ciência, Tecnologia e Inovação em Saúde, sob a coordenação de Erika Aragão e Sebastião Loureiro, discutindo, especificamente, as estratégias para a ampliação do acesso e da capacidade interna de produção de medicamentos de interesse para o SUS. A problemática dos medicamentos também é abordada no capítulo seguinte, de autoria de Ediná Costa e demais pesquisadores do eixo temático sob sua coordenação, privilegiando a reflexão sobre a assistência farmacêutica na perspectiva da vigilância sanitária.

Em seguida, o capítulo elaborado por Thadeu Borges Souza Santos e demais pesquisadores do eixo temático "Modelos de gestão hospitalar no SUS” analisa os contornos da administração pública brasileira e suas repercussões na gestão dos hospitais, tendo como ponto de partida a recuperação de uma "linha do tempo" que situa as principais mudanças ocorridas nos últimos 50 anos, enfatizando o debate recente com base na revisão da literatura latino-americana sobre o tema. 
O capítulo seguinte, elaborado por um coletivo de pesquisadores de diversas instituições que se articulam no eixo temático “Trabalho e educação na saúde”, sob coordenação de Isabela Cardoso Pinto, propõe um diálogo entre a produção científica da área e a análise das políticas governamentais no setor. Revisa, portanto, a produção nacional sobre diversos temas correlatos nessa área, e discute as lacunas existentes e os desafios para o desenvolvimento dos estudos e pesquisas no âmbito do OAPS.

Encerrando esta coletânea, o capítulo elaborado por Maria Ligia Rangel-S, Ana Oliveira e demais pesquisadores do grupo de estudos sobre Comunicação e Saúde, apresenta uma reflexão sobre a midiatização das políticas de saúde no Brasil, com base na análise de pesquisas indexadas na Biblioteca Virtual de Saúde (BVS), publicadas no período de 1995 a 2015.

Como se pode perceber, esta coletânea tem como característica fundamental a diversidade de temáticas e de abordagens aos temas que se constituíram objetos de investigação dos pesquisadores vin14 culados ao OAPS. Com a publicação desses trabalhos, esperamos contribuir para a ampliação e aprofundamento do debate acerca das alternativas teóricas e metodológicas de análise política e de análise de políticas de saúde, de modo a subsidiar, em uma conjuntura tão complexa e difícil como a que vivemos atualmente, a ação política militante dos sujeitos e dos movimentos sociais interessados na defesa dos princípios e valores que norteiam o processo de RSB.

Carmen Teixeira Janeiro de 2016. 
Ligia Maria Vieira-da-Silva, Sonia Cristina Lima Chaves, Monique Azevedo Esperidião, Sandra Garrido de Barros e Jamacy Costa Souza

\section{ANÁLISE SÓCIO-HISTÓRICA DAS POLÍTICAS DE SAÚDE algumas questões metodológicas da abordagem bourdieusiana}

\section{Introdução}

Qual a importância dos estudos sócio-históricos para a análise contemporânea das políticas de saúde? Sobretudo quando confrontados com demandas relacionadas com o monitoramento e acompanhamento de políticas, seja no curso de sua implementação, seja num horizonte de tempo considerado como atual ${ }^{1}$ Em primeiro lugar, a história serve ao pesquisador e ao gestor como proteção para evitar os problemas éticos e operacionais relacionados com a reinvenção da roda. Éticos em decorrência das implicações decorrentes

O momento atual, no caso, é o período compreendido entre o início do projeto (2014) e sua conclusão, prevista para 2018. A própria formulação do que seria o momento atual já encerra um passado. 0 projeto iniciou-se em 2014, que já é um passado recente, e deverá encerrar-se em 2018, no momento um futuro que progressivamente vai convertendo-se em passado. 
da atribuição indevida de originalidade e operacionais porque políticas e programas de saúde já testados, em outros momentos históricos, trazem consigo lições relacionadas com as razões do seu sucesso ou fracasso.

As características do processo de gestão, que requerem frequentemente a tomada de decisões urgentes, constituem-se em ambiente propício para a mobilização do senso comum ou do senso comum douto, o que cria no gestor a ilusão da inovação. Assim, a introdução do Programa de Saúde da Família (PSF), em 1994, pode ser considerada como uma inovação decorrente de iniciativas específicas daquele momento histórico. Contudo, uma análise mais cuidadosa pode revelar que as principais ideias já estavam contidas nos programas de medicina familiar dos anos 1950. Dessa forma, a construção de uma problemática de pesquisa já passa a interrogar quais as especificidades de cada momento histórico e encontrar pistas na comparação, na qual semelhanças e diferenças podem auxiliar na explicação dos fenômenos.

Uma segunda razão está relacionada com as indicações que a análise histórica fornece para o desenho de cenários futuros. Não apenas a interpretação das séries temporais que indicam tendências, mas também os exemplos das possibilidades e das impossibilidades ligadas a determinadas conjunturas históricas. Essas questões têm sido trazidas por historiadores e pesquisadores de outras disciplinas. A resposta à pergunta "A História importa?" tem sido afirmativa para diversos autores, tanto no que diz respeito à análise das políticas públicas em geral (HOCHMAN, 2013), como para as políticas de saúde em particular. (STEVENS; ROSENBERG; BURNS, 2006)

Contudo, é o sociólogo francês Pierre Bourdieu um daqueles que fundamentam de forma mais radical a importância da história para o conhecimento do mundo social, inicialmente destacando a história como recurso poderoso para a ruptura com o senso comum, operação necessária para a construção do conhecimento científico (BOURDIEU; CHAMBOREDON; PASSERON, 1999), e posteriormente como démarche necessária para a análise dos diversos cam- 
pos sociais. (BOURDIEU, 1996a, 2012) Para esse autor, o estudo sobre a gênese, que não se confunde com a busca das origens, permite escapar da ilusão do nominal. Em outras palavras, uma instituição ou mesmo uma política cujo nome se mantém ao longo da história pode corresponder a fenômenos distintos. A compreensão do que seria saúde da família dos anos 1950 pode ser completamente diferente do significado do programa que tem esse mesmo nome nos anos 1990. Da mesma forma, o Ministério da Saúde (MS) dos anos 1970 guarda identidades e diferenças com o MS dos anos 2000. O inverso também pode ocorrer: muda-se o nome e mantêm-se a mesma estrutura. Como exemplo, durante o governo Sarney, o Programa de Nutrição e Saúde (PNS), criado em 1975, passou a chamar-se Programa de Suplementação Alimentar (PSA), sem que diferenças significativas houvesse entre eles. (SOUZA, 1999)

Em segundo lugar, a análise histórica permite apreender a lógica das rupturas, das transformações, bem como as continuidades, as idas e vindas dos processos históricos. ${ }^{2}$ Uma das mais importantes contribuições dos estudos históricos apontada por aquele autor está na possibilidade de evitar o fenômeno, por ele denominado, de amnésia da gênese. No momento da emergência dos processos sociais é que os conflitos e as ambiguidades se expressam de forma explícita. Posteriormente, em decorrência das lutas e do desenvolvimento dos espaços sociais, determinados fenômenos, uma vez constituídos, passam despercebidos. (BOURDIEU, 2012) O estudo sobre a gênese do Programa de Alimentação do Trabalhador (PAT) revelouse como um caso exemplar desse efeito. Assim, o que no princípio era declaradamente um Programa de Incentivo Fiscal à Alimentação do Trabalhador (Pifat), sustentado, portanto, em uma Lei Tributária (BRASIL, 1976), passou a ser paulatinamente tratado apenas como um programa de alimentação do trabalhador, tanto nos artigos cientí-

Estudo sócio-histórico sobre a gênese da Saúde Coletiva, permitiu apreender a lógica da ruptura que possibilitou a criação da Saúde Coletiva brasileira. (VIEIRA-DA-SILVA, 2015; VIEIRA-DA-SILVA; PINELL, 2014) 
ficos como nos documentos oficiais, ainda que a lei continue em vigor. O resultado é a ocultação do que ele foi desde o seu início: preponderantemente uma política fiscal destinada à desoneração do custo de produção, mediante subsídio tributário às empresas que fornecessem alimentação aos trabalhadores do mercado formal, desde que regularmente inscritas junto ao Ministério do Trabalho (MT). (SOUZA, 2013) Nesse particular, a alimentação não é um fim da política, mas um meio a justificar uma renúncia fiscal.

Ainda como desdobramento dessa abordagem, está a possibilidade de apreender os componentes das estruturas e processos sociais que permitiram que a política tivesse sido formulada. A análise do espaço de possibilidades ao interior do qual os agentes realizaram suas trajetórias, ao mesmo tempo construindo o espaço e sendo por ele estruturados e limitados, permite identificar os possíveis realizados e os possíveis mortos. Ou seja, a análise da gênese de uma política propicia verificar as condições de possibilidade da sua emergência, em um dado momento histórico, e assim apreender os possíveis que são abertos com o evento investigado. (BOURDIEU, 2012) Alguns desses possíveis se realizam, outros não. Assim, apreender os possíveis mortos e as razões para o fechamento do espaço dos possíveis é um instrumento para os formuladores de políticas e gestores, particularmente aqueles comprometidos com as mudanças sociais.

O objetivo do presente capítulo é analisar algumas das questões teórico-metodológicas relevantes para o desenvolvimento de estudos sócio-históricos apoiados na teoria das práticas sociais de Bourdieu. Orientado também pela epistemologia desse mesmo autor, será apoiado em investigações concretas, já publicadas, procurando evitar, na medida do possível, a tentação das sínteses teóricas dissociadas do trabalho empírico.

\section{A construção do objeto}

Bourdieu, Chamboredon e Passeron (1999), apoiados na epistemologia de Bachelard (1996), ressaltam que o problema de inves- 
tigação é o resultado de uma construção que implica em rupturas com o senso comum. No caso da análise das políticas de saúde, o senso comum e o senso comum douto se apresentam como obstáculos ao desenvolvimento de investigações originais. Isso porque, frequentemente, os problemas de saúde e da gestão são confundidos com os problemas de investigação. Assim, a magnitude de um problema de saúde, a exemplo da mortalidade por neoplasias, para o qual existem políticas de saúde, não é um problema de pesquisa por si só. Uma série de perguntas precedem a construção desse problema como de pesquisa original, como pesquisa avaliativa ou como análise de política. Quais os tipos de neoplasia mais frequentes? As políticas formuladas para o controle desses tipos de neoplasias são capazes teoricamente de reduzir a mortalidade? Se a resposta é afirmativa, qual a cobertura? Se a cobertura é ampla, a qualidade do cuidado é adequada? A resposta a essas perguntas fornece informações importantes para a gestão dos serviços de saúde auxiliando no aperfeiçoamento das intervenções, porém não esclarecem os processos e as razões pelas quais as políticas foram formuladas bem como as implicações daí decorrentes para a sua operacionalização e possíveis efeitos.

Um outro grupo de perguntas poderia ser feito derivado da imagem-objetivo da abordagem do ciclo das políticas, inspiradas pela teoria da ação racional, nas suas variadas vertentes. Assim, as indagações sobre como o problema foi formulado e por quem, como entrou na agenda governamental, e como foi implementado são perguntas que auxiliam a descrever alguns dos processos relacionados com a formulação das políticas. A despeito da variedade de vertentes dessas abordagens, bem como a incorporação de elementos contraditórios e processuais em algumas dessas proposições (PINTO; VIEIRA-DASILVA; BAPTISTA, 2013), essas perspectivas de análise também não conseguem explicar os porquês do surgimento de determinadas políticas, em certos momentos históricos. Por exemplo, podem não esclarecer porque o câncer foi considerado como um flagelo social na França, entre as duas guerras mundiais, no século XX, em um momento onde sua magnitude não era ainda superior àquela das doenças 
infecciosas. Essa indagação, formulada por Pinell (2011), requeria a realização de um estudo sócio-histórico. Diversos processos sociais concomitantes que iam da ação filantrópica de segmentos das classes dominantes - as viúvas - à constituição de uma especialidade médica - a cancerologia - ao lado das lutas ao interior do campo médico e científico francês, confluíram para a constituição de um espaço social de luta contra o câncer, que resultou na incorporação, pelo Estado, dessa questão como um problema relevante de saúde, naquele momento histórico, com ações voltadas para o seu controle.

De modo semelhante, a explicação sobre as razões do surgimento de uma política de controle para a aids, no final da década de 1980, no Brasil, mesmo diante da ausência de evidências sobre a sua magnitude e antes da descoberta de um tratamento efetivo, foi possível apoiada em análise histórica. (BARROS, 2013) O espaço aids constituiu-se historicamente como espaço de luta pela organização da resposta à epidemia e de intervenção sanitária. Estavam em disputa a autoridade de falar sobre o significado da doença, suas formas de prevenção e tratamento, e estratégias para o controle da epidemia. A sua composição envolvia indivíduos com inserções diferenciadas em vários campos sociais como médicos, gestores e militantes do movimento homossexual. As peculiaridades da resposta governamental, nesse caso, foram esclarecidas por estudo sobre sua sociogênese. No caso da aids, houve uma inversão no caminho usual de formulação de outras políticas de saúde no Brasil, onde inicialmente o MS elaborava uma política nacional, seguida e operacionalizada pelos estados. As primeiras iniciativas ocorreram em São Paulo, logo após a divulgação de casos de aids no país, em um momento onde o MS negava a necessidade de intervenção. São Paulo, no início dos anos 1980, durante o governo Montoro, possuía uma gestão com caráter democrático e modernizador; uma estrutura de serviços de saúde organizada desde a década de 1960, inclusive com a carreira de sanitarista; um movimento homossexual organizado e qualificado, com lideranças com elevado volume de capital econômico e social que demandaram uma resposta do Estado à epidemia 
que se instalava. Além disso, tinha à frente da Divisão Estadual de Dermatologia Sanitária, ao interior da qual já estava se organizando um Programa de Doenças Sexualmente Transmissíveis, um médico, sanitarista e ex-militante do movimento homossexual. (BARROS; VIEIRA-DA-SILVA, 2016)

Já a política nacional foi implantada posteriormente, a partir de 1985. Foram condições para a formulação de uma política específica para a aids: o processo de transição democrática; a chegada de sanitaristas a cargos de chefia no MS; a rápida evolução da epidemia; a existência de grupos de pesquisa em doenças infecciosas e parasitárias, com patologistas que se converteram em imunologistas; os avanços no campo médico sobre a doença e o estágio de desenvolvimento da pesquisa clínica e laboratorial; a organização por alguns estados de programas de aids; e a pressão exercida por movimentos sociais e imprensa. (BARROS, 2013)

A compreensão das razões históricas para a elaboração dessa política, bem como a análise das trajetórias dos agentes e das lutas comuns ao espaço aids e ao espaço da Saúde Coletiva, ${ }^{3}$ evidenciaram empiricamente a relação da política com o movimento da reforma sanitária e seus pressupostos. Seu surgimento em um momento de ascensão do movimento sanitário e ausência de terapia específica contribuíram para a priorização inicial da prevenção. Por outro lado, a dominância do campo médico e a constituição do Sistema Único de Saúde (SUS) contribuíram para uma articulação entre as medidas preventivas e a garantia do tratamento, componente necessário para a formulação de uma política baseada na integralidade das ações, reconhecida internacionalmente como exemplar. (BARROS, 2013)

Dessa forma, investigar a emergência de uma política de saúde corresponde não apenas a indagar sobre quem, quando, onde e como foi formulada determinada política, mas envolve também a

O estudo sobre a gênese sócio-histórica da Saúde Coletiva brasileira não reuniu evidências que permitissem caracterizá-la como campo consolidado, no sentido de Bourdieu, mas sim de um espaço social que possuía um projeto de tornar-se campo. (VIEIRA-DASILVA, 2015; VIEIRA-DA-SILVA; PINELL, 2014) 
busca dos porquês, da lógica da sua constituição. Essa apreensão requer a análise da estrutura e da dinâmica de um espaço de relações entre agentes sociais (profissionais de saúde, pesquisadores, usuários, gestores, entre outros) que compartilham interesses sobre o objeto da política. Assim, no caso do estudo sobre a gênese da política de controle da aids no Brasil, correspondeu a identificar quem se interessava pela aids e por quê, o que estava em disputa no espaço aids, e porque foi possível que os agentes envolvidos com a formulação da política desenvolvessem um programa orientado pela integralidade do cuidado e universalidade da assistência, nos anos 1990, no Brasil. (BARROS, 2013)

\section{Alguns conceitos centrais: espaço social, campo, habitus, illusio e agentes}

Preliminarmente, diante dos seus diferentes significados, é necessário explicitar o sentido aqui atribuído à política e à política de saúde. (PINTO; VIEIRA-DA-SILVA; BAPTISTA, 2014) Política será aqui compreendida como ação Estatal seguindo análise de Weber (1982) e, mais especificamente, no sentido que lhe é dado por Paim (2003), segundo o qual política de saúde corresponde à ação ou omissão do Estado diante de determinado problema de saúde.

Em segundo lugar, cabe uma explicação para o uso preferencial do conceito de espaço social para designar o microcosmo eventualmente constituído para a formulação de uma política de saúde. $\mathrm{Ou}$ seja: o que se quer dizer com espaço de relações em torno de determinada política? Um dos conceitos centrais na teoria das práticas de Bourdieu é o de campo, que foi progressivamente desenvolvido por aquele autor, apoiado em diversos estudos empíricos sobre universos sociais diferentes como a alta costura, o campo literário, o campo científico, o campo burocrático entre outros. (BOURDIEU, 1996a) Um campo seria um microcosmo relativamente autônomo, uma rede de relações entre agentes e instituições dotados de um habitus 
e de uma illusio comuns. Habitus ${ }^{4}$ aí usado no sentido de sistema de disposições estruturadas e estruturantes das práticas sociais e illusio como investimento e interesse nas questões em jogo no campo. (BOURDIEU, 1996a, 2009)

O vocábulo "campo" é empregado na língua portuguesa com inúmeras finalidades, ${ }^{5}$ como sinônimo de área, setor entre outros. Em Bourdieu (1996a, p. 28), todavia, seu uso como categoria teórica para explicar o mundo social envolve uma analogia com a da física, mais especificamente do chamado "meio newtoniano", cuja objetivação pode se dar, entre outros recursos, através do emprego da análise de correspondências, ${ }^{6}$ que, segundo este autor, corresponde a uma técnica estatística relacional, ou seja, capaz de apreender as relações entre os agentes e permitir a objetivação da sua estrutura. (BOURDIEU, 2006)

Para Bourdieu (2000, p. 41), “[...] um campo é um campo de forças e um campo de lutas para transformar essas relações de força”, sendo a sua estrutura o resultado das disputas ocorridas entre agentes que ocupam posições diferentes definidas pelo volume global de capital bem como pela sua composição. O campo é um espaço de constituição de habitus específicos, sendo uma das suas características, a sua autonomia relativa a outros campos. Autonomia para estabelecer suas regras próprias de consagração e exclusão de objetos e agentes. O estudo empírico de um campo requer a análise da sua sociogênese, a partir da qual poderão ser identificadas as questões que estão em jogo, em disputa, suas lógicas internas, sua arquitetura (polos dominantes e dominados e as oposições em cada polo), a construção de

Sobre os conceitos de "campo", habitus e illusio ver: Bourdieu (1996 a, 2009).

5 O Dicionário Houaiss da Língua Portuguesa apresenta 19 substantivos e 51 locuções. Disponível em: <http://houaiss.uol.com.br/busca?palavra=campo>.

6 Nesse modelo, "as variáveis ativas são aquelas que servem para construir o espaço, ou seja, para definir a distância entre indivíduos e determinar os eixos. As variáveis suplementares intervem a posteriori para caracterizar os eixos". (LEBARON, 2015, p. 48, tradução nossa) 
sua autonomia relativa ${ }^{7}$ e seus nomotetas - os criadores de normas. A noção de subespaços auxilia na compreensão de princípios de diferenciação existentes na conformação dos campos e dos espaços sociais, correspondendo ao surgimento de lógicas específicas, como é o caso do espaço da Saúde Coletiva que se encontra permeado pelos subespaços burocrático, político e científico.

Cabe destacar ainda que, se todo campo social é também um espaço social, ocorre que nem todo espaço social é dotado de autonomia. Todavia, essa noção de espaço tem contribuído na análise de dinâmicas sociais importantes - inclusive aquelas que resultam em políticas -, mas que não chegam a lograr um grau de autonomia ao ponto de se constituir, no sentido bourdieusiano, em um campo específico. Sua viabilização e características se dão frequentemente como resultante do encontro entre agentes situados em um ou mais campos, portanto dotados de habitus e disposições diferentes, mas que possuem em comum o interesse pela política em tela. A trajetória dos agentes envolvidos lhes confere as condições materiais e 24 simbólicas que explicam os seus pontos de vista, a partir do conjunto de seus capitais ${ }^{8}$ que tanto influenciam nos princípios de diferenciação, como têm seu valor significado e resignificado de acordo com as especificidades de cada campo. ${ }^{9}$ (BOURDIEU, 2006)

Nos espaços novos criados na história da construção de um problema de saúde como problema social e sua entrada na agenda do Estado como política de saúde (isto é: a dinâmica social que leva um problema particular a se constituir em um problema do Estado,

7 Em As regras da arte: gênese e estrutura do campo literário, Bourdieu (1996a) identifica a construção desse campo na França justamente com a conquista de sua autonomia em relação ao campo econômico.

8 Capitais são, para Bourdieu (1984a, p. 3), "[...] poderes que definem as possibilidades de obtenção de benefícios em um campo determinado".

9 Bourdieu (2006, p. 107) explica que, "[...] sendo o capital uma relação social, ou seja, uma energia social que existe e produz seus efeitos apenas no campo em que ela se produz e se reproduz, cada uma das propriedades associadas à classe recebe seu valor e sua eficácia das leis específicas de cada campo". 
ao ponto de desencadear uma política), os capitais adquiridos por cada agente vão funcionar segundo a hierarquia dos campos que estão envolvidos com uma dominância do capital burocrático, tendo em vista que as decisões finais são formalizadas nesse nível, mas também do capital político. $\mathrm{O}$ fato de David Boianovsky ser um médico, especialista em nutrição, professor universitário e pesquisador foi importante para sua participação no Pifat/PAT. Todavia, todo seu capital técnico e social precisou ser convertido em capital burocrático, mediado pelo alto capital político do MT à época, para que ele pudesse coordenar o programa. Ainda assim, como era um "novato" no campo burocrático, terminou prevalecendo no desenho da política os pontos de vista de outros agentes com maior tempo de pertencimento ou articulação com o campo burocrático. E isso auxilia a compreender porque o Pifat/PAT foi de um jeito e não de outro. (SOUZA, 2013)

O fato de José Sarney ter apresentado o projeto de lei sobre a aids, ${ }^{10} \mathrm{em}$ uma primeira aproximação, poderia autorizar a atribuição, apenas a esse político, do mérito pela iniciativa, por razões quiçá de ordem pessoal, como especulado por alguns informantes. (NUNN, 2009) No entanto, a análise histórica mostrou a complexa teia de inter-relações ocorridas no espaço aids entre o sociólogo Betinho, o médico sanitarista e deputado federal pelo Rio de Janeiro, Sérgio Arouca, e o ex-ministro da saúde e, na época, chefe de gabinete do senador José Sarney, Carlos Corrêa de Menezes Sant'anna, que resultaram no encaminhamento do projeto de lei por ele. (BARROS, 2013)

Dessa forma, estudos específicos sobre políticas de saúde têm revelado que, em torno da construção social do problema e da formulação das ações estatais, que serão a posteriori caracterizadas como políticas, principalmente em decorrência da sua formalização em planos e programas, está um espaço de relações entre agentes oriundos de campos diferentes.

10 Em 1996, o então senador José Sarney apresentou o Projeto de Lei do Senado n. ${ }^{\circ} 158$, que dispunha sobre a distribuição gratuita de medicamentos aos portadores de HIV/aids. 
Assim, Pinell (2002) caracterizou o espaço associativo ao interior do qual a resposta à epidemia da aids foi construída na França, nos anos 1980 e 1990 como "espaço aids", tendo como principais agentes militantes homossexuais, mas com uma autonomia relativa em relação aos movimentos homossexuais, e médicos engajados no tratamento dos primeiros doentes. Também no Brasil, pôde ser caracterizado um espaço aids, que, no período da gênese da política nacional, era formado por agentes oriundos dos campos científico, burocrático e médico e também dos movimentos homossexuais. (BARROS, 2013) No espaço aids nos dois estudos, embora os diversos agentes possuíssem interesses comuns referentes ao mesmo problema social, possuíam representações diferentes a respeito da doença e tinham pontos de vista também distintos em relação as estratégias de screening, prevenção e tratamento.

A análise desses espaços específicos de formulação das políticas ganha assim uma complexidade adicional. $\mathrm{O}$ estudo empírico de um campo por si só já requer a adoçãode uma perspectiva relacional.

26 Em outras palavras, busca analisar o sistema de relações objetivas nas quais os indivíduos estão inseridos e as tomadas de posição, influenciadas pelas posições ocupadas e pelas trajetórias. (BOURDIEU, 1996a) Dessa forma, além do estudo do espaço específico de construção da política de saúde, o investigador precisa explorar o estado do campo onde os agentes envolvidos têm sua inserção principal.

A compreensão da natureza tributária do Pifat/PAT, e as razões desse programa ter ficado alocado no MT e não no MS, só se revelaram quando se fez a análise das trajetórias de agentes, que a literatura sobre o PAT ignorava (ou "esquecera"): nomes ligados ao grande empresariado paulista e à "Administração de Recursos Humanos" como Oswaldo Chechia, Luiz Gonzaga Ferreira e Antônio Guimarães. O momento ambíguo do governo Geisel, denominado de "abertura gradual, lenta e segura" da Ditatura Militar, permitiu que o MT se constituísse em espaço de formulação de políticas sociais. Lá encontravam-se esses agentes, executivos de grandes multinacionais, com trânsito no campo burocrático e com alto capital militante. 
Naquele espaço, embora figure como o "pai do PAT”, David Boianovsky se incorporou posteriormente, muito em razão de sua perda de posição no MS, onde chegou a ser cotado para assumir o Instituto Nacional de Alimentação e Nutrição (Inan). Foi desse modo que, para desenvolver o PAT, Boianovsky terminou produzindo um Pifat apoiado em outro programa, já em vigor no MT, coordenado por Luiz Gonzaga Ferreira, não pensado como ações de nutrição, mas destinado ao incentivo fiscal, à construção de escolas e de cursos para a capacitação de trabalhadores. Ou seja: não foi uma "lógica" nutricional ou a expertise do nutrólogo que prevaleceram, mas os pontos de vistas dominantes naquele momento de gênese: financiamento pelo Estado do custo de produção e a reprodução da força de trabalho impulsionados pelo II Plano Nacional de Desenvolvimento (IIPND). (SOUZA, 2013)

O conceito de espaço social também pode ser atribuído a universos sociais que possuem um propósito de constituírem-se em um campo, porém não apresentam ainda todas as características de um campo já consolidado como foi o caso do espaço da Saúde Coletiva no Brasil nos anos 1970. (VIEIRA-DA-SILVA, 2015, VIEIRA-DASILVA; PINELL, 2014) São microcosmos onde, à semelhança de campos consolidados, agentes dotados de diferentes capitais disputam as questões específicas daquele universo social. Porém, a pequena autonomia relativa e a inexistência de habitus específico não permite denominá-los de campo. (VIEIRA-DA-SILVA, 2015)

\section{O conceito de agente das práticas}

O uso do termo "agente das práticas", embora não sistematizado com a precisão encontrada nos demais conceitos ao longo de sua obra, traduz uma das questões centrais do pensamento de Pierre Bourdieu intimamente relacionada à sua teoria das práticas que se opõe às teorias subjetivistas, à teoria da ação racional e às concepções que priorizam as determinações externas, econômicas ou não. 
Está relacionado aos seus outros conceitos de campo, habitus e illusio ao interior dos quais ganha sentido.

O conceito de "agentes" se opõe tanto à ideia de "sujeito-criador", subjetivamente autônomo e orientado, dotado de um projeto, quanto às determinações estruturais que definem o curso da ação de forma mecânica. Também esse conceito opõe-se à ideologia do ator racional que busca a origem dos atos em uma intenção da consciência e associa-se a uma visão estreita da racionalidade das práticas. (BOURDIEU, 2009) Para ele, o ator não é mais que a "projeção imaginária do sujeito culto no agente atuante”, sendo que a teoria da ação racional "somente reconhece as respostas racionais de um agente sem história" e corresponderia "à escolha livre de um ator livre de todo o condicionamento social e econômico". (BOURDIEU; WACQUANT, 1992, p. 98-99, tradução nossa)

No estruturalismo, a noção de agente histórico, atuante na estrutura, é subsumida pela noção que é a própria estrutura, subjacente às relações sociais, que desempenha esse papel de produção e reprodução da ordem social. As estruturas e abstrações e mesmo os conceitos são interpretadas como sujeitos.

O discurso objetivista tende a constituir o modelo construído para explicar as práticas como um poder realmente capaz de determiná-los: reificando as abstrações (em frases como a 'cultura determina a idade do desaleitamento...') ele trata suas construções como 'cultura', 'estruturas', 'classes sociais' ou 'modos de produção' como realidades dotadas de eficácia social, capaz de constranger diretamente as práticas; ou então atribuindo aos conceitos o poder de agir na história [...] ele personifica os coletivos e os transforma em sujeitos responsáveis de ações históricas.(BOURDIEU, 2009, p. 62)

Bourdieu (2009) reconhece, da teoria estruturalista, que existem estruturas objetivas, independentes da consciência e da vontade dos agentes. Entretanto, para esse autor, existe uma dialética entre as estruturas objetivas e as estruturas incorporadas sob a forma de habitus, 
que ocorre em cada ação concreta. Os habitus, por sua vez, são produto das histórias individuais e das histórias coletivas. São esquemas de percepção, de pensamento e de ação dos agentes - como estruturas mentais produto de uma gênese social. Dessa forma, há uma interiorização do social pelos agentes por meio do habitus, princípio gerador de representações e práticas, vinculados às logicas de classe e de campo e da posição nele ocupada pelos agentes. (BOURDIEU 2009)

$\mathrm{O}$ conceito de agente não evidencia uma ação humana livre de contingências, uma vez que se encontra influenciada pela "estrutura estruturada" do campo, por suas regularidades e lógicas, e pelo seu sentido de jogo. $\mathrm{O}$ agente é aquele que age e luta dentro de um campo de interesses, tendo em sua ação princípios e inculcações dessas lógicas que lhe são imanentes produzidas no encontro das histórias individuais dos agentes com a história coletiva do campo. Os agentes movem-se no campo, dotados de um senso prático, um sistema adquirido de preferências, de classificações, de percepção. (BOURDIEU, 1996a)

Dessa forma, para Bourdieu e Wacquant (1992), o uso do conceito de agente não é um mero substituto dos conceitos de sujeito ou de ator. Integra sua teoria sobre o mundo social, segundo a qual para se compreender as representações sociais e as práticas sociais é necessário investigar os campos e os espaços sociais onde essas práticas se realizam como o produto do encontro de duas histórias: a história incorporada nos indivíduos sob a forma de habitus e a história incorporada nas coisas sob a forma de estruturas. Assim, conclui que o objeto próprio da ciência social não é nem o indivíduo nem os grupos, mas a dialética entre o campo, o habitus e a illusio. (BOURDIEU, 2009; BOURDIEU, WACQUANT, 1992) ${ }^{11}$

11 A esse respeito, Bourdieu (1990, p. 45) chega a considerar a oposição entre indivíduo e sociedade como absurda, "[...] oposição que a noção de habitus enquanto social incorporado, logo, individuado, visa superar." Para que essas afirmações não pareçam arbitrárias, recomenda-se a leitura dos trabalhos empíricos nos quais essa dialética fica evidenciada, particularmente o livro As regras da arte. (BOURDIEU, 1996a) 


\section{A articulação entre a análise das trajetórias e as condições históricas de possibilidade}

A apreensão empírica da dialética acima referida é complexa e requer a mobilização de diversas técnicas de objetivação e análise qualitativas e quantitativas. Ademais, toda metodologia depende da problemática de pesquisa, do momento histórico e das fontes disponíveis. Como falar em técnicas dissociadas do objeto é contraproducente, remetemos o leitor aos trabalhos empíricos que fizeram uso das mesmas.

Apenas alguns comentários sobre a relação entre a análise das trajetórias e as condições históricas de possibilidade. $\mathrm{O}$ conceito de trajetória em Bourdieu diferencia-se tanto da ideia de biografia como também não corresponde a uma modalidade de história oral. (BOURDIEU, 2006) As trajetórias possíveis, em um determinado campo, correspondem à direção que as forças que atuam no campo imprimem aos agentes, que por sua vez contribuem para a criação de polos resultante dessas trajetórias. São as posições construídas e ou ocupadas pelos agentes ao longo da vida. Na criação do campo artístico, as trajetórias de Flaubert, Manet e Baudelaire constroem essas possibilidades históricas, sendo que esses precursores inventaram o polo da arte pela arte, em contraposição à arte burguesa e o mercado por um lado, e a arte engajada por outro. (BOURDIEU, 1996a) Já na gênese do espaço da Saúde Coletiva, nos anos 1970, as trajetórias de Sérgio Arouca e Hésio Cordeiro, em um sentido, e de Cecília Donnangelo, por outro, marcaram polos importantes de desenvolvimento posterior do espaço nas áreas de Ciências Sociais em Saúde e das políticas de saúde que se distinguiam da medicina preventiva, da saúde publica tradicional e mesmo da epidemiologia clássica. Essas trajetórias foram possíveis em decorrência da conjunção de processos históricos concomitantes, tais como as contradições da conjuntura nacional e o financiamento das fundações americanas que permearam as histórias de vida desses agentes e da rede de relações criadas entre docentes de departamentos de medicina 
preventiva, militantes da luta democrática e pesquisadores inovadores. (VIEIRA-DA-SILVA, 2015)

A distribuição dos agentes no espaço social é dada pelo volume de capital de diferentes espécies, como o capital cultural, o capital econômico, o capital político, o capital simbólico, bem como outros tipos de capital específicos de cada campo, e a trajetória social dos agentes. (BOURDIEU, 1996a) A existência dessas diversas formas de capital corresponde justamente à "multiplicidade de universos socialmente diferenciados”. (PINTO, 1998, p. 215) A classificação de algumas dessas espécies de capital pode ser feita a partir da adaptação da matriz utilizada nos trabalhos desenvolvido por Vieira-daSilva e Pinell (2014) e Vieira-da-Silva (2015) inspirada nas objetivações de Bourdieu (1984b) no Homo academicus. Essas objetivações, contudo, variam a depender do momento histórico estudado, bem como das especificidades do objeto de estudo. (BARROS, 2013; FURTADO, 2014; SOUZA, 2013) Ademais, as posições e trajetórias podem corresponder a tomadas de posição que auxiliam na compreensão da estrutura do campo bem como nas questões que 31 estão em jogo.

A análise da trajetória dos agentes identificados em cada caso pode ser realizada a partir de entrevistas em profundidade e ou através de biografias. Já as condições históricas de possibilidade, a depender do objeto, podem apoiar-se em fontes bibliográficas e documentais. Em ambos os casos, a consulta a fontes primárias traz qualidade a qualquer estudo histórico, tendo em vista a variedade dos pontos de vista existentes sobre qualquer aspecto do mundo social. A inclusão de agentes em posições menos destacadas auxilia na compreensão do significado das posições dominantes e dominadas ao interior do espaço social a ser estudado.

A recuperação das trajetórias pode ser feita ou por entrevistas ou por biografias a depender do momento histórico investigado. Ressalta-se o cuidado necessário com a forma que as informações são construídas, a maneira de apreender a realidade da qual as informações são produto. Ou seja, o comportamento do entrevistador, sua 
maneira de se apresentar e de apresentar a entrevista, suas questões e silêncios, reforços e encorajamentos, são indicações e intervenções que orientam os propósitos e estruturam a entrevista. (BOURDIEU, 2006) Sobre a técnica de entrevista, Bourdieu (1991, p. 3) diz que

[...] trata-se de uma forma de escuta ativa e armada demandando uma postura aparentemente contraditória: de um lado uma disponibilidade total para a pessoa interrogada, uma submissão inteira à singularidade de seu caso particular, que pode conduzir, por um tipo de mimetismo mais ou menos controlado, à adotar sua linguagem e à entrar nas suas visões, nos seus sentimentos, nos seus pensamentos; de outro, um interrogatório metódico, forte no conhecimento das condições objetivas, comuns a toda uma categoria, e atenta aos efeitos de relação de entrevista.

O pesquisador, portanto, apoiado no referencial teórico, vai olhar para o objeto de estudo buscando dar razão, buscando compreender o seu processo histórico de construção e desenvolvimento, a trajetória dos agentes envolvidos, as estruturas objetivas e mentais criadas, e a dinâmica das relações estabelecidas, sempre na tentativa de articular o material e o simbólico.

As entrevistas são fundamentalmente recurso para a análise das sucessivas posições ocupadas pelos agentes, afim de explorar suas tomadas de posição, bem como para a localização de documentos raros e acervos pessoais. $\mathrm{O}$ confronto da história oral com fontes documentais aumenta a validade das conclusões. A esse respeito são diversas as fontes históricas que podem ser acionadas a exemplo de documentos oficiais (leis, decretos, normas, pareceres), técnicos (relatório, planos, teses) ou documentos pessoais (cartas, testamentos, inventários, autobiografias, fotografias). A crítica das fontes é de fundamental importância, pois elas não falam por si e precisam ter sua validade analisada. 


\section{A amnésia da gênese}

Segundo Bourdieu (2012), o processo de institucionalização tende a fazer esquecer as disputas iniciais, as alternativas possíveis que foram vencidas. Por isso, é importante voltar aos conflitos das origens e apreender os possíveis que se realizaram e também os possíveis excluídos. Para o autor, esse é um dos instrumentos de ruptura com o senso comum mais poderosos. A análise histórica, ao identificar os confrontos dos primeiros momentos, permite perceber as possibilidades do que poderia ter acontecido, criando alternativas para transformações sociais por meio dessa "utopia prática". ${ }^{12}$ (BOURDIEU, 2006) Como exemplo, este autor refere-se à homogeneização da escritura, da ortografia e da maneira de falar como fruto do processo de construção de Estado que, motivo de disputas em sua gênese, vai paulatinamente, geração após geração, incorporandose até tornar-se inconsciente. (BOURDIEU, 2012)

No caso do Pifat/PAT, um dos efeitos mais marcantes da amnésia da gênese foi justamente considerá-lo apenas como uma ação, um programa destinado à alimentação do trabalhador (PAT), fruto de uma racionalidade técnica operada pelo Estado brasileiro visando intervir no estado nutricional dos seus usuários. No entanto, isso não passa de um artefato. $\mathrm{O}$ estudo sociogenético do espaço evidenciou justamente o contrário: enquanto a dimensão nutricional passou a ser operada no interior do campo econômico, nas negociações entre empregadores, empregados e empresas de refeições coletivas ou tíquetes, ao Estado coube o custeio da intervenção. (SOUZA, 2013)

12 Nas palavras daquele autor: "E assim, ao revelar os possíveis mortos, permite-se reatualizar os conflitos iniciais e a possibilidade de que houvesse sido (e de que seja) de outro modo e, por meio dessa utopia prática, recoloca em questão o possível que se concretizou entre todos os outros". (BOURDIEU, 2006, p. 98) 


\section{Os possíveis mortos}

Uma segunda consequência do retorno às origens, segundo Bourdieu, é a identificação das possibilidades que não se realizaram - os possíveis mortos. Geralmente as construções históricas são tratadas como algo que deveria acontecer e não como um entre alguns possíveis realizáveis em determinado momento histórico. Ao longo do tempo, as escolhas do passado transformam-se em coerções objetivadas e incorporadas, restringindo o universo de possíveis realizáveis, de modo que alguns possíveis são completamente esquecidos. Ou seja, as alternativas que existiam naquele momento histórico são esquecidas, sepultadas. “O espaço dos possíveis não pára de se fechar a cada momento, [...] a história elimina os possíveis e os faz esquecer como possíveis, que ela torna mesmo impensáveis os possíveis.” (BOURDIEU, 2012, p. 187)

Bourdieu cita como exemplo um projeto de lei do parlamento francês nos anos 1990 que buscava criar um monopólio no campo jurídico aos portadores de diploma, explicando que, uma vez aprovado, levaria a mudanças nas estruturas objetivas (desaparecimento dos plantões jurídicos prestados por não diplomados a mulheres e desfavorecidos), de modo que, em alguns anos, o possível alternativo (existência de plantões jurídicos assegurados por não profissionais) seria esquecido. Ou a estrutura poderia mudar e as associações garantiriam a formação desses indivíduos, ou os tribunais trabalhistas poderiam ter sua dinâmica alterada, alterando também as estruturas mentais. Ou o caso da política da habitação francesa, onde

[...] a alternativa entre HLM ${ }^{13}$ coletivos ou casinhas particulares é uma falsa alternativa; há uma terceira possibilidade, a das casinhas para aluguel, que não existe. Não há um sociólogo que fale disso [...] Ou seja, a alternativa, a oposição habitat coletivo/individual é varrida por um processo histórico que constituiu o problema sob essa

13 Do francês, Habitation à Loyer Modéré, ou habitação de baixa renda. 
forma cuja genealogia podemos fazer. E há milhares de problemas desse tipo. (BOURDIEU, 2012, p. 190-191)

No que se refere ao Pifat/PAT, a conformação original do espaço resultou em, ao menos, dois "possíveis mortos" - propostas originais que não conseguiram ser viabilizadas quando o espaço se fechou: a concessão de financiamentos para construção de restaurantes por instituições civis de empregados ou empregadores; e o cadastro de restaurantes comerciais para oferecer diretamente as refeições aos trabalhadores e sem a intermediação das empresas de tíquetes. Aliás, embora essas empresas operassem desde o início do programa, sua atuação só foi regulamentada em 1991. (SOUZA, 2013)

Também a distribuição de medicamentos antirretrovirais pelo MS não era uma proposta inicial. Mas a possibilidade de implementação de uma política de controle da aids no Brasil sem acesso a antirretrovirais, seguindo as recomendações das agências internacionais para países em desenvolvimento, pode ser considerada um "possível morto”. A lei n. ${ }^{\circ}$ 9.313/1996 garantiu o acesso universal a medicamentos para o tratamento da aids, sepultando essa alternativa. (BARROS, 2013)

O projeto da Reforma Sanitária Brasileira conforme proposição dos seus fundadores incorporada pela VIII Conferência Nacional de Saúde apoiada em uma teoria social da saúde que identificava determinantes sociais para a produção da saúde-doença e requeria mudanças estruturais para a sua resolução pode ser considerado como um possível morto. (VIEIRA-DA-SILVA, 2015) Era parte do espaço de possíveis naquele momento histórico. Aquele espaço de possíveis fechou-se parcialmente com a correlação de forças presente na Constituinte de 1988 e posteriormente mais ainda com o retrocesso do governo Collor. 


\section{Considerações finais}

A análise sócio-histórica de políticas de saúde, apoiada na sociologia reflexiva e genética de Pierre Bourdieu, constitui-se em abordagem capaz de orientar investigações sobre políticas de saúde de forma fecunda e inovadora, vindo a somar-se ao conjunto de perspectivas metodológicas existentes para a análise política em saúde. Isso não quer dizer que os pesquisadores que tomam por objeto as políticas devam converter-se em historiadores ou vice-versa. Também não significa que somente poderá ser realizada por meio de uma equipe multidisciplinar. Sendo um objeto que requer a mobilização de saberes de diversas disciplinas, impõe, além do necessário diálogo entre pesquisadores com formações diferenciadas, uma apropriação transdisciplinar desse conhecimento. Se os problemas da atualidade podem ser eventualmente necessários para orientar uma pesquisa histórica relevante, o oposto é sistematicamente verdadeiro: o recuo histórico adequado esclarece dilemas e questões do momento presente.

A tentativa de aclarar alguns conceitos-chave da sociologia bourdieusiana por meio de exemplos extraídos, tanto das suas pesquisas empíricas como das investigações desenvolvidas pelos autores do presente ensaio, corresponde a uma tentativa de pôr em prática sua epistemologia onde os conceitos teóricos não fazem sentido dissociados dos estudos de realidades concretas. (BOURDIEU, 1992) Também nos pareceu necessária essa explicitação conceitual, dado que alguns de seus conceitos centrais já se converteram em senso comum douto, a exemplo do conceito de campo, ou ainda provocam reações de estranheza como o conceito de agente das práticas. No primeiro caso, foi necessária a distinção entre os conceitos de campo e espaço social, bem como a recuperação das origens do conceito que Pierre Bourdieu (1992) foi construindo pouco a pouco, por meio de suas pesquisas empíricas sobre o campo literário, o campo da alta costura, o campo científico, o campo burocrático - só para citar as mais importantes. 
Os estudos sócio-históricos, conforme vimos neste capítulo, podem ajudar na compreensão do processo social que envolve a constituição de pontos de vista dominantes, pretensamente universais, sobre um dado problema em análise. Esse tipo de análise favorece, portanto, a identificação de formas de apropriação, legitimação e dominação ao interior de espaços sociais, como no caso das políticas de saúde assumidas como intervenção do Estado. Revelar contradições e conflitos é parte do trabalho da análise da gênese das políticas de saúde, cuja formalização tende a se apresentar de modo suficientemente ambivalente, acomodando as assimetrias e neutralizando as tensões e os interesses conflitivos das quais resultaram, para então operar com uma lógica própria, constituindo seu mercado específico com agentes dotados de legitimidade em torno de uma causa defendida ou aceita por todos.

A análise sócio-histórica das políticas de saúde de orientação bourdieusiana não corresponde a um fechamento monoautoral. Implica na aderência a uma epistemologia de inspiração bachelardiana do "não", no exercício da dúvida radical. (BOURDIEU 1989) Impõe ainda um diálogo com outros pesquisadores e teóricos atuais e contemporâneos que trataram do objeto de investigação. É claro que esse diálogo tem limites diante da magnitude e extensão do conhecimento contemporâneo. Em decorrência, a seleção das fontes relevantes é sempre um exercício complexo, com as limitações dadas pelo estado atual do espaço da saúde coletiva, do campo científico e da posição que os autores ocupam nesses espaços. Portanto, sujeita a críticas e retificações.

\section{Referências}

BACHELARD, G. A formação do espírito científico: contribuição para uma psicanálise do conhecimento. Rio de Janeiro: Contraponto, 1996.

BARROS, S. G. A política nacional de luta contra a aids e o espaço aids no Brasil. 2013. 274 f. Tese (Doutorado em Saúde Coletiva) - Instituto de Saúde Coletiva, Universidade Federal da Bahia, Salvador, 2013. 
BARROS, S. G. de; VIEIRA-DA-SILVA, L. M. The genesis of the AIDS policy and AIDS Space in Brazil (1981-1989). Revista de Saúde Pública, São Paulo, v. 50, n. 43, p. 1-12, 2016.

BOURDIEU, P. A distinção: crítica social do julgamento. São Paulo:

Edusp; Porto Alegre: Zouk, 2006.

BOURDIEU, P. As regras da arte: genese e estrutura do campo literário. Lisboa: Presença, 1996a.

BOURDIEU, P. Coisas ditas. São Paulo: Brasiliense, 1990.

BOURDIEU, P. Razões práticas: sobre a teoria da ação. Campinas:

Papirus, 1996b.

BOURDIEU, P. Espace social et genèse des classes. Actes de la recherche en sciences sociales, Paris, v. 52, n. 1, p. 52-53, 1984a.

BOURDIEU, P. Homo academicus. Paris: Ed. minuit, 1984b.

BOURDIEU, P. Introduction à la socioanalyse. Actes de la recherche en sciences sociales, Paris, v. 90, n. 1, p.3-5, déc. 1991.

38 BOURDIEU, P. La noblesse d'état: grandes écoles et esprit de corps. Paris: Les Éditions de Minuit, 1989a.

BOURDIEU, P. O poder simbólico. Rio de Janeiro: Bertrand Brasil;

Lisboa: DIFEL, 1989b.

BOURDIEU, P. O senso prático. Petropolis: Vozes, 2009.

BOURDIEU, P. Propos sur le champ politique. Lyon: Presse Universitaire de Lyon, 2000.

BOURDIEU, P. Sur l'État - cours de collège de france: 1989-1992. Paris:

Raisons D'agir: Seuil, 2012.

BOURDIEU, P.; CHAMBOREDON, J. C.; PASSERON, J. C. A profissão do sociólogo: preliminares epistemológicas. Petrópolis: Vozes, 1999.

BOURDIEU, P.; WACQUANT, L. J. D. Réponses: pour une anthropologie réflexive. Paris: Seuil, 1992.

BRASIL. Lei n. 6.321, de 14 de abril de 1976. Dispõe sobre a dedução, do lucro tributável para fins de imposto sobre a renda das pessoas jurídicas, 
do dobro das despesas realizadas em programas de alimentação do trabalhador. Diário Oficial [da] Republica Federativa da Brasil. Brasília, DF, 19 abr. 1976.

CHAMPAGNE, P.; CHRISTIN, O. Pierre Bourdieu: une initiation. Lyon: Presses Universitaires de Lyon, 2012.

FREYRE, G. Casa-grande ఓ senzala. 34. ed. Rio de Janeiro: Record, 1998. cap. 4.

HOCHMAN, G. História e Políticas publicas: a política pública como campo multidisciplinar. E. MARQUES, E.; FARIA, C. A. P. (Org.). A política pública como campo multidisciplinar. São Paulo: Unesp; Rio de Janeiro: Ed. Fiocruz, 2013.

LEBARON, F. L'espace social:statistique et analyse géométrique des données dans l'ouvre de Pierre Bourdieu. In: LEBARON, F.; ROUX, B. L. (Org.). La méthodologie de Pierre Bourdieu en action: espace culturel, espace social et analyses des données. Paris: Dunod, 2015.

NUNN, A. The politics and history of AIDS treatment in Brazil. New York: Springer Science, 2009.

PAIM, J. S. Políticas de saúde no Brasil: epidemiologia e saúde. In: ROUQUAYROL, M. Z.; ALMEIDA FILHO, N. Epidemiologia \& Saúde. Rio de Janeiro: MEDSI, 2003. p. 587-603.

PINELL, P. Análise sociológica das políticas de saúde. Rio de Janeiro: Ed. Fiocruz, 2010.

PINELL, P. Une épidémie politique:la lutte contre le sida en France, 1981-1996. Paris: Presses Universitaires de France, 2002.

PINELL, P. O nascimento das Políticas contra o Cancer na França. In: PINELL, P. Analise sociológica das políticas de saúde. Rio de Janeiro: Ed. Fiocruz, 2011.

PINTO, I. C.;VIEIRA-DA-SILVA, L. M.; BAPTISTA, T. V. F. Ciclo de uma política, política pública, política social e política de saúde. In: PAIM, J.S.; ALMEIDA-FILHO, N. (Org.). Saúde coletiva: teoria e prática. Rio de Janeiro: MedBook, 2014. p. 69-81. 
PINTO, L. Pierre Bourdieu et la théorie du monde social. Paris: Albin Michel, 1998.

SOUZA, J. C. Avaliação “ex-post” de três programas de intervenção nutricional: Gente da Gente I, Gente da Gente II e Prodea. 1999, 159 f. Dissertação (Mestrado em Interunidades em Nutrição Humana Aplica) Faculdade de Ciências Farmacêuticas da USP, Faculdade de Economia e Administração, Universidade de São Paulo, São Paulo, 1999.

SOUZA, J. C. A gênese do programa de incentivo fiscal à alimentação do trabalhador (PIFAT/PAT). 2013. 261f. Tese (Doutorado em Saúde Coletiva) - Instituto de Saúde Coletiva, Universidade Federal da Bahia, Salvador, 2013.

STEVENS, R. A.; ROSENBERG, C. E; BURNS, L. R. (Ed.). History and health policy in the United States: puting the past back in new brunswick. New Jersey and London: RutgersUniversity Press, 2006.

VIEIRA-DA-SILVA, L. M. Gênese Sócio-Histórica da Saúde Coletiva. In: LIMA, N. T.; SANTANA, J. P.; PAIVA, C. H. A. Saúde coletiva: a Abrasco em 35 anos de história. Rio de Janeiro: Ed.Fiocruz, 2015. p. 25-48.

VIEIRA-DA-SILVA, L.M.; PINELL, P. The genesis of collective health in brazil. Sociology of Health \& Illness, Boston, v. 36 n. 3, p. 432-446, 2014.

WEBER, M. Ensaios de sociologia. Rio de Janeiro: LTC, 1982. 


\section{PRODUÇÃO CIENTÍFICA SOBRE POLÍTICA DE SAÚDE NO BRASIL (1988-2014) contribuição ao debate sobre a Reforma Sanitária Brasileira}

\section{Introdução}

A Reforma Sanitária Brasileira (RSB) vem sendo estudada como um fenômeno sócio-histórico, conformado por múltiplos fatos produzidos por vários atores, cujas ações configuram um processo desencadeado na sociedade brasileira em meados dos anos $1970 \mathrm{e}$ ainda em curso. Enquanto proposta, foi resultante de um movimento da sociedade civil brasileira em defesa da democracia, dos direitos sociais e de um novo sistema de saúde. (ESCOREL, 1999; FLEURY, 1994; GERSCHMAN, 1985) Transformou-se em projeto a partir da $8^{a}$ Conferência Nacional de Saúde (BRASIL, 1986a) e desenvolveu-se como processo, especialmente com a instalação da Comissão Nacional de Reforma Sanitária. (BRASIL, 1986b) Desse modo, a RSB é simultaneamente uma proposta, um projeto, um movimento e um processo. (PAIM, 2008a) 
A ideia e a proposta da RSB foram esboçadas no contexto da nova república que anunciava a recuperação dos direitos políticos para os brasileiros, apontando para a construção de um estado ampliado, onde se fariam presentes maior leque de interesses de classes, frações de classes, segmentos sociais e grupos de interesses. Marcadas ainda pelas lutas contra o autoritarismo desde a fundação do Centro Brasileiro de Estudos em Saúde (A QUESTÃO..., 1979), tais ideia e proposta expressaram-se em um complexo projeto, formalizado na Constituição Federal de 1988 (BRASIL, 1988), o qual previa que as modificações necessárias ao setor saúde transcendiam os limites de uma reforma administrativa e financeira, exigindo uma reformulação mais profunda das concepções e práticas de saúde, incluindo a reforma do setor em seus aspectos políticos, organizacionais e técnico -operacionais (PAIM, 2008a), isto é, do seu arcabouço institucional, a partir da unificação, descentralização e democratização da gestão do sistema (NORONHA; LIMA; MACHADO, 2012), bem como da mudança do modelo de atenção à saúde, com ênfase na constru42 ção da integralidade do cuidado. (TEIXEIRA; VILASBÔAS, 2014)

Conformando-se, portanto, como um conjunto de práticas ideológicas, políticas e culturais que tomam a saúde como referente fundamental, o processo de RSB pode ser descrito e analisado a partir de um ciclo integrado pelos momentos que contemplam desde a elaboração da ideia, à conformação da proposta e sistematização de um projeto político incorporado parcialmente à agenda do Estado e traduzido em políticas e ações de saúde nos últimos 25 anos. (PAIM, 2008a; PAIM, 2013a; PAIM et al., 2011; TEIXEIRA; SOUZA; PAIM, 2014)

A compreensão desse processo perpassa pelo estudo das conjunturas conformadas desde a emergência da ideia até o momento atual. As análises e avaliações das políticas de saúde do governo Lula (BAHIA, 2010; MACHADO; BAPTISTA; LIMA, 2012; TEIXEIRA; PAIM, 2005) apontam continuidades e mudanças, embora sem questionarem ou aprofundarem a análise sobre o sentido do processo da RSB, assim como a sua possível permanência. Nem mesmo os 
obstáculos e as ameaças ao Sistema Único de Saúde (SUS), identificados na conjuntura atual por diversos estudos (BORGES et al., 2012; COSTA; BAHIA; SCHEFFER, 2013; NORONHA; SANTOS; PEREIRA, 2011; OCKÉ-REIS, 2012; PAIM, 2012; PAIM et al., 2011), estimularam, até o presente, a realização de pesquisas e uma apreciação crítica da RSB que alcançassem o final do período Lula e o governo Dilma Rousseff, especialmente diante das possíveis relações com projetos políticos em disputa na sociedade brasileira. (MAGNO, 2014)

Para além dessas discussões, não há consenso entre os estudiosos sobre a própria vitalidade da RSB. Hochman (2013) defende que a RSB findou-se como conjunto de ideias e práticas políticas contextualizadas em certo tempo de transição, resultado do seu próprio êxito na proposição de uma agenda política e criação de um sistema de saúde reconhecido mundialmente, bem como da conquista da democracia em 1985. Contrariamente, Paim (2013a) defende que a RSB enquanto processo não terminou, nem tem prazo de validade, o que pode ser evidenciado pela Agenda Estratégica para a Saúde (AGENDA..., 2011; UMA AGENDA..., 2011), pelas centenas de cidadãos formados pelo Centro Brasileiro de Estudos de Saúde (Cebes) nos últimos anos (SOPHIA, 2015) e pela movimentação de milhares de participantes dos congressos da Associação Brasileira de Saúde Coletiva (LIMA; SANTANA, 2006), bem como da participação cidadã em conselhos e conferências de saúde. (CÔRTES, 2009, 2010; LABRA; FIGUEIREDO, 2002; LOBATO; FLEURY, 2009)

A reflexão sobre essa polêmica gerou o interesse em se atualizar e aprofundar a revisão bibliográfica sobre política de saúde no período pós-constituinte, tomando-se como ponto de partida os estudos já realizados nessa linha. (LEVCOVITZ et al., 2003; PAIM; TEIXEIRA, 2006; TEIXEIRA; SOUZA; PAIM, 2014) Tomando como referencial o debate sobre a permanência ou esgotamento do processo de RSB, foram elaboradas as seguintes questões: 
a. quais as características da produção científica brasileira sobre política de saúde no período 1988-2014?

b. Quais as características da evolução temporal dessa produção?

c. Quais os principais temas e questóes abordadas nos estudos realizados neste período?

d. Até que ponto os estudos realizados expressam a ocorrência de mudanças na concepção dos pesquisadores em relação à $\mathrm{RSB}$ ?

Nessa perspectiva, o objetivo geral deste capítulo é apresentar os resultados de uma revisão sistemática da literatura mediante a aplicação de métodos explícitos e sistematizados de busca, apreciação crítica e síntese (SAMPAIO; MANCINI, 2007) de artigos selecionados na base Scientific Electronic Library Online (Scielo), em 2014, procedendo-se à sua classificação segundo temas e objetos de estudo, bem como a análise de conteúdo dos resumos da subárea "análise política em saúde”, nos quais se tratou de identificar até que ponto tais estudos reafirmam ou negam a permanência do processo de RSB 44 nas diversas conjunturas, desde 1988 até o momento atual. Com isso, tratamos de discutir a manutenção, mudança ou transformação de concepções que marcaram a emergência da RSB no âmbito da comunidade científica da área de Saúde Coletiva, indicando, indiretamente, os contornos das bases de sustentação política desse processo.

\section{Aspectos teórico-metodológicos}

Tomamos como ponto de partida o conceito proposto por Paim (2003), segundo o qual "política de saúde" é a resposta social (ação ou omissão) do Estado aos problemas e necessidades de saúde da população, contemplando, portanto, a intervenção sobre a produção, distribuição, gestão e regulação de bens e serviços que afetam a saúde, inclusive o ambiente. Desse modo, abrange as questões relativas ao poder em saúde (natureza, estrutura, relações, distribuição e lutas), bem como as que se referem ao estabelecimento de diretrizes, planos e programas de saúde. Ou seja, contempla tanto os planos de 
ação governamental (KINGDON, 2011) quanto a análise das relações de poder em saúde. (TESTA, 1995)

Enquanto disciplina acadêmica, Política de Saúde inclui estudos sobre o papel do Estado, as relações Estado-Sociedade, movimentos sociais em saúde, as relações entre políticas de saúde e políticas econômicas e sociais (LEVCOVITZ et al., 2003; PAIM, 2003) e outros aspectos relativos à análise dos processos políticos que ocorrem em diversos espaços sociais. Também abarca estudos que tratam da formulação e implementação de políticas específicas no âmbito governamental, abordando, por exemplo, a conformação da agenda política em saúde, a elaboração de propostas de intervenção sobre problemas de grupos populacionais específicos bem como a gestão, implantação e avaliação de planos, programas e projetos.

Neste trabalho, o mapeamento da produção científica implicou, em primeiro lugar, na definição dos "descritores de assunto", com consulta a especialistas na área, bem como análise dos descritores disponíveis nos trabalhos anteriores, aliados ao recurso ao vocabulário controlado do Descritores em Ciências da Saúde (DeCS) e a própria estratégia de indexação da Scielo. Mediante utilização dos descritores "Política de Saúde", "Sistema Único de Saúde" e "Direito à Saúde", foram então acessados os artigos na Scielo homepage do Brasil, por abrigar em seu acervo a coleção recente de periódicos científicos brasileiros.

Foram identificados 824 artigos, dos quais foram extraídos 55 que apareceram repetidos em função do uso de três descritores correlatos. Com isso, obtivemos um total de 769 artigos publicados no período de 1988 a 2014, os quais foram submetidos a uma reclassificação a partir da leitura do título do estudo, levando-se em conta a especificidade do objeto de estudo conformea tipologia descrita no Quadro 1. Foram incluídos no primeiro grupo os estudos que tratam de análise política em saúde (politics); em um segundo conjunto, os estudos que abordam a dinâmica política em torno dos diversos componentes do sistema de saúde, quais sejam, o financiamento,a gestão/participação e controle social, os modelos de atenção, 
os recursos humanos, a informação, ciência e tecnologia em saúde; e, em um terceiro, os estudos que tratam de análises de políticas de saúde específicas (policy).

Uma vez realizada essa reclassificação, tomou-se cada um dos três conjuntos de artigos e procedeu-se a uma subdivisão temática, buscando-se identificar os subtemas abordados pelos autores. Com isso, foram construídos novos quadros que apontam o mosaico de questões selecionadas pelos diversos autores. Nessa perspectiva, os estudos que tratam de análise política ao nível macro (internacional ou nacional) foram reagrupados segundo o tema abordado. $\mathrm{O}$ mesmo foi feito com relação aos estudos sobre componentes do sistema de saúde (KLECZKOWSKI; ROEMER; VAN DER WERFF, 1984), reclassificados segundo o componente analisado. Por fim, também foram reagrupados os estudos que tratam de análise de políticas específicas, sendo que, nesse caso, adotou-se uma classificação derivada da pesquisa realizada no site do Ministério da Saúde, ${ }^{1}$ que permitiu a identificação de "políticas" elaboradas e formalizadas em documen46 tos institucionais no período de 2003-2014. (BRASIL, 2010)

Quadro 1 - Tipologia dos artigos segundo objeto de estudo. Brasil, 1988-2014

\begin{tabular}{|l|l|}
\hline \multicolumn{1}{|c|}{ Áreas } & \multicolumn{1}{c|}{ Definição } \\
\hline $\begin{array}{l}\text { 1. Análise } \\
\text { política em } \\
\text { saúde }\end{array}$ & $\begin{array}{l}\text { Política de saúde em uma perspectiva internacional; Reforma } \\
\text { Sanitária Brasileira; Processo de construção do SUS; relações } \\
\text { público-privado (SUS-SAMS). }\end{array}$ \\
\hline $\begin{array}{l}\text { 2. Componentes } \\
\text { do sistema de } \\
\text { saúde }\end{array}$ & $\begin{array}{l}\text { Financiamento da saúde (volume de recursos, formas de } \\
\text { distribuição, custos, etc,); gestão de sistemas de saúde } \\
\text { (descentralização, regionalização, modalidades alternativas de } \\
\text { gestão); participação e controle social; modelos de atenção } \\
\text { em saúde; recursos humanos em saúde; ciência, tecnologia e } \\
\text { inovação. }\end{array}$ \\
\hline
\end{tabular}

1 http://portalsaude.saude.gov.br/. 


\begin{tabular}{|l|l|}
\hline $\begin{array}{l}\text { 3. Análise } \\
\text { de políticas }\end{array}$ & $\begin{array}{l}\text { Políticas voltadas a grupos populacionais específicos (mulher, } \\
\text { criança, idoso, trabalhador etc) ou ao enfrentamento de } \\
\text { de saúde }\end{array}$ \\
específicas & $\begin{array}{l}\text { problemas específicos (aids, dengue, hipertensão arterial, } \\
\text { tuberculose etc.). }\end{array}$
\end{tabular}

Fonte: Elaborado pelas autoras.

Finalmente, foi feita uma análise do conteúdo dos títulos, resumos e palavras-chave dos 78 artigos incluídos na subárea "análise política em saúde”, com vistas a identificar a presença de expressões que indiquem a referência ao processo de RSB. Os termos utilizados nessa busca foram identificados a partir de consulta ao vocabulário controlado DeCS, no qual foi encontrado apenas o descritor "Reforma dos Serviços de Saúde" como sinônimo da RSB. Considerando que o uso dessa ferramenta pela comunidade científica é relativamente recente, optou-se por utilizar como elementos de busca além do descritor já citado, os termos: "Reforma Sanitária", "Reforma Sanitária Brasileira", "Movimento da Reforma Sanitária", "Reforma do Setor Saúde" e "Movimento Sanitário". Posto isso, os resumos dos trabalhos foram lidos utilizando a ferramenta "localizar" do Word para buscar os referidos termos no texto, extraindo-se do conjunto apenas os que continham pelo menos uma dessas expressões no título, resumo ou palavras-chave.

\section{Características e tendências da produção científica sobre política de saúde 1998-2014}

A produção científica sobre política de saúde registrada no Scielo, no período de 1988-2014, totaliza, conforme explicitado anteriormente, 769 artigos, distribuídos, segundo a data de publicação conforme a Figura 1. Verifica-se uma tendência ao crescimento do número de publicações a partir dos anos 2000, acentua-se a curva a partir do final da década, de modo que, no período 2007-2013, encontramos mais da metade das publicações (79\%). A ligeira queda 
observada em 2014, provavelmente se deve ao fato dos artigos terem sido capturados em meados do referido ano.

Figura 1 - Distribuição dos artigos por ano de publicação

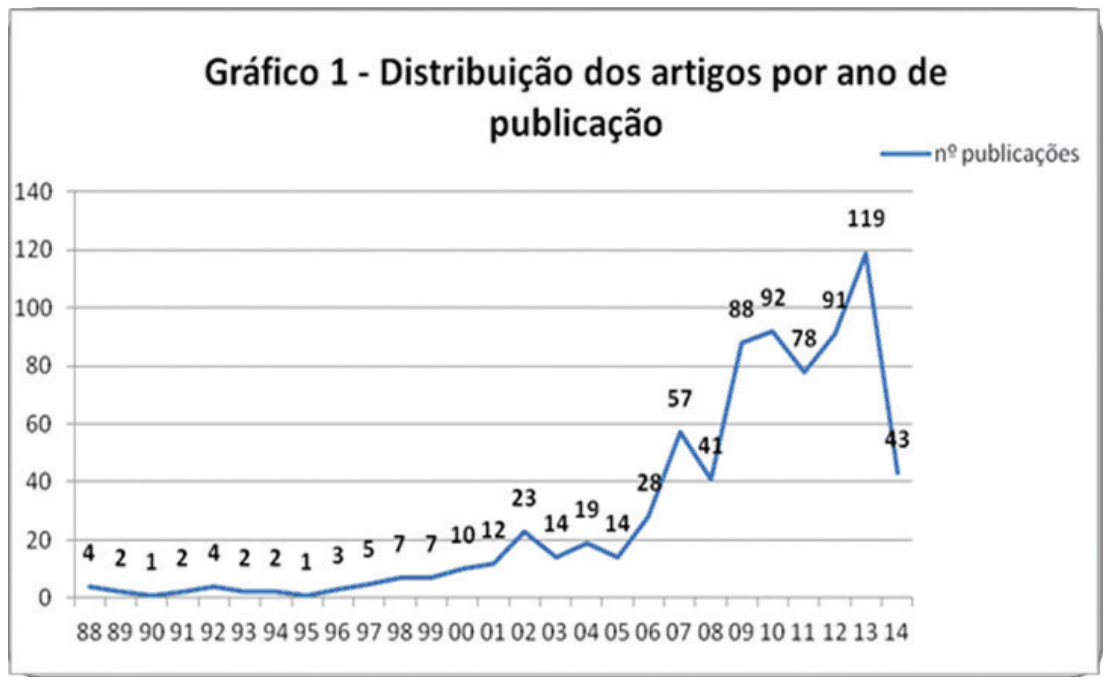

Fonte: Elaborada pelas autoras.

O aumento do número de artigos registrados na base Scielo pode estar indicando o aumento do número de periódicos que publicam trabalhos nessa área, e talvez, indiretamente, revele certo aumento do número de pesquisadores interessados nesse tema, o que, aliás, é coerente com a expansão do campo da Saúde Coletiva, especialmente dos programas de pós-graduação na área, inclusive dos mestrados profissionais (TEIXEIRA, 2006) que privilegiam a realização de estudos que abordam políticas e práticas do sistema de saúde. (ARTMANN, 2006; DOURADO et al., 2006; PIERANTONI, 2006)

A classificação do conjunto dos artigos nos grupos temáticos definidos anteriormente (Quadro 1) resultou na distribuição apresentada na Tabela 1. Do total dos estudos, 10,2\% (78) contemplam análises do processo político em saúde, enquanto 28,8\% (221) abordam aspectos referentes aos componentes do SUS. Quase metade dos trabalhos trata de análises de políticas de saúde específicas 
(49,0\%) e 12,0\% dos artigos correspondem a estudos que não se enquadram nos grupos descritos.

Tabela 1 - Distribuição dos artigos segundo objeto de estudo. Brasil, 1988-2014

\begin{tabular}{l|l|l}
\hline \multicolumn{1}{c|}{ Áreas } & \multicolumn{1}{c|}{$\mathbf{N}$} & \multicolumn{1}{c}{$\%$} \\
\hline 1. Análise política em saúde & 78 & 10,2 \\
\hline 2. Componentes do sistema de saúde & 221 & 28,8 \\
\hline 3. Análise de políticas de saúde específicas & 377 & 49,0 \\
\hline 4. Outros & 93 & 12,0 \\
\hline Total & 769 & 100,0 \\
\hline
\end{tabular}

Fonte: Elaborada pelas autoras.

\section{Distribuição dos estudos de análise política em saúde por subárea temática}

O primeiro trabalho, dentre os 78 incluídos nessa área temática, foi publicado em 1988. Durante toda a década de 1990, observou-se apenas a publicação de um trabalho por ano, sendo que, a partir do ano 2000, esse número cresceu, de modo que, no período compreendido entre 2008 e 2014, encontra-se mais da metade das publicações $(52,0 \%)$, o que evidencia, talvez, um aumento do número de pesquisadores da área que adotam uma perspectiva de análise abrangente acerca do processo político em saúde no país.

A redistribuição dos 78 artigos incluídos nesse grupo por subárea temática (Tabela 2) evidencia predominância de estudos acerca da política de saúde no Brasil (53,8\%), especialmente do processo de RSB e construção do SUS, verificando-se também estudos que abordam a política de saúde numa perspectiva internacional (20,5\%) e pequena percentagem de estudos acerca da relação entre o SUS e o Sistema de Assistência Médica Suplementar (SAMS). O restante dos trabalhos $(21,8 \%)$ trata de análise política em saúde numa perspectiva 
localizada (estudos de casos) e discussão de elementos teóricos para a análise de políticas sociais.

Esses achados evidenciam o interesse dos pesquisadores da área em acompanhar e analisar o processo de reforma do sistema de saúde ao longo dos últimos 27 anos, chamando atenção a grande quantidade de trabalhos que se focam sobre os processos que incidem sobre o sistema público, aos quais se agrega um interesse crescente na problematização das relações público-privadas, o que, de certo modo, reflete as tensões e contradições que perpassam o processo de implementação do SUS no Brasil nesse período. (PAIM, 2013a; PAIM et al., 2011; TEIXEIRA et al., 2014)

Tabela 2 - Estudos de análise política em saúde por subárea temática. Brasil, 1988-2014

\begin{tabular}{l|l|l}
\hline \multirow{2}{*}{ Subárea temática } & \multicolumn{2}{c}{ Artigos } \\
\cline { 2 - 3 } & \multicolumn{1}{c}{ No } & \multicolumn{1}{c}{$\%$} \\
\hline 1.Políticas de saúde em uma perspectiva internacional & 16 & 20,5 \\
\hline 2. Política de saúde no Brasil: RSB/SUS (Geral) & 42 & 53,8 \\
\hline 3. Relação público privado (SUS/SAMS) & 3 & 3,9 \\
\hline 4. Outros & 17 & 21,8 \\
\hline Total & $\mathbf{7 8}$ & $\mathbf{1 0 0 , 0}$ \\
\hline
\end{tabular}

Fonte: Elaborada pelas autoras.

\section{Distribuição dos estudos sobre o SUS segundo os componentes do sistema}

Sobre os componentes do sistema de saúde, foram encontrados 221 artigos (Tabela 3). A subárea temática mais frequente foi a de "gestão de sistemas e serviços de saúde" (33,4\%), seguida das subáreas "modelos de atenção à saúde" (16,7\%), "recursos humanos em saúde e ciência, tecnologia e inovação" com 15,0 \% das publicações cada uma. As subáreas "participação e controle social” (11,8\%) 
e "financiamento da saúde" apresentaram os menores números de trabalhos $(8,1 \%)$.

Tabela 3 - Estudos sobre SUS segundo componentes do sistema. Brasil, 1988-2014

\begin{tabular}{l|l|l}
\hline \multirow{2}{*}{\multicolumn{1}{c|}{ Subárea temática }} & \multicolumn{2}{c}{ Artigos } \\
\cline { 2 - 3 } \multicolumn{1}{c}{} & \multicolumn{1}{c}{ No } & \multicolumn{1}{c}{$\%$} \\
\hline a) Financiamento da saúde & 18 & 8,1 \\
\hline b) Gestão de sistemas e serviços de saúde & 74 & 33,4 \\
\hline c) Modelos de atenção à saúde & 37 & 16,7 \\
\hline d) Recursos humanos em saúde & 33 & 15,0 \\
\hline e) Ciência, tecnologia e inovação & 33 & 15,0 \\
\hline f) Participação e controle social & 26 & 11,8 \\
\hline Total & 221 & 100,0 \\
\hline
\end{tabular}

Fonte: Elaborada pelas autoras.

Essa distribuição revela o maior interesse dos pesquisadores com a problemática da gestão do sistema, abordada sob diversos ângulos, inclusive na perspectiva da chamada "gestão participativa", o que pode explicar o pequeno número de trabalhos que abordam especificamente a "participação e controle social". Chama a atenção, entretanto, o reduzido número de trabalhos sobre financiamento da saúde, um dos temas mais importantes na agenda política do setor, o que pode ter decorrido de certo viés na captura dos artigos, uma vez que não foi utilizado um descritor específico sobre esse tema.

\section{Distribuição dos estudos sobre políticas específicas do Ministério da Saúde}

Considerando que o Ministério da Saúde contempla em seu organograma, responsabilidades definidas sobre políticas específicas, os 377 artigos referentes a políticas de saúde foram distribuídos segundo essas áreas (BRASIL, 2010), a saber: "atenção à saúde”, "gestão 
do trabalho e educação da saúde", "ciência, tecnologia e insumos estratégicos", "gestão estratégica e participativa", "vigilância em saúde" e "saúde indígena" (Tabela 4).

A área de atenção à saúde é a que apresenta maior número de trabalhos (59,6\%), seguida das áreas de gestão do trabalho e educação da saúde (19,9\%), ciência, tecnologia e insumos estratégicos (10,6\%), vigilância em saúde $(7,8 \%)$, gestão estratégica e participativa $(1,6 \%)$ e, por fim, com o menor escore, a área de saúde indígena (0,5\%).

Destaca-se, na área de atenção à saúde, a predominância das publicações nas subáreas da atenção básica (19,9\%) e atenção especializada e temática (19,2\%). Na subárea "atenção básica”, a maioria dos estudos trata especificamente dessa política, provavelmente pela importância concedida à Estratégia Saúde da Família (ESF), abordada sob diversos ângulos. (TEIXEIRA; SOLLA, 2006) Em um distante segundo lugar, estão os estudos sobre a Política de Saúde Bucal, o que também parece estar vinculado à incorporação dessas ações no âmbito da atenção básica, principalmente nos últimos 12 anos. (SOUZA; RONCALLI, 2007)

Há predominância na subárea "ações programáticas e estratégicas" de estudos sobre a Política Nacional de Atenção Integral à Saúde da Mulher (6,9\%) e em segundo lugar sobre a Política Nacional de Atenção Integral à Saúde da Criança e Aleitamento Materno (4,8\%), o que pode refletir a prioridade tradicionalmente atribuída a esses dois grupos na atenção primária à saúde, embora o modelo empregado preconize uma abordagem familiar. (SANTOS NETO, 2008)

Observa-se na subárea "regulação, avaliação e controle de sistemas", o menor número de estudos $(0,8 \%)$, os quais abordavam aspectos dos sistemas de informação e controle de sistemas e serviços em detrimento da regulação e avaliação, planejamento e programação das ações, não abordados nos estudos.

Verifica-se, na subárea "atenção hospitalar e urgência” (3,2\%), discreta concentração de estudos acerca da Política Nacional de Atenção Hospitalar (1,3\%), tema que parece estar sendo abordado mais em função da relevância da atenção hospitalar ser o compo- 
nente do modelo assistencial responsável pela maior absorção de recursos (CARVALHO, 2007) do que do ponto de vista da política governamental. Já a existência de estudos sobre a Política Nacional de Transplantes de Órgãos e Tecidos (1,1\%), ainda que em número reduzido, sinaliza a importância do Programa de Doação, Captação e Transplante de Órgãos e Tecidos no Brasil, o qual realiza todos os tipos de transplantes com financiamento do SUS, incluindo oferta gratuita da medicação necessária após a realização das cirurgias, fazendo com que o Brasil possua atualmente o maior programa público de transplantes do mundo. (MARINHO, 2006)

Componente da área de "atenção à saúde", a Política Nacional de Humanização foi abordada em 4\% dos estudos, percentual esse superior à subárea anteriormente citada, tal achado demonstrando a relevância que vem sendo atribuída à mudança nos modos de gerir e cuidar em saúde, que motivou a criação da Política Nacional de $\mathrm{Hu}$ manização em 2003. (PASCHE; PASSOS; HENNINGTON, 2011)

Segunda área com maior número de publicações (19,9\%), a "gestão do trabalho e educação da saúde" concentra-se em estudos da Gestão da Educação na Saúde (17,2\%) em comparação à Política Nacional de Educação Permanente em Saúde que foi estudada em apenas 2,7\% dos trabalhos. Tal achado sinaliza maior dedicação dos estudos relacionados à formação profissional em saúde em detrimento da educação permanente dos profissionais e trabalhadores do setor, tema só mais recentemente priorizado na agenda política do sistema.

$\mathrm{Na}$ área de ciência, tecnologia e insumos estratégicos, foi encontrada percentagem quatro vezes superior de estudos sobre a Política Nacional de Assistência Farmacêutica (8,5\%), o que indica a relevância que a assistência farmacêutica tem assumido no SUS nos últimos anos na tentativa de melhorar o acesso dos brasileiros aos fármacos de que necessitam, podendo-se citar iniciativas como o Programa de Farmácia Popular criado em 2004 e sua expansão para a Rede Privada em 2006. (VIEIRA, 2010)

Contudo, o acesso ainda é limitado, motivando inclusive onda crescente de ações judiciais para fornecimento de medicamentos e 
produtos, que integram o contemporâneo fenômeno da "judicialização da saúde”. (PEPE et al., 2010) O pequeno número de estudos sobre Política Nacional de Ciência, Tecnologia e Inovação em Saúde $(2,1 \%)$, por sua vez, pode estar refletindo o mesmo processo indicado para a relação Gestão da Educação na Saúde/Educação permanente, ou seja, essa temática só ganhou relevância da agenda política nos últimos 12 anos, o que provavelmente vem estimulando a realização de estudos acerca da incorporação de tecnologias e inovações no SUS.

Tabela 4- Distribuição dos artigos segundo políticas de saúde específicas. Brasil, 1988-2014

\begin{tabular}{|c|c|c|}
\hline Artigos por áreas, subáreas temáticas e políticas & $\mathbf{N}$. & $\%$ \\
\hline Atenção à saúde & 225 & 59,6 \\
\hline 1.1 Atenção básica & 75 & 19,9 \\
\hline 1.1.1 Política Nacional de Atenção Básica & 50 & 13,3 \\
\hline 1.1.2 Política Nacional de Saúde Bucal & 13 & 3,4 \\
\hline 1.1.3 Política Nacional de Alimentação e Nutrição & 2 & 0,5 \\
\hline $\begin{array}{l}\text { 1.1.4 Política Nacional de Práticas Integrativas e } \\
\text { Complementares }\end{array}$ & 10 & 2,7 \\
\hline 1.2Atenção especializada e temática & 73 & 19,2 \\
\hline 1.2.1 Política Nacional de Saúde da Pessoa Idosa & 05 & 1,3 \\
\hline 1.2.2 Política Nacional de Média e Alta Complexidade & 19 & 5,0 \\
\hline $\begin{array}{l}\text { 1.2.3 Política/Programa de Atenção às Pessoas com } \\
\text { Doenças Crônicas }\end{array}$ & 13 & 3,4 \\
\hline 1.2.4 Política Nacional de Saúde Mental & 27 & 7,2 \\
\hline $\begin{array}{l}\text { 1.2.5 Política de Atenção Integral aos Usuários de Álcool e } \\
\text { Outras Drogas }\end{array}$ & 4 & 1,0 \\
\hline $\begin{array}{l}\text { 1.2.6 Política Nacional de Atenção Integral à Saúde do } \\
\text { Homem }\end{array}$ & 5 & 1,3 \\
\hline 1.3 Ações programáticas e estratégicas & 47 & 12,5 \\
\hline $\begin{array}{l}\text { 1.3.1 Política Nacional de Atenção Integral à Saúde das } \\
\text { Pessoas Privadas de Liberdade no Sistema Prisional }\end{array}$ & 0 & 0,0 \\
\hline
\end{tabular}




\begin{tabular}{|c|c|c|}
\hline $\begin{array}{l}\text { 1.3.2 Política Nacional de Atenção Integral à Saúde da } \\
\text { Mulher }\end{array}$ & 26 & 6,9 \\
\hline $\begin{array}{l}\text { 1.3.3 Política Nacional de Atenção Integral à Saúde da } \\
\text { Criança e Aleitamento Materno }\end{array}$ & 18 & 4,8 \\
\hline $\begin{array}{l}\text { 1.3.4 Política Nacional de Atenção Integral à Saúde do } \\
\text { Adolescente }\end{array}$ & 1 & 0,3 \\
\hline 1.3.5 Política Nacional de Saúde da Pessoa com Deficiência & 2 & 0,5 \\
\hline 1.4 Regulação, avaliação e controle de sistemas & 3 & $\mathbf{0 , 8}$ \\
\hline 1.4.1 Sistemas de informação & 2 & 0,5 \\
\hline 1.4.2 Controle de serviços e sistemas & 1 & 0,3 \\
\hline 1.4.3 Regulação e svaliação & 0 & 0,0 \\
\hline 1.4.4 Planejamento e programação das ações em saúde & 0 & 0,0 \\
\hline 1.5 Atenção hospitalar e urgência & 12 & 3,2 \\
\hline $\begin{array}{l}\text { 1.5.1 Política Nacional de Sangue, Componentes e } \\
\text { Hemoderivados }\end{array}$ & 1 & 0,3 \\
\hline 1.5.2 Rede de Atenção às Urgências e Emergências & 2 & 0,5 \\
\hline $\begin{array}{l}\text { 1.5.3 Política Nacional de Transplantes de Órgãos e } \\
\text { Tecidos }\end{array}$ & 4 & 1,1 \\
\hline 1.5.4 Política Nacional de Atenção Hospitalar & 5 & 1,3 \\
\hline 1.6 Política Nacional de Humanização & 15 & 4,0 \\
\hline Gestão do trabalho e educação na saúde & 75 & 19,9 \\
\hline 2.1 Gestão da educação na saúde & 65 & 17,2 \\
\hline 2.2 Política Nacional de Educação Permanente em Saúde & 10 & 2,7 \\
\hline Ciência, tecnologia e insumos estratégicos & 40 & 10,6 \\
\hline 3.1 Política Nacional de Assistência Farmacêutica & 32 & 8,5 \\
\hline $\begin{array}{l}\text { 3.2 Política Nacional de Ciência, Tecnologia e Inovação em } \\
\text { Saúde }\end{array}$ & 8 & 2,1 \\
\hline Gestão estratégica e participativa & 06 & 1,6 \\
\hline $\begin{array}{l}\text { 4.1 Política Nacional de Gestão Estratégica e Participativa no } \\
\text { SUS }\end{array}$ & 2 & 0,5 \\
\hline 4.2 Política Nacional de Educação Popular em Saúde & 1 & 0,3 \\
\hline
\end{tabular}




\begin{tabular}{c|l|l}
\hline 4.3 Política Nacional de Saúde Integral da População Negra & 3 & 0,8 \\
\hline $\begin{array}{l}\text { 4.4 Política Nacional de Saúde Integral de Outras Populações } \\
\text { (Lésbicas, Gays, Bissexuais, Travestis e Transexuais; Campo e } \\
\text { floresta; em Situação de rua e Cigana }\end{array}$ & 0 & 0,0 \\
\hline Vigilância em saúde & $\mathbf{2 9}$ & $\mathbf{7 . 8}$ \\
\hline 5.1 Vigilância epidemiológica & $\mathbf{0 7}$ & $\mathbf{1 , 9}$ \\
\hline 5.1.1 Programa Nacional de Controle da Tuberculose & 3 & 0,8 \\
\hline $\begin{array}{c}\text { 5.1.2 Programa Nacional de Imunizações, Controle } \\
\text { da Hanseníase, da Dengue, da Malária }\end{array}$ & 0 & 0,0 \\
\hline 5.1.3 Controle de chagas e esquistossomose & 4 & 1,1 \\
\hline 5.2 Análise de situação de saúde & $\mathbf{7}$ & $\mathbf{1 , 9}$ \\
\hline 5.2.1 Política Nacional de Promoção da Saúde & $\mathbf{7}$ & $\mathbf{1 , 9}$ \\
\hline $\begin{array}{l}\text { 5.3 Vigilância, prevenção e controle das doenças } \\
\text { sexualmente transmissíveis, síndrome da } \\
\text { imunodeficiência adquirida e hepatites virais }\end{array}$ & $\mathbf{0 8}$ & $\mathbf{2 , 1}$ \\
\hline $\begin{array}{l}\text { 5.3.1 Política Nacional de Prevenção de DST/HIV/AIDS e } \\
\text { Hepatites Virais }\end{array}$ & 8 & 2,1 \\
\hline 5.4 Vigilância em saúde ambiental e do trabalhador & $\mathbf{0 7}$ & $\mathbf{1 , 9}$ \\
\hline 5.4.1 Política Nacional de Saúde Ambiental & 1 & 0,3 \\
\hline $\begin{array}{l}\text { 5.4.2 Política Nacional de Saúde do Trabalhador } \\
\text { Saúde indígena }\end{array}$ & 6 & 1,6 \\
\hline 6.1 Política Nacional de Atenção à Saúde dos Povos Indígenas & 2 & 0,5 \\
\hline Total & $\mathbf{3 7 7}$ & $\mathbf{1 0 0 , 0}$ \\
\hline
\end{tabular}

Fonte: Elaborada pelas autoras.

$\mathrm{Na}$ área de gestão estratégica e participativa, predominam estudos acerca da Política Nacional de Saúde Integral da População Negra em detrimento de outros grupos $(0,8 \%)$, o que pode estar relacionado à representatividade e consolidação do Movimento Social Negro. (LIMA, 2010) Chama a atenção o fato de ter aparecido apenas um estudo sobre a Política Nacional de Educação Popular em Saúde e não aparecerem publicações sobre várias outras políticas que 
têm sido formuladas mais recentemente, como é o caso da Política Nacional de Saúde Integral de outras populações (Lésbicas, Gays, Bissexuais, Travestis e Transexuais; Campo e floresta; em Situação de rua e Cigana).

$\mathrm{Na}$ área de vigilância em saúde, estudos sobre a Política Nacional de Prevenção de DST/HIV/AIDS e Hepatites Virais foram os mais frequentes $(2,1 \%)$, sugerindo a relevância atribuída à temática no país que conta com movimento social organizado em torno do tema e um programa que, embora tenha dividido opiniões quanto à sua efetividade, destaca-se no mundo por oferecer tratamento antirretroviral gratuito. (VILLARINHO et al., 2013) Em segundo lugar, aparecem os estudos acerca da Política Nacional de Promoção da saúde $(1,9 \%)$, tema que tem sido abordado por vários pesquisadores, sendo que a divulgação dos resultados desses estudos não tem se dado através de artigos científicos e sim através de livros e capítulos de livro. (PELLEGRINI FILHO; BUSS; ESPERIDIÃO, 2014; TEIXEIRA, 2006) Foi encontrado também um único estudo sobre Política Nacional de Saúde Ambiental e não houve publicações sobre os Programas Nacionais de Imunizações e Controle da Hanseníase, da Dengue e da Malária.

Por fim, a área de saúde indígena foi contemplada com apenas 0,5\% das publicações. Embora corresponda a parcela numericamente pouco expressiva da população, os índios têm grande importância histórico-cultural para o país, o que poderia motivar parcela mais expressiva de estudos dedicados às suas diversas demandas, muito específicas, relativas à sua sobrevivência física e cultural diante da acelerada e complexa transformação social a que foram submetidos. (CHAVES; CARDOSO; ALMEIDA, 2006)

\section{Análise de conteúdo dos artigos de "análise política em saúde"}

Além da análise da distribuição dos artigos selecionados segundo temas e objetos de estudo, realizamos a análise dos 78 artigos in- 
cluídos na subárea "análise política em saúde” (Tabela 1) com vistas a identificar a presença ou não de referência à RSB, e caso positivo, em que período situam esse processo. Do conjunto de trabalhos analisados, apenas 16 fazem menção à RSB ou expressões correlatas, aparecendo como palavra-chave o termo "Reforma Sanitária" (9), e os termos "Movimento Sanitário" (1), "Reforma do Setor Saúde" (1), "Reforma dos Serviços de Saúde" (1), sendo que, nos demais (4), os termos aparecem apenas no texto do resumo ou no título do artigo.

Quanto à evolução temporal, apenas um trabalho foi publicado na década de 1990 (QUEIROZ; VIANNA, 1992), sendo os demais publicados a partir dos anos 2000. A análise de conteúdo desses artigos revela que a grande maioria (15) faz menção direta à RSB seja em seus títulos, objetivos ou resumos. Muitos deles contemplam algum resgate histórico do movimento da RSB, suas origens históricas, bases conceituais e características do processo político. (CAMPOS, 2007b; COELHO, 2010; CORDEIRO, 2004; FLEURY, 2009; MERHY, 2012; PAIM, 2006, 2008b; PAIVA; TEIXEIRA, 2014; QUEIROZ; VIANNA, 1992; SANTOS, 2013; SANTOS; SILVA, 2013) Destes, apenas seis fazem menção à permanência do processo de RSB na conjuntura mais recente. (CAMPOS, 2007b; COHN, 2009; FLEURY, 2009; PAIM, 2006, 2008b; SANTOS, 2013) Cabe assinalar que o artigo incluído nesse grupo que não utiliza a expressão RSB ou "reforma sanitária”, usa o descritor "reforma do setor saúde”, assumindo uma perspectiva de análise de políticas comparadas ao discutir elementos centrais desse processo em países da América Latina. (ALMEIDA, 2002)

Chama a atenção o fato de que alguns dos autores que abordam o processo de RSB são reconhecidos como militantes históricos do movimento sanitário, conforme, aliás, é apontado por um dos trabalhos selecionados (PAIVA; TEIXEIRA, 2014) e apresentam uma reflexão fundamentada na avaliação dos avanços e dificuldades enfrentadas no processo. Um primeiro grupo se atém ao debate acerca da natureza do processo de RSB e identifica os desafios políticos e institucionais para sua continuidade e aperfeiçoamento. Outros, entretanto, apesar de se 
referirem à $\mathrm{RSB}$, concentram sua análise no processo de construção do SUS, aspecto que, aliás, não passa despercebido dos primeiros, porém não é o foco central da sua análise.

Dos autores que situamos no primeiro grupo, destacam-se Jairnilson Paim, Gastão Wagner de Sousa Campos, Sonia Fleury e Nelson Rodrigues dos Santos. Paim (2008b, p. 640), aponta que apesar de suas notáveis conquistas, “[...] a RSB restringiu-se a uma reforma parcial de natureza setorial e institucional traduzida pelos 20 anos de implementação tortuosa do SUS”. As limitações da RSB também são reconhecidas por Fleury (2009), ao afirmar que, a política pública institucionalizada a partir da RSB, o [...] instituído, “[...] se impôs ao instituinte, reduzindo o caráter libertário e transformador da reforma [...]". Para a autora, "o paradoxo da reforma sanitária brasileira é que seu êxito [...] reduziu a capacidade de ruptura, inovação e construção de uma nova correlação de forças desde a sociedade civil organizada [...]”. (FLEURY, 2009, p. 751) Outro autor que analisa as dificuldades desse processo é Campos (2007b, p. 1873), para quem a concretização da RSB enfrenta barreiras, como por exemplo, a “[...] cultura patrimonialista predominante na administração pública [...]"e a falta de eficiência das Conferências e dos Conselhos de Saúde, que apesar de relevantes, não tem sido suficientes para “[...] indicar rumos e criar os consensos [...]".

Como se pode constatar, os autores acima citados, apesar das diferenças na abordagem do fenômeno "reforma sanitária brasileira", têm em comum a compreensão de que esse processo não se encontra necessariamente encerrado, considerando que, enquanto movimento social, a RS “[...] está desafiada a persistir na sua ação inovadora e criativa, na luta pelos direitos sociais". (SANTOS, 2013, p. 278)

Para isso, Paim (2008b, p. 627) considera que a análise do significado e da viabilidade do projeto da RSB exige a realização de investigações que permitam a identificação de "[...] atores sociais relevantes" capazes de manter e dar continuidade ao processo. Nessa perspectiva, Santos (2013, p. 278-279), defende a 
[...] retomada da comunicação direta com as entidades da sociedade e movimentos sociais; [...] fortalecimento dos conselhos de saúde; e [...] superação dos embates entre as causalidades governamentais e partidárias de um lado, e de outro, a conscientização e mobilização supra e apartidária por reforma do Estado, democrática e política, voltada para as diretrizes constitucionais de políticas públicas para os direitos sociais [...] .

Sonia Fleury (2009, p. 751), por sua vez, aponta alguns desafios institucionais presentes no momento atual da reforma sanitária, quais sejam:

[...] a incapacidade de implantar um modelo integral de atenção à saúde $[. .$.$] a incapacidade de implantar melho-$ rias na gestão do sistema e na gestão das unidades, $[. .$.$] a$ falta de uma renovação ética dos profissionais de saúde e [...] a dependência de insumos e medicamentos cujos preços e condições de produção por grandes empresas multinacionais fogem ao controle dos Estados nacionais [...].

Em outra perspectiva, situam-se os autores que analisam a RSB sob a ótica do processo de construção do SUS, destacando-se Amélia Cohn, para quem "o processo de implantação do SUS [...], induziu - com todos os seus méritos [...] - os militantes da área a abdicarem da Reforma Sanitária enquanto um projeto emancipatório”. (COHN, 2009, p.1616) Para a autora, talvez o que esteja ocorrendo na atualidade, seja uma "reforma da reforma", num processo em que a "[...] dimensão da política vem sendo subsumida pela dimensão técnico-cientifica, levando a uma pasteurização da própria dimensão política”. (COHN, 2009, p. 1618) A hipótese da autora é que a explicação para tal fato deriva da "[...] incapacidade da comunidade do campo sanitário de formular um novo projeto para saúde articulado com um projeto para a sociedade”. (COHN, 2009, p. 1618)

Cardoso e Campos (2013, p. 221-222), por sua vez, destacam que o 
[...] alcance incompleto e descontínuo das conquistas do movimento de reforma sanitária se relaciona à inviabilidade da estratégia de conquistas progressivas e cumulativas de direitos universais no interior do Estado brasileiro [...]. Tal Estado, marcado pela influência do grande capital sobre todas as esferas da sociedade e do poder estatal, bem como pelo ataque permanente aos direitos da classe trabalhadora [...], escancara os estreitos limites do capitalismo dependente. Assim, [...] as reivindicações em torno da 'democratização progressiva', bandeiras do movimento de luta pela reforma sanitária, se chocaram com a ordem social e política brasileira.

Coerentemente com o foco de sua análise, Cohn (2009, p. 1618) defende que a superação desses desafios implica em se buscar "[...] identificar quem são e onde se constroem novas redes de sociabilidade e novas identidades sociais" capazes de levar à frente esse projeto, perspectiva que, de certo modo, conflui com as propostas elaboradas por Paim (2013b, p. 1953) com relação à identificação dos "sujeitos da antítese" capazes de dar continuidade ao processo de RSB e também com a proposta de Fleury (2009, p. 751), acerca da necessidade de “[...] construção permanente do sujeito, aquele que poderá transformar novamente o instituído em instituinte, para de novo institucionalizar-se".

Por outro lado, Campos (2007a) elenca em seu estudo sete estratégias que se concentram, entretanto, na busca de consolidar o SUS. Para esse autor, o caminho para avançar a reforma sanitária depende, de se

[...] privilegiar, no consenso a ser instaurado, elementos da tradição dos sistemas públicos, procurando, com isto, resolver uma série de ambigüidades discursivas e pragmáticas, que tem permitido ao ideário liberal-privatista sobreviver para além do conveniente e do necessário. (CAMPOS, 2007b, p. 1873) 
Como vemos, apesar da confluência de concepções acerca da $\mathrm{RSB}$, os trabalhos analisados revelam a diferença de propostas e estratégias para se garantir a viabilidade política bem como a continuidade do processo de RSB no âmbito institucional.

\section{Considerações finais}

O mapeamento da produção científica sobre política de saúde no período 1988-2014 é uma primeira aproximação que será desdobrada em estudos posteriores que identifiquem as abordagens teóricas utilizadas pelos diversos autores. $\mathrm{O}$ estudo, entretanto, revela algumas características da prática de pesquisa que vem sendo desenvolvida na área de política, planejamento e gestão em saúde, e estimula o levantamento de propostas para a continuidade e aprofundamento da análise dos trabalhos publicados nessa área.

Em primeiro lugar, observa-se uma tendência ao aumento da quantidade de artigos publicados ao longo do período, o que certamente reflete o aumento exponencial de grupos de pesquisa nessa área, os quais somavam, em abril de 2015, cerca de 81 grupos registrados na plataforma de grupos de pesquisa do Conselho Nacional de Desenvolvimento Científico e Tecnológico (CNPq). Como apontamos anteriormente, tal fato pode estar ligado, inclusive, ao aumento do número de programas de cursos de pós-graduação na área de Saúde Coletiva, inclusive de mestrados profissionalizantes.

Em segundo lugar, chama atenção a mudança que vem se verificando na distribuição desses trabalhos por área temática, o que evidencia certa redefinição dos objetos de investigação e, provavelmente, uma diversificação de abordagens teórico-metodológicas utilizadas na análise dos diversos temas. De fato, no levantamento feito 10 anos atrás (TEIXEIRA; PAIM, 2005), observou-se que, na maioria dos estudos sobre política de saúde realizados até o início da década de 1990, predominava uma perspectiva macro, utilizando-se categorias extraídas da abordagem marxista, tendo como referencial as relações Estado-Sociedade, considerados determinantes dos pro- 
cessos políticos em saúde. Paulatinamente, foram surgindo investigações sobre políticas, instituições e práticas de saúde, valorizandose, também, estudos de avaliação de políticas e programas de saúde.

Essa tendência parece ter se intensificado nos últimos anos, uma vez que o mapeamento do conjunto da produção revela a concentração dos estudos na análise de políticas específicas, o que pode estar refletindo a própria fragmentação do processo de formulação e implementação de políticas de saúde no Brasil, com ênfase na elaboração de propostas de intervenção sobre problemas apresentados por grupos populacionais específicos, que, ao se organizarem politicamente e ocuparem espaços de decisão no âmbito governamental, passam a pressionar pela formulação e implementação de programas e ações especificamente dirigidas ao atendimento de suas demandas.

Também chama a atenção o crescimento de estudos que abordam o processo de construção do SUS, tendencialmente voltados à análise de componentes específicos do sistema, principalmente os aspectos relacionados à gestão do sistema, seguido de estudos sobre modelos de atenção, financiamento, ciência e tecnologia, recursos humanos e participação social. Nessa perspectiva, é de se esperar a incorporação de referenciais teóricos provindos de disciplinas específicas, como é o caso da administração pública, economia, educação etc., colocando-se, portanto, a necessidade de se avançar com a leitura e análise dos textos completos.

Chama a atenção, por fim, o número relativamente reduzido de estudos que abordem as questões do poder em saúde na perspectiva macropolítica, da relação entre Estado e as classes sociais no Brasil contemporâneo, especialmente tendo em vista a problematização da sustentabilidade política do processo da RSB e os determinantes das tendências atuais de valorização do mercado de serviços de saúde, expressas tanto na expansão dos planos de saúde e serviços privados quanto na privatização do sistema público. (COSTA; BAHIA; SCHEFFER, 2013; SCHEFFER, 2015; SESTELO; SOUZA, BAHIA; 2013) Como vimos, são poucos os estudos que problematizam a RSB, quer analisando as dificuldades enfrentadas no 
processo, quer apontando estratégias para garantir sua viabilidade e continuidade na conjuntura mais recente. É possível que isso reflita, indiretamente, a diversidade de concepções acerca da vitalidade do processo da RSB (HOCHMAN, 2013; PAIM, 2013b), com grande parte dos estudiosos se ocupando muito mais dos processos institucionais de construção do SUS do que da luta política mais geral para viabilizar a RSB enquanto uma reforma social, uma mudança no "modo de vida". (PAIM, 2008a)

Isso reforça a necessidade de se avançar na leitura dos textos completos desses trabalhos, de modo a identificar a filiação dos autores a determinadas correntes de pensamento, tendo como referência o debate político mais geral sobre os rumos da sociedade brasileira no contexto atual e as perspectivas que se desenham em termos de política de saúde. Do mesmo modo, isso também pode vir a ser feito com os trabalhos que abordam os diversos componentes do SUS e as políticas específicas, contribuindo para subsidiar as investigações em curso nos diversos eixos temáticos do Observatório de Análise

64 Política em Saúde (OAPS), cuja finalidade principal é subsidiar o debate sobre os modos de produzir conhecimento cientificamente fundamentado e politicamente comprometido com o aperfeiçoamento do processo de construção do SUS e da melhoria da efetividade das ações voltadas ao enfrentamento dos problemas de saúde dos distintos grupos populacionais. Esse é exatamente o desafio que estamos tratando de enfrentar como parte da pesquisa que vem sendo desenvolvida no eixo 1 do OAPS, que trata especificamente do monitoramento do processo político em saúde, com base no acompanhamento de notícias veiculadas nos sites de diversos órgãos governamentais e não governamentais, envolvidos direta ou indiretamente com o avanço do processo de Reforma Sanitária no país.

\section{Referências}

AGENDA estratégica para a saúde no Brasil. 2011. Disponível em: <http://www6.ensp.fiocruz.br/radis/sites/default/files/109/pdf/ agenda-saude-para-todos.pdf $>$. Acesso: 21 jul. 14 . 
(UMA) AGENDA estratégica para a saúde no Brasil.[S.l.], 2011.

Disponível em: <http://www.cebes.org.br/media/File/ Agenda\%20 Estrategica \%20para\%20a\%20Saudepdf|>. Acesso em: 19 jul. 2014.

ALMEIDA, C. Eqüidade e reforma setorial na América Latina:um debate necessário. Caderno Saúde Pública, Rio de Janeiro, n. 18, p. 23-36, 2002. Suplemento.

ARTMANN, E. Desafios na formação de Recursos Humanos para o SUS: a experiência do Mestrado profisisonalizante da ENSP com a SAS-MS. In: LEAL, M.C.; FREITAS, C. M. (Org.). Cenários possíveis: experiências e desafios do mestrado profissional na saúde coletiva. Rio de Janeiro: Ed. Fiocruz, 2006. p. 151-189.

BAHIA, L. A saúde em banho-maria. In: MAGALHÃES, J. P. de A. Os anos Lula: contribuições para um balanço crítico 2003-2010. Rio de Janeiro: Garamond, 2010. p. 351-368.

BORGES, F. T. et al. Anatomia da privatização neoliberal do Sistema Único de Saúde: o papel das Organizações Sociais de Saúde. São Paulo: Cultura Acadêmica, 2012.

BRASIL . Conselho Nacional de Saúde. $8^{a}$ Conferência Nacional de Saúde: relatório final. Brasília, DF, 1986a.

BRASIL. Constituição (1988). Constituição da República Federativa do Brasil. Brasília, DF: Senado, 1988.

BRASIL. Ministério da Saúde. Portaria Interministerial MEC/MS/ MPAS N. 9 02/86. Diário Oficial da União. Brasilia, DF, 22 ago. 1986b.

BRASIL. Ministério da Saúde. Secretaria Executiva. Coordenação Geral de Inovação Gerencial. Regimentos Internos e organogramas básicos do Ministério da Saúde Brasília, DF, 2010. (Série E. Legislação de saúde).

CAMPOS, G. W. de S. Reforma política e sanitária:a sustentabilidade do SUS em questão? Ciência e Saúde Coletiva, Rio de Janeiro, v. 12, n. 2, p. 301-306, abr. 2007a.

CAMPOS, G. W. de S. O SUS entre a tradição dos Sistemas Nacionais e o modo liberal-privado para organizar o cuidado à saúde. Ciência Saúde e Coletiva, Rio de Janeiro, v. 12, p. 1865-1874. nov. 2007b. Suplemento. 
CARDOSO, F. M.; CAMPOS, G. W. de S. Reformas Neoliberais, Reforma Sanitária Brasileira e Fundações Estatais de Direito Privado: análise de documento da Fundação Estatal de Saúde da Família (FESF) Bahia. Saúde em debate, Rio de Janeiro, v. 37, n. 97, p. 219-232, Jun. 2013.

CARVALHO, D. M. T. de. Financiamento da assistência médicohospitalar no Brasil. Ciência Saúde e Coletiva, Rio de Janeiro, v. 12, n. 4, ago. 2007.

CHAVES, M. de B. G.; CARDOSO, A. M.; ALMEIDA, C. Implementação da política de saúde indígena no Pólo-base Angra dos Reis, Rio de Janeiro, Brasil: entraves e perspectivas.Caderno Saúde Pública, Rio de Janeiro, v. 22, n. 2, p. 295-305, fev. 2006.

COELHO, I. B. Democracia sem equidade: um balanço da reforma sanitária e dos dezenove anos de implantação do Sistema Único de Saúde no Brasil. CiênciaSaúde Coletiva, Rio de Janeiro, v. 15, n.1, p. 171-183, jan. 2010

COHN, A. A reforma sanitária brasileira após 20 anos do SUS: reflexões. Caderno Saúde Pública, Rio de Janeiro, v. 25, n. 7, p. 1614-1619, jul. 2009. CORDEIRO, H. O Instituto de Medicina Social e a luta pela reforma sanitária: contribuição à história do SUS. Physis: Revista de Saúde Coletiva, Rio de Janeiro v. 14, n. 2, p. 343-362, jul./dez. 2004.

CÔRTES, S. V. Conselhos e conferências de saúde: papel institucional e mudança nas relações entre Estado e sociedade. In: LOBATO, L. de V. C; FLEURY; S. Participação, democracia e saúde. Rio de Janeiro: CEBES, 2010, p. 102-128. (Coleção Pensar em Saúde).

CÔRTES, S. V. Sistema Único de Saúde: espaços decisórios e a arena política de saúde. Cadernos de Saúde Pública, Rio de Janeiro, v. 25, n. 7, p. 1626-1633, jun. 2009.

COSTA, A. M.; BAHIA, L.; SCHEFFER, M. Onde foi parar o sonho do SUS? Le Monde Diplomatique, São Paulo, n. 69, p. 30-31, 2013.

DOURADO, I. et al. A experiência do mestrado profissional do Instituto de Saúde Coletiva da UFBA 2001-2004. In: LEAL, M. C.; FREITAS, C. M. (Org.). Cenários possíveis: experiências e desafios do mestrado 
profissional na saúde coletiva. Rio de Janeiro: Ed.Fiocruz, 2006.

p. 101-121.

ESCOREL, S. Reviravolta na saúde: origem e articulação do movimento sanitário. Rio de Janeiro: Ed. Fiocruz, 1999.

FLEURY, S. Estado sem cidadãos: seguridade social na América Latina. Rio de Janeiro: Ed. Fiocruz, 1994.

FLEURY, S. Reforma sanitária brasileira: dilemas entre o instituinte e o instituído.Ciência e Saúde Coletiva, Rio de Janeiro, v. 14, n. 3, p. 743-752, Jun. 2009.

GERSCHMAN, S. A democracia inconclusa: um estudo da reforma sanitária brasileira. Rio de Janeiro: Ed. Fiocruz, 1985.

HOCHMAN, G. Saudades do futuro ou um sistema de saúde em tempos democráticos. Caderno Saúde Pública, Rio de Janeiro, v. 29, n. 10, p. 1927-1953, out. 2013.

KINGDON, J. W. Agendas, alternatives, and public policies. $3^{\text {rd }}$. Washington: LONGMAN, 2011.

KLECZKOWSKI, B.; ROEMER, M.; VAN DER WERFF, A. Sistemas nacionales de salud y su reorientación hacia la salud para todos. Cuadernos de Salud Pública, La Habana, n. 77, 1984.

LABRA, M. H.; FIGUEIREDO, J. S. A de. Associativismo, participação e cultura cívica: o potencial dos conselhos de saúde. Ciência e Saúde Coletiva, Rio de Janeiro, v. 7, n. 3, p. 537-547, 2002.

LEVCOVITZ, E. et al. Produção de conhecimento em política, planejamento e gestão em saúde e políticas de saúde no Brasil (1974-2000). Brasília, DF: OPAS, 2003. (Série Técnica Projeto de Desenvolvimento de Sistemas de Serviços de Saúde, 2).

LIMA, M. Desigualdades raciais e políticas públicas: ações afirmativas no governo Lula. Novos Estudos - CEBRAP, São Paulo, n. 87, p. 77-95, July 2010.

LIMA, N. T; SANTANA, J. P. (Org.). Saúde coletiva como compromisso: a trajetória da ABRASCO. Rio de Janeiro: Ed. Fiocruz, 2006. 
LOBATO, L. de V. C; FLEURY; S. Participação, Democracia e Saúde.Rio de Janeiro: CEBES, 2009.(Coleção Pensar em Saúde).

MACHADO, C.V.; BAPTISTA, T.W.F.; LIMA, L.D. (Org.). Políticas de Saúde no Brasil: continuidades e mudanças. Rio de Janeiro: Ed. Fiocruz, 2012.

MAGNO, L. D. Dos clamores das ruas aos rumores no congresso: uma análise da conjuntura recente da saúde no Brasil. 2014. 105 f. Dissertação (Mestradoem Saúde Coletiva) -Intituto de SaudeColetiva, Universidade Federal da Bahia, Salvador, 2014. Disponível em: <http://repositorio. ufba.br/ri/handle/ri/18272>. Acesso em: 20 mar. 16.

MARINHO, A. Um estudo sobre as filas para transplantes no Sistema Único de Saúde brasileiro.Cadernode Saúde Pública,Rio de Janeiro, v. 22, n. 10, p. 2229-2239, Oct. 2006.

MERHY, E. Saúde e direitos: tensões de um SUS em disputa, molecularidades.Saúde e Sociedade, São Paulo, v. 21, n. 2, p. 267-279, Jun. 2012.

NORONHA, J.C.; LIMA, L.D.; MACHADO, C.V. O Sistema Único de Saúde. In: GIOVANELLA, L. et al. (Org.). Políticas e sistemas de saúde no Brasil. 2. ed. Rio de Janeiro: Ed. Fiocruz, 2012. p. 365-393.

NORONHA, J.C.; SANTOS, I.; PEREIRA, T. Relações entre o SUS e a saúde suplementar: problemas e alternativas para o futuro do sistema universal. In: SANTOS, N.R.; AMARANTE, P.D.C. (Org.). Gestão pública e relação público-privado na saúde. Rio de Janeiro: Cebes, 2011. p. 152-179.

OCKÉ-REIS, C.O. SUS: o desafio de ser único. Rio de Janeiro:Ed. Fiocruz, 2012.

PAIM, J. S. A Constituição cidadã e os 25 anos do Sistema Único de Saúde. Caderno Saúde Pública, Rio de Janeiro, v. 29, n. 10, p. 1927-1953, 2013a.

PAIM, J. S. Eqüidade e reforma em sistemas de serviços de saúde: o caso do SUS. Saúde e Sociedade, São Paulo, v. 15, n. 2, p. 34-46, ago. 2006. 
PAIM, J. S. O futuro do SUS. Caderno de Saúde Pública, Rio de Janeiro, v. 28, p. 612-613, 2012.

PAIM, J. S. Políticas de saúde no Brasil. In: ROUQUAYROL, M. Z.; ALMEIDA FILHO, N. Epidemiologia e Saúde. 6. ed. Rio de Janeiro: MEDSI; 2003. p. 587-603.

PAIM, J.S. Reforma Sanitária Brasileira: contribuição para a compreensão e crítica. / Salvador: EDUFBA; Rio de Janeiro: Ed. Fiocruz, 2008a.

PAIM, J. S. Reforma sanitária brasileira: eppur si muove. Caderno de Saúde Pública, Rio de Janeiro, v. 29, n. 10, p. 1927-1953, out. 2013 b.

PAIM, J. S. A reforma sanitária brasileira e o Sistema Único de Saúde: dialogando com hipóteses concorrentes. Physis, Rio de Janeiro, v. 18, n. 4, p. 625-644, 2008b.

PAIM, J. et. al. O sistema de saúde brasileiro: história, avanços e desafios. The Lancet, Estados Unidos da América, p. 12-31, 2011. Disponível em: <http://download.thelancet.com/flatcontentassets/pdfs/brazil/ brazilpor1.pdf $>$. Acesso em: 18 maio 2015.

PAIM, J. S.; TEIXEIRA, C. F. Política, planejamento e gestão em saúde: balanço do estado da arte. Revista Saúde Pública, Rio de Janeiro, n. 40, p. 73-78, 2006. Suplemento.

PAIVA, C. H. A.; TEIXEIRA, L. A. Reforma sanitária e a criação do Sistema Único de Saúde: notas sobre contextos e autores. História, Ciências, Saúde-Manguinhos, Rio de Janeiro, v. 21, n.1, p. 15-36, mar. 2014. PASCHE, D. F.; PASSOS, E.; HENNINGTON, É. A. Cinco anos da política nacional de humanização: trajetória de uma política pública. Ciência de Saúde Coletiva, Rio de Janeiro, v. 16, n. 11, p. 4541-4548, nov. 2011.

PELLEGRINI FILHO, A.; BUSS, P. M.; ESPERIDIÃO, M. A. Promoção da Saúde e seus fundamentos: determinantes sociais da saúde, ação intersetorial e políticas saudáveis. In: PAIM, J. S.; ALMEIDA FILHO, N. (Org.). Saúde coletiva: teoria e prática. Rio de Janeiro: Med Book. 2014. p. 305-326. 
PEPE, V. L. E. et al. A judicialização da saúde e os novos desafios da gestão da assistência farmacêutica. Ciência e Saúde Coletiva, Rio de Janeiro, v. 15, n. 5, p. 2405-2414, ago. 2010.

PIERANTONI, C. R. Formação de gestores para o SUS In: LEAL, M. C e FREITAS, C. M. (Org.). Cenários possíveis: experiências e desafios do mestrado profissional na saúde coletiva. Rio de Janeiro: Ed. Fiocruz, 2006. p. 123-136.

QUEIROZ, M. de S.; VIANNA, A. L. Padrão de política estatal em saúde e o sistema de assistência médica no Brasil atual. Revista de Saúde Pública, Rio de Janeiro, v. 26, n. 2, p. 132-140, abr. 1992.

(A) QUESTÃO democrática na área da saúde. Apresentado no $1^{\text {a }}$ Simpósio sobre Politica de Saúde da Câmara Federal,1979. Disponível em: <http://cebes.org.br/site/wp-content/uploads/2015/10/Cebes Saúde-e-Democracia.pdf $>$. Acesso: 4 out. 2015.

SAMPAIO, R. F.; MANCINI, M. C. Estudos de revisão sistemática: um guia para síntese criteriosa da evidência científica. Revista Brasileira de Fisioterapia, São Carlos, v. 11, n. 1, p. 83-89, jan./fev. 2007.

SANTOS NETO, E. T. dos. et al. Políticas de saúde materna no Brasil: os nexos com indicadores de saúde materno-infantil. Saúde e Sociedade, São Paulo, v. 17, n. 2, p. 107-119, Jun. 2008.

SANTOS, L. R. C. S.; SILVA, T. P. C. A utopia da Reforma Sanitária Brasileira em um discurso no Congresso da ABRASCO 2009. Saúde em debate, Rio de Janeiro, v. 37, n. 97, p. 210-2018, Jun. 2013.

SANTOS, N. R. dos. SUS, política pública de estado: seu desenvolvimento instituído e instituinte e a busca de saídas. Ciência de Saúde Coletiva, Rio de Janeiro, v. 18, n.1, p. 273-280, Jan. 2013.

SCHEFFER, M. O capital estrangeiro e a privatização do sistema de saúde brasileiro. Caderno de Saúde Pública, Rio de Janeiro, v. 31, n. 4, p. 663-666, abr. 2015.

SESTELO, J. A. de F.; SOUZA, L. E. P. F. de; BAHIA, L. Saúde suplementar no Brasil: abordagens sobre a articulação público/privada na assistência à saúde. Caderno Saúde Pública, Rio de Janeiro, v. 29, n. 5, p. 851-866, 2013. 
SOPHIA, D. C. Saúde e utopia: o Cebes e a reforma sanitária brasileira. São Paulo: Hucitec: Sobravime, 2015.

SOUZA, T. M. S. de; RONCALLI, A. G. Saúde bucal no Programa Saúde da Família: uma avaliação do modelo assistencial. Caderno de Saúde Pública, Rio de Janeiro, v. 23, n. 11, p. 2727-2739, nov. 2007.

TEIXEIRA, C. F.; PAIM, J. S. A política de saúde no governo Lula e a dialética do menos pior. Saúde em Debate, Rio de Janeiro, v. 29, n. 31, p. 268-283, 2005.

TEIXEIRA, C. F. Significado estratégico do Mestrado profissionalizante na consolidação do campo da saúde coletiva. In: LEAL, M. C.; FREITAS, C. M. (Org.). Cenários possíveis: experiências e desafios do mestrado profissional na saúde coletiva. Rio de Janeiro: Ed. Fiocruz, 2006. p. 33-47.

TEIXEIRA, C. F.; SOUZA, L. E.; PAIM, J. S. Sistema Único de Saúde, a difícil construção de um sistema universal na sociedade brasileira. In: ALMEIDA- FILHO, N.; PAIM, J. S. (Org.). Saúde coletiva: teoria e prática. Rio de Janeiro: Medbook, 2014. p. 121-137

TEIXEIRA, C. F. ; VILASBÔAS, A. L. Q. Modelos de atenção à saúde no SUS: transformação, mudança ou conservação. In: PAIM, J. S.; ALMEIDA-FILHO, N. de. Saúde coletiva: teoria e prática. Rio de Janeiro: MedBook, 2014. p. 287-301.

TEIXEIRA, C. F. Saúde da família, promoção e vigilância: construindo a integralidade da atenção à saúde no SUS. In: TEIXEIRA, C. F.; SOLLA, J. P. Modelo de atenção à saúde: vigilância e saúde da família. Salvador: EDUFBA, 2006. p. 59-83. (Sala de aula series, n. 3). Disponível em:<http://books.scielo.org>. Acesso em: 17 nov. 15.

TEIXEIRA, C. F. et al. Produção científica sobre política, planejamento e gestão no campo da saúde coletiva: visão panorâmica. In: PAIM, J. S.; ALMEIDA-FILHO, N. Saúde coletiva: teoria e prática. Rio de Janeiro: Medbook, 2014. p. 585-594.

TEIXEIRA, C. F.; SOLLA, J. P. Modelo de atenção à saúde: vigilância e saúde da família. Salvador: EDUFBA, 2006. (Sala de aula series, n. 3). Disponível em: <http://books.scielo.org>. Acesso em: 8 mar. 2013. 
TESTA, M. Pensamento estratégico e lógica de programação: o caso da saúde. São Paulo: Hucitec; Rio de Janeiro: ABRASCO, 1995.

VIEIRA, F. S. Assistência farmacêutica no sistema público de saúde no Brasil.Revista Panamericana de Salud Pública, Washington, v. 27, n. 2, feb. 2010.

VILLARINHO, M. V. et al. Políticas públicas de saúde face à epidemia da AIDS e a assistência às pessoas com a doença. Revista Brasileira de Enfermagem, Brasília, DF, v. 66, n. 2, p. 271-277, abr. 2013. 


\section{A SAÚDE NA AGENDA POLÍTICA análise das candidaturas à presidência da república em $2014^{1}$}

\section{Introdução}

O Sistema Único de Saúde (SUS), como uma macropolítica de saúde, foi implantado numa conjuntura adversa que favoreceu o projeto neoliberal, cujas relações entre Estado e sociedade se apresentavam em bases distintas das formuladas pela Reforma Sanitária Brasileira (RSB). (FLEURY, 2008)

O início do primeiro governo Lula, em 2003, manteve o projeto neoliberal e a política macroeconômica dos governos anteriores, ainda que buscasse ampliar os gastos públicos com políticas sociais. Esse momento trouxe para o movimento da RSB a expectativa de retoma-

Este capítulo é resultante da dissertação de mestrado da primeira autora, Dos clamores das ruas aos rumores no congresso: uma análise da conjuntura recente da saúde no Brasil, aprovada em 2015, que faz parte do projeto "Análise do processo da Reforma Sanitária Brasileira no período de 2007 a 2016" (processo n. ${ }^{\circ}: 303780 / 2013-4$ ) e articula-se com o

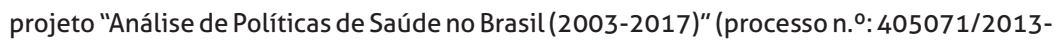
2), ambos apoiados pelo Conselho Nacional de Desenvolvimento Científico e Tecnológico (CNPq). Trata-se de um estudo qualitativo de análise de conjuntura. 
da das bases do seu projeto original diante da eleição de um governo oriundo das lutas dos trabalhadores. Entretanto, os programas priorizados foram políticas focalizadas de transferência de renda que visavam à redução da pobreza, ao invés do fortalecimento da seguridade social estabelecida pela Constituição de 1988. (PAIM, 2013)

O segundo mandato do governo Lula e o primeiro governo Dilma adotaram o chamado "neodesenvolvimentismo", assentado numa política econômica e social que visa ao crescimento econômico e ao desenvolvimento do capitalismo brasileiro com alguma transferência de renda, sem romper com os limites impostos pelo neoliberalismo, ou seja, desenvolvimentismo possível dentro do neoliberalismo. (BOITO, 2012) Para este autor, as principais características desse modelo são: políticas de valorização do salário mínimo e de transferência de renda, ampliando o poder de consumo das classes populares; elevação da dotação orçamentária do Banco Nacional de Desenvolvimento Econômico e Social (BNDES) para financiamento de grandes empresas nacionais a juros favorecidos ou subsidiados; 74 apoio à exportação de mercadorias e capitais; política econômica anticíclica nos momentos de crise; e investimento estatal em infraestrutura através de parcerias público-privadas.

Os reflexos dessa agenda na saúde são a redução dos gastos públicos e manutenção do subfinanciamento do SUS associado ao crescimento e fortalecimento do setor privado. (BAHIA, 2010; PAIM, 2013) Na mesma lógica em que o grande capital ganha com o "neodesenvolvimentismo" em outros setores, na saúde cresceram os planos e seguros privados, a incorporação de tecnologias de alto custo, a abertura para exploração do capital internacional e a financeirização do setor. (BAHIA, 2013; MACHADO; BAPTISTA;LIMA, 2012; VIANA, 2013)

Seria de esperar que esses projetos em disputa na sociedade brasileira fossem explicitados no cenário eleitoral de 2014. Publicações como a Nova Agenda Social (BACHA, SCHWARTZMAN, 2011), propondo a atualização e intensificação das reformas neoliberais da década de 1990, ao lado das diretrizes para a prospecção estratégica 
do sistema de saúde brasileiro (FUNDAÇÃO OSWALDO CRUZ, 2012), apostando na continuidade do neodesenvolvimentismo, já antecipavam os debates. (PAIM, 2013)

Nessa perspectiva, torna-se relevante a realização de estudos que contribuam para a observação do processo político em saúde, analisando como se enfrentam as forças sociais diante dessa questão e quais são os projetos políticos em disputa. Portanto, a RSB, admitida como um processo (PAIM, 2008), aponta a necessidade de novas investigações considerando a conjuntura recente.

A agenda política de um país é conformada ao longo de um processo onde os diversos sujeitos interagem disputando a prioridade do Estado. Em períodos eleitorais, parte dessa agenda é incorporada pelas candidaturas que, de acordo com seus projetos de sociedade e as frações de classe que representam, circunscrevem as mais variadas formas de dar respostas aos seus governados. Desse modo, apareceram algumas questões de investigação: qual o lugar ocupado pela saúde na agenda política das principais forças que disputaram as eleições presidenciais de 2014? Que relações poderiam ser verificadas entre a saúde, os projetos políticos em disputa, a RSB e as distintas concepções do SUS?

Neste capítulo visamos analisar o lugar ocupado pela saúde na agenda política das principais candidaturas à presidência da República do Brasil, durante as eleições de 2014. Apresenta os seguintes objetivos específicos:

a. analisar a agenda política das principais candidaturas à presidência;

b. identificar possíveis relações entre as proposições apresentadas para a saúde, o projeto da RSB e as distintas concepções do SUS. 


\section{Notas metodológicas}

O presente capítulo corresponde a um estudo qualitativo de análise de conjuntura. Compreendendo a conjuntura como a estrutura social em movimento, a análise das políticas de saúde, em uma dada situação, significa identificar os fatos e acontecimentos produzidos, os sujeitos, as contradições resultantes do processo de acumulação capitalista e as suas mediações com as condições e práticas de saúde das diferentes classes e grupos sociais, além de identificar os enfrentamentos que se dão na sociedade e atravessam o Estado que age por meio de seus aparelhos ideológicos ou repressivos. (PAIM, 2008)

Analisar uma conjuntura é examinar um conjunto de relações de forças contraditórias, onde as forças econômicas operam como um limite de variação. A análise mostra quais são os pontos de menor resistência, a partir do conhecimento do desenvolvimento desigual das relações de força em cada um dos níveis que articuladamente compõem o social, determinado por múltiplas relações, como um produto de atores sociais que se opõem e articulam entre si e possuem distintos graus de organização e coerência. (PORTANTIERO, 1983)

Souza (1985) pontua que, diante das mais diversas situações, as pessoas realizam análises de conjuntura, mesmo que não a façam de forma consciente. Quando as decisões são tomadas a partir de uma avaliação da situação, é necessário buscar um amplo leque de informações sobre o assunto, avaliar as possibilidades, descobrir sentidos, relações, elaborar hipóteses de desenvolvimento dos fatos, das reações possíveis das pessoas e grupos, medir a força ou o perigo dos eventuais adversários.

Nesse sentido, a análise de conjuntura surge como uma leitura especial da realidade e que sendo realizada em função de necessidades ou interesses, não há como ser neutra ou desinteressada. Ela não deve ser um fim em si mesma e só adquire significado se serve para justificar uma atividade prática. $\mathrm{O}$ elemento decisivo em cada situação é a força permanente organizada e predisposta de longa data, que pode fazer avançar quando a situação é favorável. (GRAMSCI, 2012) 
Os acontecimentos, as ações desempenhadas pelos sujeitos, as relações de força que determinam uma conjuntura, ocorrem dentro de um conjunto de relações sociais, econômicas e políticas mais profundas estabelecidas ao longo de um processo. Um aspecto importante da análise de conjuntura é caracterizar as questões centrais que estão colocadas em evidência na luta social e política num período determinado. Essas questões fazem parte do debate de partidos políticos, governos, sindicatos, movimentos sociais em geral e estão refletidas na grande imprensa. (SOUZA, 1985) Essa compreensão justifica as opções metodológicas em relação às fontes de dados que foram adotadas neste estudo ao considerar os fatos produzidos e acontecimentos.

Souza (1985) considera que os acontecimentos são os fatos que, por sua dimensão e seus efeitos, afetam milhões de pessoas, a sociedade em seu conjunto e que, tão fundamental quanto situar um acontecimento e apreender o seu sentido, é perceber quais as forças, os movimentos, as contradições e as condições que o geraram. Para esse autor, o cenário é o espaço onde as tramas sociais e políticas se desenvolvem e cada um deles apresenta particularidades que influenciam o desenvolvimento da luta, sendo a mudança de cenário uma importante indicação de mudanças no processo. No entanto, historiadores como Carr (2002) e Schaff (1995) utilizam, com finalidade semelhante, o conceito de "fato histórico" para se referir às manifestações da vida dos indivíduos e das sociedades escolhidas, dentre outras, por possuírem relações de causa e efeito que produzem mudanças em uma totalidade, tornando-se assim acontecimentos relevantes. A sociologia, a partir dos seus autores clássicos, considera os "fatos sociais" (DURKHEIM, 2007) como aqueles que produzem efeitos sobre os indivíduos, determinando seus comportamentos e regras de funcionamento das sociedades. Dessa forma, foram elencados para a análise os fatos produzidos considerados relevantes na conjuntura do período de estudo. 
Considerando que a agenda política das candidaturas à presidência da república é forjada ao longo de um processo de contradições e tensões sociais, a definição desse período deveu-se:

1. às manifestações populares ocorridas no Brasil, a partir de junho de 2013, como um fato relevante na conjuntura política;

2. ao ano eleitoral em que foram apontados os rumos da grande política no país e, por consequência, das políticas de saúde.

A pesquisa documental foi adotada como estratégia de produção dos dados, ainda que, ao acionar parte da mídia não impressa, tenha havido a necessidade de utilizar outras formas de registros:

c. Fontes utilizadas - Mídia: notícias e informações sobre a questão saúde no Brasil, Eleições 2014, fatos e acontecimentos no cenário político, divulgadas nos veículos de comunicação de grande circulação, com prioridade para os veículos de circulação nacional, e nos específicos da área da saúde. Foram considerados canais de televisão aberta, jornais e revistas impressos e digitais, sites e blogs de notícias, além de redes sociais. Coligações/ candidaturas: foram analisados os programas de governo das três principais candidaturas à presidência da república divulgados por material impresso, digital e audiovisual, programas eleitorais oficiais nas televisões, debates entre os candidatos, entrevistas e declarações dos candidatos na mídia, site de campanha e redes sociais. Entidades da saúde: debates, entrevistas, posicionamentos, declarações e documentos produzidos pelas principais entidades e sujeitos coletivos envolvidos no processo da RSB, como Centro Brasileiro de Estudos de Saúde (Cebes), Associação Brasileira de Saúde Coletiva (Abrasco), Conselho Nacional de Secretarias Municipais de Saúde (Conasems) e Conselho Nacional de Saúde (CNS). Além dessas, foram consideradas as entidades representativas de corporações profissionais, de seguradoras e planos privados de saúde, prestadores de serviços como o Conselho Federal de Medicina (CFM) 
Associação Médica Brasileira (AMB), Associação Nacional de Hospitais Privados (Anahp), Confederação Nacional das Empresas de Seguros Gerais, Previdência Privada e Vida, Saúde Suplementar e Capitalização (CNseg), Federação Nacional de Saúde Suplementar (FenaSaúde), dentre outras.

d. Registro dos dados - Os dados produzidos a partir das fontes consultadas foram armazenados em arquivos impressos e/ou digitalizados de acordo com o tipo de mídia utilizada. Os dados digitalizados, por sua vez, foram organizados e categorizados em pastas, e em sequencia gravados em HD externo pertencente ao grupo de pesquisa e disponibilizados para consultas posteriores dos demais pesquisadores. As notícias de jornais e revistas impressos foram catalogadas, armazenadas em arquivo pessoal e posteriormente digitalizadas. As notícias de jornais, revistas, blogs, sites institucionais e plataformas de pesquisas disponibilizadas na internet foram salvas diretamente da fonte em formato PDF, assim como os materiais de campanha eleitoral divulgados nos sites e páginas das redes sociais dos candidatos à presidência. As notícias veiculadas através de telejornais, os pronunciamentos de autoridades, propagandas eleitorais gratuitas dos candidatos, entrevistas, debates e demais materiais audiovisuais utilizados foram acessados através da plataforma de vídeos YouTube (www.youtube.com) e capturados através do programa aTubeCatcher. Da mesma forma, foram classificados e armazenados. Também foram utilizadas as notícias disponibilizadas pelo site Saúde na Mídia através do clipping do dia. Os arquivos gerados em PDF foram consultados separando por veículos (considerados os de circulação nacional), repercussão e relevância para a política de saúde.

Os dados produzidos foram examinados a partir de categorias de análise, citadas a seguir, indicadas no quadro teórico adotado e nas leituras dos documentos e fontes consultadas: fatos e acontecimentos produzidos; cenários (sociedade civil e sociedade política); 
relação de forças; Reforma Sanitária Brasileira (conceito de saúde, modelos de atenção, concepção do SUS, definição das prioridades em saúde).

Por se tratar de um estudo que acompanhou o surgimento e evolução dos fatos em um contexto de grande velocidade de informações, numa conjuntura acelerada, pode ter apresentado limitações quanto ao domínio e apreensão de todos os fatos realmente relevantes para a política de saúde.

\section{Não era primavera, mas o asfalto floriu: as jornadas de junho de 2013}

Uma flor nasceu na rua! Passem de longe, bondes, ônibus, rio de aço do tráfego. Uma flor ainda desbotada ilude a polícia, rompe o asfalto. Façam completo silêncio, paralisem os negócios, garanto que uma flor nasceu.

É feia. Mas é uma flor. Furou o asfalto, o tédio, o nojo e o ódio. (Carlos Drummond de Andrade, A rosa do povo, 2012).

As jornadas de Junho, como ficaram conhecidas as manifestações ocorridas no Brasil em 2013, que se propagaram durante o mês de julho até arrefecerem no decorrer do segundo semestre, certamente representaram um marco na democracia recente brasileira. Centenas de milhares de pessoas foram às ruas nas principais capitais e cidades do país, de uma maneira que não era vista desde as lutas pelas "Diretas já", em 1984, e os cara-pintadas pelo "Fora Collor" de 1992. (BAVA, 2013; CARVALHO, 2013; NAVARRO; BRASILINO; GODOY, 2013) Por certo tempo, permanecerá o questionamento sobre a gênese e o significado desses acontecimentos. (SINGER, 2013)

As manifestações ocorridas no dia 17 de junho cresceram mais do que qualquer analista político poderia supor e tomaram conta 
das principais capitais brasileiras: "É tanta coisa errada que não cabe em um cartaz"; "quero dinheiro pra saúde e educação"; "era um país muito engraçado, não tinha escola, só tinha estádio"; "Passe livre, Já!”; “hospital padrão-FIFA”. (VEJA..., 2013) Eram pautas que versavam sobre os direitos sociais e a ética na política. (CHAUÍ, 2013; VIANA, 2013) Apesar de toda a complexidade e diversidade, as manifestações possuíam como ponto em comum o desejo da população por mais serviços públicos e de melhor qualidade através da atuação de um Estado social. (MAIOR, 2013)

Para Singer (2013), apesar de uma heterogeneidade na composição social dos que ocuparam as ruas, é possível perceber uma maioria jovem, representante de uma "nova classe trabalhadora" que, segundo ele, teria sido beneficiada pelos programas sociais dos governos petistas, adentrando as universidades através de programas de expansão do ensino superior, mas ocupando postos de trabalho com baixas remunerações e alta rotatividade. Já Braga (2013) ao se referir a essa mesma fração da classe trabalhadora utiliza a expressão "precariado", ao inferir sobre as condições de vida dessas pessoas, 81 que após a conquista do mercado formal de trabalho, mesmo com maior escolaridade, recebem baixos salários e convivem com a caótica organização das cidades, especialmente nas periferias onde enfrentam a repressão policial.

A resposta governamental veio através do pronunciamento da presidenta Dilma Rousseff, exibido na noite de 21 de junho em cadeia nacional. Neste, a presidenta afirmava estar atenta à voz das ruas, que demonstrava a força da democracia e o desejo da juventude de fazer o país avançar. Condenou o uso da violência e indicou que as bandeiras apresentadas haviam se tornado prioridade nacional.

Esta mensagem exige serviços públicos de mais qualidade. Ela quer escolas de qualidade; ela quer atendimento de saúde de qualidade; ela quer um transporte público melhor e a preço justo; ela quer mais segurança. Ela quer mais. E para dar mais, as instituições e os governos devem mudar. 
[...]

Primeiro, a elaboração do Plano Nacional de Mobilidade Urbana, que privilegie o transporte coletivo. Segundo, a destinação de cem por cento dos recursos do petróleo para a educação. Terceiro, 'trazer de imediato milhares de médicos do exterior para ampliar o atendimento do Sistema Único de Saúde, o SUS'.

[...]

Quero contribuir para a construção de uma ampla e profunda reforma política, que amplie a participação popular. $^{2}$

Na sequência, em reunião com os governadores e prefeitos das capitais, apresentou "os cinco pactos em favor do Brasil". O primeiro pacto se referia à responsabilidade fiscal; o segundo, à construção de uma ampla reforma política; o terceiro estava relacionado à saúde; o quarto, à mobilidade urbana; e o quinto foi o pacto pela educação. (DISCURSO..., 2013)

82

Especificamente sobre a saúde, a proposta solicitava que prefeitos e governadores acelerassem os investimentos já contratados em hospitais, unidades de pronto atendimento e unidades básicas de saúde, inclusive hospitais filantrópicos, propondo a troca de dívidas por prestação de serviços. Incentivava a ida de médicos para as cidades e regiões com maior necessidade de profissionais, e não havendo médicos brasileiros disponíveis, seria feita a contratação de médicos estrangeiros para atuar exclusivamente no SUS. Tratou também, do que chamou de maior programa de ampliação de cursos de medicina do país.

Essas últimas proposições, compuseram o Programa Mais Médicos, medida prioritária na área da saúde, já anunciada no pronunciamento anterior. Embora responsável por grandes embates com a categoria médica dividindo opiniões, esse programa permitiu, em seu primeiro ano, aumento significativo no acesso aos aten-

2 Transcrição dos trechos do pronunciamento em cadeia nacional de rádio e TV da presidente Dilma em 21 de fevereiro de 2013. 
dimentos médicos com a disponibilização de aproximadamente 14.500 profissionais (principalmente oriundos de Cuba) em mais de 3.700 municípios. (OLIVEIRA, 2015)

\section{A saúde nos programas das candidaturas à presidência da república em 2014}

A elaboração de programas de governo pode sofrer influências e pressões de grupos de interesse, além de apresentar fórmulas de marketing para agradar o público sem necessariamente significar um compromisso com tais afirmações. (SCHEFFER; BAHIA, 2014) No entanto, analisar os programas e propostas defendidas pelas coligações que disputam os pleitos eleitorais pode servir como um termômetro para perceber a penetração de temas na agenda política e observar a correlação de forças entre os diversos grupos que compõem a sociedade.

Em pesquisa de opinião no período pré-eleitoral, a saúde era apontada como a principal preocupação para a população brasileira. (DATAFOLHA..., 2014) Assim, procura-se analisar a seguir, o lugar ocupado pela saúde na agenda política das três principais candidaturas presidenciais em 2014, verificando em que medida suas proposições se aproximam ou distanciam do projeto da RSB e se contemplam as necessidades e demandas da população, bem como os desafios do SUS.

\section{As proposições de Dilma Rousseff}

O Programa de Governo para a reeleição da presidenta Dilma Rousseff, coligação composta pelos partidos PT, PMDB, PSD, PP, PR, PROS, PDT, PCdoB e PRB, ${ }^{3}$ registrado no site do Tribunal

Respectivamente, Partido dos Trabalhadores, Partido do Movimento Democrático Brasileiro, Partido Social Democrático, Partido Progressista, Partido Republicano da Ordem Social, Partido Democrático Trabalhista, Partido Comunista do Brasil e Partido Republicano Brasileiro. 
Superior Eleitoral (TSE), em julho de $2014,{ }^{4}$ apresentou proposições para as áreas de infraestrutura, indústria e comércio, agronegócio, energia, petróleo e gás, meio ambiente, mobilidade urbana e saneamento básico - como primeiro pilar de desenvolvimento - além das políticas de proteção e inclusão social - segundo pilar - contemplando as áreas de desenvolvimento social, segurança pública, habitação, educação e saúde.

$\mathrm{Na}$ abordagem do "projeto" desenvolvido, foi apontado o impacto positivo sobre indicadores de saúde, como a redução da mortalidade infantil, e destacados programas realizados em parceria com estados e municípios que teriam garantido "ampliação do acesso com qualidade” às ações e serviços de saúde:

Com o Mais Médicos, garantimos melhoria na atenção à saúde para 50 milhões de pessoas, em 3.800 municípios. O Programa Aqui Tem Farmácia Popular atende a mais de 6,8 milhões de pessoas/mês e o SAMU atende $73 \%$ da população brasileira. Atualmente, 80 milhões de pessoas têm acesso à atenção de saúde bucal pelo Programa Brasil Sorridente.

O governo federal tem apoiado os municípios para construir, ampliar e reformar equipamentos de saúde, como as mais de mil Unidades de Pronto Atendimento - UPA e os mais de 26 mil Postos de Saúde. (Prg DR, p. 13)

É possível observar a adoção de uma concepção ampliada de saúde ao considerar a determinantes sociais do processo saúde-doença:

A melhoria das condições de saúde do povo brasileiro, nos últimos anos, explica-se tanto pela expansão das ações e serviços garantidos pelo SUS como pelo crescimento econômico, pela implementação de política so-

4 Disponível em: http://divulgacand2014.tse.jus.br/divulga-cand-2014/proposta/eleicao/ 2014/idEleicao/143/UE/BR/candidato/280000000083/idarquivo/194. Acesso em 13 jul. 14. Identificado no texto como Prg DR. 
ciais de combate à pobreza e pelo aumento do acesso a esgoto e água tratada durante os Governos Lula e Dilma. (Prg DR, p.13)

Entretanto, a centralidade das proposições para o setor não corroboram com essa compreensão. $\mathrm{O}$ foco é direcionado para promover melhorias na qualidade e amplitude dos serviços de saúde, implicando aprofundar programas já existentes, através de uma rediscussão federativa para aumentar a eficiência do planejamento e evitar a superposição de investimentos entre os entes federativos.

[...] expansão do Programa Mais Médicos; a ampliação da rede de Unidades de Pronto Atendimento (UPAs) destinadas ao atendimento de emergências de baixa e média gravidade; a extensão das redes de atendimento especializado, com a qualificação dos serviços hospitalares; o fortalecimento e a universalização do SAMU e a ampliação do acesso da população a medicamentos [...]

Reafirmamos o nosso compromisso com seu [do SUS] contínuo fortalecimento e aprimoramento, necessário devido a seu tamanho, à extensão dos serviços envolvidos e às sobreposições de atribuições entre os entes federativos. (Prg DR, p. 22)

Os termos "atenção básica" e "atenção primária à saúde" (que mereceram política específica em seu governo anterior) não são mencionados, ficando subentendida a sua relação com o Programa Mais Médicos, sem apresentar possíveis avanços em períodos anteriores, nem os desafios a serem superados. Também não são utilizadas noções como integralidade, promoção da saúde, intersetorialidade, políticas públicas saudáveis.

A qualidade dos serviços de saúde é abordada de forma superficial, sem apontar indicadores que possam elucidar esse aspecto. Prevalece no texto a lógica do acesso à saúde como consumo de serviços e procedimentos, do modelo de atenção hegemônico centrado no profissional médico e nas práticas tradicionais de cura, no 
planejamento das ações voltadas para os quadros agudos e demanda espontânea, sem priorizar a qualidade de vida. As propostas não abordam a integração de ações de vigilância epidemiológica, vigilância sanitária, prevenção de riscos e agravos, tratamento e reabilitação através de uma intervenção organizada para resolver as necessidades de saúde da população, visando à integralidade.

Outras lacunas referem-se à ausência de compromissos com a manutenção do direito à saúde e um SUS público alicerçado em seus princípios constitucionais, e as necessidades de ampliação do financiamento considerada por pesquisadores e gestores um nó crítico (PAIM et al., 2011) ao fortalecimento do sistema. O documento produzido pelo PT em seu congresso interno e disponibilizado no site do partido, para subsidiar o programa de governo, apresentava uma formulação mais alinhada com a RSB, abandonada nessa versão oficial, possivelmente, por conta de acordos estabelecidos com aliados, ou ainda por interferência do marketing de campanha.

Ao longo da campanha, foram apresentadas as principais ações desenvolvidas na saúde de 2010 a 2014, com grande ênfase para o Programa Mais Médicos. Novas propostas para a saúde foram incorporadas, como o Programa Mais Especialidades, apresentado no horário político eleitoral, visando complementar o Mais Médicos para facilitar o acesso a exames e consultas com especialistas. A proposta previa a criação de uma rede de clínicas e serviços especializados em todas as regiões do país, integradas por unidades do sistema público já existentes ou que seriam construídas e por clínicas privadas ou instituições filantrópicas.

No quinto dia de propaganda eleitoral gratuita na televisão, especificamente dedicado à saúde, a candidata fez uma avaliação positiva dos investimentos na área, nos últimos anos, e apresentou os seguintes desafios:

De 2002 pra cá, aumentamos o orçamento da saúde em $97 \%$ em termos reais. Garanti por lei que 25\% dos recursos do petróleo sejam investidos dentro de pouco tempo na saúde. [...] São necessários muitos passos adiante para criarmos um sistema de saúde de qua- 
lidade no país. O mais urgente é combater a demora na realização de exames e consultas com especialistas. Temos problemas graves de acesso a médicos especializados em coração, em ortopedia, pulmão, em todas outras áreas e também para realizar exames laboratoriais e especializados. É aí que pretendo avançar como nunca nos próximos quatro anos e por isso, vou criar o Programa Mais Especialidades. ${ }^{5}$

Ao enfatizar que o principal problema a ser resolvido no sistema de saúde era o acesso a consultas especializadas e estabelecer tal programa como o sua principal proposta para os próximos quatro anos de governo, a candidata Dilma, mais uma vez, reduzia a compreensão de saúde ao acesso a exames, consultas e procedimentos, reforçando a defesa do modelo hegemônico médico assistencial privatista. É importante destacar elementos em seu discurso como a referência ao sistema de saúde ou sistema público de saúde, citando o termo SUS apenas uma vez durante todo o programa, sem se referir ao mesmo em termos futuros.

Outra questão, foi a inserção das clínicas e serviços privados e filantrópicos dentro da proposta de organização da rede de serviços do Mais Especialidades, evidenciando o seu compromisso com a incorporação do setor privado na organização dos serviços de saúde como parte fundamental e não apenas suplementar ao SUS. Pode indicar uma incorporação das propostas apresentadas pelo Livro branco da saúde, documento da Associação Nacional de Hospitais Privados (ANAHP) entregue aos candidatos à presidência da república (ANAHP, 2014), que previa "estimular a coordenação e integração entre os setores público e privado" e "ampliar a participação do setor privado na formulação e implantação das Políticas Nacionais de Saúde”.

5 Transcrição do vídeo da propaganda eleitoral. 


\section{As proposições de Aécio Neves}

O Programa de Governo de Aécio Neves, coligação composta pelos partidos PSDB, PMN, SD, DEM, PEN, PTN, PTB, PTC, PTdoB,${ }^{6}$ registrado no site do TSE em julho de $2014,{ }^{7}$ teria sido elaborado através da interlocução de especialistas nas mais diversas áreas da política pública como um ponto de partida para um processo de amplos debates com a sociedade brasileira em seus diversos segmentos, nas variadas esferas que compõem a vida pública, propondo a participação popular inclusive através de mecanismos virtuais.

As oito áreas contempladas no programa - cidadania, economia, educação, Estado eficiente, relações exteriores e defesa nacional, saúde, segurança pública e sustentabilidade - deveriam "se integrar de forma holística" como uma "soma positiva de ações governamentais que se aliam na consecução do bem comum”. (Prg AN, p. 6)

A saúde foi abordada em um capítulo específico (as políticas que compõem o sistema de seguridade social foram debatidas separadamente em capítulos diversos). Inicialmente, o SUS foi enaltecido como "uma das grandes políticas de inclusão social da história do Brasil” (Prg NA, p. 58), que teria sido viabilizada pelos governos de Fernando Henrique Cardoso (FHC), informação questionada por autores que atribuem às políticas neoliberais nos governos $\mathrm{FHC} \mathrm{a} \mathrm{im-}$ plementação de um SUS distante do constitucional, bem como a redução do conceito de cidadania aplicado às políticas sociais. (FLEURY, 2008; MACHADO; BAPTISTA; LIMA, 2012; PAIM, 2008)

$O$ programa indicava que a baixa remuneração dos procedimentos realizados pelas redes pública, filantrópica ou privada complementar, assim como a destinação do orçamento federal insuficiente nos últimos 12 anos, seriam responsáveis pela ineficiência e baixa

6 Respectivamente, Partido da Social Democracia Brasileira, Partido da Mobilização Nacional, Solidariedade, Democratas, Partido Ecológico Nacional, Partido Trabalhista Nacional, Partido Trabalhista Brasileiro, Partido Trabalhista Cristão e Partido Trabalhista do Brasil.

7 Disponível em: <http://divulgacand2014.tse.jus.br/divulga-cand2014/proposta/eleicao/ 2014 /idEleicao/143/UE/BR/candidato/280000000085/idarquivo /229?x=1404680555 $000280000000085>$. Acesso em: 13 jul.14. Identificado ao longo do texto como Prg AN. 
qualidade dos serviços de saúde. Nesse aspecto, trouxe dados que confrontaram os apresentados pela campanha da presidenta Dilma à reeleição e se somaram às críticas sobre o baixo financiamento para a saúde que vem sendo explicitada por pesquisadores (PAIM et al. 2011), gestores (BRASIL, 2014) e articulações da sociedade como o Movimento Saúde Mais Dez.

Para resolver a questão do financiamento, a proposta apresentada foi uma tentativa de diálogo com entidades da RSB, porém o texto deixa dúbia a possibilidade de cumprimento da proposta derivada da Emenda Popular:

Apoio e implementação dos preceitos da Emenda Constitucional 29, nos percentuais dos pisos mínimos estabelecidos por lei para estados e municípios, e a proposta popular dos $10 \%$ da Receita Corrente Bruta da União para o setor saúde, ou política similar que garanta um crescimento progressivo de financiamento para o setor. (Prg AN p. 60)

Considerando a proposta de reforma tributária apresentada, onde questionavam a viabilidade da carga tributária para o financiamento de políticas sociais e propunham forte redução do número de impostos e contribuições, permanece em aberto quais seriam as fontes utilizadas para ampliação do financiamento para a saúde.

O texto do programa afirmava que "O fortalecimento do SUS será a permanente prioridade do governo na área da saúde” (Prg AN, p. 58), embora não deixasse explícito o que pretendia para o seu funcionamento. Vale lembrar que o Livro branco da saúde (ANAHP, 2014) também apontava como sua primeira proposta, a necessidade de fortalecimento do SUS, estimulando a coordenação e a integração entre os setores públicos e privados.

Princípios constitucionais, a exemplo da universalidade, não são reafirmados pelo programa. Algumas das 36 diretrizes apresentadas para a saúde trazem implícita uma concepção de SUS para os mais pobres e planos ou seguros de saúde para os que podem pagar, 
assimilando a lógica de "cobertura universal" proposta por organismos internacionais como Banco Mundial, Fundação Rockefeller e Organização Mundial da Saúde (OMS) (FRENK, 2015; NORONHA, 2013; ORGANIZAÇÃO MUNDIAL DA SAÚDE, 2013; TITELMAN; CETRÁNGOLO; ACOSTA, 2015):

Diretriz 1: a instituição do Cartão-Cidadão da Saúde, em articulação com o cadastro nacional único, já aqui previsto, dará a garantia de acesso a qualquer brasileiro à uma rede de saúde pública ou privada. (Prg AN p. 59)

$[\ldots]$

Diretriz 14: Integração do sistema de saúde suplementar com o SUS, para identificar oportunidades de colaboração investimento e desenvolvimento de parcerias público-privadas.

Diretriz 15: aumento da equidade na saúde, reduzindo, através das redes assistenciais integradas, a disparidade nos níveis de atenção entre os que detém planos de saúde e os usuários do SUS. (Prg AN, p. 60)

A terceira diretriz "o novo modelo de gestão da saúde se baseará na criação de redes assistenciais integradas de saúde, que permitirão o melhor uso possível dos recursos de saúde - públicos, privados e filantrópicos - ao nível de cada região" (Prg NA, p. 59), assemelha-se à proposta do Mais Especialidades da candidata petista, no sentido de construir redes regionalizadas que possibilitem o acesso à média e alta complexidade envolvendo os diversos serviços existentes e reafirmando a necessidade de aproximação entre os setores público e privado, assim como proposto pela ANAHP e outras organizações do setor. Propostas de modernização da gestão pública através de ferramentas, indicadores e práticas característicos do setor privado, podem reforçar essa ideia.

É possível observar nas formulações, a incorporação de termos adotados pelo SUS, como novo modelo assistencial com cuidado longitudinal; promoção da saúde e hábitos saudáveis de vida; ações 
intersetoriais; desospitalização; fortalecimento da saúde da família como porta de entrada do Sistema; fortalecimento do controle social; além da utilização de dados epidemiológicos para propor ações em saúde para grupos específicos. No entanto, esses termos são contrapostos em seus significados pelas expressões "mutirões de cirurgias eletivas", "eficiência”, "padrões de qualidade e processos otimizados para controle interno", "autonomia de gestão", "parceria público-privada e com terceiro setor”.

Foi proposto o aprimoramento de ações que estão em curso no governo atual como as redes assistenciais integradas e o fortalecimento de ações iniciadas nos governos do PSDB na década de 1990, como o incentivo à produção de medicamentos genéricos, o fortalecimento da Agência Nacional de Saúde Suplementar (ANS) para garantir os direitos e reduzir as reclamações de usuários de planos privados de saúde.

A proposição de uma carreira nacional para médicos possivelmente foi incorporada em atenção às reivindicações das entidades médicas rompidas com o governo do PT após o lançamento do Programa Mais Médicos. No entanto, o tema não foi aprofundado e inicialmente não considerava a necessidade de instituir uma carreira nacional para todos os profissionais de saúde. Para os demais profissionais foi proposto programas de valorização, apoio e qualificação. Ainda dialogando com a categoria médica, propuseram a realização de cursos preparatórios para que médicos estrangeiros pudessem ser submetidos ao exame de revalidação de diploma e o aprimoramento do Mais Médicos com padronização da remuneração.

Durante a campanha, foi divulgado um segundo Programa de Governo, mais completo, onde o texto sobre saúde iniciava afirmando que a mesma era a maior preocupação dos brasileiros segundo pesquisas de opinião e que, portanto, "a organização e qualificação do sistema de saúde devem ser agenda central de todas as esferas go- 
vernamentais e da sociedade civil organizada"8 (Prg AN2, p. 109) associadas ao investimento consistente em saneamento, considerado o setor mais carente da infraestrutura social. Criticava as medidas do governo Dilma para o setor adjetivando-as de "improvisos", "paliativos", "presididas pelo marketing" justificando que a sua principal marca "se resumiu a importação de médicos estrangeiros $[. .$.$] des-$ prezou [o programa] os médicos brasileiros e a certificação da qualidade do atendimento à população”. (Prg AN2, p. 111)

O termo "SUS", para se referir ao sistema de saúde brasileiro, foi utilizado em todo o texto mantendo a definição de conquista social, referenciando nessa versão, os seus princípios constitucionais como pode ser demonstrado no trecho abaixo:

Os constituintes, em nome da sociedade brasileira, fizeram uma aposta generosa e ousada. Migrar de um modelo excludente, centralizador, autoritário e hospitalocêntrico, para a construção de cidadania plena na saúde para todos os brasileiros, por meio de um sistema de acesso universal e cobertura integral, inclusivo, descentralizado, com grande integração federativa e forte participação social, focado na primazia da atenção primária como polo articulador do sistema, com ênfase na prevenção e na promoção da saúde. $\mathrm{O}$ acesso ao sistema público deixaria de ser um privilégio dos possuidores de carteira de trabalho para abranger todos os brasileiros sem nenhuma distinção, como direito do cidadão e dever do Estado. (Prg AN2, p. 110)

Como alternativa para superar os impasses do SUS, foi defendida uma forte liderança para conduzir um "choque de gestão", mais recursos, mudança do modelo de atenção e eficiente regulação da incorporação tecnológica. Outra mudança a ser considerada foi a

\footnotetext{
8 Plano de Governo de Aécio Neves e Aloysio Nunes disponíveis em: <http://campanha2014. aecioneves.com.br/downloads/plano-de-governo/plano_governo.pdf>. Acesso em 15 out. 2014. Identificado ao longo do texto como Prg AN2.
} 
utilização do termo carreira nacional do SUS, para todos os profissionais de saúde, em substituição à proposta anterior de carreira nacional para médicos. Esta seria construída a partir de diálogo com estados, municípios e entidades representativas das categorias profissionais visando superar a precarização do trabalho e a instabilidade do mercado de trabalho em saúde. Também foi incluída a proposta que objetivava a profissionalização da gestão das entidades ligadas ao Ministério da Saúde, Agência Nacional de Vigilância Sanitária (Anvisa) e ANS, priorizando a eficiência, a meritocracia, sem arranjos partidários considerados patrimonialistas e clientelistas.

Em diversos compromissos apresentados, foi reforçada a necessidade de mudança do modelo de atenção para a superação de um modelo curativo, que sofre pressão de incorporações tecnológicas, encarecendo o sistema, para um modelo voltado para as necessidades de saúde da população, priorizando a prevenção de doenças e a promoção da saúde. No entanto, as propostas apresentadas destoam dessa concepção, sendo uma das mais difundidas nas propagandas eleitorais de TV e redes sociais, a criação de "consultórios populares de saúde”. Nessa proposta, o Governo Federal ofereceria financiamento através do BNDES para que médicos especialistas pudessem abrir consultórios particulares cobrando preços menores para a população em regiões mais pobres e atendendo um número pré-determinado de pacientes pelos SUS encaminhados pelas unidades básicas de saúde. Essa proposta contrapõe a ideia de redes assistenciais integradas e continuidade do cuidado, remontando a fragmentação deste.

No programa de TV especialmente dedicado à saúde no primeiro turno (exibido em 2 de setembro de 2014), além de apresentar suas realizações em Minas Gerais, Aécio se comprometeu com a criação de "500 centros integrados de saúde chamados Saúde de Uma Vez, para agilizar o atendimento à saúde em todas as regiões do Brasil”. ${ }^{9}$

Outras propostas bastante propagandeadas foram referentes à distribuição de medicamentos e ampliação do Programa de Saúde

9 Transcrição da propaganda eleitoral exibida em 2 set. 2014. 
da Família (PSF), fazendo alusão ao programa focalizado do governo FHC e desconsiderando a concepção da Estratégia Saúde da Família. As imagens comumente utilizadas nos materiais visuais apresentavam objetos classicamente associados à saúde pela maioria da população como remédios, seringas, estetoscópios, ambulâncias, hospitais e cruzes vermelhas, reforçando o modelo assistencial hegemônico, supostamente criticado pelo seu programa.

Numa visão geral, são perceptíveis as diversas contradições do programa dessa coligação. A incorporação do discurso de sanitaristas na tentativa de dialogar com parte dos segmentos que defendem o SUS pode converter-se em retórica ao analisar as proposições que discutem gestão pública com incorporação e fortalecimento do setor privado, políticas sociais focalizadas e perspectiva do cuidado centrado na prática médica. A análise das proposições para a área econômica com protagonismo do mercado na determinação do papel do Estado também podem dar pistas de qual seria o projeto realmente implementado caso fosse esse o programa vencedor.

De Eduardo Campos à Marina Silva: programa de governo da coligação Unidos pelo Brasil

A Coligação “Unidos pelo Brasil”, composta pelos partidos PHS, PRP, PPS, PPL, PSB e PSL, ${ }^{10}$ tinha em sua liderança o ex-governador de Pernambuco Eduardo Campos e como vice Marina Silva, ambos do PSB. A ex-senadora e candidata a presidência em 2010 veio para o partido após a aliança programática construída quando a Rede Sustentabilidade teve o seu pedido de registro eleitoral indeferido. $\mathrm{O}$ programa registrado no $\mathrm{TSE}^{11}$ estava estruturado em cinco eixos estratégicos: Estado e a democracia de alta intensidade; economia para

10 Respectivamente, Partido Humanista da Solidariedade, Partido Republicano Progressista, Partido Popular Socialista, Partido Pátria Livre, Partido Socialista Brasileiro e Partido Social Liberal.

11 Programa de governo da Coligação "Unidos pelo Brasil" registrado em julho de 2014 junto ao TSE e disponível em: <http://divulgacand2014.tse.jus.br/divulga-cand-2014/ proposta/eleicao/2014/idEleicao/143/UE/BR/candidato/280000000063/idarquivo/108 
o desenvolvimento sustentável; educação, cultura e inovação; políticas sociais e qualidade de vida; e novo urbanismo e pacto pela vida.

Das três principais candidaturas, apenas essa coligação compreendia a saúde como parte do sistema de seguridade social, trazendo as propostas para essa área no eixo destinado às políticas sociais. Destacava que "o sistema de seguridade social é uma das mais importantes conquistas do período democrático e tem um papel fundamental na melhoria da qualidade de vida de nossa população”. (Prg EC, p. 44) Essa inserção, traz uma compreensão diferenciada de saúde como parte das políticas de inclusão social, cidadania e felicidade, não apenas como um setor produtivo, ou como oferta de serviços e procedimentos.

O SUS foi apresentado como uma vitória de mobilizações da sociedade, conquistado através da Constituição Cidadã de 1988, valorizado em sua concepção original, não sendo utilizados termos substitutivos para se referir ao mesmo. Seus princípios constitucionais surgiram em diversos momentos do texto sem variação de sentido. Universalidade, por exemplo, pode ser compreendido como SUS para todos os brasileiros; a integralidade foi colocada como meta da articulação de ações e serviços de promoção e atenção à saúde, além de prevenção.

O SUS é algo quase único em termos de cobertura no mundo e implica uma noção de cidadania e direito humano que emerge de gerações de lutas populares. Apesar de sua concepção revolucionária e da universalização do serviço de saúde que pretende promover, o SUS precisa ser aperfeiçoado no sentido de considerar o redirecionamento para um sistema que seja mais humano, personalizado, rápido e que ofereça respostas às demandas de todos os brasileiros. (Prg EC, p. 44)

$? x=1409866177000280000000063>$. Acesso em 13 jul. 2014. Identificado ao longo do texto como Prg EC. 
Para a sustentabilidade do SUS, foram apresentadas como propostas o aperfeiçoamento dos serviços de saúde e seu adequado financiamento, onde previa "aumentar os gastos federais com ações e serviços públicos de saúde tendo como base a Receita Corrente Bruta (RCB) da União”. (Prg EC, p. 44) Apesar de utilizar o termo "Receita Corrente Bruta", não se comprometia explicitamente com a proposta de $10 \%$ da RCB para a saúde apresentada através do projeto de lei de iniciativa popular PLP 321/2013 e não fixava em quanto deveria ser o financiamento para a saúde em seu governo, caso vitorioso. Criticava os gastos em saúde do Governo Federal trazendo informes que apontavam uma redução do investimento em saúde de 2000 a 2011 em termos proporcionais ao que foi investido por estados e municípios, contradizendo os dados apresentados pela candidata à reeleição quando afirmava que houve crescimento de investimentos no setor.

Outras propostas como a regulação de serviços de distinta complexidade, a pactuação entre níveis de governo, as relações com os 96 serviços suplementares de saúde (iniciativa privada) e com os profissionais de saúde, também foram apresentadas sem especificar como poderiam ser viabilizadas.

A relação com o setor privado foi apresentada de forma crítica quanto à incorporação pelos serviços públicos de práticas de saúde e formas de organização. Porém não ficam evidenciadas as propostas para a regulação e utilização desses serviços, se de forma suplementar ou como parte da rede de serviços de saúde.

Há uma tendência de reprodução no setor público da realidade hoje verificada no setor privado, em que predomina o polinômio especialização, procedimentos de média e alta tecnologia, alto custo de intervenção. Essa configuração, independentemente de sua qualidade técnica, não atende aos preceitos de uma saúde que pretende a universalização. (Prg EC, p. 44) 
Para a atenção básica, foi prevista a efetiva universalização para que possa ser a porta de entrada e eixo estruturante da organização e articulação de ações. Para isso, pensavam aprimorar e fortalecer o PSF, promover a formação de profissionais de saúde, priorizando médicos generalistas, enfermeiros, assistentes sociais e agentes comunitários, promover a alimentação saudável e inserir atividades físicas e práticas corporais como parte da assistência à saúde.

Outra parte fundamental das propostas apresentadas foram ações de prevenção de doenças e promoção da saúde, que evidenciavam uma concepção mais ampliada de saúde para além de ofertar serviços de saúde.

Reorientar e integrar políticas setoriais capazes de promover a saúde e a melhoria da qualidade de vida, visando criar ambientes saudáveis, proteger as pessoas contra ameaças à saúde e possibilitar aos indivíduos, famílias e comunidades a expansão de suas liberdades, capacidades e oportunidades. (Prg EC, p. 44 e 45)

Apareciam, no decorrer do texto, termos como "vigilância epidemiológica", "humanização do cuidado", "reorientação da formação profissional”, "abordagem multidisciplinar", "política de drogas com atenção integral ao usuário", que aproximam o programa do discurso do SUS e das entidades da RSB.

Antes que a campanha eleitoral ganhasse corpo e chegasse às propagandas de TV, um trágico acidente, em 13 de agosto de 2014, interrompeu o percurso dessa coligação, levando a óbito o seu representante majoritário Eduardo Campos e parte dos seus assessores. Trecho de sua entrevista ao Jornal Nacional no dia anterior à sua morte "Não vamos desistir do Brasil" passou a ser o grande mote de campanha da nova chapa configurada com Marina Silva como candidata a presidência, acompanhada por Beto Albuquerque (PSB-RS), candidato a vice.

O programa de governo da nova chapa registrado no TSE foi basicamente o mesmo, visto que foi construído como uma aliança programática entre os partidos que compunham a coligação que man- 
teve o mesmo nome e a mesma composição. Os trechos dedicados à saúde permaneceram inalterados. Logo em seguida, foi divulgado no site da campanha uma versão mais ampliada do programa inicial.

A saúde, incluída no título do eixo 4, que passou a se chamar "Políticas sociais, saúde e qualidade de vida", foi mantida no conjunto das políticas de seguridade social. $\mathrm{O}$ trecho dedicado ao tema apresentava uma explicação do que vem a ser o sistema de seguridade social, representando um avanço por possibilitar o acesso a todo cidadão e cidadã brasileira independente do nível de contribuição. Apresentava críticas à forma como o sistema de saúde é organizado atualmente que não consegue responder aos anseios da população.

$\mathrm{O}$ atendimento à saúde é a primeira das queixas e das aspirações dos brasileiros. $\mathrm{O}$ atendimento médico-hospitalar não satisfaz, e o trabalho de controle de doenças e de redução de indicadores de mortalidade - que o Sistema Único de Saúde (SUS) tem contribuído para mudar para melhor - não é notado quando exitoso, apenas quando falha. A percepção do cidadão sobre o sistema público de saúde é pautada pela visão de uma medicina de alta tecnologia e de caráter hospitalar - à qual ele, efetivamente, tem dificuldade de acesso. (Prg MS, p. 155) ${ }^{12}$

O texto mantinha os elementos do programa anterior, aprofundando as informações trazidas através de dados, indicadores e gráficos. Apresentava o SUS com um breve histórico da sua implementação, pontuava como princípios fundamentais as diretrizes do sistema (hierarquização, descentralização, regionalização, participação e controle social) e afirmava que "saúde é um direito da população e um dever do Estado”. (Prg. MS, p. 156) Foi feita uma avaliação detalhada dos gastos em saúde desde a década de 1980, através de gráficos comparativos de investimentos da união, estados e municípios;

\footnotetext{
12 Programa de governo da Coligação "Unidos pelo Brasil" divulgado no site de campanha, disponível em <http://campanha.marinasilva.org.br/programa/\#!/>. Acesso em: 30 set. 2014. Identificado ao longo do texto como Prg MS.
} 
foram apresentados indicadores de saúde como a redução da mortalidade infantil e materna, resultados do PSF e quantitativo de ações e procedimentos realizados. Esses dados pareciam revelar o intuito de contribuir para a valorização do SUS como uma política exitosa, ainda que não consiga atender plenamente aos seus objetivos. "Apesar de seus problemas, o SUS contribuiu para elevar o IDH [Índice de Desenvolvimento Humano] do Brasil de 0,493 (muito baixo) para 0, 727 (alto) em duas décadas." (Prg. MS, p. 157)

Sobre o financiamento, diferentemente do programa apresentado inicialmente, esse se comprometia em atender à reivindicação do Movimento Saúde Mais Dez e "implementar gradualmente, ao longo de quatro anos, a proposta do projeto de lei de iniciativa popular de vincular $10 \%$ da Receita Corrente Bruta da União ao financiamento das ações de saúde”. (Prg. MS, p. 157) Além disso, propunha "rejeitar qualquer Desvinculação de Receitas da União para assegurar a manutenção das fontes orçamentárias da Seguridade Social” (Prg. MS, p. 157) e "aumentar os investimentos na Atenção Básica para, no mínimo, 30\% do orçamento da saúde”. (Prg. MS, p. 161)

Além da universalização da atenção básica, já abordada, esse novo documento propunha "um ambicioso programa de ampliação da rede hospitalar e da oferta de leitos, de maternidades e de policlínicas”. (Prg. MS, p.159) Para isso, previa investimentos nas estruturas já existentes, construção e custeio de novas; convênios com a rede prestadora de serviços seriam realizados com rigorosos critérios de qualidade para reincorporar leitos perdidos pelo SUS. Também era abordada a construção de centrais de regulação, reformulação do atual modelo de gestão e atenção hospitalar, ampliação do Serviço de Atendimento Móvel de Urgência (Samu), criação de parâmetros para atendimentos às demandas individuais de procedimentos e medicamentos de alto custo via poder judiciário, tabela de remuneração de procedimentos.

Numa observação sobre o Programa Mais Médicos, foi considerado uma medida emergencial, embora passível de críticas. Reconhecia a escassez de profissionais com perfil generalista e interesse em tra- 
balhar com comunidades pobres das periferias das grandes cidades e afastadas dos centros urbanos e acreditava que investir na formação de novos profissionais de acordo com as necessidades do país e não segundo às regras de mercado seria essencial para enfrentar esse desafio e consolidar um novo modelo de atenção à saúde, que não demanda só por médicos, mas por profissionais de saúde em geral.

O Programa Mais Médicos foi a solução encontrada pelo atual governo para equacionar todas essas questões, mas não passa de uma resposta emergencial e inconsistente ao problema - especialmente em razão do convênio firmado com a Organização Pan-Americana da Saúde (OPAS) para trazer médicos de Cuba para o país. (Prg. MS, p. 163)

Para enfrentar esses desafios são apresentadas as seguintes propostas:

Liderar a construção de um pacto nacional em torno de uma política de desenvolvimento de recursos humanos para o SUS; Assegurar a fixação dos profissionais da saúde [...]; Apoiar (técnica e financeiramente) a elaboração de planos de cargos e salários a fim de estruturar carreiras de Estado para profissionais de saúde, com salários dignos, progressão e prestígio profissional. (Prg. MS, p. 163)

Com isso, respondia às demandas de entidades médicas que criticavam o Mais Médicos, através da proposição de estratégias de fixação que não previam a contratação de médicos estrangeiros e dialogavam com os demais profissionais ao propor a valorização da carreira em saúde.

O programa de Marina Silva foi o mais completo em suas formulações, apresentando propostas para cada tópico específico, assentadas em dados, indicadores e apontando as estratégias que precisariam ser adotadas para viabilizá-las. No que diz respeito à saúde, foi dentre os programa analisados, o que mais se aproximou dos valores e concepções do SUS defendidos pelo movimento da RSB, embora 
suas proposições para a política econômica deixassem dúvidas quanto à real aplicabilidade das proposições para as políticas sociais.

\section{Interseções e descompassos entre os projetos políticos}

Ao contrário do que se imaginava, após as manifestações de junho de 2013, quando a saúde parecia ser a principal preocupação da população, essa não foi prioridade nas campanhas à presidência da república. A pauta apareceu de forma pontual durante os meses de campanha, juntamente com as propostas para outros setores como educação, assistência social e segurança pública. Foram destacados alguns programas eleitorais de TV e materiais visuais específicos para o tema, onde as propostas apresentadas nos programas de governo puderam ser melhor publicizadas. Nos debates, não foi o tema dos momentos de maior destaque, nem ficaram expostos, claramente, os antagonismos entre os projetos. Esses momentos foram protagonizados por questões relativas à corrupção e política macroeconômica.

Os temas e a forma como foram abordados pelas campanhas estão sintetizados no Quadro 1, envolvendo os programas de governo apresentados ao TSE e os desdobramentos divulgados no processo, propostas apresentadas nos programas eleitorais, sites e redes sociais, comentários realizados em entrevistas e debates. 
Quadro 1 - Síntese das propostas apresentadas para a saúde pelas três principais candidaturas à presidência da república em 2014

\begin{tabular}{|c|c|c|c|}
\hline $\begin{array}{l}\text { Categoria / } \\
\text { Coligação }\end{array}$ & $\begin{array}{c}\text { “Com a Força } \\
\text { do Povo” Dilma } \\
\text { Rousseff }\end{array}$ & $\begin{array}{l}\text { "Muda Brasil" } \\
\text { Aécio Neves }\end{array}$ & $\begin{array}{c}\text { “Unidos pelo } \\
\text { Brasil” Eduardo } \\
\text { Campos / Marina } \\
\text { Silva }\end{array}$ \\
\hline $\begin{array}{l}\text { Prioridade dos } \\
\text { programas }\end{array}$ & $\begin{array}{l}\text { Desenvolvimento, } \\
\text { Crescimento } \\
\text { econômico e } \\
\text { Educação }\end{array}$ & $\begin{array}{l}\text { Política } \\
\text { Macroeconômica, } \\
\text { "choque de } \\
\text { gestão" }\end{array}$ & $\begin{array}{l}\text { Desenvolvimento } \\
\text { Sustentável e } \\
\text { Reforma Política/ } \\
\text { Democracia }\end{array}$ \\
\hline $\begin{array}{l}\text { Propostas } \\
\text { prioritárias } \\
\text { para a saúde }\end{array}$ & $\begin{array}{l}\text { Criação do } \\
\text { Programa Mais } \\
\text { Especialidades } \\
\text { e expansão do } \\
\text { Programa Mais } \\
\text { Médicos }\end{array}$ & $\begin{array}{l}\text { Aumento do } \\
\text { Financiamento, } \\
\text { construção } \\
\text { de centros } \\
\text { integrados de } \\
\text { saúde e incentivo } \\
\text { a abertura de } \\
\text { consultórios } \\
\text { populares }\end{array}$ & $\begin{array}{l}\text { Aumento do } \\
\text { Financiamento, } \\
\text { atenção integral à } \\
\text { saúde e qualidade } \\
\text { de vida }\end{array}$ \\
\hline $\begin{array}{l}\text { Compreensão } \\
\text { de saúde } \\
\text { predominante }\end{array}$ & $\begin{array}{l}\text { Acesso a serviços, } \\
\text { consultas, exames } \\
\text { e procedimentos }\end{array}$ & $\begin{array}{l}\text { Acesso a serviços, } \\
\text { consultas, exames } \\
\text { e procedimentos }\end{array}$ & $\begin{array}{l}\text { Articulação entre } \\
\text { políticas públicas } \\
\text { saudáveis e acesso a } \\
\text { serviços de saúde }\end{array}$ \\
\hline $\begin{array}{l}\text { Modelo de } \\
\text { Atenção à } \\
\text { saúde }\end{array}$ & $\begin{array}{l}\text { Hegemônico: } \\
\text { médico } \\
\text { assistencial }\end{array}$ & $\begin{array}{l}\text { Hegemônico: } \\
\text { médico } \\
\text { assistencial e } \\
\text { sanitarista }\end{array}$ & $\begin{array}{l}\text { Integração de ações } \\
\text { de promoção, } \\
\text { prevenção, } \\
\text { tratamento e } \\
\text { reabilitação }\end{array}$ \\
\hline $\begin{array}{l}\text { Promoção da } \\
\text { Saúde }\end{array}$ & $\begin{array}{l}\text { Não foi abordada } \\
\text { diretamente. } \\
\text { Melhoria das } \\
\text { condições de } \\
\text { vida, urbanização } \\
\text { e saneamento }\end{array}$ & $\begin{array}{l}\text { Promoção de } \\
\text { hábitos saudáveis; } \\
\text { urbanização e } \\
\text { saneamento }\end{array}$ & $\begin{array}{l}\text { Políticas públicas } \\
\text { intersetoriais e } \\
\text { promoção de } \\
\text { hábitos saudáveis }\end{array}$ \\
\hline
\end{tabular}




\begin{tabular}{|c|c|c|c|}
\hline $\begin{array}{l}\text { Atenção } \\
\text { Primária à } \\
\text { Saúde }\end{array}$ & $\begin{array}{l}\text { Expansão do } \\
\text { Programa } \\
\text { Mais Médicos; } \\
\text { construção e } \\
\text { reestruturação de } \\
\text { Unidades Básicas }\end{array}$ & $\begin{array}{l}\text { Porta de entrada } \\
\text { no sistema; } \\
\text { expansão do PSF } \\
\text { nas regiões mais } \\
\text { pobres }\end{array}$ & $\begin{array}{l}\text { Porta de entrada e } \\
\text { eixo estruturante } \\
\text { do sistema; } \\
\text { universalização } \\
\text { efetiva do PSF; } \\
\text { destinação de 30\% } \\
\text { do orçamento da } \\
\text { saúde }\end{array}$ \\
\hline $\begin{array}{l}\text { Atenção } \\
\text { Especializada }\end{array}$ & $\begin{array}{l}\text { Prioridade. } \\
\text { Rede de clinicas } \\
\text { e serviços } \\
\text { especializados; } \\
\text { expansão do } \\
\text { atendimento } \\
\text { a urgências e } \\
\text { emergências } \\
\text { e política de } \\
\text { medicamentos }\end{array}$ & $\begin{array}{l}\text { Rede de atenção } \\
\text { integradas, } \\
\text { centros integrados } \\
\text { de saúde e } \\
\text { consultórios } \\
\text { populares; acesso } \\
\text { a medicamentos }\end{array}$ & $\begin{array}{l}\text { Ampliação da rede } \\
\text { hospitalar e oferta } \\
\text { de leitos, construção } \\
\text { de maternidades e } \\
\text { policlínicas }\end{array}$ \\
\hline $\begin{array}{l}\text { Desafios } \\
\text { na gestão e } \\
\text { organização } \\
\text { dos serviços }\end{array}$ & $\begin{array}{l}\text { Pacto } \\
\text { interfederativo, } \\
\text { fortalecimento } \\
\text { de programas } \\
\text { existentes }\end{array}$ & $\begin{array}{l}\text { Pacto } \\
\text { interfederativo; } \\
\text { eficiência, metas, } \\
\text { protocolos } \\
\text { padronizados, } \\
\text { ações } \\
\text { programáticas } \\
\text { em saúde, } \\
\text { controle de gastos } \\
\text { desnecessários }\end{array}$ & $\begin{array}{l}\text { Pacto } \\
\text { interferderativo }\end{array}$ \\
\hline Financiamento & $\begin{array}{l}\text { Aumentado em } \\
97 \% \text {, em termos } \\
\text { reais, desde } 2002 . \\
25 \% \text { dos royalties } \\
\text { do pré-sal para } \\
\text { a saúde; não se } \\
\text { compromete } \\
\text { com aumento ou } \\
\text { outras fontes de } \\
\text { financiamento }\end{array}$ & $\begin{array}{l}\text { Insuficiente. } \\
10 \% \text { das RCB ou } \\
\text { proposta similar } \\
\text { de aumento } \\
\text { progressivo; } \\
\text { reestruturação } \\
\text { do modelo de } \\
\text { pagamento } \\
\text { por tabela de } \\
\text { procedimentos }\end{array}$ & $\begin{array}{l}\text { Insuficiente. } \\
10 \% \text { das RCB } \\
\text { gradualmente em } \\
4 \text { anos; rejeição da } \\
\text { DRU no orçamento } \\
\text { da seguridade social }\end{array}$ \\
\hline
\end{tabular}




\begin{tabular}{|c|c|c|c|}
\hline $\begin{array}{l}\text { Relação com o } \\
\text { setor privado }\end{array}$ & $\begin{array}{l}\text { Parte da Rede } \\
\text { de serviços } \\
\text { articulada e } \\
\text { integrada ao SUS }\end{array}$ & $\begin{array}{l}\text { Parceiros na } \\
\text { prestação e } \\
\text { gestão indireta } \\
\text { dos serviços; } \\
\text { fortalece o papel } \\
\text { de regulação do } \\
\text { Estado }\end{array}$ & $\begin{array}{l}\text { Convênios com } \\
\text { prestadores de } \\
\text { serviços para } \\
\text { a contratação } \\
\text { de leitos com } \\
\text { rigoroso critério de } \\
\text { qualidade }\end{array}$ \\
\hline $\begin{array}{l}\text { Política de } \\
\text { recursos } \\
\text { humanos em } \\
\text { saúde }\end{array}$ & $\begin{array}{l}\text { Aborda } \\
\text { superficialmente } \\
\text { através do } \\
\text { programa } \\
\text { Mais Médicos } \\
\text { a formação } \\
\text { de médicos } \\
\text { generalistas, } \\
\text { ampliação do } \\
\text { número de vagas } \\
\text { em Medicina } \\
\text { priorizando } \\
\text { regiões onde } \\
\text { existem vazios } \\
\text { assistenciais }\end{array}$ & $\begin{array}{l}\text { Carreira nacional } \\
\text { do SUS; política } \\
\text { de formação } \\
\text { com ênfase em } \\
\text { especialidades } \\
\text { mais necessárias; } \\
\text { incentivos para } \\
\text { a fixação de } \\
\text { profissionais; } \\
\text { profissionalização } \\
\text { da gestão federal }\end{array}$ & $\begin{array}{l}\text { Pacto nacional } \\
\text { para política de } \\
\text { desenvolvimento } \\
\text { de RH para o } \\
\text { SUS; apoio para } \\
\text { elaboração de } \\
\text { planos de carreira; } \\
\text { Formação de } \\
\text { profissionais } \\
\text { generalistas; serviço } \\
\text { civil solidário em } \\
\text { saúde }\end{array}$ \\
\hline
\end{tabular}

Fonte: Magno (2015).

Scheffer e Bahia (2014) afirmam que um dos efeitos simbólicos das manifestações de junho de 2013 nos programas de governo à presidência foi a retomada do termo SUS à cena política, praticamente desaparecido nas eleições de 2010. Porém admitem que o seu efeito positivo é um falso consenso, uma vez que não são apresentados conteúdos programáticos para enfrentar as reais necessidades e demandas numa evidente desconexão entre a saúde e o sistema de saúde, reduzindo o SUS a processos administrativos. Além disso, nenhuma candidatura discutiu a participação social como componente essencial para a preservação do direito à saúde.

As posições quanto ao financiamento do SUS exibiram incongruências entre os dados apresentados pelas três candidaturas, talvez pela utilização de memórias de cálculos diferenciadas. Os candida- 
tos da oposição reafirmavam o financiamento insuficiente e se comprometiam com as pautas populares numa tentativa de confrontar a candidata à reeleição. Entretanto, nenhuma candidatura definiu objetivamente quais seriam as novas fontes de recursos, uma delas, inclusive, apontava a redução de tributos para as políticas sociais. Dados semelhantes foram encontrados por Scheffer e Bahia (2014) em seu estudo, acrescentando que a relação entre as políticas macroeconômicas e sociais não era apresentada claramente, nem propostas visando refazer as contas do setor quanto às renúncias fiscais e isenções tributárias responsáveis por repasses de dinheiro público para financiar o setor privado.

A necessidade de reformulação dos pactos federativos para definição das atribuições da União, estados e municípios foi apontada pelas três candidaturas, porém não ocorreu aprofundamento das propostas e o assunto foi pouco retomado nas propagandas eleitorais de TV e debates.

Outra semelhança entre as campanhas foi a aproximação com o setor privado na saúde, seja através da proposição de parcerias público-privadas, na incorporação de serviços privados e filantrópicos à estrutura das redes assistenciais de saúde, na inclusão de planos e seguros de saúde nos indicadores de cobertura, ou ainda pela utilização de suas estratégias de gestão e lógica de organização de serviços. A candidatura de Marina Silva era mais sutil em expor essa relação. A aproximação com o setor privado evidencia a compreensão de coexistência entre dois sistemas de saúde no Brasil, o público e o privado, caracterizando a saúde como um setor da economia passível de exploração, inclusive sob financiamento do Estado.

Uma evidencia desse fato é a assimilação, pelas candidaturas, da agenda dos empresários da saúde materializada através do Livro branco da saúde (ANAHP, 2014), enquanto que a agenda do movimento da RSB apresentada através do manifesto "Por um SUS de todos os brasileiros", (POR..., 2014) assinado por oito entidades comprometidas com a construção da política de saúde no Brasil há décadas, teve pouca influência nas formulações. Temas como revisão 
da Lei de Responsabilidade Fiscal - em relação ao limite da despesa de pessoal com saúde; extinção dos subsídios diretos ao setor privado, ressarcimento do SUS, considerados importantes pelo manifesto, não foram mencionados pelas candidaturas.

\section{Comentários finais}

O presente estudo contemplou uma conjuntura iniciada com uma ampla mobilização popular, na qual o processo eleitoral e seus resultados parecem reiterar contradições não resolvidas na formação social brasileira, sugerindo certo aguçamento das lutas de classes, ainda que através de manifestações fenomênicas diversas.

As jornadas de junho de 2013 sinalizavam parte dessas contradições e lutas. Entretanto, apesar de representantes do Estado afirmarem que as vozes das ruas haviam se tornado prioridade nacional, não foi essa a realidade observada nas campanhas eleitorais à presidência da república. $\mathrm{O}$ estudo realizado evidenciou uma agenda política conformada com maior influência dos setores econômicos, meios de comunicação e ação de marqueteiros. Todas as candidaturas analisadas citaram as manifestações de 2013 em seus programas de governo, propagandas eleitorais, debates e materiais de campanha - cada uma com suas interpretações do que seriam as vozes das ruas - no sentido de referendar seus projetos e não de necessariamente apresentarem respostas às demandas sociais.

Para a política de saúde, não ficaram tão explícitas no processo eleitoral as divergências de projetos no que dizia respeito à saúde nos três polos de disputa com maior viabilidade eleitoral. Foi perceptível nas três candidaturas um mix de propostas com a utilização de informações sobre o SUS, dados epidemiológicos e tendências demográficas pertinentes ao documento editado pela Fundação Oswaldo Cruz (Fiocruz), em 2012 , com estratégias de gestão das políticas sociais e definição de prioridades à luz da nova agenda social (BACHA; SCHWARTZMAN, 2011), além da marcante influ- 
ência das contribuições dos empresários do setor no Livro branco da saúde. (ANAHP, 2014)

Costa e Sestelo (2015) ressaltaram a relação entre o Livro branco da saúde e as propostas apresentadas no processo eleitoral, supondo tratar-se de uma estratégia articulada entre agentes estrangeiros interessados na venda de serviços de saúde, apoiados por parlamentares brasileiros, imprensa e agentes públicos com função de governo. Sobre o programa da presidenta eleita para a área da saúde, afirmavam que "omissões e silêncios" não evidenciavam um projeto mais comprometido com os direitos sociais em detrimento dos interesses de acumulação privada do "mercado". Para os autores, esse processo vem sendo gestado há tempos no interior do governo, uma vez que a presidente se reuniu com os empresários do setor em diversos momentos, e não abriu as portas ao movimento sanitário que sucessivamente tem sido desqualificado em debates com representantes do governo.

Assim, os acordos "pelo alto" na definição do jogo político e a lógica de coalizão de classes e interesses distintos mantém as classes subalternas afastadas dos espaços decisórios efetivos, reproduzindo a "revolução passiva" e o "transformismo". (COUTINHO, 1988; SCHLESENER, 2009; VIANA, 2004) Para superar esses obstáculos, as forças progressistas necessitam "dessetorializar" o debate da saúde, exercer maior protagonismo na esfera pública e construir unidade com os setores populares, organizações sindicais, movimentos sociais e movimentos de juventude em defesa do projeto da RSB.

\section{Referências}

ANAHP. Livro Branco: Brasil Saúde 2015: a sustentabilidade do sistema de saúde brasileiro: caderno de propostas, [S.1.], 2015. Disponível em: <http://anahp.com.br/a-anahp/publica\%C3\%A7\%C3\%B5es-anahp/ livro-branco-brasil-sa\%C3\%BAde-2015-caderno-de-propostas $>$. Acesso em: 23 set. 2014. 
ANDRADE, C. D. A rosa do povo. São Paulo: Companhia das Letras, 2012.

BACHA, E. L.; SCHWARTZMAN, S. (Org.). Brasil: a nova agenda social. Rio de Janeiro: LTC, 2011.

BAHIA, L. O prazo de validade do SUS. Caderno de Saúde Pública, Rio de Janeiro, v. 29, n. 10, p. 1940-1942, out. 2013.

BAHIA, L. A saúde em banho-maria. In: MAGALHÃES, J. P. de A. Os anos Lula: contribuições para um balanço crítico 2003-2010. Rio de Janeiro: Garamond, 2010. p. 351-368.

BAVA, S. C. Para onde vai o governo? Le Monde Diplomatique Brasil, São Paulo, v. 6, n. 72, jul. 2013.

BOITO, A. As bases politicas do neodesenvolvimentismo. Trabalho apresentado no Fórum Econômico da FGV, São Paulo, 2012. Disponível em: <http://eesp.fgv.br/ sites/eesp.fgv.br/files/file/Painel\%203\%20 -\%20Novo\%20Desenv\%20BR\%20-\%20Boito\%20-\%20Bases\%20Pol\%20 Neodesenv\%20-\%20PAPER.pdf >. Acesso em: 23 abr. 2014. BRASIL. Conselho Nacional de Secretarias Municipais de Saúde CONASEMS. Carta de Serra/Es 2014. apresentado no XXX Congresso Nacional de Secretarias Municipais de Saúde. Brasília, DF, 2014.

Disponível em: <http://www.conasems.org.br/images/carta_de_serra. pdf $>$. Acesso em: 7 out. 2014.

BRAGA, R. Sob a sombra do precariado. In: VAINER. C. et al. Cidades rebeldes: passe livre e as manifestações que tomaram as ruas do Brasil. São Paulo: Carta Maior: Bomtempo, 2013. p. 79-82.

CARR, E.H. O que é história. 8. ed. Rio de Janeiro: Paz e Terra, 2002. CARVALHO, I. Uma cronologia das manifestações. Revista Fórum, São Paulo, v. 12, n. 124, jul. 2013. Edição especial.

CHAUÍ, M. As manifestações de junho de 2013 na cidade de São Paulo. Teoria e Debate, n. 113, jun. 2013. Disponível em: <http://www. teoriaedebate.org. br/materias/nacional/manifestacoes-de-junho-de2013-na-cidade-de-sao-paulo>. Acesso em: 11 fev. 2014. 
COSTA, A. M.; SESTELO, A. J. A vaca tosse vai para o brejo e pode atolar o SUS. Viomundo. [S.l.], 10 fev. 2015. Disponível em: <http:// www.viomundo.com. br/denuncias/ana-costa-e-antonio-sestelo-vacatosse-vai-para-o-brejo-e-deixa-o-sus-atolado.html?fb_action_ids= 796856673696099\&fb_action_types=og.likes $>$. Acesso em: 12 fev. 2015.

COUTINHO, C. N. As categorias de Gramsci e a realidade brasileira. In: COUTINHO, C. N.; NOGUEIRA, M. A. Gramsci e a América Latina. Rio de Janeiro: Paz e Terra, 1988. p. 103-127.

DATAFOLHA aponta saúde como principal problema dos brasileiros. Folha de São Paulo, São Paulo, 29 mar. 2014. Disponível em: http:// www1.folha.uol.com.br/seminariosfolha/2014/03/1432478-datafolhaaponta-saude-como-principal-problema-dos-brasileiros.shtml $>$. Acesso em: 31 mar. 2014.

DISCURSO da Presidenta da República, Dilma Rousseff, durante reunião com governadores e prefeitos de capitais. Portal do Planalto, Brasília, DF, 24 jun. 2013. Disponível em: <http://www2.planalto.gov. br/acompanhe-o-planalto/discursos/discursos-da-presidenta/discursoda-presidenta-da-republica-dilma-rousseff-durante-reuniao-comgovernadores-e-prefeitos-de-capitais>. Acesso em: 22 set. 2014.

DURKHEIM, E. As regras do método sociológico. 3. ed. São Paulo: Martins Fontes, 2007.

FUNDAÇÃO OSWALDO CRUZ. Saúde no Brasil em 2030: diretrizes para a prospecção estratégica do sistema de saúde brasileiro. Rio de Janeiro, 2012.

FLEURY, S. Reforma do Estado, Seguridade Social e Saúde no Brasil. In: MATTA, G. C. ;LIMA, J. C. F. Estado, sociedade e formação profissional em saúde: contradições e desafios em 20 anos de SUS. Rio de Janeiro:

Ed. Fiocruz, 2008. p. 49-87.

FRENK, J. Leading the way towards universal health coverage: a call to action. The Lancet, [S.1.], v. 385, p.1352-1358, abr. 2015. 
GRAMSCI, A. Análise de situações: relações de força. In: SADER, E. (Org.). Gramsci: poder, política e partido. 2. ed. São Paulo: Expressão Popular, 2012. p. 37-50.

MAIOR, J. L. S. A vez do direito social e da descriminalização dos movimentos sociais. In: VAINER. C. et. al. Cidades rebeldes: passe livre e as manifestações que tomaram as ruas do Brasil. São Paulo: Carta Maior: Bomtempo, 2013. p. 83-88.

MACHADO, C. V.; BAPTISTA, T. W. F.; LIMA, L. D. (Org.). Política de saúde no Brasil, continuidades e mudanças. Rio de Janeiro: Ed. Fiocruz, 2012.

MAGNO, L. D. Dos clamores das ruas aos rumores no Congresso: uma análise da conjuntura recente da saúde no Brasil. 2015. 105 f. Dissertação (Mestrado em Saúde Coletiva) - Instituto de Saúde Coletiva, Universidade Federal da Bahia, Salvador, 2015. Disponível em: < http://www.analisepoliticaemsaude.org/ up/oaps/producao /9cfa9668242186748ea6acb23f5c4c5c/ b2096d2e4efc06b24fec11b1a6664132/ e297dfbf76f9e4c6065ddc6be5bb321c.pdf?0.28304900\%20 1477057654>. Acesso em: 9 out. 2015.

NAVARRO, C.; BRASILINO, L.; GODOY, R. O junho de 2013. Le Monde Diplomatique Brasil, São Paulo, v. 6, n. 72, jul. 2013.

NORONHA, J. C. Cobertura universal de saúde: como misturar conceitos, confundir objetivos, abandonar princípios. Caderno de Saúde Pública, Rio de Janeiro, v. 29, n. 5, p. 847-49, maio 2013.

OLIVEIRA, F. P. de et al. Mais médicos: um programa brasileiro em uma perspectiva internacional. Interface, Botucatu, v. 19, n. 54, p. 623-634, set. 2015. Disponível em: <http://www.scielo.br/pdf/icse/v19n54/18075762-icse-19-54-0623.pdf. Acesso em: 18 out 2015.

ORGANIZAÇÃO MUNDIAL DA SAÚDE. Relatório mundial da saúde 2013: pesquisa para a cobertura universal de saúde. Genebra, 2013.

PAIM, J. S. Reforma Sanitária Brasileira: contribuição para a compreensão e crítica. Salvador: EDUFBA; Rio de Janeiro: Ed. Fiocruz, 2008. 
PAIM, J. S. A constituição cidadã e os 25 anos do Sistema Único de Saúde (SUS). Caderno de Saúde Pública, Rio de Janeiro, v. 29, n. 10, p. 1927-1936, out. 2013;

PAIM, J. S. Reforma Sanitária Brasileira: eppur si muove. Caderno de Saúde Pública, Rio de Janeiro, v. 29, n. 10, p. 1952-1953, out. 2013.

PAIM J. S. et al. O sistema de saúde brasileiro: história, avanços e desafios. The Lancet. London, v. 377, n. 9779, p. 1778-1797, 2011, p. 1778-1797, 2011.

PORTANTIERO. J. C. Gramsci y el análisis de coyuntura (algunas notas). In: PORTANTIERO. J. C. Los usos de Gramsci. México: Folio ediciones, 1983. p. 177-193.

POR um SUS de todos os brasileiros: propostas do movimento da reforma sanitária para o debate nacional. Vitória: ABRASCO, 3 jun. 2014. Disponível em: <http://cebes.org.br/site/wp-content/ uploads/2014/05/Por-um-SUS-de-todos-os-brasileiros2.pdf > . Acesso em: 4 jun 2014.

SCHAFF, A. História e verdade. 6. ed. São Paulo: Martins Fontes,1995.

SCHEFFER, M.; BAHIA, L. A saúde nos programas de governo dos candidatos a Presidente da República do Brasil nas eleições de 2014: notas preliminares para o debate. Relatório de pesquisa.

[S. 1.], 2014. Disponível em: < http://cebes.org.br/site/wp-content/ uploads/2014/07/proposta-sa\%C3\%BAde-presidenciaves-2014.pdf>. Acesso em: 31 jul. 2014.

SCHLESENER, A. H. Intelectuais e política: observações acerca do transformismo nos escritos de Antonio Gramsci. Revista Outubro, [S.l.], n. 18, p. 201-222, 2009. Disponível em: <http://outubrorevista. com.br/wp-content/uploads/2015/02/Revista-Outubro-

Edic\%CC\%A7a\%CC\%83o-18-Artigo-08.pdf >. Acesso em: 23 jun. 2014.

SINGER, A. Brasil, junho de 2013: classes e ideologias cruzadas. Dossiê mobilizações, protestos e revoluções. Novos Estudos CEBRAP, São Paulo, n. 97, nov. 2013. Disponível em: <http://www.scielo.br/scielo. php?pid=S0101-33002013000300003\&script=sci_arttext\&tlng=p $>$. Acesso em: 23 jun 2014. 
SINGER, A. Sinais trocados. Folha de São Paulo, São Paulo, 1 nov. 2014. Disponível em: <http://www1. folha.uol.com.br/colunas/andresinger/ 2014/11/1541738-sinais-trocados.shtml>. Acesso em: 16 nov. 2014.

SOUZA, H. J. Como se faz análise de conjuntura. 3. ed. Petrópolis: Vozes, 1985.

TEIXEIRA, C. F.; PAIM, J. S. A política de saúde no governo Lula e a dialética do menos pior. Saúde em debate, Rio de Janeiro, v. 29, n. 31, p. 268-283, 2005.

TITELMAN, D.; CETRÁNGOLO, O.; ACOSTA, O. L. Universal health coverage in Latin American coutries: how to improve solidarity-based schemes. The Lancet, London, v. 385, p. 1359-1363, Apr. 2015.

VEJA as reivindicações levadas às ruas durante manifestações. Folha de São Paulo. São Paulo, 20 fev. 2013. Disponível em: <http://www1.folha. uol.com.br/cotidiano/2013/06/1298127-veja-as-reivindicacoes-levadasas-ruas-durante-manifestacoes.shtml>. Acesso em: 11 fev 2014.

VIANA, A. L. D. Longos dias tem cem anos. Caderno de Saúde Pública, Rio de Janeiro, v. 29, n. 10, p. 1942-1944, out. 2013.

VIANA, L. W. A revolução passiva: iberismo e americanismo no Brasil. 2. ed. Rio de Janeiro: Renavan, 2004. 
Ana Maria Costa, Raquel Abrantes Pêgo, Fabiana da Cunha Saddi, Daniel Adolpho D. Assis, Lidiane F. Gonçalves e Alyne Alvarez Silva

\section{SAÚDE NO PODER LEGISLATIVO objeto, investigação e tendências}

\section{Introdução}

O Poder Legislativo constitui um ator político fundamental no processo de definição e na determinação da política de saúde, particularmente, na imprescindível associação existente entre política social e democracia. Neste capítulo, que trata o Legislativo como objeto de pesquisa, os autores apresentam inicialmente uma revisão da bibliografia especializada sobre o tema. Em seguida, a partir de observações preliminares de campo de pesquisa referente às quatro últimas legislaturas $\left(52^{\mathrm{a}}, 53^{\mathrm{a}}, 54^{\mathrm{a}}\right.$ e $\left.55^{\mathrm{a}}\right)$, identificam tendências e aspectos das dinâmicas sobre a saúde. Destaca-se nesse campo de força e poder político, de um lado, a tendência associada ao mercado e à privatização e, de outro, às religiões e à moral. Sob a lente dos primeiros achados exploratórios, os temas estudados são submetidos à análise tomando por base as respectivas decisões e iniciativas parlamentares correlacionadas aos interesses associados a esses dois polos de força. 
Partindo da premissa que a política social tem como objetivo central estabelecer e manter um padrão de coesão sociopolítico, é mister admitir que essa política está sujeita, permanentemente, a um conjunto de forças em conflito, com recursos e poder distintos, que disputam interesses diversos na sua formulação e condução. É resultado de conquistas, acumulações e perdas presentes no conflito social e, assim sendo, envolve considerar na sua análise o contexto histórico, as relações de poder entre os grupos, bem como a própria orientação político-ideológica do Estado e as complexas relações que se estabelecem entre Estado, economia e setores da sociedade. Essas relações ocorrem no enfrentamento de problemas de domínio público que afetam o bem-estar, originados em diferentes âmbitos do edifício social e que mobiliza espaços de representação, interlocução e negociação. (WANDERLEY, 2015)

A existência do Estado nas suas distintas formas, países e regimes políticos, encontra-se sempre associada à noção de interesses coletivos amplos, considerados como de domínio público. A cons114 trução do interesse público por sua vez, confunde-se com a própria justificativa do Estado e resulta de processos históricos e culturais específicos, moldado nas tensões e conflitos entre classes e grupos de interesses portadores de ideologias diversas e distintas. Nas políticas públicas, o significado de interesse público adquire uma conotação mais plural ou universal assim como um significado normativo. Este "que remete ao interesse de todos e ao reconhecimento do direito de todos à participação na coisa pública, o que interpela o Estado e a sociedade civil”. (WANDERLEY, 2015, p. 812)

O mundo contemporâneo encontra-se dominado pela economia de mercado que produz e aprofunda as desigualdades e a exclusão social. Seus interesses que, geralmente, incidem sobre a desconstrução dos interesses públicos universais, podem ser evidenciados nos diferentes momentos ou etapas do processo de construção de uma política pública quando atuam as diversas forças e projetos políticos-ideológicos de distintas naturezas e interesses. 
A formulação da política pública ocorre sob marcos institucionais específicos que expressam pactos de dominação das forças hegemônicas e relações de poder. Estas ocorrem entre os grupos sociais e indivíduos e suas assimetrias e constituem atualmente uma das bases da análise das políticas públicas e, para isso, o investigador desse campo deve conhecer e considerar as relações de poder, que atravessam permanentemente seu objeto de estudo, identificando os atores que influenciam, direta ou indiretamente, na formulação e execução da política pública, em diferentes momentos. Sob essa perspectiva, para a análise da política há que se considerar também a natureza desses grupos e atores políticos, suas percepções, recursos, formas e estratégias adotadas, bem como as respectivas relações e redes de interações entre atores públicos e privados, sociais e políticos.

Em suma, o investigador de políticas públicas deve identificar os distintos atores e suas ações nos diferentes níveis institucionais e sociais, atentando aos respectivos pactos ou acordos, explícitos ou implícitos, envolvidos, assim como os objetivos, metas e perspectivas presentes nos governos e no conjunto da sociedade. Aqui, é importante valorizar o papel determinante do Estado e suas instituições de governo nos rumos da política, uma vez que as práticas de negociação de seus protagonistas refletem, na maioria das vezes, suas alianças políticas com os grupos sociais com maior hegemonia e poder na sociedade e são orientadas, predominantemente, por escolhas ou critérios materiais e morais. Por instituições de governo, entende-se todas as instituições públicas, vinculadas ao Legislativo, Executivo e Judiciário, cujas decisões ou leis mudam, regulam ou interferem na vida da sociedade. Cabe retomar que o objeto de estudo a ser discutido e analisado, neste capítulo, restringe-se aos jogos de força que se dão no Parlamento acerca das legislações afetas à política de saúde. 


\section{Notas sobre a conquista e obstáculos ao direito universal à saúde}

Considerando que as dinâmicas dos sistemas de proteção social - onde se localiza a saúde - estão interligadas com as transformações sociais, demográficas, econômicas, políticas e culturais, a hipótese estruturante que orienta esta pesquisa diz respeito à presença de um processo parlamentar de desconstrução dos direitos sociais inscritos na Constituição Federal de 1988. Esse processo ora conta com a clara adesão do Poder Executivo, ora constitui-se em uma agenda própria do Congresso Nacional, que age em nome de grupos de interesse. $\mathrm{O}$ estudo verifica ainda as alianças entre o Poder Legislativo e forças sociais econômicas e culturais de cunho ideológico e religioso, cujas agendas nem sempre convergem ou potencializam o conjunto das diretrizes constitucionais que orientam o Sistema Único de Saúde (SUS).

A Constituição estabeleceu um Sistema de Seguridade Social baseado na Saúde, Previdência e Assistência Social e promoveu a saúde à condição de direito associado à cidadania, em um contexto histórico tardio em relação ao que vinha ocorrendo nos países europeus em termos dos direitos sociais e políticas universais, que ali estão presentes desde o período posterior à Segunda Guerra Mundial. Historicamente, vale notar que, na América Latina, o processo brasileiro ocorreu depois do projeto de universalização da saúde no Chile, sumariamente abortado pelo golpe militar que destituiu Salvador Allende e fez do país território de alta influência liberal.

$\mathrm{O}$ desenvolvimento dos direitos de cidadania compreende alguns elementos fundamentais que conformam o conjunto dos direitos que garantem as liberdades individuais de ir e vir, de imprensa, de pensamento e de prática do credo. O elemento político da cidadania envolve o direito de participar e o exercício do poder político materializado nas institucionalidades como é o caso do Parlamento, tanto como sujeito que corporifica o poder instituído, como na condição instituinte de eleitor. 
Sob o ponto de vista social, a cidadania mostra-se como um processo de construção no seio da política e na sociedade, garantida pelas instituições políticas e sociais que cumprem o papel de promoção do bem-estar social e de justiça, de acordo com os padrões reconhecidos e aceitáveis na sociedade. Os três elementos - cidadania, bem-estar e justiça - necessariamente devem estar integrados e articulados, já que são interdependentes, e qualquer ruptura compromete a condição da cidadania plena. (MARSHALL, 1967) Entretanto, essa relação é encontrada sob formas distintas nos diferentes países, o que pode ser associado às suas distintas etapas de desenvolvimento social e econômico e às diferenças de regimes políticos. A Seguridade Social brasileira, cujo modelo é inspirado nos estados de bem-estar social da Europa, está sob constante tensão no campo das forças políticas presentes no interior do Estado e da sociedade. Da linhagem do modelo inglês de Beveridge, esse sistema baseia-se no princípio da universalidade e da justiça, pois é financiado por orçamento proveniente dos impostos no qual parte da população paga para produzir cobertura universal dos benefícios e assistência. Sua aprovação no processo constituinte é interpretada por muitos analistas e estudiosos como advinda de uma janela de oportunidade em um contexto político democrático favorável ao projeto universalista de seguridade social e de saúde acumulado pelo movimento da reforma sanitária. No processo constituinte, a vitória desse projeto é resultante da ausência de propostas consistentes do campo liberal para o setor. Essa configuração permitiu trânsito ao conjunto de mudanças propostas para a Reforma Sanitária potencializados pela força e poder da demanda popular por democracia e direitos sociais.

Entretanto esse cenário político por direitos e políticas sociais universais durou pouco e o rearranjo das forças liberais vem garantindo seus interesses como, por exemplo, abrindo espaço para o mercado da medicina privada, hoje como caráter suplementar ao SUS. Logo na fase da formulação da Lei Orgânica da Saúde (Leis 8.080 e $8.142 / 1991$ ) esses grupos de interesse antagônicos marcaram presença nos processos legislativos obstaculizando a legislação para o 
cumprimento do direito universal à saúde tal como ocorre até o presente. O rearranjo das forças políticas liberais que vem se expandindo no cenário politico é protagonizado pelos mesmos grupos que, desde o início da vigência da nova Constituição, vêm obstruindo a consolidação e efetivação dos direitos e conquistas associados à cidadania e aos direitos sociais. As evidências são de que está sob risco a condição da universalidade e da integralidade do SUS para ceder lugar ao caráter subsidiário em relação aos planos de saúde, seguros e outras empresas do mercado da saúde.

\section{O Poder Legislativo, políticas públicas e saúde}

Para conhecer e mapear a produção científica sobre o Poder Legislativo, pretende-se incialmente registrar alguns estudos focando, em primeiro lugar, na modalidade de literatura que abrange e conecta as políticas públicas e o Congresso Nacional e que incorpora essa instância como um ator importante do processo de decisão das políticas públicas. Em seguida, serão explorados os estudos que se dedicam de forma mais específica à saúde no Poder Legislativo.

Para fins do cumprimento dessa tarefa, será analisada outra literatura, muito própria das Ciências Políticas, centrada nos estudos acerca do Congresso Nacional enquanto instância política, com suas regras e dinâmicas próprias. Verificam-se, ainda nesse cenário, os estudos de Sociologia Política que foram hegemônicos e predominantes no período conhecido como "democracia populista", dos anos 1940 até o período pré-constituinte, cujo legado permanece até hoje. Entre os estudos que privilegiam o método da Sociologia Política, acrescem aqueles que utilizam conceitos como "sistemas políticos", "federalismo" e "presidencialismo de coalizão", dentre outros temas clássicos associados ao Legislativo. Tais referências são geralmente ancoradas em análises típicas das relações Estado-Sociedade sob o foco dos arcos de alianças, valores e interesses presentes nos contextos políticos e econômicos. (ABRANCHES, 1988; ABRUCIO, 1998; SALLUM JÚNIOR, 1996; SANTOS, 1997) 
Cabe observar, a partir de Melo (1999) e Arretche (2003 apud PITTOL TREVISAN; VAN BELLEN, 2008), que o campo de investigação em políticas públicas no Brasil tem características próprias e isso ocorre, em parte, pela ausência de pesquisa em algumas temáticas. Uma dessas questões, pouco estudada, diz respeito ao processo de decisão e formulação de políticas no Brasil, já que as análises dominantes do campo de políticas públicas, e em subáreas correlacionadas, tendem a focalizar a capacidade de atuação da burocracia ou do Estado em relação a políticas públicas, ou mesmo o perfil e desempenho dos burocratas. Outro tema que requer mais investigação é o referente à implementação das políticas e dos programas. A chamada "caixa de pandora" da política social onde se localizam os estudos sobre a atuação das distintas forças políticas como a pressão do mercado ou dos grupos ideológicos, como no caso dos interesses religiosos, continua desafiando os pesquisadores a desvelar as inter-relações e interações que ocorrem no interior das negociações, acordos e alianças que resultam ou não na política.

Verifica-se o crescimento de uma agenda de pesquisas voltada às análises do processo decisório centradas no Congresso Nacional, em particular na Câmara dos Deputados. De um modo geral, podese dizer que são os cientistas políticos que dominam esse tipo de produção focada no Congresso. Essas análises se localizam, sobretudo, em períodos de criação do arcabouço constitucional, na redemocratização ou em período de criação de novos programas do executivo que demandam aprovação do Congresso, mostrando-se esparsas, alternadas e escassas nas fases de regulamentação dos dispositivos constitucionais. Já no que diz respeito à literatura produzida sobre o Congresso Nacional, são raras as análises interdisciplinares, uma vez que os estudos realizados provêm, na sua grande maioria, da Ciência Política. Nesse grupo de literatura, destacam e assumem importância ainda, os estudos realizados por assessores parlamentares e de lobistas, bem como pesquisas acadêmicas desenvolvidas pela sociologia política, ciência política. 
Assessores e lobistas buscam respostas ou maior entendimento e compreensão sobre o processo legislativo. Dedicam-se, sobretudo, aos estudos legislativos, com ênfase em temas ou processos institucionais específicos, os quais privilegiam regras institucionais ou atuação de determinado ator ou setor, atuação de partidos, arranjos institucionais e monitoramento de temas ou assuntos. Utilizam métodos de pesquisa variados conforme o tema, fazendo uso dos conceitos de "regime político", "sistemas partidários" e outros. No entanto, estes podem ser interpretados como estudos avaliativos de tipo "político", produzidos para fins específicos, conforme objetivo dos avaliadores em questão. Traduzem-se também, muitas vezes, como um briefing ou resumo, ou mesmo como relatório político do processo ou tema em questão. (FIGUEIREDO; LIMONGI, 1995,1999; MAINWARING; PÉREZ LIÑÁN, 1998; PITANGUY, 2002; SANTOS, 1997, 2008)

Nas análises das ciências políticas sobre Congresso Nacional, predominam os estudos teóricos e de base empírica do novo insti120 tucionalismo, presentes no Brasil desde os anos 1990. Destacam-se aqui os trabalhos desenvolvidos por Figueiredo e Limongi (1995, 1999), Mainwaring e Pérez Liñán (1998), Santos (1997), Pereira e Muller (2003), Ames (1995 e 2003), dentre outros. Trata-se de estudos baseados no individualismo metodológico, da perspectiva da escolha racional, com forte influência do tipo de produção existente dos Estados Unidos sob a forma de estudos comparados sobre o Legislativo, em que destaca um número reduzido de variáveis utilizadas nos diversos modelos. O início dessa influência no Brasil ocorreu a partir da publicação de Limongi (1994). Essa vertente ganhou força nesse contexto de propagação dos ideais liberais, em que o componente metodológico reorientou as pesquisas no mundo e redirecionou as agendas de pesquisa na área da ciência política relacionadas a vários temas, incluindo o Poder Legislativo.

Manuel Santos (2008) contribui com algumas observações sobre a produção da ciência política brasileira em relação ao Legislativo para um período de 10 anos (1994 a 2005) e, no que se refere aos as- 
pectos metodológicos, a opção por métodos quantitativos predominou entre os pesquisadores. Nesse contexto, a ciência política avançou da descrição para a explicação, vindo o próprio alicerce empírico do Congresso contribuir nas suas teorias. No que tange à agenda de pesquisa mais influenciada pelo positivismo norte-americano, os temas mais presentes foram "o papel dos partidos, o poder da agenda do Presidente, abdicação $\mathrm{x}$ delegação de poderes do Legislativo para o Executivo, conexão eleitoral, as carreiras parlamentares, o processo orçamentário, os outputs legislativos e o sistema de comissões". (SANTOS, 2008, p. 25)

O autor ressalta que uma das limitações é a ausência de estudos sobre o processo decisório de políticas públicas dedicados à forma como se dá a relação entre Congresso, grupos de interesse e burocracia no decorrer do processo decisório. As lacunas de conhecimento indicadas na literatura sobre política pública e Congresso Nacional no Brasil, particularmente nas desconexões existentes em relação às temáticas de poder e parlamento, permitem asseverar a relevância do tipo de análise proposto nessa modalidade de estudo que pretende identificar cenários e forças políticas que influenciam os processos da política pública. Tal intenção mostra-se ainda mais relevante para a saúde cujo arcabouço constitucional elevou o direito universal à saúde norteados pela política de um sistema único exigindo um papel relevante do Estado. Na mesma direção, mobilizam distintos interesses alguns temas particulares da saúde que, nas últimas décadas, têm sido considerados nos estudos sobre a atuação parlamentar no Brasil.

Desde a década de 1970, muito se escreveu sobre a política de saúde executada pelo regime civil-militar (1964-1985), ora abordando o caráter autoritário e privatista do setor da saúde, ora identificando e ressaltando as demandas e pressão da sociedade civil por melhores serviços de saúde. Os atores sociais se tornam importantes e visíveis na cena política à medida que as forças democráticas vão conquistando espaço na condução do processo de transição. Assim é que, por ocasião da mobilização por uma nova Constituição, existia um projeto político defendido por um amplo movimento organiza- 
do que demandava uma reforma sanitária. Esse movimento, com sua capacidade de articulação e negociação, acabou constituindo-se em uma poderosa força política na construção da Constituição Cidadã, marco fundamental para as políticas sociais e de direitos humanos. (CARRARA, 2010; PAIM, 2008)

No período pós-Constituinte, cresce o papel que o Poder Legislativo passa a exercer para efetivar o direito à saúde, passando à condição de ator central enquanto formulador de leis que orientarão a política de saúde. Sob essa perspectiva, o Legislativo é contemplado nos estudos sobre política de saúde e essa nova onda de estudos envolve olhares sobre os grupos de interesse, de pressão, os partidos e as coalizões. Gradativamente, essa abordagem passa a ocupar a agenda de pesquisa, mas, como observa Baptista (2010), a lacuna de estudos é grande, particularmente no que refere à análise do processo político. Nas palavras e interrogações da autora, identifica-se novos desafios para pesquisas: "como as demandas são encaminhadas; que grupos são mais atuantes; quais interesses mais presentes; como e por qual razão alguns temas se transformam em leis; por que algumas leis são efetivamente implementadas e outras não". (BAPTISTA, 2010, p. 98)

Ao calor do processo constituinte e da promulgação da Constituição e, particularmente, após a aprovação da Lei Orgânica da Saúde, em um clima de disputa e de mobilização para superar e barrar a retomada liberal, é que se observa um incremento na análise das dinâmicas políticas no Congresso. Essas análises, na sua maioria, possuem como intenção conhecer a complexidade da nova composição e alianças partidárias e da representação dessas forças políticas e suas consequências para as conquistas de direitos sociais plasmadas na Constituição. Romero (2000), por exemplo, registra que seu estudo foi alentado pelo debate que surge em 1992 no Congresso, mediante a primeira proposição de regulamentação, no âmbito do Senado Federal, do dispositivo da Constituição que atribui ao SUS a competência para ordenar a formação de recursos humanos na área da saúde. Esse mesmo autor realizou, em 2000, um estudo caracterizando e 
descrevendo a atividade dos senadores em saúde pública e os fatores que influenciaram suas decisões para o período de 1995-1996.

Assim, seguindo as tendências já apontadas na literatura de políticas públicas e de ciência política também no campo da política de saúde e de sua relação com o Legislativo, analisa-se, de forma comparada e relacional, a capacidade dos Poderes Executivo e Legislativo de legislar e, em particular, de gerar um marco normativo próximo ao SUS Constitucional. (BAPTISTA, 2003, 2009, 2010; GOMES, 2011; RODRIGUES; ZAULI, 2002) São estudos centrados no processo de decisão e nas suas consequências para o SUS e pautados, sobretudo, no conhecimento da dinâmica legislativa, sua relação com o Executivo e com os grupos de interesses.

O estudo de Rodrigues e Zauli (2002) para o período de 19851999 identifica que a força do executivo para governar à margem do Congresso Nacional é mínima. Também demonstra a recuperação da capacidade "legiferante" do legislativo. O estudo comprova que a capacidade de legislar das duas instâncias não é uma prerrogativa dos dispositivos institucionais nem do conteúdo das propostas. $\mathrm{O}$ que consideram que define a capacidade de legislar é a estratégia adotada pelos atores envolvidos no processo de tomada de decisão e dos recursos políticos por eles utilizados.

Outro trabalho que se sobressai e foca-se no exercício efetivo do poder e suas relações com a sociedade no campo da saúde pública é o de Baptista $(2003,2009,2010)$. A autora realiza uma análise comparada da atuação do Poder Executivo e o Legislativo durante o período de 1990-2006 e identifica três períodos de elaboração de leis na saúde:

a. 1990-1994 é o período que, no Executivo, predominam os interesses macroeconômicos orientados por uma visão liberal contrariando a extensão dos direitos de proteção social e de definição da base institucional do SUS (Lei Orgânica da Saúde, 8.080 e 8.142/1991, e a lei de extinção do INAMPS, 8.689/93); 
b. 1995-2002, de expansão de políticas técnicas e específicas de saúde, seguidas de política de regulação do mercado de saúde, quando os movimentos corporativos e sociais são escutados pelo legislativo;

c. 2003-2006, o Governo Federal é que lidera a agenda com um foco na correção da desigualdade.

Da comparação, Baptista destaca a capacidade do Poder Executivo em propor e ter agilidade com relação ao processo decisório - fortalecendo o poder de governar, de concentrar poder e decidir sobre políticas, que são negociadas por meio de processos não muito transparentes.

Também identifica a autora, uma conexão eleitoral entre o Legislativo e os movimentos sociais e corporações, ao responder seus interesses e visualiza inflexões no debate sobre o direito à saúde que marcarão o processo decisório. Observa a conformação de três tendências na abordagem do direito no âmbito das leis: uma reafirma o direito; outra o segmenta; a terceira muda sua concepção. A primeira se manifesta nas leis que avançam no controle sanitário e na produção de ambientes saudáveis, promove a regulação de áreas estratégicas de atenção à saúde, atende demandas de áreas específicas da atenção e que, em maior parte, são demandas dos movimentos sociais. A tendência que segmenta o direito à saúde se faz a partir da discriminação negativa dos direitos para alguns grupos e se soma aquelas que introduzem mudanças e desvios na concepção do direito. (BAPTISTA, 2010)

Gomes (2011) também se propõe analisar a interação entre o Executivo e o Legislativo na produção de políticas de saúde. Seguindo a preocupação de muitos cientistas políticos, sua pergunta de investigação gira em torno da capacidade do arranjo institucional brasileiro do presidencialismo de coalizão para produzir consistentemente políticas públicas que contraponham ao predomínio de interesses particulares. Para responder a pergunta, propõe, a partir de estudos sobre a relação entre o presidente e o congresso nos EUA, 
um método de análise do processo de produção legislativa para o modelo presidencialista nacional e testa o poder explicativo do mesmo, tendo a política de saúde e seu financiamento como estudo de caso. O período que abrange seu estudo é de 1999 a 2006. O modelo proposto permitiu observar quatro tipos de interações entre os atores segundo os padrões de conflito e liderança dos mesmos: liderança da coalizão, liderança do legislativo, cooperação e impasse.

Ao aplicar seu modelo de análise ao campo da saúde, o autor encontrou fundamentos que permitem rejeitar a tese de paralisia decisória do Legislativo ou mesmo a tendência muito presente em alguns estudos que alertam quanto à predominância do Executivo. No entanto, o autor reconhece que existem fatores que limitam a produção de políticas mais equitativas.

Outro conjunto de estudos tem seu foco colocado nas complexas relações entre a sociedade e o poder Legislativo buscando perceber a capacidade do Legislativo de representar as demandas de diversos movimentos sociais. Importante citar os estudos focados nas demandas do movimento social e em especial do movimento de mulheres. São estudos preocupados com a representatividade das mulheres no congresso e em acompanhar os avanços, impasses e recuos da agenda feminista no campo do direito ao aborto (ALVES , 2004, BARRERAS; WEBER, 2015; LUNA, 2014), dos direitos reprodutivos (DINIZ, 2006) e também de olho no aumento da bancada evangélica e de suas consequências, seja com relação à política de saúde mental (CAMPOS, 2014, 2015) ou aos direitos reprodutivos e legalização do aborto. (ROCHA,1996) Alguns desses estudos vinculam o retrocesso com o aumento da representação religiosa no Congresso, mas também com a falta de posicionamento do Executivo frente à expansão da agenda conservadora.

Outro conjunto de estudos está orientado pela atividade de advocacy realizada como ação afirmativa para orientar o trabalho de incidência junto aos congressistas. (DALLARI, 1996) Inclui nessa perspectiva o lobby do batom (PITANGUY, 2002), os trabalhos do Departamento Intersindical de Assessoria Parlamente (DIAP), 
do Centro de Estudos Feministas (Cfemea) (2001), o próprio Observatório da Lei Maria da Penha. Existe uma relação entre esses estudos e os anteriores dado que são tributários da Constituição e dos grupos e movimentos sociais.

Por fim, vale mencionar os estudos de Scheffer e Bahia (2011) que inauguraram para a saúde uma linha de pesquisa que fazia falta no Brasil: vincular o financiamento das campanhas presidenciais e de deputados aos grupos de interesse do setor saúde, em particular, os planos de saúde. Com isso, lançam luzes sobre a influência desses grupos na conformação das agendas legislativas referentes à saúde.

\section{As forças do mercado e da religião no Congresso Nacional nos assuntos da Saúde}

Nas últimas legislaturas, dois fenômenos interligados chamam atenção: a celeridade no desmonte dos direitos sociais presentes na Constituição de 88 e o crescimento político das representações religiosas. A crise global do capitalismo repercute na situação econômica do país com real impacto na situação fiscal do país e com repercussões perversas sobre a desigualdades, o trabalho e nas condições de vida da população. Se para a população, é um momento de expansão de suas necessidades de serviços públicos de saúde, a escolha do Estado tem sido pelo fortalecimento e ampliação do mercado privado da saúde. O papel preponderante do Poder Legislativo tem surpreendido com a aprovação de medidas que descontroem os princípios e bases da Constituição e do SUS, pautados pela suposta contenção orçamentário-financeira gerados pela crise econômica.

De fato, o enfrentamento com relação aos direitos conquistados na Constituição se faz presente logo no início da década dos 1990, momento em que o país adota o caminho da redução da presença do Estado e políticas econômicas de contenção do gasto público e com explícito favorecimento aos interesses do capital financeiro. Essa tendência que também reforça o empresariado da saúde em contradição 
com a política universalista do SUS se espraia nas alianças políticas e financeiras do mercado com o Congresso Nacional.

Um dos fatores que reforça essa aliança, de acordo com os estudos de Bahia e Scheffer $(2011,2015)$, é o financiamento privado das campanhas aos candidatos a deputados estaduais, deputados federais, senadores e cargos no executivo, governadores e presidente. Esse financiamento tem crescido de forma exponencial desde 2002 e reafirma a força e a capacidade de articulação das operadoras, seguradoras e empresas de medicina de grupo. De acordo com Scheffer e Bahia (2015, p. 38):

Deputados federais e senadores eleitos com apoio dos planos de saúde tendem a integrar bancadas mobilizadas para apresentar projetos de lei, relatórios, pareceres, requerimentos e votações em defesa dos interesses dos planos de saúde. Também atuam para vetar proposituras que contrariam esses mesmos interesses ou em manifestações de descrédito dirigidas à saúde pública.

Se em 2014, o vínculo entre deputados e mercado de seguro foi mais explícito, como veremos mais adiante, essa não foi a tônica do passado. As estratégias usadas privilegiavam o debate político, em que a Frente Parlamentar em Defesa da Saúde foi um lócus privilegiado, e manobras permitidas pelo estatuto do parlamento.

A Frente Parlamentar em defesa da Saúde, criada em março de 1993, em um contexto inicial de mobilização em defesa do SUS, terá seus integrantes assediados pelas forças de mercado, fragmentando e tencionando os interesses no seu interior. Em 2007, a Frente mobilizou, no Congresso Nacional, 248 deputados federais e 27 senadores e foi decisiva na aprovação de importantes proposições em defesa do SUS. Em particular, com a proposta de regulamentação da Emenda Constitucional n. ${ }^{\circ} 29$ (EC 29), essencial para a sobrevivência do SUS, que padecia de regulamentação desde 2004. A EC 29 fixava à vinculação dos recursos orçamentários que seriam destinados à saúde pelas três esferas de governo, incumbindo o Congresso Nacional 
de regulamentar a matéria de forma a assegurar que os recursos sejam, efetivamente, empregados no SUS.

A derrota da União em prorrogar a Contribuição Provisória sobre Movimentação Financeira (CPMF), em 2007, favoreceu o revigoramento da Frente mobilizada pela regulamentação da EC 29. O debate foi contundente e arrastou-se até 2011, quando finalmente a Câmara dos Deputados concluiu, em 21 de setembro de 2011, a aprovação do Projeto de Lei Complementar (PLP) n. ${ }^{\circ} 306$ de 2008, que regulamenta a EC 29. O Senado aprovou o projeto em 7 de dezembro de 2011 e a presidente Dilma Rousseff sancionou em 15 de janeiro de 2012.

Como foi dito, ao longo da legislatura passada, observa-se a apresentação de projetos que explicitamente defendem interesses do mercado. Destacam-se dois projetos: um que autoriza a ação do capital estrangeiro na saúde, objeto da inclusão do tema na Medida Provisória n. ${ }^{\circ}$ 656/2014, de autoria de Manuel Junior (PMDB-PB) e relatada pelo deputado Eduardo Cunha (PMDB-RJ). Esta, depois de aprovada, transforma-se na Lei n. ${ }^{\circ} 13.097$, de 2015, que permite a participação de empresas e do capital estrangeiro, direta ou indiretamente, nas ações e cuidados à saúde,favorecendo de forma explícita a exploração da saúde pelo capital financeiro. Vale destacar que Cunha foi eleito, de acordo com informação do portal de transparência do Tribunal de Contas do Estado (TCE), com recursos provenientes dos grupos Bradesco e BTG Pactual, ambos vinculados ao mercado de seguros e de prestação de serviços privados no Brasil.

O outro projeto é a Proposta de Emenda Constitucional (PEC) 451 de autoria do deputado Eduardo Cunha. Essa medida determina o provimento de planos privados de saúde para todo o conjunto de trabalhadores, criando assim um mercado cativo para as empresas de seguro privado, sacrificando o direito à saúde integral presente no projeto universalista do SUS.

A tônica de desmonte do SUS e favorecimento do setor privado continua em 2015 e 2016 com a aprovação da EC 86. Sua aprovação atinge o SUS não só pela diminuição dos recursos federais, mas 
também pela criação da imposição dos interesses dos parlamentares ao orçamento da saúde, ou seja, muda a lógica da transferência automática dos recursos federais para os orçamentos municipais e estaduais, conferindo aos parlamentares o poder de devolvê-los de acordo com interesses políticos particulares. (CONASS, [201-]) Dessa forma, o orçamento do SUS, que deveria garantir o atendimento às necessidades de saúde expressas em planos de saúde e aprovados nos conselhos, passam a constituir objeto de negociações eleitorais ou partidárias. Não bastasse, a desvinculação parcial de recursos, de que tratam as PECs 04/2015, 87/2015, 143/2015 e 31/2016, e o estabelecimento de teto fiscal atrelado à correção do gasto pela inflação do ano anterior, previsto na PEC 241/2016, trazem maior preocupação com a sustentabilidade e sobrevivência do SUS.

Por sua vez, ao largo dessas duas décadas, observa-se também o crescimento da representação religiosa, em particular, a bancada evangélica. Os parlamentares dessa bancada focam seus mandatos políticos em projetos de leis que dificultam ou impedem os direitos sexuais e reprodutivos, particularmente, a legalização do aborto e do uso de drogas. Porém, os interesses desses parlamentares não se restringem a esses temas: abarcam os direitos humanos, em geral, e têm atingido, especialmente, para além da agenda de gênero, sobre a juventude, a população negra, indígenas, sobre a questão da legalização e atendimento a usuários de drogas e suas famílias. Entretanto, é sobre a questão do aborto e das drogas que as tensões, intolerâncias e intervenções sobre a decisão final, por parte dos deputados, são mais explícitas e agressivas. Deputados como Miguel Martini (PHSMG), ${ }^{1}$ dr. Talmir (PV-SP), Henrique Afonso, Luiz Bassuma (PT-BA, posteriormente expulso ${ }^{2}$ ), por exemplo, dedicaram seus mandatos exclusivamente para essa finalidade. Ademais, os deputados evangé-

\footnotetext{
Autor ou coautor de cinco projetos sobre aborto.
}

2 Atualmente sem partido, uns dos líderes da Frente Parlamentar em Defesa da Vida e da Família, não foi reeleito. Um dos autores do estatuto do nascituro. 
licos estão presentes em todos os partidos, independente das tendências ideológicas.

Como se sabe, o resultado das eleições de 2014 acentuou no Congresso Nacional o caráter mais conservador se comparado a todos os tempos, incluindo os tempos da Ditadura Militar. (PASSOS, 2014) O número de parlamentares evangélicos chegou a compor $16 \%$ dos eleitos. ${ }^{3}$ Desde já, contudo, advertimos que a quantidade de evangélicos presentes no Congresso não necessariamente se confunde com a porcentagem de evangélicos defensores dos discursos produzidos no interior e a partir da bancada evangélica, nos temas mais conservadores. Daí que, mais adiante, será comentado de forma mais restrita, o comportamento centrado na disputa evangélica pela questão das drogas e aborto. A Figura 1 abaixo ilustra a composição evangélica na atual legislatura (Leg. 55).

Figura 1 - Taxa de composição evangélica por partido

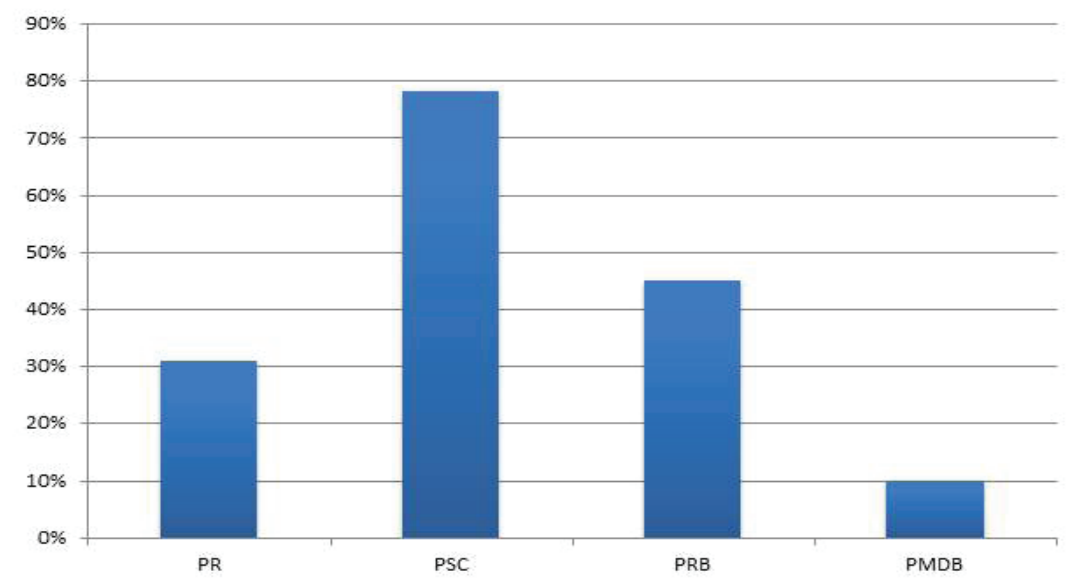

Fonte: Elaborada pelos autores 4 .

3 Fonte: DIAP. Disponível em <http://www.diap.org.br/index.php?option=com_content\&view=articlefid=14637-evangelicos-crescem-no-congresso-psc-lidera-em-numero-de -parlamentares> Acesso em: 20 set. 2015.

4 A partir de dados produzidos pelo Grupo de Pesquisa: Análise Política em Saúde. 
Em termos partidários, na ordem decrescente, PSC, PRB, PR e PMDB foram as legendas que mais elegeram parlamentares autodeclarados evangélicos e manifestamente engajados nessa bandeira como estratégia de vitória no sufrágio e de incidência pela via legislativa. Com 11 deputados e senadores evangélicos eleitos, o PR tem neles $31 \%$ do quadro interno e o PMDB, ao ganhar com nove políticos desse campo religioso, tem $10 \%$ de ocupação evangélica. Em contrapartida,o PSC chega a ser composto por $78 \%$ dessa linha protestante e o $\mathrm{PRB}$, tendo 10 parlamentares evangélicos eleitos, tem $45 \%$ do quadro interno.

Mesmo que tenham deixado o qualificativo de "nanicos", PSC, PRe PRB podem ser ainda considerados, individualmente, de menor impacto nos processos decisórios. ${ }^{5}$ Porém, apresentam capacidade articulatória significativa por sediarem a aglutinação das bandeiras midiáticas conservadoras - também fortalecidas, quando conveniente, por partidos hegemônicos -, sendo a intensificação do controle sobre o uso de drogas uma delas, pautando-se no retrocesso das diretrizes do SUS, que são, historicamente, vanguardistas na atenção psicossocial humanizada e não proibitiva em relação às drogas.

Para um dos principais cargos do congresso, Presidência da Câmara dos Deputados, foi eleito Eduardo Cunha (PMDB-RJ), evangélico, religião sob cujo discurso ascendeu ao poder instituído. Junto com ele, cresceu politicamente a bancada evangélica. Sua eleição foi para além de um jogo de forças entre PT e PMDB: contou com o apoio do PSDB e dos deputados religiosos de todos os partidos. Essa eleição representa um golpe direto e certeiro aos avanços democráticos e ampliação dos direitos de cidadania no cenário legislativo.

No âmbito da saúde, de modo geral, o impacto desse novo cenário é significativo - pois se torna um potente agenciador de interesses que colocam em risco a laicidade das políticas públicas -, vindo a saúde mental e os direitos sexuais e reprodutivos a serem os temas mais atingidos. Nos últimos anos, o assunto prioritariamente

$5 \quad$ PR conta com 6\% dos deputados e senadores eleitos; PRB, com 3,5\%; PSC, com 2,2\%. 
explorado no contexto da política de saúde mental tem sido o uso de drogas. Nesse tema, encontramos a volúpia punitiva e segregadora por parte, justamente, da bancada evangélica. Moralismos, crenças pessoais, interesses financeiros é o que orienta as proposições legislativas e ação política desses parlamentares, em desrespeito à realidade de vida, à saúde pública e aos interesses das mulheres e feministas e de amplos setores da sociedade.

A Frente Parlamentar Evangélica (FPE, 1990) é a principal sede de agregações estratégicas para ampliação do poder da respectiva bancada no cotidiano congressual, servindo, no mais das vezes, de trampolim estratégico para muitas pautas conservadoras.

\section{Saúde mental e a influência da bancada evangélica na política sobre drogas}

Como evidência das tendências da ação do legislativo, aqui serão identificados alguns sinais de ofensiva conservadora. Na saúde mental, o tema das drogas é o de principal ocupação política da expressão religiosa no interior do Congresso. Para tanto, o período de referência temporal será o de 2003 a (junho de) 2015.

Em levantamento realizado sobre as iniciativas de parlamentares federais, nos portais das duas Casas Legislativas, foram identificados 320 documentos inaugurados sobre saúde mental, entre requerimentos, conversão de medida provisória em lei, Projetos de Lei (PL), sugestões, PECs etc., sendo $200 \mathrm{PL}$, dos quais $25 \%$ versavam sobre uso de drogas. Essa linha de produção, contudo, tem sido oscilante. Houve três períodos de maior produção legislativa nesse contexto temático: os anos de 2003 e 2004 concentraram 22\% do total; 2007 e 2008, cerca de 15\%; 2011 a 2013, 30\% dos documentos em tramitação. Cabe, logo, um comparativo entre esses picos legislativos e a inauguração de novas agendas do poder executivo com relação à temática.

Internalizada desde a Convenção Contra o Tráfico Ilícito de Entorpecentes e Substâncias Psicotrópicas, de 1988 (BRASIL, 1991), a expressão oficial "guerra às drogas" marcou um caminho 
que orientou as medidas repressivas do século XXI, vigentes à luz da musicalmente parodiada ${ }^{6}$ lei federal n. ${ }^{\circ}$ 6.368/76 (BRASIL, 1976), até a nova lei n. ${ }^{\circ}$ 11.343/2006 (BRASIL, 2006), em vigor, instituinte do Sistema Nacional de Políticas Públicas sobre Drogas. O uso de drogas, nesse momento, é despenalizado, sendo reprimido apenas por meio de penas não privativas de liberdade. $\mathrm{O}$ distanciamento que a nova lei promove em relação ao ambiente prisional torna a resposta estatal, contudo, mais próxima da psiquiátrica. Logo antes dela, fora promulgada a lei n. ${ }^{\circ} 10.216 / 2001$, que, apelidada Lei da Reforma Psiquiátrica, "dispõe sobre a proteção e os direitos das pessoas portadoras de transtornos mentais e redireciona o modelo assistencial em saúde mental" (BRASIL, 2001), em acordo com a qual todo o normativo nacional deve estar. Surge, então, o primeiro emparelhamento temporal: a lei que orienta a atenção psicossocial (Lei n. 10.216/01) é imediatamente seguida por um conjunto denso de ações parlamentares (2003-2004). A seguir, a própria lei n. ${ }^{\circ}$ $11.343 / 06$ abre alas para o segundo momento de movimentação legislativa (2007-2008).

A primeira fase do emparelhamento, de assentamento do SUS sob o paradigma positivado pela recente Lei da Reforma Psiquiátrica - e líder isolado na condução da política, pois ainda sem a concorrência do futuro Sistema Nacional de Política Públicas sobre Drogas -, produz uma tendência legislativa de produção de conhecimento e alterações tímidas nas leis basilares, com a tônica na elaboração de documentos como requerimentos para realização de eventos, visitas etc. Sugestões ao poder executivo e projetos de lei de adequação das leis anteriores às recentemente promulgadas, como a própria lei n. ${ }^{\circ}$ 10.216/01.

A segunda etapa desse processo começou a anunciar o aumento da escalada evangélica sobre os muros do Congresso Nacional e a

O sambista Bezerra da Silva utilizou os artigos 12 e 16 da famigerada lei em versos lúdicos como os presentes na música Malandragem, dá um tempo: "É que o [artigo] 281 [do código penal] foi afastado / o [artigo] 16 e o [artigo] 12 [da lei 6.368/76] no lugar ficou / e uma muvuca de espertos demais / deu mole e o bicho pegou". 
intensificação punitiva das agências penais sobre o comércio de drogas, abrangendo um público em crescente encarceramento, ${ }^{7}$ acompanhada do refreamento do financiamento no campo sanitário das drogas a partir do contingenciamento do orçamento. (Cf. Acórdão n. 360/2012, do Tribunal de Contas da União)

A partir da nova lei de drogas, inicia-se a mais complexa agenda política nacional referente ao tema. Em resposta à necessidade de regulamentação dessa lei, os anos de 2006 a 2010 foram intensos na produção administrativa: a Portaria GM/MS n.o 1190/09, que instituiu o "Plano Emergencial de Ampliação do Acesso ao Tratamento e Prevenção em Álcool e outras Drogas no Sistema Único de Saúde” (BRASIL, 2009) e o Decreto Presidencial n. 7.179/2010 (BRASIL, 2010), que instituiu o "Plano Integrado de Enfrentamento ao Crack e outras Drogas, cria o seu Comitê Gestor, e dá outras providências", convergem para a inauguração do Programa Crack, é Possível Vencer (BRASIL, 2011), ${ }^{9}$ guiado pela Presidência da República. Em paralelo - mas necessária convergência -, a Portaria GM/MS n. 3.088/2011 134 (BRASIL, 2011), que institui a Rede de Atenção Psicossocial (mais importante e atual orientadora das ações de atenção psicossocial no país), inclui, pela primeira vez, o serviço Comunidade Terapêutica, ${ }^{10}$

7 Os dados podem ser conferidos no portal do Departamento Penitenciário do Ministério da Justiça. Disponível em: www.infopen.gov.br.

8 Notória a distinção hierárquica institucional entre ambos documentos precursores do projeto nacional de enfrentamento às drogas: a Portaria ainda sinalizava a atenção especializada e estratégico-institucional setorializada no Governo Federal (Ministério da Saúde); já o Decreto apresenta um novo espaço do tema na agenda presidencial, sobretudo construído pela Casa Civil, ministério-chefe do Poder Executivo. (ASSIS, 2012)

9 Disponível em: http://www2.planalto.gov.br/acompanhe-o-planalto/caderno-destaques/ marco-2012/plano-integrado-de-enfrentamento-ao-crack-e-outras-drogas. Acesso em: 3 ago. 2015.

10 Levada a cabo pelo sul-africano Maxwell Jones nos anos 1950 ingleses, a comunidade terapêutica era uma prática grupal de resistência às práticas autocráticas hospitalares e aprimoramento do ambiente institucional (JONES, 1972) Não visava, portanto, a extinguir o hospital psiquiátrico ou deslocar a centralidade do cuidado para o meio comunitário, como defenderam movimentos contemporâneos mais radicais. Atualmente, multiplicam-se e criam filiais no exterior, seguindo, rigorosamente, diretrizes como "prática da espiritualidade", 
emblema da bancada evangélica no lobby frente aos poderes executivo e legislativo. Embora tais documentos tenham sido publicados no âmbito do poder executivo, não é possível descartar o poder e a ação do legislativo como uma das forças responsáveis para a implementação das políticas de saúde mental e de drogas.

Ainda que conflituosa, do ponto de vista dos princípios, a convergência dos programas de atenção ao uso de drogas possibilitou a ascensão das comunidades terapêuticas. Com o crescimento de oportunidades para esse setor, surge o terceiro período de alta incidência legislativa sobre a política de saúde mental, justamente no momento de maior crescimento dos evangélicos no Congresso Nacional - eleições de 2010 e 2014 . Exemplo disso é a comunicação, em 2011, entre a então ministra da casa civil, Gleisi Hoffmann, e um líder de comunidades terapêuticas do Paraná - mesmo estado da ministra, uma interlocutora privilegiada dos evangélicos - em que esse lhe cobra "flexibilização" do processo seletivo de comunidades terapêuticas candidatas ao recurso de $\mathrm{R} \$ 100$ milhões naquele período providenciados para acesso via edital. ${ }^{11}$

Não satisfeitas com a única opção de serem contempladas via edital do Ministério da Saúde e da Secretaria Nacional de Políticas sobre Drogas/Ministério da Justiça (Senad/MJ), as lideranças das comunidades terapêuticas intensificaram as ações no âmbito legislativo, contribuindo para a criação de nova onda de iniciativas legais, porém repressivas, na interface que recupera as ultrapassadas ações de internação e resgate psiquiátricos ${ }^{12}$ e de isolamento, abstinência

"internação", manter-se "livre de práticas sexuais", "utilização do trabalho" e imediata ruptura no contato com as substâncias (Febract e as diretrizes para as comunidades terapêuticas, em Parana Portal. Disponível em <http://www.paranaportal.com.br/blog/2015/01/20/ febract-e-as-diretrizes-para-as-comunidades-terapeuticas/>. Acesso em: 20 set. 2015).

11 Fonte: Frente Nacional Drogas e Direitos Humanos. Disponível em <http://drogasedireitoshumanos.org/2012/06/26/nota-da-frente-nacional-de-drogas-e-direitos-humanossobre-informacoes-publicadas-na-materia-gleisi-padilha-e-o-pastor-do-jornal-correio -braziliense/\#more-39>. Acesso em: 20 set. 2015.

12 Exemplos são encontrados nos links: http://www.recantovida.org.br/rv-resgate-humanizado.html; http://ctespecializada.com.br/clinicas-tratamento-dependentes-quimicos/ 
forçada e ruptura da comunicação com familiares, o que difere totalmente das diretrizes do SUS.

Como afirmado anteriormente, é a partir das eleições federais de 2014 que as forças evangélicas encontram-se no auge parlamentar. No que tange às ações em saúde mental, a identificação das Frentes Parlamentares afins - e a respectiva composição evangélica de cada qual - é adotada como indicador da incidência política religiosa. Por meio do levantamento realizado pelos próprios autores desse capítulo, foram encontradas, em vigência, seis Frentes pertinentes: Frente Parlamentar da Saúde, Frente Parlamentar em Defesa das Pessoas com Deficiência, Frente Parlamentar em Defesa das Comunidades Terapêuticas, Acolhedoras e APACs (Associação de Proteção e Assistência ao Condenado), Frente Parlamentar em Defesa dos Direitos Humanos, Frente Parlamentar Mista de Combate às Drogas e Frente Parlamentar Mista em Defesa da Juventude e Combate às Drogas.

Primeiro dado levantado, a quantidade de parlamentares de um partido destinado à composição de uma Frente pode demonstrar o 136 investimento da legenda na temática. É o que notamos no gráfico abaixo, sobre o PR.

itemlist/user/513-superuser?start=30. As práticas de resgate foram objeto de processo criminal (cf. http://g1.globo.com/minas-gerais/triangulo-mineiro/noticia/2015/04/socios-de-clinica-terapeutica-sao-denunciados-por-tortura-em-mg.html). 
Figura 2 - Participação do PR nas Frentes Parlamentares

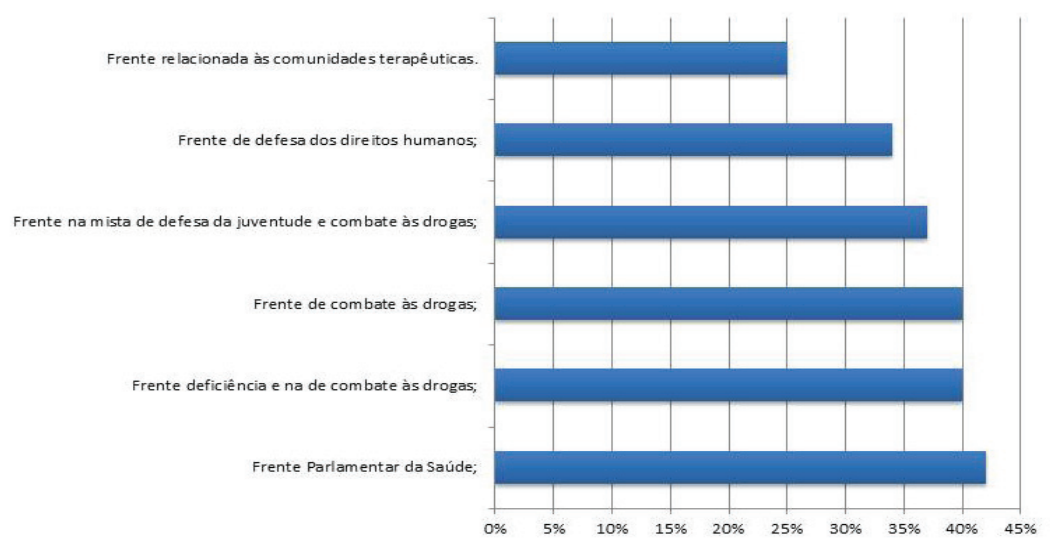

Fonte: elaborada pelos autores.

Dentre as seis Frentes, o PR destina $42 \%$ do quadro na Frente Parlamentar da Saúde; 40\% nas Frentes relacionadas à pessoa com deficiência e de combate às drogas; $37 \%$ na mista de defesa da juventude e combate às drogas; $34 \%$ na de defesa dos direitos humanos; e $25 \%$ na relacionada às comunidades terapêuticas.

Figura 3 - Participação do PSC nas Frentes Parlamentares

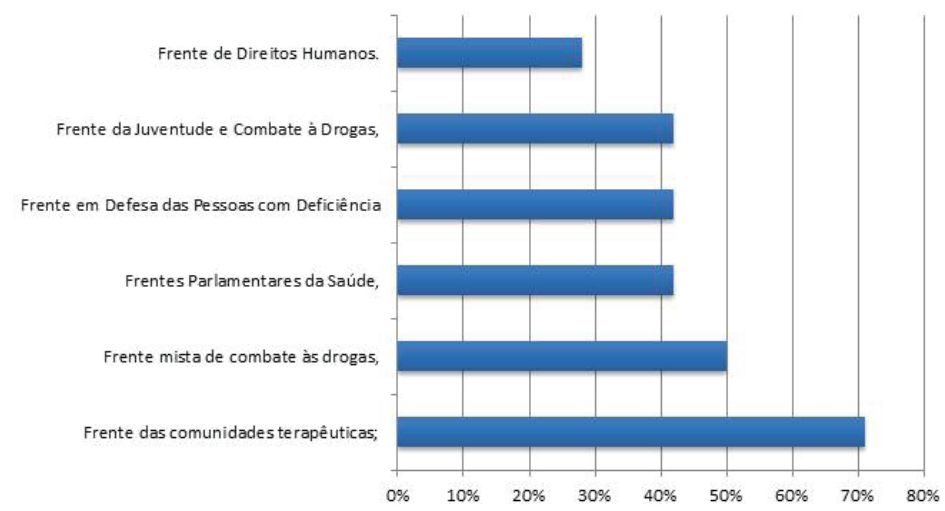

Fonte: elaborada pelos autores.

Já o PSC inverte: destina ao trato com comunidades terapêuticas $71 \%$ de seu quadro; à Frente mista de combate às drogas, 50\%; às Frentes Parlamentares da Saúde, em Defesa das Pessoas com 
Deficiência e da Juventude e Combate a Drogas, $42 \%$, incidindo na de Direitos Humanos com apenas 28\%.

Figura 4 - Participação do PRB nas Frentes Parlamentares

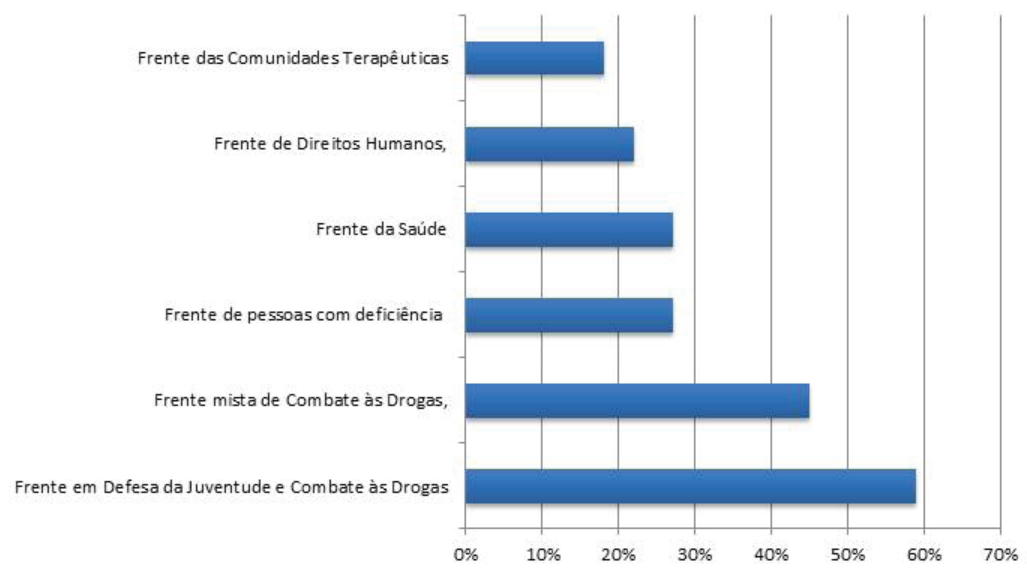

Fonte: elaborada pelos autores.

O PRB, por sua vez, inverte e destina maioria de seu quadro (59\%) à Frente em Defesa da Juventude e Combate às Drogas, ofertando $45 \%$ à mista de Combate às Drogas, $27 \%$ à de pessoas com deficiência e da Saúde, $22 \%$ à de Direitos Humanos, $18 \%$ à das Comunidades Terapêuticas.

A seguir, foi calculada a porcentagem de parlamentares dos quatro partidos que mais elegeram evangélicos, conforme indicado acima. 
Figura 5 - Taxa de ocupação das Frentes Parlamentares pelos quatro partidos políticos

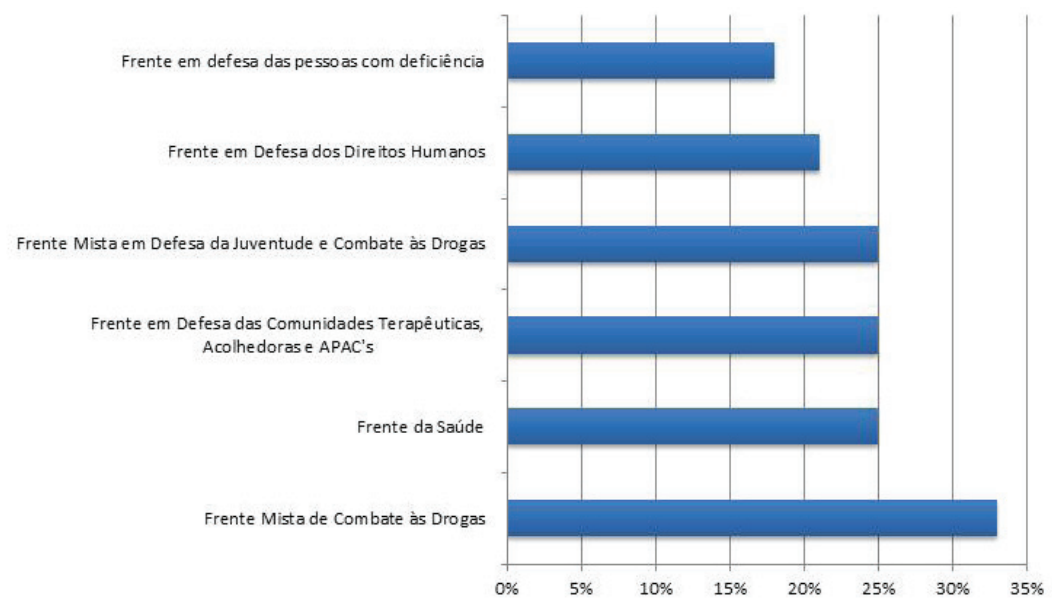

Fonte: elaborada pelos autores.

Em ordem crescente, temos as Frentes mais ocupadas pela bancada: Frente Parlamentar em defesa das pessoas com deficiência, com $18 \%$ pertencentes aos partidos com maior representação evangélica; Frente Parlamentar em Defesa dos Direitos Humanos, com 21\%; Frente Parlamentar da Saúde, Frente Parlamentar em Defesa das Comunidades Terapêuticas, Acolhedoras e APACs e Frente Parlamentar Mista em Defesa da Juventude e Combate às Drogas contam, cada uma, com 25\% de parlamentares; Frente Parlamentar Mista de Combate às Drogas tem 33\% de seus legisladores oriundos dos partidos.

Excluindo o PMDB, por ser o partido com maior representação no Congresso Nacional, identificam-se três faixas de ocupação por PR, PSC e PRB: 15\% de representação nas Frentes nomeadas por "combate às drogas", $12 \%$ na de Comunidades Terapêuticas e $10 \%$ nas demais. A despeito dos quatro partidos de maior representação evangélica, eleitos em 2014, priorizarem as Frentes de modo distinto, pode-se inferir que, dentre as seis Frentes Parlamentares relacionadas à saúde mental, as duas de "combates às drogas" e a de comunidades terapêuticas são as prioritárias. De outro lado, são es- 
sas mesmas Frentes as com maior representação dos partidos com grande eloquência evangélica. Por fim, é expressivamente inteligente a composição equilibrada, nas Frentes, pelos três partidos menores (PR, PSC e PRB), que atuam com maior presença exatamente nas relacionadas ao "combate às drogas" e de "defesa das comunidades terapêuticas".

Nesse sentido, dentre os cenários encontrados, tem-se que:

a. a bancada evangélica do Congresso Nacional tem priorizado Frentes Parlamentares de caráter repressivo quanto à relação da população com as drogas;

b. a mesma bancada tem preferido, como se tratasse de uma resposta criada à repressão autopropagada, propor a ampliação das comunidades terapêuticas (e não dos serviços do SUS em geral - sediados na Frente da Saúde e dos Direitos Humanos).

A conjugação dessas conclusões leva a uma nova constatação no que tange à questão das drogas, principal mobilizadora da política de saúde mental nos últimos anos. A bancada evangélica tem ocupado posições estratégicas sustentadas no retrocesso. Esse retrocesso expressa-se pela via formal de defesa de um serviço - comunidade terapêutica - que não encontra respaldo nas diretrizes do SUS e que contraditoriamente é incorporado no sistema de saúde desde 2011 devido a pressões políticas evidentes no período de vigência da nova lei de drogas. Tal retrocesso se manifesta ainda pela intensificação do controle e da repressão sobre o uso das substâncias psicoativas.

Os PLs n.o 7.663/2010 (BRASIL, 2010b) e n.o 5.618/2013 (BRASIL, 2013) ilustram as conclusões acima. De autoria do deputado Osmar Terra (PMDB-RS), o primeiro PL demarcou o aumento vertiginoso da dedicação política da bancada evangélica na agenda nacional, refletindo nos programas relacionados ao controle do crack por meio do cerco às drogas ocorrido entre 2009 e 2011 - que expressaram a investida da bancada evangélica no aspecto repressivo. Além de aumentar a pena para tráfico de drogas, institui, originalmente, as comunidades terapêuticas como centralidade estratégica 
no cuidado, podendo, ademais, ser sede de internações compulsórias e involuntárias.

Já o PL n. ${ }^{\circ}$ 5.618/13 (BRASIL, 2013), de autoria do deputado Erivelton Santana (PSC-BA), contém um viés preventivo contido na proposta da institucionalização do programa Fé na Prevenção. Esse programa visa fortalecer tecnicamente as ações das instituições religiosas, ${ }^{13}$ sendo que os "beneficiários do programa são agentes religiosos ligados a instituições sem fins lucrativos” (art. $4^{\circ}$ ).

\section{Direitos sexuais, reprodutivos e aborto: tendências no Congresso Nacional}

O aborto é um tema frequente e recorrente no Congresso Nacional. Desde 1940, quando é incluído no Código Penal até final de outubro de 2015, ao todo, tramitaram 131 PLs na Câmara dos Deputados sobre o assunto, sendo que o primeiro deles foi o PL 810/1949, proposto pelo deputado Arruda Câmara (PDC-PE), que pretendeu revogar o artigo 128 do Código Penal, cuja norma admite dois permissivos para a prática do aborto: o risco de morte materno e gravidez decorrente de estupro. ${ }^{14}$

Nos anos 1980 e 1990, os projetos existentes no Congresso Nacional sustentado por um debate na sociedade, apontava forte tendência de avanços rumo à consolidação da autonomia e dos direitos das mulheres na interrupção da gravidez. (ROCHA, 2006) Entretanto, do início do ano 2000 até o presente, há um franco retrocesso. Nas últimas legislaturas, o tema vem ganhando outro tratamento que afasta cada vez mais a possibilidade de sua legalização. É

13 São os objetivos inscritos no art. 20: "I - capacitar agentes religiosos para auxiliarem o poder público no enfrentamento ao uso de drogas ilícitas e na realização de ações de prevenção; II - fortalecer as redes de mútuo apoio que se estabelecem com base nas instituições religiosas; III - fortalecer as ações de busca ativa e de redução de danos que são realizadas pelas instituições religiosas.".

14 Essa informação foi do site da câmara e a própria câmara observa que pode ter lacunas em seus registros devido à ausência de registros eletrônicos. 
particularmente agravado quando, em 2010, o alinhamento em torno de pautas conservadoras assume dimensão ainda maior. Em 2014, devido ao processo eleitoral, ainda que no Congresso não tenha havido apresentação de projetos de lei sobre essa temática, no âmbito da sociedade, o conjunto de temas associados à moral sexual e controle da fecundidade foi objeto de uma das mais significativas e polarizadas arenas de disputa. Essa tendência de relacionar determinadas candidaturas a pautas e temas "polêmicos" como aborto e casamento homoafetivo vem sacrificando políticas e princípios associados aos direitos humanos.

Em 2015, a eleição de Eduardo Cunha à presidência da Câmara dos Deputados reafirma a tendência conservadora e é o prenúncio de enfrentamento claro com setores favoráveis aos direitos sexuais e reprodutivos, que compõem a base social do governo. Logo depois de eleito, anuncia ao país que a legalização do aborto assim como a regulação da mídia ${ }^{15}$ estava fora da pauta e que "só serão votados passando por cima do meu cadáver”. (BARBOSA, 2015) Fato é que 142 após assumir o cargo, o tema do aborto alinhado à defesa da vida e da família ganha destaque passando a ser alvo de interesse de legisladores. Desenterraram projetos arquivados com foco na criminalização do aborto, o que intensifica o debate nas duas Casas Legislativas.

Até outubro de 2015, na Câmara Legislativa, existiam 12 projetos que tratam sobre direitos do nascituro, 12, sobre direitos do embrião, e 28 , acerca do aborto, sendo que, desses 52 projetos, apenas 4 propunham avanços no que se refere aos direitos sexuais e reprodutivos.

Entre esses projetos, um em especial seguiu tramitando e colocou o tema do aborto em debate e provocou manifestações públicas significativas em diversas cidades das diferentes regiões brasileiras. Trata-se do PL n.o 5.069/2013, projeto de autoria dos deputados

15 Carta capital revela dados de um levantamento realizado pelo Instituto de Estudos da Religião (ISER) em 2009. 20 redes de televisão no Brasil transmitiam conteúdo religioso, sendo que 11 delas eram evangélicas e 9 católicas. A Igreja Universal controla mais de 20 emissoras de televisão, 40 de radio além de gravadoras, editoras e a segunda maior rede televisiva do país, a Record (MARTIS, 2012). 
Eduardo Cunha (PMDB-RJ), Isaias Silvestre (PSB-MG), João Dado (PDT-SP) e outros autores. ${ }^{16}$ Foi apresentado em fevereiro de 2013 e propõe acrescentar o art. 127-A ao Decreto-Lei n. ${ }^{\circ} 2.848$, de 7 de dezembro de 1940 - Código Penal incluindo um novo crime contra a vida, o anúncio de meio abortivo, a orientação ou o auxílio como crimes no referido código cuja pena é aumentada no caso de funcionário da saúde pública

Art. 127-A. Anunciar processo, substância ou objeto destinado a provocar aborto, induzir ou instigar gestante a usar substância ou objeto abortivo, instruir ou orientar gestante sobre como praticar aborto, ou prestar-lhe qualquer auxílio para que o pratique, ainda que sob o pretexto de redução de danos. (BRASIL, 2013, p. 2)

No mesmo ano, na Comissão de Constituição, Justiça e Cidadania, o deputado Leonardo Picciani (PMDB-RJ) emitiu parecer favorável, com apenas um substitutivo. $\mathrm{O}$ texto desdobra um artigo em dois: "Induzir ou instigar a gestante a praticar aborto ou ainda lhe prestar qualquer auxílio para que o faça, ainda que sob o pretexto de redução de dano" e "Anunciar processo, substância ou objeto destinado a provocar aborto", não havendo alteração no conteúdo final.

Em 2014, não houve qualquer movimentação desse projeto. Em janeiro de 2015, como de praxe, foi arquivado, conforme regimento interno. No entanto, no início de fevereiro de 2015, vários deputados apresentaram pedidos de desarquivamento. Em agosto, foi devolvido ao relator, deputado Leonardo Picciani e, surpreendentemente, em apenas quatro dias, designado novo relator, deputado Evandro Gussi (PV-SP), que em uma nova sequência de surpresas apresentou novo parecer favorável com proposta de substitutivo, em apenas uma semana. Esses tempos não são usuais naquela Casa.

16 Eduardo Cunha (PMDB-RJ), Isaias Silvestre (PSB-MG), João Dado (PDT-SP), André Moura (PSC-SE), Aroldo de Oliveira (PSD-RJ), Padre Ton (PT-RO), Arnaldo Faria de Sá (PTB-SP), Áureo (PRTB-RJ), Lincoln Portela (PR-MG), João Campos (PSDB-GO), Roberto de Lucena (PV-SP), Marcos Rogério (PDT-RO) e José Linhares (PP-CE). 
O novo texto agrega ao anterior a alterar a Lei n. ${ }^{\circ} 12.845$, de $1^{\circ}$ de agosto de 2013. Essa Lei dispõe sobre o atendimento obrigatório e integral de pessoas em situação de violência sexual. O novo texto suprime o inciso que prevê o atendimento à contracepção de emergência, retomando o conceito de violência sexual tal como abordado no Código Penal de 1940 que define violência sexual como conjunção carnal com marcas físicas e não como uma relação não consentida, tal como é o conceito da lei. Ademais, exige boletim de ocorrência e exame de corpo delito para realização do aborto por violência sexual.

Vários deputados e deputadas pediram "vistas" e ao tomar pé da gravidade da proposta que retira o direito adquirido pelas mulheres violentadas de serem atendidas pelo SUS na contracepção de emergência e atendimento à interrupção da gestação decorrente de estupro, prevista no Código Penal de 1940, foram emitidos alguns votos em separado e os debates se tornaram cada momento mais acalorados com a participação de grupos de mulheres e feministas e grupos antiaborto. Diante disso, por diversas vezes, o PL foi retirado de pau144 ta ou a discussão se estendeu até iniciar a ordem do dia, quando todas as comissões encerram os trabalhos para participar do Plenário.

Diversos parlamentares votaram contra o PL n.o 5.069/2013. Entre eles, destaca-se pela força dos argumentos Cristiane Brasil (PTB-RJ), Chico Alencar (PSOL-RJ) e Ivan Valente (PSOL-SP), Rubens Pereira Júnior (PC do B-MA), Erika Kokay (PT-DF). Em outubro, o projeto é discutido em apenas uma sessão e, a toque de caixa, é aprovado com apenas uma audiência pública.

Por fim, o PL n. ${ }^{\circ}$ 5.069/2013 tomou outro corpo em relação ao seu original e ao substitutivo proposto o relator deputado Evandro Gussi, que reverteu e manteve a oferta da contracepção de emergência, entretanto os profissionais de saúde não são obrigados a ofertá-la. Resumidamente, propõe a criminalização de quem presta qualquer auxílio a quem quer realizar ou realizou o aborto. Tornam-se crime a informação, a orientação, a venda ou entrega, ainda que gratuita para fins de realização de aborto. Também configura crime anunciar processo, substância ou objeto destinado a provocar aborto. Em to- 
dos os casos anteriores, tem a pena aumentada se for profissional de saúde. E ainda exige corpo de delito e boletim de ocorrência para a realização de aborto por violência sexual, que, por sua vez, como dito anteriormente, só é configurada se resultar em danos físicos e psicológicos e deve ter comprovação pelo Instituto Médico Legal.

Entre os projetos progressistas, estão: o $\mathrm{PL}$ n. ${ }^{0}$ 7.633/2014, que dispõe sobre a humanização da assistência à mulher e ao neonato durante o ciclo gravídico-puerperal e dá outras providências e o PL n. ${ }^{\circ}$ 882/2015, também de autoria do deputado Jean Wyllys (PSOL-RJ), que estabelece as políticas públicas no âmbito da saúde sexual e dos direitos reprodutivos; o PL n. ${ }^{\circ}$ 20/1991, do deputado Eduardo Jorge do (PT-SP), que dispõe sobre a obrigatoriedade de atendimento dos casos de aborto previstos no Código Penal, pelo SUS; e, por último, o PL n. ${ }^{\circ}$ 4.430/2004, de autoria das deputadas Jandira Feghali (PC do B-RJ), Alice Portugal (PC do B-BA), Iara Bernardi (PT-SP) e outros, que acrescenta inciso ao art. 128 do Decreto-Lei n. ${ }^{\circ} 2.848$, de 7 de dezembro de 1940 - Código Penal, despenalizando aborto de feto com anomalia incompatível com a vida.

Entretanto, grupos da sociedade vinculados a movimentos de direitos humanos, de mulheres, profissionais da saúde, operadores do direito, comunidade científica, querem ampliar o debate sobre o aborto como uma questão de saúde pública e de direito das mulheres. Isso pode ser evidenciado nas diversas audiências públicas onde representantes desses setores se manifestam em confronto com aqueles que defendem a criminalização do aborto. As audiências são espaços de debate para fundamentação das posições dos parlamentares e, geralmente, para o qual são convidados especialistas e lideranças para exporem e argumentarem sobre o tema. A polarização tem sido uma marca dessas audiências. Os grupos a favor da legalização do aborto constroem seus argumentos com base nos direitos humanos e nas fundamentações das ciências humanas, jurídicas e de saúde pública frente à pantomima e ao discurso religioso dos grupos antiaborto. Aplaudir as falas, argumentar com vigor, expressar através de vaias suas posições é parte do ambiente das audiências. No entanto, 
os antiaborto chegam portando bíblias, exibindo crianças filhas de mães violentadas, fazem uso de palavras de ordem agressivas (chamam a oposição de "criminosa"), e estratégias de argumentação de manipulação de resultados de pesquisa e dados oficiais com franco desrespeito ao debate democrático. ${ }^{17}$

No Senado, a primeira audiência de 2015 que abordou, mesmo que sem exclusividade, o tema aborto, ocorreu em 30 de abril solicitada pela senadora Regina Souza (Piauí-PT) para tratar do Relatório da Anistia Internacional, o qual relata graves violações aos direitos humanos. Longe de seguir avançando na promoção e proteção dos direitos humanos de todos sem discriminação, o Relatório aponta importantes retrocessos no período de 2013 e 2015. Nessa perspectiva, apontando diversos aspectos e situações de violações dos Direitos Humanos relacionados à imigração, mortalidade da juventude negra, manifestações de rua e populações indígenas, como violência policial, impunidade, torturas constaram do debate provocado por essa audiência.

146 Uma situação apresentada de violação de direitos humanos foi acerca dos dois casos que vieram a público em setembro de 2014: Jandira dos Santos Cruz e Elisângela Barbosa morreram ao fazer aborto clandestino no Rio de Janeiro. O corpo de Jandira dos Santos Cruz foi escondido de seus familiares e incinerado por funcionários da clínica. A Anistia Internacional manifestou na audiência a intenção de denunciar o governo brasileiro em Corte Internacional. Outra expressão da porosidade da questão do aborto na sociedade são as Sugestões de Iniciativa Popular, conhecidas por SUG, previstas no âmbito do Senado e da Câmara Federal, ${ }^{18}$ através das Comissões de

17 Verificar vídeo da audiência.

18 No caso da Câmara, houve historicamente apenas uma SUG 180/2009 CLP de autoria da Associação Eduardo Banks apresentada em 17 de novembro de 2009, que sugere PL para alterar o art. 128 do Código Penal, estabelecendo, para as situações de aborto previstas nesse dispositivo, as mesmas penas constantes do art. 124 ou do art. 126 do mesmo diploma legal, com redução de um sexto a um terço. 0 texto propunha a "substituição" da isenção de pena do aborto praticado por médico, por uma redução da resposta penal, 
Legislação Participativa. Foi apresentada ao Senado Nacional, em dezembro de 2014, de uma SUG, proposta de legalização do aborto até a $12^{\text {a }}$ semana de gestação. Essa SUG foi apoiada por mais de 20 mil assinaturas. Esse mecanismo de participação da sociedade está previsto pela Constituição Federal de 1988, por meio da Comissão de Legislação Participativa (CLP). Após aprovação Legislativa dada pelo portal e-Cidadania, a Comissão de Direitos Humanos realizou audiências públicas para debater a Sugestão Legislativa n. ${ }^{\circ}$ 15/2014, que prevê a interrupção voluntária da gravidez, o aborto, até 12 semanas de gravidez (três meses) com atendimento pelo SUS.

\section{Um esboço de conclusões}

Este capítulo procurou analisar o panorama do Poder Legislativo em relação à saúde e captar tendências na ação das forças ligadas aos interesses religiosos e do mercado, no Congresso Nacional, especialmente afetas à política de saúde mental, álcool e outras drogas e ao campo dos direitos sexuais e reprodutivos. Pelo que se pôde apurar, são fortes os indícios que associam o poder do mercado e da religião na política e nas decisões do Congresso Nacional, tal como constatado nas interferências dessas forças sobre os rumos do setor da saúde nesses dois campos da saúde pública.

Nas últimas décadas, a sociedade brasileira acumulou ampla consciência no plano da cidadania e da democracia, o que se expressa nas práticas de ativismo de centenas de milhares de entidades e organizações da sociedade civil. Esse acúmulo político demanda a instituição e permanência da laicidade do Estado e envolve, entre suas bandeiras, os direitos sexuais e reprodutivos, entre outros direitos humanos e sociais.

de um sexto a um terço da pena prevista, nos casos de aborto necessário, sentimental e eugênico (caso de feto anencefálico ou inviável, por má-formação ou desenvolvimento insuficiente), entretanto foi arquivada. 
A questão do abortamento tem especial relevância para a saúde pública em virtude de suas repercussões nas taxas de morbidade e mortalidade de mulheres em idade reprodutiva. Realizado na maioria das vezes em condições inseguras, devido às grandes restrições legais para a sua prática, depois das internações para partos, o abortamento é a causa mais importante de ocupação de leitos obstétricos no SUS, atingindo cerca de 200 mil internações por ano, segundo os registros do Sistema de Internações Hospitalares do DATASUS do Ministério da Saúde. Complicações devido ao abortamento inseguro figuram entre quarta ou quinta causa de morte materna no país, sendo que em algumas cidades chega a ser a primeira causa de mortes entre mulheres associado à gravidez, ao parto e ao puerpério.

No rastro do alargamento dos direitos humanos, o Brasil aprovou uma legislação avançada para orientar sobre as modalidades de cuidado do sofrimento psíquico e dos transtornos mentais, incluindo as necessidades decorrentes do uso de álcool e outras drogas. Essa conquista da democracia vem sendo implementada por meio da po148 lítica nacional de saúde mental, álcool e outras drogas, pari passu à concretização da Reforma Psiquiátrica nas redes de atenção à saúde do SUS. Entre outras direções, visa a enfrentar a situação histórica de violação de direitos humanos à qual as pessoas com transtorno mental eram submetidas, o que era prevalentemente representado pela institucionalização em hospitais psiquiátricos.

Apesar de toda evidência científica - quer seja epidemiológica, jurídica e social - quanto a ineficácia da criminalização do aborto e das drogas para conter a sua prática e uso, o Congresso Nacional tem votado projetos de leis que resultam no recrudescimento da legislação brasileira, sobretudo por meio da aprovação de leis penais. Durante as últimas cinco legislaturas, nas quais cresce a participação dos partidos "nanicos" nas alianças, o setor religioso também acompanha essa ascensão - com expressiva proeminência evangélica, tornando-se aliado decisivo nas negociações e coalizões voltadas às votações punitivistas. Em consequência, o Congresso Nacional tem produzido projetos de leis cujo conteúdo mais conservador parece 
estar anacrônico diante das conquistas e dos debates já realizados nos anos 1980. Com grande forma, são posturas que saem da hibernação e surpreendem no cenário parlamentar. Além dos projetos apresentados no texto que violam direitos humanos no âmbito da saúde mental e constrangem a prática do aborto - restringindo os direitos conquistados -, a constatação dessa tendência convida a destacar projetos de lei como o da "bolsa estupro", o estatuto do nascituro, o estatuto da reprodução humana e o estatuto da família. Todos recolocam um conjunto de valores incompatíveis com o Estado laico e com o Estado constitucional de liberdades civis e políticas, expressões do Estado Democrático de Direito instituído na Constituição de 1988.

Os indícios quanto aos interesses que comandam o cenário político nacional colocam em jogo a própria democracia estruturada nos direitos sociais e nos demais direitos humanos. Sob essa perspectiva de risco, está o direito universal à saúde, tal como definido pela Carta Magna de 1988, que merece outros olhares e perguntas para estudos futuros abordando a ação do Congresso sobre as questões estruturantes para a consolidação desse sistema social. Por outro lado, tomando o foco dos temas abordados pelo capítulo, tal como na saúde mental, verifica-se uma incidência negativa na autonomia reprodutiva resguardada pela prerrogativa moral das mulheres decidirem sobre seus corpos.

\section{Referências}

ABRANCHES, S. H. H.de. Presidencialismo de coalizão: o dilema institucional brasileiro. Dados: Revista de Ciências Sociais, Rio de Janeiro, v. 31, n.1, p. 5-34, 1988.

ABRUCIO, F. L. Os barões da Federação: os governadores e a redemocratização brasileira. São Paulo: Hucitec, 1998.

ALVES, J. E. D. A Mulher na politica e a politica de cotas. Ouro Preto: REM, 2003. Disponível em: <http://www.spm.gov.br/assuntos/poder-eparticipacao-politica/programas-acoes/desigualdades-entre-mulheres-e- 
homens/politica/a_mulher_na_politica_e_a_po.pdf $>$. Acesso em: 8 mar. 2016.

AMES, B. Electoral rules, constituency pressures, and Pork Barrel: bases of voting in the brazilian congress. The Journal of Politics, Cambridge, v. 57, n. 2, p. 324-343, 1995.

AMES, B. Os entraves da democracia no Brasil. Rio de Janeiro: FGV, 2003.

ANISTIA INTERNACIONAL. O estado dos direitos humanos no mundo: informe 2014/15. 2015. Disponível em: <https://anistia.org.br/wpcontent/uploads/2015/02/Web-Informe-2015-03-06-final.pdf >. Acesso em: 15 fev. 2016.

ASSIS, D. A. D. Risco social e saúde mental como argumentos para o encarceramento de crianças e adolescentes. 2012. 179 f. Dissertação (Mestreado em Adolescência em Conflito com a Lei) - Universidade Bandeirante de São Paulo, São Paulo.

BAPTISTA, T. W. de F. Análise da produção legislativa em saúde no Congresso Nacional brasileiro (1990-2006). Caderno de Saúde Pública, Rio de Janeiro, v. 26, n. 1, p. 97-109, 2010. Disponível em: <http://www. scielosp.org/pdf/csp/v26n1/11.pdf>. Acesso em: 15 fev. 2016.

BAPTISTA, T. W. de F. Políticas de saúde no pós-constituinte: um estudo da política implementada a partir da produção normativa dos Poderes Executivo e Legislativo no Brasil. Rio de Janeiro: Universidade Estadual do Rio de Janeiro, 2003.

BAPTISTA, T. W. de F.; MACHADO, C. V.; LIMA, L. D. de.

Responsabilidade do Estado e direito à saúde no Brasil: um balanço da atuação dos Poderes. Ciência \& Saúde Coletiva, Rio de Janeiro, v. 14, n. 3, p. 829-839, 2009.

BARBOSA, G. Eduardo Cunha sobre aborto: "vai ter que passar por cima do meu cadáver para votar”. O Globo. Rio de Janeiro, 9 set. 2015 Disponível em: <http://oglobo.globo.com/brasil/eduardo-cunhasobre-aborto-vai-ter-que-passar-por-cima-do-meu-cadaver-paravotar-15290079>. Acesso em: 15 fev. 2016.

BARRERAS, S. B. de; WEBER, M. H. Eleições, aborto e temas controversos: o ativismo político-midiático de grupos religiosos e o 
silenciamento do governo. Contemporânea: Revista de Comunicação e Cultura, Salvador, v. 13, n. 2, p. 243-260, 2015.

BITTENCOURT, F. M. R. Relações Executivo-Legislativo no presidencialismo de coalizão: um quadro de referência para estudos de orçamento e controle. Textos para discussão, Brasilia, DF, n. 112, abr. 2012. Disponível em: <http://www12.senado.gov.br/publicacoes/ estudos-legislativos/tipos-de-estudos/textos-para-discussao/td-112relacoes-executivo-legislativo-no-presidencialismo-de-coalizao-umquadro-de-referencia-para-estudos-de-orcamento-e-controle/view $>$. Acesso em: 18 fev. 2016.

BRASIL. Decreto n. 7.179, de 20 de maio de 2010. Institui o Plano Integrado de Enfrentamento ao Crack e outras Drogas, cria o seu Comitê Gestor, e dá outras providências. Diário Oficial [da] República Federativa do Brasil. Brasília, DF, 21 maio 2010.

BRASIL. Decreto n. 154, de 26 de junho de 1991. Promulga a Convenção Contra o Tráfico Ilícito de Entorpecentes e Substâncias Psicotrópicas. Diário Oficial [da] República Federativa do Brasil. Brasília, DF, 27 jun. 1991.

BRASIL. Lei n. 6.368, de 21 de outubro de 1976. Dispõe sobre medidas de prevenção e repressão ao tráfico ilícito e uso indevido de substâncias entorpecentes ou que determinem dependência física ou psíquica, e dá outras providências. Diário Oficial [da] República Federativa do Brasil. Brasília,DF, 22 out. 1976.

BRASIL. Lei n. 10.216, de 6 de abril de 2001. Dispõe sobre a proteção e os direitos das pessoas portadoras de transtornos mentais e redireciona o modelo assistencial em saúde mental. Diário Oficial [da] República Federativa do Brasil. Brasília, DF, 9 abr. 2001.

BRASIL. Lei n. 11.343, de 23 de agosto de 2006. Institui o Sistema Nacional de Políticas Públicas sobre Drogas - Sisnad; prescreve medidas para prevenção do uso indevido, atenção e reinserção social de usuários e dependentes de drogas; estabelece normas para repressão à produção não autorizada e ao tráfico ilícito de drogas; define crimes e dá outras providências. Diário Oficial [da] República Federativa do Brasil. Brasília, DF, 24 ago. 2006. 
BRASIL. Lei n. 13.097, de 19 de janeiro de 2015. Reduz A Zero As Alíquotas Da Contribuição Para O PIS/PASEP, Da COFINS, Da Contribuição Para O PIS/Pasep-Importação E Da Cofins-Importação Incidentes Sobre A Receita De Vendas E Na Importação De Partes Utilizadas Em Aerogeradores; Prorroga Os Benefícios Previstos Nas Leis $\mathrm{N}^{o s}$ 9.250. Diário Oficial [Da] Republica Federativa Do Brasil. Brasília, DF, 19 Jan. 2015.

BRASIL. Projeto de Lei n. 5.618, de 21 de maio de 2013. Autoriza o Poder Executivo a transformar em Projeto de Estado o Programa denominado Fé na Prevenção. 2013. Disponível em: <www.Camara.Gov. $\mathrm{Br}>$. Acesso em 20 out. 2015.

BRASIL. Projeto de Lei n. 7.663, de 14 de Julho de 2010. Acrescenta e altera dispositivos à Lei n. 11.343, de 23 de agosto de 2006, para Tratar Do Sistema Nacional De Políticas Sobre Drogas, Dispor Sobre A Obrigatoriedade Da Classificação Das Drogas, Introduzir Circunstâncias Qualificadoras Dos Crimes Previstos Nos Arts. 33 A 37, Definir As Condições De Atenção Aos Usuários Ou Dependentes De Drogas E Dá Outras Providências. 2010. Disponível em: <www.Camara.Gov.Br>. Acesso em: 10 out. 2015.

BRASIL. Tribunal de Contas da União. $2^{\mathrm{a}}$ Camara. Acordão n. 360, De 15 De Fevereiro De 2012. Disponível em: <www.Portal2.Tcu.Gov.Br>. Acesso em: 20 out. 2015.

BRASIL. Ministério da Saúde. Portaria n. 3.088, de 23 de dezembro de 2011. Institui a Rede de Atenção Psicossocial para pessoas com sofrimento ou transtorno mental e com necessidades decorrentes do uso de crack, álcool e outras drogas, no âmbito do Sistema Único de Saúde. Diário Oficial da União. Brasília, DF, 26 dez. 2011.

BRASIL. Ministério da Saúde. Portaria n. 1190, de 4 de junho de 2009. Institui o Plano Emergencial de Ampliação do Acesso ao Tratamento e Prevenção em Álcool e outras Drogas no Sistema Único de Saúde - SUS (PEAD 2009-2010) e define suas diretrizes gerais, ações e metas. Diário Oficial da União. Brasília, DF, Brasília, DF, 2009. 
CAMPOS, M. da S. Crime e Congresso Nacional: uma análise da política criminal aprovada de 1989 a 2006. Revista Brasileira de Ciência Política, Brasília, DF, n. 15, p. 315-347, dez. de 2014.

CAMPOS, M. da S. Entre doentes e bandidos: a tramitação da lei de drogas (no 11.343/2006) no Congresso Nacional. Revista de Estudos Empíricos em Direito, [S.1.], v. 2, n. 2, p. 156-173, jan. 2015.

CARRARA, S. Políticas e direitos sexuais no Brasil contemporâneo. Bagoas, Natal, v. 4, n. 5, p. 132-148, 2010. Disponível em: <http:// periodicos.ufrn.br/bagoas/article/viewFile/2316/ 1749>. Acesso em: 15 fev. 2016.

CONASS. Implicações da Emenda Constitucional n. 86/2015 para o processo de financiamento do Sistema Único de Saúde. [201-]. Disponível em: <http://www.conass.org.br/consensus/implicacoes-daemenda-constitucional-n-862015-para-o-processo-de-financiamentosistema-unico-de-saude/>. Acesso em: 25 fev. 2016.

DALLARI, S. G. et al. Advocacia em saúde no Brasil contemporâneo. Revista de Saúde Pública, São Paulo, v. 30, n. 6, p. 592-601, 1996.

DINIZ, D. Tecnologias reprodutivas no debate legislativo. MultiCiência, São Paulo, n. 6, p. 1- 22, 2006. Disponível em: <http://www.cocen. unicamp.br/cai/resolucoes/26.pdf>. Acesso em: 15 fev. 2016.

DINIZ, S.; RIBEIRO, C. O. The role of the Brazilian congress in foreign policy: an empirical contribution to the debate. Brazilian Political Science Review, Rio de Janeiro, v. 3, 2008. Edição especial.

FIGUEIREDO, A.; LIMONGI, F. Executivo e Legislativo na Nova Ordem Constitucional. São Paulo: Fundação Getúlio Vargas, 1999.

FIGUEIREDO, A.; LIMONGI, F. Mudança constitucional, desempenho do legislativo e consolidação institucional. Revista Brasileira de Ciências Sociais, Rio de Janeiro, v. 29, p. 175-200, 1995.

GOMES, F. de B. C. Impasses no financiamento da saúde no Brasil: da constituinte à regulamentação da emenda 29/00. Saúde em Debate, Rio de Janeiro, v. 38, n. 100, p. 6-17, 2014. 
GOMES, F. de B. C. Interações entre o Legislativo e o Executivo federal do Brasil na definição de políticas de interesse amplo : uma abordagem sistêmica, com aplicação na saúde. 2011.337 f. Tese (Doutorado Sociologia e Ciência Política) - Instituto de Estudos Sociais e Políticos , Universidade Estadual do Rio de Janeiro, Rio de Janeiro, 2011. Disponível em: <http://www.plataformademocratica.org/Publicacoes/ 22050.pdf>. Acesso em: 15 fev. 2016.

JONES, M. A comunidade terapêutica. São Paulo: Vozes, 1972.

LIMONGI, F. O novo Institucionalismo e os estudos legislativos: a literatura norte-americana recente. BIB, Rio de Janeiro, v. 37, p. 3-38, 1994.

LUNA, N. Aborto no Congresso Nacional: o enfrentamento de atores religiosos e feministas em um Estado laico. Revista Brasileira de Ciência Política, Brasília, DF, v. 14, p. 83-109, 2014.

MAINWARING, S.; PÉREZ LIÑAN, A. Party discipline in the Brazilian Constitutional Congress. Lua Nova: Revista de Cultura e Política, São Paulo, n. 44, p. 107-136, 1998.

MARSHALL, T. H. Cidadania, classe social e status. Rio de Janeiro: Zahar Editores, 1976.

MARTIS, R. A avalanche evangélica. Carta Capital. 25 jul. 2012. p. 42-47.

OLIVEIRA, R. de F. O papel do poder legislativo na formulação das políticas sobre financiamento da educação. Revista Brasileira de Política e Administração da Educação, Porto Alegre, v. 24, n. 2, p. 235- 247, 2011. Disponível em: <http://seer.ufrgs.br/index.php/rbpae/article/ view/19253>. Acesso em: 18 fev. 2016.

PAIM, J. S. A reforma sanitária brasileira e o Sistema Único de Saúde: dialogando com hipóteses concorrentes. Physis, Rio de Janeiro, v. 18, n. 4, p. 625-644, 2008. Disponível em: <http://www.scielo.br/pdf/ physis/v18n4/v18n4a03.pdf>. Acesso em: 10 ago. 2016.

PASSOS, N. Congresso eleito é o mais conservador desde o fim da ditadura, diz Diap. Carta Maior.[S.l.], out. 2014 Disponível em: <http:// www.cartamaior.com.br/?/Editoria/Politica/ Congresso-eleito-e-o-mais- 
conservador-desde-o-fim-da-ditadura-diz-Diap/4/31948>. Acesso em: 15 fev. 2016.

PEREIRA, C.; MUELLER, B. Comportamento estratégico em presidencialismo de coalizão: as relações entre executivo e legislativo na elaboração do orçamento brasileiro. Dados: Revista de Ciências Sociais, Rio de Janeiro, v. 45, n. 2, p. 265-301, 2002.

PEREIRA, C.; MUELLER, B. Partidos fracos na arena eleitoral e partidos fortes na arena legislativa: a conexão eleitoral no Brasil. Dados: Revista de Ciências Sociais, Rio de Janeiro v. 46, n. 4, p. 735-771, 2003.

PITANGUY, J. Movimento de Mulheres e Políticas de Gênero no Brasil. [S.l.], 2002. Disponível em: <http://www.cepal.org/mujer/proyectos/ gobernabilidad/documentos/jpitanguy.pdf>. Acesso em: 8 mar. 2016.

PITOLLTREVISAN A.;VAN BELLEN, H. M. Avaliação de políticas públicas: uma revisão teórica de um campo em construção. $R A P$, Rio de Janeiro, v. 42, n. 3, p. 529-50, maio/jun. 2008.

ROCHA, M. I. B. da . Questão do Aborto no Brasil: o debate no Congresso. Estudos Feministas, Florianópolis, v. 4, n. 2, p. 381-398,1996. Disponível em: <file:///Users/usuario/Downloads/16809-51817-1-PB. PDF $>$. Acesso em: 10 ago 2016.

ROCHA, M. I. B. da. A discussão política sobre aborto no Brasil: uma síntese. Revista Brasileira de Estudos de População, São Paulo, v. 23, n. 2, p. 369-374, 2013.

RODRIGUES, A. Cidadania das mulheres e Legislativo Federal: novas e antigas questões em fins do século XX no Brasil. Brasília, DF: CFEMEA, 2001. Disponível em: <http://www.bibliotecadigital.abong.org.br/ bitstream/handle/11465/267/CFEMEA_cidadania_mulheres_ legislativo_federal.pdf? sequence=1>. Acesso em: 15 fev. 2016.

RODRIGUES, M. M. A.; ZAULI, E. M. Presidentes e Congresso Nacional no Processo Decisório da Política de Saúde no Brasil Democrático (1985-1998). Dados: Revista de Ciências Sociais, Rio de Janeiro, v. 45, n. 3, p. 387-428, 2002.

ROMERO, L. C. et al. Atividades do Senado Federal brasileiro na área de saúde pública, 1995 e 1996. Revista Panamericana de Salud Pública, 
Washington, v. 7, n. 2, p. 69-78, 2000. Disponível em: <http://www. scielosp.org/pdf/rpsp/v7n2/1240.pdf>. Acesso em: 15 fev. 2016.

SADDI, F. C. Política e saúde no Brasil e no México: em tempos de dupla transição política. Curitiba: Appris, 2014.

SALLUM JUNIOR, B. Labirintos: dos generais à Nova República. São Paulo: Hucitec, 1996.

SANTOS, F. Patronagem e poder de agenda na política brasileira. Dados: Revista de Ciências Sociais, Rio de Janeiro, v. 40, n. 3, 1997. Disponível em: <http://www.scielo.br/scielo.php?script=sci_abstract\&pid=S001152581997000300007\&lng=en\&nrm=iso\&tlng=pt. $>$. Acesso em: 15 fev. 2016.

SANTOS, M. Representação de Interesses na Câmara dos Deputados: o Lobby e o Sucesso da Agenda Legislativa da Indústria. Revista IberoAmericana de Estudos Legislativos, v. 3, n. 1, 2014. Disponível em: <http:// bibliotecadigital.fgv.br/ojs/index.php/riel/article/view/18029>. Acesso em: 15 fev. 2016.

SANTOS, M. L. Teoria e método nos estudos sobre o Legislativo Brasileiro: uma revisão da literatura no período 1994-2005. BIB, Rio de Janeiro,, v. 66, p. 65-89, 2008.

SCHEFFER, M.; BAHIA, L. Representação política e interesses particulares na saúde: a participação de empresas de planos de saúde no financiamento de campanhas eleitorais em 2014. 2015. (Relatório de pesquisa). Disponível em: <http://www.abrasco.org.br/site/wpcontent/uploads/2015/02/Planos-de-Saude-e-Eleicoes-FEV-2015-1. pdf >. Acesso em: 23 fev. 2016.

SCHEFFER, M.; BAHIA, L. Representação política e interesses particulares na saúde: o caso do financiamento de campanhas eleitorais pelas empresas de planos de saúde privados no Brasil. Interface, Botucatu, v. 15, n. 38, p. 947-956, 2011.

WANDERLEY, L. E. Dicionário de políticas públicas. 2. ed. São Paulo: UNESP, 2015. 
Apêndice - Siglas partidárias

\begin{tabular}{|l|l|}
\hline PB & Partido do Brasil \\
\hline PDT & Partido Democrático Brasileiro \\
\hline PMDB & Partido do Movimento Democrático Brasileiro \\
\hline PP & Partido Progressista \\
\hline PR & Partido da República \\
\hline PRB & Partido Republicano Brasileiro \\
\hline PS & não consta nos registros de 49 até o registro atual do TSE \\
\hline PSB & Partido Socialista Brasileiro \\
\hline PSC & Partido Social Cristão \\
\hline PSD & Partido Social Democrático \\
\hline PSDB & Partido da Social Democracia Brasileira \\
\hline PSOL & Partido Socialismo e Liberdade \\
\hline PT & Partido dos Trabalhadores \\
\hline PV & Partido Verde \\
\hline
\end{tabular}




\section{PROBLEMAS, OBJETOS E INVESTIGAÇÕES ACERCA DA JUDICIALIZAÇÃO DA SAÚDE NO BRASIL a contribuição do Observatório de Análise Política em Saúde}

\section{Introdução}

A Constituição Federal Brasileira de 1988 representou um significativo avanço na democratização do país, incluindo o direito universal à saúde. Na prática, contudo, esse direito não é assegurado plenamente e, com isso, diversas pessoas, de forma individual ou coletiva, têm recorrido aos tribunais para ter garantido seu direito à saúde. Esse novo papel atribuído ao Poder Judiciário significa uma inevitável ampliação de sua atuação, fenômeno que vem sendo chamado de judicialização da saúde. (MACHADO; DAIN, 2012)

A judicialização se refere ao ativismo do Poder Judiciário no âmbito das relações sociais e políticas. Santos e colaboradores (1996) definem a judicialização como fenômeno sócio-histórico, caracterizado pela ampliação da interferência dos tribunais nessas relações, 
dotando o Poder Judiciário de grande protagonismo. Verifica-se assim um alargamento da órbita de atuação do Poder Judiciário sobre espaços que deveriam ser ocupados pelas políticas sociais como, por exemplo, a política de saúde.

As demandas judiciais relacionadas à saúde vêm crescendo exponencialmente no Brasil. É um fenômeno complexo que envolve diversos objetos, incluindo a busca por acesso a internações, a leitos de Unidades de Tratamento Intensivo (UTI), a consultas e exames médicos, a insumos e medicamentos, principalmente. Dessa forma, a intervenção do Poder Judiciário na saúde determina a prestação de serviço ou o fornecimento de medicamentos, almejando à concretização dos direitos fundamentais previstos na Constituição. (DRESCH, 2014)

As ações judiciais, visando a garantir o acesso a bens e serviços de saúde, tiveram grande repercussão no início dos anos 2000, devido ao elevado número de demandas relacionadas aos medicamentos para o tratamento da Síndrome da Imunodeficiência Adquirida (aids), lançados no período. Cerca de 10 anos depois, em 2011, o número de ações relativas à saúde chegou a aproximadamente 240 mil, incluindo demandas de acesso a medicamentos e procedimentos médicos pelo Sistema Único de Saúde (SUS), vagas para internamento em hospitais públicos e ações diversas movidas por clientes de planos e seguros privados de saúde. (SCHEFFER;SALAZAR; GROU, 2005; CONSELHO NACIONAL DE JUSTIÇA, 2011)

Nesse sentido, o estudo da judicialização da saúde é de grande relevância para a Saúde Coletiva, pois ajuda a entender as dificuldades relacionadas à gestão e à organização dos sistemas e dos serviços de saúde para assegurar o acesso da população a bens e serviços de ordem sanitária. É também relevante por permitir identificar os impactos das decisões judiciais na formulação e implantação de políticas de saúde, assim como na estruturação, no financiamento e no planejamento dos serviços e sistemas de saúde.

Além disso, o estudo das causas do fenômeno pode levar à compreensão das diversas relações existentes entre os interessados nos 
processos de demandas judiciais em saúde, dentre eles os usuários dos serviços e as organizações nãogovernamentais, os gestores e os profissionais de saúde, os operadores do direito, o setor produtivo, entre outros, que representam elementos de pressão da sociedade sobre os sistemas públicos e privados de saúde para o uso e a incorporação de tecnologias em saúde.

Vale ressaltar, ainda no âmbito da Saúde Coletiva, que a judicialização da saúde leva a um debate sobre o direito individual versus o direito coletivo, na medida em que muitas das ações individuais envolvem tecnologias de alto custo, com impacto orçamentário significativo e, portanto, levantam a questão de até que ponto essas ações são justas, já que vão reduzir os recursos que seriam empregados em outros problemas de saúde da população, que podem atingir parcelas significativas da população.

A saúde é um bem comum, um direito social, a ser garantido de forma equitativa. Como os recursos são finitos, os gestores têm a responsabilidade de definir prioridades, respeitando, entre outros, o princípio da igualdade. Nesse sentido, sempre que uma sentença judicial impõe a oferta de um tratamento de alto custo, não previsto nas prioridades, a uma única pessoa coloca-se a questão sobre a equidade, dado que o custeio desse tratamento pode significar a falta de recursos para o cuidado a muitas outras pessoas. (BORGES; UGÁ, 2009; D’ESPINDULA, 2013)

A rigor, a decisão jurídica relativa ao caso individual daquela pessoa que recorreu ao Judiciário não deveria desconsiderar a política pública destinada a garantir o mesmo direito a toda a coletividade, sob pena de privilegiar o interesse de um em detrimento ao de outros. (MARQUES; DALLARI, 2007)

Assim, a judicialização da saúde é um problema de pesquisa. É um fenômeno complexo, de múltiplos determinantes, que envolve dilemas e questões de ordem ética, legal, política e econômica. $\mathrm{E}$, apesar de diversos pesquisadores virem se debruçando sobre o tema e produzindo importantes trabalhos ao longo dos últimos 10 anos (BORGES; UGÁ, 2010; CHIEFFI; BARATA, 2009, 2010; 
DINIZ; MEDEIROS; SCHWARTZ, 2012; LOPES et al., 2010; MESSEDER; OSORIO-DE-CASTRO; LUIZA, 2005; SANTOS; TERRAZAS, 2014; TORRES, 2013;VIEIRA, 2008), há ainda lacunas no conhecimento a serem exploradas. Continua relevante, portanto, identificar problemas, construir objetos e conduzir investigações acerca do fenômeno da judicialização da saúde.

\section{Problemas e objetos de investigação acerca da judicialização da saúde}

Dado que as decisões judiciais relativas às questões sanitárias têm influenciado os processos de formulação e implantação das políticas de saúde, é imperativo estudar essas decisões, sejam as de primeiras instâncias, sejam as de instâncias recursais, através da análise de seus aspectos políticos, sociais, éticos, jurídicos, médicos e sanitários, no intuito de compreender o fenômeno e de trazer elementos para o aprimoramento das políticas de saúde em curso.

Em vista disso, o grupo responsável pelo acompanhamento das decisões judiciais relativas à saúde do Observatório de Análise Política em Saúde (OAPS) do Instituto de Saúde Coletiva da Universidade Federal da Bahia (ISC/UFBA) direciona seu olhar, desde a perspectiva da saúde coletiva, para o fenômeno da judicialização da saúde no Brasil, buscando compreender a sua dinâmica, as suas causas e os seus efeitos em suas relações com os sistemas de saúde público e privado.

Desde 2012, esse grupo vem realizando investigações científicas para analisar essas decisões judiciais relativas à saúde. Tem definido problemas e objetos de estudos que se projetam no espaço das relações sociais que envolvem o fenômeno e revelam as suas múltiplas facetas - ideológicas, éticas, econômicas, políticas e sociais - a partir dos pontos de vista de distintos sujeitos que atuam nos campos da saúde e do direito. Nessa direção, tem procurado realizar investigações cujos objetos possam apreender o fenômeno da judicialização à saúde na sua complexidade e nas suas diversas dimensões. 
Os problemas e os objetos de que tratam esses estudos dizem respeito, especificamente: à questão da judicialização de medicamentos no Brasil (como caracterizá-la?); ao acesso ao tratamento da diabetes na Bahia (por que se recorre ao judiciário para obter acesso a esse tratamento?); à judicialização da assistência médica suplementar em Pernambuco (são distintas suas características em relação aos estados do centro-sul do país?); à influência da judicialização na incorporação de biomedicamentos ao SUS (as sentenças judiciais têm influenciado ou não as decisões acerca da incorporação de biotecnologias ao SUS?); e ao panorama da judicialização da saúde no estado da Bahia (qual a dimensão e as características do fenômeno no estado?).

Os distintos objetos escolhidos para estudo buscam descrever e analisar, de maneira articulada, as diversas dimensões da judicialização da saúde, de modo que não se constituem em investigações isoladas, mas conformam um único programa de pesquisa que representa um esforço para a apreensão da complexidade do fenômeno. Desse modo, adotou-se a opção de apresentar detalhadamente, neste capítulo, os cinco estudos desenvolvidos pela equipe de pesquisadores do eixo de acompanhamento das decisões judiciais em saúde, sendo três deles já concluídos e dois em andamento.

Apesar de ter adquirido relevância social e política recentemente, a judicialização já motivou a realização de uma grande quantidade de estudos com variadas abordagens. (BORGES; UGÁ, 2010; CHIEFFI; BARATA, 2009, 2010; DINIZ; MEDEIROS; SCHWARTZ, 2012; LOPES et al., 2010; MESSEDER, 2005; SANTOS; TERRAZAS, 2014; TORRES, 2013; VIEIRA, 2008)

No caso do acesso a medicamentos, já foram realizados muitos estudos que descrevem ou caracterizam a situação fática da judicialização no Brasil. Nesse sentido, foi oportuno produzir uma síntese do que já se conhece sobre o tema. Com esse propósito, foi desenvolvido o primeiro estudo do grupo que traçou o perfil da produção acadêmica sobre esse tema, através da análise dos estudos publicados de 1988 a 2011 e da descrição das características das ações judiciais quanto 
aos elementos processuais, médico-sanitários e político-administrativos e as características sociodemográficas dos autores dos processos.

Conhecido o perfil da produção acadêmica sobre a judicialização de medicamentos no Brasil, o segundo estudo tomou como objeto as ações judiciais impetradas contra a Secretaria da Saúde do Estado da Bahia (Sesab), para se obter o acesso ao tratamento da diabetes, em especial, os argumentos ou as motivações dos autores das ações e do réu, no período de 2010 a2013. A escolha da diabetes como patologia específica para estudo se justificou por ser uma doença crônica de alta prevalência na Bahia e no Brasil. Segundo dados da Sesab, em 2009 cerca de 6,5\% da população baiana, aproximadamente 636 mil pessoas, sofrem com a diabetes. (BAHIA, 2012) Além disso, Torres (2010) demonstra que, entre 2002 e 2008, houve uma grande quantidade de ações judiciais para o fornecimento de medicamentos para o tratamento da diabetes, sendo que, dos quatro medicamentos mais solicitados, nesse período, dois são para o tratamento dessa patologia.

164 Com o propósito de analisar a judicialização da saúde no sistema privado, foi desenvolvido um terceiro estudo, sob forma de dissertação de mestrado, que tomou como objeto as decisões judiciais relativas à assistência médica suplementar. Os poucos trabalhos que se debruçam sobre esse tema foram realizados na região Sudeste, notadamente em São Paulo e Rio de Janeiro.

Em vista disso, a pesquisa conduzida pelo OAPS voltou seu foco para a região Nordeste, analisando as ações judiciais contra operadoras de planos e seguros de saúde em Pernambuco. Procurou, assim, contribuir para preencher a lacuna de conhecimento sobre a judicialização fora do eixo Rio-São Paulo, além de avançar na discussão de questões centrais para o campo da saúde coletiva como a segmentação do sistema, a regulação do mercado, a incorporação tecnológica e as relações entre atores políticos como os tribunais e os operadores do direito, as empresas de planos e seguros, os profissionais de saúde e a sociedade civil. 
O estudo em questão se apresentou sob a forma de dois artigos. Enquanto o primeiro artigo descreveu as características gerais das ações judiciais, o segundo analisou a fundamentação jurídica e argumentativa das sentenças judiciais, buscando identificar os marcos regulatórios e legais da saúde suplementar utilizados pelos tribunais.

Além das três pesquisas já concluídas, estão sendo desenvolvidas duas teses de doutorado que buscam compreender outras dimensões do fenômeno da judicialização da saúde.

Um desses estudos, intitulado As decisões judiciais e a incorporação de medicamentos biológicos ao SUS, toma como objeto a influência das sentenças judiciais no processo de decisão relativo à incorporação de biomedicamentos ao SUS, no período de 2010 a 2015.

O interesse pela temática decorre do fato de que o recurso do cidadão ao Poder Judiciário para ter garantido o que entende ser um direito seu está impulsionando, na prática, a compra e o fornecimento de medicamentos essenciais ou de alto custo por parte do MS e das secretarias estaduais e municipais de saúde e, portanto, pode estartambém influenciando o processo de incorporação de tecnologias pelo SUS.

Ressalta-se que os gastos do SUS com medicamentos biotecnológicos são significativos e têm aumentado nos últimos anos. Conforme dados do MS, trazidos por Reis, Pieroni e Souza (2010) o total de gastos do SUS com medicamentos de alto custo no ano de 2008 foi de R\$ 2,3 bilhões (contra R 513 milhões em 2003). Foram 220 medicamentos destinados ao tratamento de 76 doenças que afetaram aproximadamente 730 mil usuários. Deste total, 41\% foram gastos com medicamentos biológicos. Em termos de volume, no entanto, os biológicos respondem por apenas $2 \%$ do total de medicamentos adquiridos, revelando um grupo de altíssimo valor agregado. (REIS; PIERONI; SOUZA, 2010) Em 2013, os biomedicamentos representaram 5\% dos medicamentos disponibilizados pelo SUS, seus custos, contudo, representaram $43 \%$ dos gastos totais do MS com medicamentos. O orçamento do MS para a compra de medicamentos cresceu 78\% entre os anos de 2010 e 2014. Em 2010, 
foram investidos R \$ 6,9 bilhões e em 2014 o orçamento previsto foi de R\$ 12,4 bilhões. (BRASIL, 2013, 2014)

Nessa perspectiva, pode-se afirmar que o aumento dos gastos púbicos com medicamentos pode estar associado, dentre outras causas, à incorporação de novas tecnologias ao SUS, que, por sua vez, pode estar relacionada às decisões judiciais que obrigam o fornecimento de medicamentos pela União, pelo estado ou pelo município. (CHIEFFI; BARATA, 2009, 2010; LOPES, 2010; VIEIRA, 2008; VIEIRA; ZUCCHI, 2009)

Apesar de terem sido realizados, ao longo dos últimos anos, diversos estudos para avaliar os efeitos da judicialização sobre as políticas de saúde, ainda não se conhecem seus efeitos específicos sobre o processo de incorporação de medicamentos biotecnológicos.

O outro estudo em desenvolvimento - uma tese de doutorado - trata das decisões judiciais no âmbito da Sesab. Toma como objeto de investigação a evolução da judicialização no âmbito da Sesab, desde a primeira demanda judicial contra o estado até a última demanda de 2016, tendo como objetivos específicos:

a. caracterizar as ações judiciais quanto aos seus elementos médico-sanitários e político-administrativos e;

b. discutir a relação entre as políticas de saúde do estado da Bahia e as demandas judiciais no decorrer do tempo analisado.

A originalidade dessa pesquisa se atém ao fato de buscar delinear um panorama da judicialização, abarcando todos os objetos das ações judiciais, sejam bens (medicamentos, próteses, insumos etc.), sejam serviços (internações, exames, homecare etc.). Visa assim produzir conhecimentos que ajudem a compreender a diversidade concreta do fenômeno da judicialização e possam subsidiar o processo de formulação e implantação de políticas de saúde. 


\section{Abordagens metodológicas dos estudos sobre a judicialização}

Para abordar os problemas e os objetos de investigação acima apresentados, os estudos do OAPS adotaram ou adotam estratégias metodológicas diferenciadas, incluindo abordagens quantitativas e qualitativas. As técnicas de coleta e produção de dados incluem: busca dos processos judiciais nos sítios eletrônicos dos tribunais de justiça, entrevistas com informantes-chaves, observação sistemática e pesquisa documental. As estratégias de análise envolvem análise de conteúdo, triangulação de dados, além da análise dos dados quantitativos através do programa STATA versão 12 .

Nesse ponto, vale destacar que tem sido enriquecedor aliar a consulta às sentenças em segunda instância, disponíveis na internet, com a consulta direta aos processos judiciais disponibilizados, no caso, pela Sesab. Entre outras coisas, as primeiras fornecem informações objetivas sobre o fundamento legal das decisões e os aspectos processuais das ações, enquanto os processos iniciais fornecem um conjunto amplo de informações que favorecem a caracterização dos autores e dos aspectos médico-sanitários e político-administrativos. Além disso, junto com as entrevistas e os registro das observações, essa aliança aumenta a força da triangulação de dados.

A primeira pesquisa realizada no âmbito do OAPS - Judicialização de medicamentos no Brasil: uma revisão sistemática (TORRES, 2013) - adotou um método de revisão sistemática estruturado em seis etapas:

a. formulação do problema, através de uma pergunta de investigação;

b. pesquisa na literatura -identificação das fontes (base de dados) a serem consultadas, definição de palavras-chaves, estratégia de busca, estabelecimento de critérios de inclusão e exclusão;

c. avaliação da qualidade;

d. análise dos dados; 
e. interpretação dos resultados; e

f. apresentação das conclusões. (COOPER; HEDGES, 2009)

Utilizaram-se como fontes de informação as bases Literatura Latino-Americana e do Caribe em Ciências da Saúde (Lilacs), Scientific Electronic Library Online (Scielo), Medical Literature Analysis and Retrieval System Online (Medline), o banco de teses e dissertações da Coordenação de Aperfeiçoamento de Pessoal de Nível Superior/Conselho Nacional de Desenvolvimento Científico e Tecnológico (Capes/CNPq), o Google Acadêmico, além das referências dos estudos selecionados.

Fruto dessa pesquisa, elaboraram-se dois artigos.

O primeiro artigo relaciona certas características dos estudos revisados: o ano de publicação, a filiação institucional do autor principal, a localização regional da instituição, o tipo de publicação (artigo, dissertação, tese ou capítulo de livro), as palavras-chave utilizadas e a área do saber. A seguir, descreve a natureza das pesquisas, os objetivos de investigação e as características gerais das ações judiciais avaliadas.

$\mathrm{O}$ segundo artigo analisa os trabalhos de natureza empírica que permitem caracterizar detalhadamente as ações judiciais e os seus autores. Com base no Manual Indicadores de Avaliação e Monitoramento das Demandas Judiciais de Medicamentos (PEPE, 2011), foram identificadas nos trabalhos selecionados as características das ações judiciais quanto aos elementos processuais, médico-sanitários e político -administrativos e as características sociodemográficas dos autores dos processos.

Outro estudo realizado no âmbito do OAPS se intitulou Acesso ao tratamento da diabetes na Bahia: por que se recorre ao Judiciário? (LISBOA, 2015) e teve por objetivo analisar as ações judiciais impetradas contra a Sesab, para se obter o acesso ao tratamento da diabetes. Em especial, buscou identificar as motivações do autor da ação e os argumentos do réu.

Tratou-se de um estudo documental retrospectivo (TOBAR; YALOUR, 2001), cuja unidade de análise foi à ação judicial movida 
contra a Sesab para o fornecimento de medicamentos para o tratamento da diabetes no período compreendido entre os anos de 2010 e 2013. Foram identificadas 325 ações judiciais e, ao final, selecionadas para análise 154 ações. A análise foi dividida em duas etapas: a primeira contemplou as características das ações judiciais e a segunda os motivos ou os argumentos do autor que recorreu à via judicial, assim como os do réu.

Na primeira etapa, as categorias tiveram como referência quatro dimensões: características sociodemográficas dos autores e características processuais, médico-sanitárias e político-administrativas das ações. (PEPE, 2011) Na segunda etapa, as motivações ou os argumentos do autor da ação foram classificados em quatro categorias:

a. necessidade do uso da insulina análoga,

b. hipossuficiência financeira,

c. dever do estado em fornecer o medicamento,

d. questões burocráticas que dificultam o acesso.

Os argumentos do réu, por sua vez, foram ordenados em duas categorias:

a. desobrigação do fornecimento de medicamentos não padronizados pelo SUS e

b. (inexistência de evidências científicas da superioridade terapêutica das insulinas análogas em relação às disponíveis pelo SUS, NPH e a Regular.

O estudo intitulado $A$ judicialização da assistência médica suplementar: um estudo de caso em Pernambuco (ABADE, 2015) apresenta como primeiro artigo uma descrição das características gerais das ações judiciais, cumprindo a função de caracterizar a judicialização da saúde suplementar em um estado do Nordeste. O segundo artigo representa um esforço de apreender e compreender a fundamentação jurídica e argumentativa das decisões judiciais, buscando identificar o marco regulatório da saúde suplementar acionado pelos tribunais. 
Trata-se de uma pesquisa que analisa todas as ações judiciais do tipo Agravo de Instrumento que diziam respeito à assistência médica suplementar, julgadas em segunda instância no Tribunal de Justiça de Pernambuco (TJPE) no biênio 2012-2013. A busca foi realizada no sítio eletrônico do tribunal, com os descritores: plano de saúde, seguro-saúde e saúde suplementar. Os critérios de exclusão foram: ações repetidas e que tratavam bens ou serviços odontológicos.

Para a coleta de dados, foi utilizado um roteiro semiestruturado, dividido em três dimensões:

a. características da ação judicial: identificação dos acórdãos, data do julgamento, titularidade do autor da ação, tema da ação, modalidade da operadora, nome da operadora, forma e data de contratação do plano/seguro, resultado do processo;

b. base legal: leis, súmulas ou jurisprudências utilizadas; e

c. aspectos regulatórios: normas da Agência Nacional de Saúde Suplementar (ANS), normas anteriores à criação da ANS publicadas por outros órgãos, pareceres ou outras publicações de associações e entidades.

A análise dos dados foi realizada em duas etapas. Na etapa quantitativa, utilizou-se o programa STATA versão 12 para o cálculo de frequências absolutas e relativas. Para a análise da distribuição dos tipos de operadoras nas ações judiciais, foi calculado o indicador de litigância, dividindo a população litigante pela população total de clientes de cada modalidade contabilizada pela ANS no período. Na etapa qualitativa, empregou-se a análise de conteúdo. (BARDIN, 1977)

Em relação às investigações em desenvolvimento, o estudo $A s$ decisões judiciais e a incorporação de medicamentos biológicos ao Sistema Único de Saúde, de abordagem qualitativa, encontra-se em fase de produção de dados através da realização de entrevistas semiestruturadas com os membros da Comissão Nacional de Incorporação de Tecnologias em Saúde (Conitec), de pesquisa documental e da observação sistemática. A triangulação de dados entre essas técnicas será utilizada para reforçar a confiabilidade dos achados. Essas técni- 
cas de pesquisa servirão tanto para produzir dados que permitam a descrição geral do processo de trabalho da Conitec, quanto para a realização de um estudo de caso referido ao traztuzumabe (Herceptin), primeiro biomedicamento incorporado ao SUS após decisão favorável da Conitec, através das portarias n. ${ }^{\circ}$ 18/2012 e n. ${ }^{\circ}$ 19/2012 da Secretaria de Ciência, Tecnologia e Insumos Estratégicas. A análise das entrevistas, dos documentos e dos registros da observação será feita por meio da análise de texto. (RYAN; BERNARD, 2000)

$\mathrm{O}$ segundo estudo em desenvolvimento, sobre as decisões judiciais no âmbito da Sesab, também de abordagem qualitativa, tomará como base para a produção de dados o Manual de Indicadores de Avaliação e Monitoramento das Demandas Judiciais de Medicamentos. (PEPE , 2011) Assim, por meio de pesquisa documental, será realizada a caracterização das ações judiciais, quanto aos elementos médico-sanitários e político-administrativos no âmbito da Sesab, após acesso aos processos judiciais existentes nessa secretaria. Além disso, informantes-chaves serão entrevistados, com o intuito de se obter informações acerca da relação entre as políticas de saúde do estado e as ações judiciais transitadas no decorrer do tempo analisado.

\section{Principais resultados}

$\mathrm{O}$ artigo "Produção acadêmica sobre as demandas judiciais de medicamentos no Brasil: uma revisão sistemática” (TORRES, 2013) analisou 86 estudos, observando uma publicação contínua de trabalhos desde 2003, quando foi divulgada a primeira pesquisa sobre o tema.

Dentre os principais achados do estudo, verificou-se que o assunto tem sido bastante explorado por autores vinculados a instituições de váriasregiões do país, com destaque para o Sudeste. A Escola Nacional de Saúde Pública (ENSP), situado no Rio de Janeiro, é a instituição com o maior número de publicações, alcançando $13 \%$ do total de estudos analisados. Outras cinco instituições publicaram, 
cada uma, cinco estudos: MS, Universidade de São Paulo (USP), Universidade Federal de Minas Gerais (UFMG), Universidade Federal de Santa Catarina (UFSC) e Universidade de Brasília (UnB).

No que se refere aos tipos de documento, os artigos representam mais de 50\% das publicações, o que indica que o tema, apesar de recente, já está incorporado à agenda científica. Evidencia-se ainda que a saúde é a área que mais tem abordado o tema, especialmente a Saúde Coletiva, o que pode estar relacionado aos impactos da judicialização no funcionamento do sistema de saúde como um todo. Esses estudos têm destacado, especialmente, as características médico-sanitárias e político-administrativas das demandas judiciais, considerando a eficácia, a efetividade e a segurança dos produtos ofertados e a competência administrativa e econômica da administração pública na organização da assistência farmacêutica.

Quanto aos objetivos de investigação, os estudos evidenciam o amplo escopo do debate sobre a judicialização do acesso a medicamentos. Abordam, dentre outros temas: o acesso a medicamentos que integram as listas do SUS e a existência de alternativas terapêuticas para aqueles que não constam nos elencos; a análise dos argumentos dos atores envolvidos nos processos; a interferência dessas demandas nas políticas públicas e as estratégias para o enfrentamento da judicialização da saúde.

No que diz respeito ao segundo artigo, "Caracterização da judicialização do acesso a medicamentos no Brasil: uma revisão sistemática”, fruto da mesma pesquisa, a análise dos 37 estudos empíricos selecionados permite identificar os aspectos já conhecidos do fenômeno, assim como os pontos pouco esclarecidos e as lacunas do conhecimento.

Em primeiro lugar, alguns fatos já estão bem estabelecidos pelas pesquisas. A prescrição médica é o documento fundamental - necessário e suficiente - para o deferimento do pedido liminar pelo juiz. Quase todos os pedidos são acolhidos com a antecipação da tutela, sem qualquer outra exigência judicial. Ademais, a decisão inicial é, quase sempre, mantida quando da sentença ou do acórdão. 
Os estados são os réus mais frequentes nos processos. Prevalecem os pedidos individuais sobre os coletivos e predomina a prescrição pelo nome comercial, em detrimento da denominação genérica. Parcela considerável das ações poderia ter sido evitada, caso fossem observadas as alternativas terapêuticas presentes nas listas do SUS. Os medicamentos sem registro na agência reguladora e com indicação de uso off label constituem exceções nas demandas judiciais.

Em segundo lugar, há diversos pontos ainda não esclarecidos perfeitamente. Pelo número reduzido de estudos que analisam as características sociodemográficas, não se pode caracterizar o autor das demandas judiciais. Há indícios de que a judicialização esteja favorecendo indivíduos com boas condições socioeconômicas, mas são necessários estudos mais abrangentes para traçar o perfil do demandante no país como um todo. De modo similar, não se pode afirmar que os valores gastos com a compra de medicamentos demandados judicialmente comprometam o orçamento do SUS. Também não se sabe ao certo qual o percentual de pacientes que recorreram ao Judiciário, depois de terem feito demandas por via administrativa. Tampouco se sabe se os medicamentos que pertencem aos componentes da Política de Assistência Farmacêutica foram demandados judicialmente por falhas na gestão ou porque constavam da mesma prescrição de um medicamento nãopertencente que teria motivada a demanda ou ainda por outra razão.

Em terceiro lugar, a análise dos estudos permitiu a identificação de lacunas no conhecimento sobre a judicialização do acesso a medicamentos, em especial: quais os desfechos da utilização do medicamento demandado judicialmente; se é o desabastecimento que tem gerado os pedidos judiciais; qual o nível de conhecimento pelos prescritores das listas do SUS e o seu grau de adesão às mesmas.

O estudo intitulado Acesso ao tratamento da diabetes na Bahia: por que se recorre ao Judiciário? (LISBOA, 2015) constatou que, dentre as ações judiciais, houve o predomínio de requisições de análogos de insulina. A demanda foi crescente até o ano de 2012, ocorrendo 
uma queda nas ações em 2013 que decorreu, certamente, da incorporação desses medicamentos pelo estado.

Constatou também que a maioria dos autores é do sexo feminino, a faixa etária maior que 60 anos é predominante e os autores das ações recebiam de até um salário mínimo. Eram, na sua maioria aposentados $(39 ; 24,7 \%)$, salientando que $51(32,3 \%)$ autores não tiveram a ocupação informada. A maioria residia na capital Salvador (65 autores; 41,1\%). (LISBOA, 2015) Essa caracterização sociodemográfica mostra que prevalecem setores sociais desfavorecidos economicamente e pessoas situadas na faixa etária de maior prevalência da diabetes. Isso sugere que, nesse caso, indivíduos com condições socioeconômicas limitadas tiveram acesso à Justiça, diferentemente do que encontraram outros estudos acerca da judicialização. A maior demanda por autores residentes na capital e em cidades do interior de grande porte demonstra que estes têm maior acesso aos serviços jurídicos e de saúde.

Quanto aos aspectos processuais, o estudo evidenciou a fre174 quente atuação da Defensoria Pública do Estado. Curiosamente, contudo, prevalece a prescrição emitida por médicos não vinculados ao SUS, o que indica que mesmo pessoas desfavorecidas economicamente recorrem aos médicos particulares. Na hora de comprar o medicamento prescrito, no entanto, essas pessoas, não dispondo de recursos, buscam o Judiciário. Dentre as motivações dos autores, destacam-se a hipossuficiência financeira, a necessidade do tratamento não disponível pelo SUS, o direito à saúde e as dificuldades de acesso. A defesa do réu se concentra nas estratégias de eximir-se da responsabilidade do fornecimento de medicamentos não padronizados pelo SUS e de afirmar que não há evidências científicas da superioridade terapêutica das insulinas análogas em relação às disponíveis pelo SUS (NPH e regular).

$\mathrm{O}$ fato, constatado nesse estudo, dos juízes estarem deferindo solicitações de medicamentos que não constam das listas do SUS ou são prescritos pelo nome comercial revela o desconhecimento por parte do Judiciário das políticas de medicamentos e de assistência 
farmacêutica e, em particular, das normas sanitárias que orientam o uso racional dos medicamentos, incluindo a recomendação do uso do nome genérico pelas prescrições do SUS, o que pode, no limite, representar uma ameaça à segurança do requerente.

Percebe-se, portanto, que, na maioria das vezes, o Poder Judiciário ignora que a política de assistência farmacêutica é um meio de garantia do direito a saúde e não só do direito ao medicamento. Ignora também o fato de que muitas prescrições e muitos relatórios médicos estão sendo feitos de forma inadequada, sem respeitar as orientações e normas sanitárias.

Com efeito, a utilização, em algumas sentenças, do argumento de que o Estado tem obrigação de fornecer o medicamento independentemente do que é previsto nos protocolos da rede pública de saúde demonstra o desconhecimento, por parte de alguns juízes, das políticas de saúde vigentes. Cabe destacar, ainda nesse estudo sobre o tratamento para a diabetes, que o recurso ao Judiciário não decorreu de um problema gerencial da Sesab, em relação à falta dos medicamentos. No entanto, o fato da dispensação das insulinas análogas acontecer somente na capital mostra que é necessário melhorar a logística e descentralizar a dispensação desses medicamentos.

Vale também acrescentar que o fato das insulinas análogas não fazerem parte das listas oficiais do SUS não significa que essas listas estejam desatualizadas como, às vezes, argumentam os autores das ações. Nesse caso, as insulinas não constam das relações oficiais, pois não foram recomendadas pela Conitec para incorporação pelo SUS. É preciso ainda registrar que se trata de solicitações de medicamentos de marca, no caso das insulinas análogas, para as quais existem equivalentes já incorporados ao SUS, no caso, as insulinas NPH e regular. Assim, os achados empíricos analisados nesse estudo mostram que as pessoas recorrem ao Poder Judiciário porque os prescritores que as orientam creem que as insulinas análogas são melhores do que a insulina humana regular e a NPH. Por serem medicamentos de alto custo, que não são dispensados pelo sistema público usualmente, os 
pacientes alegam não terem condições financeiras de arcar com os custos desses medicamentos.

Por fim, o terceiro estudo realizado, A judicialização da assistência médica suplementar: um estudo de caso em Pernambuco (ABADE, 2015), deu origem a dois artigos. O primeiro deles, intitulado "Características gerais das sentenças judiciais relativas à assistência médica suplementar proferidas no Tribunal de Justiça de Pernambuco em 2012 e 2013” (ABADE, 2015), identificou que:

a. das 326 ações judiciais estudadas, a maior parte é de autoria individual (95,71\%);

b. as operadoras mais acionadas judicialmente são as de medicina de grupo $(55,52 \%)$ e as empresas de autogestão (26,69\%);

c. os planos antigos estão presentes em $16 \%$ das ações;

d. a principal questão das ações judiciais é a negação de cobertura $(55,8 \%)$;

e. entre os bens e serviços mais citados estão: os medicamentos, as próteses e outros materiais, as cirurgias e os serviços de homecare;

f. em $91 \%$ das ações, a decisão foi favorável aos clientes.

Esses resultados permitem, por um lado, perceber as diferenças regionais no que diz respeito à assistência médica suplementar. Entre elas, vale destacar, em Pernambuco, a grande proporção de empresas de autogestão citadas nas ações, com valores bem superiores à proporção de ações impetradas nos tribunais do Sudeste que citam empresas de autogestão. Outra diferença importante é a aparição, com destaque, das coberturas psiquiátricas como fonte de litígio na assistência médica suplementar.

Por outrolado, deixam ver que dois nós críticos da judicialização da assistência médica suplementar ocorrem tanto em Pernambuco quanto no Rio de Janeiro ou em São Paulo: a coletivização dos planos privados e persistência dos planos não regulados pela Lei n. ${ }^{\circ}$ 9656/98 (por terem sido contratados antes da promulgação da lei). 
Com efeito, quanto às características dos planos e seguros privados de saúde, dois aspectos são importantes para o estudo da judicialização: o tipo de contratação do plano - coletivo ou individual e data da contratação do plano - antes ou depois da Lei n. ${ }^{0}$ 9656/98 -, uma vez que os planos coletivos e aqueles contratados em data anterior à da lei ainda carecem de legislação específica capaz de dirimir os conflitos.

Nesse estudo, é possível observar que os planos coletivos estão presentes em $41,72 \%$ das ações. Os anteriores à lei somam 15,95\%. Nesse cenário, a ocorrência desses nós críticos é resultado da omissão do Estado, no processo de regulação da saúde suplementar. Essa omissão mantém-se como verdadeira leira para conflitos entre clientes e operadoras, sendo do Judiciário a colheita final. Não restam dúvidas que a redução de conflitos na assistência médica suplementar presume a superação dessas duas barreiras.

Quanto à cobertura, principal fonte de litígio, é preciso destacar que se refere, principalmente, a bens e serviços de alto custo, em torno dos quais os interesses de restabelecimento da saúde disputam espaço com os interesses do mercado, dos profissionais e das operadoras. Isso tudo resulta numa complexa teia que precisa ser elucidada, a fim de evitar o uso indevido dos tribunais para a garantia do lucro, em detrimento da saúde da população. Por fim, esse estudo permite afirmar que o perfil das ações judiciais encontrado à luz da segmentação do sistema de saúde brasileiro, do aumento progressivo da cobertura de planos e seguros privados de saúde estimulada pelas políticas governamentais e das fragilidades da regulação, desenham uma tendência de acirramento da litigiosidade.

O segundo artigo fruto dessa dissertação, "Fundamentação das sentenças judiciais relativas à assistência médica suplementar proferidas no Tribunal da Justiça de Pernambuco em 2012 e 2013" (ABADE, 2015), mostra, nas 326 ações judiciais analisadas, que o Código de Defesa do Consumidor (CDC) foi a legislação mais utilizada (45,5\%), possuindo mais do que o dobro de citações da Lei n. ${ }^{\circ}$ 9656/98 (19\%) que regulamenta os planos e seguros privados de 
saúde. As súmulas emitidas pelos tribunais estaduais e pelo Superior Tribunal de Justiça vêm ganhando espaço e já ocupam a segunda posição (20\%). A Constituição Federal de 1988 foi destacada em um número pouco expressivo de litígios (2,6\%). A Lei Orgânica da Saúde não apareceu nas ações analisadas, enquanto que as publicações da ANS estiveram presentes em apenas $10 \%$ das ações, sendo o rol de procedimentos a norma mais citada. Foi possível concluir, a partir do estudo, que o Poder Judiciário, ao dirimir os conflitos entre os clientes e as operadoras de planos e seguros privados de saúde, assumiu o CDC como a legislação prioritária. Ainda que com grande capacidade resolutiva, o uso preponderante do CDC põe a tônica da argumentação na lógica do abuso da relação de consumo, o que demonstra que o conflituoso mosaico estrutural entre o público e privado no sistema de saúde brasileiro não tem sido problematizado nos tribunais.

A análise sobre o uso da regulação demonstra que, ao mesmo tempo em que a ANS se consolidou como o legítimo lócus regulatório, sua atuação é incipiente, limitada a temas específicos, como cobertura e reajustes. Mesmo quando citadas, suas normas não são determinantes das tomadas de decisão. Por sua vez, as falhas da regulação têm oportunizado o aumento do uso das súmulas e de leis específicas, como o Estatuto do Idoso, que legislam, especialmente, nas lacunas da regulação. Vale acrescentar que as questões ligadas ao SUS pouco aparecem na fundamentação das ações. O ressarcimento está completamente ausente e reforça uma compreensão sobre sistema de saúde brasileiro, segundo a qual os sub-sistemas público e privado são independentes.

\section{Considerações finais}

Em tese, o Poder Judiciário pode contribuir para a implantação no Brasil de um sistema de saúde capaz de oferecer um cuidado integral, reduzir iniquidades sociais e superar o modelo biomédico e mercantilista hegemônico. Para tanto, todavia, seria necessário que os princípios construídos no seio da Reforma Sanitária e consagrados 
na Constituição Federal chegassem até o conhecimento dos tribunais e passassem a fundamentar as sentenças que, assim, seriam capazes de influenciar o comportamento de autores e réus de ações judiciais para que ficassem atentos à importância de um sistema de saúde universal para a promoção da justiça social.

Na prática, no entanto, o Poder Judiciário está envolto nas tensões da disputa política que se desenvolve entre os dois projetos de sistemas de saúde que permeiam a sociedade brasileira: se aquele definido na Constituição, que se propõe a ser único e orientado para o atendimento das necessidades de saúde e para a promoção da igualdade, ou se outro, baseado na segmentação da oferta de serviços, de acordo com a capacidade de pagamento das famílias e das empresas.

É justamente para enriquecer o debate e, assim, informar a decisão que a sociedade vier a tomar nessa disputa que as pesquisas científicas sobre a judicialização à saúde são realizadas, produzindo conhecimento que aprofunde a compreensão do fenômeno na sua totalidade, através da análise de suas diversas dimensões éticas, políticas, econômicas, médicas e sociais.

Vale acrescentar que o conhecimento produzido por tais pesquisas pode também subsidiar a formulação e a implantação de políticas de saúde específicas que ajudem a enfrentar os problemas evidenciados pela judicialização - como as falhas da gestão - ou os problemas provocados pela judicialização - como gastos desnecessários ou iníquos.

Os membros do OAPS, responsáveis pelo eixo de acompanhamento das decisões judiciais relativas à saúde, esperam contribuir, com suas pesquisas, para enriquecer o debate científico e político. Além disso, com base nos resultados das pesquisas já realizadas, identificam lacunas no conhecimento sobre o fenômeno que indicam as perspectivas de novos estudos.

Em primeiro lugar, é necessária uma maior compreensão do perfil dos autores das ações judiciais, tendo em vista que a definição desses perfis poderá demonstrar como a judicialização tem modificado o acesso aos serviços de saúde, especialmente, no âmbito do SUS. 
Uma questão correlata se refere à caracterização dos vários atores envolvidos ou interessados no processo da judicializacão da saúde. Tanto os estudos realizados no âmbito do OAPS quanto vários outros já citados (BORGES; UGÁ, 2010; CHIEFFI; BARATA, 2010; DINIZ;MEDEIROS; SCHWARTZ, 2012) identificam a participação de operadores do direito, empresas produtoras ou distribuidoras de bens e insumos para os serviços de saúde, profissionais de saúde, gestores, usuários ou organizações nãogovernamentais na teia da judicialização. Nenhum, contudo, chega a explicitar e discutir as relações e os conflitos de interesses que estabelecem entre si.

Uma terceira questão que deve ser melhor estudada, já sinalizada por alguns estudos (BAPTISTA; MACHADO, 2009; GOMES et al., 2009; HUNT, 2008; PANDOLFO, DELDUQUE, AMARAL, 2012) é a relação entre o campo do direito e o campo da saúde. A ampliação da presença do Poder Judiciário na resolução de conflitos que abarcam as necessidades de saúde, os direitos instituídos e as instituições públicas e privadas que atuam na saúde evidenciou as diferenças entre a racionalidade sanitária e a racionalidade jurídica que, muitas vezes, coloca gestores, usuários, técnicos e magistrados num verdadeiro campo de batalha. O desafio de encontrar uma forma de diálogo entre essas duas racionalidades não é exclusivo do Brasil, mas se faz agudo nos países com pretensos sistemas de saúde universais, nos quais o direito coletivo e direito individual seguem em permanente disputa.

Além de problemas e objetos ainda não analisados, existem os desafios teóricos-metodológicos a superar. Em especial, é preciso discutir quais as melhores formas de se avaliar os impactos da judicialização sobre o sistema de saúde. Apesar da iniciativa pioneira e bastante útil do Manual de Indicadores de Avaliação e Monitoramento das Demandas Judiciais de Medicamentos (PEPE, 2011), ainda não foram apresentadas propostas sistematizadas que abarquem o impacto da judicialização em todas as suas dimensões. Que marco(s) teóri$\mathrm{co}(\mathrm{s})$ podem enriquecer a perspectiva da saúde coletiva na abordagem do fenômeno da judicialização? Quais os métodos mais adequados? 
Enfim, reconhecida a importância do estudo das ações judiciais em seus aspectos políticos, sociais, éticos, jurídicos e sanitários, no aprimoramento das políticas de saúde em curso, avançar nas lacunas empíricas e teórico-metodológicas aqui citadas é um desafio que se impõe para todo o campo da saúde coletiva e que o OAPS se propõe a ajudar a enfrentar.

\section{Referências}

ABADE, E. A. A Judicialização da Assistência Médica Suplementar: um estudo de caso em Pernambuco. 2015. 85 f. Dissertação (Mestrado em Saúde Coletiva) - Instituto de Saúde Coletiva, Universidade Federal da Bahia, Salvador, 2015.

AGÊNCIA NACIONAL DE SAÚDE SUPLEMENTAR. Caderno de informação da saúde suplementar: beneficiários, operadoras e planos. Rio de Janeiro, 2014. Disponível em: <http://www.ans.gov.br/materiaispara-pesquisas/perfil-do-setor/dados-e-indicadores-do-setor $>$. Acesso em: 6 mar. 2014.

BAHIA. Secretaria da Saúde do Estado da Bahia. Centro de Diabetes e Endocrinologia da Bahia. Informe Cedeba, Salvador, ano 4, n. 12, set./out. 2012. Disponível em: <http://www.saude.ba.gov.br/cedeba/informe. pdf $>$. Acesso em: 6 out.2015.

BARDIN, L. Análise de conteúdo. Lisboa: Edições 70:LDA, 1977.

BAPTISTA, T. W. de F.; MACHADO, C. V.; LIMA, L. D.

de.Responsabilidade do Estado e direito à saúde no Brasil: um balanço da atuação dos Poderes. Ciência Saúde Coletiva, Rio de Janeiro, v. 14 n. 3, p. 829-839, Jun. 2009.

BORGE, D. C. L, UGÁ, M. A. D. As ações individuais para o fornecimento de medicamentos no âmbito do SUS: características dos conflitos e limites para a atuação judicial. Revista Direito Sanitário, São Paulo, v. 21, n. 3, p. 438-47, 2009.

BORGES, D. C. L.; UGÁ, M. A. D. Conflitos e impasses da judicialização na obtenção de medicamentos: as decisões de 1a instância nas ações 
individuais contra o Estado do Rio de Janeiro, Brasil, em 2005. Caderno de Saúde Pública, Rio de Janeiro, v. 26, n.1, p. 59-69, jan. 2010.

BRASIL. Amplia produção de medicamentos biológicos. Protec, Rio de janeiro, jun. 2013. Disponível em: <http://site.protec.org.br/farmacose-medicamentos/29185/brasil-amplia-producao-de-medicamentosbiológicos $>$. Acesso em: 15 jul. de 2013.

BRASIL. Ministério da Saúde. Ministro da Saúde apresenta Parcerias de Desenvolvimento Produtivo para empresários. Portal da saúde. Brasília, DF, 2014. Disponível em: <http://www.brasil.gov.br/saude/2014/09/ ministro-da-saude-apresenta-parcerias-de-desenvolvimento-produtivopara-empresarios $>$. Acesso em: 20 de maio de 2015.

CHIEFFI, A. L.; BARATA, R.B. Judicialização da política pública de assistência farmacêutica e eqüidade. Caderno Saúde Pública, Rio de Janeiro, v. 25, n. 8, p. 1839-1849, 2009.

CHIEFFI, A.L, BARATA, R. B. Ações judiciais: estratégica da indústria farmacêutica para introdução de novos medicamentos. Revista de Saúde Pública, São Paulo, v. 44, n. 3, p. 421-429,2010.

CONSELHO NACIONAL DE JUSTIÇA (Brasil). Brasil tem mais de 240 mil processos na área de Saúde. Brasília, DF, 2011. Disponível em: <http://www.cnj.jus.br/noticias/cnj/56636-brasil-tem-mais-de-240-milprocessos-na-area-de-saude>. Acesso em: 23 out. 2015.

COOPER, H.M.; HEDGES, L.V. Research synsthesis as a scientific process. In: COOPER, H.M.; HEDGES, L. V. The handbook of research synthesis and meta-analysis. $2^{\text {nd }}$. New York: The Russel Sage Fundation, 2009. p. 3-16.

D’ESPINDULA, T. C. de A. S. Judicialização da medicina no acesso a medicamentos: reflexões bioéticas. Revista Bioética, Brasília, DF, v. 21, n. 3, p. 438-447. dez. 2013.

DINIZ, D.; MEDEIROS, M.; SCHWARTZ,I.D.D. Consequências da judicialização das políticas de saúde: custos de medicamentos para as mucopolissacaridoses. Caderno Saúde Pública, Rio de Janeiro, v. 28, n. 3, p. 479-489, mar. 2012. 
DRESCH, R. L. Federalismo solidário: a responsabilidade dos estes federativos na área da saúde. In: SANTOS, L.; TERRAZAS, F. (Org.). Judicialização da saúde no Brasil. Campinas: Saberes, 2014. Cap. 1.

GOMES, D. F. et al. Judicialização da saúde e a audiência pública convocada pelo Supremo Tribunal Federal em 2009: o que mudou de lá para cá? Saúde em debate, Rio de Janeiro. v. 38 n. 100, p. 139-156, mar. 2014.

GUIMARÃES, R.et al. Não há saúde sem pesquisa: avanços no Brasil de 2003 a 2010. Revista Baiana de Saúde Pública, Salvador, v. 36, n. 1, p. 55-65, 2012.

HUNT, P.; KHOSLA, R. The human rights to medicines.Sur. Revista Internacional de Direitos Humanos. São Paulo, v. 5, n. 8, p. 101-121, jun. 2008.

LISBOA, E.S. Acesso ao tratamento da diabetes na Bahia: por que se recorre ao judiciário? 2015. 78 f. Dissertação (Mestradoem Saúde Coletiva) - Instituto de Saúde Coletiva, Universidade Federal da Bahia, Salvador, 2015.

LOPES, L.C. et al. Uso racional de medicamentos antineoplásicos e ações judiciais no Estado de São Paulo. Revista Saúde Pública, Rio de Janeiro, v. 44, n. 4, p. 620-628, 2010.

MACHADO, F. R. S.; DAIN, S. Direito e saúde: contribuições para o estudo da judicialização. In: ASENSI, F. D.; PINHEIRO, R. (Org.). Direito sanitário. Rio de Janeiro: Ed. Elsevier, 2012. Cap. 26. p. 463-489.

MARQUES, S. B.; DALLARI, S. G.. Garantia do direito social à assistência farmacêutica no Estado de São Paulo. Revista de Saúde Pública,São Paulo, v. 41 n. 1, p. 101-107, 2007.

MESSEDER, A. M.; OSORIO-DE-CASTRO, C. G. S.; LUIZA, V. L. Mandados judiciais como ferramenta para garantia do acesso a medicamentos no setor público: a experiência do Estado do Rio de Janeiro, Brasil. Cadernos de Saúde Pública, Rio de Janeiro, v. 21, n. 2, p. 525-534, 2005.

PANDOLFO, M.; DELDUQUE, M. C.; AMARAL, R.G. Aspectos jurídicos e sanitários condicionantes para o uso da via judicial no acesso 
aos medicamentos no Brasil. Revista Salud Pública, Rio de janeiro, v. 14, n. 2, p. 340-349, 2012.

PEPE, V. L. E. (Org.). Manual indicadores de avaliação e monitoramento das demandas judiciais de medicamentos. Rio de Janeiro: Fundação Oswaldo Cruz, Escola Nacional de Saúde Pública Sergio Arouca, 2011. RYAN, G.W.; BERNARD, H. R. Data management and analysis methods. In: DENZIN, N. K.; LINCONL, Y.S. Handbook of qualitative research. Califórnia: Sage Publications, 2000. p. 769-802.

REIS, C.; PIERONI, J. P.; SOUZA, J. O. B. Biotecnologia para saúde no Brasil-BNDES. Setorial, Rio de Janeiro, n. 32, p. 193-230, 2010.

SANTOS, B. S. Os tribunais nas sociedades contemporâneas: o caso português. Porto: Ed. Afrontamento, 1996. (Coleção Saber Imaginar o Social, n. 8).

SANTOS, L.; TERRAZAS, F. Judicialização da saúde no Brasil. Campinas: Saberes, 2014.

SHEFFER, M. Coberturas assistenciais negadas pelos planos e seguros de saúde em ações julgadas pelo tribunal de justiça do estado de São Paulo. Revista Direito Sanitário, São Paulo, v. 14, n. 1, p. 122-132, 2013. SCHEFFER, M.; SALAZAR, A. L.; GROU, K. B. O remédio viaJustiça: um estudo sobre o acesso a novos medicamentos e exames em HIV/Aids no Brasil por meio de ações judiciais. Brasília, DF: Ministério da Saúde, 2005.

TOBAR, F.; YALOUR, M. R. Como fazer teses em saúde pública: conselhos e ideias para formular projetos e redigir teses e informes de pesquisa. Rio de Janeiro: Ed. Fiocruz, 2001.

TORRES, I. D. C. Judicialização do acesso a medicamentos no Brasil: uma revisão sistemática. 2013. 86 f. Dissertação (Mestrado em Saúde Coletiva) - Instituto de Saúde Coletiva, Universidade Federal da Bahia, Salvador, 2013.

TORRES, I. D. C. Análise das ações judiciais de medicamentos na Secretaria de Saúde do Estado da Bahia - 2002 a 2008. 2010. 67 f. Trabalho 
de Concurso de Curso (Especialização) - Faculdade de Farmácia, Universidade Federal da Bahia, Salvador, 2010.

VIEIRA, F. S. Ações judiciais e direito à saúde: reflexão sobre a observância aos princípios do SUS. Revista de Saúde Pública, São Paulo, p. 365-369, v. 42 n. 2, p. 365-369, abr. 2008.

VIEIRA F. S.; ZUCCHI, P. Demandas judiciais e assistência terapêutica no Sistema Único de Saúde. Revista da Associação Médica Brasileira,São Paulo, v. 55, n. 6, p. 672-683, 2009. 


\section{AS ORGANIZAÇÕES DO MOVIMENTO NEGRO E O PROCESSO DE IMPLEMENTAÇÃO DA POLÍTICA NACIONAL DE SAÚDE INTEGRAL DA POPULAÇÃO NEGRA (2006-2014)}

\section{Introdução}

A formulação de políticas públicas dirigidas aos problemas de saúde prevalentes em determinados grupos sociais não se configura como uma novidade no âmbito do sistema público de saúde brasileiro. A discussão sobre a saúde da mulher e seus direitos reprodutivos, nos anos 1980, na qual se destaca a problemática das mulheres negras, a saúde indígena e a epidemia de aids, de alguma forma expressam a conjuntura mundial de duas décadas anteriores que colocaram na cena política do ocidente, a participação de novos atores sociais e políticos, mobilizados pela problemática de gênero, raça e sexualidade, para citar alguns. (BERNARDES, 2011; MELLO et al., 2011; OSIS, 1998)

A partir de então, a consolidação de movimentos sociais e ações coletivas em torno dessas pautas passaram a ter destaque no Brasil, 
colocando em evidencia temas até então negligenciados, influenciando nas décadas seguintes a formulação de políticas públicas de saúde com esses recortes. É nesse contexto que emerge a temática da saúde da população negra e, no início do século XXI, o surgimento de uma política nacional de saúde voltada para esse setor que compõe mais de $50 \%$ da população brasileira.

Embora seja conhecida a participação dos movimentos sociais na construção de agendas governamentais, inclusive das organizações do Movimento Negro em relação a políticas de saúde voltadas para população negra (ALMEIDA, 2013; BRASIL, 2011; ARAUJO; TEIXEIRA, 2013), pouco se sabe sobre a participação desses atores no processo de implementação de uma determinada política pública, uma vez que essa fase é dominada majoritariamente pelos técnicos do governo, embora possam dela participar representantes dos movimentos sociais.

Assim, este capítulo, resultado de uma investigação sobre o discurso de lideranças do Movimento Negro atuantes no campo da saúde, busca desenvolver um olhar sobre a participação das principais organizações da sociedade civil de atuação nacional, vinculadas a esse movimento, no processo de implementação da Política Nacional de Saúde Integral da População Negra (PNSIPN) entre 2006 a 2014.

\section{Breve resgate histórico da atuação do Movimento Negro no Brasil: a aproximação com as políticas de saúde}

A aprovação da Lei Áurea, embora tenha formalmente extinguido a escravidão no Brasil, não implicou em mudanças significativas nas condições de vida da grande maioria da população negra brasileira. Pelo contrário, a legislação que vigorou até a primeira metade do século XX em diferentes momentos, reforçou um processo de marginalização dos negros (JACCOUD, 2008), ao tempo em que as políticas econômicas e sociais implementadas pelo Estado, praticamente ignoraram os problemas enfrentados por esse segmento populacional, 
contribuindo, assim, para reforçar as desigualdades raciais e sociais existentes no país. (FERRAZ; SANTOS FILHO, 2007)

Ainda assim, um conjunto de associações, clubes, organizações filantrópicas e beneficentes voltadas para a população negra, durante esse período, buscavam a inclusão, ascensão social e participação igualitária dos negros em instâncias de poder nacional. (SILVA, 2011) Organizações como a Frente Negra Brasileira, indicavam representações negras em cargos eletivos, bem como, buscavam a inserção de negros no âmbito parlamentar (estaduais ou municipais) para aliarem-se aos quadros da organização. (SILVA, 2003)

Apesar disso, o combate ao racismo, especificamente, recebeu pouca atenção por parte dos governos na primeira metade do século XX. Mesmo com a Lei Afonso Arinos, em 1951, considerada a primeira lei penal sobre discriminação no Brasil, e, portanto um ponto de apoio importante na "luta antirracista", as ações por parte do Estado não se tornaram mais incisivas em coibir as ações racistas no Brasil. (GRIN; MAIO, 2013)

A partir dos anos 1960, as lutas e conquistas do Movimento Negro americano pelos direitos civis influenciam diretamente o Movimento Negro brasileiro, constituído nos anos 1970 (TRAPP; SILVA, 2010), no bojo do fortalecimento das lutas sindicais e populares que marcaram o processo de resistência à Ditadura Militar e luta pela democratização política do país. Com o surgimento do Movimento Negro Unificado (MNU ), o debate sobre a problemática racial ganhou maior espaço na sociedade civil, a partir da denúncia do mito da "democracia racial" no país e da exigência da criação e extensão dos direitos sociais para a população negra. (DOMINGUES, 2007; KÖSSILING, 2007)

Em 1985, o Movimento conseguiu uma importante conquista com a lei 7.437/85, a chamada Lei CAO, que substituiu a Lei Afonso Arinos, incluindo entre as contravenções penais, a prática e atos resultantes de preconceito de raça, de cor, de sexo ou de estado civil, sendo essa lei considerada o embrião do artigo $\mathrm{V}$ da Constituição Federal elaborada três anos mais tarde. (GUIMARÃES, 2001) No que se 
refere às questões específicas do tema racial, a Constituição Federal de 1988 passa a caracterizar a prática de racismo como crime inafiançável e imprescritível, sujeito à pena de reclusão, além de reconhecer a propriedade definitiva das terras aos remanescentes de quilombos que estivessem ocupando suas terras, e o direito à preservação da cultura dessa população. (GUIMARÃES, 2001; PIANA, 2009)

Como se sabe, a aprovação da "constituição cidadã" implicou na adoção de políticas sociais universais, a exemplo da criação do Sistema Único de Saúde (SUS), bem como na expansão dos serviços e benefícios da assistência social, gratuidade, estabelecimento da obrigatoriedade do ensino fundamental, reconhecimento dos direitos previdenciários. (FLEURY; OUVERNEY, 2008) Face à persistência de desigualdades raciais no acesso a bens e serviços, essas políticas foram consideradas insuficientes pelo Movimento Negro, o qual passou a priorizar em sua agenda, a análise das políticas públicas sob a ótica racial. Vale destacar que ainda nos anos 1980, surgiram as primeiras intervenções do Movimento de Mulheres Negras, a partir da atuação das ativistas desse movimento sobre a problemática dos direitos sexuais e reprodutivos, nos espaços institucionais das secretarias municipais e estadual no Estado de São Paulo. (MAHER, 2005; PINTO; SOUZAS, 2002)

Com a Marcha Zumbi dos Palmares contra o Racismo, pela Cidadania e pela Vida, que reuniu cerca de 30 mil pessoas em Brasília em 20 de novembro de 1995, o Movimento Negro apresentou uma carta ao Estado, contendo suas principais reivindicações e demandas, o que gerou a criação do um Grupo de Trabalho Intersetorial para a Valorização da População Negra. A conformação desse grupo contemplou um subgrupo específico de Saúde da População Negra que passou a se responsabilizar pela elaboração e implantação de ações nessa área. (LEITÃO, 2012)

Em 1996 esse grupo de trabalho realizou uma reunião técnica sobre Saúde da População Negra, contando com a participação de vários pesquisadores, dirigentes e profissionais de saúde e militantes do Movimento Negro, com o objetivo de discutir políticas afir- 
mativas para a população negra no campo da saúde. (OLIVEIRA, 2001) A partir daí, foi criado o Programa de Anemia Falciforme no âmbito do Ministério da Saúde (MS) e incorporado o quesito cor nos instrumentos de informação em saúde, destacando-se a variável raça nos estudos sobre a prevalência de doenças como diabetes mellitus, hipertensão arterial, miomas e anemia falciforme na população feminina, além de discutirem os efeitos do racismo na produção das desigualdades em saúde, inclusive no acesso e qualidade dos serviços prestados no âmbito do SUS. (ADORNO; ALVARENGA; VASCONCELLOS, 2004)

Mas é a partir da III Conferência Mundial contra o Racismo, Discriminação Racial, Xenofobia e Intolerância Correlata, realizada em Durban, na África do Sul, em setembro de 2001, que os ativistas da questão da saúde da população negra, ampliam sua mobilização e com apoio da Programa das Nações Unidas para o Desenvolvimento da Organização das Nações Unidas (PNUD/ONU) conseguem aprofundar essas discussões junto ao governo brasileiro. (CARNEIRO, 2002; BENTES, 2002; LOPES, 2005)

O marco desse processo é o documento produzido a partir do Workshop Interagencial sobre Saúde da População Negra, em Brasília, no ano de 2001, por iniciativa do PNUD e da Organização Pan-Americana da Saúde (OPAS), que contou com a presença de diversos profissionais de várias organizações internacionais, do Movimento Negro e de representantes da academia. O documento reconhece a ausência do MS no enfrentamento das questões raciais e define a área de saúde da população negra como uma área de estudo inter e transdisciplinar. Ainda, parte da constatação de que o racismo e a discriminação racial expõem mulheres e homens negros a situações mais perversas de vida e de morte e argumenta que estas só podem ser modificadas pela adoção de políticas públicas capazes de reconhecer os múltiplos fatores que resultam em condições desfavoráveis de vida. (ORGANIZAÇÃO PANAMERICANA DA SAÚDE, 2001) 
Esse documento também é a base para a construção da PNSIPN (ALMEIDA, 2013; BRASIL, 2011), aprovada por unanimidade no Conselho Nacional de Saúde (CNS), em 2006, consolidando assim a responsabilidade do SUS em promover ações favoráveis à saúde da população negra, considerando que, apesar das conquistas institucionais do Movimento Negro, o racismo, como condição histórica, imersa na cultura brasileira, segue agravando a vulnerabilidade desse segmento populacional. (BRASIL, 2011)

Em 2009, foi instituída, por meio de portaria MS n. ${ }^{\circ} 992 \backslash 2009$, a PNSIPN, cujo objetivo é "promover a saúde integral da população negra, priorizando a redução das desigualdades étnico-raciais, o combate ao racismo e à discriminação nas instituições e serviços do SUS”. Inclui ainda nos seus objetivos específicos “o acesso da população negra do campo e da floresta, em particular as populações quilombolas, às ações e aos serviços de saúde”. (BRASIL, 2009) No ano seguinte, com a aprovação da lei n. ${ }^{\circ}$ 12.288/10, que institui o Estatuto da Igualdade Racial, marcado por intensos conflitos entre as organizações do Movimento Negro, foi aprovado o capítulo da saúde baseada na portaria do MS, ampliando assim a abrangência da responsabilidade do Estado sobre a temática.

As diferentes conjunturas político-governamentais nas quais se desenvolveram as ações do Movimento Negro, em relação às suas pautas de ação afirmativa, e particularmente da saúde da população negra, não foram, portanto, empecilhos para que fossem formuladas políticas públicas voltadas à intervenção sobre a realidade vivenciada pela população negra no Brasil, ainda que guardada as devidas particularidades. Para Lima (2010), os anos do governo Fernando Henrique Cardoso (FHC) marcaram uma relação de "exterioridade" na relação entre o Movimento Negro e o Estado, sendo ao movimento reservado um papel de demandante e pouca inserção no aparato governamental, ao contrário do governo Lula que incorporou quadros do Movimento Negro no governo, tanto ocupando cargos como representando a sociedade civil nos espaços de controle social. 
A aprovação da PNSIPN no CNS, em 2006, a publicação da portaria em 2009, e a aprovação do capítulo de saúde na lei do Estatuto da Igualdade Racial, constituem o marco legal a partir de onde se desenvolve o processo de implementação dessa política. Fase esta que não se resume à execução de ações meramente administrativas, mas o momento de "colocar em prática as soluções apontadas", o que envolve questões estratégicas relativas aos interesses de múltiplos atores. (PINTO; VIEIRA-DA-SILVA; BAPTISTA, 2014)

Portanto, nem todas as decisões relevantes são definidas durante as fases de formulação, pois envolvem conflitos, negociações e compromissos com interesses antagônicos. Assim, uma definição feita em fase anterior pode ser modificada ou mesmo rejeitada e alterar o argumento principal da política; novas negociações são processadas e por consequência novas decisões e formulações são apresentadas reiniciando assim o ciclo. Como assinalam Viana e Baptista (2008, p. 101)

[...] se o momento de formulação é uma ocasião dos grandes consensos, em que tudo é possível, é no momento de implementação que se descobre a real potencialidade de uma política, quem são os atores que a apoiam, o que cada um dos grupos disputa e seus interesses.

\section{As relações entre Estado e organizações da sociedade civil}

O ponto de partida para a construção do referencial teórico desse estudo foi a revisão das contribuições da teoria gramsciana, utilizada por um conjunto de autores brasileiros da área de ciências políticas (COUTINHO, 1993; NOGUEIRA, 1999; SEMERARO, 2006), inclusive na Saúde Coletiva, em estudos de políticas de saúde. (PAIM, 2008)

Gramsci (2000) desenvolve o conceito de Estado que está para além do governo administrativo. O Estado ampliado é o somatório 
da sociedade política mais a sociedade civil, tratando-se de uma unidade-distinção, uma vez que guardada as devidas características, essas instâncias não se constituem oposição. A sociedade política é constituída pelo "[...] conjunto dos mecanismos através dos quais a classe dominante detém o monopólio legal da coerção; trata-se daquilo que muitas vezes se chama de Estado em sentido estrito ou Estado-coerção, formado pelas burocracias ligadas às forças armadas e à aplicação das leis, ou seja, o governo [...]”. (COUTINHO, 2011, p. 25) Por sua vez, a sociedade civil é o espaço em que as classes se organizam, elaboram e difundem valores, cultura e ideologias, através de partidos, sindicatos, associações, igreja, imprensa, escolas etc., confrontando projetos de sociedade.

Essa concepção coloca em evidência a complexidade do Estado, que, em seu desenvolvimento histórico, na fase capitalista, passa a buscar outras formas de manutenção de poder, não se restringindo ao uso da força. Para Gramsci (2000, p. 331), “[...] o Estado é todo o complexo de atividades práticas e teóricas com as quais a classe 194 dirigente não só justifica e mantém seu domínio, mas consegue obter o consenso ativo dos governados [...]". Segundo Vasconcelos, Silva e Schamller (2013, p. 87) essa compreensão revela a concomitante função do Estado: assegurar as condições necessárias à expansão da economia e "educar para alcançar o consenso".

Assim, a função primordial do Estado se define na garantia da hegemonia da classe dominante. Hegemonia compreendida não como dominação, mas como capacidade de direção, de obter e manter poder sobre todos os aspectos da sociedade, político, econômico, ideológico, fundamentada no consenso, ou seja, fazendo os interesses da classe dominante parecerem como universais, garantido, de maneira consentida, por meio do apoio e legitimação das massas. (COUTINHO, 1993)

Porém, esse processo não ocorre de maneira unilateral e mecânica, ao contrário é um processo dinâmico marcado por disputas e lutas entre as classes e no interior das próprias classes, assim como também não se trata de um processo natural, e conta com a mediação 
da política. Na perspectiva gramsciana, as realidades históricas são construções que se transformam, sendo dependentes da intervenção humana, resultando, portanto, das variadas dimensões das relações de forças, da organização e consciência dos grupos sociais, e da práxis individual e coletiva. (SEMERARO, 2006)

Nesse sentido, as ideologias, entendidas como visão de mundo, “[... 'organizam' as massas humanas, formam o terreno no qual os homens se movimentam, adquirem consciência de sua posição e lutam" (GRAMSCI, 1999, p. 237), processo este que abre espaço para o desenvolvimento da autoconsciência e a organização dos diferentes grupos. Ainda segundo o autor, o grau de consciência política envolve três diferentes fases. A primeira refere-se ao momento econômico-corporativo ou "egoístico passional"; a segunda, a um momento de solidariedade de interesses entre grupos, mas ainda no campo econômico; e a terceira remete ao momento "ético-político", de superação das necessidades corporativas e a sua universalização, sintetizada na "catarse". (GRAMSCI, 2000)

Desse modo, em meio às contradições características da própria luta entre as classes, desenvolvem-se as práticas políticas das organizações da sociedade civil. A manutenção do poder da classe dominante não prescinde de estratégias que atraiam para o seu campo as demais camadas de intelectuais e partidos, produzindo aquilo que é denominado de transformismo. Segundo Coutinho (2010, p. 38), o transformismo envolve "[...] um processo de cooptação das lideranças políticas e culturais das classes subalternas", excluindo-as "de todo efetivo protagonismo nos processos de transformação social”, que, aliada ao consenso passivo, leva as massas a naturalizarem a ordem constituída, sem visualizarem possibilidades de transformação. Em suma, as relações que se estabelecem entre as organizações da sociedade civil e o Estado podem ser de conservação, reprodução ou transformação da ordem política, econômica e social.

Com base no que foi exposto até aqui, compreendemos o Movimento Negro como uma organização que aglutina segmentos oriundos das classes subalternas, no âmbito da sociedade civil, 
e também desenvolve uma práxis no campo da saúde, podendo se constituir como conservador ou reprodutor do modo como as políticas públicas abordam a saúde da população negra ou desempenhar um papel transformador dessas políticas, quer contribuindo para a introdução de temas específicos e/ou concepções inovadoras e mais abrangentes, que vinculem as questões de saúde aos determinantes sociais e políticos que incidem especificamente sobre essa população, a exemplo do racismo.

\section{A contribuição do pensamento estratégico em saúde para a análise das lideranças dos movimentos sociais enquanto atores da ação institucional}

Estudos sobre movimentos sociais contemporâneos (GOHN, 2011) apontam que, a partir da década de 1990, ocorreu um aumento cada vez maior da atuação dessas organizações, bem como das Organizações Não Governamentais (ONGs) e sindicatos, em diversos espaços institucionais, a exemplo de conselhos gestores e comitês técnicos, (PINTO, 2006; RAMOS, 2004; TORRONTEGUY; DALLARI, 2012), atuando como portadores de inúmeras demandas sociais.

Na medida em que as organizações do Movimento Negro participam desse processo, constata-se que as relações que vêm se estabelecendo entre tais organizações e os gestores e técnicos que atuam em diversos espaços institucionais influenciam o processo de implementação da PNSIPN, demonstrando tanto as correlações de forças estabelecidas nesse processo como a capacidade do Movimento de superar (ou não) uma pauta corporativa. (LEITÃO, 2012; RIOS, 2012)

Considerando a importância de se levar em conta a análise da ação institucional, dos atores políticos do Movimento Negro, que participam da disputa pelo poder, acionando estratégias no âmbito institucional, torna-se relevante a incorporação de conceitos provindo do pensamento estratégico em saúde desenvolvida por Mário Testa (1995), autor que, nas últimas três décadas, vêm sub- 
sidiando os estudos na área de política, planejamento e gestão no campo da saúde coletiva.

Para Testa (1995), a instituição é uma organização, onde é estabelecida uma série de estruturas e sistemas formais e informais, cuja coerência é assegurada por associações de ideias, valores e crenças de diferentes grupos de poder, conforme a capacidade de traduzir seus interesses em arranjos organizacionais. Por trás das questões organizacionais e administrativas, sempre estarão relações de poder, entendido, por esse autor, como a capacidade geral de agir e produzir efeitos e também de determinar o comportamento de outro(s) indivíduo(s), ou seja, fazer com que este realize a sua própria vontade mesmo contra a resistência deste ou de outros que participam da ação. Essa capacidade implica em manipular recursos (poder administrativo), informações (poder técnico) e interesses (poder político), que estão alocados nas mãos de algumas pessoas, grupos sociais e instituições. (TESTA, 1992)

Nessa perspectiva, as mudanças na forma de enfrentamento dos problemas de saúde passam pela mudança do comportamento dos atores sociais. Para entrar no jogo, em condições de obter triunfo sobre aqueles que se opõe a uma determinada política, é necessário que "os competidores", os sujeitos, possuam alguma forma de poder. Nesse sentido, a estratégia não pode ser compreendida como simples meio para se alcançar um determinado fim e torna-se um conceito operacional que permite identificar a disponibilidade de poder de cada grupo. Trata-se do comportamento de um ator social (indivíduo, grupo, instituição) cujo objetivo é adquirir liberdade de ação que lhe permita ganhar espaço de manobra para implementar os objetivos buscados. Esses objetivos são os conteúdos específicos da política que, para esse autor, é uma proposta de distribuição de poder. (TESTA, 1992)

Assim, a participação dos diversos atores na formulação e implementação de políticas de saúde pode configurar uma processo que implique deslocamento e/ou consolidação do poder de grupos sociais concretos, que, através de suas lideranças possam produzir 
consensos em torno da incorporação de conteúdos específicos na política, bem como desenvolver ações que viabilizem a formação de alianças que debilitem o poder dos grupos que se opõem a essa política. Por fim, na perspectiva de Testa, uma proposta de mudança social não pode ser efetivada apenas por mudanças setoriais; entretanto, estas podem criar condições para abrir caminhos para a modificação esperada. A análise das práticas políticas dos atores da sociedade civil envolvidos no desenvolvimento desses processos pode fornecer subsídios para se compreender as potencialidades desses espaços na perspectiva da transformação.

Em síntese, os sujeitos coletivos se transformam em atores no contexto da ação estratégica; a partir da problematização das relações sociais, reivindicação de espaços de poder e luta por transformações, envolvem-se na decisão política (sociedade política) ou no desenho estratégico das ações nos diversos terrenos da atividade social (sociedade civil) (RIVERA, 1995), perspectiva a partir da qual ganha inteligibilidade a ação institucional dos atores do Movimento Negro.

\section{Racismo, saúde e Estado: o olhar das lideranças da sociedade civil}

As entidades do Movimento Negro no Brasil são caracterizadas pela sua diversidade e heterogeneidade, no que diz respeito às suas pautas, suas estruturas político-organizativas e mesmo suas orientações ideológicas, porém comungam entre si a atuação política no enfrentamento das condições desiguais e perversas as quais estão submetidas a população negra.

Dentre as principais organizações à frente dos processos de formulação e implementação da PNSIPN nos últimos anos, destacam-se a Associação Cultural de Mulheres Negras (ACMUN), Geledés Instituto da Mulher Negra, Criola, Federação Nacional de Associações das Pessoas Com Doença Falciforme (Fenafal), União dos Negros pela Igualdade (Unegro), Rede Nacional de Religiões Afro-Brasileiras e Saúde (Renafro). Em sua maioria, essas lideranças 
feministas negras vêm atuando nos últimos 20 anos no campo da saúde, articulando o debate entre o racismo e a saúde no Brasil

Para esse conjunto de lideranças, o racismo é considerado principal elemento que afeta as condições de saúde da população negra no Brasil. Enquanto ideologia, segue existindo na sociedade brasileira, tendo se tornado mais visível a partir do aumento do número de denúncias feitas por parte de pessoas negras, vítimas de discriminação racial. Persistindo as desigualdades raciais, impondo diferenças entre negros e brancos ainda que a população negra venha alcançando algumas melhorias no acesso ao mercado de consumo.

O racismo está onde sempre esteve, atuando violentamente contra nós [...] ao mesmo tempo ele está mais visivel, mais desnaturalizado [...]. (CRIOLA)

[...]... eu acho que o racismo sofre um recrudescimento [...] talvez pela própria divulgação de dados, pela visibilização dos negros, ocupando espaços ou ocupando pouquíssimos espaços, mas disputando espaços [...] Parece que o pessoal saiu do armário, sabe assim?! (GELEDES)

[...]

Nos últimos dez anos o racismo foi mais denunciado... (UNEGRO)

o racismo cada vez vai ficando mais forte. Ainda que nós, população negra, [por mais que] estejamos alcançando alguma mobilidade social. [...] não conseguimos alcançar patamares como o da população branca. (RENAFRO)

Apesar dessa análise sobre a persistência do racismo na sociedade brasileira, para elas, nos últimos 10 anos, houve avanços na atuação do Governo Federal em relação a governos anteriores, notadamente em função de uma maior abertura política para debater o tema. Apesar disso, consideram que as ações governamentais ainda são insuficientes, sobretudo quando se trata de investimento de 
recursos financeiros, humanos e logísticos nas ações que coíbam o racismo e promovam a igualdade racial:

Isso não significa que o governo Lula e o governo Dilma foram excepcionais. Não são excepcionais. Mas nós saímos do marco zero. 'Nós vivíamos' no marco zero. (UNEGRO)

[...] não investe o que é preciso, não assume a sua tarefa de agir pelo antirracismo. Eu acho que o governo federal não faz, governos estaduais não fazem, governos municipais menos ainda [...] mas reconheço também que existem algumas ações, eu digo, são ações e como ações são insuficientes, algumas de qualidade e outras não. (CRIOLA)

Eu acho que muito pouco. Eu acho assim é... eu acho que tivemos é... alguns ganhos, né? É claro que é importante [...] a gente não pode dizer que não teve ganho. (RENAFRO)

Ao referirem-se, porém, às políticas de saúde do Governo Federal, a maioria enfatiza o fracasso das políticas em produzir uma mudança do perfil de morbimortalidade da população negra, chamando a atenção para a insuficiência dos recursos, bem como apontando a priorização de ações de alta complexidade e a insuficiência das ações de prevenção e promoção. Uma das lideranças atribui isso à disputa dos interesses do mercado por dentro do Estado, no setor público, responsabilizando o governo pela omissão diante do interesse público.

O orçamento do SUS é o maior orçamento da união então tá sempre em disputa [...] eu acho que a gestão da política não tem tido coragem de ir fundo na defesa do interesse público, e tão sempre negociando, fazendo acordos, mas acordos que terminam por prejudicar $e$ entregar cada vez mais fatias do interesse público ao mercado [...] 
concentram todo o dinheiro da saúde mais em procedimento do que em promoção, porque em procedimento tem uma série de empresários e pessoas que vão ganhar dinheiro, mas em promoção já não tem mais tanta gente. (CRIOLA)

[...] tem dados de que mulheres negras morrem mais de complicações de parto, os casos de AIDS eles diminuem, eles estabilizam, mas não estabilizam na população negra. (ACMUN)

Apesar de todos os avanços, eu acho que o investimento para saúde deveria ser... [maior] [...] Talvez se o investimento fosse maior aí você pensava realmente no que é saúde, que é vida, não em desenvolver política para o adoecimento, porque se você pensa em saúde como vida, você vai pensar em investir para que essas pessoas não adoeçam, que é a prevenção. (FENAFAL)

Em suma, elas apontam para uma situação social de agudização dos problemas, tanto do fortalecimento do racismo quanto da privatização do sistema público de saúde, demonstrando o complexo entrelaçamento dessas duas problemáticas no Brasil. Porém, reconhecem certo avanço nas ações do governo, no âmbito do executivo, um pouco mais nas questões diretamente vinculados ao tema racial do que nas questões da saúde. Essa visão das lideranças fornece pistas sobre a estratégia priorizada, as disputas que estabelecem, suas análises do processo político bem como as dissonâncias e convergências que emergem no processo de implementação da PNSIPN.

\section{Estratégia, política e as disputas ideológicas}

Todas as lideranças expressam que o eixo central da sua estratégia para o acompanhamento da implementação da PNSIPN tem sido a ocupação de espaços em instâncias de gestão participativa e em comissões técnicas criadas no âmbito do SUS. Assim, relatam a ocupação do assento no CNS (ACMUN, Unegro, Fenafal e Renafro), 
instância gestora do SUS ao nível nacional e comentam que, apesar de algumas lideranças terem assento no Comitê Técnico de Saúde da População Negra de (CTSPN) (Criola, Fenafal), alocado na Secretaria de Gestão Participativa do Ministério da Saúde, estrutura institucional destinada ao acompanhamento e decisões técnicas da PNSIPN, percebem haver certa desvalorização dessa instância por parte do governo.

O Conselho Nacional de Saúde tem 64 anos. Tem apenas dois mandatos do conselho que tem a representação do movimento negro... nunca teve... (UNEGRO) ter uma vaga no conselho nacional de saúde significa dizer que tem uma comissão no conselho nacional de saúde dedicada a monitorar pelo lado de dentro ofuncionamento, a implementação da política. (CRIOLA) ... nosso principal espaço para a implementação dessa política né?! É estar no conselho nacional de saúde. Eu acho que a gente avança, quando a gente consegue ampliar essa participação no conselho nacional de saúde [...] (ACMUN)

Dentro do comitê [técnico de saúde da população negra] a gente participa de todo processo de sugestões, de encaminhamentos, da discussão, de como que deve fazer, do que deve mudar, aquilo que deu certo como que tem que incentivar mais a participação dos municípios e dos estados que a missão do comitê né?! [mas] reconhecemos que houve 'um retrocesso', uns dois anos, teve aquele avanço aquele, deu uma parada e que teve uma retomada agora! (FENAFAL)

Ao mesmo tempo, as lideranças constituem alianças, que podem ser provisórias ou permanentes, de acordo com a pauta pleiteada, no intuito de alcançar maior amplitude de suas ações. Essas alianças são construídas com os movimentos sociais, nos Conselhos; com outras instituições governamentais, a exemplo da Secretaria de Políticas de Promoção da Igualdade Racial (Seppir), na articulação com os 
ministérios; e com parlamentares da base do governo do Partido Comunista do Brasil (PC do B) e do Partido dos Trabalhadores (PT), na Câmara Federal dos deputados, na intervenção em temas legislativos de interesse, a exemplo do Estatuto da Igualdade Racial e de peças orçamentárias em relação à política.

[...] exceto nós [organizações que militam em torno da PNSIPN], contamos com o apoio do movimento LGBT em muitos momentos, do movimento do pessoal da terra até então, dos movimentos mais populares a gente contou com apoio, voto! (CRIOLA)

[... na feitura do estatuto de igualdade racial... a deputada Janete Pietá né?! liderou junto com um grupo né?! deparlamentares, da frente parlamentar do antirracismo, frente parlamentar negra [Frente Parlamentar Mista da Igualdade Racial], mas foi ela que nos levou ao debate, foi ela que negociou, que nós negociamos com ela que se o estatuto da igualdade racial vai ter um capitulo de saúde que ele fosse nos mesmos termos com que a gente construiu a política nacional de saúde integral da população negra [...] deputado Luís Alberto, que é do PT, e deputado Daniel Tourinho, PCdoB, e do deputado Carlos Santana, do PT. (CRIOLA)

[estamos] Tentando interferir no orçamento, nos PPAS, na LDO, na LOA, pra introduzir a questão da saúde da população negra. São peças orçamentárias com emendas parlamentares. (UNEGRO)

[...] a SEPPIR nacionalmente tem dialogado com os ministérios pra implementação da política nacionalmente, então são 11 ministérios no grupo intersetorial ministerial para trabalhar a questão da saúde inclusive, no ministério da saúde, não trabalha só saúde, trabalha também outras politicas, mas lá tem saúde, tem técnica lá dentro da SEPPIR. (UNEGRO) 
Chama atenção o fato dessas lideranças apenas considerarem aliados aqueles com os quais estabelecem aliança permanente, baseados em interesses estratégicos comuns, sujeitos diretamente vinculados a PNSIPN e à Seppir. Com relação aos opositores da Política, atribuem termos abstratos como "os racistas", "o resto de mundo", "o governo", discorrendo mais sobre os obstáculos enfrentados ao longo do processo do que necessariamente sobre os sujeitos e/ou organizações que desenvolvem práticas racistas.

Nesse particular, afirmam encontrar resistências em alguns espaços do MS e até mesmo no CNS em relação à temática, sendo acusadas diversas vezes de negarem o princípio da universalidade do SUS em detrimento de uma pauta corporativa. Para as lideranças, fica claro que a intensidade da disputa ideológica no campo da saúde acerca das relações entre o racismo e suas implicações no quadro sociossanitário da população brasileira tem implicações diretas no processo político, delineando a correlação de forças nas decisões acerca da implementação da Política.

[dizem que] a gente fica insistindo em falar coisa de negro e falar de raça quando não tem nada a ver, o SUS é universal, o SUS é pra todo mundo, que a gente tá defendendo uma bandeira particular. (CRIOLA) existem pessoas que estão dentro...que poderiam contribuir e que não contribui por não acreditar que existe o racismo e achar que a gente quer um SUS separado. (FENAFAL)

Esse é o debate que a gente vai pra cima mesmo e eles mantêm. "Mas eu não sou racista, acho que não cabe, vai dividir o SUS" e quem mais divide são eles quando eles ele aprovam determinadas políticas de pesquisa, inclusive, pra determinadas patologias e nunca prevalece a doença falciforme nessa politica (UNEGRO).

Assim a participação no CNS como estratégia prioritária na implementação da PNSIPN, em função da desvalorização do governo 
em relação a CTSPN, as articulações parlamentares, a aliança com a Seppir indicam os caminhos percorridos pelo coletivo de lideranças na disputa ideológica e política em relação às implicações do racismo na saúde da população negra.

\section{0 desenvolvimento do processo político e a percepção das relações de poder}

O processo político que se desenvolve em torno da implementação da PINSPN é marcado por contradições na relação que se estabelece entre o coletivo de lideranças e as instituições do governo vinculadas à questão. Se por um lado estabelecem uma relação de cooperação com a Seppir, com o MS, apresentam constantes tensões do ponto de vista político:

O que acontece que a gente vem acompanhando por um balanço feito inclusive pelo Ministério da Saúde, é que são ações isoladas e descontínuas. E ação isolada e descontinua não chega a lugar nenhum. (RENAFRO)

Tem ações que quando o Ministério da Saúde quer, ou a secretaria quer, eles fazem de um dia pro outro basta um telefonema e as coisas acontecem (GELEDES)

Eu acho que a política não tem sido implementada, não tem havido nenhum investimento. (FENAFAL)

Afinal o SUS que cujo universo com que ele trabalha basicamente pessoas negras né?! então já tá na disputa de que não querem oferecer grande coisa pra 'essa gente' né?! Que eu imagino que éo que deve ser que passar na cabeça daquelas pessoas [gestores].(CRIOLA)

com o sistema de informação do Ministério da Saúde, eles não provocam em nome da independência federativa da autonomia federativa - não é nem independente, autonomia federativa - "mas não posso intervir no estado", mas quando eles querem eles podem.(UNEGRO) 
Nesse particular, apontam os principais elementos de divergências do ponto de vista técnico e administrativo:

Então precisa maior investimento financeiro no mecanismo de gestão competente pra gestão do antirracismo no SUS, o SUS garantindo que o financiamento não seja uma partição do SUS, mas que altere a lógica do SUS, pra ele poder ser acolhido, pra política nacional de saúde da população negra ser bem sucedida. (CRIOLA)

houve um grande empenho, isso eu não posso negar. Mas se o empenho tivesse sido maior, a política teria sido de fato implementada, porque por mais... que... o governo federal ele não pode obrigar, aí a gente sabe que o SUS ele tá nas três esferas de governo, a gente sabe que o ministério não pode obrigar, mas... ele tem uma força de pressão! (FENAFAL)

uma outra coisa também que o próprio Ministério da Saúde fortaleceu, é não ter comitês técnicos de saúde da população negra. Fica no comitê de equidade. Quando você coloca no comitê de equidade, você amplia... o número de pessoas, o número de ações e... o número de problemas, porque no comitê de equidade está muita gente... da população ribeirinha, população LGBT, população indígena, população quilombola... (UNEGRO)

É um obstáculo você não ter pessoas preparadas que conheçam a importância da saúde pra gerenciar desde o ministério até o município. Nós não temos. (ACMUN)

Uma das lideranças questiona a relação estabelecida entre o poder político e o poder técnico no âmbito do MS.

[...] em termos de dados também hoje você tem muitos dados e dizer que tem falta de dados, mentira, existe dados, né, existe os dados. Mas não tem decisão política a partir desses dados. Ué? Pra quê existem dados 
então? Se eu tenho todos os dados e eu não tomo a decisão política a partir desses dados, nada vai acontecer. (RENAFRO)

Ainda, em termos de divergências com o MS, as lideranças veem incompatibilidade entre a política e a instância institucional de execução da mesma.

... O Ministério da Saúde chamou pra... reestruturar o comitê técnico de saúde da população negra e... foi criada uma área que vai ficar abaixo do que a saúde da população negra já esteve. Então ela é executada pela Secretaria de Gestão Estratégica e Participativa (SGEP) e... mais especificamente dentro de um departamento da SGEP. E agora ela está abaixo desse departamento. Então é muito complicado tu achar que uma política nacional que deve dar conta de toda uma população, em relação à saúde, possa ser executada por uma 'sub-cordenação'. (ACMUN)

Em relação à proposta de reorganização do CTSPN, chama atenção a fala de alguns entrevistados que expressam implicitamente uma certa dissonância sobre a questão.

[...] no comitê técnico de saúde da população negra hoje tem uma mudança no comitê, sai todos os pesquisadores e os militantes que já eram antigos pra entrar novos militantes. Se é bom? É. Mas tem uma coisa nessa novidade... é que alguns desses que estão entrando detém poucas informações e quem detém informação, detém poder. (RENAFRO)

Não aceitavam que como ativistas participássemos de um órgão consultivos que forneceria insumos pro ministério da saúde construir uma política duma área que ele desconhecia e que até hoje desconhece, né?! que é o antirracismo. Então, achava que não tínhamos pra sermos aceitas e aceitos pelos brancos, pelos dirigentes, 
o acordo que a SEPPIR fez foi nos chamar de pesquisadores e pesquisadoras. (CRIOLA)

[...] esse comitê [CTSPN] sendo reestruturado perde completamente o seu papel fundamental que é assessorar tecnicamente o Ministério da Saúde. A ideia agora é colocar maioria de sociedade civil de organizações da sociedade civil, que são importantes sim... mas muitas vezes não vão responder para questões técnicas. Uma coisa é... ter conhecimento de qual é minha direção comunitária e conseguir colocar minha demanda, mas pra assessorar tecnicamente o Ministério tem que ser pesquisadores e esse comitê vem sendo. reestruturado, diminuindo o numero de pesquisadores! O que perde todo o sentido?! Não vai ser mais um comitê, vai ser uma comissão formada por entidades e a gente se posicionou contra. (ACMUN)

Pelo exposto, é possível perceber que as diferenças entre essas lideranças sobre o CTSPN, refletem uma discrepância com a redefinição das funções e competências dessa instância, que para alguns deve ter um caráter político e para outros um caráter mais técnico. De um modo geral, apesar das diferenças do ponto de vista técnico, político e administrativo, há certa consonância no discurso das lideranças. Porém, isso não implica em homogeneidade do Movimento que, ao contrário, apresenta discordâncias entre as próprias lideranças que atuam na saúde e dessas com o conjunto maior do Movimento Negro em relação ao curso da atuação política.

\section{Para além das estratégias setoriais: consonâncias e diferenças no Movimento}

Além da atuação no CNS, uma das principais estratégias referidas pelo conjunto de lideranças diz respeito à fundamentação legal da PNSIPN, tendo em vista que esta deixe de ser somente uma portaria do MS e alcance o status de lei a partir do Estatuto da Igualdade Racial. 
A gente trata o estatuto como lei. A gente tem esse estatuto como se fosse a bíblia dentro da nossa organização. A gente distribui pra a população que a gente trabalha, [... sempre que pauta a questão da saúde da população negra, a gente pauta como lei, porque o primeiro artigo do estatuto tem a questão da saúde!

As lideranças, porém, apresentam diferenças no entendimento do conteúdo do Estatuto. Embora a maioria delas acredite que o fato da PNSIPN ter se tornado lei consista em um avanço, duas posições sobre o tema deixam mais explícita algumas discordâncias sobre essa questão.

Deixou de fora quilombolas, deixou de fora um montão de pautas que tava aguda e importante pra o movimento. Vi o estatuto da igualdade racial naquele momento como uma derrota, mas depois daquele momento vejo ele como uma lei né? 'Uma lei que também tá sendo fruto de disputa, porque as leis nos Brasil elas são fruto de disputa, não é?'

Um ganho para o movimento negro. Pra a sociedade brasileira [...] ele não traz 'dinheiro' para fazer o que ele prega. Esse é o ponto fraco! Não tem pontos fracos... é 'um' ponto fraco.

O processo de mobilização da sociedade civil em torno da aprovação do Estatuto da Igualdade Racial evidenciou, portanto, importantes tensões no que diz respeito à relação das organizações do Movimento Negro com o governo, permeadas por relações político-partidárias:

[...] houve um embate muito duro do movimento negro, dos partidos pra aprovação do estatuto contra nós que dizíamos que tinha que não podia ser a qualquer custo. muito... difícil. De você ver companheiros negros combativos que foram referência pra mim, ou pro movimento ou pra outros. Naquele espaço de lá de dentro 
da corda, sabe assim, fazendo defesa de coisas que nem eles acreditavam, mas que tinham que fazer por um compromisso partidário?! [...] o estatuto da igualdade racial não seria a lei que eu ou que o setor político que eu represento aprovaria e diria que tá fazendo em defesa da população negra, foi basicamente uma conveniência politica, os partidos quiseram mostrar alguma coisa no processo eleitoral deles. (CRIOLA)

Outros entrevistados denunciam essa situação, apontando as dificuldades enfrentadas em outros espaços institucionais, em virtude da mudança de posição de antigos companheiros que passaram a fazer parte do governo, ocupando cargos na burocracia estatal:

[...] vão às reuniões, escutam, mas dão as costas e parece que nada aconteceu. Fazem o que querem. E por outro lado isso é bem complicado, porque estamos lidando com pessoas da sociedade civil que hoje estão no Governo, sempre foram nossos parceiros, sempre estiveram do nosso lado, [...] E é nesse sentido que a gente acaba não fazendo, enquanto a ACMUN, essa filiação partidária! ela é muito complicada assim nesses momentos, assim. (ACMUN)

Porque a partidarização do movimento compromete o controle social... das politicas publicas, entendeu? Primeiro vira um pouco de chantagem, quando você vai pra cima de um... do governo ou do Estado, dizendo: 'Olha, as políticas não tão sendo implementadas' e demonstra com dados... ah... tem um seguimento do movimento que diz: 'Não... mas pera aí... tem lei...', enfim, a partidarização dificulta muito o controle social em relação a implementação de políticas. (GELEDES)

As lideranças apresentam diferentes visões acerca da relação entre as organizações e os partidos políticos. Algumas organizações defendem a importância do partido político para os movimentos sociais como forma de ampliar suas pautas para o conjunto da socieda- 
de, bem como potencializar a sua intervenção no Estado, seja elegendo parlamentares ou interferindo na elaboração de políticas públicas. (Unegro, Fenafal e Renafro)

Já outra organização defende a necessidade de não partidarização como estratégia de maior flexibilização na negociação com diferentes governos de diferentes orientações partidárias (ACMUN). Porém, duas das organizações são enfáticas em afirmar a necessidade de distanciamento entre o partido e o movimento social, reivindicando a "autonomia" como elemento importante para garantir a integridade das bandeiras de luta.

[...] a gente não tem 'muita' proximidade com... o movimento negro partidário né?!, assim, e tem algumas organizações muito partidárias, particularmente ligadas aos partidos $\mathrm{PSB}, \mathrm{PT}, \mathrm{PCdoB}$ né?! que são as maiores organizações partidárias entre nós, mas também tem organizações de PSOL, a gente não quer muita ligação com partido... com as organizações partidárias porque eu acho que... aí não é agenda do antirracismo?! é agenda do que tem sido, mais infelizmente, agenda do partido participando do antirracismo e dos seus próprios termos e não dos termos que o antirracismo permite, muito menos do antirracismo patriarcal e do interesse das mulheres negras. (ACMUN)

a ACMUN não levanta bandeira partidária! 'sempre' teve relação com governos, então pra nós é muito' complicado, sempre teve projeto financiado pelos governos né?!. Não quer dizer que a gente não vote no PT ou que a gente não faça de alguma maneira campanha 'pra' candidatos negros que estãono PT ou que estão no campo de esquerda... no nosso campo político, mas sempre 'absolutamente' mantendo a nossa independência... (ACMUN)

Como a UNEGRO não é partido a gente tem que ta em algum partido, então a maioria deles são do PCdoB. Como tem do PDT conheci vários agora no encontro de 
mulheres. São da UNEGRO e são do PDT.Tem PSB... (UNEGRO)

A gente faz política, mas não faz política partidária [...] mas na medida que você tem uma bancada evangélica muito forte, uma bancada católica, nós também vamos ter que fazer os nossos, entendeu? Para que possam também essar dialogando, para que possam defender causas nossas. (RENAFRO)

Chama atenção que as mesmas organizações que apresentam diferenças em relação aos partidos nos movimentos sociais recorreram aos partidos da base aliada do governo para articular a pauta de saúde da população negra no estatuto:

Na feitura do estatuto de igualdade racial... a deputada Janet Pietá $[P T]$ liderou junto com um grupo de parlamentares, da frente parlamentar do antirracismo, frente parlamentar negra [Frente Parlamentar Mista da Igualdade Racial], mas foi ela que nos levou ao debate, foi ela que negociou, que nós negociamos com ela que se o estatuto da Igualdade Racial vai ter um capitulo de saúde que ele fosse nos mesmos termos com que a gente construiu a Política Nacional de Saúde Integral da População Negra [...] deputado Luís Alberto, que é do PT, e deputado Daniel Tourinho, PCdoB, e deputado Carlos Santana PT. (CRIOLA)

Desse modo, as disputas políticas engendradas pelas lideranças das organizações do Movimento Negro, em alguma medida passam pela mediação dos partidos políticos, seja no interior do próprio Movimento, através de lideranças que militam nessas organizações, no parlamento, através dos deputados e senadores de partidos que apoiam bandeiras das questões raciais, e até mesmo no executivo, por meio da gestão. Embora no marco geral todas essas organizações estejam situadas em um mesmo "campo político", essas relações, na visão dessas lideranças, alterna-se entre tensão e cooperação, a depender da conjuntura específica e dos interesses estratégicos em jogo. 


\section{Movimento Negro na saúde e os paradoxos na ação}

A visão das lideranças sobre a situação do racismo e da saúde no Brasil, expressa, em alguma medida, a complexa conjuntura política frente a governos de expoentes contradições nos últimos 10 anos. Se, por um lado, essas organizações encontram na sociedade civil apoio dos partidos que historicamente deram suporte às suas reivindicações, por outro encontram obstáculos com esses mesmos partidos, frente aos interesses macropolíticos e econômicos do governo, em aliança com setores da classe dominante, conforme aponta Coutinho (1993), e que em alguns momentos se confrontam com os interesses desse coletivo de organizações.

O mito da democracia racial, ou "racismo à brasileira" (TELLES, 2003), consenso construído pelas classes dominantes entre as classes subalternas, vem sendo cada vez mais problematizado pelas organizações da sociedade civil. $\mathrm{O}$ aumento do número de denúncias de discriminação racial por parte de pessoas não organizadas na sociedade civil dá indícios sobre as conquistas alcançadas a partir da disputa ideológica desenvolvida pelo conjunto do Movimento Negro na sociedade brasileira.

Por outro lado, a diversificação das estratégias de repactuação desse consenso por parte das classes dominantes modela novas configurações dessa disputa. Ao mesmo tempo em que o Governo Federal reconhece a existência do racismo, negada por tantos anos, também disputam os conteúdos políticos e ideológicos dessa problemática, o que se reflete inclusive na limitação de recursos para a execução de ações de grande amplitude.

Na saúde, ao mesmo tempo em que estabelecem o fortalecimento do SUS no programa de governo, ao negligenciarem as determinações sociais na saúde, restringindo a saúde aos limites da oferta de serviços, centrado nas tecnologias de alta complexidade, refletiriam segundo (TEIXEIRA, 2001) a manutenção do modelo médico-hegemônico. Excluindo as ações de promoção, o Estado constrói consensos em torno de uma visão hegemônica da saúde, abrindo es- 
paço para a participação de setores privados, que disputam o financiamento destinado ao setor. (SCHEFFER, 2015)

Porém, a percepção dessas contradições por parte das lideranças não os colocam em oposição frontal em relação ao governo, muito menos desautoriza o Estado enquanto possibilidade de concretização de suas pautas reivindicatórias. Ao contrário colocam-se na posição de buscar negociações com vistas a garantir, ainda que de maneira parcial, avanços em relação a implementação da Política Nacional Integral de Saúde da População Negra.

Nesse particular, vale dessacar que o racismo enquanto ideologia dominante atravessa todas as práticas sociais, inclusive as práticas de saúde. Embora se expresse concretamente nos atos de preconceitos e discriminação racial, no âmbito das relações interpessoais entre profissional-usuário nos serviços de saúde, na estereotipação das pessoas negras, na incipiente produção técnico-científica das doenças que prevalecem na população negra, na resistência das políticas de saúde em reconhecer as desigualdades raciais, o racismo não se resume a essas práticas da vida cotidiana.

Porém, a abordagem dessa questão por parte desse coletivo de organizações situa-se no entrelaçamento entre a problemática da discriminação racial e a precarização do Sistema Único de Saúde, que tem implicações negativas no acesso aos serviços de saúde e no perfil de morbimortalidade da população negra, constituindo-se uma complexa arena de tensões (CORTES, 2009) entre as lideranças do movimento negro e gestores da saúde no que diz respeito à implementação da PNSIPN.

Uma vez que as políticas de saúde estejam relacionadas com a distribuição de poder, as estratégias empreendidas por essas lideranças no âmbito do setor saúde também expressam o conteúdo dos projetos pretendidos. $\mathrm{O}$ deslocamento de recursos técnicos, financeiros e administrativos com objetivo de modificar as ações em relação à saúde da população negra no âmbito da gestão, dos serviços de saúde, da formação de pessoal e do sistema de informação, não encerram em si o projeto dessas organizações. 
No caso da PNSIPN quando optam por participar do jogo institucional (TESTA, 1995), elas entram com o intuito de modificar comportamentos dos agentes do Estado, e das próprias instituições em relação ao racismo na saúde, para que desenvolvam práticas políticas em favor da população negra. Por sua vez, o MS, detentor do poder técnico e do poder administrativo, maneja politicamente conforme os interesses estratégicos do governo.

No que diz respeito à correlação de forças no âmbito do MS, o poder político adquirido por essas organizações do Movimento Negro pode ser compreendido, a partir da legitimidade conferida pela sociedade civil pelo seu histórico de intervenção no enfrentamento as desigualdades raciais na saúde. Entretanto, a capacidade de distribuição de recursos, elaboração de informações e decisão, conduzida pela burocracia estatal se faz pouco permeável, na prática, a acolher o tema racial no setor saúde. Restringe a condução da política a uma estrutura institucional do MS com fortes limitações para gerar impactos sobre outros setores governamentais (educação, trabalho, previdência etc.) de modo a "transversalizar" a Política.

Assim, a aparência técnica na implementação das PNSIPN, na verdade, esconde os interesses em disputa no âmbito da sociedade política e da sociedade civil. A correlação de forças no âmbito da gestão na saúde se dá de maneira desequilibrada, tendo nas organizações do Movimento Negro seu elo mais frágil. Contudo, a estratégia de ampliar a questão da saúde da população negra para uma responsabilidade não só do MS, mas de todo o Estado brasileiro, através da lei do Estatuto da Igualdade Racial, demonstra a dinamicidade do Movimento em reorientar suas estratégias diante dos obstáculos e constituir alianças com outras instituições, como é o caso da Seppir.

Desse modo, por dentro dessas instituições do executivo estabelecem-se também o poder de diversificadas forças políticas que compõem o governo, podendo existir instâncias com maior interlocução com as ONGs e movimentos sociais, como é o caso da Seppir ou com menos interlocução, onde predomina a perspectiva técnico-burocrática, como caso do MS, principal espaço de decisão em 
relação à Política. Porém, essas diferenças não sugerem dissonância na forma de condução da política governamental, e sim, variadas estratégias de construção de consensos por parte do Estado.

Com isso, verifica-se não existir uma divisão esquemática entre sociedade política como espaço do uso da força e sociedade civil como espaço da construção do consenso. Não sendo possível, portanto, tomar o Estado como um bloco monolítico, ainda que no conjunto desenvolva ações em uma direção política e ideológica majoritária. (GRAMSCI, 2000)

Nesse sentido, a construção de consensos em torno do projeto social dos partidos que compõem o governo não está isenta de dissonâncias no desenvolvimento da prática política na relação com essas organizações do Movimento Negro. As tensões entre parte das lideranças que se reivindicam apartidárias e as lideranças partidárias expressam de alguma forma a resistência à cooptação por parte do Estado. Porém, essa desconfiança de cooptação, atribuída ao papel dos partidos no seio dos movimentos sociais apresentam contradições no seu desenvolvimento prático, uma vez que nenhuma das lideranças se opõe ao projeto estratégico disputado por essas organizações partidárias na sociedade brasileira.

Nesse caso, parece tratar-se de uma concepção que compreende a sociedade civil como algo que está fora da órbita do Estado, configurada como espaço para se buscar soluções para as questões econômicas, políticas e sociais. Nessa direção, as organizações das classes subalternas deveriam orientar suas demandas para a defesa de interesses puramente corporativos e setoriais. Porém, ainda que não pareçam dispor de vinculação partidária direta, ao identificarem esses partidos como aliados, inclusive no âmbito do poder legislativo, agem politicamente em consonância com a agenda governamental defendida por esses parlamentares no Congresso. Desse modo, as disputas empreendidas pelo coletivo de organizações do Movimento Negro na saúde também refletem os interesses das forças políticas com as quais se identificam em seus projetos societários. 


\section{Considerações finais}

Ao investigar a visão das organizações do Movimento Negro acerca da participação e avaliação política do processo de implementação da PNSIPN, demonstramos as contradições subjacente ao discurso das lideranças. Ao mesmo tempo em que situam relevantes ações por parte do governo na temática racial, reconhecem um atraso no setor saúde, contradições essas que podem ser interpretadas pelas disputas políticas em relação a temática, evidenciada no processo de elaboração e aprovação da lei Estatuto da Igualdade Racial.

Em suma, essas organizações partem das demandas vivenciadas pela população negra no que diz respeito ao direito à saúde para formular e atuar no campo da saúde, reproduzindo uma visão setorial sobre a questão, ainda que no marco da defesa do SUS e da transversalização da sua pauta nos diversos serviços e âmbitos do sistema. Esse processo acaba por expressar certo distanciamento da atuação das organizações desse Movimento com os pressupostos do Movimento da Reforma Sanitária, ao tempo que o Movimento Sanitário, ao propor uma "revolução no modo de vida" (PAIM, 2008), parece não contemplar em sua elaboração a centralidade o debate racial, para pensar uma verdadeira democratização da saúde brasileira, visto que a população negra compõe a maior parte dessa população em todo território.

Por fim, este estudo aponta para a necessidade de uma maior articulação do Movimento Negro com o Movimento da Reforma Sanitária. A interpretação das lacunas do Movimento Negro, tomando como referência o debate acumulado no Movimento Sanitário, não diminui o papel protagonista que este pode cumprir no campo da saúde. Ao contrário, busca lançar luz para seu fortalecimento, e reflexões não só para o Movimento Negro, mas principalmente para aqueles compromissados com a Reforma Sanitária Brasileira, afim de repensarmos a superação desse capítulo da história social brasileira que é a persistência da marginalização da população negra. 


\section{Referências}

ADORNO, R. C. F.; ALVARENGA, A. T.; VASCONCELLOS, M. P. Quesito cor no sistema de informação em saúde. Estudos Avançados, São Paulo, v. 18, n. 50, p. 119-123, 2004.

ALMEIDA, M.V.B. Caminhos da Política Nacional de Saúde da População Negra: Ideias, Atores, Interesses e Institucionalidade. 2013. $100 \mathrm{f}$. Dissertação (Mestrado em Ciências da Saúde) - Faculdade de Ciências da Saúde, Universidade de Brasília, Brasília, DF, 2013.

ARAUJO, M. V. R.; TEIXEIRA, C. F. A participação dos atores na formulação da política de saúde da população negra na cidade de Salvador. Physis, Rio de Janeiro, v. 23, n. 4, dez. 2013. Disponivel em: $<$ http://www.scielo.br/scielo.php?script=sci_arttext\&pid= S010373312013000 400004\&lng=en\&nrm=iso >. Acesso em : 30 mar. 2015.

BENTES, N. Brasil-Durban-Brasil: um marco na luta contra o racismo. Revista Estudos Feministas, Florianópolis, v. 10, n. 1, p. 229-236, 2002. BERNARDES, A. G. Saúde indígena e políticas públicas: alteridade e estado de exceção. Interface, Botucatu, v. 15, n. 36, mar. 2011.

Disponívele em: <http://www.scielo.br/scielo.php?script=sci arttext\&pid $=S 141432832011000100012 \& \operatorname{lng}=$ en $\& n r m=i s o>$. Acesso em: 4 abr. 2015

BRASIL, S. A. A Política de Saúde da População Negra no Brasil: atores políticos, aspectos étnico-raciais e principais tensões do campo. 2011. 147 f. Dissertação (Mestrado em Saúde Comunitária) - Instituto de Saúde Coletiva, Universidade Federal da Bahia, Salvador, 2011.

BRASIL. Ministério da Saúde. Secretaria de Gestão Estratégica e Participativa. Política Nacional de Saúde integral da população negra: uma política para o SUS. Brasília, DF, 2009. Disponível em:<http://bvsms. saude.gov.br/bvs/saudelegis/gm /2009/prt0992_13_05_2009.html>. Acesso em: 30 nov. 2013.

CARNEIRO, S. A batalha de Durban. Revista Estudos Femininos. Florianópolis, v. 10, n. 1, p. 209-214, 2002. 
CORTES, S. V. Sistema Único de Saúde: espaços decisórios e a arena política de saúde. Caderno de Saúde Pública, Rio de janeiro, v. 25, n. 7, p. 1626-1633, 2009.

COUTINHO, C. N. De Rousseau a Gramsci: ensaios de teoria política. São Paulo: Boitempo, 2011. 184p.

COUTINHO, C. N. As categorias de Gramsci e a realidade brasileira. In: COUTINHO, C.N.; NOGUEIRA, M. A. Gramsci e a América Latina. Rio de Janeiro: Paz e Terra, 1993. p. 103-127.

COUTINHO, C. N. A hegemonia da pequena política. In: OLIVEIRA, F.; BRAGA, R.; RIZEK, C. (Org.). Hegemonia às avessas. São Paulo: Boitempo, 2010.p. 29-43

DOMINGUES, P. Movimento negro brasileiro: alguns apontamentos históricos. Tempo, Rio de Janeiro, v. 12, n. 23, p. 100-1 22, 2007.

FERNANDES, F. A integração do negro na sociedade de classes: o legado da raça branca. 3. ed. São Paulo: Ática, 1978.

FERRAZ, J. M; SANTOS FILHO, A. O pós-abolição na Bahia: memória à construção da vida livre. In: NASCIMENTO, A. D.; HETKOWSKI, T. M. (Org.). Memória e formação de professores. Salvador: EDUFBA, 2007. p. 17-42.

FLEURY, S.; OUVERNEY, A. M. Políticas de Saúde: uma política social. In: GIOVANELLA, L. et al. (Org.). Políticas e Sistemas de Saúde no Brasil. Rio de Janeiro: Ed. Fiocruz, 2008. p. 23-64

GOHN, M.G. Teorias dos movimentos Sociais: paradigmas clássicos e contemporâneos. São Paulo: Loyola, 2011.

GRAMSCI, A. Cadernos do cárcere. Rio de Janeiro: Civilização Brasileira, 1999. v. 1.

GRAMSCI, A. Cadernos do cárcere. Rio de Janeiro: Civilização Brasileira, 2000. v. 3.

GRIN, M.; MAIO, M. C. O antirracismo da ordem no pensamento de Afonso Arinos de Melo Franco. Topoi, Rio de Janeiro, v. 14, n. 26, p. $33-$ 45, 2013. 
GUIMARÃES, A. S. A. A questão racial na política brasileira (os últimos quinze anos). Tempo Social, São Paulo, v. 13, n. 2, p. 121-142, 2001.

JACCOUD, L.O Combate ao racismo e à desigualdade:o desafio das políticas públicas de promoção da Iguaçdade Racial. In: THEODORO, M. (Org.). As políticas pú- blicas e a desigualdade racial no Brasil: 120 anos após a abolição. Brasília, DF; Instituto de Pesquisa Econômica Aplicada, 2008. p. 176.

KÖSSLING, K.S. As lutas anti-racistas de afro-descendentes sob vigilância do DEOPS/SP (1964-1983). 2007. 314 f. Dissertação (Mestrado em História Social) - Faculdade de Filosofia e Ciências Humanas, Universidade de São Paulo, São Paulo, 2007.

LIMA, M. Desigualdades raciais e políticas públicas: ações afirmativas no governo Lula. Novos Estudos. - CEBRAP, São Paulo, n. 87, p. 77-95, 2010.

LEITÃO, L. R. S. Oportunidades políticas e repertórios de ação: o movimento negro e a luta de combate. 2012. $152 \mathrm{f}$. Tese (Doutorado em Sociologia) - Instituto de Filosofia e Ciências Humanas da Universidade Federal Universidade Federal do Rio Grande do Sul, Porto Alegre, 2012. LOPES, F. Para além da barreira dos números: desigualdades raciais e saúde. Caderno de Saúde Pública, Rio de Janeiro, v. 21, n. 5, p. 595-160, 2005.

MAHER, C. M. Nem tudo é estar fora: o movimento de mulheres negras e as articulações entre saúde e raça. 2005. 146 f. Dissertação (Mestrado em Antropologia Social) - Instituto de Filosofia e Ciências Humanas, Universidade Estadual de Campinas, Campinas, 2005.

MELLO, L. et al. Políticas de saúde para lésbicas, gays, bissexuais, travestis e transexuais no Brasil: em busca de universalidade, integralidade e equidade. Sexualidad, Salud y Sociedad, Rio de Janeiro, n. 9, p. 7-28, 2011. Disponível em: <http://www.scielo.br/scielo.php?script=sci_ arttext\&pid $=$ S198464872011000400002\&lng $=$ en\&nrm=iso $>$. Acesso em: 4 abr. 2015.

NOGUEIRA, M. A. Um Gramsci todo dedicado à política. In : KRITSCH, R.; MELLO, L. I. A; VOUGA, C. Oliveiros S. Ferreira : um pensador da política. São Paulo: Humanitas, 1999. p. 133-156. 
OLIVEIRA, F. Saúde da População Negra: Brasil, ano 2001. Brasília, DF: Secretaria Especial de Políticas de Promoção da Igualdade Racial. Brasília, 2001.

OSIS, M. J. M. D. Paism: um marco na abordagem da saúde reprodutiva no Brasil. Caderno de Saúde Pública, Rio de Janeiro, v. 14, n. 1, 1998. Suplemento. Disponível em: <http:// www.scielo.br/scielo.php?script=sci_arttext\&pid=S010231 1X1998000500011\&lng=en\&nrm=iso >. Acesso em: 4 abr. 2015.

ORGANIZAÇÃO PANAMERICANA DA SAÚDE-OPAS. Seminário Política Nacional de Saúde da População Negra: uma questão de equidade. Brasília, DF, 2001.

PAIM, J. S. Reforma sanitária brasileira: contribuição para compreensão e crítica.Salvador: EDUFBA, 2008.

PIANA, M. C. As políticas sociais no contexto brasileiro: natureza e desenvolvimento. In: PIANA, M. C. A construção do perfil do assistente social no cenário educacional. São Paulo: Editora UNESP; Cultura Acadêmica, 2009. p. 21-56.

PINTO, E. A.; SOUZAS, R. Etnicidade e saúde da população negra no Brasil. Cadernos de Saúde Pública, Rio de Janeiro, v. 18, n. 5, p. 1144-1145, 2002.

PINTO, C. R. J. As ONGs e a política no Brasil: presença de novos atores. Dados: Revista de Ciências Sociais, Rio de Janeiro, v. 49, n. 3, 2006. Disponível em: <http://www.scielo.br/scielo.php?script=sci_ arttext\&pid=S001152582006000300008\&lng=en\&nrm=iso $>$. Acesso em: 30 mar. 2015.

PINTO, I. C. M; VIERA-DA-SILVA, L.M; BAPTISTA, T.V. F. Ciclo da Política: problematização, construção da agenda, institucionalização, formulação, implementação e avaliação. In: PAIM, J. S.; ALMEIDAFILHO, N. A. Saúde Coletiva: teoria e prática. Rio de Janeiro: MedBook, 2014. p. 69-81.

RAMOS, S. O papel das ONGs na construção de políticas de saúde: a Aids, a saúde da mulher e a saúde mental.

Ciência Saúde Coletiva, Rio de Janeiro, v. 9, n. 4, dez. 2004. 
Disponível em:<http://www.scielo.br/scielo.php?script=sci arttext\&pid=S141381232004000400027\&lng=en\&nrm=iso $>$. Acesso em: 30 mar. 2015

RIOS, F. O protesto negro no Brasil contemporâneo (1978-2010). Lua Nova, São Paulo, p. 41-79, n. 85, 2012. Disponível em: <http://www.scielo.br/scielo.php?script=sci arttext\&pid $=$ S010264452012000100003\&lng=pt\&nrm $=$ iso $>$. Acesso em: 17 mar. 2015.

RIVERA, F. J. U. A teoria do planejamento estratégico no setor social e da saúde à luz do agir comunicativo: o contexto latino-americano. In: RIVERA, F. J. U. Agir comunicativo e Planejamento Social. Uma crítica ao enfoque estratégico. Rio de Janeiro: Ed. Fiocruz, 1995. p. 144-211.

SCHEFFER, M. O capital estrangeiro e a privatização do sistema de saúde brasileiro. Caderno Saúde Pública, v. 31, n. 4, p. 663-666, 2015.

SEMERARO, G. Gramsci e os novos embates da filosofia da práxis. Aparecida, SP: Idéias \& Letras, 2006. SILVA, F.O. Os negros, a constituição de espaços para os seus e o entrelaçamento desses espaços: associações e identidade em Pelotas (1820/1943). 2011. 228 f. Dissertação (Mestrado em História) Pontifícia Universidade Católica do Rio Grande do Sul, Porto Alegre, 2011.

SILVA, J. A União dos Homens de Cor: aspectos do movimento negro dos anos 40 e 50. Estudos Afro-Asiáticos, Rio de Janeiro, v. 25, n. 2, p. 215-235, 2003.

TEIXEIRA, C. F. O futuro da prevenção. Salvador: Casa da Qualidade, 2001.

TELLES, E. Racismo à brasileira: uma nova perspectiva sociológica. Rio de Janeiro: Relume-Dumará: Fundação Ford, 2003.

TESTA, M. Pensamento estratégico e lógica de programação: o caso da saúde. São Paulo: Hucitec; Rio de Janeiro: ABRASCO, 1995.

TORRONTEGUY, M. A. A.; DALLARI, S. G. O papel das organizações não-governamentais na cooperação internacional em 
saúde pública. Saude Sociedade, São Paulo, v. 21, n. 2, jun. 2012.

Disponível em: <http://www.scielo.br/scielo.php?script=sci

arttext\&pid=S010412902012000200006\&lng=pt\&nrm=iso $>$. Acesso

em: 30 mar. 2015

TESTA, M. Pensar em saúde. Porto Alegre: Artes Médicas: ABRASCO, 1992.

TRAPP, R. P.; SILVA, M. L. da. Movimento Negro no Brasil contemporâneo: estratégias identitárias e ação política. Revista Jovem Pesquisador, Santa Cruz do Sul, v. 1, p. 89-98, 2010.

VIANNA, A. L. D.; BAPTISTA, T. W. F. Análise de políticas de saúde. In: GIOVANELLA, L. et al. (Org.). Políticas e sistema de saúde no Brasil. Rio de Janeiro: Ed. Fiocruz, 2008. p. 65-105.

VASCONCELOS, K. E. L; SILVA, M. C.; SCHAMLLER. V. P. V. (Re) visitando Gramsci: considerações sobre o Estado e o poder. Revista katálysis, Florianópolis, v. 16, n. 1, p. 82-90, 2013. 
Anexo - Trajetória metodológica do capítulo

Esta pesquisa fez parte da execução do projeto do doutorado em Saúde Coletiva, desenvolvido no Programa de Pós-Graduação em Saúde Coletiva do Instituto de Saúde Coletiva da Universidade Federal da Bahia (PPGSC/ISC/UFBA), no período de 2011 a 2014. Trata-se de um estudo centrado na produção e análise de informações qualitativas acerca das concepções e práticas de lideranças do Movimento Negro com relação à problemática de saúde. Fez parte deste estudo lideranças de entidades e organizações do Movimento Negro (ONGs, religiosas, políticas, associações etc.) que desenvolvem práticas relacionadas ao que vem sendo denominado de "campo de saúde da população negra", no âmbito da sociedade civil e das instituições públicas do Governo Federal. Inicialmente, foi feito a exploração, através do Google, das entidades e organizações do Movimento Negro que participaram dos principais eventos nacionais da sociedade civil impulsionados pelo Movimento Negro nos últimos 15 anos (Seminários de Articulação Pré-Durban; Seminários Nacionais de Saúde da População Negra; Comitê de Organização Zumbi + 10 - II Marcha contra o Racismo, pela Igualdade e a Vida debates sobre o Estatuto da Igualdade Racial). Uma vez gerada uma lista de 15 organizações, foram selecionadas aquelas com intervenção nacional. Em seguida, o nome das organizações foi associado ao termo "saúde", e depois "saúde da população negra" chegando-se a um número de 11 entidades. Posto isso, foi feito o contato com uma liderança cujo nome estava entre os 11 e, através da técnica da bola de neve e posterior comparação com a lista dos 11, chegou-se a um conjunto final de nove, das quais uma não se sentiu apta a abordar sobre tema e as outras duas não retornaram contato.

Os dados foram produzidos, entre os meses de abril e agosto de 2014, através de entrevistas online, via SKYPE e software de gravação Audacity (4), e presenciais, com uso de gravador (2), utilizandose um roteiro de entrevista semiestruturada à visão das lideranças destas organizações sobre o processo de implantação da PNSIPN. Os discursos produzidos através das entrevistas foram transcritos 
e organizados em matrizes de dados com base no quadro teórico e tendo referência no método SWOT (OPS, 1994), contemplando os seguintes aspectos: a) caracterização do cenário: diz respeito ao contexto político e institucional onde se desenvolvem as ações do Movimento Negro, ou seja, se as ações do governo em relação ao tema racial convergem e/ou favorecem ganhos para o Movimento ou não; b) identificação dos aliados e oponentes, isto é, atores e políticos, tanto da sociedade civil quanto do Estado com os quais foi possível estabelecer relações de apoio total e/ou parcial (aliados) ou àqueles que não só divergem como também dificultam a criação de condições, seja de maneira explícita ou implícita, a decisões favoráveis ao processo de implementação da política (oponentes); c) facilidades/oportunidades bem como dificuldades/obstáculos que se apresentaram no processo.Uma vez organizados na matriz, foi utilizado a técnica de análise de conteúdo, com base nas categorias definidas no referencial teórico: sociedade política e sociedade civil; estratégia; poder e ideologia.

Por fim, cabe registrar que o projeto que deu origem a esta pesquisa foi submetido e aprovado no Comitê de Ética do ISC/UFBA, em conformidade com a Resolução CNS/MS 196/96. Todos os sujeitos foram orientados quanto à natureza e os objetivos da pesquisa e aceitaram participar da entrevista assinando o Termo de Consentimento Livre e Esclarecido, enviado por e-mail, assinado, digitalizado e enviado ao pesquisador, autorizando a reprodução de suas entrevistas no trabalho. 
Maria Guadalupe Medina, Rosana Aquino, Ana Luiza Queiroz Vilasbôas, Cristiane Abdon Nunes e Nília Maria de Brito Lima Prado

\section{ATENÇÃO PRIMÁRIA À SAÚDE reflexões sobre a política a partir da prática de pesquisa}

\section{Introdução}

A Atenção Primária à Saúde (APS) tem sido prioridade das políticas públicas nas últimas décadas no Brasil e no mundo. Em diversos movimentos de reforma dos sistemas de saúde, atribui-se à APS um papel central na mudança dos modelos de atenção e das práticas sanitárias, enfatizando, especialmente, que esse nível de organização do sistema é lócus privilegiado para a implementação de ações de promoção da saúde e de articulação intersetorial. (AQUINO et al., 2014)

O eixo "Estudos e Pesquisas em Atenção Primária e Promoção da Saúde” - do Observatório de Análise Política em Saúde (OAPS) toma como seu objeto de investigação e análise as políticas de atenção primária e promoção da saúde implementadas no Brasil nos últimos anos, vale dizer, as ações do governo brasileiro frente às necessidades de saúde da população, que se expressam diretamente em intervenções operadas por sistemas locais de saúde, especialmente pelo trabalho dos serviços de atenção primária. 
Sistematizar a experiência desse grupo de pesquisa é um empreendimento de natureza complexa e exige, de pronto, que se façam algumas ressalvas, seja para não criar no leitor expectativas que não serão atendidas neste texto, seja para esclarecer os pontos de ancoragem em que as autoras se sustentam, ao mesmo tempo limitantes do recorte adotado e das opções de abordagem do tema, que são inúmeras. Ressaltamos, desde já, que nossa reflexão circunscreve-se ao objeto APS, não sendo o propósito deste capítulo aprofundar as questões específicas das políticas de promoção da saúde.

Reconhece-se que há diferentes análises possíveis sobre a(s) política(s) de APS, por inúmeras razões. Em primeiro lugar, porque a compreensão sobre o objeto "atenção primária à saúde" é distinta em função da posição em que o pesquisador se coloca. Há, pois, que iniciar a análise produzindo uma reflexão sobre o próprio objeto, indagando de que atenção primária se fala, que proposições têm sido formuladas ao longo do tempo e em que contextos. Essa preocupação pode ser considerada como recurso metodológico se assumirmos, como Bourdieu (1999), que a primeira ação do pesquisador é pôr em questão seu próprio objeto, compreender a genética dos conceitos, ou seja, sua construção sócio-histórica. Trata-se aqui de fazer aflorar uma dúvida radical, necessária à construção dos objetos científicos, rompendo com " $[. .$.$] representações partilhadas por todos, quer se$ trate de simples lugares comum da existência vulgar, quer se trate de representações oficiais frequentemente inscritas nas instituições”. (BOURDIEU, 1999, p. 34) O primeiro tópico deste texto, portanto, buscará de forma breve, problematizar a APS como objeto de investigação, apresentando algumas concepções adotadas em tempos e conjunturas distintos e alguns recortes possíveis para a sua análise.

Um segundo esclarecimento ao leitor refere-se à dupla dimensão de análise da APS presente nos estudos desenvolvidos pelo eixo "política e prática”. Embora essas duas dimensões necessariamente se articulem, uma vez que qualquer política exige uma tradução operacional enquanto prática, e que a organização de práticas (assistenciais e gerenciais) é também determinada pela política, a análise de tais di- 
mensões é distinta. Isso significa que há recortes teóricos e percursos metodológicos particulares a cada uma dessas dimensões. Esse aspecto será explorado, especialmente, no segundo tópico deste capítulo.

Não restringimos a análise ao escopo da política por duas razões: primeiro, porque a grande maioria dos estudos sobre a atenção primária no Brasil e no mundo circunscreve aspectos específicos das práticas desenvolvidas no âmbito da APS; segundo, porque uma questão central na análise da política de APS é compreender os limites e possibilidades de mudança de modelos de atenção à saúde, o que implica a análise das práticas. A incipiência de uma abordagem científica na análise política da política de APS no Brasil é uma limitação concreta com que temos de lidar neste trabalho.

Ao elencar como política as intervenções implementadas no âmbito do sistema de saúde (senso amplo), não se ignora que a análise do espaço da política deve iluminar, também, as omissões do Estado frente às necessidades de saúde da população, como bem assinala Paim e Teixeira(2006) na sua formulação original do conceito de política de saúde. Nesse sentido, a análise da produção científica desenvolvida neste capítulo pretende destacar elementos importantes da (não) direcionalidade da política de APS na construção de sistemas universais de saúde.

Por fim, concluímos o capítulo apontando alguns desafios colocados hoje para a investigação de APS no país. Esperamos que este capítulo possa contribuir com a reflexão sobre os rumos da saúde no Brasil, especialmente nesse cenário marcado por tantas incertezas.

\section{A APS como objeto de investigação: problemática e recortes possíveis}

Qual o objeto da pesquisa em atenção primária em saúde? Em 2003, um editorial publicado no jornal científico Lancet, "Is primary-care research a lost cause?", com o propósito de discutir os desdobramentos de uma conferência sobre pesquisa em APS da Organização Mundial de Médicos de Família (WONCA EUROPA, 
2002), questionou a pertinência da especificidade desse tema como objeto de pesquisa. O editorialista defendeu a ideia de que, se existisse um foco diferenciado de investigação nessa área, este deveria ser o estudo das relações entre doença e família, dadas as profundas transformações e diversidade de modelos familiares nas sociedades modernas, a proximidade da APS a esses contextos e o impacto dessas mudanças nos processos de adoecimento. (DOUGLAS, 2003) Esse pronunciamento suscitou um grande debate entre os investigadores que reconheciam a importância daquela conferência internacional, que cunhou uma definição europeia de APS e medicina de família (general practice/family medicine), para o delineamento de políticas e estratégias de fortalecimento da capacidade investigativa em APS naquele continente. (DOUGLAS, 2003; HOWE, 2003) Em defesa da relevância da pesquisa em contextos de APS e da sua diferenciação da pesquisa clínica "tradicional", foram levantados argumentos contrários à restrição do foco ao estudo das relações entre família e adoecimento, uma proposta ultrapassada, com referência aos mode230 los de APS da década de 1970, e distante dos desafios atuais para organizar sistemas de saúde baseados na APS. (DELANEY, 2004)

Nessa arena de discussões, que permanece atual, prevalecem não apenas questões epistemológicas e metodológicas, como outros aspectos que contribuem para conformar o campo da pesquisa em saúde, a exemplo das discussões sobre as relações entre a política editorial dos periódicos científicos e as lógicas de financiamento da pesquisa em saúde que seriam determinantes da baixa produção em pesquisa em APS. (DELANEY, 2004) Fortemente subsidiada pela indústria farmacêutica, a pesquisa clínica tem um padrão de fomento muito diverso ao da pesquisa em APS que não só depende quase que exclusivamente de financiamento público, como também tem uma participação minoritária no conjunto dos recursos públicos destinados a esse fim. Mesmo em países com APS forte, como é o caso da Austrália, Holanda, Nova Zelândia e no Reino Unido, o percentual do financiamento da pesquisa na área oscilava em torno de $5 \%$ no início dos anos 2000. (GROL; JONES, 2000) 
Entendendo que o foco da pesquisa é a própria APS, suas práticas e modelos de organização, vários pesquisadores defendem a necessidade de desenvolvimento de modelos conceituais e metodologias em APS para produção de evidências da efetividade e custo-efetividade dos cuidados primários na resolução de problemas de saúde, frente a outros modelos de organização dos sistemas de saúde. (MACINKO et al., 2004; NEDEL et al., 2011; VIACAVA et al., 2004)

Além disso, o conhecimento obtido pelas pesquisas produzidas por especialistas e em contextos hospitalares tem, muitas vezes, pouca aplicabilidade no âmbito da atenção primária à saúde. As condições e problemas de saúde manejados na APS são de frequência e natureza diversas daquelas que são comuns aos especialistas, assim como é diferenciado o cuidado em saúde no âmbito comunitário, onde se desenvolvem as ações de APS, intervenções complexas, que buscam abarcar não apenas o cuidado com os doentes, mas a prevenção de riscos e agravos e a promoção da saúde. (STARFIELD, 2002)

Finalmente, são necessárias investigações que possam subsidiar a reorganização e avaliação desse nível de atenção e das suas inter-relações com os demais níveis do sistema de saúde, com outros setores governamentais fora do setor saúde, com organismos não governamentais e organizações comunitárias.

A produção científica nesse campo deve contemplar, por um lado, modelos teórico-lógicos que explicitem um conjunto de princípios, dimensões e atributos com vistas à construção e operacionalização de conceitos de APS que possam ter aplicabilidade universal; e por outro lado, abordagens metodológicas que permitam apreender as formas concretas e diversas de organização da APS nos diferentes contextos, dado que sua implementação é contexto-dependente. (MEDINA; HARTZ, 2009)

Em que pese o crescimento da produção na área nos últimos 20 anos, podemos dizer que há um aparente paradoxo entre a produção de diversos documentos de posição de organismos internacionais, a exemplo da World Health Organization (WHO) e Organização Pan-americana de Saúde (OPAS), na defesa de reforma dos sistemas 
nacionais de saúde para sistemas centrados em APS, e o não desenvolvimento equivalente da capacidade de pesquisa sobre o tema para embasar e subsidiar as reformas propostas. Assim, embora exista um consenso internacional sobre a efetividade de sistemas de saúde orientados pela APS, isso contrasta com a falta de prioridade em pesquisa sobre o tema (HUMMERS-PRADIER et al., 2009; MCAVOY, 2005) e a ausência de centralidade das questões de investigação na problemática dos processos de trabalho e de organização da APS na sua relação com o sistema de saúde.

Para a construção do objeto APS, se tomarmos como ponto de partida as definições disponíveis em documentos normativos, como a Política Nacional de Atenção Básica (PNAB) (BRASIL, 2012), o documento de posição da Panamericana de Salud Organización (, 2007), a definição da Wonca Europa (2002) ou de autores clássicos, como Barbara Starfield (1979), concluímos que estamos diante de um objeto multifacetado, com múltiplas dimensões e categorias(Quadro 1), que dificilmente poderiam ser apreendidas em uma única pesquisa, mas, ao contrário, exigem uma diversidade de abordagens teórico-conceituais e metodológicas. Além disso, por ser espaço de desenvolvimento de práticas e implementação de programas ou políticas, muitas pesquisas não investigam a APS enquanto objeto, mas apenas como cenário, fazendo-se necessário distinguir pesquisa "em" de pesquisa "na” APS. 


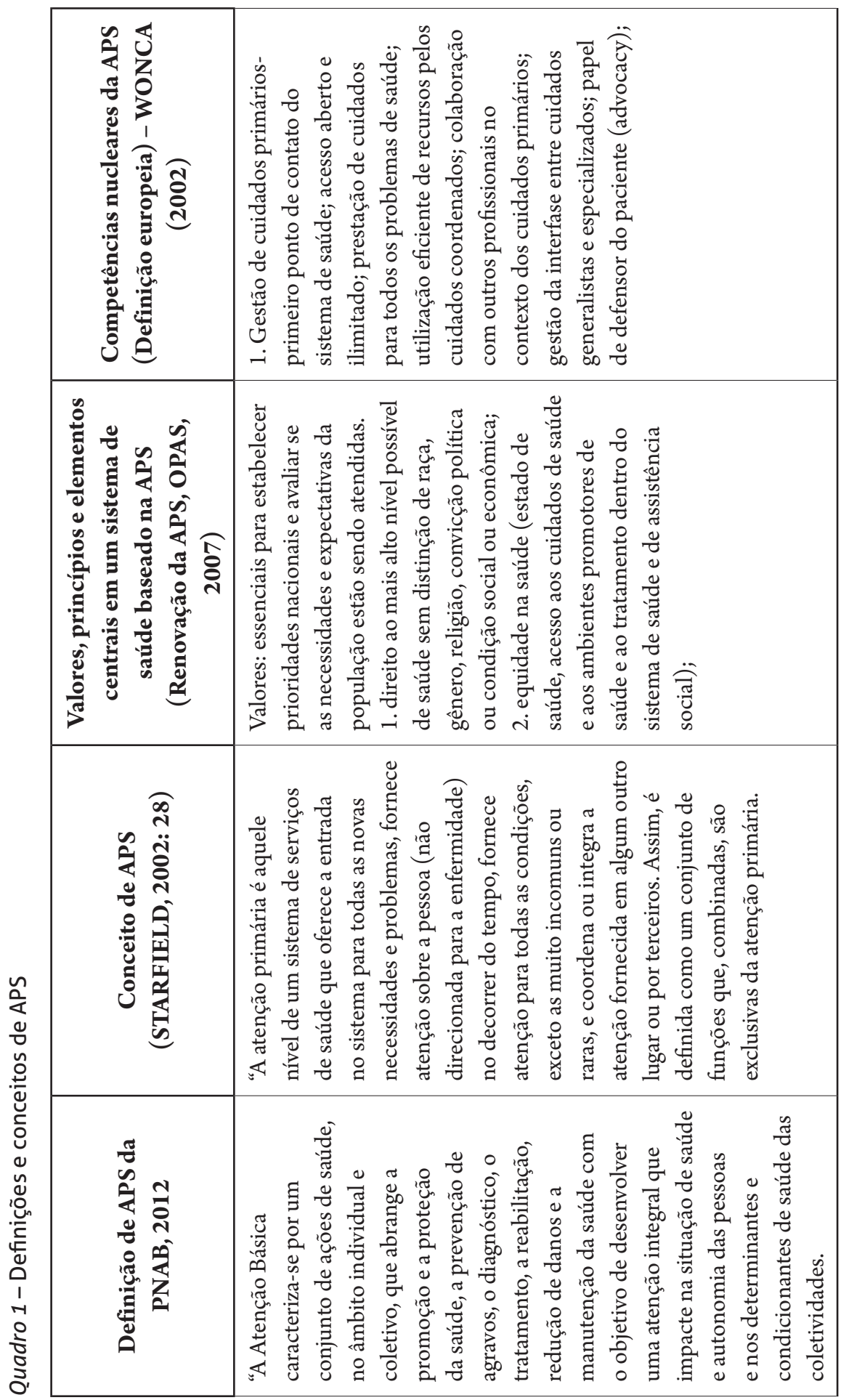




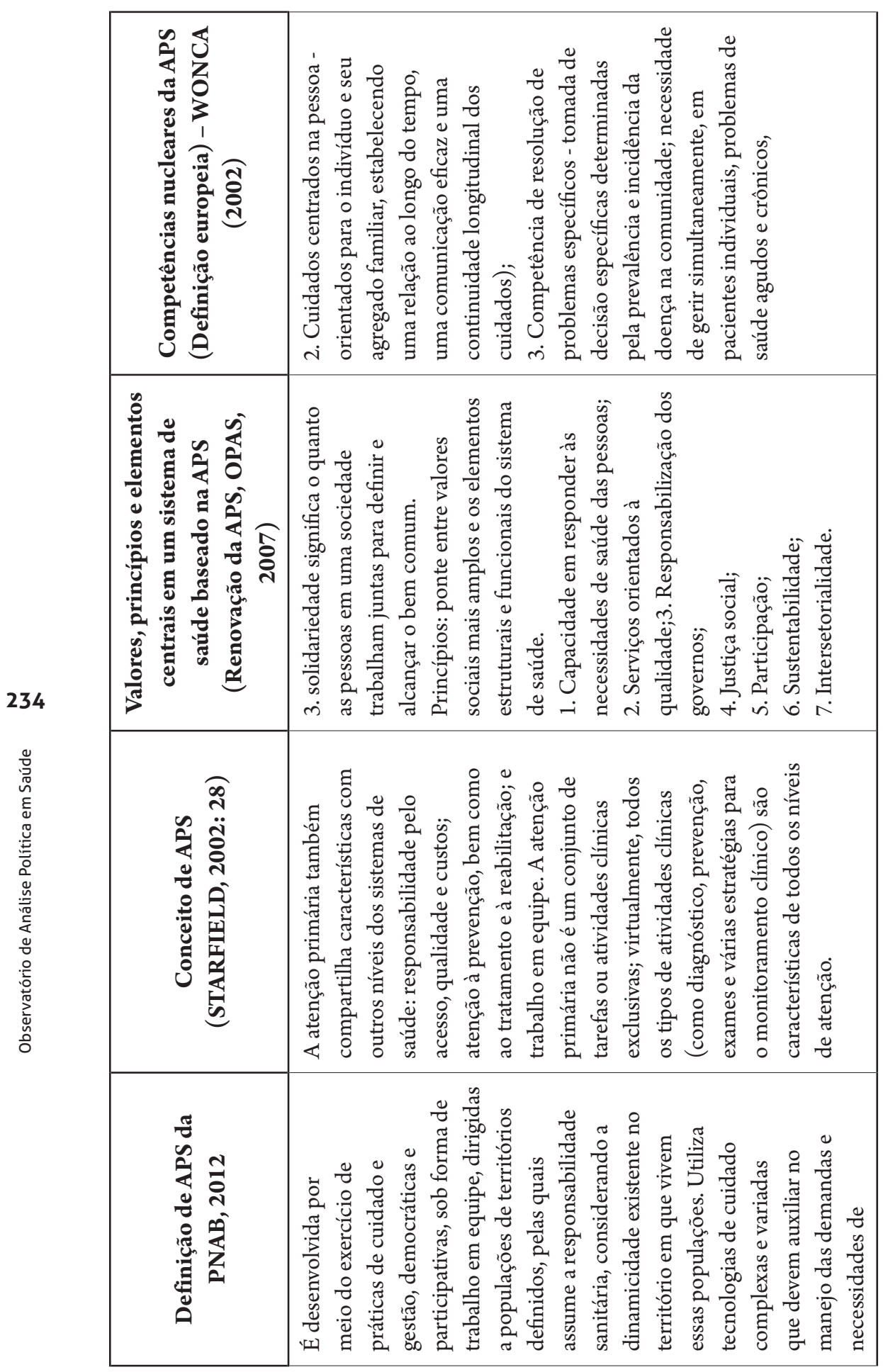




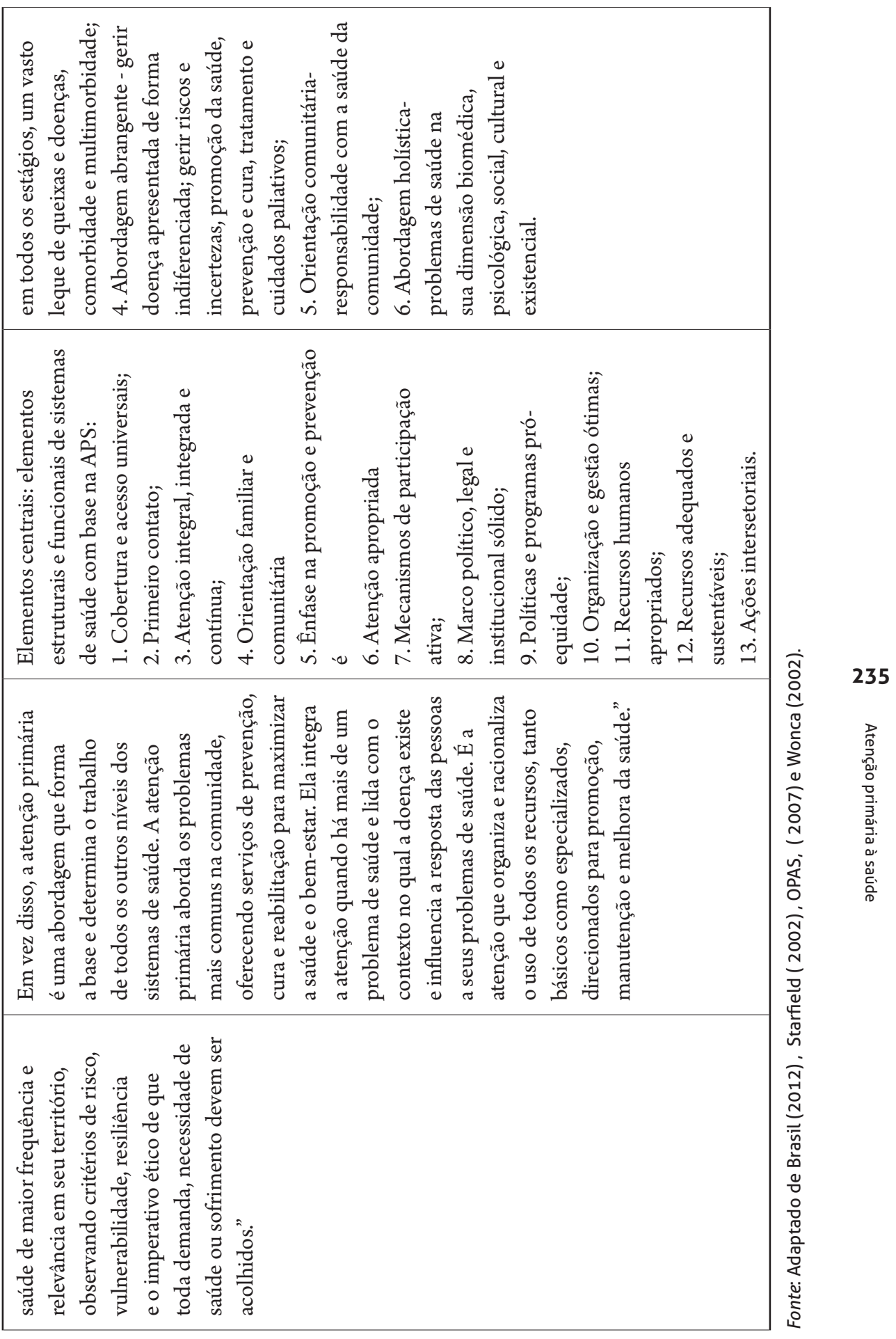


Podemos destacar várias questões-chaves de investigação:

- Problemas de saúde e seus determinantes. A natureza dos problemas de saúde no contexto da APS é bastante diversa da natureza dos problemas manejados nos demais níveis do sistema de saúde. Primeiro, porque para desenvolver ações de promoção da saúde e prevenção de doenças, faz-se necessário ampliar o olhar e o elenco de questóes e problemas, para além das doenças na sua expressão individual. Segundo, porque mesmo sendo doenças ou agravos, estes se apresentam em contextos de baixa incidência e prevalência, o que coloca questóes específicas que dificultam a sua identificação, relacionados a duração e severidade das doenças. Terceiro, são diversos os fatores que influenciam a decisão do usuário em consultar e não consultar o serviço e, na maioria das vezes, os problemas de saúde que levam os usuários a buscar os serviços de APS, ao invés de doenças bem definidas, são sintomas indiferenciados, multifatoriais em origem, diversos em espectro, frequentemente de curta duração e muitos de causa desconhecida. Assim, podem ser destacadas algumas questóes acerca dos padróes e significado clínico do adoecimento, que são específicas dos contextos de APS. (STARFIELD, 2002)

+ Concepções e modelos de APS. Diversas são as características e dimensões centrais da APS que demandam investigações teórico-conceituais e estudos avaliativos. Como ordenadora do sistema de saúde, a APS deve constituir-se no primeiro contato dos usuários com os serviços, na maioria das condições e problemas de saúde, garantindo acesso universal, e oferecer e coordenar a atenção integral, integrada e continuada a indivíduos, famílias em seus territórios de atuação. Além disso, para romper com modelos de atenção fragmentados, preconiza-se a orientação familiar e comunitária, a ênfase na promoção da saúde e prevenção de agravos, o desenvolvimento de ações intersetoriais e a 
promoção de mecanismos de participação ativa. (AQUINO et al., 2014; RASELLA et al., 2013, 2014)

- Práticas e processos de trabalho das equipes multiprofissionais de APS. A necessidade de abarcar intervenções de promoção da saúde, prevenção e cuidado exige competências específicas que permitam que os profissionais lidem com a incerteza e complexidade desses problemas, estabeleçam relaçôes de cooperação entre si, priorizando o trabalho multiprofissional, e desenvolvam relaçôes de corresponsabilidade, que favoreçam a autonomia dos usuários. Destaca-se, ainda, que o manejo de sintomas indiferenciados apresenta questões específicas do âmbito da APS: o tratamento, muitas vezes, independe do diagnóstico, estando centrado nos sintomas e queixas dos usuários; é preciso estabelecer o valor preditivo dos sintomas de alta frequência na população para identificação de doenças graves de baixa incidência - como dor de cabeça/tumor de cérebro; é preciso identificar condições onde intervenções precoces podem ser benéficas sem resultar em "medicalização" excessiva; e, finalmente, existem condições frequentes cujo conhecimento acumulado, através de estudos em serviços especializados e hospitalares, tem pouco aplicabilidade em contexto de APS (epidemiologia da dor crônica baseado em casos graves que representam um percentual pequeno). Assim, são colocadas novas e diversas questóes de pesquisa, que possam abarcar essas dimensões sobre o cuidado em saúde. (CARVALHO et al., 2015; PEDUZZI, 2003; SOUZA, 2015)

- Modelos de gestão da APS.As questões de investigação nessa área referem-se desde o marco político, legal e institucional que rege os sistemas de saúde, as formas de organização e gestão dos serviços, até os mecanismos que promovem a incorporação de pessoal e tecnologias, bem como a formação de profissionais. (MACINKO et al., 2004; SPEDO; TANAKA; PINTO, 2009) 
No Brasil, grande parte das investigações desenvolvidas na última década centrou atenção na Estratégia Saúde da Família (ESF), eleita como política de reorganização da APS no país. Assim, a partir dos anos 2000, tem-se observado o aumento do número de estudos de caso por todo o país, estudos de abrangência nacional com a utilização de dados secundários e, mais recentemente, grandes inquéritos com centralidade nessa política.

Estudos de caso têm evidenciado inovações organizacionais da ESF em aspectos como abordagem territorial, trabalho em equipes multiprofissionais e articulação de ações preventivas, de promoção e cuidado em saúde, mas dificuldades relativas à participação social, e implantação da APS em zonas rurais (MEDINA; HARTZ, 2009; NUNES, 2011), bem como incipiência na realização ações de planejamento e vigilância da saúde. (SANTANA; AQUINO; MEDINA 2012; VILASBÔAS; PAIM, 2008)

Estudos comparativos têm sido bastante utilizados para investigar diferenças entre a ESF e o modelo tradicional de APS centrado em Unidades Básicas de Saúde (UBS) e alguns resultados apontam para melhor desempenho da ESF em ações programáticas (TOMASI et al., 2015), cuidado integral, visitas domiciliares e relação com a comunidade, principalmente em regiões mais pobres e com populações mais vulneráveis. (FACCHINI et al., 2006; PICCINI et al., 2006, TOMASI et al., 2011) Recente inquérito nacional sobre as práticas dos agentes comunitários de saúde, conduzido por grupos de pesquisa do OAPS, demonstrou consolidação de ações essenciais de saúde da mulher e da criança, embora inovações nas práticas de promoção e de vigilância tenham sido incipientes. (NUNES et al., 2015)

Importantes estudos de abrangência nacional desenvolvidos com dados secundários, a partir dos sistemas de informação em saúde, têm demonstrado impacto da ESF na mortalidade infantil e de menores de cincoanos (AQUINO; OLIVEIRA; BARRETO, 2008; MACINKO; ALMEIDA, 2006; MACINKO et al., 2007), destacando-se, também, a redução da mortalidade por diarreia e pneumonia (RASELLA; AQUINO; BARRETO, 2010) e redução das hospita- 
lizações por condições sensíveis à atenção primária. (DOURADO et al., 2011; MACIEL et al., 2014; PEREIRA SILVA; NETO, 2014; RASELLA et al., 2013; RODRIGUES-BASTOS et al., 2014; ROSANO et al., 2012)

No âmbito do OAPS de, algumas investigações se encontram em curso no eixo "Estudos em Atenção Primária e Promoção da Saúde”, sendo que algumas delas já foram concluídas. A seguir são apresentadas questões gerais de investigação sobre as quais o grupo tem se debruçado:

+ Quais são os modelos de APS adotados no país?

- As políticas de APS têm favorecido um modelo de atenção que prioriza a promoção da saúde e favorece a integralidade do cuidado?

+ A APS contribui para promover a equidade em saúde?

- O processo de implementação do Sistema Único de Saúde (SUS) aponta para o fortalecimento e centralidade da APS na organização do sistema de saúde?

- Que inovações organizacionais tem sido implementadas no âmbito da APS?

- A APS tem contribuído para promover a saúde na esfera individual e nas coletividades humanas?

- Qual o desempenho da APS no cumprimento de suas funções essenciais?

No Quadro 2, estão sistematizados os estudos concluídos e em andamento por referência a essas questões gerais. 


\begin{tabular}{|c|c|c|c|c|}
\hline 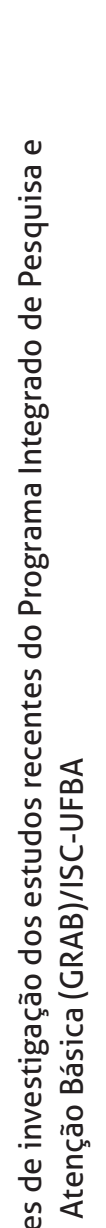 & & 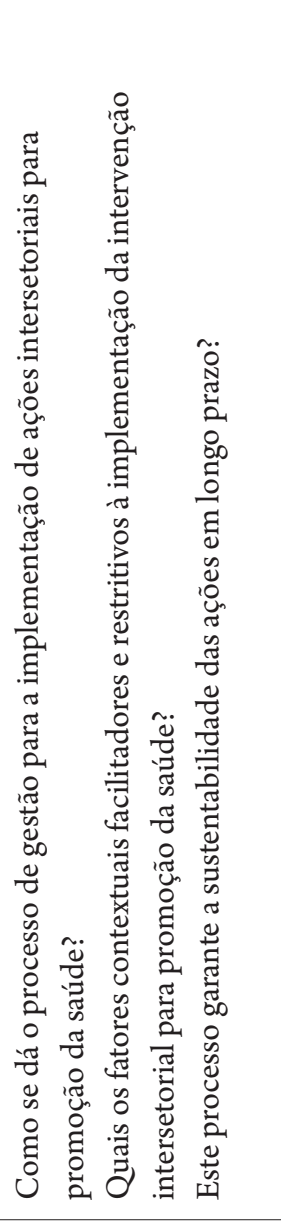 & 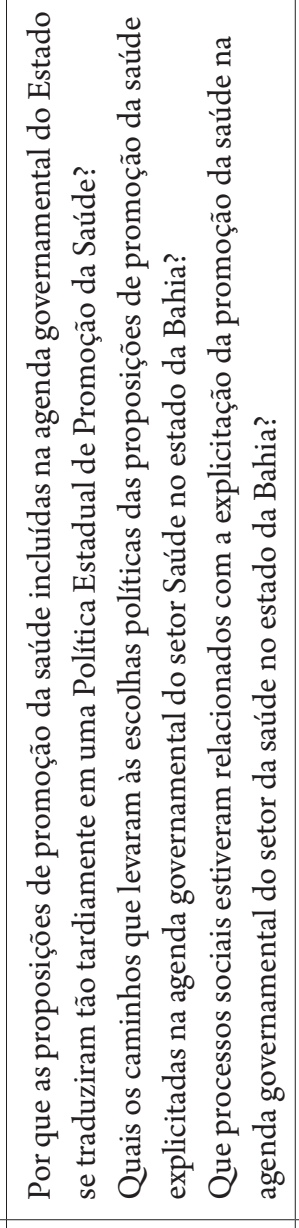 & 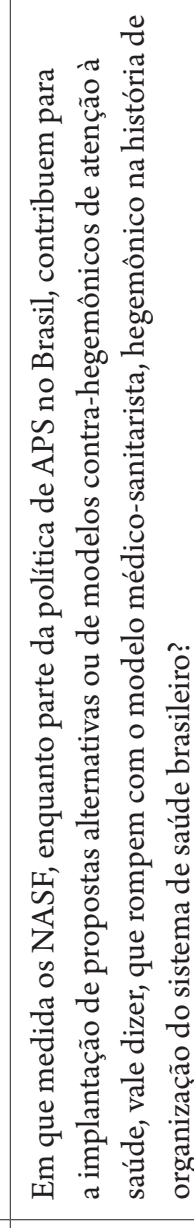 \\
\hline 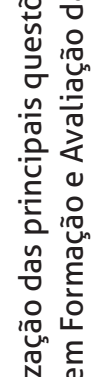 & 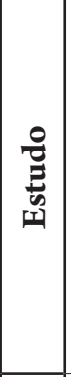 & 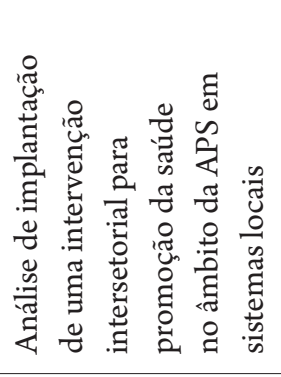 & 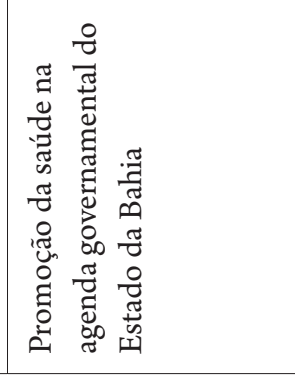 & 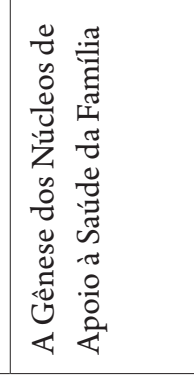 \\
\hline 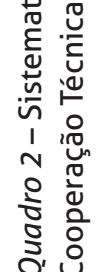 & 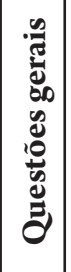 & \multicolumn{3}{|c|}{ 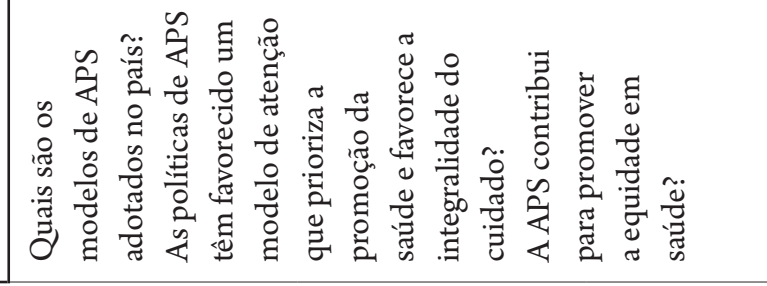 } \\
\hline
\end{tabular}




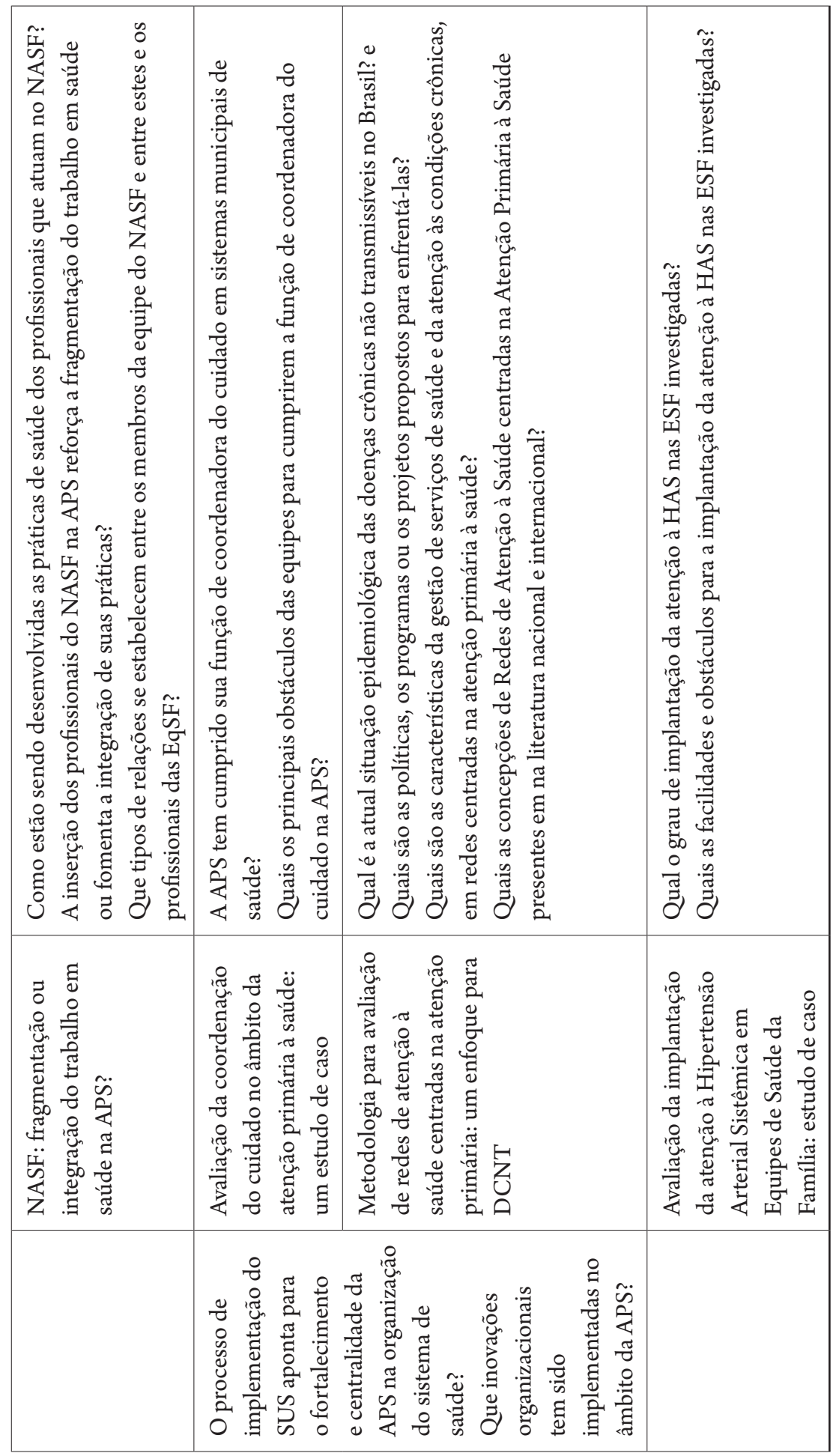

241

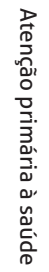




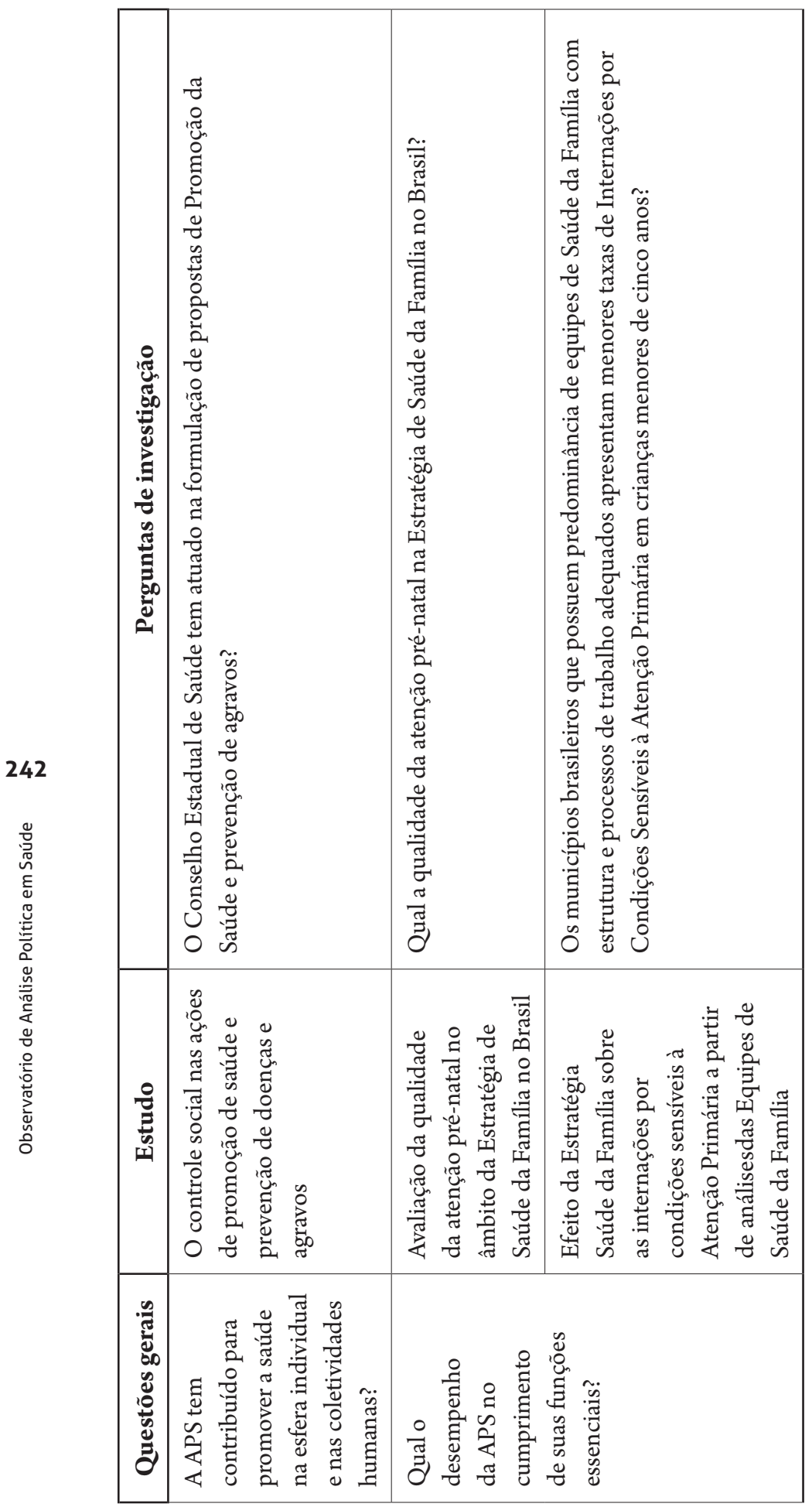

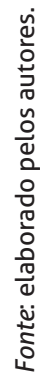




\section{Teorias e métodos na apreensão do objeto APS}

A APS, enquanto objeto de investigação, tem sido apropriada, pelo menos, em duas perspectivas analíticas: como prática ou como política. Em qualquer uma das perspectivas assinaladas, é possível abordá-las quanto ao seu "processo" ou quanto aos seus "resultados" ou efeitos. A experiência do nosso grupo de pesquisa tem sido a de realizar estudos que tratam de práticas de saúde na APS, de efetividade da política sobre determinados problemas de saúde da população e, mais recentemente, projetos de pesquisa que abordam a sociogênese da política de APS no Brasil, a formulação e implementação de políticas intersetoriais de promoção da saúde.

As duas perspectivas analíticas mencionadas, prática e política, têm se sustentado em referenciais de tradição sociológica (Marx, Bourdieu, Latour). No caso particular da produção científica latino -americana em Saúde Coletiva, destaca-se o uso das contribuições de Mendes-Gonçalves e Mário Testa, especialmente no que tange à apreensão de práticas de APS, tanto na dimensão técnica, propriamente dita, quanto na dimensão gerencial. Quanto à análise sócio -histórica das políticas de APS, é importante mencionar o trabalho de Pinell (2011), ancorado na sociologia bourdieusiana.

Quanto às práticas de APS, nos últimos 10 anos, destacam-se estudos (em sua maioria, dissertações de mestrado e teses de doutorado) sobreos agentes, suas relações sociais e técnicas, posições e disposições no espaço social (MEDINA, 2006; NUNES, 2011; SILVA, 2004); meios de trabalho empregados, atividades realizadas e racionalidades tecnológicas subjacentes (COSTA, 2009; SILVA, 2014); as relações entre o contexto e a implementação das práticas de APS em nível local. (MEDINA; HARTZ, 2009; VILASBÔAS; PAIM, 2008)

Parte desses estudos indicam que as escolhas teóricas dos autores partem do pressuposto que toda prática de saúde é histórica e socialmente determinada, e possui dimensão política para além de sua tecnicalidade. Essa perspectiva inspira-se nos estudos seminais 
sobre práticas de saúde da autoria de Cecília Donnângelo, continuados pelos pesquisadores do Departamento de Medicina Preventiva da Universidade de São Paulo (USP) (DONNANGELO, 1975, 1976; MENDES-GONÇALVES, 1992; SCHRAIBER, NEMES, MENDES-GONÇALVES, 2000; SCHRAIBER et al., 1999), de clara filiação marxista.

A produção de Mendes-Gonçalves sobre o processo de trabalho em saúde tem sido bastante utilizada nos estudos sobre práticas do Programa Saúde da Família (PSF). (COSTA, 2009; SILVA, 2004, 2014) Tal perspectiva teórica tem permitido um certo adensamento analítico em estudos exploratórios nos quais é possível caracterizar os objetos, meios de trabalho, finalidades e agentes das práticas investigadas e problematizar os limites do PSF quanto a possíveis mudanças na organização tecnológica do trabalho em APS.

Outro recorte proposto é o que permite investigar as práticas de gestão na APS. Nesse caso em particular, o Postulado de Coerência, proposição de autoria de Mario Testa (2004), foi utilizado em um 244 estudo sobre práticas de planejamento relacionadas à organização da atenção básica no âmbito municipal. Segundo o Postulado de Coerência, os propósitos de uma instituição, os métodos que utiliza para alcançá-los e a organização que assume devem ser coerentes. Há relações de determinação e condicionamento entre os três elementos do postulado, que, por sua vez, seriam sobre determinados pela história, pelo papel do Estado e pela teoria. A operacionalização das categorias analíticas do Postulado, em variáveis que compuseram a produção e análise dos dados empíricos, permitiu problematizar as relações interfederativas e ao interior da administração municipal que facilitaram ou restringiram a organização da APS no caso estudado. (VILASBÔAS; PAIM, 2008)

As investigações sobre efeitos do PSF sobre determinados problemas de saúde da população, a exemplo da mortalidade infantil, apresentam "sofisticação" metodológica e produção criativa de alternativas analíticas na realização de estudos ecológicos, com uso de dados secundários de sistemas oficiais de informação em saúde. 
(AQUINO; OLIVEIRA; BARRETO, 2008; RASELLA; AQUINO; BARRETO, 2010)

Estudos que buscaram interpretar as práticas de APS em função da posição e disposições dos agentes, a saber, profissionais de saúde atuantes em equipes de PSF e em coordenações municipais de atenção básica, fizeram-no a partir da sociologia reflexiva de Pierre Bourdieu. (MEDINA, 2006; NUNES, 2011) Esse referencial apresenta um conjunto de conceitos fundamentais - entre eles, habitus, campo, capital - empregados em estudos de diversas áreas, inclusive da saúde, com o intuito de entender os significados e conteúdo das práticas, em espaços sociais de saberes e disputas.

Bourdieu (2002) vê o espaço social como um campo de lutas onde os agentes (indivíduos e grupos) elaboram estratégias que permitem manter ou melhorar sua posição social. Essas estratégias estão relacionadas com os diferentes tipos de capital (simbólico, social, intelectual, cultural, econômico, político, militante e burocrático) (BOURDIEU, 1996), sendo importante compreender o significado de cada um dos capitais. O poder é uma resultante dessas diversas espécies de capital que se expressa na relação entre os agentes.

O referencial teórico de Bourdieu tem iluminado o estudo da gênese de políticas no campo da saúde. Para esse autor, a "amnésia da gênese", com o esquecimento das possibilidades que não se concretizaram, uma vez que foram derrotadas no curso das lutas políticas entre os agentes de um campo, precisa ser tomada como objeto de investigação e é um recurso metodológico importante no estudo de qualquer espaço social. (BOURDIEU, 2012)

Os estudos de Patrice Pinell (2011) sobre as políticas de aids, controle de drogas, e medicalização da falência escolar na França, nos séculos XIX e início do século XX, foram inovadores na aplicação da abordagem sócio-histórica às políticas de saúde e sustentaram a criação de uma linha de análise sócio histórica no Instituto de Saúde Coletiva (ISC), com estudos pioneiros como o de Barros (2013), que investigou a emergência do Programa de Incentivo Fiscal à Alimentação do Trabalhador, e o de Souza (2013), que analisou a 
gênese e consolidação da política nacional de controle da aids no Brasil. Essa é uma abordagem promissora, pelo seu potencial explicativo da determinação da gênese e consolidação do campo da APS, e vem muito recentemente, sendo adotada em alguns estudos.

Raros estudos no Brasil têm adotado a teoria do ator-rede na análise de práticas e políticas de atenção primária. No eixo APS, apenas um estudo adotou como referencial a teoria do ator-rede na análise de sustentabilidade do PSF em um município baiano. (OLIVEIRA, 2014) A utilização da teoria do ator-rede na análise da implementação do PSF em um município baiano trouxe como contribuição a realização de uma etnografia do Programa com detalhamento circunstanciado do seu processo de implementação, da dinâmica da intrincada rede de relações dos atores, e a identificação de fatores estratégicos que favoreceram a sustentabilidade do Programa ao longo do tempo. A nosso ver, a combinação de ferramentas desenvolvidas pela utilização dessa abordagem tem um potencial descritivo importante e pode ser combinada com referenciais mais robustos 246 para a compreensão de processos, especialmente na gestão de programas e intervenções no âmbito da APS.

A pouca utilização desse referencial na análise das práticas e políticas de APS contrasta com uma produção relativamente expressiva dessa abordagem em estudos brasileiros sobre promoção da saúde, vide, por exemplo, duas publicações em formato de livro que sistematizaram a utilização dessa teoria em pesquisas latino-americanas. (HARTZ; POTVIN; BODSTEIN, 2014; POTVIN; MCQUEEN, 2008) Registre-se que, em ambos os casos, houve parceria com a Universidade de Montreal, cujos pesquisadores são expoentes internacionais de linhas de investigação em promoção da saúde, vinculados a grupos de pesquisa de universidades brasileiras.

A teoria do ator-rede ou teoria da tradução é uma abordagem sociológica - sociologia das associações - desenvolvida, principalmente, por Bruno Latour (1994, 2006) e Michel Callon (1986, 2006) para a análise da dinâmica social, que enfatiza a conformação de redes sociotécnicas estabelecidas entre atores humanos e não 
humanos, portadores de interesses, e onde se constroem relações cuja intermediação exige um papel de tradução, desempenhado por porta-vozes das entidades ou agrupamentos (conjunto de atores). Latour (2006) critica a natureza social do social, rechaçando o determinismo como externalidade e o sujeito como agente (voluntarismo). Latour é reticente em relação à noção de grupo social. Para o autor, pertencer a um grupo é estar mobilizado por laços incertos, frágeis, controversos e constantemente flutuantes. Ao compreender que a ação [social] é, antes de tudo, surpresa, "alvo em movimento", sem causas ou consequências previsíveis, as abordagens que se baseiam em Latour tendem a ir de encontro a toda a tradição de análise política da Saúde Coletiva brasileira (pelo menos, da subárea de política, planejamento e gestão) e da tradição de pesquisa de grande parcela dos estudiosos da área.

Em que pese, entretanto, a existência de certa fragilidade teórica na explicação daquilo que determina uma ação social ou seu efeito, ao menos para quem se afilia a uma tradição não positivista de produção do conhecimento científico, há que considerar as contribuições dessa teoria no desenvolvimento de instrumentos que permitem descrever processos, especialmente na esfera da micropolítica, no espaço das relações interpessoais e da dinâmica do cotidiano, âmbitos pouco capturados por abordagens estruturalistas e, talvez, seja útil na compreensão dos obstáculos observados nas relações intersetoriais, cujas interfaces parecem exigir um verdadeiro trabalho de tradução de códigos de linguagem na definição de um possível interesse comum.

Ainda que seja uma apreciação preliminar, vale a pena problematizar algumas questões acerca do uso dos referenciais aqui apresentados. A produção dos pesquisadores indica um esforço de superar o senso-comum ou o senso douto acerca das dimensões assinaladas. Boa parte dos estudos apresentam pressupostos ou hipóteses derivados da construção teórica dos objetos de investigação que, por sua vez, sustentam as opções metodológicas na produção dos dados empíricos. Trata-se de um esforço analítico de des-naturalizar os 
processos de produção/desenvolvimento/realização de práticas ou de gênese/formulação/implementação de políticas de APS, isto é, de "objetivar" tais objetos.

A análise das posições e disposições dos agentes indicam hipóteses explicativas acerca das dificuldades na mudança da organização das práticas, em direção do ideal da integralidade, por exemplo. Ao mesmo tempo, o tratamento teórico dado ao contexto de implementação das práticas apresenta pistas para a interpretação das relações entre a micro e a macro política, ou entre sujeito e estrutura, indicando relações de condicionamento entre os agentes das práticas e o contexto político-institucional no qual as organizações se inserem, que podem restringir ou facilitar a realização de práticas de APS na perspectiva da Reforma Sanitária.

A adoção dos referenciais explicitados indica a filiação dos pesquisadores à Saúde Coletiva brasileira que, em parte, é espaço de produção de conhecimento científico objetivado e politicamente engajado na defesa do direito à saúde da população a ser assegura248 do pelo Estado. Esse posicionamento aumenta o compromisso dos pesquisadores com a qualidade acadêmica da investigação que, por ser a favor do interesse público, impõe a explicitação de suas opções teóricas e caminhos metodológicos.

\section{Cenário atual e sistematização de resultados da pesquisa em APS no Brasil}

A reforma do setor saúde que deu origem ao SUS e à atual forma de organização da APS no país ocorreu pari passu com o processo de democratização da sociedade brasileira e envolveu a participação de indivíduos e profissionais, de movimentos e organizações sociais. No momento atual, várias conquistas do movimento da reforma sanitária estão ameaçadas e o retrocesso a situações anteriores à década de 1990 é um horizonte que não pode ser descartado. A crise econômica e política brasileira, agudizada em 2016, com reforço às medidas de austeridade, restrição de recursos de financiamento global da 
saúde, resultado das pressões de lobistas e do setor privado, expressas em emendas constitucionais que foram e estão sendo objeto de votação do Congresso (como o orçamento impositivo e a Emenda Constitucional que prevê a expansão dos planos privados de saúde de baixa qualidade para todos os trabalhadores), a crise institucional no Executivo com substituição de gestores que representavam parcelas de movimentos sociais (como a coordenação de saúde mental e saúde bucal do Ministério da Saúde) e vários outros fatos recentes são expressão de mudanças que afetam profundamente os pilares sobre os quais o SUS foi construído.

O maior desafio, nesse contexto, é político e diz respeito à capacidade de mobilização da sociedade em prol da garantia do direito à saúde, articulado à defesa mais global da democracia e dos direitos humanos na sociedade brasileira. Reconhecer isso não é secundarizar as lutas específicas nem negar a importância de uma análise cuidadosa dos limites, impasses e possibilidades que conformaram o processo político de implementação das políticas de atenção primária à saúde no Brasil, na direção da construção de um sistema universal de saúde.

Aqui já se assume com menos reticência o vocábulo no plural políticas -, pois a trajetória da implementação da atenção primária à saúde no Brasil revela, por um lado, uma dinâmica de movimentos que traduz, possivelmente, visões diferentes da gestão no nível nacional em diferentes conjunturas históricas, diferenças da força de grupos de pressão que assumiram posição de destaque no cenário nacional e, por outro, um conjunto de iniciativas de diversas naturezas - financiamento, formação de pessoal, mecanismos de indução de preenchimento de vazios assistenciais, entre outros - que foram conformando e configurando os modelos de prestação de cuidados em contextos municipais marcados pela pluralidade e desigualdade.

Neste capítulo, não foi possível aprofundar tais questões. Para nós, empreender uma análise de base científica do processo político do desenvolvimento das políticas de APS em seus espaços (geral e singular), caracterizando os atores e interesses em jogo e as relações entre estes e a dinâmica do processo político mais global, é, ainda, 
uma tarefa a ser realizada, hoje, formulada como projeto prioritário de pesquisa desse eixo.

Do ponto de vista do desenho, pode-se afirmar que a ESF desenvolveu-se, nos últimos 20 anos, em direção a propostas de atenção primária à saúde integral e que, no discurso oficial, essa política tem sido apresentada como prioritária para a organização da APS e para a reorientação do modelo de atenção à saúde nas três esferas administrativas do SUS. (BRASIL, 1997a, 1997b, 2006, 2012)A distância entre discurso oficial, projeto expresso no texto das políticas, e a operacionalização de práticas organizacionais e assistenciais no âmbito dos serviços de APS e de sua articulação com o sistema de saúde são imensas. (MEDINA et al., 2014)

Os estudos em APS nos permitem realizar um balanço, sistematizados a seguir.

A expansão da cobertura e da utilização de serviços de APS no Brasil é fato incontestável. Ainda assim, permanecem problemas de acessibilidade, equidade e resolubilidade no cuidado prestado. 250 (ALVES et al., 2014; CASOTTI et al., 2014; FAUSTO et al., 2014; MENDES et al., 2014)

A APS tem demonstrado efetividade para lidar com um conjunto de problemas de saúde passíveis de resolução nesse âmbito, abarcando tanto condições agudas quanto crônicas. Algumas dessas conquistas são surpreendentes e mostram-se sinérgicas com outras políticas públicas, reforçando importância da articulação intersetorial nas intervenções mais globais para a conquista de melhor nível de saúde dos grupos populacionais. Entretanto, inúmeros problemas relacionados a escopo e qualidade da atenção permanecem, incluindo desde insuficiências na implementação de ações de prevenção e promoção da saúde até limitações na oferta e qualidade do cuidado prestado. Isso sem falar nas dificuldades relacionadas à coordenação do cuidado e articulação entre APS e demais serviços da rede, limitando a acessibilidade a outros níveis do sistema e, por conseguinte, a continuidade do cuidado. (ALMEIDA et al., 2010; ALVES et al., 2014; 
CASOTTI et al., 2014; FAUSTO et al., 2014; FONSECA et al., 2014; MENDES et al., 2014; MEDINA et al., 2014; RODRIGUES, 2014)

Se por um lado, tais limites, em parte, exigem respostas de natureza política, financeira, administrativa ou gerencial, por outro, na perspectiva da pesquisa, algumas questões não estão suficientemente respondidas.

No que diz respeito à promoção da saúde e intersetorialidade, o discurso retórico não tem instrumentalizado as equipes na condução de processos reais de articulação, devendo a pesquisa contribuir com o desenvolvimento e avaliação de estratégias que favoreçam a operacionalização de tais diretrizes. (AZEVEDO et al., 2012; ANDRADE, 2015; DIAS, 2014; MORETTI, 2010; RANTALA, 2014; TEIXEIRA; PAIM, 2000) Ressalva-se, entretanto, que ações sobre os determinantes desenvolvidas no âmbito da APS não podem ser levadas a cabo sem uma orquestração mais ampla que envolve políticas econômicas e sociais mais gerais, por exemplo, no âmbito da produção e distribuição de alimentos, de ocupação do espaço urbano, de enfrentamento da violência, entre outras.

251

Quanto às práticas de cuidado, aqui, como em diversos países do mundo, faltam ferramentas que auxiliem os profissionais nas decisões clínicas; alguns protocolos têm sido criticados pelo seu uso excessivamente normativo ou descontextualizado e pouco se tem estudado sobre as modificações que o uso de protocolos impõe na organização das práticas de cuidado. Assim cabe, também, à pesquisa, apoiar o desenvolvimento e avaliar a utilização de instrumentos inovadores pautados em evidências científicas, e seus efeitos, tanto na melhoria do cuidado quanto na organização dos processos de trabalho dos profissionais de saúde. (ALELUIA, 2014; RODRIGUES, 2014)

A pesquisa tem revelado a imensa heterogeneidade no país quanto à organização das práticas de cuidado e aos modelos de atenção, o que, de certa forma, é esperado dada a diversidade de contextos. Mas, também esses estudos têm demonstrado distanciamento dos "modelos observados" com os "modelos idealizados", mesmo em casos considerados exemplares no que diz respeito à implementação 
do SUS. (MEDINA; HARTZ, 2009; SANTOS, 2014; SOUZA, 2015) Isso significa que se mantém como desafio (permanente) da pesquisa a compreensão dos determinantes dos diferentes modelos e do insucesso ou sucesso na implementação das ações, assim como das novas configurações que surgem a partir dos novos arranjos e dos novos atores que entram em cena.

Finalmente, no que concerne à organização dos serviços, especialmente, de redes de atenção à saúde orientadas pela APS, a pesquisa tem revelado os limites nos processos de coordenação do cuidado (ALELUIA, 2014; ALMEIDA et al., 2010) e a necessidade de desenvolver tecnologias e propostas que permitam avaliar o desempenho dos serviços e de sua articulação, a efetividade das ações e as inovações que vão sendo construídas em processos singulares de organização e que, se estudadas, podem ser apropriadas em contextos semelhantes.

\section{Desafios e armadilhas da pesquisa em APS no Brasil}

Finalmente, gostaríamos de assinalar aqui alguns desafios de natureza epidemiológica, metodológica, epistemológica e ética que o trabalho de pesquisa em atenção primária evidenciam.

\section{Desafios conceituais e metodológicos}

Novos desafios epidemiológicos estão colocados com o crescimento das doenças crônicas no mundo, o desenvolvimento de novas ferramentas de cuidado e o avanço tecnológico. Há evidências na literatura de que a prevenção de doenças crônicas na APS exige a combinação de estratégias voltadas para a população em geral com a implementação de políticas regulatórias e controle ambiental capazes de contribuir com a redução desigualdades sociais - com abordagens individuais direcionadas para indivíduos com alto risco de doenças. Estas últimas, apesar de incapazes de produzir efeitos amplos em nível populacional, são efetivas para a prevenção de doenças nessa população. 
Os estudos mostram que as políticas globais, voltadas para a população em geral, são mais custo-efetivas e que uma pequena redução no risco global pode prevenir mais casos de doenças que tratar um pequeno número de pessoas com alto risco. Se isso é verdade, por outro lado, a população-alvo dos serviços de atenção primária tradicionalmente tem sido composta por indivíduos doentes ou que apresentam algum tipo de problema expresso em "sintomas". Em poucas experiências internacionais, e aí pode-se mencionar o Brasil como uma das exceções, a população em geral é, de fato, a população-alvo da APS.

Vale lembrar que os determinantes das causas não são os determinantes da incidência das doenças. E que uma intervenção sobre causas não utiliza das mesmas estratégias de uma intervenção sobre a doença.

Assim, seria possível dizer que o compromisso de uma APS efetiva e de qualidade - para além do cuidado primário em saúde - seria o de protagonizar ambas as estratégias de prevenção primária: estratégias que abordem globalmente a população e estratégias voltadas para a população de risco. Com grande ousadia, diríamos que o papel da APS seria o de coordená-las. Essa proposição se afina com um conceito ampliado de saúde e sublinha a necessidade de atuação sobre causas em vários níveis de determinação dos problemas de saúde - causas distais, intermediárias e proximais - e que conformam no Brasil um modelo de atenção denominado de modelo da vigilância da saúde.

$\mathrm{Na}$ experiência brasileira, as tentativas de articulação de atenção individualizada, atendendo às necessidades dos usuários, e políticas públicas mais globais, através de ações intersetoriais, são pouco expressivas e com algumas evidências de sucesso justamente onde se consegue operacionalizar o conceito de território.

A implantação de uma atenção primária territorializada viabiliza as oportunidades de encontro entre os profissionais e a população da área e favorece o estreitamento dos laços e a compreensão do contexto sociocultural e familiar no qual a equipe se insere.

A abordagem da APS, enquanto objeto complexo e multifacetado, traz desafios de natureza metodológica, especialmente relacio- 
nados a desenhos, indicadores e instrumentos de investigação. A defesa de uma perspectiva ampliada de saúde e de modelos de atenção inclusivos e integrais precisa ser acompanhada por formas de investigação e mensuração da realidade capazes de capturar inovações e transformações, o que não é possível com um elenco restrito de indicadores e instrumentos que foram desenvolvidos, principalmente, para descrever e analisar doenças, agravos e intervenções de forma descontextualizada.

A febre por publicação, resultados de sistemas de avaliação e fomento que estimulam a competitividade entre grupos de pesquisa e pesquisadores, tem tido consequências nefastas para a pesquisa com a reiteração daquilo que já se sabe. (CARVALHO; TRAVASSOS; COELI, 2013) É preciso arriscar mais e ter mais criatividade na criação de modelos de mensuração e avaliação que capturem as inovações. Macinko (2011) faz algumas sugestões nessa linha como a inclusão de componentes da APS em estudos de base populacional, a adaptação e utilização de instrumentos de vigilância, tais como

254 Internações por Condições Sensíveis à Atenção Primária (ICSAP), no âmbito da APS, o investimento em inquéritos específicos em atenção primária e o uso de métodos experimentais para testar inovações.

\section{Desafios epistemológicos e éticos}

O espaço social da APS é marcado por disputas de natureza política e ideológica entre atores, cujos interesses se manifestam e se traduzem no campo científico. Isso não é particular a esse espaço social. Compreender quais são essas disputas e interesses e os mecanismos pelos quais elas produzem efeitos no campo científico é imperativo.

Nessa seara, nos parece que uma das questões relevantes é o dilema entre imposição de problemática versus absenteísmo político. Como mencionamos anteriormente neste capítulo, a pesquisa em atenção primária é subfinanciada e grande parte dos recursos destinados a ela provêm de fontes ligadas ao Governo Federal, impondo uma agenda de pesquisa afinada com seus propósitos de implemen- 
tação de políticas. Configura-se, assim, uma "imposição de problemática” (BOURDIEU, 2002) em relação à qual é necessária uma vigilância epistemológica.

Ceder à imposição de problemática é estudar apenas o que se coloca como relevante pelas instituições do Estado e de financiamento da pesquisa. Limitar a agenda de grupos de pesquisa à problemática do governo, especialmente em circunstâncias onde recursos são escassos e a luta pela sobrevivência desses grupos está na ordem do dia, traz consigo grandes riscos e exige vigilância redobrada. Vale a pena ressaltar que temáticas por vezes triviais podem revelar e contribuir muito mais com a produção do conhecimento científico do que problemas tidos como prioritários. Estes, muitas vezes, são problemas de gestão ou da prática cotidiana dos serviços, travestidos de problemas de pesquisa.

Para compreender a sociedade francesa de seu tempo, os mecanismos de reprodução das desigualdades e de dominação, Bourdieu (2007) precisou estudar a arte, a fotografia e o esporte e elaborou uma teoria muito fecunda sobre a ação social. Para dar um exemplo mais próximo à nossa realidade, a tese de Arouca (1975), o dilema preventivista, marco da constituição do campo da Saúde Coletiva brasileira, não surgiu de uma demanda institucional, governamental, mas do incômodo essencial do pesquisador na busca da compreensão de fenômenos contemporâneos. Foi defendida na surdina, quase clandestinamente, sem audiência.

Assim, postulamos que um dos desafios da pesquisa em APS, e mesmo na temática geral de política, planejamento e gestão em saúde, é a garantia do grau de autonomia e distanciamento necessários à produção de um conhecimento relevante, seja recolocando ou promovendo a releitura das questões postas pelo Estado através das instituições e seus atores (gestores e profissionais) e pela sociedade, através dos grupos sociais e suas representações, seja trazendo para o escopo das preocupações de pesquisa questões que, na sua aparência, são desinteressantes na perspectiva de uma solução imediata para os problemas da atualidade. 
Isso não deve significar, entretanto, adotar o absenteísmo político como máxima da prática de pesquisa. $\mathrm{O}$ contraponto do risco da imposição de problemática (BOURDIEU, 2002) é o absenteísmo político, uma forma de alienação intelectual (BURAWOY, 2010), que significa a realização de uma pesquisa asséptica, distanciada e avessa aos problemas da contemporaneidade e de suas soluções; arredia ao compromisso social de produção intelectual relevante para a sociedade e de uma prática política que lhe seja consequente. Uma pesquisa que não quer e não pretende comunicar, que não ousa estabelecer relações de solidariedade com a sociedade, que pensa o "pensar" como atividade nobre e o fazer como atividade espontânea, que não se preocupa em "transformar" nem a sociedade, nem os sujeitos, muito menos a si própria. E por isso não é capaz de trazer uma contribuição relevante ao mundo social que a acolhe a sustenta.

Em se tratando de um espaço de lutas políticas e ideológicas, enfrentar o risco de submissão ao senso comum e ao senso comum douto, ou seja, de sucumbir ao pré-conceito, é também um desafio que se coloca no plano da ética. É necessário ter cuidado para que a filiação a uma escola de pensamento não se transforme em ideologia acadêmica e que a luta (fértil) de ideias não se transforme, exclusivamente, em disputa de prestígio e de espaços de poder no seio das instituições, sejam elas acadêmicas ou de serviços. Essa armadilha é tão nociva à Academia quanto ao SUS, pois tem como resultado a perda do rigor científico e a produção de uma "pesquisa panfletária" que desconhece a própria história da produção de conhecimento em um determinando ponto da história. Nesse ponto, se é possível ser complacente com militantes gestores, usuários e alunos, pegos por esse tipo de armadilha, o pesquisador, além de defender enquanto militante o seu projeto ético-político de sociedade, deve ter, pensamos nós, o compromisso militante de preservar a história dos conceitos, a constituição genética de suas origens, sua aplicação científica e o justo valor de sua contribuição social. 


\section{Referências}

ANDRADE, L. O. M. et al. Social determinants of health, universal health coverage, and sustainable development: case studies from. Latin American countries, [S.I.] v. 385, n. 9975, p. 1343-1351, Apr. 2015.

AQUINO, R.; OLIVEIRA N. F. de; BARRETO M. L. Impact of the family health program on infant mortality in Brazilian municipalities. American Journal of Public Health, New York, v. 99, p. 87-93, 2008.

AQUINO, R. et al. Estratégia saúde da família e o reordenamento do sistema de serviços de saúde. In: PAIM, J. S.; ALMEIDA-FILHO, N. de. (Org.). Saúde coletiva:teoria e prática. 1. ed. Rio de Janeiro: Medbook, 2014. p. 3-695. v. 1.

ALELUIA, I. R. S. Avaliação da coordenação do cuidado no âmbito da atenção primária à saúde: um estudo de caso. 2014. 115 f. Dissertação (Mestrado em Saúde Comunitária) - Instituto de Saúde Coletiva, UFBA. Salvador. 2014.

ALVES, M. G. M. et al. Fatores condicionantes para o acesso às equipes da Estratégia Saúde da Família no Brasil. Saúde em debate, Rio de Janeiro, v. 38, p. 34-51, 2014. Edição especial.

ALMEIDA, P. F. et al. Desafios à coordenação dos cuidados em saúde: estratégias de integração entre níveis assistenciais em grandes centros urbanos. Caderno Saúde Pública, Rio de Janeiro, n. 26, v. 2, p. 286-298, 2010 .

AROUCA, A. S. S. O dilema preventivista: contribuição para a compreensão e crítica da medicina preventiva. 1975. 197 f. Tese(Doutorado de Ciências Médicas) - Faculdade de Ciências Médicas, Universidade Estadual de Campinas, 1975.

AZEVEDO, E.; PELICIONE, M. C. F; WESTPAL, M. F. Práticas intersetoriais nas políticas públicas de promoção de saúde. Revista de Saúde Coletiva, Rio de Janeiro, v. 22, n. 4, p. 1333-1356, 2012.

BARROS S. G. A política nacional de luta contra a aids e o espaço aids no Brasil. 2013. 274 f. Tese (Doutorado em Saúde Pública) - Instituto de Saúde Coletiva, Universidade Federal da Bahia, Salvador, 2013. 
BRASIL. Ministério da Saúde. Política Nacional de Atenção Básica. Brasília, DF: 2012. (Série E. Legislação em Saúde)

BRASIL. Ministério da Saúde. Secretaria de Atenção à Saúde.

Departamento de Atenção Básica. Política nacional de atenção básica Brasília, DF, 2006.

BRASIL. Ministério da Saúde. Norma Operacional Básica do Sistema Único de Saúde/SUS. Brasília, DF, 1997a.

BRASIL. Ministério da Saúde. Saúde da Família: uma estratégia para a reorientação do modelo assistencial. Brasília, DF, 1997b.

BOURDIEU, P. Campo de poder, campo intelectual e habitus de classe. In: BOURDIEU, P. Economia das trocas simbólicas. Rio de Janeiro: perspectiva, 1992. p. 201-220.

BOURDIEU, P. Razões práticas: sobre a teoria da ação. Tradução de Mariza Corrêa. Campinas: Papirus, 1996.

BOURDIEU, P. A distinção: crítica social do julgamento. Porto Alegre: Zouk, 2007.

BOURDIEU, P. O poder simbólico. Rio de Janeiro: Bertrand Brasil, 2002.

BOURDIEU, P. Sur l'État: cours au Collège de France 1989-1992. Paris: Éditions Raisons d'agir Éditions Seuil, 2012.

BOURDIEU, P. A ordem do discurso: aula inaugural no College de France, pronunciada em 2 de dezembro de 1970. 5.e d. São Paulo: Loyola, 1999.

BURAWOY, M. O marxismo encontra Bourdieu. Tradução de Fernando Rogério Jardim. Campinas: Editora da UNICAMP, 2010.

CALLON, M. Éléments pour une sociologie de la traduction. L'année sociologique,[S.1.], n. 36, p. 169-208, 1986.

CALLON, M. Quatre modeles pour decrire la dynamique de la science. In: AKRICH, M; CALLON, M.; LATOUR, B. Sociologie de la traduction: textes fondateurs. Paris: PressesMines, 2006. p. 201-252.

CARVALHO, M. S.; TRAVASSOS, C., COELI, C.M. More ofthesameepidemiology? Caderno Saúde Pública, Rio de Janeiro, v. 29, n. 11, p. 2141-2143, 2013. 
CASOTTI, E. et al. Atenção em Saúde Bucal no Brasil: uma análise a partir da Avaliação Externa do PMAQ-AB. Saúde em debate, Rio de Janeiro, v. 38, p. 140-157, 2014. Edição especial.

CARVALHO, S. C.; MOTA, E.; DOURADO, I.; AQUINO, R.; TELES, C., MEDINA, M. G. Hospitalizations of children due to primary health care sensitive conditions in Pernambuco State, Northeast Brazil. Caderno de Saúde Pública, Rio de Janeiro, v. 31, n. 4, p. 744-754, 2015.

COSTA, J. G. O modo tecnológico da vigilância à saúde e o trabalho das equipes de Saúde da Familia. 2009. 132 f.Dissertação (Mestrado em Saúde Comunitária) - Instituto de Saúde Coletiva, Universidade Federal da Bahia, Salvador, 2009.

DELANEY, B. Primary care research in the postmodern world. Family Practice, Oxford, v. 21, n. 2, p. 123-124, 2004.

DIAS, M. S. A. et al. Intersetorialidade e estratégia saúde da família: tudo ou quase nada a ver? Ciência \& Saúde Coletiva, Rio de Janeiro, v.19, n. 11, p. 4371-4382, 2014.

DONNANGELO M. C.; PEREIRA, L. Saúde e sociedade. São Paulo:

Duas Cidades; 1976.

DONNANGELO, M. C. F. Medicina e sociedade: o médico e seu mercado de trabalho. São Paulo: Pioneira, 1975.

DOUGLAS, J. D. M. Is primary care research a lost cause [lette]? Lancet, London, n. 361, p. 1473-1474, 2003.

DOURADO, I. et al. Trends in primary health care sensitive conditions in Brazil: the role of the Family Health Program (Project ICSAP-Brazil). Medical Care, Philadelphia,v. 49, n. 6, p. 579-584, 2011.

FACCHINI, L. A. et al. Desempenho do PSF no Sul e no Nordeste do Brasil: avaliação institucional e epidemiológica da Atenção Básica à Saúde. Ciência Saúde Coletiva, Rio de Janeiro, v. 11, n. 3, p. 669-681, 2006.

FAUSTO, M. C. R. et al. A posição da Estratégia Saúde da Família na rede de atenção à saúde na perspectiva das equipes e usuários participantes do PMAQ-AB. Rio de Janeiro, v. 38, n. especial, p. 13-33, 2014. 
FONSECA SOBRINHO, D. et al. Compreendendo o apoio matricial e o resultado da certificação de qualidade nas áreas de atenção à criança, mulher, diabetes/hipertensão e saúde mental. Saúde em debate, Rio de Janeiro, v. 38, p. 83-93, 2014. Edição especial.

GROL, R.; JONES, R. Twenty years of implementation research. Family Practice, Oxford, v. 17, p. 32-35, p. 2000.

HARTZ, Z.; POTVIN, L.; BODSTEIN, R. (Org.). Avaliação em promoção da saúde: uma antologia comentada da parceria entre o Brasil e a Cátedra de Abordagens Comunitárias e Iniquidades em Saúde (CACIS), da Universidade de Montreal de 2002 a 2012. Brasília, DF: CONASS, 2014.

HOWE, A. Isprimary care research a lost cause [letter]? Lancet, London, v. 361, p. 1473-1474, 2003.

HUMMERS-PRADIER, E., et al. Research agenda for general practice / family medicine and primary health care in Europe.Maastricht: WONCA Europe, 2009. LATOUR, B. Jamais fomos modernos. Rio de Janeiro: Nova fronteira, 1994.

LATOUR, B. Changer de societé: refaire de la sociologie. Paris: la découverte, 2006.

MACIEL, A. G.; CALDEIRA, A. P.; DINIZ, F. J. P. S. Impacto da Estratégia Saúde da Família sobre o perfil de morbidade hospitalar em Minas Gerais. Saúde em Debate. Rio de Janeiro, v. 38, p. 319-330, 2014. Edição especial.

MACINKO J.; DOURADO I.; GUANAIS, F. C. Chronic diseases, primary care and health systems performance diagnostics, tools and interventions. [S.1.]: Inter-American Development Bank, 2011.

MACINKO, J.; ALMEIDA, C. Validação de uma metodologia de avaliação rápida das características organizacionais e do desempenho dos serviços de atenção básica do sistema de saúde (SUS) em nível local. Brasília, DF: Organização Panamericana da Saúde, 2006. (Série técnica desenvolvimento de sistemas e serviços de saúde, 10). 
MACINKO, J. et al. Going to scale with community-based primary care: An analysis of the family health program and infant mortality in Brazil, 1999-2004. Social Science \& Medicine, [S.I.] p. 2070-2080, 2007.

MACINKO, J et al. Organization and delivery of primary health care services in Petrópolis, Brazil. The International Journal of Health Planning and Management, Chichester,v. 19, n. 4, p. 303-317, 2004.

MCAVOY, B. R. Primary care research: what in the world is going on? The Medical Journal of Australia, Sydney, v. 182, n. 32, p. 110-112, 2005.

MENDES- GONÇALVES,R. B. Práticas de saúde: processos de trabalho e necessidades. São Paulo: CEFOR, 1992.

MENDES-GONÇALVES, R. B. Tecnologia e organização social das práticas de saúde: características tecnológicas do processo de trabalho na rede estadual de centros de saúde de São Paulo. São Paulo: Hucitec: Abrasco, 1994.

MENDES, L. V. et al. Disponibilidade de medicamentos nas unidades básicas de saúde e fatores relacionados: uma abordagem transversal. Saúde em debate, Rio de Janeiro, v. 38, p. 109-123, 2014. Edição especial.

MEDINA, M. G. O contexto local, a organização da atenção primária e a implementação de redes integradas de atenção à saúde: resultados da avaliação de dois estudos de caso. 2006. $261 \mathrm{f}$. Tese (Doutorado em Saúde Pública) - Instituto de Saúde Coletiva, Universidade Federal da Bahia, Salvador, 2006.

MEDINA, M. G; HARTZ, Z. M. A. The role of the Family Health Program in the organization of primary care in municipal health systems. Caderno de Saúde Pública, Rio de Janeiro, v. 25, n. 5, p. 1153-1167, 2009.

MEDINA M. G. et al. Promoção da saúde e prevenção de doenças crônicas: o que fazem as equipes de Saúde da Família? Saúde Debate, Rio De Janeiro, v. 38, p. 69-82, 2014. Edição especial.

MORETTI, A. C. Intersetorialidade nas ações de promoção de saúde realizadas pelas equipes de saúde bucal de Curitiba (PR). Ciência \& Saúde Coletiva, Rio de Janeiro, v.15, n. 1, p. 1827-1834, 2010. Suplememento. 
NEDEL, B. et al. Conceptual and methodological aspects in the study of hospitalizations for ambulatory care sensitive conditions. Ciência \& Saúde Coletiva, Rio de Janeiro, v. 16, p. 1145-1154, 2011.

NUNES, C. A. A integralidadeda atenção e o programa de saúde da família: estudo de caso em um município do interior da Bahia. 2011. $192 \mathrm{f}$. Tese (Doutorado em Saúde Pública) - Instituto de Saúde Coletiva, Universidade Federal da Bahia, Salvador, 2011.

NUNES, C. A. et al. Avaliação do perfil dos agentes comunitários de saúde (ACS) no processo de consolidação da atenção primária à saúde no Brasil: tomo 2 - Práticas dos ACS. Salvador: Instituto de Saúde Coletiva, Universidade Federal da Bahia, 2015.(Relatório Preliminar de Projeto de pesquisa).

OLIVEIRA, S. R. A. Sustentabilidade da estratégia saúde da familia: o caso de um município baiano. 2014.143 f. Tese (Doutorado em Saúde Pública) - Instituto de Saúde Coletiva. Universidade Federal da Bahia, Salvador, 2014.

ORGANIZACIÓN PANAMERICANA DE SALUD - OPAS. Renovação da Atenção Primária nas Américas: documento de posicionamento da Organização Panamericana de Saúde/Organização Mundial de Saúde (OPAS/OMS). Washington, 2007.

PAIM, J. S.; TEIXEIRA, C. F. Política, planejamento e gestão em saúde: balanço do estado da arte. Revista de Saúde Pública, Rio de janeiro, v. 40, p. 73-78, 2006.

PEDUZZI, M. Mudanças tecnológicas e seu impacto no processo de trabalho em saúde. Trabalho, Educação e Saúde, Rio de Janeiro, v. 1, n. 1, p. 75-91, 2003.

PEREIRA, F. J. R.; SILVA, C. C.; NETO, E. A. L. Condições sensíveis à atenção primária:uma revisão descritiva dos resultados da produção acadêmica brasileira. Saúde em Debate, Rio de Janeiro, v. 38, p. 331-342, 2014. Edição especial.

PINELL, P. Análise Sociológica das políticas de saúde. Rio de Janeiro: Fiocruz, 2011. 
PICCINI, R. X. et al. Necessidades de saúde comuns aos idosos: efetividade na oferta e utilização em atenção básica à saúde, Ciência e Saúde Coletiva, Rio de Janeiro, v. 11, n. 3, p. 657-667, 2006.

POTVIN, L.; MCQUEEN, D. Health promotion evaluation in the Americas: values and research.New York: Springer, 2008.

RANTALA, R. et al. Intersectoral action: local governments promoting health. Health Promotion International, Oxford, v. 29, n. 1, 2014.

RASELLA, D.; AQUINO, R.; BARRETO, M. L. Impact of the family health program on the quality of vital information and reduction of child unattended deaths in Brazil: an ecological longitudinal study. BMC Public Health, London, v. 10, n. 380, p. 1-8, 2010.

RASELLA, D. et al. Impact of primary health care on mortality from heart and cerebrovascular diseases in Brazil: a nationwide analysis of longitudinal data. BMJ, [S.1.], v. 3, n. 349, p. 1-10, 2014.

RASELLA, D. et al. Effect of a conditional cash transfer programme on childhood mortality: a nationwide analysis of Brazilian municipalities. The lancet, Londom,v. 382, n. 9886, p. 57-64, July 2013.

RODRIGUES-BASTOS, R. M. et al. Internações por condições sensíveis à atenção primária, Minas Gerais, 2000 e 2010. Revista Saúde Pública, Rio de Janeiro, v. 48, n. 6, p. 958-967, 2014.

RODRIGUES, F. F. Avaliação dos serviços farmacêuticos na atenção primária à saúde no cuidado ao paciente com tuberculose em unidades de saúde do município de Salvador-BA. 2014. 136 f. Dissertação Mestrado (Mestrado em Saúde Comunitária) - Instituto de Saúde Coletiva, Universidade Federal da Bahia, Salvador, 2014.

ROSANO, A. The relationship between avoidable hospitalization and accessibility to primary care: a systematic review. European Journal of Public Health, Oxford, v. 23, n. 3, p. 356-360, 2012.

SCHRAIBER, L. B.; NEMES, M. I. B.; MENDES-GONÇALVES, R. B. (Org.). Saúde do adulto: programas e ações na unidade básica. 2. ed. São Paulo: Hucitec, 2000. 
SCHRAIBER L. B. et al. Planejamento, gestão e avaliação em saúde: identificando problemas. Ciência Saúde Coletiva, Rio de Janeiro, v. 4, n. 2, p. 221-242, 1999.

SANTANA, M.; AQUINO, R.; MEDINA, M. G. Efeito da Estratégia Saúde da Família na vigilância de óbitos infantis. Revista de Saúde Pública, São Paulo, v. 46, n. 1, p. 59-67, 2012.

SANTOS L. T. S. O controle social nas ações de promoção da saúde e prevenção de doenças e agravos. 2014. 82 f. Dissertação (Mestrado em Saúde Comunitária) - Instituto de Saúde Coletiva, Universidade Federal da Bahia, Salvador, 2014.

SOUZA, J. C. A gênese do programa de incentivo fiscal à alimentação do trabalhador (PIFAT/PAT). 2013. 261 f. Tese (Doutorado em Saúde Pública) - Universidade Federal da Bahia, Instituto de Saúde Coletiva, Salvador, 2013.

SILVA, V. C. Avaliação da implantação da atenção à hipertensão arterial sistêmica em unidades de saúde da familia: estudo de caso. 2014. $131 \mathrm{f}$. Dissertação (Mestrado em Saúde Comunitária) - Instituto de Saúde Coletiva, Universidade Federal da Bahia, Salvador, 2014.

SILVA, I. Z. Q.J. Equipe de saúde da família: problematizando a articulação técnica e a interação entre profissionais. 2004. Dissertação (Mestrado em Saúde Comunitária) - Instituto de Saúde Coletiva, Universidade Federal da Bahia, Salvador, 2004.

STARFIELD, B. Measuring the attainment of primary care. Medical Education, Oxford, v. 54, n. 5, p. 361-369, 1979.

STARFIELD, B. Atenção primária à saúde: equilíbrio entre a necessidade de saúde, serviços e tecnologias. Brasília, DF: UNESCO: Ministério da Saúde, 2002.

SOUZA, T. S. NASF: fragmentação ou integração do trabalho em APS? 2015. 149 f. Dissertação (Mestrado em Saúde Comunitária) - Instituto de Saúde Coletiva, Universidade Federal da Bahia, Salvador, 2015.

SPEDO, S. M; TANAKA, O. Y.; PINTO, N. R. S. O desafio da descentralização do Sistema Único de Saúde em município de grande 
porte: o caso de São Paulo, Brasil. Caderno de Saúde Pública, Rio de Janeiro, v. 25, n. 8, p. 1781-1790, ago. 2009.

TEIXEIRA, C.; PAIM, J. Planejamento e programação de ações intersetoriais para a promoção da saúde e da qualidade de vida. Revista de Administração Pública, Rio de Janeiro, v. 3, n. 6, p. 63-80, nov./dez, 2000.

TESTA, M. Pensar em salud. $3^{\text {a }}$ ed. Buenos Aires: Lugar Editorial, 2004.

TOMASI, E. et al. Características da utilização de serviços de atenção básica à saúde nas regiões Sul e Nordeste do Brasil: diferenças por modelo de atenção. Ciência de Saúde Coletiva, Rio de Janeira, v. 16, n. 11, p. 4395-4404, nov. 2011.

TOMASI, E. et al. Estrutura e processo de trabalho na prevenção do câncer do colo de útero na atenção básica à saúde no Brasil: Programa de Melhoria do Acesso e da Qualidade PMAQ. Revista Brasileira de Saúde Materno Infantil, Recife, v, 15, n. 2, p. 171-180, abr./jun. 2015.

VIACAVA, F. et al. Uma metodologia de avaliação do desempenho do sistema de saúde brasileiro. Ciência \& Saúde Coletiva, Rio de Janeiro, v. 9, n. 3, p. 711-724, 2004.

VILASBÔAS, A. L. Q.; PAIM, J. S. Práticas de planejamento e implementação de políticas no âmbito municipal. Caderno Saúde Pública, Rio de Janeiro, v. 24, n. 6, p. 1239-1250, 2008.

VIEIRA-DA-SILVA L. M.; PINELL, P. The genesisofcollectivehealth in Brazil. Sociology of health \& Illness, Oxford, v. 36, n. 3, p. 432-46, 2014.

WONCA EUROPA. A definição européia de medicina geral e familiar: (clínica geral/medicina familiar). [S.l.], 2002. 
Sônia Cristina Lima Chaves, Paulo Frazão, Sandra Garrido de Barros, Denise Nogueira Cruz, Thais Regis Aranha Rossi e Ana Maria Freire de L. Almeida

\section{ANÁLISE DE POLÍTICAS DE SAÚDE BUCAL NO BRASIL estado da arte e possíveis contribuições teórico-metodológicas}

\section{Introdução}

Estudos de análise de políticas públicas de saúde bucal no Brasil são recentes e com incipiente produção de conhecimento, ainda que haja esforço teórico empreendido nas duas últimas décadas. Nesse sentido, este capítulo está apresentado em três tópicos. $\mathrm{O}$ primeiro busca mapear a produção científica nacional sobre as políticas de saúde bucal no Brasil, em três importantes eixos: atenção básica, atenção especializada e fluoretação das águas de abastecimento público. No segundo tópico, apresenta os principais objetivos e estudos já conduzidos e em curso do eixo temático de análise de políticas de saúde bucal do Projeto do Observatório de Análise Política em Saúde. Ao final, apresenta as principais abordagens teóricas e metodológicas que possibilitem a compreensão do processo de formulação e implementação no país, buscando orientar estudos futuros. 


\section{Estado da arte sobre a Política Nacional de Saúde Bucal segundo os eixos}

O objetivo deste tópico é fazer um breve balanço do estado da arte e das principais evidências trazidas por publicações científicas dos últimos 11 anos, que correspondem ao período de existência da política de saúde bucal brasileira.

\section{Atenção à saúde bucal na atenção primária}

A Política Nacional de Saúde Bucal (PNSB), lançada em 2004 e denominada Brasil Sorridente, aponta diretrizes para organização da atenção tendo em vista o princípio da integralidade do cuidado, assumindo, inclusive, a atenção primária à saúde como nível prioritário para estruturação da rede de serviços de saúde bucal e porta de entrada do usuário no sistema de saúde, com destaque para a Estratégia Saúde da Família (ESF). (BRASIL, 2004)

Os pressupostos e princípios norteadores da PNSB foram mantidos no período transcorrido ao seu lançamento e, também, observa-se um crescimento do número de Equipes de Saúde Bucal (ESB) implantadas no país, de modo que, em dezembro de 2004, eram 8.234 equipes modalidade I na ESF e, em setembro de 2015, esse número correspondia a 22.309, segundo dados do Ministério da Saúde. (BRASIL, 2015)

A expansão das ESB na atenção primária é um elemento que tem provocado a realização de estudos empíricos e de reflexões sobre a atenção à saúde bucal. Nesse sentido, a revisão de trabalhos publicados em formato de artigo, entre 2004 e novembro de 2015, que tinham a PNSB/2004 como descritor revela importantes contribuições, mas, também, lacunas que impõem novas investigações.

Como principais contribuições, pode-se afirmar que tal revisão revela que os estudos tratam em sua maioria da organização/modelo de atenção à saúde bucal, incluindo nessa dimensão o processo de trabalho das ESB na ESF; de estudos na perspectiva da avaliação dos 
serviços, com estudos com análise de indicadores e da produção ambulatorial. Poucos estudos refletem sobre a implementação da PNSB.

Os estudos empíricos sobre o processo de trabalho, seja na construção do cuidado em saúde bucal (AQUILANTE; ACIOLE, 2015) ou no cotidiano das ESB/ESF (PIMENTEL et al., 2010), revelam desafios na concretização das práticas dos profissionais, bem como dos pressupostos da PNSB para o primeiro nível de atenção.

A avaliação da organização da atenção primária à saúde bucal, a partir da PNSB, seja por meio da análise de documentos institucionais (DITTERICH; R.; DITTERICH, A.; BALDANI, 2015) ou a partir dos dados de produção ambulatorial e de repasses financeiros (MAIA; KORNIS, 2010) também revelam limites na atuação das ESB e aponta que a expansão da saúde bucal na atenção primária à saúde parece estar mais associada aos repasses dos recursos financeiros do que a um planejamento estratégico situacional.

A distância existente entre os resultados apresentados nas investigações e os pressupostos da PNSB também foi observada em uma análise foucaultiana da organização dos modelos de atenção à saúde bucal e as políticas de saúde no Brasil. (PIRES; BOTAZZO, 2015) Percebe-se ainda que há poucos trabalhos sobre a implementação da PNSB que tenham alguma direcionalidade para a atenção primária. (NASCIMENTO et al., 2009; SOARES et al., 2011) Neste particular, destaca-se que os limites na implementação da PNSB, no âmbito municipal, podem estar relacionados com a "baixa capacidade de governo", e também ausência de "um projeto de saúde bucal consistente”. (SOARES; PAIM, 2011, p. 972)

Por fim, é fundamental registrar que não foi observado nenhum artigo que fizesse uma análise política do Brasil Sorridente no âmbito da atenção primária.

\section{Atenção odontológica especializada}

A carta de intenção da PNSB - Brasil Sorridente, lançada em 2004, chamava atenção para a baixa capacidade de oferta dos servi- 
ços de atenção especializada, que não passavam de 3,5\% do total de procedimentos clínicos odontológicos no ano de 2003. (BRASIL, 2004) Os resultados de dois inquéritos epidemiológicos, o Relatório do Projeto SBBrasil (2003) e a Pesquisa Nacional por Amostra de Domicílio (PNAD) (2003), revelaram que a proporção de brasileiros que declarou nunca ter feito uma consulta ao dentista permaneceu muito alta (15,9\%), e maior entre os residentes das áreas rurais e entre os mais pobres. Os dados do SBBrasil mostraram também a elevada perda dental e edentulismo em adultos e idosos e permanência de diferenças regionais, sendo as regiões Norte e Nordeste com predomínio dos maiores índices de dentes perdidos em todas as PNSB, que teve a organização da atenção especializada, aqui entendida como sinônimo de atenção secundária, como um de seus principais eixos. (BRASIL, 2004) Com a implementação dos Centros de Especialidades Odontológicas (CEO), em 2004, a atenção odontológica especializada teve seu financiamento ampliado, aumentou consideravelmente o número de profissionais e municípios atendidos em relação aos governos anteriores a 2003. A criação dos Laboratórios Regionais de Próteses Dentárias (LRPD), a partir do ano de 2010, também possibilitou crescimento na oferta desse serviço de reabilitação oral.

É inegável o avanço da atenção odontológica especializada no âmbito do Sistema Único de Saúde (SUS), a partir da PNSB. Entre 2004 e 2014, foram implantados 1.030 CEOs em 854 municípios de todas as regiões do país, com maior concentração no Nordeste e Sudeste. Distribuição semelhante ocorre quanto aos LRPDs, que se encontram em maior quantidade nas regiões Nordeste e Sudeste, que apresentam o maior número de próteses dentárias entregues. (BRASIL, 2015)

Os CEOs devem se constituir como o principal serviço de referência para a atenção básica no que tange aos procedimentos odontológicos especializados. Vazquez e colaboradores (2014) destacam que a relação entre a atenção básica e os demais níveis da atenção não deve se restringir a fluxos e sim a processos (dinâmicos, democráticos 
e fundados na equidade), e ainda que para o alcance da integralidade deva haver o estabelecimento de interface entre os níveis de atenção.

Na saúde bucal, o acesso aos serviços e a continuidade do cuidado são desafios enfrentados pelos gestores. Atender a demanda por saúde bucal que emerge na atenção primária incluindo outros níveis de atenção, na perspectiva da integralidade é um problema para a maioria dos municípios. Estudo em um município paulista verificou que o CEO referencia, contrarreferencia e atende à maioria da demanda, independentemente da especialidade, porém, ainda há muita evasão durante o tratamento odontológico, o que serve de alerta para os gestores desenvolverem métodos de controle dos pacientes atendidos, com vistas à diminuição de gastos e ao aumento da resolutividade dos serviços, com a conclusão dos tratamentos iniciados. (SALIBA et al., 2013) A integralidade na prática é sempre uma construção local, com limites e possibilidades de cada equipe, dos recursos disponíveis, da atuação dos gestores ou das cobranças dos usuários. (SANCHEZ et al., 2015)

Outro fator relevante para a garantia da integralidade na assis271 tência à saúde bucal nos CEOs é a maior cobertura da atenção primária no território em que o serviço especializado se situa. (CHAVES et al., 2010; MACHADO; SILVA; FERREIRA, 2015) Chaves e colaboradores (2010) reforçam que a instalação de CEOs em cidades com atenção primária não estruturada pode levar ao atendimento da livre demanda e de procedimentos básicos nesses serviços. Há locais onde o melhor cumprimento de metas do CEO ainda se concentra no subgrupo de procedimentos de atenção básica em detrimento dos demais subgrupos. (GÓES et al., 2012; OLIVEIRA, E.; QUEIRÓZ; OLIVEIRA, R. , 2014)

Além da interface entre a atenção primária e a especializada, outra questão discutida na literatura é a acessibilidade. A acessibilidade diz respeito às características dos serviços e dos recursos de saúde que facilitam ou limitam seu uso por potenciais usuários. A acessibilidade é, assim, fator da oferta importante para explicar as variações no uso de serviços de saúde de grupos populacionais, e representa 
uma dimensão relevante nos estudos sobre a equidade nos sistemas de saúde. (TRAVASSOS e MARTINS, 2004)

Pinto e colaboradores (2014) analisaram a acessibilidade à atenção especializada numa região com 24 municípios após a implantação de um CEO regional no estado do Ceará, e verificaram que apesar de o serviço estar adequadamente preparado para atender à demanda pactuada, existem barreiras geográficas (distância e carência de transporte), financeiras (custo do transporte) e organizacionais (falta de dados epidemiológicos para pactuação e oferta de vagas à noite) que dificultam a acessibilidade e melhores taxas de aproveitamento e utilização dos serviços oferecidos nessa unidade. O simples fato de aumentar a oferta de um serviço especializado não é suficiente para que se obtenha acesso e uma maior resolutividade. (GOÉS et al., 2012; PINTO et al., 2014)

Zaitter e colaboradores (2009) apontam a falta de recursos materiais e profissionais na atenção básica como um fator gerador do aumento na demanda em algumas especialidades odontológicas, es272 pecialmente na endodontia. Os autores sugerem a realização de triagem (pré-avaliação) constante nos pacientes que aguardam em fila de espera pelo especialista, priorizando o agendamento da consulta além de favorecer a relação paciente-profissional.

Estudo em municípios baianos apontou que aqueles com menor escolaridade e expostos a uma pior organização do serviço usaram menos o CEO. Os autores verificaram também uma tendência pró equidade no atendimento público odontológico dos municípios pesquisados, o que corrobora os avanços conquistados pelo SUS no âmbito da oferta de serviços. Essa tendência pode camuflar um processo de universalização seletiva, com focalização dos serviços de atenção primária para grupos mais vulneráveis e de atenção especializada para aqueles que possivelmente têm mais capital para romper as barreiras de acesso, sejam elas organizacionais ou socioculturais. (SOARES; CHAVES; CANGUSSU, 2015)

Estudos sobre as taxas de utilização de procedimentos especializados odontológicos em cidades com CEOs apontam que sua 
implementação significou melhoria na utilização desses serviços em relação a cidades sem CEOs, todavia, o desempenho desses centros nas diversas dimensões como da qualidade técnico-científica do cuidado, do cumprimento ao princípio da integralidade, da sua equidade, ainda carecem de investigações. (CELESTE et al., 2014)

O não cumprimento das metas mínimas de produção nas três especializadas básicas (endodontia, periodontia e cirurgia oral) tem sido uma realidade apontada por diversos estudos. (GÓES et al., 2012; LINO et al., 2014) Alguns fatores são apontados como críticos: o poder que cada serviço tem de direcionar a produção desses procedimentos no sentido de atingir essas metas (LINO et al., 2014); o sistema de remuneração fixa, que pode desencorajar os profissionais a cumprirem metas mínimas de oferta de serviços; a não incorporação de novas tecnologias, a exemplo de instrumentos rotatórios para a endodontia (LINO et al., 2014); o não cumprimento de carga horária dos profissionais; a dupla inserção dos dentistas no setor público e privado (CHAVES et al., 2011) aliado ao recebimento de baixos valores remuneratórios e ausência de estabilidade laboral. (OLIVEIRA, E.; QUEIRÓZ; OLIVEIRA, R., 2014)

Machado, Silva e Ferreira (2015) apontam que o melhor desempenho dos CEOs está associado às formas de organização do processo de trabalho dos profissionais, da formação das redes regionais de atenção à saúde e às características contextuais e políticas locais como a maior cobertura da ESF, desenvolvimento humano e capacidade de governo na sua implementação.

Para a melhoria de qualidade dos CEOs, Góes e colaboradores (2012) destacam a necessidade de qualificação do processo de trabalho, com ações de educação permanente e criação de residência em atenção secundária; a avaliação de tecnologias e procedimentos próprios aos CEOs, podendo ser conduzido mediante o estabelecimento de Rede de Pesquisas Clínicas para atenção secundária e ainda, a realização de pesquisa sobre o impacto da implantação do CEO no Brasil. Esses autores evidenciam também a necessidade de revisão no marco legal para a implantação e implementação dos 
CEOs pela readequação dos critérios e normas, além de definições de novos padrões e cumprimento de metas para avaliação e monitoramento de tais serviços.

Outros trabalhos que não dizem respeito especificamente a um dos eixos apresentados poderiam ser sublinhados. (CARVALHO et al., 2009; PORTILHO; FERREIRA, 2011) Entretanto, este capítulo não teve por objetivo esgotar a literatura sobre o tema, e sim reunir algumas evidências que indicam a necessidade de produzir pesquisas que contemplem as diversas lacunas metodológicas e de conhecimento existentes sobre a evolução da política, a atenção primária, a atenção odontológica especializada, a fluoretação das águas, seja em âmbito nacional, estadual ou loco-regional. Diante do cenário político e econômico desfavorável que o país atravessa em 2015, não se espera para os próximos anos aporte financeiro significativo na política de saúde bucal, havendo inclusive possibilidade de recuo dessa institucionalidade recém constituída.

\section{Fluoretação das águas de abastecimento público}

A fluoretação das águas de abastecimento público é uma estratégia populacional de prevenção da cárie dentária que consiste no ajuste do teor de fluoreto na água de consumo humano. $\mathrm{O}$ método tem sido empregado em vários países desde 1951, quando passou a ser política oficial nos Estados Unidos da América (EUA). Pela multiplicidade de interesses associados, pela complexidade das decisões envolvidas e pelos requisitos administrativos e de gestão relacionados com sua implementação, ela é considerada uma política pública. (NARVAI; FRAZÃO, 2006)

A primeira publicação que sistematizou os conhecimentos sobre a distribuição das principais doenças bucais foi a obra $A$ epidemiologia da saúde bucal (1969), de Walter J. Pelton. (FRAZÃO, 2003) Segundo o prefácio da obra, 
A odontologia passou do empirismo para o conhecimento científico no início da década de 1930 quando dois grupos no âmbito do Serviço de Saúde Pública dos EUA produziram uma ruptura teórica pela aplicação de métodos epidemiológicos nos estudos de cárie dentária. (FRAZÃO, 2003, p. 73)

Documentos mostram que foi em Oakley (estado de Idaho EUA) que, pela primeira vez, uma comunidade se posicionou politicamente para enfrentar um problema de saúde bucal. Em 1925, a autoridade sanitária de Oakley procurou McKay para transmitir as queixas dos pais sobre os dentes das crianças e a constatação de que em comunidades vizinhas tais danos não se verificavam na dentição. A hipótese recaiu sobre a fonte de captação da água de abastecimento público. Mesmo sem dispor de conhecimentos sobre a causa exata do problema, nem poder oferecer uma maior segurança, a comunidade aprovou a mudança da fonte de captação da água e uma campanha para criação de um fundo foi liderada pela liga cívica das mulheres da cidade. Sete anos e meio depois da votação que aprovou o fundo e da instalação da nova fonte de água, a população verificou o benefício da medida quando os dentes das crianças de 6 a 7 anos de idade foram examinados por McKay. Esse evento ocorreu antes do reconhecimento do flúor como fator responsável pela ocorrência dessas alterações, e é considerado um marco na história das medidas de prevenção ampla ou coletiva. (MCKAY, 1933) De fato, a fluorose dentária endêmica, antes da cárie dentária, foi o primeiro problema de saúde bucal a ser coletivamente controlado através de medida sanitária.

Embora as observações de McKay, não tivessem ainda, do ponto de vista epidemiológico, algumas características metodológicas relevantes, e que mais tarde, seriam introduzidas nas pesquisas do Serviço de Saúde Pública dos EUA, em certo sentido, sua contribuição para demonstrar a importância da epidemiologia em saúde bucal para a qualidade da vida em sociedades humanas foi tão significativa quanto a de John Snow, cuja atitude fez cessar a epidemia de cólera em Londres, a despeito de ambos desconhecerem o agente 
etiológico do agravo, respectivamente, o Vibrio cholerae e o teor excessivo de flúor na água.

A utilização dos fluoretos como meio preventivo e terapêutico da cárie dentária iniciou-se em 1945 e 1946 nos EUA e Canadá com quatro estudos pioneiros, cujo principal objetivo foi investigar a efetividade da medida. (BURT; EKLUND, 1999) Nessas pesquisas, a concentração de fluoreto foi ajustada artificialmente nas águas de abastecimento público de algumas cidades para atingir o teor adequado, enquanto em outras, o teor de fluoreto mantido foi aquele presente naturalmente na água e considerado baixo para prevenção da cárie.

Comprovada sua eficácia e segurança, ela se expandiu paulatinamente. Entre 1960 e 2006, o número de residentes beneficiados pela medida passou de cerca de 50 para 180 milhões de habitantes nos EUA, alcançando uma taxa de $60 \%$ de cobertura. Os primeiros anos de implementação da medida despertam interesse entre os pesquisadores mesmo na segunda década do século XXI. (CARSTAIRS, 2015) Ao lado da vacinação, dos dispositivos de segurança no trânsito e nos locais de trabalho, das atividades de controle das doenças infecciosas, do reconhecimento do tabagismo como prejudicial à saúde, do consumo de alimentos mais saudáveis e seguros, e de um melhor planejamento familiar, a fluoretação da água foi considerada uma das 10 medidas de saúde pública mais importantes do século XX. (FROM..., 1999)

Para o Centro de Controle e Prevenção de Doenças (CDC) dos EUA, o poder preventivo da água fluoretada varia entre $40 \%$ a $70 \%$ em crianças, a depender da prevalência de cárie, além de reduzir a perda dentária em adultos em decorrência do método possuir grande abrangência, beneficiar todos os grupos socioeconômicos e ter excelente relação custo-benefício. (FROM..., 1999) A política pública tem sido recomendada pela Organização Mundial da Saúde (OMS) e pela International Association for Dental Research (IADR), dentre outras importantes organizações de projeção internacional, por sua efetividade, segurança e baixo custo, devendo ser implementada e mantida onde for possível. (NARVAI, 2000) No início do sé- 
culo XXI, a fluoretação para fins de prevenção da cárie beneficiava cerca de 400 milhões de pessoas em diferentes países no mundo. (FRAZÃO; PERES; CURY, 2011)

Como parte da agenda política internacional de saúde pública (WORLD HEALTH ORGANIZATION, 2007), a fluoretação da água de consumo tem sido objeto de muitos estudos e pesquisas abordando diferentes aspectos a ela relacionados.

Combinado à expansão do uso de fluoretos, observou-se importante declínio da prevalência de cárie a partir dos anos 1970 nos países industrializados. De fato, a elevação e o declínio da prevalência da cárie dentária em várias regiões do mundo, no século $\mathrm{XX}$, são atribuídos principalmente à disseminação do mercado de açúcar e à expansão do uso de fluoretos agregado à água de consumo, ao sal de cozinha ou ao creme dental. (FRAZÃO, 2012) No que pese esse declínio, a doença mantém-se como um significativo problema de saúde pública na maioria dos países desenvolvidos por ser importante causa de dor e perda dentária, levando ao absenteísmo no trabalho e na escola, e ainda afetando negativamente as atividades diárias e a estabilidade emocional dos indivíduos. (SHEIHAM, 2005)

As causas do declínio em cada país têm características específicas relacionadas às políticas que dão suporte às principais estratégias populacionais de prevenção de cárie. Conforme as características de implementação e de cobertura da fluoretação da água, o declínio pode ser mais lento e desigual. Enquanto política de saúde bucal, essa estratégia populacional de prevenção da cárie pode expressar desigualdades relacionadas à implementação de políticas públicas (PERES FERNANDES; GLAZER, 2004) e funcionar como um marcador de desigualdade sociodental. (GABARDO et al., 2008)

Em países onde a cárie dentária está declinando e existem outras possibilidades de acesso aos fluoretos, pesquisas sobre sua efetividade ressurgem com relevância. (ARMFIELD, 2010) Entre 2000 e 2015, cinco importantes revisões, sendo três delas sistemáticas, foram publicadas sobre o assunto. (AUSTRALIAN GOVERNMENT, 
2007; EUROPEAN COMMISSION, 2010; IHEOZOR-EJIOFOR et al., 2015; MCDONAGH et al, 2000; TRUMAN et al., 2002)

No que pese sua segurança e custo-efetividade, a fluoretação das águas tem suscitado debates acadêmicos sobre a violação do princípio ético da autonomia (COHEN; LOCKER, 2001; KALAMATIANOS; NARVAI, 2006); sobre a efetividade do método (KUMAR, 2008) e ainda sobre a possibilidade de ocasionar riscos para a saúde. (GAZZANO et al., 2010; PECKHAM; AWOFESO, 2014)

No Brasil, após alguns estudos em cidades brasileiras, a fluoretação das águas de abastecimento público passou a ser medida obrigatória nos locais em que existe estação de tratamento de água, desde 1974. (NARVAI, 2000) Em 2004, a fluoretação foi inscrita como parte da Política Nacional de Saúde, reafirmando-se a necessidade do desenvolvimento de ações intersetoriais para expandir a medida em todo o território, garantir sua continuidade e controle por meio de sistemas de vigilância compatíveis, cuja organização compete aos órgãos de gestão do SUS. (BRASIL, 2011)

Segundo o Ministério da Saúde, mais de 100 milhões de pessoas em todo o país são beneficiadas pela medida. (ANTUNES; NARVAI, 2010) Contudo, não se dispõe de informações fidedignas para avaliar a extensão da cobertura dessa política pública intersetorial em todo o território nacional. Os dados disponíveis resultam de processos de coleta relativamente imprecisos e não validados com o emprego de técnicas adequadas. (FRAZÃO et al., 2013)

Se considerarmos a fluoretação como uma medida eficaz e eficiente, por que ainda hoje se levantam vozes contra ela? Para compreender o debate que envolve a medida, Frazão (2006, p. 137) comenta que

É necessário examinar de modo profundo as diferentes situações, desde aquelas onde a aplicação da medida foi aceita e é mantida ainda hoje, até aquelas onde sua aplicação foi recusada ou em determinado momento interrompida. O debate não se dá acima dos conflitos de interesses e da arena onde ocorre a disputa das políticas públicas de 
saúde e saneamento. Os diferentes agentes políticos, entre os quais, autoridades governamentais, parlamentares, lideranças comunitárias e representantes de empresas e organizações não levam em consideração apenas as evidências científicas, mas também e, sobretudo, questões de ordem ética, econômica, legal e ambiental que decorrem dos diferentes valores que orientam a ação dos atores políticos.

Apesar das tentativas de privatização, a água é um bem público imprescindível para a vida humana, e cada vez mais, fator de proteção social, soberania e riqueza econômica dos países. E acrescenta:

Sendo a água processada pelas estações de tratamento, o veículo do fluoreto; aspectos relacionados à propriedade e à capacidade dos mananciais e demais fontes para sua obtenção, à cobertura da rede de abastecimento, à aceitação da população em consumi-la, e à repartição dos custos do seu tratamento e distribuição, tanto pelo Estado quanto pela sociedade, são aspectos geradores de intensas disputas e debates. (FRAZÃO, 2006, p. 137)

Para compreender tais aspectos, são necessários estudos de opinião (WHYMAN; MAHONEY; BORSTING, 2015), estudos qualitativos (FERREIRA; NARVAI, 2015) e estudos embasados nas ciências humanas e sociais que reconheçam a inserção do tema dentro de uma problemática mais geral relacionada ao acesso e à qualidade da água como um bem público que mobiliza múltiplos interesses muitas vezes inconciliáveis. (EASLEY, 2013; NARVAI; FRAZÃO, 2006) Tais estudos ainda são escassos em nosso meio e vão exigir forte colaboração entre pesquisadores de diferentes áreas, podendo contribuir para um melhor entendimento do papel das instituições políticas e econômicas e dos movimentos e grupos sociais na defesa de recursos cada vez mais escassos como a água de consumo humano. $\mathrm{O}$ conflito entre grupos rivais pela apropriação de recursos escassos é central à vida política. Os interesses que movem os atores se constituem em 
um dos lugares para onde se deve olhar quando se busca investigar por que uma política pública ocorre de uma forma e não de outra. No caso do Brasil, na qual o Estado foi historicamente central na produção de políticas públicas é importante examinar também o papel das instituições políticas e econômicas e os diferentes arranjos que vão conformar a distribuição de poder e de recursos, a fim de melhor compreender a dinâmica federativa e as regras do poder local.

\section{Principais estudos do eixo temático já conduzidos e em curso}

O eixo temático da análise de política de saúde bucal no Brasil tem buscado compreender o processo de implementação entre os anos de 2002 e 2017. Assim, há estudos que visam:

a. Caracterizar o espaço social da política de saúde bucal, identificando as instituições governamentais e não governamentais e principais agentes interessados na sua implementação no período considerado;

b. Descrever e analisar as principais propostas e tomadas de posição das instituições não governamentais com relação à implementação da PNSB no período considerado;

c. Descrever a implementação da PNSB no âmbito estadual e municipal bem como os processos sócio-históricos desse desenvolvimento;

d. Analisar os processos legislativos relacionados à saúde bucal, identificando os principais agentes envolvidos, suas disposições e tomadas de posição;

e. Caracterizar a inserção do componente da saúde bucal na rede de atenção à pessoa com deficiência e também na atenção à fissura labiopalatina, e seus antecedentes. 


\section{Abordagens teóricas mobilizadas em torno da proposta}

Para o conjunto dos estudos em curso, algumas possíveis abordagens teóricas poderão ser mobilizadas.

\section{Ciclo da política}

A teoria do ciclo da política pública (Policy Cicle) tenta explicar a interação entre intenções e ações, ao tempo em que busca desvendar a relação entre ambiente social, político e econômico de um lado e o governo de outro. (PINTO, 2003) O estudo do ciclo da política pública pode se configurar em cinco grandes fases: o reconhecimento do problema, que corresponde à fase de entrada de um conflito na agenda política; a definição de propostas de soluções, que corresponde à fase de formulação da política; a escolha de uma solução, que corresponde à fase de tomada de decisão; o momento de pôr uma solução em andamento, o que equivale à fase de implementação; e, finalmente, o monitoramento de resultados ou fase de avaliação da política. Já Knoepfel, Larrue e Varone (2007) descrevem como fases do ciclo das políticas públicas: percepção e emergência de problemas, agenda, formulação da política, implementação e avaliação.

Apesar das variações encontradas na literatura, é possível observar convergências nas abordagens. Pinto (2003) entende o ciclo político nas seguintes etapas:

a. determinação da agenda, onde a dinâmica da definição do problema é questão essencial para a compreensão da política pública;

b. formulação e legitimação da política (seleção de proposta, construção de apoio político, formalização em lei);

c. implementação de políticas (operacionalização da política em planos, programas e projetos no âmbito da burocracia pública e sua execução); 
d. avaliação de políticas (relato dos resultados alcançados com a implementação das propostas e programas de governo, avaliação dos impactos dos programas e sugestão de mudanças).

A fase de implementação de políticas corresponde à etapa em que a política formulada se transforma em planos, programas e projetos no âmbito da burocracia pública e na sua execução (PINTO, 2003), à adaptação do programa às situações concretas encontradas, bem como ao momento de colocar uma determinada solução em prática. (KNOEPFEL; LARRUE ; VARONE; 2007)

A fase de implementação como momento crucial e etapa mais crítica no ciclo da política pública que envolve uma série de sistemas ou atividades da administração pública: o sistema gerencial e decisório, os sistemas de informação, os agentes implementadores da política, os sistemas logísticos e operacionais (recursos materiais e financeiros). Essa etapa pode ser considerada enquanto um jogo, no qual a autoridade central procura induzir agentes, nesse caso, implementadores, a colocar em prática objetivos e estratégias que lhe são alheias. (VIANNA; BAPTISTA, 2008)

Segundo essas autoras, a resposta dos agentes dependerá do entrosamento entre formuladores e implementadores, da compreensão da política, do conhecimento de cada fase do processo e da quantidade de mudança envolvida com a nova política. Assim, a maior clareza e conhecimento dos implementadores facilitaria o processo em si de implementação de uma política e, por outro lado, quanto maior mudança for demandada, maiores serão os obstáculos a serem superados.

Nesse sentido, Vianna e Baptista (2008) afirmam que para uma análise de implementação é necessário responder às seguintes perguntas:

+ a formulação da política apresenta objetivos, metas e direção claros?

+ os recursos necessários para sua implementação foram considerados no momento da formulação/implementação? 
- o processo de construção da estratégia de implementação é claro? Em especial quanto à divisão de atribuições e atividades? Exige mudança organizacional?

+ os atores envolvidos estão de acordo e compreendem a política traçada?

Muitos trabalhos utilizaram esse referencial teórico-metodológico para o estudo das políticas de saúde bucal. Citam-se como exemplos os estudos de Soares e Paim (2011) que analisaram a implementação da PSNB no município de Salvador, Bahia; Rendeiro (2011) que analisou a agenda de governo e a formulação da política de saúde bucal de 2000 a 2010; Rossi e Chaves (2015) que analisaram desde a entrada na agenda até a implementação dos CEOs em dois municípios de médio porte na Bahia.

\section{O Triângulo de Governo}

A obra do economista Carlos Matus (1996) é extensa e muitas são as contribuições desse autor para a análise de políticas. Neste capítulo, será destacado seu construto teórico sobre o "Triângulo de Governo”. O conceito de Triangulo de Governo (MATUS, 1996) refere-se a três variáveis que conformam os vértices de um triângulo: o projeto de governo, a capacidade de governo e a governabilidade.

Matus (1996) aborda que o projeto de governo seria um sistema propositivo ou conjuntos de propostas de ações realizadas por um ator no intuito de alcançar sua meta. Entretanto, não são apenas as circunstâncias e interesse do ator que determinam o conteúdo propositivo de suas ações e sim sua capacidade de governo.

A capacidade de governo seria a capacidade de condução ou direção e refere-se ao acervo de técnicas, métodos, destrezas, habilidades e experiências de um ator e sua equipe de governo, para conduzir o processo social a objetivos declarados, levando em consideração a governabilidade do sistema e o conteúdo propositivo do projeto de governo. A capacidade de governo se expressa na capacidade de direção, de gerência, de administração e de controle. Através das teorias, 
técnicas e métodos de planejamento é possível alterar ou melhorar a capacidade de governo e o domínio dessas técnicas constitui-se numa das variáveis mais importantes na determinação da capacidade de governo de uma equipe.

É dito que, para aprimorar a capacidade para governar, existem dois caminhos polares: o primeiro, pelo uso paciente do tempo, o que geraria após séculos, uma maturidade institucional que prescindiria métodos formais, pois estes já estariam implícitos e seriam naturais na prática da gestão pública; o segundo consiste na economia do tempo, e prioriza os métodos formais de governo e a formação acelerada de quadros de liderança tecnopolítica, a fim de forçar uma prática que não decorre naturalmente da maturidade institucional. Na visão do autor, para os países da América Latina, a única via possível seria a segunda, pois, quanto menor é a maturidade institucional, mais necessários são os métodos e as técnicas de direção e planejamento para que, dessa forma, a prática seja forçada e a maturação dos quadros burocráticos apressada.

284 O terceiro vértice do Triângulo de Governo que, somado ao projeto de governo e à capacidade de governo, representam variáveis que se entrelaçam e condicionam-se mutuamente é a governabilidade.

A governabilidade do sistema é uma relação entre o peso das variáveis que o ator controla e não controla, no processo de governo. O autor afirma que quanto mais variáveis o ator controla, maior será sua liberdade de ação e maior será, para ele, a governabilidade do sistema. A governabilidade de um sistema expressa o poder que determinado ator tem para realizar seu projeto. É uma categoria relativa a um determinado ator, às demandas e exigências que o projeto de governo impõe a ele, e à sua capacidade de governo. (MATUS, 1996)

Referente à governabilidade o autor aponta três relativizações:

a. a primeira aborda que um sistema não oferece a mesma governabilidade a todos os diferentes atores sociais, pois cada um deles controla proporções diversas de variáveis do sistema; 
b. a segunda refere-se que a governabilidade de um sistema depende do conteúdo propositivo do projeto;

c. e a terceira relativização indica que a governabilidade de um sistema é maior se o ator tem alta capacidade de governo.

Na diferenciação entre as três variáveis é possível reconhecer sistemas de natureza diferente: o sistema propositivo de ações (projeto), o sistema social (governabilidade) e o sistema de direção e planejamento (capacidade de governo). Guimarães e colaboradores (2004) apontam que o Triângulo de Governo privilegia tanto categorias normativas (existência de projetos) e categorias administrativas (capacidade técnica) como categorias políticas (governabilidade do sistema).

Observa-se importante contribuição teórico-metodológica desse referencial nos estudos na saúde bucal. Autores utilizaram o Triângulo de Governo e o Planejamento Estratégico Situacional, do mesmo autor, para construção de uma proposta de planejamento seguindo as diretrizes da PNSB. (BITTAR et al., 2009) Já Chaves e Vieira-da-Silva (2007) trabalharam a relação entre as características de governo e a atenção à saúde bucal em dois municípios da Bahia, tendo observado influências de características do governo municipal e da gestão da saúde para a organização da atenção em saúde bucal, assim como Rossi e Chaves (2015) também verificaram na implementação dos CEOs. Conforme já citado, o estudo de Soares e Paim (2011) também analisaram a implementação da PNSB no nível municipal, através das variáveis do Triangulo de Governo.

\section{Postulado de Coerência e tipologia do poder em saúde}

Elementos conceituais e metodológicos podem ser utilizados para análises políticas a partir das contribuições sobre o planejamento em saúde e das análises sobre a realidade política latino-americana desenvolvida por Mário Testa. (TEIXEIRA, 2010) Nesta seção, terão destaque o "Postulado de Coerência" e sua elaboração sobre a tipologia de poder. 
Testa (1992), através do Postulado de Coerência, aponta que os propósitos de uma instituição, os métodos que utiliza para alcançá-los e a organização que assume devem ser coerentes. Essa relação de coerência exprime-se de duas maneiras: determinação e condicionamento. A relação entre esses elementos é descrita em forças positivas, determinantes dos limites dentre os quais devem se dar as realizações, sua lógica não é estritamente causal, e forças negativas ou condicionantes, que fixam limites para a não ocorrência delas.

O método refere-se à "teoria do problema que o método procura resolver”. No Postulado de Coerência, os propósitos determinam os métodos e esses determinam a organização, na medida em que esta última condicionará os métodos e esses poderão condicionar os propósitos.

No que tange à organização, quanto à relação de coerência, esta será determinada pelo propósito de governo e pela organização. Para Testa (1992), a organização constitui-se "uma cristalização da história”. A análise de organização em um dado momento retrata indiretamente outras determinações advindas do passado juntamente com as atuais.

A tipologia para análise do poder em saúde traz a distinção entre os poderes político, técnico e administrativo. (TESTA, 1992) Existem diversos autores que trazem conceitos e reflexões sobre o poder que podem ser bastante úteis para o estudo de políticas. Entretanto, neste tópico, será focalizada a contribuição de Mário Testa. O poder político expressa a capacidade de mobilizar grupos sociais em defesa de suas necessidades e interesses. Essas características expressam a capacidade de manipular recursos, informações e interesses que acumulam determinadas pessoas, grupos sociais e/ou instituições. Essa modalidade de poder surge como expressão da ideologia em dois eixos: saber e prática. Na dinâmica do poder, os poderes técnico e administrativo ficam subordinados ao poder político em algum momento. (TESTA, 1992)

O poder técnico consiste na capacidade do sujeito/dirigente/ técnico de gerar, aceder, lidar com a informação de características 
distintas. As informações por ele geradas podem estar em variados aspectos (médico, sanitária, administrativo e marco teórico) e operar em muitos âmbitos (docência, investigação, serviços, administração superior, população). Refere-se às instâncias e procedimentos de geração, processamento (transformação dos dados em informação) e uso da informação em relação aos grupos sociais que lidam com cada uma dessas instâncias. (TESTA, 1992)

O poder administrativo representa a capacidade do sujeito de se apropriar e distribuir recursos. O financiamento apresenta-se como sua maior expressão, sendo fundamental nos deslocamentos do poder dentro do setor, sem contudo, produzir mudanças que possam alterar a estrutura social. Essa modalidade de poder deve ser analisada referindo-se à tomada de decisões, pois o uso desse poder (decisões administrativas) implica eficácia e eficiência política, isto é, possui uma consequência sobre grupos sociais afetados pela decisão. Tal consequência pode se traduzir em aumento ou diminuição do apoio que cada grupo presta aos que tomam as decisões e a todos os demais e produzem mudanças que viabilizam outras decisões. Assim, ao se tomar uma decisão administrativa, iniciam-se dois tempos: o político, que corresponde ao tempo que a decisão leva para produzir apoio ou oposição dos grupos sociais interessados ou afetados pelo problema, e o técnico, compreendendo o tempo que leva a decisão para ser implementada até obter a eficácia operativa. (TESTA, 1992)

Foi realizada uma articulação entre o Triangulo de Governo e o Postulado da Coerência por Vilasbôas e Paim (2008) que foi adaptado por Rossi e Chaves (2015) para o estudo da implementação da atenção especializada em saúde bucal. As contribuições de Carlos Matus e Mário Testa também foram utilizadas para avaliar o planejamento estratégico de saúde bucal na ESF em um município de Santa Catarina. (BASTOS SORATTO; SÔNEGO, 2013)

\section{Processo de trabalho em saúde}

A organização das práticas pode ser estudada através da teoria do processo de trabalho em saúde proposto por Mendes-Gonçalves 
(1992). O autor estudou a aplicação da teoria marxista do trabalho ao campo da saúde. (PEDUZZI; SCHRAIBER, 2009) Na concepção de Mendes-Gonçalves (1992), trabalho é a transformação de fragmentos parciais da natureza, através de gasto de energia e com a utilização de certos recursos. O autor situa o processo de trabalho em saúde como um dos polos de uma tríplice relação dialética entre o homem e a natureza.

No estudo do processo de trabalho em saúde, Mendes-Gonçalves (1992) analisa os seguintes componentes: o objeto do trabalho, os instrumentos, a finalidade e os agentes. Destaca ainda, que esses elementos precisam ser examinados de forma articulada, pois, somente na sua relação recíproca, configura um dado processo de trabalho específico.

O objeto, em sua relação com o processo de trabalho, não se delimita por si mesmo, é delimitado por um olhar que contém um projeto. O objeto será o alvo da transformação, representado na saúde pelo que Mendes-Gonçalves (1992) chama de carecimentos, entendido como necessidades de saúde. A apreensão do objeto consiste em identificar as características que permitem a visualização do produto final, antevisto nas finalidades do trabalho. (MENDESGONÇALVES, 1994) "O objeto não se impõe em nenhum caso naturalmente, mas corresponde a um olhar enviesado que nele discrimina a potencialidade do produto." (MENDES-GONÇALVES, 1994) Outro aspecto importante a ressaltar é a noção de finalidade e do sentido teleológico do processo de trabalho humano. A finalidade é chamada de tensão da vontade.

Para apreender o objeto de trabalho, o agente opera saberes. O saber consiste em "generalizações conscientes e estruturadas a partir da prática e que expressam tanto nos instrumentos quanto nos discursos a sua materialidade sob formas diversas". (MENDESGONÇALVES, 1994) O instrumento de trabalho serve para intermediar a ação humana sobre os objetos conforme o processo social e histórico que inclui a reprodução social. Os instrumentos de trabalho representam a forma pela qual a energia se incorpora no 
processo de trabalho e devem ter capacidade de sintetizar as qualidades do objeto e o projeto de mudança numa ação transformadora. Dessa forma, o meio de trabalho é o complexo de coisas que o trabalhador insere entre si e o objeto de trabalho e lhe serve para dirigir sua atividade sobre esse objeto. (MENDES-GONÇALVES, 1992)

Ao discutir as relações que ocorrem no processo de trabalho das equipes de saúde, Mendes-Gonçalves (1994) considera que a tecnologia é um conjunto de saberes e instrumentos que expressa, nos processos de produção dos serviços, a rede de relações sociais entre agentes e práticas, conformada em uma totalidade social, que é constituída não apenas pelo saber, mas também pelos seus desdobramentos materiais e não materiais.

Há diferenciação de instrumentos materiais e não materiais. Os primeiros são os equipamentos, material de consumo, medicamentos, instalações, outros. Os segundos são os saberes, que articulam em determinados arranjos os sujeitos (agentes do processo de trabalho) e os instrumentos materiais. Estes se constituem nas ferramentas principais do trabalho de natureza intelectual. $\mathrm{O}$ autor salienta que esses saberes são também os que permitem a apreensão do objeto de trabalho. (PEDUZZI; SCHRAIBER, 2009)

O caráter de movimento e historicidade é destacado, fazendo alusão a um "retrato estático da realidade deveras dinâmica", que só tem sentido se servir de aproximação à prática, vinculada e desenvolvida ao homem prático. Assim, as práticas de saúde representam a "reiteração articulada de um modo de inserção na divisão social do trabalho relacionada à reprodução de padrões histórica e socialmente significativos de normatividade”. (MENDES-GONÇALVES, 1992 , p. 65)

$\mathrm{O}$ agente do trabalho pode ser interpretado, ele próprio, como instrumento do trabalho e, imediatamente sujeito da ação, na medida em que traz, para dentro do processo de trabalho, além do projeto prévio e sua finalidade, outros projetos de caráter coletivo e pessoal. (PEDUZZI; SCHRAIBER, 2009) 
O processo de trabalho tem sido alvo de muitos estudos em saúde bucal. Entretanto, poucos vêm utilizando a perspectiva defendida por Mendes Gonçalves. Um estudo utilizou o referencial descrito na análise da atenção secundária (ROSSI; CHAVES, 2015), entretanto os outros diversos estudos encontrados utilizam outras perspectivas para análise do processo de trabalho, muitas vezes sem mesmo referir o referencial teórico que embasou o estudo.

\section{0 uso do referencial bourdieusiano na análise de políticas de saúde bucal}

Para Bourdieu (1996), a análise sociológica é um poderoso instrumento de conhecimento de si, como ser social e singular, visto que fundamenta sua teoria na ação humana/individual. Atribui primazia às relações, opondo-se ao pensamento substancialista e do senso comum, que considera a relação entre posições sociais e gostos como mecânica e direta, como uma propriedade substancial, uma espécie de essência biológica ou cultural. Tem como conceitos fundamentais de sua teoria da ação as noções de espaço, campo, habitus ${ }^{1}$ e capital. Busca romper com noções incorporadas ao discurso acadêmico como sujeito, motivação, ator, papel, e com oposições como individual-coletivo, objetivo-subjetivo, consciente/inconsciente. (BOURDIEU, 1996)

Os agentes distribuem-se no espaço social ocupando posições de acordo com seu volume de capital global, em especial os capitais cultural e econômico, bem como os capitais político, científico, burocrático e simbólico. As diferentes posições sociais correspondem

1 Habitus é o princípio gerador e unificador que representa as características intrínsecas e relacionais de uma posição em um estilo de vida (escolhas de pessoas, bens e práticas), gerando práticas distintas e distintivas. É o senso prático do que se deve fazer em uma dada situação. Corresponde às disposições dos agentes, seus esquemas de percepção, produzidos pela história coletiva, modificados pela história individual de cada um, e incorporados de forma inconsciente. (BOURDIEU, 1996) 
a diferentes disposições ou gostos (habitus) e tomadas de posição. (BOURDIEU, 1996, 2008)

Bourdieu adota o conceito de agente para romper com as tradições que consideram as ações individuais como resultantes de processos interiores, mentais, independentes de qualquer influência externa. Assim, nem toda ação humana seria uma ação consciente, como se os agentes agissem sempre de maneira a obter o máximo de eficácia com o menor custo, pautados pelo interesse econômico. Compreende as ações individuais como resultantes dos constrangimentos objetivos do campo e das determinações subjetivas resultantes do habitus. Ou seja, a teoria da ação de Bourdieu (1996, 2008) considera que a maior parte das ações humanas tem por base algo além da intenção, e, mesmo que lúcidas, são uma construção social.

Bourdieu (1996) considera que a maioria das condutas humanas acontece em espaços de jogo, mas muito raramente estão assentadas em intenções estratégicas verdadeiras. A antecipação do jogador é imediata, dada ao conhecimento do jogo, é o senso prático: o jogador sabe onde deve estar e o que deve fazer, pois tem o sentido do jogo. É como se algo que não é imediatamente percebido já estivesse ali. Faz parte do habitus do agente do campo.

Nesse sentido, o objeto de pesquisa deve ser definido em função de uma problemática teórica que questione sistematicamente aspectos da realidade e diferentes técnicas podem contribuir para o seu conhecimento, desde que a sua utilização seja adequada ao objeto em questão e que esta seja objeto permanente de reflexão, de forma a controlar a aplicação da(s) técnica(s). (BOURDIEU; CHAMBOREDON; PASSERON, 2007)

Assim, a aplicação de diferentes técnicas pertinentes ao estudo do objeto pode ser verificada nos trabalhos empíricos de Bourdieu, como por exemplo, em A Distinção, onde se utiliza de dados secundários, de dados primários relativos a uma pesquisa através de questionários, associada ao uso de fotografias; sempre reconhecendo e tentando superar os limites da utilização de dados secundários e dos questionários; 
bem como, a utilização de estratégias de observação e entrevistas em situação real e do diário de pesquisa. (BOURDIEU, 2008)

Bourdieu (1996) aponta o estudo da gênese como importante estratégia de ruptura com o senso comum. A análise sócio-histórica contribui para identificação dos agentes e disputas envolvidos na constituição de um campo ou subespaço social, permite compreender que o que ocorreu não era a única possibilidade, evidenciando possíveis não realizados, bem como as condições históricas que possibilitaram que aquele desfecho fosse possível. (BARROS, 2013)

A análise a partir do referencial teórico bourdieusiano permite a articulação entre estruturas objetivas e mentais, internas e externas, e as trajetórias dos agentes envolvidos, buscando uma integração entre o material e o simbólico. O referencial e a epistemologia bourdieusianos foram utilizados por Patrice Pinell (2010) para a análise sociológica da gênese de quatro políticas públicas de saúde na França (política em favor da infância anormal, política de luta contra a toxicomania, política de luta contra o câncer e política de 292 luta contra a aids). Nos estudos de Pinell (2010), a política aparecia como pano de fundo de um problema sociológico objeto de estudo, de modo que o autor realizou um esforço inverso ao da maioria dos pesquisadores de ciências políticas, analisando a política a partir de um referencial teórico sociológico, mas sem uma teoria prévia a ter sua pertinência verificada pela análise dos casos. A posteriori, Pinell (2010) elaborou proposições acerca dos processos comuns à emergência das políticas por ele estudadas quanto à sua gênese e evolução.

Para a emergência de uma política pública de saúde, identificou:

a. O reconhecimento pelo poder público da necessidade de medidas específicas para o enfrentamento de um determinado problema que não tem solução satisfatória no âmbito das instituições e/ou leis existentes;

b. A responsabilização do Estado a partir da identificação de um problema já existente e da inadequação das políticas de organização e/ou das práticas institucionais existentes; 
c. A necessidade de alianças entre os diferentes grupos sociais interessados no reconhecimento de determinado problema, construindo uma definição comum do problema, apesar dos diferentes pontos de vista sobre o que é o problema ou sobre as medidas a serem tomadas;

d. A negociação para a definição de uma visão comum do problema pode levar a conflitos, a uma luta simbólica pela definição do problema e suas consequências, haja vista a concorrência aparentemente irredutível entre os grupos com interesse em construir o problema social;

e. A definição do problema constrói-se pela dinâmica de um jogo social, como produto da interpenetração das estratégias dos diferentes grupos de agentes interessados a construírem o problema como um problema social. Nesse contexto, a definição será tanto mais precisa (e restrita) quanto mais forte a concorrência entre os grupos de agentes e tanto mais imprecisa quanto os grupos interessados não são concorrentes;

f. Quando os grupos chegam a superar seus eventuais conflitos de interesse, a lógica para a elaboração de um projeto comum não é o acordo sobre uma definição precisa do problema e de suas soluções, mas de produzi-las de forma suficientemente ambíguas para não evidenciar eventuais contradições;

g. A definição do problema e das soluções construídas antes do reconhecimento do problema pelo Estado leva a remodelações quando tem início a formulação da política específica pelos poderes públicos. A definição e a implantação de uma nova política levam à necessidade de ajustamento das políticas, instituições e estruturas já existentes. Isso se deve ao fato de que:

+ A expansão ou a criação de um novo espaço social com suas questões simbólicas, institucionais, profissionais e materiais em jogo tende a modificar os equilíbrios pré-existentes no mundo social; 
- A pressão sobre os poderes públicos de apresentar a nova política como uma expressão do interesse coletivo.

Com relação à evolução das políticas, considera-se que a implantação e a evolução de uma política de saúde são produtos da dinâmica de um jogo social complexo que deve considerar:

a. As evoluções de ordem médica (epidemiologia e conhecimento médico sobre a doença, técnicas, tratamentos) e de ordem social (transformações na mobilização contra a doença);

b. Os efeitos concretos da implantação da política (novas instituições, desenvolvimento de grupos profissionais, emergência de novas estruturas associativas) e os obstáculos encontrados;

c. As mudanças de governo, sendo possível a manutenção ou a mudança da maioria política;

d. As mudanças independentes da política que afetam as instituições do campo médico (reformas hospitalares, estudos médicos) ou de outros campos implicados naquela política (educação, justiça, etc.) e mais globalmente toda a sociedade (guerras ou mudanças de costumes e nas formas de controle social). (PINELL, 2010)

O referencial bourdieusiano foi utilizado por Vieira-da-Silva e Pinell (2014) para estudar a gênese da Saúde Coletiva no Brasil. Esse referencial associado às proposições de Pinell acerca dos processos comuns à emergência das políticas na sua gênese e evolução, foram utilizados no Brasil para a análise da gênese da política de controle da aids. (BARROS, 2013) e do Programa de Alimentação do Trabalhador. (SOUZA, 2013) Alguns estudos em andamento vêm se apoiando nesse referencial também para a análise das políticas de saúde bucal, bem como alguns já publicados onde os conceitos de habitus, campo e poder simbólico também foram utilizados. (AGUIAR et al., 2014; CHAVES; VIEIRA-DA-SILVA, 2008) 


\section{Considerações finais}

Espera-se, portanto, produzir conhecimento válido e teoricamente embasado que possa subsidiar a prática técnica e política daqueles que militam na área, bem como a própria reflexão sobre as relações de poder inerentes a esses processos políticos em curso, incluindo a atual conjuntura política e econômica de 2015, com mudanças dos agentes do campo burocrático da saúde bucal, incluindo a própria coordenação nacional de saúde bucal, refletindo as relações de poder do campo político que interferem nesse espaço em particular.

\section{Referências}

ANTUNES, J. L. F.; NARVAI, P. C. Políticas de saúde bucal no Brasil e seu impacto sobre as desigualdades em saúde. Revista de Saúde Pública, São Paulo, v. 44, n. 2, p. 360-5, 2010.

AGUIAR, D.M.L. et al. Oral health technicians in Brazilian primary health care: potentials and constraints. Caderno de Saúde Pública, Rio de Janeiro, v. 30, n. 7 p. 1560-1570, 2014.

AQUILANTE, A. G.; ACIOLE, G. G. O cuidado em saúde bucal após a Política Nacional de Saúde Bucal - "Brasil Sorridente": um estudo de caso. Ciência Saúde e Coletiva, Rio de Janeiro, v. 20, n. 1, p. 239-248, 2015.

ARMFIELD, J. M. Community Effectiveness of Public Water Fluoridation in Reducing Children's Dental Disease. Public health reports, Washington, v. 125, n. 5, p. 655-664, 2010.

AUSTRALIAN GOVERNMENT. National Health and Medical Research Council. A systematic review of the efficacy and safety of fluoridation. Part A: reviewofmethodologyandresults. 2007.

BARROS, S.G. A política nacional de luta contra a aids e o espaço aids no Brasil. Salvador. 2013. 274 f. Tese (Doutorado em Saúde Pública) Instituto de Saúde Coletiva, Universidade Federal da Bahia, Salvador, 2013. 
BASTOS, P. G. S.; SORATTO, M. T.; SÔNEGO, F. G. F. Planejamento estratégico em saúde bucal. Revista Inova Saúde, Criciúma, v. 2, n. 1, p. 111-117, jul. 2013.

BITTAR, T. O. et al. O PES e a construção de uma Política Nacional de saúde Bucal no Brasil. Revista da Faculdade de Odontologia, Passo Fundo, v. 14, n. 1, p. 71-76, 2009.

BOURDIEU, P. Razões práticas: sobre a teoria da ação. Campinas: Papirus. 1996.

BOURDIEU, P. A distinção: crítica social do julgamento. São Paulo: Edusp; Porto Alegre: Zouk, 2008.

BOURDIEU, P.; CHAMBOREDON, J.-C.; PASSERON, J.-C. Ofício de sociólogo: metodologia da pesquisa na sociologia. 6. ed. Petrópolis: Vozes, 2007.

BRASIL. Coordenação Nacional de Saúde Bucal. Departamento de Atenção Básica, Secretaria de Atenção à Saúde, Ministério da Saúde. Diretrizes da Política Nacional de Saúde Bucal. Brasília, DF, 2004. BRASIL. Ministério da Saúde. Portaria n ${ }^{\circ}$ 2.914, de 12 de dezembro de 2011. Dispõe sobre os procedimentos de controle e de vigilância da qualidade da água para consumo humano e seu padrão de potabilidade. Diário Oficial da União, Brasília, DF, 14 dez 2011. Seção 1, n. 239, p. 39.

BRASIL. Ministério da Saúde. Sala de Apoio a Gestão Estratégica (SAGE). Número de equipes de saúde bucal na ESF, Centros de Especialidades Odontológicas, Laboratórios de Prótese Dentária implantados e valores transferidos fundo a fundo no Brasil. Disponível em: <http://189.28.128.178/sage/>. Acesso em: 20 out 2015.

BURT, B. A.; EKLUND, S. A. Dentistry, dental practice and the community. $5^{\text {th }}$. Philadelphia: WB Saunders, 1999.

CARSTAIRS, C. Debating Water Fluoridation before Dr. Strangelove. American Journal of Public Health, New York, v. 105, n. 8 p. 1559-69, 2015.

CARVALHO, L. A. C. et al. Procedimentos coletivos de saúde bucal: gênese, apogeu e ocaso. Saúde e Sociedade, São Paulo, v. 18, n. 3, 2009. 
FROM the centers for disease control and prevention.achievements in public health, 1900-1999: fluoridation of drinking water to prevent dental caries. Jama, Chicago, v. 48, n. 41, p. 933-940, 1999.

CELESTE, R. K et al. Análise da produção ambulatorial em municípios com e sem centros de especialidades odontológicas no Brasil em 2010. Caderno Saúde Pública, Rio de Janeiro, v. 30, n. 3, p. 511-521, 2014.

CHAVES, S. C. L et al. Política Nacional de Saúde Bucal: fatores associados à integralidade do cuidado. Revista Saúde Pública, São Paulo, v. 44, n. 6, p. 1005-1013, dez. 2010.

CHAVES, S. C. L.; VIEIRA-DA-SILVA, L. M. Oral health care and health decentralization in Brazil: two case studies in Bahia State. Caderno de Saúde Pública, Rio de Janeiro, v. 23, n. 5, p. 1119-1131, 2007.

CHAVES, S.C. L. et al. Avaliação da oferta e utilização de especialidades odontológicas em serviços públicos de atenção secundária na Bahia, Brasil.Caderno Saúde Pública, Rio de Janeiro, v. 27, n. 1, p. 143-54, 2011.

COHEN, H.; LOCKER, D. The science and ethics of water fluoridation. Canadian Dental Association, Ottawa, v. 67, n. 10, p. 578-80, 2001.

DITTERICH, R.G.; DITTERICH, A. C. R.; BALDANI, M. H. A política de saúde bucal em pauta no Conselho Municipal de Saúde no Município de Nova Friburgo - RJ. Revista de odontologia da UNESP, Marília, v. 44, n. 3, p. 143-151, 2015.

EASLEY, M.W. Dental public health practice: political science meets health science - a case study in successful technology transfer. Journal of Theory and Practice of Dental Public Health, [S.I.] v. 1, n. 1., p.15-18, 2013.

EUROPEAN COMMISSION. Scientific Committee on Health and Environmental Risks. Critical review of any new evidence on the hazard profile, health effects, and human exposure to fluoride and the fluoridating agents of drinking water. Bruxelas, 2010.

FERREIRA, R. G. L. A.; NARVAI, P. C. Fluoretação da água: significados e lei da obrigatoriedade na visão de lideranças em saúde. Revista da Associação Paulista de Cirurgiões Dentistas, São Paulo, v. 69, n. 3, p. 266-71, 2015. 
FRAZÃO, P. Debate ultrapassa fronteira da ciência. Revista da Associação Brasileira de Odontologia, São Paulo, v. 14, n. 10, p. 136-7, 2006.

FRAZÃO, P. Epidemiologia da saúde bucal. In: PEREIRA, A. C. Odontologia em saúde coletiva. Porto Alegre: Artmed, 2003. p. 64-82 .

FRAZÃO, P.; PERES, M. A.; CURY, J. Qualidade da água para consumo humano e concentração de fluoreto. Revista de Saúde Pública, São Paulo, v. 45, n. 5, p. 964-973, 2011.

FRAZÃO, P. Epidemiology of dental caries: when structure and context matter. Brazilian oral research, São Paulo, v. 26, p. 108-114, 2012. Suplemento.

FRAZÃO, P. et al. Fluoretação da água e insuficiências no sistema de informação da política de vigilância à saúde. Revista da Associação Paulista de Cirurgiões Dentistas, São Paulo, v. 67, n. 2, p. 94-100, 2013.

GABARDO, M. C. et al. Waterfluoridation as a marker for socio dental inequalities. Community dentistry and oral epidemiology, Copenhagen, $\mathrm{v}$. 36, n. 2, p. 103-107, 2008.

GAZZANO, E. et al. Fluoride effects: the two faces of janus. Current Medicinal Chemistry, Schiphol, v. 17, p. 2431-2441, 2010.

GOES, P. S. A. et al. Avaliação da atenção secundária em saúde bucal: uma investigação nos centros de especialidades do Brasil. Caderno Saúde Pública, Rio de Janeiro v. 28, p. 81-89, 2012. Suplemento.

GUIMARAES, M. C. L. et al . Avaliação da capacidade de gestão de organizações sociais: uma proposta metodológica em desenvolvimento. Caderno de Saúde Pública, Rio de Janeiro, v. 20, n. 6, p. 1642-1650, 2004.

IBGE. Pesquisa nacional por amostra de domicilios. Rio de Janeiro, 2003. IHEOZOR-EJIOFOR et al. Water fluoridation for the prevention of dental caries. The Cochrane database of systematic reviews, Oxford, n. 6, 2015 .

KALAMATIANOS, P. A.; NARVAI, P. C. Aspectos éticos do uso de produtos fluorados no Brasil: uma visão dos formuladores de políticas públicas de saúde. Ciência e Saúde Coletiva, Rio de Janeiro, v. 11, n. 1, p. 63-69, 2006. 
KNOEPFEL, P.; LARRUE, C.; VARONE, F. Public Policy Analysis. Bristol: The Policy Press, 2007.

KUMAR, J. V. Is Water fluoridation still necessary? Advances in Dental Research, Alexandria, v. 20, p. 8-12, 2008.

LINO, P. A. et al. Análise da atenção secundária em saúde bucal no estado de Minas Gerais, Brasil. Ciência Saúde Coletiva, Rio de Janeiro. v. 19, n. 9, p. 3879-3888, 2014.

MACHADO, F. C. A.; SILVA, J. V.; FERREIRA, M. A. F. Fatores relacionados ao desempenho de Centros de Especialidades Odontológicas. Ciência Saúde Coletiva, Rio de Janeiro, v. 20, n. 4, p. 1149-1163, abr. 2015.

MAIA, L.S.; KORNIS, G. E. M. A Reorganização da Atenção à Saúde Bucal frente aos incentivos federais: a experiência fluminense. Revista de atenção primária saúde - APS, Juiz de Fora, v. 13, n. 1, p. 84-95, 2010.

MATUS, C. Política, planejamento e governo. 2. ed. Brasília, DF: IPEA. 1996.

MATUS, C. Teoria do jogo social. São Paulo: FUNDAP, 2005.

MCDONAGH, M. et al. A systematic review of public water fluoridation. York: NHS Centre for Reviews and Dissemination. University of York, 2000. (Report 18).

MCKAY, F. S. Mottled Enamel: the prevention of its further production through a change of the water supply at Oakley, IDA. Journal of the American Dental Association- JADA, Chicago, v. 20, n.7, p.1137-49, 1933.

MENDES-GONÇALVES, R. B. Práticas de Saúde: processos de trabalho e necessidades. São Paulo: CEFOR, 1992.

MENDES- GONÇALVES, R. B. Tecnologia e organização social das práticas de saúde: características tecnológicas de processo de trabalho na rede estadual de centros de saúde de São Paulo. São Paulo: Hucitec: Abrasco, 1994.

NASCIMENTO, A. C. et al. Oral health in the family health strategy: a change of practices or semantics diversionismo. Revista de Saúde Pública, São Paulo, v. 43, n. 3, p. 455-462, 2009. 
NARVAI, P. C.; FRAZÃO, P. Epidemiologia, política e saúde bucal coletiva. In: ANTUNES; J. L. F.; PERES, M. A. (Ed.). Epidemiologia da saúde bucal. Rio de Janeiro: Guanabara Koogan; 2006. p. 346-362.

NARVAI, P. C. Cárie dentária e flúor: uma relação do século XX. Ciência e Saúde Coletiva, Rio de Janeiro, v. 5, n. 2, p. 381-92, 2000.

OLIVEIRA, E. R. S. B.; QUEIRÓZ, D. M.; OLIVEIRA, R. F. Avaliação da atenção odontológica no município de Montes Claros (MG) utilizando o Sistema de Informações Ambulatoriais do Sistema Único de Saúde. Unimontes Científica, Montes Claros, v. 16, n.1, p. 4-14, jan./jun. 2014.

PECKHAM, S.; AWOFESO, N. Water fluoridation: a critical review of the physiological effects of ingested fluoride as a public health intervention. The Scientific World Journal, [S.I.] v. 2014, p. 1-10, 2014.

PEDUZZI, M.; SCHRAIBER, L. B. Processo de trabalho em saúde: dicionário da educação profissional em saúde. Rio de Janeiro: Fundação Oswaldo Cruz, 2009.

PERES, M. A.; FERNANDES, S. L.; GLAZER, P. K. Inequality of water fluoridation in Southern Brazil :the inverse equity hypothesis revisited. Social Science \& Medicine, New York, v. 58, n .6, p.1181-1189, 2004.

PIMENTEL, F.C. et al. Análise da atenção à saúde bucal na estratégia de saúde da família do distrito sanitário VI, Recife (PE). Ciência e Saúde Coletiva, Rio de Janeiro, v.15, n.4, p. 2189-2196, 2010.

PINELL, P. Análise sociológica das políticas de saúde. Rio de Janeiro: Ed. Fiocruz, 2010.

PINTO, I. C. M. Ascensão e Queda de uma questão na agenda governamental: o caso das organizações sociais da saúde na Bahia. Salvador, 2003. 238f. Tese (Doutorado em administração) - Faculdade de administração, Universidade Federal da Bahia, Salvador, 2003.

PINTO, V. P. T. et al. Avaliação da acessibilidade ao Centro de Especialidades Odontológicas de abrangência macrorregional de Sobral, Ceará, Brasil.Ciência e Saúde Coletiva, Rio de Janeiro, v. 19, n. 7, p. 2235$2244,2014$. 
PIRES, F. S.; BOTAZZO, C. Organização tecnológica do trabalho em saúde bucal no SUS: uma arqueologia da política nacional de saúde bucal. Saúde e Sociedade, São Paulo, v. 24, n. 1, p. 273-284, 2015.

PORTILHO, J. A. C.; FERREIRA, L. B. Sobre os avanços da Política Nacional de Saúde Bucal. Tempus: actas de saúde coletiva, Brasília, DF, v. 5, n. 3, p. 35-47, 2011.

RENDEIRO, M. M. P. O ciclo da política de saúde bucal no sistema de saúde brasileiro: atores, ideias e instituições. Rio de Janeiro, 2011. $188 \mathrm{f}$. Tese (Doutorado em Saúde pública) - Escola Nacional de Saúde Pública Sergio Arouca, Fundação Oswaldo Cruz, 2011.

ROSSI, T. R. A.; CHAVES, S. C. L. Implementação da atenção especializada em saúde bucal em dois municípios na Bahia/ Brasil. Saúde em Debate Rio de Janeiro, v. 39, p. 196-206, dez. 2015. Edição especial.

SALIBA, N. A. et al. Organização da demanda de um Centro de Especialidades Odontológicas. Revista de Odontologia da UNESP, Marília, v. 42, n. 5, p. 317-323, 2013.

SANCHEZ, H. F. et al. Integrality in everyday dental care: review of the literature. Trabalho, Educação e Saúde, Rio de Janeiro, v. 13, n. 1, p. 201-214, 2015.

SHEIHAM, A. Oral health, general health and quality of life. Bull World Health Org, Genebra, v. 83, n. 9, p. 644, 2005.

SOARES, C. L. M.; PAIM, J. S. Aspectos críticos para a implementação da política de saúde bucal no Município de Salvador, Bahia, Brasil.

Caderno de Saúde Pública, Rio de Janeiro, v. 27, n. 5, p. 966-974, maio 2011.

SOARES, F. F. et al. Atuação da equipe de saúde bucal na estratégia saúde da família: análise dos estudos publicados no período 2001-2008. Ciência e Saúde Coletiva, Rio de Janeiro, v. 16, n. 7, p. 3169-3180, 2011.

SOARES, F. F.; CHAVES, S. C. L.; CANGUSSU, M. C. T. Governo local e serviços odontológicos: análise da desigualdade na utilização local. Caderno de Saúde Pública, Rio de Janeiro, v. 31, n. 3, p. 586-596, 2015. 
SOUZA, J. C. A gênese do programa de incentivo fiscal à alimentação do trabalhador (PIFAT /PAT). 2013. 261 f. Tese (Doutorado em Saúde Pública) - Instituto de Saúde Coletiva, Universidade Federal da Bahia, Salvador, 2013.

TEIXEIRA, C. F. Enfoques teórico-metodológicos do planejamento em saúde. In: TEIXEIRA, C. Planejamento em saúde: conceitos, métodos e experiências. Salvador: EDUFBA, 2010.

TESTA, M. Pensar em Saúde. Porto Alegre: Artes Médicas, 1992.

TRAVASSOS, C.; MARTINS, M. Uma revisão sobre os conceitos de acesso e utilização de serviços de saúde. Caderno de Saúde Pública, Rio de Janeiro, v. 20, p. 190-8, 2004.

TRUMAN, B. I. et al. Reviews of evidence on interventions to prevent dental caries, oral and pharyngeal cancers, and sports-related craniofacial injuries. American Journal of Preventive Medicine, Washington, v. 23, n.1, p. 21-54, 2002.

VAZQUEZ, F. L. et al. Referencia e Contrarreferencia na atencao Secundaria em odontologia em Campinas, SP, Brasil. Ciência e Saúde Coletiva, Rio de Janeiro, v. 19, n. 1, p. 245-256, 2014.

VIANA, A. L. D. V; BAPTISTA, T. W. F. Análise de Políticas de Saúde. In: GIOVANELLA, L. et al. Políticas e sistemas de saúde no Brasil. Rio de Janeiro: Ed.Fiocruz, 2008. p. 65-106.

VIEIRA-DA-SILVA, L; PINELL, P. The Genesis of Collective Health in Brazil. Sociology of Health \& Illness, Oxford, v. 36, n. 3, p. 432-446, 2014.

VILASBÔAS, A. L. Q.; PAIM, J. S. Práticas de planejamento e implementação de políticas no âmbito municipal.Cadernos de Saúde Pública, Rio de Janeiro, v. 24, p. 1239-1250, 2008.

WORLD HEALTH ORGANIZATION- WHO. Sixtieth World Health Assembly.Resolution. Geneva, 2007.

WHYMAN, R. A.; MAHONEY, E. K.; BORSTING, T. Community water fluoridation: attitudes and opinions from the New Zealand Oral Health Survey. Australian and New Zealand journal of public health. Canberra, v. 401, n. 2, p. 186-192, 2015. 
ZAITTER W. M. et al. Avaliação da acessibilidade do paciente à clínica de especialidades de Endodontia em dois distritos de saúde do município de Curitiba (PR). Revista Sul-brasileira de Odontologia, Joinville , v. 6, n. 4, p. 413-420, 2009. 
Monique Azevedo Esperidião, Carla Soares, Carolina Rodrigues, Marta Caires de Souza, Raquel Malheiros, Andréa Montalvão e Laiana Behy

\section{A INFÂNCIA COMO OBJETO DE ANÁLISE POLÍTICA EM SAÚDE}

\section{Introdução}

As políticas de atenção à saúde da criança, no Brasil, vêm sofrendo transformações em função de sua inserção histórica, dos avanços do conhecimento científico e da constituição de um espaço médico especializado, bem como de influências de organismos internacionais, configurando-se no interior de um espaço social que envolve o engajamento de distintos agentes sociais. A mortalidade infantil ainda vem sendo apontada como grande desafio para o país e a tomada deste tema pelo Estado brasileiro reveste-se de uma perspectiva desenvolvimentista, sendo a saúde das crianças a garantia da prosperidade da nação. (ARAÚJO et al., 2014)

Em geral, os estudos sobre as políticas de saúde voltadas para a infância analisam seu impacto na mortalidade infantil, a sua implementação bem como a qualidade do cuidado prestado. Alguns trabalhos mostram, contudo, que a sua formulação responde a determinações históricas e estruturais que têm sido pouco investigadas no nosso meio. (WARDE, 2007) O acompanhamento dessas políticas 
com o objetivo de produzir conhecimento capaz de contribuir para o seu aperfeiçoamento requer ,além de estudos avaliativos, a identificação desses processos sociais subjacentes.

Por essas razões, a construção e implementação de políticas voltadas para "proteção à infância" devem ser analisadas à luz das transformações nas relações entre o processo de especialização do campo médico e a questão da medicalização da infância (medicalização de doenças, incluindo transtornos do comportamento e escolares; e de práticas sociais com intervenções sobre a família, como a inculcação da higiene nas mães de famílias pobres).

Faz-se necessário analisar a constituição da infância como um problema das sociedades contemporâneas que requer intervenção estatal, tendo como resposta as políticas de luta contra a mortalidade infantil, a emergência da puericultura e de uma medicina da primeira infância e da atenção ao recém-nascido.

\section{Políticas de combate à mortalidade infantil}

A chamada "morte menina" (VAILATI, 2010), outrora esperada no Brasil dos oitocentos, há quase dois séculos, vem sendo temida e enfrentada pelo Estado e sociedade brasileiros. Seguramente, inúmeras conquistas são hoje festejadas - o país conseguiu exceder as Metas do Milênio da Organização das Nações Unidas (ONU), de redução de dois terços da mortalidade infantil de 1990 até 2015, em 2011, quatro anos antes do prazo assumido perante a organização. Além da redução na mortalidade infantil, o país vem apresentando resultados satisfatórios na queda do déficit de altura de crianças menores de cinco anos de idade e na melhoria ao acesso aos serviços de saúde, com coberturas quase universais para imunização e atendimento hospitalar ao parto. (VICTORA et al., 2011) Contudo, o Brasil enfrenta ainda os reflexos da perversa iniquidade regional e socioeconômica que marca o país e, em bolsões de miséria, perdem-se crianças antes de completarem o primeiro ano de vida. (VICTORA et al., 2011) 
Até o início do século XX, a atenção dispensada às crianças tinha um caráter filantrópico, assentada em propostas da puericultura. Surgiram as primeiras instituições de assistência e proteção à infância, bem como institutos profissionalizantes voltados às crianças doentes e abandonadas. (NOVAES, 1979)

As primeiras políticas organizadas pelo Estado brasileiro dirigidas à saúde das crianças remontam à criação do Estado Novo, pelo presidente Vargas. Em 1940, foi instituído o Departamento de Saúde da Criança, como forma de proteção social e melhoria das condições de vida e saúde da nascente classe trabalhadora no país. Tratava-se da organização de serviços, como creches, junto às fábricas. Tal departamento ocupou-se por quase 30 anos de uma série de ações programáticas com baixa integração. (TYRREL, 1997)

Ainda na década de 1970, sob a influência dos movimentos da medicina preventiva e comunitária, a importância da saúde materno -infantil foi reafirmada, mas as políticas implantadas tiveram pequeno alcance uma vez que o modelo assistencial vigente conformava-se pela divisão entre a saúde pública e a assistência médica individual com forte exclusão social. Em 1973, foi lançado o Programa Nacional de Imunizações (PNI), com o objetivo de coordenar as ações de imunizações, até então de caráter episódico e de reduzida cobertura. Tratava-se de experiências de caráter vertical, centralizadas e com viés tecnocrata. (TYRREL, 1997) O Programa de Atenção à Criança, implantado em 1976, resultou em um atendimento público racionalizador e burocrático. (ZANOLLI; MERHY, 2001)

Na década de 1980, já sob influência das lutas trazidas pelo movimento da Reforma Sanitária Brasileira, surge o Programa Nacional de Incentivo ao Aleitamento Materno, de 1981. Considerado exitoso, tinha a finalidade de incentivar o aleitamento materno e reduzir o desmame precoce. (BRASIL, 1991)

Em 1984, foi implantado o Programa de Assistência Integral à Saúde da Criança (PAISC), organizado como estratégia de combate à mortalidade infantil, considerada elevada, com ações voltadas para o enfrentamento às adversidades nas condições de saúde das 
crianças. (BRASIL, 1995) O PAISC representou assim uma iniciativa para promover a saúde de forma integral, priorizando agravos e crianças mais vulneráveis e propondo a expansão da cobertura. As ações estavam centradas no acompanhamento do crescimento e desenvolvimento, incentivo ao aleitamento materno, controle das doenças diarreicas, controle das infecções respiratórias agudas e na imunização. Surge, nesse período, o primeiro Cartão de Saúde da Criança. A abordagem epidemiológica desse programa encontravase relacionada à explicação do binômio desnutrição-infecção na estrutura de morbimortalidade infantil, sendo evidenciada uma cadeia de determinantes sociais ligados ao quadro de precárias condições de vida a que estava submetida a maioria das crianças brasileiras. (FIGUEIREDO; MELLO, 2007)

Com a criação do Sistema Único de Saúde (SUS), nos anos 1990, a saúde passa a ser assegurada como direito dos brasileiros e surge uma nova concepção organizativa do sistema de saúde, numa compreensão descentralizada, hierarquizada e regionalizada. A saúde da criança ganha novas perspectivas e impulsos. A consolidação do Programa Agentes Comunitários de Saúde (PACS) e do Programa Saúde da Família (PSF), especialmente nos municípios de pequeno porte das regiões Norte e Nordeste, foi decisiva para ampliação do acesso aos serviços com repercussões diretas à saúde das crianças. Posteriormente, com expansão da Estratégia Saúde da Família (ESF), essa conexão ficará mais forte. (FIGUEIREDO; MELLO, 2007)

Em 1995, o Ministério da Saúde (MS) lançou o Projeto de Redução da Mortalidade Infantil (PRMI) (BRASIL, 1995) com a finalidade de alcançar as Metas da Cúpula Mundial em Favor da Infância. O projeto visava a redução dos óbitos infantis e a melhoria da situação de saúde das crianças por meio da articulação intersetorial entre distintos programas governamentais, articulação com organizações nãogovernamentais, sociedades científicas, conselhos de secretários de saúde e a sociedade, além de cooperação com organismos internacionais, o Fundo das Nações Unidas para a Infância (Unicef) e a Organização Pan-Americana da Saúde (Opas). 
Em 1997, inicia-se, primeiramente em quatro estados (Pará, Pernambuco, Sergipe e Ceará), a iniciativa Atenção Integrada às Doenças Prevalentes na Infância (AIDPI), promovida pela OMS, Opas e Unicef. A AIDPI tinha por objetivo a redução da mortalidade em crianças menores de cinco anos e a organização da assistência à criança na atenção primária à saúde, enfatizando para além das ações assistenciais, propostas voltadas para promoção da saúde, prevenção de doenças e agravos. Em 2001, todos os estados e o Distrito Federal já haviam implantado a AIDPI. (BRASIL, 2002a)

Ainda no âmbito da atenção básica à saúde, foi lançado pelo MS, em 2002, o Caderno de atenção básica - Saúde da Criança: acompanhamento do crescimento e desenvolvimento infantil (BRASIL, 2002a), que reunia medidas para o crescimento e o desenvolvimento saudáveis. Tais medidas deveriam ser integradas ao AIDPI.

No ano de 2004, o MS reconheceu aravidade das taxas de mortalidade materna e neonatal brasileiras, entendendo que estas mortes representam formas de violação aos direitos humanos de mulheres e crianças. Por essa razão, propôs o Pacto pela Redução da Mortalidade Materna e Neonatal, cujo objetivo era criar soluções sustentáveis e dividir responsabilidades entre entes federativos e sociedade civil contra a mortalidade materna e neonatal. (BRASIl, 2004a)

Ainda em 2004, o MS apresentou a Agenda de Compromissos com a Saúde Integral da Criança e a Redução da Mortalidade Infantil, que visava à criação de uma rede única integrada de assistência à criança. $\mathrm{O}$ documento propunha uma série de ações para superar a falta de articulação entre os diversos níveis de atenção à saúde, garantindo a continuidade e a efetividade dos cuidados prestados às crianças. Também em 2005 foram criados os comitês locais para prevenção da mortalidade infantil. (BRASIL, 2004b)

Em 2006, a redução da mortalidade infantil foi ratificada como política de governo e incluída no Pacto pela Vida, expressando compromissos sanitários com a saúde da criança. (BRASIL, 2006) Em 2008, no Programa Mais Saúde, eixo "Promoção da Saúde", destacase a política "Brasileirinhos Saudáveis: primeiros passos para o de- 
senvolvimento nacional", que previa um conjunto de ações voltadas para a promoção da saúde e o acompanhamento de gestantes e crianças de zero a cinco anos. (BRASIL, 2008)

Em 2012, foi lançado o Programa Brasil Carinhoso que destacou o compromisso do Governo Federal em fortalecer estratégias para o desenvolvimento integral da primeira infância brasileira, envolvendo os ministérios da Saúde, Educação e Desenvolvimento Social e Combate à Fome. O Brasil Carinhoso previu a ampliação do Programa Bolsa Família para crianças até seis anos, maior acesso a creches por meio do Programa Saúde na Escola, maior prevenção de anemia por deficiência de ferro e prevenção da deficiência de vitamina A, com a suplementação oferecida nos centros de saúde como importante ação que impacta diretamente no crescimento da criança, na capacidade de aprendizagem e no desenvolvimento cognitivo. (BRASIL, 2015a)

Apenas em novembro de 2014, foi aprovada a Política Nacional de Atenção Integral à Saúde da Criança (PNAISC), bastante feste310 jada e comemorada pelos atores envolvidos na luta em favor da infância. A política possibilita a integração dos programas existentes e tem em vista a atenção integral às crianças, especificamente para primeira infância. A política foi proposta pela Coordenação de Saúde da Criança e Aleitamento Materno (CGSCAM) do MS, em parceria com a equipe da Estratégia Brasileirinhas e Brasileirinhos Saudáveis, do Instituto Nacional de Saúde da Mulher, da Criança e do Adolescente Fernandes Figueira(IFF).

A PNAISC procura implementar os direitos das crianças, previstos na Constituição Federal e no Estatuto da Criança e do Adolescente (ECA), contemplando crianças e adolescentes menores de 16 anos com especial atenção à primeira infância e às crianças em situação de maior vulnerabilidade, para reduzir a morbimortalidade e favorecer um ambiente facilitador à vida e ao pleno desenvolvimento.

No âmbito da sociedade civil, algumas iniciativas recentes merecem ser destacadas, como a Rede Nacional Primeira Infância (RNPI). A RNPI iniciou suas ações em 2007 e hoje compreende 
mais de 160 organizações de todas as regiões do Brasil mobilizadas pela causa da infância. Ela foi responsável pela elaboração do Plano Nacional pela Primeira Infância, priorizando todos os direitos da Primeira Infância, com metas até 2022. O plano foi aprovado pelo Conselho Nacional pelos Direitos da Criança (Conanda), em 2010, e acolhido pela Secretaria de Direitos Humanos da Presidência. Em 2014, foi criado também o Comitê de Especialistas e Mobilização Social para o Desenvolvimento na Primeira Infância, no MS.

Finalmente, cabe refletir que as políticas que tomam a infância como objeto são majoritariamente setoriais, limitadas a intervenções pontuais e fragmentadas. O lançamento da política nacional, apenas em dezembro de 2014, ilustra como as ações encontravam-se pulverizadas e desconexas. Investimentos estruturais, com ação coordenada sobre as condições de vida, em especial na educação e na geração de emprego para as famílias, representam perspectivas mais promissoras e com maior impacto. (VICTORA, 2001) De fato, trabalhos recentes mostram efeito positivo de programas sociais como Bolsa Família (RASELLA etal., 2013) e da ESF na redução da mortalidade infantil. (AQUINO; OLIVEIRA; BARRETO, 2009) Ao lado do desafio de redução das desigualdades, persiste a necessidade de redução do elevado número de cesarianas, nascimentos pré-termo e abortos inseguros. (VICTORA et al., 2011)

\section{Reflexões acerca do conceito de infância}

A conceitualização da infância tem sido objeto de luta entre diferentes campos científicos, teorias e instituições. Na antiguidade, a infância não existia enquanto objeto de discurso ou de preocupações específicas, sendo a criança considerada apenas um adulto em miniatura. Conforme destaca Ariès (1986), não havia um sentimento de infância. A preocupação e a conceitualização da infância surge com a modernidade, porém não tinha o cuidado à criança como um fim em si mesmo, mas com o adulto do futuro. A criança era, portanto, conceitualizada pelo seu devir. 
Nos séculos XIX e XX, surge a infância científica, com o reconhecimento desta como uma etapa do desenvolvimento e objeto de estudo de diversas áreas do saber. Surgem então múltiplas prescrições para cuidados nesse período: normas de higiene, campanhas de amamentação, instituições de atendimento, entre outros. (BARBOSA, 2006)

O conceito biológico, predominante no senso comum e em políticas públicas, demarca a infância como etapa do desenvolvimento marcada por um intervalo delimitado cronologicamente ( 0 aos 12 anos, 0 aos 9 anos) ou por maturação anatômica e fisiológica (nascimento à entrada na puberdade). Essa perspectiva é a mais utilizada por documentos institucionais e políticas públicas, pelo menos no que tange à definição. Nesse sentido, o documento nacional mais recente (BRASIL, 2015a) se refere à criança como a pessoa na faixa etária de zero a nove anos. A definição do PNAISC difere de documentos nacionais e internacionais anteriores, uma vez que o ECA (BRASIL, 1990) define o limite etário do fim da infância aos 12 anos e a Convenção dos Direitos da Criança (ONU, 1989) o coloca aos 18 anos.

Conceitos frequentemente utilizados pela psicologia do desenvolvimento e pela educação modernas partiram também da perspectiva de infância como fase do desenvolvimento, na qual a criança, progressivamente e dadas as condições necessárias, adquire as características de um adulto. Assim, a criança foi teorizada da perspectiva do seu desenvolvimento cognitivo, moral, emocional, entre outros.

Buscando um conceito de infância para a pós-modernidade, a educação, a psicologia e áreas do conhecimento, fortemente encabeçadas pela sociologia da infância propõem rompimento com o paradigma de fragilidade, inocência, dependência e incapacidade que costumavam nortear essa conceitualização. Passam a reconhecer a criança como sujeito ativo, coconstrutor de conhecimento, identidade e cultura. (BARBOSA, 2006; JAVEU, 2005; QVORTRUP, 2010; SARMENTO, 2005) 
Nesse sentido, iniciam por problematizar "a negatividade constituinte da infância” (SARMENTO, 2005, p. 368), que tende a definir essa categoria pelas suas faltas: infância, idade do não falante ou inarticulado; juridicamente inimputável e socialmente interditado. Embora essas características e interdições sejam a base da proteção da criança e, portanto, avanços civilizatórios, o autor as utiliza para enfatizar o fato de que os esforços de definição e descrição da condição infantil partiram do que lhes falta, em lugar de buscar o que positivamente lhes define. Destaca o autor que há “ [...] um efeito simbólico de conceptualização e representação sócio-jurídica da infância pela determinação dos factores de exclusão e não, prioritariamente, pelas características distintivas ou por efectivos direitos participativos”. (SARMENTO, 2005, p. 368)

Outro ponto importante da conceitualização pós-moderna de infância é a busca desses teóricos por uma diferenciação conceitual entre infância e criança. Considera-se infância, portanto, como uma categoria social do tipo geracional, e criança como sujeito concreto integrante dessa categoria, e também ator social com outro pertencimentos, como classe e gênero. (QVORTRUP, 2010; SARMENTO, 2005)

Numa diferenciação similar, Javeu (2005), vai mais além, com as categorias criança, infância, crianças, às quais atribui a diferentes áreas do conhecimento. $\mathrm{O}$ autor atribui o termo "criança" ao campo da psicologia, cujas disciplinas relacionadas, de acordo com o autor, legitimaram um discurso sobre etapas de desenvolvimento da criança. A "criança”, nesse caso, é pensada como objeto abstrato “[...] destinado a passar por níveis diversos e sucessivos na aquisição de competências, cada um deles constituindo uma etapa na fabricação da personalidade dos indivíduos". (JAVEU, 2005, p. 382)

O termo "infância" é atribuída pelo autor à perspectiva demográfica, na qual é colocada lado a lado com outras faixas etárias (adolescência, idade adulta, terceira idade), e caracterizada pela sua improdutividade. O termo "crianças" pertence ao último campo semântico listado pelo autor, o da antropologia, que tem como foco o 
grupo de indivíduos no seu território, com suas estruturas e modelos de comportamento específicos. (JAVEU, 2005)

Essas perspectivas emergentes sobre criança e infância trazem consigo mudanças nas reflexões sobre aspectos heterogêneos e homogêneos desta geração. Compreende-se a infância como historicamente construída, através de um longo e continuamente atualizado processo que elabora as bases ideológicas e normativas do lugar da criança na sociedade. Participam desse processo variações demográficas, relações econômicas, políticas públicas, dispositivos simbólicos e estilos de vida. (QVORTRUP, 2010;SARMENTO, 2005) Nesse sentido, discute-se que se trata de "infâncias", no plural, pela forma como a categoria geracional em questão está imbrincada com outras de ordem étnica, social, econômica e de gênero.

\section{Estado da arte sobre políticas de saúde da criança}

A criança é um ser que vive intensas transformações, tanto biológicas quanto afetiva, psicológicas e sociais, desde sua vida intrauterina até o seu completo desenvolvimento que culmina com o final da adolescência. Portanto, pensar na saúde de seres que vivem uma série de transformações tão complexas é adquirir uma visão integral e multidisciplinar da saúde. No entanto, a criação e implementação de políticas públicas voltadas para essa faixa etária enfrenta uma série de dificuldades, inclusive porque a compreensão da infância foi bastante controversa ao longo dos séculos.

Para Araújo e colaboradores (2014), a criança ocupou diferentes papéis na sociedade, que, ao longo dos anos, sofreu inúmeras transformações. Essas modificações conduziram ao enfrentamento de diversas situações que repercutiam em sua qualidade de vida e, consequentemente, na saúde. Desse modo, com o transcorrer do tempo, a criança adquiriu um caráter de sujeito social assumindo as características próprias de acordo com o seu período de vida.

Até o século XVI, a sociedade não percebia as particularidades da infância e as crianças eram tratadas da mesma forma que os adul- 
tos. Sendo assim, não havia uma compreensão do significado da infância para o desenvolvimento humano. A partir do século XVII, a criança passou a ocupar um espaço social, uma vez que as famílias passam a demonstrar sentimentos familiares pelos infantes. No entanto, a preocupação com a saúde e o bem estar da criança só é percebido pela sociedade a partir do século XX. (ARAÚJO et al., 2014)

Em 1920, as entidades públicas e privadas demonstraram preocupação com a saúde infantil uma vez que as crianças eram dependentes dos trabalhadores das fábricas, sobretudo das mulheres. Assim, nesse período, passou-se a discutir sobre o aleitamento materno, uma vez que a amamentação reduzia o adoecimento de crianças ainda na primeira infância, o que permitia que suas mães cumprissem a jornada de trabalho com mais regularidade. (ARAÚJO et al., 2014)

Entre os anos de 1930 e 1940, alguns programas voltados à maternidade e infância foram criados de acordo com as propostas do Departamento Nacional da Criança. No entanto, essas ações voltadas para a gravidez e a primeira infância possuíam um caráter individualizado, curativo e voltado para um modelo de saúde altamente hospitalocêntrico. Portanto, não considerava a importância de ações coletivas com foco na promoção da saúde e não apenas na prevenção, e tampouco que as características individuais repercutem no quadro de saúde e bem estar de toda uma sociedade e não apenas de uma pessoa ou família. (ARAÚJO et al., 2014; ROCHA et al., 1998; SOUZA; OLIVEIRA, 2004)

Para Souza e Oliveira (2004), partir de 1930, a política de saúde nacional foi centralizada em dois subsetores: a saúde pública e a medicina previdenciária, sendo a saúde pública mais prevalente. Com o desenvolvimento do ensino da pediatria, a assistência à criança foi institucionalizada através da puericultura e da assistência médica privada. Porém, a política social tinha como pilar central o assistencialismo de caráter populista.

Ramos e Maia (1999) afirmaram que o desenvolvimento de políticas de saúde é realizado através do planejamento social de políti- 
cas de saúde e, sendo assim, fazem parte de um ato político e social. Portanto, os planejadores de políticas públicas devem não apenas exercer o seu papel, mas também, adquirir uma competência política.

Crianças e adolescentes estão em pleno desenvolvimento e, a depender de cada fase de crescimento, possuem necessidades específicas. A condição de existência e a qualidade de vida de uma criança estão diretamente relacionadas às suas fragilidades e riscos de adoecimento. No entanto, as disparidades apresentadas nessa faixa etária transcendem as diferenças biológicas do organismo uma vez que as desigualdades e iniquidades sociais são determinantes igualmente relevantes para o amadurecimento pleno de uma criança. (ROCHA et al., 1998)

Dessa forma, o ECA, lei 8.069 de 1990, regulamenta que a criança possui direito à vida e à saúde desde o momento da concepção até a adolescência e que cabe ao Estado, por intermédio do SUS, promover programas de assistência médica e odontológica para prevenção das comorbidades recorrentes na população infantil e campanhas 316 de educação sanitária nas escolas e para os familiares. (CABRAL; AGUIAR, 2003)

No entanto, analisando as políticas de saúde voltadas para a infância, percebemos através de investigações mais atuais que a sociedade ainda atribui, de forma centralizada, os cuidados da saúde em dois polos: a rede hospitalar e os serviços nas comunidades. (ROCHA et al., 1998)

Oliva e Kauchakje (2009) realizaram uma pesquisa sobre os direitos de crianças e adolescentes com ênfase na efetivação de políticas voltadas para a educação, saúde e assistência social nas capitais brasileiras e perceberam que há uma heterogeneidade de ações entre as capitais, entretanto, políticas públicas com ações voltadas para a educação ainda são maioria quando comparadas com as demais políticas públicas do estudo. Ainda segundo essa pesquisa, os objetivos voltados à política de saúde são os menos mencionados, e quando surgem, aparecem em maior quantidade no sul do país. 
Por meio desse estudo, podemos perceber que a efetivação de políticas públicas voltadas para a saúde da criança e do adolescente ainda são negligenciadas perante o governo e a sociedade, apesar dos esforços e dos debates constantes sobre essa temática no nosso país.

Ao avaliar o uso de serviços da atenção primária à saúde pela população infantil do estado do Maranhão, Cunha e colaboradores (2013) observaram que praticamente todas as variáveis do estudo obtiveram um incremento positivo em relação ao estudo da década passada. O acesso ao serviço público ascendeu cerca de $17 \%$ e as consultas de puericultura no primeiro ano de vida e antes do primeiro mês de vida cresceram em média $10 \%$. Assim, analisando as políticas de saúde voltadas para a infância, há uma década, observou-se a melhoria em alguns indicadores de atenção à saúde da criança do estado do Maranhão, que possivelmente está relacionada aos processos de implementação e aperfeiçoamento da ESF.

Segundo uma pesquisa realizada por Finkler e colaboradores (2014), a maioria dos atendimentos realizados às crianças na atenção básica ocorre por meio de consultas médicas onde o foco principal são as situações de agudização dos processos de doença. Assim, a saúde da criança não contempla a integralidade do cuidado e propõe um acesso à atenção primária a saúde fragilizado, fragmentado e descoordenado.

De acordo com Pimenta, Rocha e Marcondes (2015), as políticas públicas brasileiras voltadas para intervenções na obesidade infantil conduzem suas ações na prevenção da doença e na promoção de uma vida futura mais saudável através de ações de educação, orientação e estímulo de atividades físicas e de uma dieta equilibrada. Por conseguinte, os autores defendem que as políticas públicas voltadas para intervenções na obesidade infantil não devem se restringir apenas ao âmbito da saúde. Essas ações, portanto, devem possuir um caráter intersetorial abrangendo o máximo de setores do serviço público.

A Política Nacional de Alimentação e Nutrição (PNAN) e a Política nacional de Promoção à Saúde (PNPS) possuem ações es- 
pecíficas, segundo os determinantes sociais da saúde. A PNAN enfatiza a promoção de uma vida saudável bem como melhoria das condições de alimentação, nutrição e saúde da população brasileira, mediante práticas de alimentação saudáveis, vigilância alimentar e nutricional e prevenção e cuidado dos agravos relacionados à nutrição e a dieta. (PIMENTA; ROCHA; MARCONDES, 2015)

Já as ações da PNPS possuem um foco maior na capacidade de autorregulação do indivíduo com relação ao seu próprio cuidado em parceria com o Estado, que jamais deve se ausentar da sua responsabilidade. Assim, a PNPS promove a divulgação e implantação da política nacional de promoção à saúde, alimentação saudável e prática de exercícios físicos, prevenção e controle do tabagismo, que se relacionam diretamente com a obesidade. (PIMENTA; ROCHA; MARCONDES, 2015)

Além disso, o Programa de Saúde na Escola (PSE) e a Câmara Interministerial de Segurança Alimentar e Nutricional (Caisan), que lançou o Plano Intersetorial de Prevenção e Controle da Obesidade, também possuem estratégias para prevenir e controlar a obesidade infantil. Porém, Pimenta, Rocha e Marcondes (2015) pontuam ainda que a não eficácia de medidas corretivas, preventivas e de promoção no tocante à obesidade infantil são decorrentes também do sistema político e econômico vigente no país e que a compreensão da obesidade infantil no âmbito das Políticas Públicas - uma macro perspectiva - é de extrema relevância.

Para Couto, Duarte e Delgado (2008), que descreveram e analisaram a situação atual de desenvolvimento da política pública brasileira de saúde mental infantil e juvenil, os dados obtidos no presente estudo sugerem a existência de três grandes desafios a serem enfrentados pelo setor específico da saúde mental infantil e juvenil: inicialmente, através da situação de implantação de dispositivos para a atenção à saúde mental infantil e juvenil, em que se faz necessária a expansão dos diferentes serviços que compõem a rede de cuidados; o número insuficiente de Centros de Atenção Psicossocial (CAPSi), assim como o de ambulatórios e demais dispositivos de saúde men- 
tal, sobretudo aqueles que são voltados especificamente para a infância e adolescência.

Ainda segundo Couto, Duarte e Delgado (2008), essas necessidades estão presentes em todas as regiões do país, sobretudo no Norte e Centro-Oeste. No entanto, o enfrentamento desse problema depende da conscientização de gestores e da sociedade sobre a relevância da saúde mental para a política de saúde da infância.

A criação do protocolo dos Indicadores Clínicos de Risco para o Desenvolvimento Infantil (IRDI) foi uma grande contribuição da psicologia atual para as políticas de saúde, pois articula entre os âmbitos sociais e psíquicos na construção de uma política pública relacionada com o cuidado no desenvolvimento. Sendo assim, a aplicação do protocolo de IRDI e dos seus fundamentos tem sido uma excelente experiência para os profissionais da atenção básica que passam a compreender a singularidade dos indivíduos envolvidos na avaliação e nas orientações realizadas durante todo o processo. Por conseguinte, o IRDI representa um grande avanço para as ações de política de saúde da criança. (LERNER et al., 2013)

Apesar da existência de vários métodos legais de proteção à criança e ao adolescente, a violência, muitas vezes, não é percebida como tal, pois se traveste de forma disciplinatória ou punitiva e, portanto, não compreendida como uma forma de agressão. No entanto, a violência doméstica pode ser considerada uma questão de saúde pública, pois está relacionada tanto com o desenvolvimento social quanto econômico, além de ir contra os direitos humanos. Nos últimos anos, a violência adquiriu um caráter endêmico, e por esse motivo é preciso formular projetos que previnam esse problema social.

Apesar de ter sido implementada uma Política Nacional de Redução da Morbimortalidade por Acidentes e Violência, tornou-se obrigatório a notificação de todos os casos, suspeitos ou confirmados de violência com objetivo de iniciar um processo para interromper com as atitudes do agressor, além de promover cuidados sociais e sanitários voltados às vítimas. No entanto, muitos profissionais da área de saúde são despreparados e deixam de realizar as notificações 
por acreditarem que esse é um problema jurídico e não de saúde pública. Portanto, apesar de haver uma política para redução da violência contra criança, existem diversas lacunas nas notificações e identificações desses casos pelos profissionais e, por conseguinte, é preciso criar mais programas permanentes de educação nesse âmbito.

Para Marques (2010), ainda faltam muitas conquistas dentro das políticas públicas voltadas para a infância. Apesar de ter acontecido alguns avanços na criação de um sistema de garantia de direitos, as infraestruturas institucionais ainda são bastante precárias e o não cumprimento do que a Constituição e o ECA instituem há décadas gera grandes deficiências na efetivação do atendimento intersetorial e na integração do atendimento à criança e adolescentes.

Desse modo, ao realizarmos uma análise das políticas públicas voltadas para a saúde da criança instituída nesses últimos anos no nosso país, percebemos que, apesar dos esforços para melhorar a qualidade de vida das crianças, resultando consequentemente na diminuição das taxas de mortalidade e desnutrição infantil, ainda 320 presenciamos muitos contrastes dentro do Brasil. A região Nordeste, por exemplo, é detentora da maior taxa de mortalidade infantil do país, uma vez que concentra metade dos óbitos ocorridos nessa faixa etária no Brasil. (BRASIL, 2002b)

Assim, espera-se que, com a criação da Política Nacional de Atenção à Saúde da Criança, sejam fortalecidas ações integradas para atingir essa população alvo não apenas no combate a mortalidade e desnutrição infantil, mas auxiliando a sociedade a compreender que esse grupo de indivíduos também são seres biopsicossociais. Uma criança que completa seu crescimento e desenvolvimento de maneira integral e saudável tende a manter um comportamento saudável na vida adulta, influenciando na qualidade de vida da população de um modo geral.

Desse modo, a criação de uma política nacional de saúde voltada para a população infantil é um passo bastante significativo para a saúde pública brasileira. Além disso, carrega a grande responsabilidade de chamar a atenção e conduzir ações para um público tão 
negligenciado ao longo da história. Ainda há um longo caminho a percorrer para vencer as iniquidades encontradas no nosso país, sobretudo na primeira infância, porém todos esses passos que já foram dados até hoje representam o fortalecimento e a evolução na saúde pública brasileira.

\section{Eixo "Infância" no Observatório de Análise Política em Saúde: projetos em curso}

Nesta seção final do capítulo, apresentaremos, numa descrição panorâmica, o conjunto de pesquisas que compõem o eixo "Infância" ao interior do Observatório de Análise Política em Saúde; algumas ainda em curso, apresentadas como projetos, outras que já forma finalizadas e que trazem uma visão geral dos resultados alcançados. São projetos realizados por pesquisadores, em sua maioria, do Instituto de Saúde Coletiva da Universidade Federal da Bahia (ISC/ UFBA), assim como alunos do Programa de Pós-Graduação, em seus projetos de tese e dissertação.

De modo geral, os trabalhos estão dirigidos a responder as seguintes questões de investigação: quais as razões para o estabelecimento de uma política que responda à magna causa da infância? Como vem se constituindo no Brasil a chamada cruzada da infância? Por que a persistência dos estudos? Qual a situação atual das políticas? Organiza-se desta forma, ao interior do grupo, três perspectivasanalíticas, quais sejam:

1. Acompanhamento das políticas implantadas nos últimos 10 anos por meio da análise de sua situação atual, bem como seu seguimento até 2017;

2. Estudos de caso e estudos avaliativos sobre políticas específicas no âmbito da saúde integral da criança no Brasil e Bahia;

3. Estudos sócio-históricos sobre a gênese da política voltados a indagar sobre processos sociais subjacentes e suas determinações históricas e estruturais. 
Serão descritos a seguir os principais estudos já conduzidos eprojetos de pesquisa em andamento que compõe o eixo Infância:

+ Pesquisa "Saúde na escola: analisando os caminhos da intersetorialidade"

A intersetorialidade tem sido concebida como uma estratégia importante e necessária para a efetividade das políticas públicas. $\mathrm{Na}$ saúde, está fortemente vinculada à discussão sobre os Determinantes Sociais da Saúde e à Promoção da Saúde. (BUSS, 2000; JACKSON et al., 2007) Na educação, é vinculada à ideia de parceria e colaboração. (BRASIL, 2014; OLIVEIRA; SANTANA, 2010) Entretanto, estudos apontam diversos entraves e desafios para a implementação da intersetorialidade. (FERNANDES, 2005, FERREIRA; VIEIRADA-SILVA, 2005, SANTOS, 2011) No intuito de articular as ações de saúde às ações da educação básica, o PSE é concebido como um programa intersetorial com vistas à melhoria da saúde e da educação dos estudantes das creches e das escolas públicas. (BRASIL, 2007; 2013) Tendo em vista que a intersetorialidade é um princípio do PSE, a presente pesquisa buscou a seguinte investigação: como a intersetorialidade tem sido implementada no PSE? O objetivo da pesquisa foi analisar a ação intersetorial entre os setores saúde e educação utilizada no processo de implementação do PSE.

Tratou-se de uma pesquisa exploratória e descritiva, estudo de caso, realizada em um município da Bahia. Para a produção dos dados, realizaram-se entrevistas semiestruturadas, análise documental e observação, e ao final, optou-se pela triangulação dos dados. A pesquisa envolveu gestores das secretarias municipais de educação e de saúde, o grupo de trabalho intersetorial municipal e profissionais de duas equipes de saúde da família e profissionais de três escolas públicas (duas municipais e uma estadual). Para a análise dos dados, houve a construção do modelo lógico do programa e a elaboração de uma matriz de análise, contendo como categoria analítica a intersetorialidade e as dimensões processo político-gerencial e processo de trabalho. 
Os resultados mostraram que conceitualmente a intesertorialidade é pouco compreendida, como também é pouco praticada, havendo mais justaposição de ações. Na implementação do programa, notou-se uma liderança do setor saúde, tanto no que diz respeito ao processo decisório quanto na alocação e mobilização de recursos como nas atividades que são realizadas nas escolas, os gestores da educação e a equipe escolar têm uma atuação coadjuvante. Identificou-se que as atividades são focadas na prevenção e na assistência à saúde dos estudantes. Os principais achados evidenciam que o PSE fortaleceu a relação entre os dois setores, entretanto, a articulação intersetorial no processo político-gerencial e no processo de trabalho mostrou-se frágil e limitada.

- Pesquisa "O abandono do tratamento no contexto dos cuidados de saúde mental para crianças e adolescentes"

Esse projeto corresponde a uma dissertação de mestrado acadêmico realizada no Programa de Pós-Graduação em Saúde Coletiva. O estudo foi dividido em uma revisão de literatura seguida de estudo empírico.

São poucos e divergentes estudos a respeito do conceito de abandono do tratamento e sobre os fatores predisponentes para este em serviços de saúde mental infanto juvenil. Essa pesquisa teve por objetivo apresentar e discutir quais os conceitos e os principais fatores associados ao abandono do tratamento de saúde mental entre crianças, adolescentes e suas famílias, em publicações científicas.

Trata-se de uma revisão sistemática da literatura que consultou as bases de dados Scientific Electronic Library Online (Scielo), Literatura Latino-Americana e do Caribe em Ciências da Saúde (Lilacs), Medical Literature Analysis and Retrieval System Online (Medline), PubMed e National Center for BiotechnologyInformation(NCBI), ultilizando-se artigos publicados desde o primeiro estudo divulgado em 1956, por meio dos seguintes descritores: "pacientes desistentes do tratamento", "abandono", "dropout" e "desistência do paciente", correlacionados à "saúde mental” e "crianças e adolescentes”. A partir 
da aplicação dos critérios de inclusão e exclusão na busca dos artigos, foram encontrados 326 estudos que versavam sobre o abandono do tratamento em saúde mental, sendo que 34 destes versavam sobre o tema na população de crianças e adolescentes. Dos 34 estudos, 11 foram excluídos por não preencherem os critérios de inclusão delimitados, totalizando 23 estudos selecionados para a análise.

Os resultados encontrados evidenciaram o predomínio de trabalhos quantitativos, com significativas divergências conceituais e sobre os resultados produzidos. Alguns fatores foram levantados com maior recorrência entre os estudos como possivelmente associados ao abandono do tratamento entre crianças e adolescentes, tais como a monoparentalidade esobrecarga do cuidado na figura de um único cuidador; uso abusivo de substâncias psicoativas entre os jovens e seus pais; violência intrafamiliar; baixa escolaridade dos pais; baixo capital econômico; discrepâncias entre as expectativas dos familiares e profissionais quanto ao tratamento; atitudes e comportamentos do terapeuta como empatia e disponibilidade subjetiva; pouca clareza 324 sobre os objetivos e métodos de tratamento; barreiras de acesso e acessibilidade; formas de acolhimento; vinculo terapêutico frágil, dentre outros.

Discute-se que conhecer os possíveis preditores para o abandono do tratamento de saúde mental possibilita que os profissionais possam identificar precocemente pacientes pertencentes ao grupo de risco para abandono, oportunizando-lhes trabalhar preventivamente e mais diretamente aspectos que dificultam a permanência desses pacientes e seus familiares na instituição. Apesar da significativa contribuição que esses estudos têm realizado para a produção no conhecimento, ressaltamos a necessidade de realizar novos estudos de cunho qualitativo junto aos familiares, usuários e profissionais do CAPSi, a fim de compreender melhor a realidade desse espaço de cuidado tão diverso dos modelos de tratamento ofertados em outros países.

O estudo empírico tem por objetivo de analisar os elementos relacionados ao abandono do tratamento em um CAPS para crianças e adolescentes, considerando as experiências de adoecimento e 
de cuidado construídas pelos usuários e familiares em sua busca por tratamento de saúde mental. Foram entrevistados familiares e profissionais que participaram diretamente no cuidado das crianças e adolescentes, no período de sua permanência no serviço, bem como realizado um grupo focal com profissionais do CAPSi. Como resultados do estudo, identifica-se dificuldades dos familiares quanto à compreensão das novas propostas de cuidados em saúde mental propostas pelo CAPS, as quais podem interferir diretamente na continuidade do cuidado do familiar no serviço. Identificou-se que os cuidados das crianças e adolescentes em sofrimento psíquico estão centrados na figura de um único cuidador do sexo feminino. Duas das três famílias demonstraram dificuldade em administrar o papel de cuidador e conciliá-lo às exigências das condições concretas de vida. A ênfase no hospital psiquiátrico enquanto espaço de eleição de cuidados ainda pode ser observada no discurso das famílias.

Como aspectos relacionados à adesão e ao abandono do tratamento no serviço, identificam-se: aspectos relacionados às características familiares (escolaridade dos pais, monoparentalidade, escassa rede de suporte afetiva, discrepâncias entre as expectativas dos familiares e profissionais quanto ao tratamento, baixo capital econômico, incompreensão sobre o modelo de tratamento, baixa crença na efetividade do tratamento, sentimento de desesperança, valorização do tratamento farmacológico etc); aspectos relacionados ao paciente e ao processo de sofrimento (agressividade, gravidade do caso, uso de spas, piora do quadro etc); aspectos ligados às características dos serviços de saúde (fragilidade do vínculo terapêutico, ausência de grupos de apoio para os pais, distância entre o local de moradia e o serviço, fontes de encaminhamento, pouca clareza sobre os objetivos e métodos de tratamento); e aspectos comunitários tais como violência urbana, foram alguns dos motivos apontados para o abandono. Discute-se que o abandono do tratamento, nos três casos, relacionou-se a diversos fatores, nem sempre evidentes para os familiares. 
- Pesquisa "Análise da Implantação da Rede Cegonha: desafios e perspectivas para redução da sífilis congênita na atenção básica"

O estudo, resultado de projeto de dissertação de Mestrado Acadêmico em Saúde Coletiva do Programa de Pós-Graduação em Saúde Coletiva da UFBA, teve por objetivo estimar o grau de implantação das ações dirigidas ao controle da sífilis congênita no prénatal, no âmbito da Rede Cegonha, na atenção básica no município de Palmas. Para realização da pesquisa, foi utilizada uma abordagem avaliativa do tipo análise de implantação do componente pré-natal da Rede Cegonha no município de Palmas, em Tocantins. Tendo em vista explicitar a intervenção, foi elaborado um modelo lógico do programa por meio de consultas a documentos oficiais, portarias que regulamentam o programa, assim como realização de entrevistas com membros da equipe da ESF das unidades básicas de saúde envolvidos com o processo de implantação da Rede Cegonha em Palmas. Para classificação dos achados, utilizou-se uma matriz de implantação derivada do modelo lógico, aplicada em oito unidades básicas de saúde selecionadas por sorteio.

Os resultados desse estudo demonstraram que o grau de implantação das ações dirigidas ao controle da sífilis congênita, no âmbito da Rede Cegonha, na atenção básica no município de Palmas, encontra-se parcialmente implantado. Revelou-se ainda a baixa adesão dos parceiros das gestantes, tanto para realização do teste rápido quanto para o tratamento da sífilis, o que contribui para o aumento da transmissão vertical da sífilis. Recomenda-se ações que favoreçam a inserção do parceiro no pré-natal e uma maior integração entre as atividades desenvolvidas na implantação da saúde da mulher e saúde do homem. 
- Projeto "Espaço social de luta pela infância: gênese e transformações"

O estudo sócio-histórico interessa-se pelas seguintes questões: por que e como o Estado brasileiro assume o problema da mortalidade infantil e a atenção à infância como sua responsabilidade? Qual a situação da implantação das políticas de atenção à infância ao longo do período 2003-2013? Possui como objetivos: analisar a emergência e transformações das políticas de saúde materno infantil no Brasil, identificando suas condições de possibilidade históricas; analisar a gênese e evolução de espaços profissionais especializados nos problemas da infância no Brasil.

O estudo será apoiado no referencial teórico da sociologia reflexiva de Bourdieu (1996), autores que discutem a sociogênese das políticas sociais (PINELL, 2010), bem como naqueles que contribuem para a análise da infância numa perspectiva sócio-histórica. (ARIÈS, 1986) A abordagem sócio-histórica interessa-se em analisar os agentes e instituições envolvidas na emergência da política bem como as condições históricas de possibilidade que resultaram em sua constituição.

Trata-se de estudo histórico sobre a gênese e transformações das políticas de saúde materno infantil no Brasil, no período compreendido entre o início dos anos 1970, período em que há a formulação de políticas e programas voltados à infância, como Programa Nacional de Imunizações (1973), Programa nacional de saúde materno-infantil (1975), Programa Nacional de Aleitamento Materno (1981). Será realizado igualmente um acompanhamento das políticas implantadas nos últimos 10 anos (2003-2013), a partir de diversos estudos de caso sobre políticas específicas no âmbito da saúde integral da criança no Brasil e Bahia. Durante a fase exploratória do estudo, esse período da análise será melhor delimitado por meio da análise documental sobre as ações do Estado brasileiro relativas à saúde da infância em períodos anteriores. 
Para produção dos dados, em um primeiro momento, será realizado um estudo exploratório buscando identificar os principais marcos históricos e agentes relacionados com o objeto da pesquisa, bem como os informantes chave. Para investigar a trajetória dos agentes, serão realizadas entrevistas em profundidade (presenciais ou por Skype) com os informantes chave, responsáveis pela implantação das políticas. Para os já falecidos, serão consultadas biografias publicadas, entrevistas outrora concedidas ou seus descendentes. Será realizada ainda consulta aos currículos dos diversos agentes, em particular aqueles disponíveis na Plataforma Lattes. ${ }^{1}$ Para análise das condições de possibilidade de surgimento das políticas, serão consideradas as fontes bibliográficas e documentais que permitam reconstituir as principais conjunturas política, econômica e social da época. Serão realizadas ainda buscas sistemáticas na internet e nos acervos dos jornais e revistas especializadas, tais como a Gazeta Médica da Bahia, ${ }^{2}$ o Estado de São Paulo, ${ }^{3}$ a Folha de S. Paulo ${ }^{4}$ e outros que as fase exploratória da investigação indicar.

- Projeto "Análise da situação atual da Política Nacional de Atenção Integral da Criança”

A política nacional de saúde voltada para a população infantil é um passo bastante significativo para a saúde pública brasileira. No entanto, ainda há um longo caminho a percorrer para vencer as iniquidades encontradas no nosso país, sobretudo na primeira infância. Uma forma importante de acompanhar e mensurar os avanços na promoção de saúde na infância através de uma política de saúde pública é acompanhar todas as notícias e portarias disponíveis sobre o assunto. Portanto, destaca-se a importância da monitorização de no-

\footnotetext{
1 http://lattes.cnpq.br/.

2 http://www.gmbahia.ufba.br/index.php/gmbahia/login.

3 http://acervo.estadao.com.br/

4 http://acervo.folha.com.br/
} 
tícias sobre a Política Nacional de Atenção Integral da Criança para registrar os seus avanços com o decorrer dos anos.

O Projeto de Monitorização das notícias sobre a Política Nacional de Atenção Integral da Criança tem como principais objetivos registrar informações coletadas em matriz de análise para sistematização de documentos e notícias bem como realizar uma descrição das políticas identificadas, destacando agentes envolvidos, objetivos, estratégias; cobertura e implantação; principais resultados alcançados; controle social, bem como outras categorias de análise propostas. A estratégia metodológica da pesquisa inclui o levantamento e sistematização de documentos sobre políticas de saúde voltadas ao público materno infantil nos sites de referência do MS, das Secretarias Estaduais de Saúde, das Secretarias Municipais de Saúde (SMS), do Conselho Nacional de Secretários de Saúde (Conass), do Conselho Federal de Medicina (CFM), do Centro Brasileiro de Estudos de Saúde (Cebes), da Associação Brasileira de Saúde Coletiva (Abrasco), entre outros.A pesquisa encontra-se em fase de registro das informações lançadas após o decreto da portaria assinada pelo Ministro Arthur Chioro da Política Nacional de Assistência a Saúde Integral da Criança.

- Projeto "A violência doméstica contra crianças como problema social e de saúde: experiências familiares e respostas sociais em um bairro popular de Salvador/BA"

Estudos dos últimos anos sobre violência contra crianças têm abordado, por um lado, as consequências do agravo e os fatores de proteção e de risco presentes no seu ambiente (ALVES; EMMEL, 2008; DE ANTONI; KOLLER, 2000, 2010; GABATZ et al., 2010a; 2010b; MARTINS et al., 2007) e, por outro, a avaliação dos serviços de atenção e as perspectivas dos diferentes profissionais sobre sua atuação diante desse problema. (BAZON; FALEIROS, 2013; GOMES et al., 2002; SILVA, L.; FERRIANI; SILVA, M., 2012) Destaca-se a relevância da ação interinstitucional e intersetorial como facilitador de uma intervenção efetiva. As questões de como 
a família experiencia o fato, qual a sua trajetória entre os diferentes serviços e quais as situações promotoras de vulnerabilidade ou resiliência nesse processo permanecem sem uma resposta que abarque a complexidade do fenômeno.

Nesse sentido, esse projeto tem como objetivo geral analisar problemas e necessidades sociais e de saúde de famílias com história de violência doméstica contra crianças, destacando serviços de proteção e respostas sociais empreendidas em um bairro popular de Salvador/BA. Especificamente, pretende descrever a trajetória de famílias no cuidado a crianças com história de violência doméstica; caracterizar os serviços de proteção social e da saúde utilizados no cuidado a crianças em situação de violência doméstica; identificar situações de vulnerabilidade, resiliência, risco e proteção em crianças submetidas à violência doméstica; e analisar possíveis linhas de cuidado e/ou itinerários terapêuticos percorridos por crianças vítimas de violência doméstica.

Trata-se de uma pesquisa exploratória, qualitativa, com dese330 nho de estudo de caso. (YIN, 2001) Considerando a complexidade do fenômeno violência, foi feita uma escolha pela triangulação metodológica, combinando entrevistas semiestruturadas com 5 famílias e 10 representantes de instituições da rede de proteção referidas pelas famílias nas entrevistas. Os resultados serão analisados à luz da bioecologia do desenvolvimento humano (BRONFENBRENNER, 1996; KOLLER; DE ANTONI, 2004), especificamente seus conceitos de contextos de desenvolvimento, fatores de risco e fatores de proteção. Adicionalmente ao modelo, serão utilizados os conceitos adjacentes de resiliência e vulnerabilidade (SELIGMAN; CSIKSZENTMIHALYI, 2000; YUNES; MIRANDA; CUELLO, 2004) e de linha de cuidado (MALTA; MERHY, 2010) e itinerários terapêuticos. (ALVES; SOUZA, 1999) 
- Projeto "Espaço de luta e de atenção à criança com deficiência na Bahia"

Esse projeto parte da seguinte pergunta de investigação: como está o movimento político em defesa dos direitos das crianças com deficiência na Bahia? Como está organizada a rede de atenção à criança portadora de deficiência na Bahia? Tem como objetivo registrar a situação atual do movimento político em defesa dos direitos das crianças com deficiência na Bahia e a sua rede de atenção e de cuidado a essas crianças. De forma específica visa identificar os atores sociais envolvidos na luta pelos direitos das crianças com deficiência na Bahia; identificar as políticas públicas que contribuíram para a garantia dos direitos das crianças portadoras de deficiência e mapear a rede de atenção e de cuidado à criança com deficiência na Bahia.

Como estratégia metodológica serão realizadas entrevistas em profundidade com os agentes protagonistas na luta em defesa das crianças com deficiência na Bahia, considerando os envolvidos no movimento, na assistência a essas crianças, além de visitar os serviços de cuidado e de realizar pesquisas em documentos, livros e documentários.

\section{Referências}

ALVES, P. C.; SOUZA, I. M. Escolha e avaliação de tratamento para problemas de saúde: considerações sobre o itinerário terapêutico. In: RABELO, M. C.; ALVES, P. C.; SOUZA, I. M. Experiência de doença e narrativa. Rio de Janeiro: Ed. Fiocruz; 1999. p. 125-138.

ANDRADE, L. B. P. Educação infantil: discurso, legislação e práticas institucionais. São Paulo: Ed. UNESP: Cultura Acadêmica, 2010.

AQUINO, R.; OLIVEIRA, N. F. de; BARRETO. M. L. Impact of the family healthprogram on infant mortality in Brazilian municipalities. American Journal of Public Health, New York, p. 87-93, 2009. 
ARAÚJO, J. P. et al. História da saúde da criança: conquistas, políticas e perspectivas. Revista Brasileira de Enfermagem, Brasília, DF, v. 67, n. 6, p. 1000-1007, nov./dez. 2014.

ARIÈS, P. História social da criança e da família. Tradução de Dora Flaksman. 2.ed. Rio de Janeiro: Guanabara, 1986.

BARBOSA, M. C. S. Por amor e por força: rotinas na educação infantil. Porto Alegre: Artmed, 2006.

BAZON, M. R.; FALEIROS, J. M. Identificação e notificação dos maustratos Infantis no Setor Educacional. Paidéia, Ribeirão Preto, v. 23, n. 54, abr. 2013.

BRASIL. Decreto no 6.286, 5 de dezembro de 2007. Institui o Programa Saúde na Escola - PSE, e dá outras providências. Diário Oficial [da] República Federativa. Brasília, DF, 6 dez. 2007. Disponível em<http:// www.planalto.gov.br/ccivil_03/_ato2007-2010/2007/decreto/d6286. htm>. Acesso em: 10 ago. 2015.

BRASIL. Lei n. 8.069, de 13 de julho de 1990. Dispõe sobre o Estatuto da Criança e do Adolescente e dá outras providências. Diário Oficial [da] República Federativa doBrasil. Brasília, DF, 16 jul.1990. p. 13.563.

BRASIL. Ministério da Saúde. Programa nacional de incentivo ao aleitamento materno - PNIAM. Brasília, DF,1991.

BRASIL. Ministério da Saúde. Instrumento gerencial da saúde da mulher, da criança e do adolescente: avaliação, sistema de informação e programação. Brasília, DF, 1995.

BRASIL. Portaria no 399, de 22 de fevereiro de 2006. Divulga o Pacto pela Saúde 2006 - Consolidação do SUS e aprova as Diretrizes Operacionais do Referido Pacto. Diário Oficial [da] União, Brasília, DF, 23 fev. 2006.

BRASIL. Ministério da Saúde. Secretária de Politicas ed Saúde. Saúde da criança: acompanhamento do crescimento e desenvolvimento infantil. A. Normas e Manuais Técnicos. Brasília, DF, 2002a. (Série Cadernos de Atenção Básica, n. 110). 
BRASIL. Ministério da Saúde. Secretaria de Atenção à Saúde.

Departamento de ações programáticas estratégicas. Pacto Nacional pela redução da morte materna e neonatal. Brasília, DF, 2004a.

BRASIL. Ministério da Saúde. Secretaria de Atenção à Saúde.

Departamento de Ações Programáticas Estratégicas. Área técnica da saúde da criança e aleitamento materno: agenda de compromissos para a saúde integral da criança e redução da mortalidade infantil. Brasília, DF, 2004b.

BRASIL. Ministério da Saúde. Mais saúde direito de todos, 2008-2011. 2. ed. Brasília, DF, 2008.

Brasil. Ministério do Desenvolvimento Social. Brasil Carinhoso. Brasília, DF, 2015a. Disponível em: <http://mds.gov.br/brasil-sem-miseria/ acesso-a-servicos/brasil-carinhoso >. Acesso em: 24 jul. 2016.

BRASIL. Ministério da Educação. Plano Nacional da Educação - PNE 2014-2024. Brasília, DF, 2014. Disponível em: <http://pne.mec.gov.br>. Acesso em: 10 set. 2015.

BRASIL. Ministério da Saúde. Portaria Interministerial no 1.413, de 10 de julho de 2013. Redefine as regras e critérios para adesão ao Programa Saúde na Escola (PSE) por Estados, Distrito Federal e Municípios e dispõe sobre o respectivo incentivo financeiro para custeio de ações. Diário Oficial da União. Brasília, DF, 2013. Disponível em: <http:// bvsms.saude.gov.br/bvs/saudelegis/gm/2013/pri1413_10_07_2013. htm>. Acesso em: 20 ago. 2015.

BRASIL.Ministério da Saúde Portariano 1.130, de 5 de agosto de 2015. Institui a Política Nacional de Atenção Integral à Saúde da Criança (PNAISC) no âmbito do Sistema Único de Saúde (SUS). Diário Oficial da União. Brasília, DF, 5 out. 2015b.

BRASIL. Ministério da Saúde. Secretaria de Políticas de Saúde. Área da Saúde da Criança. Programas e Projetos da Saúde da Criança: responsabilidades compartilhadas em benefício das crianças brasileiras. Revista Brasileira de Saúde Materno Infantil, Recife, v. 2, n. 2, p. 193-196, maio/ago. 2002b.

BOURDIEU, P. As regras da arte: gênese e estrutura do campo literário. Lisboa: Presença, 1996. 
BUSS, P. M. Promoção da saúde e qualidade de vida. Revista Ciência e Saúde Coletiva, Rio de Janeiro, v. 5, n. 1, p. 163-177, 2000.

BRONFENBRENNER, U. A ecologia do desenvolvimento humano: experimentos naturais e planejados. Porto Alegre: Artes Médicas, 1996.

CABRAL, I. E.; AGUIAR, R. C. B. de. As políticas públicas de atenção à saúde da criança menor de cinco anos: um estudo bibliográfico. Revista Enfermagem UERJ, Rio de Janeiro, v. 11, p. 285-291, 2003.

COUTO, M. C. V.; DUARTE, C. S.; DELGADO, P. G. G. A saúde mental infantil na Saúde Pública brasileira: situação atual e desafios. Revista brasileira de psiquiatria, São Paulo, v. 30, n. 4, p. 384-389, dez. 2008.

CUNHA, C.L.F.et al . O uso de serviços de atenção primária à saúde pela população infantil em um estado do nordeste brasileiro. Caderno de Saúde Coletiva, Rio de Janeiro, v. 21, n. 2, p. 115-120, June 2013.

CUNHA, A. C. B. da; BENEVIDES, J. Prática do psicólogo em intervenção precoce na saúde materno-infantil. Psicologia em Estudo, Maringá, v. 17, n. 1, p. 111-119, mar. 2012.

334 DE ANTONI, C.; KOLLER, S. H. A visão de família entre as adolescentes quesofreramviolência intrafamiliar. Estudos de Psicologia, Natal, v. 5, n. 2, p. 2000.

DE ANTONI, C.; KOLLER, S. H. Uma família fisicamente violenta: uma visão pela teoria bioecológica do desenvolvimento humano. Temas em Psicologia, Ribeirão Preto,v. 18, n. 1, p. 2010.

FERNANDES, D. M. Análise da articulação intersetorial na implementação de um programa social em nivel local: experiência do município de Petrópolis/ RJ. 2005. Dissertação (Mestrado em Saúde Pública) Fundação Oswaldo Cruz, Escola Nacional de Saúde Pública, 2005.

FERREIRA, V.S.C, VIEIRA-DA-SILVA, L. M. Intersetorialidade em saúde: um estudo de caso. In: HARTZ, Z. M. (Org.). Avaliação em saúde: dos modelos teóricos à prática na avaliação de programas e sistemas de saúde. EDUFBA, 2005. p. 103-150. 
FINKLER, A. L. et al. $\mathrm{O}$ acesso e a dificuldade na resolutividade do cuidado da criança na atenção primária à saúde. Acta Paulista de Enfermagem. São Paulo, v. 27, n. 6, p. 548-53, 2014.

FIGUEIREDO, G. L. A.; MELLO, D. F. de. Atenção à saúde da criança no Brasil: aspectos da vulnerabilidade programática e dos direitos humanos. Revista Latino-Americana de Enfermagem, Ribeirão Preto, v. 15, n. 6, p. dec. 2007.

GABATZ, R. I. B. et al. Fatores relacionados à institucionalização: perspectivas de crianças vítimas de violência intrafamiliar. Revista Gaúcha de Enfermagem, Porto Alegre, v. 31, n. 4, p. 670-677, dez. 2010a.

GABATZ, R. I. B.et al. O significado de cuidado para crianças vítimas de violência intrafamiliar. Escola Anna Nery, Rio de Janeiro,v.14, n.1, p. 135-142, mar. 2010b.

GOMES, R., et al. A abordagem dos maus-tratos contra a criança e o adolescente em uma unidade pública de saúde. Ciência e Saúde Coletiva, São Paulo, v. 7, n. 2, p. 275-283, 2002.

JACKSON, F.S. et al. Integrated health promotion strategies: a contribution to tackling current and future health challenges. Health Promotion International, Oxford, v. 21, n. 1, p. 75-83, 2007

JAVEAU, C. Criança, infância(s), crianças: que objetivo dar a umaciência social da infância? Educação e Sociedade, Campinas, v. 26, n. 91, p. 379-89, ago. 2005.

KOLLER, S. H.; DE ANTONI, C. Violência intrafamiliar: uma visão ecológica. In: KOLLER, S. H. (Org.). Ecologia do desenvolvimento humano: pesquisa e intervenção no Brasil. São Paulo: Casa do Psicólogo, 2004. p. 293-310.

LERNER, R. et al . A Psicologia na articulação entre os âmbitos coletivo e psíquico: construção de uma política pública em saúde de cuidado com o desenvolvimento. Psicologia: Ciência e Profissão, Brasília, DF, v. 33, p. 100-111, 2013. Edição especial.

MALTA, D.C.; MERHY, E.E.The path of the line of care from the perspective of nontransmissiblechronic diseases. Interface. Botucatu, v.14, n. 34, p. 593-605, jul./set. 2010. 
MARQUES, E.P. Infância e políticas públicas: a intersetorialidade como estratégia de atenção integral à saúde da criança. Sociedade em Debate, Pelotas, v. 16, n. 1, p. 107-120, jan./jun.2010.

MARTINS, C. S. et al. Family dynamics from the perspective of parents and children involved in domestic violence against children and adolescents. Revista Latino-Americana de Enfermagem, Ribeirão Preto, v. 15 , n. 5, p. 889-894, Oct. 2007

NOVAES, M. H. D.A puericultura em questão. 1979. Dissertação (Mestrado em Medicina) - Faculdade de Medicina, Universidade de São Paulo, São Paulo, 1979.

OLIVA, J. C. G. A.; KAUCHAKJE, S. As políticas sociais públicas e os novos sujeitos de direitos: crianças e adolescentes. Revista katálysis, Florianópolis, v. 12, n. 1, p. 22-31, Jun. 2009.

OLIVEIRA, R. P.; SANTANA, W. (Org.). Educação e federalismo no Brasil: combater as desigualdades, garantir a diversidade. Brasília, DF: Unesco, 2010.

PIMENTA, T. A. M.; ROCHA, R.; MARCONDES, N. A.V. Políticas Públicas de intervenção na obesidade infantil no Brasil: uma breve análise da política nacional de alimentação e nutrição e política nacional de promoção da saúde. Unopar científica: Ciências biológicas e da saúde, Londrina, v. 17, n. 2, p. 139-146, 2015.

PINELL, P. Análise sociológica das políticas de saúde. Rio de Janeiro: Ed. Fiocruz, 2010.

UNICEF.A Convenção sobreos Direitos da Criança: adoptada pela Assembleia Geral nas Nações Unidasem 20 de Novembro de 1989 e ratificada por Portugalem 21 de Setembro de 1990.[2004?]. Disponível em: <http://www.unicef.pt/docs/pdf_publicacoes/convencao_ direitos_crianca2004.pdf >. Acesso em: 15/08/2014.

QVORTRUP, J. A infância enquanto categoria estrutural. Educação e Pesquisa, São Paulo, v. 36, n. 2, p. 631-644, ago. 2010

RAMOS, B. de C.; MAIA, L. C. Cárie tipo mamadeira e a importância da promoção de saúde bucal em crianças de 0 a 4 anos. Revista de 
Odontologia da Universidade de São Paulo, São Paulo, v. 13, n. 3, p. 303-311, 1999.

RASELLA D. et al.Effect of a conditional cash transfer programme on childhood mortality: a nationwide analysis of Brazilian municipalities. The Lancet, London, v. 382, n. 9886, p. 57-64, July 2013.

ROCHA, S. M. M. et al. Estudo da assistência integral à criança e ao adolescente através da pesquisa qualitativa. Revista Latino-Americana de Enfermagem, Ribeirão Preto, v. 6, n. 5, p. 5-15,1998.

SANTOS, N. N. A intersetorialidade como modelo de gestão das políticas de combate à pobreza no Brasil: o caso do programa bolsa família no município de Guarulhos. 2011. Dissertação (Mestrado em Administração) - Escola de Administração, Fundação Getúlio Vargas, São Paulo, 2011.

SARMENTO, M. J. Geração e alteridade: interrogação a partir da Sociologia da Infância.Educaçãoł Sociedade, Campinas, v. 26, n. 91, p. 361-78, maio/ago. 2005.

SELIGMAN, M. E. P.; CSIKSZENTMIHALYI, N. Apositive psychology: an introduction. American Psychologist, Washington, v. 55, n. 1, p. 5-14, 2000

SILVA, L. M. P. da; FERRINI, M. das G. C.; SILVA, M. A. I. O Poder Judiciário como última instância de proteção às crianças e aos adolescentes: ações intersetoriais, investimento em recursos humanos e estruturação dos serviços. Revista Latino-Americana de Enfermagem," Ribeirão Preto, v. 20, n. 3, jun. 2012.

SOUZA, M. C; OLIVEIRA, I.C. Assistência de enfermagem à criança hospitalizada: breve retrospectiva. Revista Brasileira de Enfermagem, Brasília, DF, v. 57, n. 2, p. 247-249, mar./abr. 2004.

TYRREL,M. A. R. B. Programas nacionais de saúde materno infantil: impacto social e inserção da enfermagem. Revista Brasileira de Enfermagem,Brasília, DF, v. 1, n. 1, p. 119-134, 1997.

UNICEF. Declaração Universal Dos Direitos Das Crianças. 1959.

Disponível em: <http://bvsms.saude.gov.br/bvs/publicacoes/ declaracao_universal_direitos_crianca.pdf>. Acesso em: 15 ago. 2014. 
VAILATI, L. L. A morte menina. Infância e morte infantil no Brasil dos oitocentos (Rio de Janeiro e São Paulo). São Paulo: Alameda, 2010, VICTORA, C. G. Intervenções para reduzir a mortalidade infantil préescolar e materna no Brasil. Revista Brasileira de Epidemiologia, São Paulo, v. 4, n. 1, p. 3-53, 2001.

VICTORA, C. G. et al. Saúde das mães e crianças no Brasil: progressos e desafios. The Lancet, London, p. 32-46, maio 2011.

WARDE, M. J. Repensando os estudos sociais de história da infância no Brasil. Perspectiva, Florianópolis, v. 25, n. 1, p. 21-39, jan. 2007.

YIN, R. K. Estudo de caso: planejamento e métodos. Porto Alegre:

Bookman, 2001.

YUNES, M. A. A.; MIRANDA, A. T.; CUELLO, S. E. S. Um olhar ecológico para os riscos e as oportunidades. In: KOLLER, S. H. (Ed.). Ecologia do desenvolvimento humano: pesquisa e intervenção no Brasil. São Paulo: Casa do Psicólogo, 2004. p.197-218.

ZANOLLI, M. L.; MERHY, E. E. A pediatria social e as suas apostas reformistas. Caderno de Saúde Pública, Rio de Janeiro, v. 17, n. 4, p. 977-987, ago. 2001. 
Maria Cristina de Camargo Fonseca, Erika Aragão, Jane Mary Guimarães, Bethania de Araújo Almeida e Sebastião Loureiro

\section{POLÍTICA NACIONAL DE CIÊNCIA, TECNOLOGIA E INOVAÇÃO EM SAÚDE NO BRASIL} impacto na ampliação do acesso e na produção de tecnologias voltadas às demandas do Sistema Único de Saúde

\section{Introdução}

A Política de Ciência, ${ }^{1}$ Tecnologia ${ }^{2}$ e Inovação ${ }^{3}$ (PNCTIS), criada em 2004 no Brasil, foi construída num contexto de forte pressão das indústrias produtoras de tecnologias em saúde para a

Refere-se a um sistema de aquisição de conhecimento. Tradicionalmente relacionado à observação e à experimentação para descrever e explicar fenômenos naturais. (ALMEIDAFILHO; BARRETO; ROUOUAYROL, 2011)

2 Refere-se ao estado de conhecimentos sob as formas de recursos convertendo em artefatos. (FREEMAN, 1975)

3 É a implementação de um produto ou processo novo ou significativamente melhorado (bem ou serviço), um novo método de marketing, ou um novo método organizacional das práticas de negócios, entre outros. (SCHUMPETER, 1942) 
incorporação delas internacionalmente e no sistema de saúde brasileiro. Estima-se que um terço do aumento dos gastos com saúde em relação ao Produto Interno Bruto (PIB) dos países seja fruto da incorporação de novas tecnologias, o que pode comprometer a sustentabilidade dos sistemas de saúde, particularmente daqueles com renda baixa ou média, e com cobertura universal, como o Brasil. (ARAGÃO, 2011)

Ao estabelecer a saúde como um direito a ser assegurado pelo Estado, regido pelos princípios da universalidade, integralidade e igualdade ( BRASIL, 1990), entre as competências do Sistema Único de Saúde (SUS) está o incremento do desenvolvimento científico e tecnológico em sua área de atuação, bem como a produção de tecnologias de interesse social.

Tendo em vista a forte pressão pela incorporação sistemática de tecnologias no sistema de saúde brasileiro, o país tem buscado incentivar a ampliação da capacidade científica e tecnológica interna, a partir das demandas do SUS. Nessa perspectiva, a inovação no 340 âmbito do sistema de saúde tem grande relevância para o desenvolvimento social e econômico do Brasil e traz grandes desafios para ser concretizada, em função da complexidade das atividades de desenvolvimento científico e tecnológico, da articulação política e institucional necessária e da escassez de recursos, bem como pela natureza da produção do conhecimento e dos mecanismos de apropriação, elementos centrais da PNCTIS.

Novas tecnologias na área da saúde geralmente são associadas à melhoria da saúde da população, entretanto sinalizam preocupações quanto à ampliação de desigualdades na saúde, já elevadas, tendo em vista que, de um lado, seu consumo é determinado por diversos fatores, dentre eles o status socioeconômico da população ou existência de sistemas públicos que garantam acesso às mesmas. As inovações em saúde ocorrem numa estrutura de mercado oligopolista, ou seja, um conjunto de empresas são responsáveis por parte significativa da oferta de medicamentos no mundo, muitos deles protegidos 
por patentes, ${ }^{4} \mathrm{o}$ que significa que são praticados preços de monopólio, descolados fortemente dos custos de produção. (ARAGÃO; LOUREIRO; TEMPORÃO, 2014)

Para tanto, estas empresas investem expressivamente em Pesquisa e Desenvolvimento (P\&D) visando à diferenciação através da inovação e adotam uma estratégia de proteção patentária extremamente agressiva de gastos elevados em marketing e propaganda, seja diretamente ao paciente, ou, indiretamente, através do médico e outros provedores. (MALERBA; ORSENIGO, 2001)

Em países avançados, os esforços de $\mathrm{P} \& \mathrm{D}$ podem eventualmente resultar em inovações impulsionadas pela tecnologia, apesar do alto grau de incerteza. Já em países em desenvolvimento, a demanda constitui o principal estímulo à inovação. Nessa perspectiva, o marco legal e a organização dos sistemas de saúde podem direcionar a geração de conhecimento, produção e difusão das tecnologias aos interesses sociais ou permitir com que o processo ocorra de forma mais alinhada com os interesses mercadológicos, o que poderia ampliar as desigualdades no acesso aos serviços, já elevadas como demonstram uma série de estudos. (ARAGÃO, LOUREIRO; TEMPORÃO, 2014; GADELHA, COSTA, 2012; LOUREIRO et al., 2007)

A sustentabilidade dos sistemas de saúde, pois, tem constituído um dos maiores desafios para a gestão pública em nível mundial, particularmente para países com sistemas universais como o Brasil. Considerado um país de renda média segundo classificação do Banco Mundial, ${ }^{5}$ possui uma população de mais de 200 milhões de habitantes, no qual a saúde, desde 1988, passou a ser um direito e sua oferta dever do Estado, devendo ser assegurada a todos os ci-

4 Uma "patente", na sua formulação clássica, é uma concessão pública, conferida pelo Estado, que garante ao seu titular a exclusividade ao explorar comercialmente a sua criação. Em contrapartida, é disponibilizado acesso ao público sobre o conhecimento dos pontos essenciais e as reivindicações que caracterizam a novidade no invento.

5 Os grupos são: baixa renda, \$1,035 ou menos; baixa renda média, \$1,036 - \$4,085; alta renda média $\$ 4,086$ - \$12,615; e alta renda,\$12,616 ou mais". (WORLD BANK GROUP, [201-]) 
dadãos, necessária para garantir a integralidade dos serviços. O que passa pela construção e implementação de uma PNCTIS articuladas às demais políticas setoriais.

O objetivo principal do capítulo é analisar os desdobramentos dessa política no Brasil particularmente no que se refere à ampliação do acesso e da produção de inovações de interesse público. Para tanto, além da introdução, este capítulo conta com os seguintes tópicos: antecedentes da relação entre ciência e tecnologia e desenvolvimento; o processo de construção da PNCTI em Saúde no Brasil; estratégias para ampliação do acesso e da capacidade interna de produção voltada aos interesses do SUS.

\section{Antecedentes da relação entre ciência e tecnologia e desenvolvimento}

Ao longo das últimas décadas, a disseminação da associação entre as atividades de Ciência, Tecnologia e Inovação (CT\&I) e o 342 desenvolvimento econômico e social tem motivado uma ênfase crescente ao tema na agenda de políticas públicas.

Kline e Rosenberg (1986) argumentam que o modelo de inovação largamente aceito após a Segunda Guerra Mundial, adotado pela maioria dos países industrializados, difundiu uma concepção da dinâmica da inovação que ficou conhecida como o chamado "modelo linear", segundo o qual o processo de inovação ocorreria por etapas sucessivas em sequência natural das atividades de pesquisa básica e aplicada para o desenvolvimento experimental e, em seguida, para a produção e comercialização. Esses autores propõem, então, uma alternativa ao modelo linear que denominam "modelo elo de cadeia" (chain-linked model) em que admitem que a inovação resultaria da interação entre as oportunidades de mercado e a base de conhecimentos e capacitações do segmento produtivo.

Desse modo, a discussão sobre as fontes mais importantes de inovação polarizava-se entre aqueles que atribuíam maior importância ao avanço do desenvolvimento científico (science push) e os que 
destacavam a relevância das pressões da demanda por novas tecnologias (demand pull). (CASSIOLATO; LASTRES, 2005)

Schumpeter foi o primeiro autor a identificar a inovação como a principal força motriz do desenvolvimento, dotada de dinâmica própria que atua diretamente sobre as estruturas fundantes da ordem econômica, além de ressaltar a importância da distinção entre crescimento e desenvolvimento econômico. (SCHUMPETER, 2004) O primeiro consistia apenas na ampliação dos meios de produção, ou seja, num ganho quantitativo, ao passo que o desenvolvimento só ocorreria quando fossem introduzidas mudanças qualitativas, isto é, inovações por indivíduos empreendedores. (SCHUMPETER, 1997)

Destaca-se que foi Schumpeter quem formulou o conceito de respostas criativas ou adaptativas, geradas para responder a mudanças endógenas no ambiente econômico. Nesse ponto, importa delinear esse conceito, as respostas criativas apresentam três características distintas: vinculam-se estreitamente à ação individual; são impossíveis de se prever; e tendem a moldar os eventos posteriores a seu aparecimento, já as adaptativas consistiriam em expansão da força de trabalho ou dos meios de produção. Desse modo, há necessidade de analisar os fatores que favorecem ou inibem a atividade inovadora na sociedade capitalista.

Schumpeter (1975) concebeu a inovação como uma destruição criativa capaz de desenvolver novas e melhores combinações produtivas com o consequente abandono de produtos e práticas antigos e obsoletos. Nesse contexto, uma inovação pode ser considerada como um novo uso de possibilidades e componentes pré-existentes.

Para Conde e Araújo-Jorge (2003), um outro modelo que também tem a adesão de inúmeros autores, é o modelo da Tripla Hélice (Triple Helix), formulado por Etzkowitz e Leydesdorff (2000). Contrapondo-se à tradição schumpeteriana, que associa a inovação às empresas, os autores conferem lugar de destaque às universidades e também incluem o governo como ator relevante em seu modelo. $\mathrm{O}$ modelo considerado dentre as abordagens não lineares ou interativas, seria representado por uma espiral com três hélices que se 
entrelaçam por meio de múltiplas interações entre as três esferas por elas representadas: a universidade, a indústria e o governo.

Para Dosi (2006), a inovação tecnológica é um instrumento de concorrência que gera uma vantagem competitiva de custos ou qualidade podendo ser real ou simbólica para o inovador. Portanto, é um processo heterogêneo e complexo, e sua dinâmica difere entre países, setores e empresas, o que torna a inovação uma variável fundamental para o desenvolvimento econômico e social.

Entretanto para Nelson e Winter (2005), na perspectiva evolucionária, o crescimento econômico em qualquer economia seria considerado um processo de desequilíbrio que envolve uma combinação de firmas que empregam diferentes "safras" de tecnologias, que se modificam ao longo do tempo. Esses autores consideram que nos países menos desenvolvidos as novas tecnologias passam a participar dessas combinações, na medida em que as tecnologias dos países de alta renda passam a ser adotadas.

Portanto, mesmo com a multiplicidade de abordagens e mode344 los que emergiram nas duas últimas décadas, é interessante ressaltar que as novas concepções de inovação enfatizam as noções de processo e de interatividade, além de incluírem novos atores que não aqueles tradicionalmente envolvidos com as atividades de P\&D. Como consequência desse deslocamento, o termo inovação do modelo linear foi substituído por processos de inovação ou atividades de inovação nas novas abordagens, bem como a noção de redes.

Num período marcado pela crescente incorporação de conhecimentos nas atividades produtivas, inclusive no segmento da saúde, a inovação passou a ser entendida como variável ainda mais estratégica para a competitividade de organizações e países.

Gadelha, Costa e Maldonado (2012), ressalta que ao institucionalizar a saúde como direito da população e assegurar o dever do Estado em provê-la, a Constituição de 1988 afirmou o papel desse campo como elemento estruturante do Estado de Bem-Estar. Dessa forma, a saúde foi consolidada como parte inerente da dimensão social do desenvolvimento. Além dessa dimensão, a saúde articu- 
la um sistema produtivo de forma interdependente, denominado Complexo Econômico-Industrial ${ }^{6}$ da Saúde (CEIS) que envolve subsistemas de base industrial (química, biotecnológica, mecânica, eletrônica e de materiais) e de serviços.

Essa tipologia busca explicar as diversas relações entre esses atores, entre os quais a indústria farmacêutica se apresenta como um dos maiores agentes de pressão para a incorporação de suas tecnologias pelos sistemas de saúde. Destaca-se que no âmbito dessa indústria passaram a conviver duas trajetórias tecnológicas distintas: uma baseada na química fina, que teve origem no final do século XIX e resultou nos fármacos tradicionais, e aquela nascida dos avanços da biologia molecular, bioquímica, e disciplinas afins, fortemente baseadas em técnicas de genômica e proteômica ${ }^{7}$ e $\mathrm{DNA}^{8}$ recombinante, que começou a se desenvolver a partir da década de 1970. (ARAGÃO, 2011; MALERBA; ORSENIGO, 2001; ORSENIGO; PAMMOLLI; RICCABONI, 2001) Motivo pelo qual, como será visto a seguir, foi construída no Brasil uma política que tem como eixo central o desenvolvimento científico, tecnológico e a inovação na área da saúde.

\section{Antecedentes da PNCTIS}

A garantia da assistência terapêutica integral prevista constitucionalmente requer desenvolvimentos científico e tecnológico que permitam ao país gerar inovações voltadas a atender as necessidades

6 Um conjunto selecionado de atividades produtivas que mantêm relações intersetoriais de compra e venda de bens e serviços (sendo captadas, por exemplo, nas matrizes de insumo-produto nas contas nacionais) e/ou de conhecimentos e tecnologias [...]. (GADELHA, 2003, p. 523)

7 As técnicas genômicas buscam estudar o conjunto dos genes ao passo que na proteômica se busca compreender as redes funcionais que são estabelecidas entre as proteínas codificadas pelos genes.

8 DNA Recombinante são moléculas de DNA que possuem fragmentos de DNA derivados de duas ou mais fontes, geralmente de espécies diferentes. 
de saúde da população brasileira. Nessa direção, o inciso V do artigo 200 da Constituição Federal estabelece entre as competências do SUS o incremento do desenvolvimento científico e tecnológico em sua área de atuação. Por sua vez, a Lei Orgânica da Saúde, em 1990, já previa também como papel do SUS a formulação da política de medicamentos, equipamentos, imunobiológicos e outros insumos de interesse para a saúde e a participação na sua produção.

Desde os anos 1990, algumas iniciativas foram colocadas na perspectiva de materializar o papel do SUS como ator chave nas políticas de C\&T e produção em saúde. No caso de medicamentos, por exemplo, a Lei n. ${ }^{\circ}$ 9.787, de 1999, que estabeleceu a criação da política de medicamentos genéricos no Brasil e regulamentou a produção e comercialização desses produtos, assegurou que as empresas brasileiras, públicas ou privadas, pudessem produzir medicamentos cujas patentes já tivessem expirado. Os genéricos são cópias dos originais, comercializados pela denominação genérica de fármaco e que passaram por equivalência farmacêutica e bioequivalência, estes últimos 346 realizados em seres humanos. (ANVISA, 2014) São esses testes que garantem que os medicamentos genéricos possuem o mesmo grau de eficácia, qualidade e segurança dos medicamentos de referência. Do ponto de vista institucional, a Lei de Genéricos foi fundamental no cenário de abertura comercial e mudança dos marcos normativos de propriedade intelectual.

Em 1996, o Brasil aderiu ao Trade-Related Aspects ofIntellectual Property Rights (TRIPS), ${ }^{9}$ da Organização Mundial do Comércio (OMC) que previa o reconhecimento de patentes farmacêuticas. Ao passar a reconhecer as patentes farmacêuticas imediatamente após a

9 Esse tratado internacional foi um dos mais importantes assinados pelo Brasil nos últimos tempos, pois tutela a propriedade das marcas, a proteção ao nome empresarial e o direito de impedir terceiros pelo uso de produto patenteado. Em todos os acordos internacionais firmados, a propriedade intelectual é item obrigatório na negociação entre pares ou Estados. Após a sua assinatura e ratificado pelo presidente, tem força de lei no país, que, inclusive, ensejou a elaboração da lei de propriedade industrial atual. (BRASIL, 1996) Essa lei está em consonância com as leis sobre a matéria na maioria dos países membros, um total de148 países, respeitando suas especificidades e soberania de cada país. 
assinatura do acordo, a indústria farmacêutica nacional passou por importantes mudanças.

Essa iniciativa impactou negativamente a indústria farmacêutica nacional, que tinha como um de seus pilares competitivos a produção e comercialização de medicamentos similares e não estava apta para concorrer com os grandes oligopólios internacionais na produção de bens inovadores, sendo a produção de genéricos um nicho importante nesse contexto institucional. (ARAGÃO; LOUREIRO; TEMPORÃO, 2014; CAPANEMA; PALMEIRA FILHO, 2004)

Por iniciativa dos países em desenvolvimento, as questões referentes à saúde pública inseridas no Acordo TRIPS redundaram na adoção, em 2001, da Declaração de Doha ${ }^{10}$ sobre o Acordo TRIPS e a Saúde Pública, que reconhece a "gravidade" dos problemas de saúde pública que afligem países pouco desenvolvidos e em desenvolvimento, destacando os que decorrem de aids, tuberculose, malária e outras epidemias - mas não se limitando a estes. A Declaração reflete as preocupações desses países sobre as implicações do Acordo TRIPS em relação à saúde pública em geral, sem se restringir a determinadas doenças. (CORREA, 2005)

Concomitantemente, em função da crescente pressão pela incorporação de novas tecnologias em saúde, o Ministério da Saúde (MS) desenvolveu iniciativas para buscar o estabelecimento de políticas de avaliação das mesmas na sua estrutura regimental. Apesar de o incentivo à pesquisa, desenvolvimento e inovação em saúde no Brasil constar na Lei Orgânica da Saúde desde 1990, e políticas científicas e tecnológicas específicas para a área da saúde foram iniciadas em 1994. (NOVAES; ELIAS, 2013)

Partindo-se da necessidade histórica de se articular uma política em C\&T que envolvesse tanto o setor privado quanto o setor público, foram criados em 1999 os Fundos Setoriais (FS), cuja concepção deu início à implantação de um novo instrumento de finan-

10 Declaração de Doha, IV Conferência Ministerial da OMC realizada em DOHA, Catar, 9 a 14 de novembro de 1994 . 
ciamento de projetos de pesquisa, desenvolvimento e inovação no país. De acordo com informações divulgadas pela Financiadora de Estudos e Projetos (Finep) ${ }^{11}$ (2016), a administradora dos Fundos (com exceção do Fundo para o Desenvolvimento Tecnológico das Telecomunicações, administrado pelo Ministério da Comunicação), os FSs representam um novo padrão de financiamento para a CT\&I, e pretendem garantir a constância de recursos e alcançar a eficiência na gestão das atividades, promovendo sinergia entre as universidades, centros de pesquisa e o setor produtivo. Para Sá (2005), a implementação dos FSs representou um novo mecanismo de estímulo ao fortalecimento do sistema de C\&T nacional.

Foi nesse contexto de articulação interinstitucional que aconteceu em 1994 a I Conferência Nacional de Ciência e Tecnologia em Saúde (CNCT\&I/S), que apresentou a proposição de um novo paradigma de ação e de um novo projeto nacional para a pesquisa em saúde. No qual o MS destaca a importância de seu papel como indutor da pesquisa, desenvolvimento e inovação. (GUIMARÃES 348 et al., 2002)

Morel (2004) aponta que as resoluções da conferência propõem que a política de pesquisa em saúde integre a política nacional de saúde e recomendam que o sistema nacional de pesquisa em saúde siga os seguintes princípios:

a. prioridade aos projetos capazes de aumentar o grau de equidade do sistema de saúde;

b. respeito permanente a padróes éticos consensualmente estabelecidos nos projetos executados;

11 A Finep foi criada em julho de 1967 para financiar a elaboração de estudos para projetos e programas de desenvolvimento econômico, mas também para atuar no aperfeiçoamento da tecnologia nacional. Com a criação do então Ministério da Ciência e Tecnologia (MCT), em março de 1985, a Finep passa a se vincular à pasta. Sua gestão e execução são orientadas a partir do conjunto de diretrizes das políticas públicas federais, no âmbito da Estratégia Nacional de Ciência, Tecnologia e Inovação (ENCTI) e da Política Brasil Maior (PBM). 
c. estímulo permanente às práticas investigativas que somem esforços e fomentem a integração de grupos de pesquisa e instituições;

d. estabelecimento de padrões de qualidade científica ou tecnológica segundo a avaliação dos pares como critério de base para o financiamento de projetos;

e. garantia do acompanhamento e desenvolvimento da C\&T na fronteira do conhecimento dos diferentes campos estratégicos.

A II CNCT\&I/S, recomendada pela XI Conferência Nacional de Saúde, foi realizada em 2004, e teve como temas de pauta: "O sistema nacional de C\&T em saúde”, destacando a necessidade de que a pesquisa em saúde fosse um componente da Política Nacional de Saúde, de modo a poder implementar os Planos Estratégicos Plurianuais.

Nesse sentido, a PNCIS, estabelecida em 2004, como resultado da segunda conferência de CTI e saúde, tornou-se um elemento estratégico no âmbito das políticas públicas setoriais pois coloca o SUS como orientador das políticas de desenvolvimento produtivo. O papel da saúde de incrementar em sua área de atuação o desenvolvimento científico e tecnológico e a participação e indução aos interesses públicos já estavam previstos na Constituição de 1988, porém como foi visto sua atuação estruturada nessas frentes de fato só começa a ser institucionalizada no final da década subsequente.

No entanto, ou a inovação em saúde é incorporada na mudança do padrão de desenvolvimento brasileiro em direção aos interesses da sociedade ou perde o sentido. É nessa dimensão que se coloca o tema do complexo econômico-industrial da saúde (sistema produtivo farmacêutico, de equipamentos e materiais e de serviços de saúde), assumido nas estratégias recentes de política de desenvolvimento e consolidando-se com o aparato normativo do Brasil Maior. (GADELHA; COSTA, 2012)

A PNCTIS foi concebida como um componente da Política Nacional de Ciência, Tecnologia e Inovação (PNCTI). Em ambas, estava explícito que o desenvolvimento nacional deveria ser estabe- 
lecido com sustentabilidade, e com foco na produção de conhecimentos técnicos e científicos ajustados às necessidades econômicas, sociais, culturais e políticas do país. (ARAGÃO; LOUREIRO; TEMPORÃO, 2014) Desde então, as demais políticas industriais e de comércio exterior têm colocado a saúde em suas prioridades.

Como o desenvolvimento científico, tecnológico e a inovação são elementos complexos que requerem intervenções de diferentes campos para serem concretizados, um conjunto de marcos regulatórios tem sido criado, tais como a Lei n. ${ }^{\circ} 10.972$, de 2004, denominada Lei da Inovação, ${ }^{12}$ e a lei do Bem, ${ }^{13}$ de 2005 , ambas importantes para ampliação da colaboração entre universidades e empresas. A segunda amplia as possibilidades de financiamento mediante concessões fiscais às empresas de base tecnológica, com possibilidade de impactos positivos à pesquisa, pela articulação e colaboração entre universidades e empresas.

Concomitantemente, o MS estava em processo de institucionalização dessas áreas. Esse tem sido um processo que envolve esforços conjuntos de vários níveis do governo, tendo o MS papel de destaque nessa articulação, com a criação do Departamento de Ciência e Tecnologia (Decit), em 2000, incorporado posteriormente à Secretaria de Ciência e Tecnologia e Insumos Estratégicos (SCTIE), criada em 2003.

A SCTIE tem sido um agente central no processo de formulação e implantação da política de ciência, tecnologia e inovação no âmbito do SUS e articulação com outras instâncias. Em função de sua complexidade, o sucesso dessa política depende da interação entre diversos segmentos da sociedade, desde os órgãos da administração governamental (saúde, educação, indústria e comércio, agricultura, ciência e tecnologia etc.) até os setores produtivos, passando

12 Dispõe sobre incentivos à inovação e à pesquisa científica e tecnológica no ambiente produtivo e dá outras providências. Nova redação dada pela Lei n. ${ }^{\circ}$ 13.243, de 2016.

13 A Lei n. ${ }^{\circ}$ 11.196/05, chamada de "Lei do bem", oferece incentivos fiscais às pessoas jurídicas que realizarem pesquisa e desenvolvimento e inovação tecnológica. 
pelas instituições acadêmicas. Elementos como fomento à $\mathrm{P} \& \mathrm{D}$ e disponibilização de linhas de financiamento têm sido disponibilizados através dos esforços dos Ministérios da Ciência, Tecnologia e Inovação (MCTI), da Saúde e de Desenvolvimento, Indústria e Comércio Exterior (MDIC).

Foram criadas redes importantes que integram um conjunto de esforços de articulação de competências em áreas estratégicas, a exemplo da Rede Nacional de Avaliação de Tecnologias em Saúde (Rebrats) e da Rede Nacional de Pesquisa Clínica (RNPS). O Instituto de Saúde Coletiva (ISC), por meio do Programa Economia, Tecnologia e Inovação em Saúde (PECS), foi um dos primeiros membros da primeira, tendo sido selecionado no primeiro edital do Decit para a formação de RH na área de Avaliação de Tecnologias em Saúde.

Aqui cabe destacar o esforço brasileiro recente no caminho de construir uma base regulatória para o complexo processo de gestão de tecnologias em saúde. Através da Portaria GM 152/2006, foi regulamentada a Comissão para Incorporação de Tecnologias em Saúde (Citec), no âmbito da Secretaria de Atenção à Saúde (SAS), que posteriormente passou a ficar subordinada à SCTIE. Em 2011, foi sancionada a Lei n, ${ }^{\circ} 12.401$, de 28 de abril de 2011, que criou a Comissão Nacional de Incorporação de Tecnologias em Saúde (Conitec), ${ }^{14}$ pela lei 12.401 , de 28 de abril de 2011, substituindo a Citec. Dentre as mudanças ocorridas com a publicação da Lei n. ${ }^{\circ}$ 12.401 e do decreto $n .^{\circ} 7.646$, de 22 de novembro de 2011 , o qual re-

14 A Conitec no SUS foi criada pela lei n. ${ }^{0}$ 12.401, de 28 de abril de 2011, substituindo a Citec. Enquanto a Citec contava com cinco representantes, a Conitec conta com (13. A participação social está presente pelo CNS, que reúne representantes de entidades e movimentos de usuários, de trabalhadores da área da saúde, do governo e de prestadores de serviços de saúde. A participação dos estados e municípios também está garantida pela representação do Conselho Nacional de Secretários de Saúde (Conass) e do Conselho Nacional de Secretários Municipais de Saúde (Conasems). Ainda, temos a participação do Conselho Federal de Medicina (CFM), como órgão de classe envolvido diretamente com a legitimação das ações e procedimentos médicos, portanto de elevado interesse para as discussões da Conitec. 
gulamenta a composição, as competências e o funcionamento da Conitec, temos nova composição do plenário da Comissão, ampliando a participação da sociedade e do próprio MS.

É responsabilidade da Conitec assessorar o MS na incorporação, exclusão ou alteração pelo SUS de novas tecnologias em saúde, como medicamentos, produtos e procedimentos, tais como vacinas, produtos para diagnóstico de uso in vitro equipamentos, procedimentos técnicos, sistemas organizacionais, informacionais, educacionais e de suporte, programas e protocolos assistenciais, por meio dos quais a atenção e os cuidados com a saúde são prestados à população.

Cabe aqui também falar sobre a atuação da Conitec na constituição e alteração de protocolos clínicos e diretrizes terapêuticas, podendo requisitar a sua elaboração ou revisão, conforme o interesse para o SUS, lembrando que um protocolo clínico e diretriz terapêutica estabelece critérios para o diagnóstico da doença ou do agravo à saúde; o tratamento preconizado, os medicamentos e demais produtos apropriados, quando couber; as posologias recomendadas; os mecanismos de controle clínico; e o acompanhamento e a verificação dos resultados terapêuticos, a serem seguidos pelos gestores do SUS.

Com vistas à aproximação da saúde com os segmentos produtivos, foi criado, em 2009, no MS, o Departamento do Complexo Industrial e Inovação em Saúde (Deciis). Neste, a atuação do Grupo Executivo do Complexo Industrial da Saúde (Gecis), coordenado pelo MS, tem contribuído para a promoção de medidas e ações visando ampliação e estruturação do marco regulatório brasileiro, referente à estratégia de desenvolvimento do Governo Federal para a área da saúde, segundo as diretrizes das políticas nacionais de fortalecimento do complexo produtivo e de inovação em saúde.

A articulação intersetorial tem possibilitado a criação de marcos regulatórios importantes, que tendem a impactar positivamente o segmento da saúde, que além de um direito é considerada estratégica para o desenvolvimento do país, como reflete a política industrial, tecnológica e de comércio exterior do governo federal, no qual a saúde ampliou sua inserção desde 2004. 
Essa maior articulação tem se traduzido em ampliação dos investimentos do MS, conjuntamente com o MCTI e MDIC, na área de pesquisa e no processo de inovação e modernização da indústria de saúde brasileira, particularmente no segmento (bio) farmacêutico, tendo em vista o peso desses medicamentos para o orçamento do MS. Essas e outras iniciativas se traduziram no aumento do investimento em atividades de P\&D no âmbito da indústria farmacêutica e em outros segmentos do setor saúde no Brasil.

A PNCTS, formalizada em 2004, incluiu entre as suas estratégias a avaliação de tecnologias em saúde como instrumento que contribui para o aprimoramento da capacidade regulatória do Estado na incorporação de tecnologias nos sistemas de saúde. Isso porque, a incorporação de tecnologias em saúde tem constituído um dos principais componentes do aumento dos gastos com saúde como proporção do PIB dos países, inclusive no Brasil. Um dos segmentos que mais pressionam o SUS para incorporação de seus produtos é a indústria farmacêutica. Como será visto a seguir, isso pode comprometer a sustentabilidade do sistema sobretudo porque parte significativa dos medicamentos incorporados nos últimos anos são biológicos, cujos valores ainda são muito superiores aos dos fármacos tradicionais.

\section{Estratégias para ampliação do acesso e da capacidade interna de produção de medicamentos voltados aos interesses do SUS}

De acordo com a Pesquisa de Inovação (Pintec), em 2003, o investimento em $\mathrm{P} \& \mathrm{D}$ da indústria farmacêutica correspondia a $0,5 \%$ da receita líquida de vendas (RLV). Em 2011, esse valor passou para 0,7\% . (IBGE, 2011)

Em países avançados, os esforços de $\mathrm{P} \& \mathrm{D}$ podem eventualmente resultar em inovações impulsionadas pela tecnologia, apesar do alto grau de incerteza. Já em países em desenvolvimento, como o Brasil, a demanda constitui o principal estímulo à inovação. Nessa perspec- 
tiva, o marco legal e a organização do SUS tem buscado direcionar a difusão das tecnologias aos interesses sociais ao invés de permitir que o processo ocorra apenas alinhado aos interesses mercadológicos.

Desse modo, observa-se que os investimentos para o adensamento da cadeia farmacêutica constante na PNCTIS, por exemplo, tem se refletido na consolidação de segmentos estratégicos para a saúde pública, como o de genéricos. No país, desde 2004, o mercado farmacêutico vem crescendo em ritmo acelerado, tanto em quantidade (9\% a.a.) quanto em valor real (10\% a.a.), atingindo $\mathrm{R} \$$ 45 bilhões em 2012. O mercado de genéricos tem influenciado fortemente esse crescimento, tendo sua participação no mercado em unidades vendidas saltado de $9 \%$ em 2004 para 24\% em 2013, enquanto os medicamentos de referência caíram de $38 \%$ para cerca de $17 \%$ no mesmo período. (GOMES et. al., 2014; KAPLAN, WIRT; STEPHENS, 2013)

Desse modo, tem-se, trabalhando de modo mais articulado, o importante tripé formado pelo MS, MCTI e Ministério de 354 Desenvolvimento, Indústria e Comércio Exterior capaz de permitir uma construção articulada e compartilhada das políticas científica, tecnológica e de inovação, política industrial e política de saúde. Iniciativas lideradas pelo MS visando ampliar o acesso de tecnologias utilizadas na prevenção e cuidados com a saúde passam pela atuação nas áreas de C\&T e estímulo à produção e distribuição das mesmas.

De acordo com a Pesquisa de Orçamentos Familiares 2008-2009 (POF), do Instituto Brasileiro de Geografia e Estatística (IBGE) (2011), os medicamentos respondem por 4,2\% dos gastos das famílias que recebem até $\mathrm{R} \$ 830,00$ por mês. Tais gastos correspondem a 76,4\% do dispêndio com saúde efetuado pelas famílias nessa faixa de renda. Já para aquelas com rendimentos acima de $\mathrm{R} \$ 10.375,00$, os gastos com medicamentos consumem apenas 1,9\% da renda. $\mathrm{Ou}$ seja, o grau de comprometimento da renda familiar com medicamentos é maior para os que ganham menos. Nesse sentido, o SUS constitui um instrumento decisivo para a redução de iniquidades. 
As Parcerias para o Desenvolvimento Produtivo (PDP), instituídas em 2008 e cujos marcos regulatórios foram aperfeiçoados em 2012 e 2014, têm como objetivo fortalecer a indústria nacional farmoquímica e de medicamentos, particularmente nas áreas mais inovadoras, como a de biotecnologia, de modo a reduzir a dependência externa em áreas estratégicas para o país e disponibilizar medicamentos de alto custo para a população brasileira.

\section{As Parcerias para o Desenvolvimento Produtivo (PDPs)}

As PDPs foram instituídas pelo MS em 2008 tendo seu marco normativo passado por aperfeiçoamento em 2012, quando ganharam essa nomenclatura. Estas estão alinhadas à PNCTIS, a Política de CT\&I e a Política Industrial e de Comércio Exterior do Brasil. Tais parcerias que têm como uma das diretrizes o foco em inovação e no crescimento produtivo do parque industrial brasileiro passaram a ser um dos componentes do Programa de Investimento no Complexo Industrial da Saúde (Procis), lançado em 2012, que integra a estratégia nacional de promoção do desenvolvimento e inovação no campo da Saúde, por meio de investimento nos produtores públicos e na infraestrutura pública de produção e inovação. Dessa forma, visa fortalecer a indústria brasileira, dando maior autonomia ao país em relação à produção de tecnologias estratégicas ao SUS.

O SUS possui, atualmente, 19 laboratórios públicos, parte deles envolvidos nos processos das PDPs. Tais instituições são responsáveis pela produção de medicamentos, soros e vacinas para atender às necessidades da rede pública do país. Entretanto, muitos produtos disponibilizados pelo SUS ainda são importados de outros países e há carência da produção nacional.

As parcerias envolvem laboratórios públicos e o setor produtivo privado, com objetivo de absorver a tecnologia de novas formulações. Assim, as empresas privadas que detêm o domínio tecnológico se comprometem a transferir a tecnologia para a produção do me- 
dicamento e do Insumo Farmacêutico Ativo (IFA) - a substância responsável pelo tratamento -, para empresas nacionais, no prazo de cinco anos. Como contrapartida, o governo garante exclusividade na compra desses produtos - pelos menores valores cotados no mercado mundial - durante esse mesmo período. Desde 1985, quando foi lançado o programa de autossuficiência em imunobiológicos, não havia um programa de estímulo e investimento na produção pública.

Após o prazo para a transferência de tecnologia, o laboratório público nacional inicia, de forma autônoma, a produção completa do medicamento visando atender à demanda nacional. Com a produção sendo realizada no país, os laboratórios públicos passarão a contribuir para reduzir a dependência de importação, ampliando sua competitividade e capacitação tecnológica. Atualmente o déficit comercial de medicamentos gira em torno de 6 bilhões de dólares (Figura 1).

Figura 1 - Balança comercial brasileira da área de medicamentos

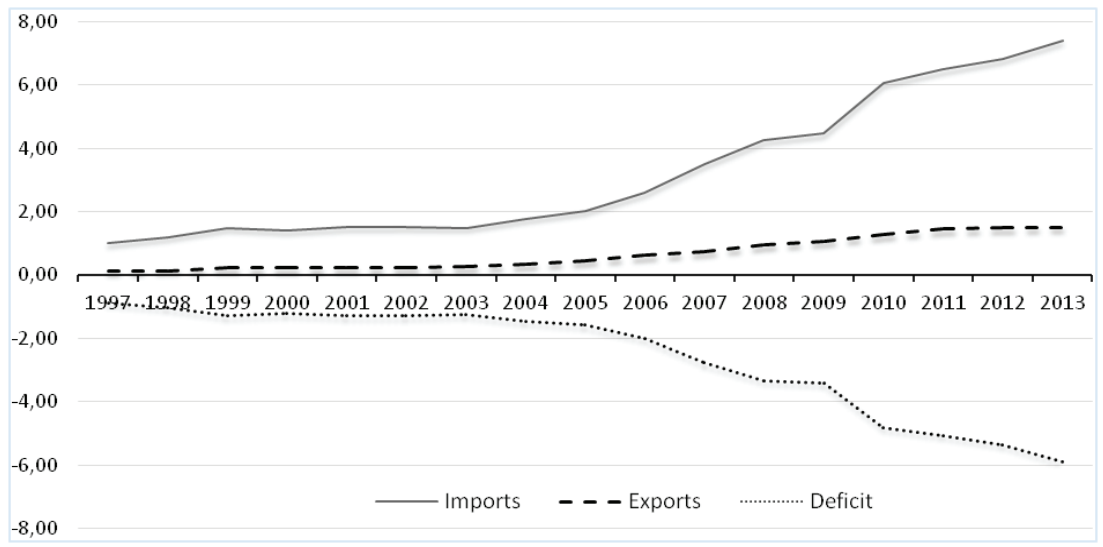

Fonte: Interfarma (2014).

Além de gerar uma significante economia para o MS (estimada em cerca de R 4 bilhões por ano) e contribuir para a redução da dependência do país para a importação desses produtos, as parcerias firmadas até o momento tem se traduzido em benefícios à popula- 
ção, pois garantem o abastecimento de medicamentos estratégicos à rede SUS.

Essas parcerias têm como um dos focos principais a produção de medicamentos biológicos, cujos valores médios são significativamente superiores aos dos fármacos tradicionais. Tais medicamentos são utilizados, sobretudo, para o tratamento de doenças crônicas não transmissíveis, como os diversos tipos de câncer e problemas reumáticos. Apesar dos medicamentos biológicos equivalerem a cerca de $5 \%$ dos medicamentos comprados pelo MS, eles representam $49 \%$ dos gastos. A importação desses produtos tem sido uma dos grandes responsáveis pelo aumento do déficit comercial da saúde. (ARAGÂO; LOUREIRO; TEMPORÃO, 2014)

A redução da dependência de biofármacos, aproveitando o espaço temporal de queda de uma série de patentes desses produtos previstas para os próximos anos, pode ampliar o acesso da população a tratamentos de doenças nos quais tais tecnologias se mostrem mais efetivas que os fármacos tradicionais.

No caso específico do câncer, a possibilidade da introdução dos biofármacos no tratamento se mostrou importante para a redução de iniquidades no acesso a esse tipo de tecnologia. Estudo de Aragão, Loureiro e Temporão (2014) mostrou que biofármacos não incorporados ao SUS eram usualmente acessados via ação judicial e seu uso restrito a esses demandantes, prioritariamente usuários do sistema privado de saúde. Em 2010, US\$ 3,4 milhões foram gastos pelo Governo Federal para atender demandas judiciais relativas ao fornecimento de biológicos contra o câncer, parte deles já incorporados pelo SUS desde 2012. Isso significou gastos per capita de até 183,3 mil dólares ano. (ARAGÃO; LOUREIRO; TEMPORÃO, 2014)

Até 2015, foram enviados pelos Laboratórios Públicos 265 projetos de PDPs sendo que 105 (39,6\%) eram referentes à biológicos. Destas, 116 foram aprovadas, 47 (40,5\%) eram destinados à transferência de tecnologia para a produção desses produtos. (ARAGÃO; LOUREIRO; TEMPORÃO, 2014) 
Figura 2 - PDPs solicitadas e aprovadas entre 2009/2015

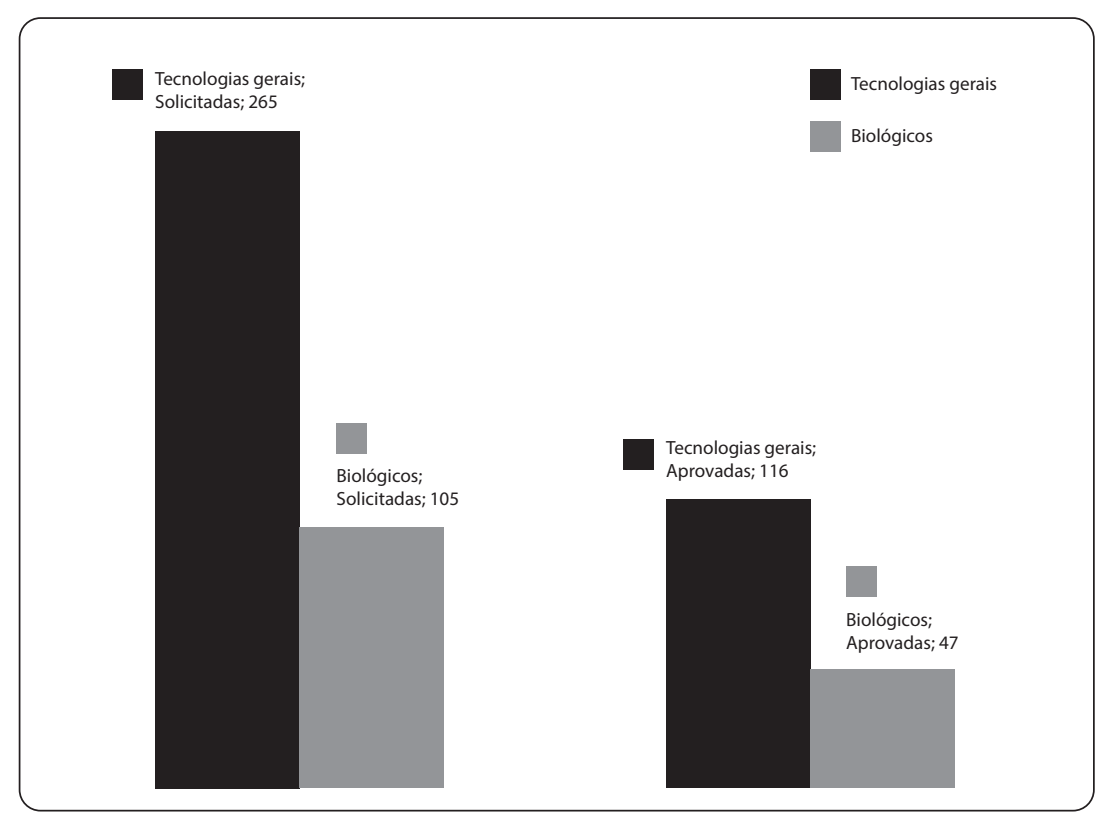

Fonte: adaptado de Brasil (2015).

Esse perfil dos projetos segue orientações normativas que visam a produção de tecnologias recém incorporadas, em processo de avaliação para incorporação ou que possam ter impactos significativo para o orçamento do MS. Isso pode ser verificado quando analisamos as solicitações de incorporação de tecnologias a Conite (Figura 3$).{ }^{15}$

15 Os autores agradecem à Juliana Genonadio de Oliveira, bolsista, pelo empenho na consolidação dos dados da Conitec e PDPs. 
Figura 3 - Solicitações e incorporações à Conitec (2012 a novembro de 2015)

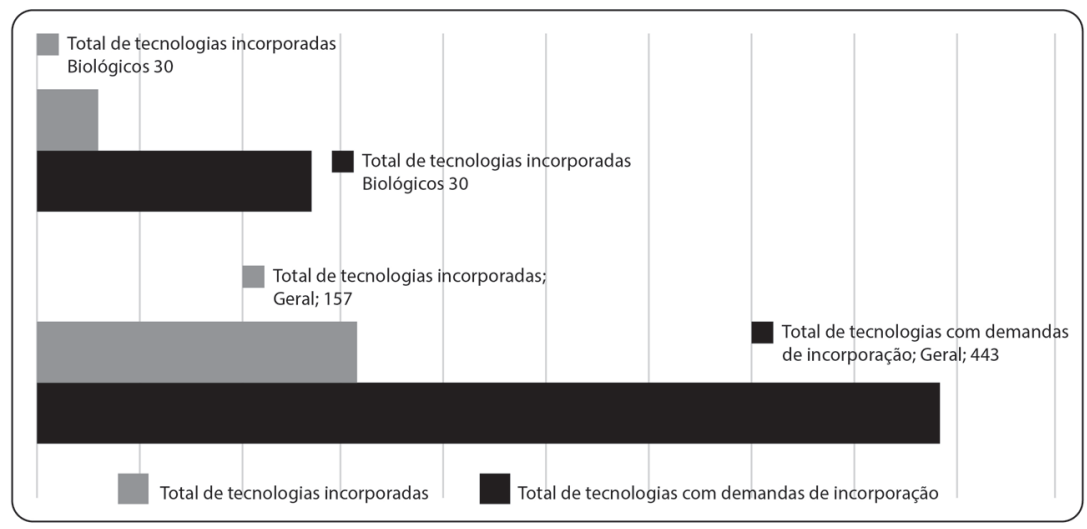

Fonte: adaptado da Conitec (2014).

De 2012 até novembro de 2015, a Conitec recebeu 443 propostas de incorporação/exclusão/ampliação de uso de novas tecnologias. Desse total, 30,47\% (135) referiam-se à biológicos. Dentre as 157 solicitações aprovadas para incorporação no SUS, 19,11\% (30) correspondiam a biofármacos.

\section{Oportunidades e desafios}

Utilizar o poder de compra e estabelecer políticas de fomento para a indústria farmacêutica nacional, inclusive os laboratórios públicos, são formas de proteção do exercício de práticas monopolísticas exercidas pelas grandes corporações farmacêuticas. Práticas essas possíveis em função de um regime de proteção intelectual extremamente favorável às economias dos países desenvolvidos. Em um segmento em que a substituição de bens é bastante limitada, a persistência dessas práticas certamente aprofundará as desigualdades sociais tanto em nível internacional como nacional. Nessa perspectiva, políticas que levam em conta o grau de concentração de mercados podem assegurar a introdução de tecnologias inovadoras e ao mesmo tempo reduzir as desigualdades no acesso aos medicamentos. 
Por fim, cabe ressaltar que as PDPs já incluem uma estratégia de desenvolvimento social, iniciativas asseguradas na política de C\&T em Saúde e de um conjunto de marcos regulatórios e institucionais que nos permite refletir sobre a necessidade de avançar ainda na perspectiva de segurança sanitária, que não deve estar subordinada à lógica de competitividade da indústria, mas sim, que fortaleçam a articulação da lógica produtiva à lógica da saúde pública.

\section{Referências}

AGÊNCIA NACIONAL DE VIGILÂNCIA SANITÁRIA -ANVISA. 2014. Disponível em : <http://s.anvisa.gov.br/wps/s/r/cR7o>. Acesso: 25 mar. 2015.

ALMEIDA-FILHO, N; BARRETO, M.; ROUQUAYROL, Z. Introdução ao método epidemiológico. In: ALMEIDA-FILHO, N. (Org.). Epidemiologia \& saúde: fundamentos, métodos, aplicações. Rio de Janeiro: Guanabara koogan, 2011.

ARAGÃO, E. Colaboração e inovação na área de biotecnologias aplicadas à saúde humana. 2011. 120 f. Tese (Doutorado em Saúde Coletiva) Instituto de Saúde Coletiva, Universidade Federal da Bahia, Salvador, 2011.

ARAGÃO, E.; LOUREIRO, S.; TEMPORÃO, J. G Trajetórias tecnológicas na indústria farmacêutica: desafios para a equidade no Brasil. In: PAIM, J. S.; ALMEIDA-FILHO, N. (Org.). Saúde coletiva: teoria e prática. Rio de Janeiro: Medbook, 2014. p. 185-194

BRASIL. Conselho Nacional de Desenvolvimento Industrial. Brasil maior: inovar para competir. Competir para crescer: acompanhamento das medidas setoriais. Brasília, DF, 2013. Disponível em: <http://www. abdi.com.br/Estudo/Agendas\%20Setoriais\%20-\%20Acompanhamento. pdf $>$. Acesso em: 13 out. 2016.

BRASIL. Constituição (1988). Constituição da República Federativa do Brasil. Brasília, DF, Senado, 1998. Disponível em: < http://www.senado. gov.br/legislacao/const/con1988/CON1988_16.02.1998/CON1988. shtm>. Accesso em: 13 fev. 2015. 
BRASIL. Decreto no 7.546, de 2 de agosto de 2011. Regulamenta o disposto nos $\$ \$ 5$ o a 12 do art. 3o da Lei no 8.666, de 21 de junho de 1993, e institui a Comissão Interministerial de Compras Públicas. Diário Oficial [da] República Federativa do Brasil. Brasília, DF, 3 ago. 2011. Disponível em: <http://www.planalto.gov.br/ccivil_03/_ato20112014/2011/Decreto/D7546.htm>. Acesso: 25 mar de 2015.

BRASIL. Lei n. 8.080, de 19 de setembro de 1990. Dispõe sobre as condições para a promoção, proteção e recuperação da saúde, a organização e o funcionamento dos serviços correspondentes e da outras providencias. Diário Oficial [da] República Federativa do Brasil. Brasília, DF, 20 set. 1990.

BRASIL. Lei 11.196, 21 de novembro de 2005. Institui o Regime Especial de Tributação para a Plataforma de Exportação de Serviços de Tecnologia da Informação - REPES, o Regime Especial de Aquisição de Bens de Capital para Empresas Exportadoras - RECAP e o Programa de Inclusão Digital; dispõe sobre incentivos fiscais para a inovação tecnológica; altera o Decreto-Lei no 288, de 28 de fevereiro de 1967, o Decreto no 70.235, de 6 de março de 1972, o Decreto-Lei no 2.287, de 23 de julho de 1986, as Leis nos 4.502, de 30 de novembro de 1964, 8.212, de 24 de julho de 1991, 8.245, de 18 de outubro de 1991, 8.387, de 30 de dezembro de 1991, 8.666, de 21 de junho de 1993, 8.981, de 20 de janeiro de 1995, 8.987, de 13 de fevereiro de 1995, 8.989, de 24 de fevereiro de 1995, 9.249, de 26 de dezembro de 1995, 9.250, de 26 de dezembro de 1995, 9.311, de 24 de outubro de 1996, 9.317, de 5 de dezembro de 1996, 9.430, de 27 de dezembro de 1996, 9.718, de 27 de novembro de 1998, 10.336, de 19 de dezembro de 2001, 10.438, de 26 de abril de 2002, 10.485, de 3 de julho de 2002, 10.637, de 30 de dezembro de 2002, 10.755, de 3 de novembro de 2003, 10.833, de 29 de dezembro de 2003, 10.865, de 30 de abril de 2004, 10.925, de 23 de julho de 2004, 10.931, de 2 de agosto de 2004, 11.033, de 21 de dezembro de 2004, 11.051, de 29 de dezembro de 2004, 11.053, de 29 de dezembro de 2004, 11.101, de 9 de fevereiro de 2005, 11.128, de 28 de junho de 2005, e a Medida Provisória no 2.199-14, de 24 de agosto de 2001; revoga a Lei no 8.661, de 2 de junho de 1993, e dispositivos das Leis nos 8.668, de 25 de junho de 1993, 8.981, de 20 de janeiro de 1995, 10.637, de 30 de dezembro de 2002, 10.755, de 3 de novembro de 2003, 10.865, de 30 de 
abril de 2004, 10.931, de 2 de agosto de 2004, e da Medida Provisória no 2.158-35, de 24 de agosto de 2001; e dá outras providências. Diário Oficial [da] República Federativa do Brasil. Brasília, DF, 22 nov. 2005. Disponível em:<http://www.planalto.gov.br/ccivil_03/_ato20042006/2005/lei/111196.htm. Acesso em: 15 mar. 2015.

BRASIL. Lei no 10.973, de 2 de dezembro de 2004. Dispõe sobre incentivos à inovação e à pesquisa científica e tecnológica no ambiente produtivo e dá outras providências. Diário Oficial [da] República Federativa do Brasil. Brasília, DF, 3 dez. 2004. Disponível em: <http:// www.planalto.gov.br/ccivil_03/_ato2004-2006/2004/lei/110.973.htm>. Acesso em: 3 abr. 2015.

BRASIL. Lei no 9.279, de 14 de maio de 1996. Regula direitos e obrigações relativos à propriedade industrial. Diário Oficial [da] República Federativa do Brasil. Brasília, DF, 15 maio 1996. <http://www.planalto. gov.br/ccivil_03/leis/19279.htm>. Acesso em: 3 fev. 2015.

BRASIL. Ministério da Saúde. Departamento de Ciência e Tecnologia. Política nacional de ciência, tecnologia e inovação em saúde 2. ed. Brasília, DF, 2008. (Série B. Textos Básicos em Saúde).

BRASIL. Ministério da Saúde. Portaria n. 152, de 19 de janeiro de 2006. Institui o fluxo para incorporação de tecnologias no âmbito do Sistema Único de Saúde. Diário Oficial [da] União. Brasília, DF, 2006.

BRASIL. Ministério da Saúde. Portaria no 837, de18 de abril de 2012. Define as diretrizes e os critérios para o estabelecimento das Parcerias para o Desenvolvimento Produtivo (PDP). Diário Oficial da União. Brasília, DF, 2012. Disponível em: <http://bvsms.saude.gov.br/bvs/ saudelegis/gm/2012/prt0837_18_04_2012.html>. Acesso em: 3 abr. 2015.

BRASIL. Lei no 9.787, de 10 de fevereiro de 1999. Altera a Lei no 6.360, de 23 de setembro de 1976. Dispõe sobre a vigilância sanitária, estabelece o medicamento genérico, dispõe sobre a utilização de nomes genéricos em produtos farmacêuticos e dá outras providências. Diário Oficial [da] República Federativa do Brasil. Brasília, DF, 11 fev. 1999.

BRASIL. Ministério da Saúde. Secretaria de Ciência, Tecnologia e Insumos Estratégicos. 2013. Disponível em: <http://portalsaude.saude.gov.br/ 
index.php/o-ministerio/principal/secretarias/sctie>. Acesso em: 22 abr. 2015.

CAPANEMA, L. X. de L.; PALMEIRA FILHO, P. L. A cadeia farmacêutica e a política industrial: uma proposta de inserção do BNDES. BNDES Setorial, Rio de Janeiro, n. 19, p. 23-48, 2004.

CASSIOLATO, J. E.; LASTRES, H. M. M. Sistemas de inovação e desenvolvimento as implicações de política, São Paulo em Perspectiva, São Paulo, v. 19 n. 1, jan./mar. 20052005.

CONDE, M. V. F.; ARAUJO-JORGE, T. C. de. Modelos e concepções de inovação: a transição de paradigmas, a reforma da C\&T brasileira e as concepções de gestores de uma instituição pública de pesquisa em saúde. Ciência e Saúde Coletiva, São Paulo, v. 8, n. 3, p. 727-741, 2003. Disponivel em: <http://www.scielo.br/scielo.php?script $=$ sci arttext\&pid=S1413-81232003000300007\&lng=en\&nrm =iso $>$. Accesso em: 16 nov. 2015.

CORREA, C. M. O Acordo TRIPS e o acesso a medicamentos nos países em desenvolvimento. Sur. Revista Internacional de Direitos Humanos, São Paulo, v. 2, n. 3, p. 26-39, dez. 2005. Disponível em:<http://www.scielo. br/scielo.php?script=sci_arttext\&pid=S1806-64452005000200003\&lng $=$ en $\&$ nrm $=$ iso $>$. Acesso em: 28 out. 2015.

COSTA SOUZA, J.; BRUNO-FARIA, M. de F. Processo de inovação no contexto organizacional: uma análise de facilitadores e dificultadores BBR. Brazilian Business Review, Vitória, v. 10, n. 3, p. 113-136, July/sept. 2013.

DOSI, G. Mudança e técnica e transformação industrial: a teoria e uma aplicação à Indústria dos Semicondutores. São Paulo: Unicamp, 2006.

ETZKOWITZ, H.; LEYDESDORFF, L. The dynamics of innovation: from national systems and 'mode 2' to a Triple Helix of UniversityIndustry-Government relations. Research Policy, Amsterdam, v. 29, n. 2, p. 109-123, 2000.

FREEMAN, C. La teoría económica de la innovación industrial. Madrid: Alianza Editorial, 1975. 
FINANCIADORA DE ESTUDOS E PROJETOS - Finep. O que são Fundos Setoriais. Disponivel em: <http://www.finep.gov.br/a-finepexterno/fontes-de-recurso/fundos-setoriais/o-que-sao-fundossetoriais $>$. Acesso em: 13 out. 2016.

FIOCRUZ. Produção e Inovação. Rio de Janeiro , [200-]. Disponível em: <http://portal.fiocruz.br/pt-br/content/produ\%C3\%A7\%C3\%A3o-einova\%C3\%A7\%C3\%A3o>. Acess: 20 mar. 2015.

GADELHA, C. A. G. Desenvolvimento, complexo industrial da saúde e política industrial. Revista de Saúde Pública, São Paulo, v. 40, p. 11-23, 2006. Edição especial.

GADELHA, C. A. G. O complexo industrial da saúde e a necessidade de um enfoque dinâmico na economia da saúde. Ciência e Saúde Coletiva, v. 8, n. 2, p. 521-535, 2003.

GADELHA, C. A. G; COSTA, L. S; MALDONADO, J. O complexo econômico-industrial da saúde e a dimensão social e econômica do desenvolvimento. Revista de Saúde Pública, São Paulo, v. 46, p. 21-28, 2012.

GADELHA, C. A. G; COSTA, L. S. A saúde na política nacional de desenvolvimento: um novo olhar sobre os desafios da saúde. In: FUNDAÇÃO OSWALDO CRUZ. A saúde no Brasil em 2030: diretrizes para a prospecção estratégica do sistema de saúde brasileiro. Rio de Janeiro, 2012.p. 103-131.

GOMES, R. P. et. al. O novo cenário de concorrência na indústria farmacêutica brasileira. BNDES Setorial, Rio de Janeiro, n. 39, p. 97-134, 2014.

COMISSÃO NACIONAL DE INCORPORAÇÃO DE TECNOLOGIAS NO SUS- CONITEC. Tecnologias demandadas. 2014.

GUIMARÃES, R. A migração de pesquisadores do Brasil. Ciência Hoje, São Paulo, v. 32, n. 187, p. 40-43, 2002.

GUIMARÃES, R. et al. Política nacional de ciência, tecnologia e inovação em saúde: uma proposta Rio de Janeiro: Abrasco, 2002. 
IBGE. Pesquisa de orçamentos familiares 2008-2009: análise do consumo alimentar pessoal no Brasil. Rio de Janeiro , 2011.

IBGE. Pesquisa de inovação tecnológica. Rio de Janeiro, 2011. Disponível em: <http://www.pintec.ibge.gov.br/index.php?option=com_content_ extjs\&view=article\&id=17\&Itemid=6>. Acesso em: 1 mar. 2015.

INTERFARMA-ASSOCIAÇÃO DA INDÚSTRIA FARMACÊUTICA DE PESQUISA -. Guia 2014. São Paulo, 2014. Disponível em:

<http://www.interfarma.org.br/uploads/biblioteca/48-handbook-2014baixa.pdf>. Acesso: 21 mar 2015.

KAPLAN, W. A. WIRTZ, V. J. ; STEPHENS, P. The Market Dynamics of Generic Medicines in the Private Sector of 19 Low and Middle Income Countries between 2001 and 2011: a descriptive time series analysis. Public Library of Science - One, Plos, [S.l.], 2013. Disponível em: <http:// www.plosone.org/article/ info\%3Adoi\%2F10.1371\%2Fjournal. pone.0074399>. Acesso em: 26 fev. 2015.

KLINE, S.; ROSENBER, G. An overview of innovation, In: LANDAU, R., ROSENBERG, N. (Ed.). The positive sum strategy: harnessing technology for economic growth. Washington: National Academy Press, 1986. p. 275-305.

LOUREIRO, S. A. L. S. et al. Moura; MOTA, F.; DAMASCENO, L. Diffusion of medical technology and equity in health in Brazil: an exploratory analysis. European Journal of Development Research. p. 6680, London, 2007. Disponível em: <http://www.researchgate .net/ publication/24080394_Diffusion_of_Medical_Technology_and Equity_in_Health_in_Brazil_an_Exploratory_Analysis $>$. Acesso: 10 fev. 2015.

MALERBA, F .; ORSENIGO. L. Towards a history-friendly model of innovation, market structure and regulation in the dynamics of the pharmaceutical industry: The Age of Random Screening Milan: CESPRI Working Paper, 2001.

MOREL, C. M. A pesquisa em saúde e os objetivos do milênio: desafios e oportunidades globais, soluções e políticas nacionais. Ciência e Saúde Coletiva, Rio de Janeiro, v. 9, n. 2, p. 261-270, 2004. 
NELSON, R. R.; WINTER, S. G. Uma teoria evolucionária da mudança econômica. Campinas: Unicamp, 2005.

NOVAES, H. M. D.; ELIAS, F. T. S. Uso da avaliação de tecnologias em saúde em processos de análise para incorporação de tecnologias no Sistema Único de Saúde no Ministério da Saúde. Caderno e Saúde Pública, Rio de Janeiro, v. 29, n.1, p. 7-16, 2013. Suplemento. Disponivel em: <http://www.scielo.br/scielo.php?script= sci arttext\&pid=S0102311X2013001300002\&lng=en\&nrm=iso >. Accesso em: 29 nov. 2015.

OLIVEIRA, E. A. et al. A produção pública de medicamentos no Brasil: uma visão geral. Caderno Saúde Pública, Rio de Janeiro, v. 22, n. 11, p. 2379-2389, nov. 2006.

ORSENIGO, L.; PAMMOLLI, F.; RICCABONI, M. Technological change and network dynamics: lessons from the pharmaceutical industry. Research Policy, Brighton,v. 30, n. 3, p. 485-508, 2001.

SÁ, C. Reserach policy in emerging economies: Brazil's sector funds. Minerva, [S.I.], v. 43, n. 3, p. 245-263, 2005.

SALA DE SITUAÇÃO EM SAÚDE, 2015. Disponível em: <http://189.28.128.178/sage/paineis/aqt/tabelaFP.php?ufcidade $=$ Brasil\&ufs $=\&$ ibges $=\& \mathrm{cg}=\& \mathrm{tc}=\& \mathrm{re} \_$giao $=\& \mathrm{rm}=\& \mathrm{qs}=\&$ ufcidade $=$ Brasil $\& q \mathrm{t}=5570 \% 20$ munic $\% C 3 \% A D$ pios $\&$ pop $=202799518 \&$ co $>$. Acesso em: 21 dez. 2015.

SCHUMPETER, J. A. The theory of economic development.Cambridge: Harvard University, 1957.

SCHUMPETER, J. A. The theory of economic development. New Brunswick: Transaction Publishers, 2004.

SCHUMPETER, J. A. Capitalism, socialism and democracy. Nova York: Harper\&Row, 1975.

SCHUMPETER, J. A. Essays on entrepreneurs, innovations, business cycles and the evolution of capitalism. New Brunswick: Transaction Publishers, 1997. 
WORLD BANK GROUP. World Bank Country and Lending Groups. Washington, [201-]. Disponível em: < http://data.worldbank.org/ about/countryclassifications $>$. Acesso em: 10 jun. 2016.

WORLD HEALTH ORGANIZATION- WHO. Estatísticas da saúde mundial, 2012. Disponível em: <http://www.who.int/gho/publications/ world_health_statistics/2012/en/. Acesso em: 13 mar. 2015. 
Ediná Alves Costa, Gisélia Santana Souza, Patrícia Sodré Araújo, Tatiane de Oliveira Silva Alencar, Rafael Damasceno de Barros, Mariluce Karla Bonfim de Souza e Yara Oyram Ramos Lima

\section{MEDICAMENTO, ASSISTÊNCIA FARMACÊUTICA E VIGILÂNCIA SANITÁRIA NA ATENÇÃO INTEGRAL À SAÚDE}

\section{Introdução}

Considerado um dos mais eficientes instrumentos da terapêutica moderna (LEFÈVRE, 1991), o medicamento é um objeto complexo, portador de muitas faces; segundo Pignarre (1999), um objeto estranho entre ciência, mercado e sociedade. A tecnologia mais utilizada nos serviços de saúde (BARROS, 2008b) e amplamente fora deles (BARROS, 2008a) é, ao mesmo tempo, um bem social e uma mercadoria singular que se encontra permeada por distintos interesses e muitas questões que afetam a coletividade. Tema de vasta produção bibliográfica, o medicamento é essencial para a efetivação do direito à saúde e pode ser analisado em suas múltiplas dimensões: técnicocientífica, econômica, social, política, sanitária, cultural e simbólica.

O tema dos medicamentos e suas questões é objeto de debate internacional e se revela, historicamente, como um dos mais sensíveis nos sistemas de saúde em todo o mundo. O medicamento tem 
forte peso na estrutura de gastos público e privado em saúde e a promoção do acesso a esse bem se apresenta como um desafio global.

Este capítulo tem o objetivo de delinear, sem exaustividade, questões essenciais dos medicamentos, na perspectiva de um marco de referência para a reflexão acerca das políticas de medicamentos, assistência farmacêutica e vigilância sanitária no contexto atual das políticas de saúde no Brasil, bem como para orientar os estudos dessa temática a serem desenvolvidos no Observatório de Análise Política em Saúde (OAPS).

\section{Situação geral do acesso a medicamentos no mundo}

Documento da Organização Mundial de Saúde (OMS) de 2004 estimava que nos países em desenvolvimento cerca de $25 \%$ a $70 \%$ dos custos em saúde correspondiam a gastos com medicamentos, enquanto nos países desenvolvidos o percentual se situava em torno de $15 \%$. (WORLD HEALTH ORGANIZATION, 2004)

Em muitos países desenvolvidos, estimou-se que o gasto total com medicamentos aumenta $10 \%$ a $18 \%$ ao ano, bem mais rapidamente que o índice de preços ao consumidor e o crescimento anual do Produto Interno Bruto (PIB). O aumento rápido e crescente desses gastos se deve, principalmente, à introdução de medicamentos novos e custosos no mercado e ao aumento geral do consumo. (ORGANIZACIÓN MUNDIAL DE LA SALUD, 2002) Autores chamam a atenção de que o incessante crescimento da demanda por medicamentos relaciona-se, entre outros fatores, ao envelhecimento populacional, como também ao fenômeno da medicalização, promovido pelo marketing farmacêutico que difunde a ideia de que o consumo de medicamentos é um indicador de bons níveis de saúde. (BARROS 2004; LEFÈVRE 1991)

Face à situação, torna-se fundamental que os países atuem para aumentar o financiamento dos medicamentos como parte do financiamento da saúde em geral, como também para promover a aplicação do conceito de medicamentos essenciais, de modo a obter os melhores 
resultados possíveis nos limites dos recursos disponíveis nos sistemas de saúde. (ORGANIZACIÓN MUNDIAL DE LA SALUD, 2002)

Estima-se que um terço da população mundial permanece sem acesso regular aos medicamentos essenciais, situação que afeta mais de $50 \%$ da população nas áreas pobres da África e Ásia. E quando disponíveis, os medicamentos podem ser falsificados ou de má qualidade (sub-standards) devido à fraca regulação. (ORGANIZACIÓN MUNDIAL DE LA SALUD, 2000) Os países da África, América Latina e Caribe e Oriente Médio, cujas populações representam 80\% da população mundial, respondem apenas por $14 \%$ do mercado farmacêutico. (LUIZA; BERMUDEZ, 2004)

Em todo o mundo, o debate sobre medicamentos é intenso, pois esses insumos representam um elemento importante nas despesas totais em saúde. (CHIEFFI; BARATA, 2009; VIEIRA; ZUCCHI, 2013) De acordo com a OMS, em 27 países em desenvolvimento, a média da disponibilidade de medicamentos essenciais no setor público foi de 34,9\%. (WORLD HEALTH ORGANIZATION, 2009)

Nos países desenvolvidos com sistemas de saúde universais, a 371 questão dos medicamentos, especialmente no que diz respeito ao direito ao acesso, apresenta algumas particularidades e diferentes modalidades para a aquisição de medicamentos visando a garantia do direito. (ALENCAR, 2016)

Até 2011,60 países do mundo ainda não reconheciam o direito à saúde em suas respectivas Constituições, persistindo iniquidades na saúde, de modo que pelo menos um terço da população mundial se mantém sem acesso regular a medicamentos. (WORLD HEALTH ORGANIZATION, 2011) Observa-se ainda que, no cenário mundial, a disponibilidade de medicamentos essenciais no setor público é menor que no setor privado, havendo grandes desigualdades na disponibilidade e no acesso a esses medicamentos e, ainda, preços excessivos. (CAMERON et al., 2009; UNITED NATIONS, 2012)

Além da persistência de problemas relativos ao acesso, à qualidade dos medicamentos e até mesmo de falsificação, também existem problemas relativos à utilização. Quando disponíveis e com qualida- 
de assegurada, nem sempre são utilizados adequadamente. Há estudos que mostram, inclusive, que em muitos países, mais da metade de todas as prescrições são desnecessárias ou incorretas e, em metade dos casos, os medicamentos prescritos são utilizados incorretamente pelos pacientes. (WORLD HEALTH ORGANIZATION, 2009)

A crise econômica europeia, que ganhou força a partir de 2008, também tem implicado mudanças nos sistemas de saúde daqueles países, inclusive nas políticas farmacêuticas, com consequências para a universalidade. (NORONHA; GIOVANELLA; CONILL, 2014) Em geral, houve redução nos gastos públicos com medicamentos, maior regulação e controle no catálogo de serviços e produtos ofertados e os desafios para enfrentamento da medicalização permanecem.

No Brasil, o reconhecimento do direito à saúde como direito humano e universal assegurou o acesso aos medicamentos pelo Sistema Único de Saúde (SUS), firmado em um arcabouço legal que resguarda o direito dos cidadãos à assistência terapêutica integral, inclusive a farmacêutica. Como direito social e dever do Estado firma372 do na Constituição Federal de 1988, a efetivação do direito à saúde exige do Estado a formulação e implementação de políticas sociais e econômicas com a finalidade de reduzir riscos de doenças e agravos, bem como o acesso universal e igualitário a ações e serviços para a promoção, proteção e recuperação da saúde. Parte dessas prestações, como responsabilidade do Estado, diz respeito à assistência farmacêutica que abrange o acesso a medicamentos de qualidade com os necessários cuidados farmacêuticos, e um amplo conjunto de ações a serem desenvolvidas junto aos prescritores, profissionais de saúde, cidadãos e ao segmento produtivo farmacêutico para que essa tecnologia seja, de fato, um insumo de saúde. Essas ações são garantidas mediante um conjunto de políticas farmacêuticas, a exemplo da Política Nacional de Medicamentos (PNM) (BRASIL, 1998), a Política de Medicamentos Genéricos (BRASIL, 1999) e a Política Nacional de Assistência Farmacêutica (PNAF) (BRASIL, 2004), entre outras políticas específicas. 
A PNM (BRASIL, 1998), legalmente estabelecida em 1998, afirma o propósito de "garantir a necessária segurança, eficácia e qualidade desses produtos, a promoção do uso racional e o acesso da população àqueles considerados essenciais". Nesse marco referencial, também foi definida como uma das diretrizes prioritárias a reorientação da assistência farmacêutica, com vistas à descentralização da gestão, ampliação da aquisição e distribuição de medicamentos e a promoção do uso racional.

\section{O Brasil no mercado farmacêutico mundial}

A produção de medicamentos no mundo é uma atividade econômica fortemente concentrada, especialmente nos países da América do Norte, da Europa e do Japão, que respondem por cerca de $88 \%$ do total mundial. Essa concentração foi resultado de processos de fusões e aquisições, caracterizando a indústria farmacêutica como um oligopólio diferenciado; a diferenciação dos produtos é pautada na Pesquisa e Desenvolvimento (P\&D) e no marketing (GADELHA; MALDONADO, 2008), que requerem investimentos continuados e de grande porte. (GADELHA, QUENTAL; FIALHO, 2003)

Estima-se que o percentual do faturamento das empresas que lideram o setor destinado às atividades de Pesquisa e Desenvolvimento (P\&D) situa-se entre $10 \%$ e $20 \%$ e chega a $40 \%$ no caso das despesas com marketing. (GADELHA; QUENTAL; FIALHO, 2003) Sem obscurecer as relevantes contribuições dos medicamentos para a saúde, não se pode olvidar que as atividades publicitárias no ramo farmacêutico, como em outros ramos industriais no contexto capitalista, têm papel decisivo na indução ao consumo e na ampliação da oferta de medicamentos, com todas as suas consequências para a saúde da população, advindos dos potenciais efeitos danosos dos medicamentos, que podem causar uma verdadeira "iatrogenia medicamentosa”. (BARROS, 2008a)

O ciclo produtivo do medicamento é um processo longo, complexo e oneroso que demanda altos investimentos de ordem finan- 
ceira e de tempo para que um produto passe da fase de pesquisa para a fase de comercialização. Estudos estimam que, nos Estados Unidos, o tempo utilizado para descobrir, desenvolver e registrar um novo medicamento é em média de 14,2 anos. (DEVALLAPALLY; CHAKLAM; AMIJI, 2007)

A produção de medicamentos no Brasil é dominada pela indústria transnacional, que, praticamente não investe em $P \& D$ no país, em que pese a alta margem de seus lucros. Estima-se que o Brasil possui cerca de 400 empresas farmacêuticas e que 20multinacionais dominam cerca de $80 \%$ do mercado. As 380 empresas de capital nacional são responsáveis por, aproximadamente, $20 \%$ do faturamento total. Considera-se o parque industrial brasileiro de medicamentos bastante desenvolvido com relação à capacidade de fabricação de produtos finais, mas, ao mesmo tempo, fortemente dependente da importação de farmoquímicos. (OLIVEIRA; LABRA; BERMUDEZ, 2006) Assim, o grau de complexidade tecnológica e intensidade de P\&D das empresas farmacêuticas que atuam no Brasil, inclusive das 374 multinacionais, é inferior ao observado nas matrizes das mesmas empresas no exterior. (HASENCLEVER et al., 2008)

O Brasil se encontra entre os 10 maiores mercados consumidores de produtos farmacêuticos do mundo, com faturamento anual em torno dos 15 bilhões de dólares. (MELO, 2015) Essa posição, que configura um imenso mercado, distingue o Brasil em relação a outros países em desenvolvimento e estimula o interesse das empresas farmacêuticas transnacionais. Outro elemento digno de nota, distintivo do país, é a existência de um parque industrial estatal de produção de medicamentos, instalado em várias regiões do Brasil, voltado para a produção de medicamentos destinados, prioritariamente, aos programas de saúde pública. (OLIVEIRA; LABRA; BERMUDEZ, 2006) A produção dos laboratórios farmacêuticos oficiais atende em torno de $40 \%$ da demanda de medicamentos pelo SUS. (GOMES; CHAVES; NINOMYA, 2008)

A partir de 2004, foram instituídas políticas de incentivo à Ciência e Tecnologia (C\&T) em saúde, que priorizaram a articu- 
lação intersetorial entre a saúde, a economia e o desenvolvimento social, oportunizando novos rumos para o setor farmoquímico, estimulando as empresas privadas nacionais e também os laboratórios oficiais. Entre essas políticas destacam-se: o Programa de Apoio ao Desenvolvimento da Cadeia Produtiva Farmacêutica (Profarma), a Rede Brasileira de Produção Pública de Medicamentos, o Fundo Nacional de Desenvolvimento Científico e Tecnológico (FNDCT), o Fórum de Competitividade da Cadeia Produtiva Farmacêutica (FCCPF), o Grupo Executivo do Complexo Industrial da Saúde (Gecis), acordos de transferência de tecnologia e as Parcerias para Desenvolvimento Produtivo (PDP). Tais políticas têm sido fundamentais para o projeto de desenvolvimento da C\&T em saúde no país, mas permanecem importantes desafios a serem superados para garantir a sustentabilidade desse projeto no SUS. (ALENCAR, 2016)

Em face da posição do Brasil no segmento produtivo de medicamentos e da imensa demanda pública, em virtude da construção do SUS e o princípio da universalidade, a PNM (BRASIL, 1998) também definiu, entre suas diretrizes, o desenvolvimento científico e tecnológico e a promoção da produção de medicamentos, na perspectiva da integração entre centros de pesquisa, universidades e empresas do segmento produtivo farmacêutico, incluindo a promoção de pesquisas de fitoterápicos da flora nacional e a produção de medicamentos genéricos. A diretriz da promoção da produção de medicamentos visa, principalmente, os medicamentos da Relação Nacional de Medicamentos Essenciais (Rename) - cuja revisão periódica é uma das diretrizes da PNM - mediante a modernização e o aumento da capacidade produtiva e eficiência da indústria farmacêutica nacional, o incentivo aos medicamentos genéricos e a redução de preços.

\section{Regulação de medicamentos}

A PNM também definiu, entre suas diretrizes, a regulamentação sanitária dos medicamentos e a garantia da segurança, eficácia e qualidade dos medicamentos. Essas diretrizes remetem às respon- 
sabilidades e competências do gestor federal na regulamentação, autorização de funcionamento das empresas farmacêuticas, no registro de medicamentos, no acompanhamento da pesquisa clínica, nas ações de inspeção e fiscalização sanitária e na farmacovigilância, entre outras, além das responsabilidades das demais esferas de gestão, no processo de descentralização do SUS.

A regulação de medicamentos é uma tarefa complexa que requer ações de natureza técnico-científica, política e administrativa, a serem desenvolvidas de forma articulada, e abrange a regulação econômica, que tem importante função no acompanhamento e estabelecimento de limites para os preços praticados pelas empresas farmacêuticas.

A qualidade, a segurança, a eficácia e a informação são elementos centrais na regulação sanitária de medicamentos e constituem os fundamentos de um conjunto amplo de estratégias regulatórias para que os medicamentos cumpram sua função nos sistemas de saúde, com o máximo possível de benefícios e um mínimo de riscos. 376 Regulação e vigilância sanitária constitui intervenção nas relações sociais produção-consumo no interesse público. É necessariamente uma função do Estado, que se realiza por intermédio de um conjunto de práticas desenvolvidas pela instituição regulatória estatal voltadas aos agentes econômicos nos segmentos relacionados à saúde, tendo por finalidade a proteção da saúde, um direito social. (COSTA, 2004) Essas práticas, fundamentais à organização econômica da sociedade, articulam-se com outros setores em torno de funções, sinalizadas por Offe (1984), voltadas para as condições e pressupostos institucionais e sociais, para as atividades de produção e reprodução da sociedade. (COSTA, 2004)

As atividades de regulação sanitária ocorrem em ambientes sujeitos a pressões, pelos interesses econômicos contrariados, mas são parte de uma racionalidade do estado capitalista na "forma de serviço público estatal" para cumprir suas funções sociais e administrativas; integram o conjunto de serviços públicos de saúde na dimensão coletiva, especialmente voltados à proteção da saúde e prevenção 
de agravos e doenças; têm características técnicas e sociais específicas que os distinguem dos serviços de assistência direta à saúde. (SOUZA; COSTA, 2010)

As ações e atividades de regulação de medicamentos são essenciais para o alcance dos objetivos da Política Nacional de Saúde, notadamente das políticas farmacêuticas - PNM e PNAF. Dessa forma, cabe ao sistema regulatório avaliar riscos e desenvolver ações específicas que devem estar fundamentadas em conhecimento científico e informações atualizadas para prevenir, minimizar e eliminar riscos, de modo a proteger e promover a saúde da população. Essa tarefa é de competência própria do Estado que tem a função de preservar os interesses sanitários da coletividade e significa ir além das atividades de mercado e proteção dos consumidores para abranger a saúde da população como um todo, o meio ambiente e, inclusive, a economia do país. (COSTA 2004, 2013a, 2013b)

Assim como outros objetos sob regulação e vigilância sanitária, os medicamentos, em especial, portam riscos intrínsecos e riscos potenciais, e mesmo que adequadamente formulados, produzidos, acondicionados, conservados, transportados, armazenados, prescritos e utilizados sempre conterão um grau de risco e poderão afetar a saúde dos seus usuários. Além de danos possíveis decorrentes dos riscos intrínsecos, existe ainda a possibilidade de serem adicionados riscos ao longo das diversas atividades desenvolvidas no ciclo de vida dos medicamentos, que podem ser acrescentados em decorrência das mais diversas razões, inclusive por práticas ilícitas e ou inadequadas de fabricantes e comerciantes e, ainda, por prestadores de serviços que utilizam medicamentos. (COSTA, 2004)

Uma efetiva regulação e vigilância sanitária dos medicamentos constitui um desafio para os sistemas regulatórios em todo o mundo. Medicamentos falsificados e de má qualidade são encontrados com muita frequência no mercado farmacêutico e qualquer classe de medicamentos pode ser afetada. A quantidade de medicamentos falsificados e de má qualidade em circulação é de difícil estimativa, assim como o impacto do problema para a sociedade, decorrente 
de mortes e doenças, como também pelo tempo e recursos financeiros dispendidos com seu o uso. (BUCKLEY; GOSTIN, 2013; INSTITUTE OF MEDICINE, 2013)

Apenas a título de ilustração, conforme divulgado pela Agência Nacional de Vigilância Sanitária (Anvisa), no Brasil, de 144 produtos falsificados identificados entre 1999 e 2014, mais de $80 \%$ eram medicamentos. (ANVISA, 2016a) Somente no ano de 2014, foram encontradas quase duascentenas de medicamentos com as mais diversas irregularidades e desvios de qualidade, envolvendo mais de 70 empresas, muitas reincidentes. (ANVISA, 2016b) Tal fato demonstra que, mesmo ativa, a fiscalização sanitária com as demais instâncias de controle não são capazes de impedir os atos ilegais e antiéticos de produtores e comerciantes.

A regulação e vigilância sanitária de medicamentos no Brasil, de modo geral, acompanha o desenvolvimento dessa atuação no mundo. $\mathrm{O}$ marco regulatório brasileiro - apesar de uma legislação fragmentada, alterada e, em alguns aspectos, desatualizada, princi378 palmente em relação a mudanças que acompanharam a implementação do SUS - guarda semelhanças com o marco regulatório global. São exemplos, entre outros, os dispositivos legais que determinam a obrigatoriedade das boas práticas, a adequação da legislação sanitária ao acordo Trips - Agreementon Trade Related Aspects of Intellectual Property Rights - (BERMUDEZ et al., 2000) e, em decorrência, a atual Lei de Patentes, a implementação de uma política de medicamentos genéricos, a criação de uma organização central no modelo de agência regulatória, a inserção do Brasil, em 2001, como país-membro oficial do Programa Internacional de Monitorização de Medicamentos. Com a referida inserção, a instituição reguladora assumiu a responsabilidade em desenvolver a imprescindível atividade de vigilância de eventos adversos por medicamentos, de acordo com os conceitos acordados pelos países-membros, sob a coordenação da OMS. (COSTA, 2013b)

A farmacovigilância surgiu em resposta à tragédia da talidomida, em 1961, quando crianças nasceram com malformações em 
decorrência do uso desse medicamento por gestantes. Desde então, esforços são realizados para abordar questões de segurança no uso dos medicamentos. "A farmacovigilância consiste da ciência e das atividades relativas à detecção, avaliação, compreensão e prevenção de efeitos adversos ou quaisquer outros possíveis problemas relacionados a medicamentos”. (ORGANIZACÃO MUNDIAL DA SAÚDE, 2005, p. 8) O Brasil vem conformando um conjunto de ações coordenadas pela Anvisa para implementar a farmacovigilância, envolvendo sistema de notificação, centros de referência, rede de hospitais sentinela e sistemas de alertas e informes que devem acompanhar o desempenho do medicamento após sua comercialização. A função é contribuir com as atividades das autoridades reguladoras de medicamentos na melhoria do perfil de segurança dos medicamentos, porém, ainda é incipiente a cultura da notificação, pelos profissionais de saúde, dos eventos adversos relacionados aos medicamentos.

Atualmente, as agências reguladoras de medicamentos dos diversos países, mediante acordos entre si ou através da participação em redes formais, buscam estabelecer cooperação para o compartilhamento de informações, o intercâmbio de experiências e a harmonização de conceitos e normas regulatórias, na busca de favorecer o comércio internacional, além, é claro, de estratégias que contribuam para a garantia da segurança, eficácia e qualidade dos medicamentos, um processo que historicamente conta com o estímulo e a ativa participação da OMS.

No contexto atual, o conceito que se soma ao da harmonização na articulação internacional no âmbito da regulação de medicamentos é o da convergência regulatória. Conforme Aith e colaboradores (2014, p. 24),

A convergência regulatória é o processo pelo qual o processo pelo qual diferentes Estados Nacionais adotam padrões convergentes de regulação, capazes de garantir a qualidade, segurança e eficácia dos produtos. Na convergência regulatória, os Estados mantêm a sua autono- 
mia para, de acordo com suas peculiaridades, elaborarem suas normas. Ao realizar as suas políticas de regulação de medicamentos, os Estados consideram mecanismos regulatórios comuns, tais como a exigência de boas práticas de fabricação e os registros. Nesses casos, os diferentes países podem construir padrões regulatórios convergentes que permitam a chamada convergência regulatória e, assim, consequentemente, admitem a existência de reconhecimento recíproco de certas práticas regulatórias.

\section{O controle da propaganda/publicidade do medicamento}

À medida que o medicamento é um bem de consumo no mercado, os sistemas regulatórios enfrentam desafios para regular a propaganda/publicidade desses bens e as poderosas estratégias de marketing da indústria farmacêuticapara estimular o consumo. Esse aspecto, crucial na regulação de medicamentos, não parece ser objeto de significativa harmonização, tampouco de convergência regulatória.

A indústria farmacêutica transnacional se caracteriza pelo intensivo processo de P\&D na busca de novos medicamentos; conta com forte suporte econômico, político e ideológico e amplo respaldo do sistema internacional de propriedade intelectual; possui alto grau de internacionalização e realiza gastos expressivos em estratégias mercadológicas de comercialização e marketing. (BARROS, 1995; BASTOS, 2005; BERMUDEZ, 1995; BUSFIELD, 2006; CAPANEMA; PALMEIRA FILHO, 2004; GADELHA, 2002) Os gastos das indústrias farmacêuticas com atividades de propaganda e promoção podem chegar a cerca de $30 \%$ do seu faturamento global (BARROS, 1995; OLIVEIRA, 1997) e até mesmo a $40 \%$. (GADELHA; QUENTAL; FIALHO, 2003)

$\mathrm{O}$ controle e a regulação de medicamentos também se aplicam ao marketing comercial farmacêutico - no qual se inserem a propaganda e outras estratégias mercadológicas adotadas pelas empresas 
- e visam minimizar a assimetria de informação junto ao usuário do medicamento, buscando a veiculação de informações seguras e confiáveis e reduzir a influência da indústria farmacêutica no processo de prescrição médica. As estratégias de propaganda e promoção da indústria farmacêutica contam com um "exército" de seus representantes que tem como principal função abordar os profissionais prescritores, especialmente os médicos, no sentido de elevar a venda dos produtos. $\mathrm{O}$ medicamento como uma mercadoria singular não permite sempre a autonomia do consumidor no processo de escolha de qual medicamento usar, isso porque, para o consumo do medicamento (exceto para aqueles isentos de prescrição) é necessária a mediação do profissional médico, que possui o poder técnico e legal de definir qual o medicamento, o modo de usá-lo, a posologia e a frequência.

Desse modo, o médico é o principal alvo da indústria farmacêutica nas estratégias de propaganda e promoção dos medicamentos. A esses profissionais são oferecidas participações em congressos e viagens, entre outras benesses. Uma das estratégias considerada das mais bem-sucedidas é a distribuição de amostras grátis, que é realizada quando da visita do representante de laboratório ao médico. (BREEN, 2004; LIMA; NUNES; BARROS, 2010) No Brasil, a normatização acerca da amostragrátis de medicamentos ainda é insuficiente. Considera-se que muitas questões carecem de discussão e regulamentação. (LEITÃO; SIMÕES; FRANÇA, 2012) Diversos estudos já demonstraram que a propaganda consegue influenciar e alterar os padrões de prescrição. (AVORN; CHEN;HARTLEY, 1982; BARROS 1995; LEXCHIN 1993; MANSFIELD 1996; WADE, MANSFIELD, MCDONALD, 1989)

Historicamente, o debate sobre a regulação da propaganda de medicamentos tem sido bastante conflitivo, inclusive, com forte posicionamento do movimento da Reforma Sanitária Brasileira para a sua proibição total nos veículos de comunicação de massa. Contudo, divergências existentes na relação entre a regulação sanitária para a preservação do interesse público e os interesses do mercado evidenciavam-se cada vez mais tênues, com favorecimento ao segundo 
componente, indicando o predomínio da lógica econômica sobre a lógica sanitária. (ALENCAR, 2016)

Em uma pesquisa realizada junto a 50 médicos em Brasília/DF, $98 \%$ confirmaram que recebiam visitas de representantes e $86 \%$ afirmaram receber brindes durante as visitas. A maioria disse não ser influenciada pela publicidade na prescrição dos medicamentos, entretanto, $14 \%$ disseram prescrevê-los em função do recebimento de prêmios. No que tange à opinião sobre a influência da propaganda na prescrição de medicamentos, $68 \%$ acreditam existir uma influência direta da propaganda sobre a prescrição. Ainda, $68 \%$ acreditam haver inverdades ou incorreções nas peças publicitárias, no entanto, $22 \%$ dos médicos entrevistados disseram confiar plenamente nas informações recebidas. (FAGUNDES et al., 2007)

\section{Acesso aos medicamentos e a política de assistência farmacêutica no Brasil}

A reorientação da assistência farmacêutica no país teve início em período recente, após a extinção formal da Central de Medicamentos (Ceme) em 1997, que se deu em meio a denúncias de corrupção e outras irregularidades e forte distanciamento da proposta ampla de assistência farmacêutica nos marcos de sua criação, em 1971. (BERMUDEZ; OLIVEIRA; LUIZA. 2014) Até o ano de 2000, a assistência farmacêutica não constava da estrutura organizacional do Ministério da Saúde (MS), funcionando como uma assessoria técnica vinculada à Secretaria de Políticas de Saúde. Pode-se considerar um marco de sua institucionalização a criação, na estrutura do MS, em 2003, da Secretaria de Ciência, Tecnologia e Insumos Estratégicos e seu Departamento de Assistência Farmacêutica e Insumos Estratégicos, que substituiu a Gerência Técnica de Assistência Farmacêutica, que vigorou entre 2000 e 2003.

No bojo de um intenso movimento de discussão sobre assistência farmacêutica no país que incluiu o debate na Conferência Nacional de Medicamentos e Assistência Farmacêutica, ocorrida 
em 2003, o Conselho Nacional de Saúde aprovou a PNAF, com a Resolução n.o 338/2004 (BRASIL, 2004), que estabeleceu os princípios orientadores dessa política. No ano seguinte, a Portaria ministerial n. ${ }^{\circ}$ 2.084/2005 dispôs sobre o financiamento e as respectivas responsabilidades das três esferas de gestão (BRASIL, 2005), provocando significativas mudanças no financiamento da assistência farmacêutica.

O Documento do Instituto de Pesquisa Econômica Aplicada (Ipea) aponta a crescente evolução dos gastos totais com saúde em saúde no Brasil. (PIOLA et al, 2013) Tendências com relação ao financiamento da assistência farmacêutica têm sido observadas e, em geral, apontam crescimento do gasto com medicamentos no SUS. (VIEIRA, 2009; VIEIRA; ZUCCHI, 2013) Nota-se também aumento das transferências federais para os estados, o Distrito Federal e os municípios, com maiores percentuais para os municípios do que para os estados, contribuindo para a continuidade da política de descentralização da assistência farmacêutica.

Pontua-se ainda que o gasto do MS com o componente especializado aumentou em $252 \%$ no período de 2003 a 2007 e que têm sido implementadas diversas estratégias para assegurar maior eficiência no uso de recursos do Componente Básico da Assistência Farmacêutica, a exemplo de arranjos intermunicipais para viabilizar as compras de medicamentos em maior escala. (VIEIRA, 2010)

Embora tenha havido ampliação do gasto com medicamentos, nota-se que a participação em relação ao gasto total com ações e serviços públicos de saúde ainda está aquém da necessidade. Os recursos do MS para investimentos voltados a melhorar a gestão permanecem insuficientes e ainda persistem problemas estruturais importantes que acabam por refletir em precárias condições sanitárias dos medicamentos. (VIEIRA; MARQUES; JEREMIAS, 2014)

Cabe mencionar o fenômeno da judicialização, que tem constituído um desafio para a assistência farmacêutica e para o SUS. Tal fenômeno é produzido tanto por uma dada interpretação do artigo n. 196 da Constituição Federal - que destaca a "saúde como direito 
de todos e dever do Estado" - como também pode expressar dificuldades reais de acesso aos medicamentos básicos. Isso tem gerado litigâncias jurídicas nas três esferas de governo e provocado despesas extras à programação orçamentária e financeira do Ministério e Secretarias de Saúde.Desse modo, há um consenso, no campo da saúde coletiva, de que a judicialização se constituiu uma ameaça à sanidade financeira e administrativa do SUS. (CHIEFFI; BARATA, 2009; LEITE et al., 2009; PEPE; ACÚRCIO, 2014; PEPE et al., 2010; VIEIRA; ZUCCHI, 2013)

É possível constatar avanços significativos, mas o acesso aos medicamentos essenciais ainda constitui um importante problema de saúde no Brasil; percebe-se avanço no acesso a medicamentos para o tratamento das doenças crônicas mais prevalentes, porém não se pode dizer o mesmo do tratamento de afecções ou episódios agudos. O inquérito domiciliar sobre acesso e utilização de medicamentos, realizado no âmbito da Pesquisa Nacional sobre Acesso, Utilização e Uso Racional de Medicamentos (PNAUM), concluído 384 em janeiro de 2014, revelou elevados índices de acesso aos medicamentos para hipertensão e diabetes: $97,9 \%$ dos que referiram ter hipertensão e $97,8 \%$ dos que referiram ter diabetes tiveram acesso total aos medicamentos, sendo que destes, $57 \%$ e $60 \%$, respectivamente, obtiveram os medicamentos em unidades do SUS, enquanto que $16 \%$ e 18\% em unidades do Programa Farmácia Popular do Brasil (PFPB). (BRASIL, 2015) Esse programa do Governo Federal prevê o subsídio com copagamento de um elenco de medicamentos e gratuidade para alguns grupos terapêuticos, a exemplo de hipoglicemiantes e anti-hipertensivos. Na Pesquisa Nacional de Saúde, 35,9\% das pessoas que referiram diagnóstico de hipertensão e $57,4 \%$ das que referiram ter diabetes obtiveram pelo menos um medicamento no PFPB. (IBGE, 2014)

Observa-se, entretanto, que o acesso, no SUS, aos medicamentos para o tratamento de episódios e afecções agudas é muito baixo: $81,2 \%$ dos medicamentos para afecções respiratórias agudas são pagos pelo paciente, assim como os $79 \%$ dos medicamentos para dor; 
69,9\% para febre; $63,7 \%$ para infecção e $54,8 \%$ para afecções gastrointestinais. (BRASIL, 2015)

A partir dos dados da PNAUM, surge um importante alerta, suscitando questionamentos quanto à qualidade da atenção às doenças crônicas, que foram utilizadas como traçadoras nessa pesquisa. Observou-se 10,4\% de abandono do tratamento medicamentoso para hipertensão e que $29 \%$ das pessoas tratadas recebem cuidado inadequado no manejo dessa doença. Verificou-se uma situação ainda pior no tratamento da diabetes, com uma proporção de $13,7 \%$ de abandono do tratamento; e do total das pessoas que estão sendo tratadas com medicamentos, $41 \%$ delas estão recebendo cuidados inadequados para o controle da glicemia (BRASIL, 2015), o que talvez explique a significativa proporção de $13,4 \%$ de pessoas que são hospitalizadas por complicações da diabetes. (IBGE, 2014)

As dificuldades para o acesso aos medicamentos para doença respiratória pulmonar crônica no SUS são preocupantes, visto que o acesso total é de $91 \%$, porém, somente $42 \%$ obtêm o medicamento no SUS e 51\% obtêm por desembolso direto. (BRASIL, 2015) A situação se mostra de grande gravidade, quando se verifica que há uma taxa de abandono de tratamento de $29,8 \%$ e que $70 \%$ das pessoas tratadas estão recebendo cuidado inadequado, para o controle dessa doença. (BRASIL, 2015) A asma é uma das doenças pulmonares crônicas com alto potencial incapacitante para os doentes, com uma prevalência de 4,4\% na população brasileira acima de 18 anos, sendo que $81,5 \%$ possuem grau intenso ou muito intenso de limitações nas atividades habituais devido à asma. (IBGE, 2014)

Como se vê, as pesquisas revelam que a medida do acesso aos medicamentos deve ser compreendida como a capacidade mais geral dos sistemas de saúde em responder às necessidades do cuidado com a saúde da população. Nesse sentido, o acesso é mais do que a simples obtenção ou disponibilidade do medicamento, como já evidenciado, observando-se elevados índices de obtenção dos medicamentos, contrastando com a grande proporção de cuidado inade- 
quado para o controle das doenças crônicas traçadoras: hipertensão, diabetes e doenças respiratórias crônicas.

As pesquisas referidas corroboram com a visão de Penchansky e Thomas (1981) sobre "acesso como o grau de ajuste entre os clientes e o sistema”, no qual se relacionam cinco dimensões: availability (disponibilidade de recursos e serviços ofertados); accessibility (oferta de serviços em lugar e momento oportuno); accomodation (adequação e organização dos recursos disponíveis e habilidades de adaptação dos clientes); affordabilty (capacidade aquisitiva, dimensão relacionada a preço, custos); acceptability (relacionada à atitude e práticas de provedores e clientes quanto aos serviços ofertados).

Ainda faltam pesquisas que abordem todas as dimensões envolvidas na problemática do acesso a medicamentos no Brasil. A PNAUM é, até então, a pesquisa mais abrangente sobre essa temática e contou com um componente de inquérito populacional e outro componente sobre os serviços farmacêuticos na atenção básica. Os resultados preliminares sobre o último componente apontam sérios problemas de infraestrutura e de gestão da assistência farmacêutica que envolvem a seleção, programação, aquisição, distribuição e dispensação dos medicamentos, além de também evidenciar graves problemas relacionados às condições sanitárias desses produtos. (BRASIL, 2015)

Certamente, esses problemas impactam no acesso, tanto na dimensão da disponibilidade quanto na qualidade dos medicamentos e dos serviços farmacêuticos ofertados à população; por conseguinte, na resolubilidade e eficácia das ações de cuidado às doenças crônicas, com importante repercussão na saúde e qualidade de vida das pessoas. Além de dispor do medicamento em condições sanitárias satisfatórias de transporte, armazenamento e distribuição, é preciso que a prescrição seja adequada e que os serviços farmacêuticos disponham de condições de infraestrutura e pessoal qualificado, para $o$ atendimento às necessidades dos cidadãos. Destaca-se também o trabalho do farmacêutico e suas atividades de natureza clínica, realizadas com os usuários de medicamentos e outras atividades junto 
ao sistema de saúde e prescritores para promover o uso racional de medicamentos.

A atividade farmacêutica de natureza clínica, denominada no Brasil também de atenção farmacêutica, tem sido colocada como uma estratégia que contribui com a promoção do uso racional de medicamentos, mas ainda é embrionária no país. A atenção farmacêutica integra a PNAF da mesma forma como tem ocorrido em diversos países. Essa prática tem sido assumida como uma política estratégica para a redução do impacto da morbimortalidade relacionada ao uso de medicamentos. (YORDANOVA; PETKOVA, 2013)

Johnson e Bootman (1995) desenvolveram um modelo conceitual de morbidade e mortalidade relacionadas ao uso de medicamentos em que estimaram os custos desse problema em uma unidade ambulatorial nos Estados Unidos. $\mathrm{O}$ estudo apontou que o gasto estimado associado a essa problemática foi de cerca de 76,6 bilhões de dólares naquele país. Esses números contribuíram para o estabelecimento de políticas e estratégias para o enfrentamento dessa questão. Assim, a atenção farmacêutica se coloca como uma importante estratégia que contribui para a redução da morbimortalidade relacionada ao uso de medicamentos. (ERNST; GRIZZLE, 2001; JOHNSON, BOOTMAN, 1995)

O uso racional dos medicamentos envolve sujeitos importantes, o prescritor, o paciente, o dispensador, entre outros, que interagem numa dinâmica influenciada pelas políticas farmacêuticas, as relações com o mercado farmacêutico e seu marketing, a organização da rede de serviços de saúde, o grau de educação da sociedade e fatores culturais. (WORLD HEALTH ORGANIZATION, 2004) Num esforço para compreender como se articulam essas relações e quais os seus determinantes, somam-se contribuições de diversas áreas de conhecimento, entre as quais, a farmacoeconomia, a farmacoepidemiologia, os Estudos de Utilização de Medicamentos (EUM), a farmacovigilância.

As questões até aqui apresentadas de forma panorâmica demonstram o largo espectro de possibilidades de aprofundamento 
de estudos e pesquisas na temática dos medicamentos e assistência farmacêutica e dos desafios às ações de regulação e vigilância sanitária e às políticas de saúde nesse âmbito, de modo a que se efetive a atenção integral à saúde. Nesse segmento, em que grandes interesses econômicos estão em jogo, necessidades são continuamente produzidas e estimuladas, gerando padrões de consumo em que o medicamento é colocado na centralidade da abordagem dos problemas de saúde, na contramão da busca de entendimento e intervenção nos seus determinantes.

Desse modo, considera-se relevante investigar a atuação do Estado brasileiro nas políticas de medicamentos e de assistência farmacêutica, no âmbito dos Poderes Executivo, Legislativo e Judiciário e da instituição regulatória, bem como o posicionamento de sujeitos políticos de destaque na arena da saúde - a exemplo dos conselhos gestores, conselhos profissionais e entidades do campo da saúde coletiva - que possibilitem identificar e analisar desafios, tendências e perspectivas dessas políticas, face à necessária garantia constitucional do direito à saúde.

\section{Referências}

AITH F. M. A et al.A regulação de medicamentos no Brasil: desafios no contexto do mundo globalizado. In: AITH, F.; DALLARI, S. G. (Org.). Regulação de medicamentos no mundo globalizado. São Paulo: Cepedisa, 2014. p. 18-30.

ALENCAR, T. de O. S. A Reforma Sanitária Brasileira e a questão medicamentos/assistência farmacêutica. 2016. 439 f. Tese (Doutorado em Saúde Coletiva) - Instituto de Saúde Coletiva, Universidade Federal da Bahia, Salvador, 2016.

AGÊNCIA NACIONAL DE VIGILÂNCIA SANITÁRIA -ANVISA. Lista de produtos falsificados identificados entre 1999 e 2014. [S.1.], [2016a]. Disponível em: <http://portal.anvisa.gov.br/documents/33864/284176 /Lista\%2Bde\%2BProdutos\%2BFalsificados\%2B_1999-2014_Ordem\% 
2BCronol\%25C3\%25B3gica.pdf/a24f6e23-a458-42b1-831e-b604ce 2688b7>. Acesso em: 10 out. 2015.

AGÊNCIA NACIONAL DE VIGILÂNCIA SANITÁRIA-ANVISA. Lista de Produtos e Empresas Irregulares - Medicamentos. [S.1.], [2016b]. Disponível em: <http://portal.anvisa.gov.br/wps/wcm/ connect/204d590048006075ad22adbdc15bfe28/MEDICAMENTOS IRREGULARES_2014_2013_2012_2011_2010_2009. pdf?MOD=AJPERES $>$. Acesso em: 10 out. 2016.

AVORN, J.; CHEN, M.; HARTLEY, R. Scientific versus commercial sources of influence on the prescribing behavior of physicians. American Journalof Medicine,New York, v. 73, n. 1, p. 4-8, 1982.

BARROS, J. A. C. Antigas e novas questões: enfrentando uma conjuntura desfavorável. In: BARROS, J. A. C. (Org.). Os fármacos na atualidade: antigos e novos desafios. Brasília, DF: Anvisa, 2008a. p. 24-78.

BARROS, J. A. C. Nuevas tendências de la medicalización. Ciência e Saúde Coletiva, Rio de Janeiro, v. 13, n. 4 p. 579-587, 2008b. Suplemento.

BARROS, J. A. C. Propagandas de medicamentos: atentado à saúde? São Paulo: Hucitec: Sobravime, 1995.

BARROS, J. A. C. Políticas farmacêuticas: a serviço dos interesses da saúde? Brasília, DF: Organização das Nações Unidas para a Educação, a Ciência e a Cultura/Agência Nacional de Vigilância Sanitária, 2004.

BASTOS, V. D. Inovação farmacêutica: padrão setorial e perspectiva para o caso brasileiro. BNDS Setorial, Rio de Janeiro, n. 22, p. 271-296, set. 2005 .

BERMUDEZ, J. Z. Medicamento, estado e sociedade. São Paulo: Hucitec: Sobravime, 1995.

BERMUDEZ, J. Z.; OLIVEIRA, M. A.; LUIZA, V. L. Assistência Farmacêutica. In: GIOVANELLA, L. et al. (Org.). Politicas e sistema de saúde no Brasil. 2. ed. Rio de Janeiro: Ed. Fiocruz, 2014. p. 657-685.

BERMUDEZ, J. Z. et al. O acordo TRIPS da OMC e a proteção patentária no Brasil. Rio de Janeiro: Ed. Fiocruz: ENSP, 2000. 
BRASIL.Lei no 9.787, de 10 de fevereiro de 1999. Altera a Lei no 6.360, de 23 de setembro de 1976, que dispõe sobre a vigilância sanitária, estabelece o medicamento genérico, dispõe sobre a utilização de nomes genéricos em produtos farmacêuticos e dá outras providências. Diário Oficial da União, Brasília, DF, 11 fev. 1999. Disponível em: < http://www. planalto.gov.br/ccivil_03/leis/19787.htm>. Acesso em: 6 jul. 2016.

BRASIL. Ministério da Saúde. Conselho Nacional de Saúde. Resolução no 338, de 6 de maio de 2004. Aprova a Política Nacional de Assistência Farmacêutica. Disponivel em: <http://bvsms.saude.gov.br/bvs/ saudelegis/cns/2004/res0338_06_05_2004.html>. Acesso em: 6 jul. 2016.

BRASIL. Ministério da Saúde. Portaria no 2.084, de 28 de outubro de 2005. Estabelece normas, responsabilidades e recursos a serem aplicados no financiamento da assistência farmacêutica na Atenção Básica e define o Elenco Mínimo Obrigatório de Medicamentos. Diário Oficial da União, Brasília, DF, 28 out. 2005. Seção 1, p. 71. Disponível em: <http://www. aids.gov.br/sites/default/files/anexo_3_3_003.pdf $>$. Acesso em: 6 jan. 2016

BRASIL. Ministério da Saúde. Portaria no 3.916, de 30 de outubro de 1998. Dispõe de política devidamente expressa relacionada à questão de medicamentos.Diário Oficial da União, Brasília, DF, 1998. Disponível em: <http://bvsms.saude.gov.br/bvs/saudelegis/gm/1998/ prt3916_30_10_1998.html>.Acesso em: 3 jan.2016.

BRASIL. Ministério da Saúde. Seminário da pesquisa nacional sobre acesso e promoção do uso racional de medicamentos(PNAUM). Brasília,DF, 9 dez. 2015. (Folder). Disponível em:<http://www.ufrgs.br/pnaum/projeto-1/ arquivos/pnaum-primeiros-resultados $>$. Acesso em: 6 jul. 2016.

BREEN, K. J. The medical profession and the pharmaceutical industry: when will we open our eyes? Medical Journal of Australia, Sydney,v. 180, n. 8, p. 409-10, Apr. 2004.

BUCKLEY, G. J.; GOSTIN, L. O. Countering the problem offalsified and substandard drugs. Washington, DC: National Academic of Sciences, 2013. 
BUSFIELD, J. Pills, power, people: sociological understanding of the pharmaceutical industry. Sociology, London, v. 40, n. 2, Apr. 2006.

CAMERON, A. et al. Medicine prices, availability, and affordability in 36 developing and middle-income countries: a secondary analysis. Lancet, London, v. 373, p. 240-249, 2009.

CAPANEMA, L. X. de L.; PALMEIRA FILHO, P. L. A cadeia farmacêutica e a política industrial: uma proposta de inserção do BNDES. BNDES Setorial, Rio de Janeiro, n. 19, p. 23-48, mar. 2004.

CHIEFFI, A. L.; BARATA, R. B. Judicialização da política pública de assistência farmacêutica e equidades. Caderno de Saúde Pública, Rio de Janeiro,v. 25, n. 8, p. 1839-1849, 2009.

COSTA, E. A. Vigilância sanitária: Proteção e defesa da saúde. 2. ed. São Paulo: Sobravime, 2004.

COSTA, E. A. Regulação e vigilância sanitária para a proteção da saúde. In: VIEIRA, F. P.; REDIGUIERI, C. F. (Org.). Análise bioética da propaganda e publicidade de medicamentos.Porto Alegre: Artmed, 2013a, p. 22-37.

COSTA, E. A. Regulação e vigilância sanitária: proteção e defesa da saúde. In: ROUQUAYROL, M. Z; GURGEL, M. Epidemiologia \& Saúde. Rio de Janeiro: Medbool, 2013b. p. 493-520.

DEVALLAPALLY, H.; CHAKILAM, A.; AMIJI, M. M. Role of nanotechnology in pharmaceutical product development. Journal of Pharmaceutical Science, Easton, v. 96, n. 10, p. 2547-2565, 2007.

ERNST, F.R.; GRIZZLE, A.J. Drug-related morbidity and mortality: updating the cost-of-illness model. Journal of the American Pharmaceutical Association,Washington,v. 41, p. 192-199, 2001.

FAGUNDES, M. J. D. et al. Análise bioética da propaganda e publicidade de medicamentos. Ciência e Saúde Coletiva, Rio de Janeiro, v. 12, n. 1, jan./mar. 2007.

GADELHA, C. A. G. Estudo de competitividade por cadeias integradas no Brasil:impactos das zonas de livre comércio. Cadeia: Complexo da Saúde, 2002. 
GADELHA, C. A. G.; MALDONADO, J. M. S. de V. O papel da inovação na indústria farmacêutica: uma janela de oportunidade no âmbito do complexo industrial da saúde. In: BUSS, P. M.;

CARVALHEIRO, J. R.; CASAS, C. P. R. (Org.). Medicamentos no Brasil: inovação e acesso. Rio de Janeiro: Ed. Fiocruz, 2008. p. 41-59.

GADELHA, C.A.G.; QUENTAL, C.; FIALHO, B.C. Saúde e inovação: uma abordagem sistêmica das indústrias de saúde. Caderno Saúde Pública, Rio de Janeiro v. 19, n. 1, p. 47-59, 2003.

GOMES, C. A. P.; CHAVES, J. G.; NINOMYA, T. Os laboratórios farmacêuticos oficiais e a produção pública de medicamentos. In: BUSS, P.M.; CARVALHEIRO, J. R.; CASAS, C. P. R. (Org.). Medicamentos no Brasil: inovação e acesso. Rio de Janeiro: Ed. Fiocruz, 2008. p. 251-267.

HASENCLEVER, L. et al. Diagnóstico e papel dos laboratórios públicos na capacitação tecnológica e atividades de $\mathrm{P} \& \mathrm{D}$ da indústria farmacêutica brasileira. In: BUSS, P. M.; CARVALHEIRO, J. R.; CASAS, C. P. R. (Org.). Medicamentos no Brasil: inovação e acesso. Rio de Janeiro: Ed. Fiocruz, 2008. p. 199-231.

IBGE. Pesquisa Nacional de Saúde 2013: percepção do estado de saúde, estilos de vida e doenças crônicas. Brasil, grandes regiões e unidades da federação. Rio de Janeiro, 2014.

INSTITUTE OF MEDICINE-IOM. Countering the problem offalsified and substandard drugs. Washington: The National Academic Press, 2013.

JOHNSON, J. A.; BOOTMAN, J. L. Drug-related morbidity and mortality: a cost of-illness model. Archives of Internal Medicine,Chicago, v. 155, p. 1949-1956, 1995.

LEFÈVRE, F. O medicamento como mercadoria simbólica. São Paulo: Cortez, 1991.

LEITÃO, L. C. A.; SIMÕES, M. O. S; FRANÇA, I. S. A saúde pública e a indústria farmacêutica: implicações bioéticas na produção do cuidado. Revista Brasileira de Ciências da Saúde, João Pessoa, p. 295-302, v. 16, n. 3, p. 295-302, 2012. 
LEITE, S. N. et al. Ações judiciais e demandas administrativas na garantia do direito de acesso a medicamentos em Florianópolis-SC. Revista Direito Sanitário, São Paulo, v. 10, n. 2, p. 13-28, jul./out. 2009.

LEXCHIN, J. Interactions between physicians and the pharmaceutical industry: what does the literature say? Canadian Medical AssociationJournal,Ottawa, v. 149, n. 10, p. 1401-1407, nov. 1993.

LIMA, G. B.; NUNES, L. C.C.; BARROS, J. A. C. Uso de medicamentos armazenados em domicílio em uma população atendida pelo Programa Saúde da Família. Ciência e Saúde Coletiva, Rio de Janeiro, v.15, n. 3, p. 3517-3522, nov. 2010. Suplemento.

LUIZA, V.L.; BERMUDEZ, J.A.Z. Acesso a medicamentos: conceitos e polêmicas. In: BERMUDEZ, J. A. Z. OLIVEIRA, M. A.; ESHER, A.(Org.). Acesso a medicamentos: derecho fundamental, papel del Estado. Rio de Janeiro: Escola Nacional de Saúde Pública, 2004. p. 45-67.

MANSFIELD, P. Drug advertising affects your prescribing. Australian Prescriber, v. 19, p. 103, 1996;

MELO, L. As 10 maiores farmacêuticas do Brasil em vendas até setembro. Exame, São Paulo, 27 out. 2015. Disponível em:<http://exame.abril.com. $\mathrm{br} /$ negocios/noticias/as-10-maiores-farmaceuticas-do-brasil-em-vendasate-setembro>. Acesso em: 6 jan. 2016.

NORONHA, J. C; CONILL, E.; GIOVANELLA, L. Sistemas de saúde da Alemanha, do Canadá e dos Estados Unidos: uma visão comparada. In: PAIM, J. S; ALMEIDA-FILHO, N. Saúde coletiva: teoria e prática. Rio de Janeiro: MedBook; 2014. p. 151-172.

OBSERVATÓRIO DE ANÁLISE POLÍTICA EM SAÚDE OAPS. Políticas de Medicamentos, Assistência Farmacêutica e Vigilância Sanitária. Salvador, [201-]. Disponível em: <http://www.analisepoliticaemsaude.org/oaps/eixos/ apresentacao $/$ ? idx=bf9689622d73e9bb52de07b97d81a297>. Acesso em: 6 jul. 2016.

OFFE, K. Problemas estruturais do Estado capitalista. Rio de janeiro: Tempo Brasileiro, 1984. 
OLIVEIRA, E. A.; LABRA, M. E; BERMUDEZ, J. A. Z. Produção pública de medicamentos no Brasil: uma visão geral. Caderno Saúde Pública, Rio de Janeiro, v. 22, n. 11, p. 2379-2389, nov. 2006.

OLIVEIRA, G. G. A indústria Farmacêutica e o controle internacional de medicamentos.Brasília, DF: Gráfica do Senado, 1997.

ORGANIZACIÓN MUNDIAL DE LA SALUD. Selección de medicamentos esenciales. Perspectivas políticas sobre medicamentos de la OMS, Ginebra, n. 4, p. 1-6, 2002. Disponível em: <http://apps.who.int/ iris/bitstream/10665/67377/1/WHO_EDM_2002.2_spa.pdf $>$. Acesso em: 28.12.2015.

ORGANIZACÃO MUNDIAL DA SAÚDE. Departamento de medicamentos essenciais e outros medicamentos. A importância da farmacovigilância: monitorização da segurança dos medicamentos. Brasilia, DF, 2005.

PENCHANSKY, R; THOMAS, J. W. The concept of access: definition and relationship to consumer satisfaction. Medical Care, Philadelphia, v. 21, n. 2, p.127-140, Feb. 1981.

PEPE, V. L. E. et al. Judicialização da saúde e os novos desafios da gestão da assistência farmacêutica.Ciência Saúde Coletiva, Rio de Janeiro, v. 15, n. 5, p. 2405-241, ago. 2010.

PEPE, V. L. E.; ACÚRCIO, F. A. Assistência farmacêutica e demandas judiciais de medicamentos no Sistema Único de Saúde. In: OSÓRIO-DECASTRO, C.G. S. et. al (Org.). Assistência farmacêutica: gestão e prática para profissionais de saúde. Rio de Janeiro: Ed. Fiocruz, 2014. p. 325-339. PIGNARRE, P. O que é o medicamento? um objeto estranho entre ciência, mercado e sociedade. Tradução de Paulo Neves. São Paulo: Ed. 34, 1999. PIOLA, S. F. et al. Financiamento público da saúde: uma história à procura de rumo. Rio de Janeiro: Ipea, 2013. (Texto para discussão). Disponível em: <http://repositorio.ipea.gov.br/bitstream/11058/1580/1/ TD_1846.pdf>.Acesso em: 9 out. 2016.

SOUZA, G. S; COSTA, E.A. Considerações teóricas e conceituais acerca do trabalho em vigilância sanitária, campo específico do trabalho em 
saúde.Ciência Saúde Coletiva, Rio de Janeiro,v. 15, n. 3, p. 3329-3340, 2010. Suplemento.

UNITED NATIONS. World population prospects: The 2012 Revision, Highlights and Advance Tables. New York, 2013. Disponível em: <https://esa.un.org/unpd/wpp/publications/Files/WPP2012_ HIGHLIGHTS.pdf $>$. Acesso em: 6 jul. 2016.

VIEIRA, F. S. Assistência farmacêutica no sistema público de saúde no Brasil. Organización Panamericana de la Salud, Washington, v. 27, n. 2, p. 149, 2010. Suplemento.

VIEIRA, F. S. Avanços e desafios do planejamento no Sistema Único de Saúde. Ciência e Saúde Coletiva, Rio de Janeiro, v. 14, n. 1, p. 1565-1577, 2009.

VIEIRA, F. S.; MARQUES, D. C.; JEREMIAS, S. A. Assistência farmacêutica no Sistema Único de Saúde.In: CASTRO, C. G. S. O. de et al. (Org.). Assistência farmacêutica: gestão e prática para profissionais de saúde. Rio de Janeiro: Ed. Fiocruz, 2014. p. 39-50.

VIEIRA, F.S.; ZUCCHI, P. Financiamento da assistência farmacêutica no sistema único de saúde.Saúde e Sociedade, São Paulo, v. 22, n. 1, p. 73-84, 2013.

WADE, V.A; MANSFIELD, P.R.; MCDONALD, P.J. Drug companies: evidence to justify advertising. Lancet, London, v. 2, n. 8674, p.1261-1264, 1989.

WORLD HEALTH ORGANIZATION-WHO. Medicines strategy: framework for action in essential drugs and medicines policy - 2000 - 2003. Genebra, 2000. Disponível em: <http://apps.who.int/ medicinedocs/en/d/Jwhozip16e/3.html\#Jwhozip16e.3>. Acesso em: 28 dez. 2015.

WORLD HEALTH ORGANIZATION-WHO.The WorldMedicines Situation: access to essencial medicines. Genebra, 2004. Disponível em: <http://apps.who.int/medicinedocs/en/d/Js6160e/3.html\#Js6160e.3>. Acesso em: 27 dez. 2015.

WORLD HEALTH ORGANIZATION-WHO. World Health Statistics 2009. [S.1.], 2009. Disponivel em: <http://www.who.int/gho/ 
publications/world_health_statistics/EN_WHS09_Full.pdf $>$. Acesso em: 6 jul. 2016.

WORLD HEALTH ORGANIZATION-WHO. World health statistics 2011.[S.1.], 2011. Disponivelem: <http://www.who.int/whosis/ whostat/EN_WHS2011_Full.pdf>. Acesso em:6 jul. 2016.

YORDANOVA, S.; PETKOVA, V. Pharmaceutical care in some european countries, Australia, Canada and USA. International Journal of Pharmacy and Pharmaceutical Sciences, Madhya Pradesh, v. 2, n. 5, p. 2291-2208, 2013. 
Thadeu Borges Souza Santos, Silvânia Sales de Oliveira, Silvana Lima Vieira e Isabela Cardoso de Matos Pinto

\section{CONTORNOS DA ADMINISTRAÇÃO PÚBLICA E REPERCUSSÕES NO ÂMBITO DA GESTÃO HOSPITALAR problemáticas, objetos e perspectivas}

\section{Introdução}

A atenção hospitalar vem sendo objeto de estudos e preocupação por parte dos gestores públicos desde a eclosão da crise do sistema de assistência médica previdenciária, no início dos anos 1980. (OLIVEIRA; TEIXEIRA, 1989) A análise desse fenômeno pode ser feita de distintas maneiras, enfatizando-se aspectos econômicofinanceiros, político-gerenciais, organizacionais ou assistenciais que compõem, em seu conjunto, as diversas dimensões do que hoje se conhece como "crise hospitalar". (SOLLA; CHIORO, 2012)

Para o desenvolvimento deste capítulo, inicialmente, será apresentado numa perspectiva crítico-reflexiva e histórica a conformação da atenção hospitalar no Brasil, com seus antecedentes e marcos importantes para a compreensão do contexto onde os estudos se inserem. Tomou-se algumas dimensões de análise orientadoras para situar a perspectiva escolhida acerca do tema: na primeira dimensão, 
serão discutidos os antecedentes e marcos importantes que embasaram a atenção hospitalar brasileira; na segunda dimensão, serão apresentadas as influências internacionais e mudanças recentes na administração pública brasileira que introduziram novas formas de gestão hospitalar no Sistema Único de Saúde (SUS); e a terceira dimensão contempla as tendências da produção científica latino-americana sobre gestão hospitalar, identificando-se os temas abordados e as lacunas no conhecimento disponível. Finalmente, destacamos as questões de investigação que emergiram e se constituem em possíveis objetos de estudo nas pesquisas em curso no eixo temático sobre Modelos de Gestão Hospitalar do Observatório de Análise Política em Saúde (OAPS).

\section{Antecedentes e marcos importantes - linha de base da atenção hospitalar brasileira}

A princípio, vale destacar que no Brasil, não é recente o investimento estatal na assistência hospitalar. As Santas Casas foram as primeiras unidades hospitalares implementadas a partir de 1543 e tinham como característica a dependência de subsídios provenientes do governo da colônia, situação mantida até a primeira república. (PAIM, 2009)No início do século XX, com a eclosão de epidemias na capital da república, a saúde da população se torna uma questão política, gerando a intervenção estatal através de campanhas sanitárias. (FLEURY; OUVERNEY, 2012) Posteriormente, a assistência médica, hospitalar e farmacêutica aparece como um dos itens reivindicados pelos trabalhadores na organização das Caixas de Aposentadorias e Pensões (CAPS), precursoras das instituições que materializaram a política previdenciária desenvolvida no período Vargas (PAIM, 2009), notadamente a criação dos Institutos de Aposentadorias e Pensões (IAPS) de diversas categorias de trabalhadores.

Não cabe aqui discorrer sobre a trajetória da assistência médica previdenciária, objeto de vários estudos, cabendo destacar, entretanto, que as opções adotadas implicaram no fortalecimento do modelo 
assistencialista-médico-hospitalocêntrico-liberal (PAIM, 2009), no qual, como o termo indica, ganha relevância o hospital, enquanto instituição que materializa a predominância da concepção biomédica, centrada na clínica, e no "hospital de clínicas". Tratava-se de uma forma privilegiada de resposta aos problemas, necessidades e demandas da população brasileira, que vivia o processo de industrialização, urbanização e migração campo-cidade, que marcou a dinâmica societária, especialmente a partir da segunda metade do século XX.

Na década de 1960, a expansão da assistência à saúde ampliava os atendimentos através de hospitais públicos em meio a conjuntura política de fomento ao desenvolvimentismo nacional que adotou a proposta de privatização; situação potencializada no período do Regime Militar. (PAIM, 2009) Característica marcante até a rediscussão no processo de redemocratização do país nos anos 1980 (PAULA, 2005), período em que a atenção hospitalar se conformou com personalidades jurídicas filantrópica e liberal-privatista. (PAIM, 2009)

Importante destacar o intenso movimento iniciado na década de 1970 por uma comunidade de especialistas e ampliado com o envolvimento de outras forças sociais (sindicatos, associações médicas e de profissionais de saúde, associações comunitárias, parlamentares) que culminou na proposta da Reforma Sanitária Brasileira (RSB). Esse movimento partiu de uma crítica ao modelo assistencial então vigente que se baseava no paradigma clínico, individualista e com práticas hospitalocêntricas. Tornou-se um amplo movimento político pela democratização da saúde que implicou na incorporação do direito à saúde na Constituição Federal de 1988.

Nesse sentido, vale a pena destacar que, da proposta de "democratização da saúde”, como estratégia que contribuiria para a construção de um "movimento democrático-popular" (GOHN, 1997), a proposta da RSB se destinou à construção de um sistema de saúde universal, igualitário e equitativo, com financiamento e gestão estatal e prestação de serviços constituída por serviços de prestação pública direta, privada complementar ao público ou privada de caráter suplementar 
Os anos 1990 foram marcados pelas ações governamentais de implementação do Sistema Único de Saúde (SUS), contemplando a formulação de normas e estratégias de mudança em dois grandes eixos: a mudança de gestão do sistema e a mudança do modelo de atenção à saúde. Foram sancionadas as Leis Orgânicas da Saúde n. ${ }^{\circ}$ 8.080 e n.o 8.142 de 1990 , e outros documentos oficiais que orientavam o processo de implementação da política pública de saúde. Entre esses documentos estão as Resoluções n.o 258/1991, n. ${ }^{\circ}$ 543/1993 e n. ${ }^{\circ} 2203 / 1996$, que instituíram as Normas Operacionais Básicas (NOB) que apontavam, no que tange à atenção hospitalar, o financiamento por meio das Autorizações de Internação Hospitalar (AIH), a notificação através do Sistema de Informações Hospitalares (SIH) e a criação de instrumentos gerenciais hospitalares fomentando a eficácia e alcance de resultados.

Na virada para o século XXI, Fernando Henrique Cardoso (FHC) se reelegeu e, em seu segundo mandato, foram publicadas as Portarias n.o 95/2001 e n.0373/2002, que instituíam as Normas 400 Operacionais de Assistência à Saúde (NOAS), definindo mecanismos para o fortalecimento da capacidade de gestão do SUS e estabelecendo o Termo de Compromisso para contratualização dos serviços hospitalares entre entes públicos. A Portaria n.o 1101/2002 definiu então os parâmetros assistenciais de cobertura e produtividade.

No início de 2003, o presidente Lula tomou posse e o ministro da saúde nomeado explicitou respeito aos princípios da RSB e compromisso com o SUS. A partir desse momento, anunciou-se reforço à atenção à urgência e emergência e inovação no modelo de gestão dos hospitais (TEIXEIRA; PAIM, 2005); ascendeu na agenda política a atenção às urgências como política pública de saúde; reiterouse a promessa de credenciamento de leitos hospitalares com apoio financeiro (TEIXEIRA; PAIM, 2005) e foi apresentada a Reforma da Atenção Hospitalar Brasileira. (BRASIL, 2004) No entanto, somente em 2004, com a Portaria n. ${ }^{\circ}$ 1.044, foi publicada a Política Nacional para os Hospitais de Pequeno Porte, que estabeleceu as atribuições dos gestores das unidade hospitalares. Foi com o Pacto 
de Gestão, instituído pela Portaria n. o 699/2006, que se estabeleceu responsabilidades entre os entes com termo de compromisso e respectiva necessidade de indicadores de monitoramento. Em 2008, através da Portaria n. ${ }^{\circ} 1.559$, foi instituída a Política Nacional de Regulação do SUS, que especificou sobre os complexos regulatórios inclusive à atenção hospitalar. E, no ano de 2010, a participação complementar das instituições privadas ou sem fins lucrativos de assistência à saúde no âmbito do SUS foi instituída com a Portaria n. ${ }^{\circ}$ 1.034, em 2010. Cabe destacar a preocupação do Governo Federal com as urgências, quando, em 2011, publica a Portaria n. ${ }^{\circ} 2.395$, que tem como objetivo estabelecer as diretrizes para organizar o componente hospitalar da rede de atenção às urgências no âmbito do SUS.

No final do primeiro mandato da presidente Dilma Rousseff, foi publicada a Política Nacional de Atenção Hospitalar (PNHOSP). (BRASIL, 2013) Deve-se destacar que esse foi um marco histórico importante, envolvendo resoluções e portarias que constituem o marco jurídico da atenção hospitalar brasileira. Nesse sentido, serão apresentados a seguir os dispositivos jurídico-legais (leis, regula401 mentos, portarias e regras) que estabeleceram as bases para a atenção hospitalar e que foram discorridos anteriormente.

Quadro 1- Marco jurídico normativo da PNHOSP brasileira

\begin{tabular}{|c|c|c|c|c|c|c|c|c|}
\hline \multirow{3}{*}{$\begin{array}{l}\text { CFB } 1988 \\
\text { LOS } 8080 / 90 \\
\text { LOS } 8142 / 90\end{array}$} & \multirow{2}{*}{\multicolumn{2}{|c|}{ Resoluçâo 258/91 }} & \multirow{3}{*}{\multicolumn{2}{|c|}{ Resolução 2203/96 }} & \multirow{3}{*}{$\begin{array}{l}\text { Portaria } 96 / 01 \\
\text { Portaria } 373 / 02 \\
\text { Portaria } 1101 / 02\end{array}$} & \multirow{3}{*}{\begin{tabular}{|l|} 
Portaria 1044/04 \\
Portaria $699 / 06$
\end{tabular}} & \multirow{3}{*}{$\begin{array}{l}\text { Portaria } 1558 / 08 \\
\text { Portaria } 1034 / 10\end{array}$} & \multirow{3}{*}{$\begin{array}{l}\text { Portaria } 2395 / 11 \\
\text { Portaria } 3390 / 13\end{array}$} \\
\hline & & & & & & & & \\
\hline & Resoluçã & o 543/93 & & & & & & \\
\hline Gov. Sarney & Gov. Collor & Gov. Itan & mar & Gov. FHC 1 & Gov. FHC 2 & Gov. Lula 1 & Gov. Lula 2 & Gov. Dilma 1 \\
\hline $1985-1989$ & 1990-1992 & $1992-199$ & & 1995-1998 & 1999-2002 & 2003-2006 & $2007-2010$ & 2011-2014 \\
\hline
\end{tabular}

Fonte: elaborado pelos autores.

A relevância da PNHOSP, formulada em 2012 e instituída em 2013 pela Portaria n. ${ }^{\circ}$ 3.390, está na apresentação das diretrizes a seguir:

1. princípios da universalidade, equidade, integralidade e controle social; 
2. regionalização da atenção e continuidade da atenção por meio da articulação regulada com os outros serviços;

3. modelo de atenção centrado no cuidado humanizado e interdisciplinar;

4. financiamento tripartite conforme pactuação e;

5. monitoramento, avaliação, transparência e eficiência na aplicação dos recursos.

Destaca-se como um dos eixos estruturantes da PNHOSP a gestão com foco na qualidade da assistência, no cumprimento das metas contratualizadas, na eficiência, transparência e no planejamento participativo. Todavia, o processo de implementação dessa política tem enfrentado muitos desafios e, atualmente, problemas como alto custo, financiamento, incorporação/sobreposição de tecnologias e necessidade de formação de pessoal especializado. (SOLLA; CHIORO, 2012) Outros aspectos podem ser descritos como desafios da implementação do SUS, que apontam para limites de acessibilidade e integralidade dos serviços, ineficiente sistema de regulação, insuficiente sistema de referências, heterogênea distribuição territorial e problemas administrativo-gerenciais. (SILVA, 2010; VAITSMAN; MOREIRA; COSTA, 2009)

No que tange ao desempenho gerencial, destacam-se a pouca agilidade nos processos de aquisição e contratação de serviços, dificuldades para a incorporação de pessoal qualificado e gestão não profissionalizada. (BRAGA NETO et al., 2012; PINTO et al., 2014) Por outro lado, os gestores destacam dificuldades enfrentadas na prática cotidiana com relação a restrição orçamentária e alocação dos recursos cumprindo as recomendações contidas na Lei de Responsabilidade Fiscal. De fato, essas questões são apontadas como as principais justificativas e motivo direto pelo qual se decide utilizar os novos arranjos institucionais (GARCES; SILVEIRA, 2002), considerados como opção ao enfrentamento dos problemas que repercutem na implementação da atenção hospitalar no SUS. 
Assim, a implantação de inovações institucionais e a reconfiguração da relação entre o público e o privadotem se colocado como uma preocupação com o chamado "padrão dual de atenção" que envolve tensões e contradições, decorrentes da crescente delegação de responsabilidades para o setor privado. Destaca-se, então, uma complexa dimensão a ser analisada no sistema de saúde e a necessidade de aprimoramento da gestão do SUS, da capacidade de regulação e da articulação público-privada. É na perspectiva dessa problemática que se define enquanto fenômeno a expansão da gestão indireta como modalidade de administração pública para unidades hospitalares no SUS.

\section{O contexto latino-americano e a mudanças na administração pública brasileira}

Para melhor entendimento sobre a gestão pública e sua correlação com o fenômeno dos modelos de gestão apontados como alternativas para a atenção hospitalar no SUS, é importante ressaltar as influências dos debates internacionais sobre gestão pública na América Latina e no Brasil. Destacam-se, nessa dimensão, a relevância histórica da relação brasileira com os processos reformistas do aparelho público e as relações entre o público e o privado remodelando as funções desse Estado na contemporaneidade.

No pós-Segunda Guerra Mundial, estabeleceram-se três alternativas organizacionais ao setor saúde: o modelo Beveridge, o modelo Bismarck e o modelo de mercado. O primeiro se baseava no financiamento fiscal, universalidade de acesso e gratuidade independente dos níveis de complexidade. $\mathrm{O}$ segundo se estabelece pelo seguro social, corporativismo e tendo acesso condicionado à situação de emprego. No modelo de mercado, o acesso se estabelece pelo consumo do serviço e se fundamenta em função da capacidade individual de compra de seguro-saúde por pessoas ou empresas. (COSTA; SILVA; RIBEIRO, 2000) 
O modelo inglês conhecido como thatcherismo, ${ }^{1}$ ganhou relevante notoriedade na reforma do setor saúde nas décadas de 1980 e 1990, caracterizando-se pela adoção de novos instrumentos de gestão voltados à melhoria da eficiência, responsabilização das organizações nos sistemas de saúde, flexibilização administrativa pública e adoção de contratualizações.

O propósito central se dirigiu a microeficiência da gestão que implicou na incorporação das seguintes inovações no âmbito dagestão hospitalar:

a. contenção da autonomia decisória médica que, desconsiderando custos e focada na cultura de decisão técnica, é uma geradora de despesas;

b. constituição de viabilidades para melhoria da qualidade e da infraestrutura através de serviços de terceiros;

c. flexibilização na divisão de trabalho;

d. introdução de novos métodos de controle, incorporação de tecnologias e das metas contratuais; $\mathrm{e}$

e. fortalecimento do processos de pagamento vis-à-vis aos hospitais. Essa via levou à constituição do quase-mercado ${ }^{2}$ e de

1 O chamado thatcherismo se caracteriza pela descentralização do aparelho estatal, privatização, terceirização dos serviços públicos, regulação estatal das atividades públicas desenvolvidas pelo setor privado e adoção de ideias e ferramentas gerenciais do setor privado. Constituiu as correntes teóricas do neoinstitucionalismo, do gerencialismo e da boa governança que possibilitaram a reestruturação do modelo de Estado burocrático para o gerencial que se fundamenta na competição e nos resultados. (CAPOBIANGO et al, 2013)

2 O quase-mercado é a tradução para o termo internalmarket que se define pela presença de organizações nãolucrativas em competição, centralização do poder de compra, representação dos consumidores por agentes e o contrato passa a ser o principal instrumento de coordenação, sistema de credenciamento e contratualização entre os entes. Aí está a notória mudança organizacional e cultural do modelo inglês em fins da década de 1940 . Neste, o foco da relação entre o principal (Estado) e o agente (terceiro) não é a congruência de interesses que interfiram nos resultados,com um Estado que monitore o desempenho e minimize o risco de não alcançar os resultados contratualizados. Essa teoria do principal-agente enfatiza o controle através do monitoramento da performance. (COSTA; SILVA; RIBEIRO, 2000) 
contratualização na gestão da saúde. (CAPOBIANGO et al., 2013; COSTA; SILVA; RIBEIRO, 2000)

Ocorrido entre as décadas de 1980 e 1990, o processo de reforma estatal dos países latino-americanos é marcado por algumas características comuns ou mesmo marcantes em alguns países. Tema central da agenda política mundial, a origem desse processo está no momento em que o modelo de Estado dos países desenvolvidos no pós-guerra, antes responsável por uma era de prosperidade, entrou em crise no final da década de 1970. (CENTRO LATINO AMERICANO DE ADMINISTRAÇÃO PARA O DESENVOLVIMENTO, 1998) Conforme se verifica pelo Quadro 2, a crise estrutural, econômica e fiscal é um aspecto relevante que exigiu mudanças na forma de gerir os Estados latino-americanos, especialmente em razão de demandas sociais da população por melhor qualidade dos serviços que lhe são oferecidos, principalmente em um contexto de grandes desigualdades sociais. De certo modo, essa pressão também é fruto da maior participação e controle social nos processos decisórios do Estado, até então desobrigado de prestar contas a seus representados.

Contudo, a grande mudança no papel do Estado está no plano econômico e político, ao concentrar suas atividades na regulação e, nesse contexto, as privatizações e a criação de agências reguladoras tornaram-se medidas importantes em países, como o Chile. Na área social, o Estado coloca-se como formulador e financiador das políticas públicas tentando atrair a comunidade, as empresas ou o terceiro setor para compartilhar a responsabilidade na execução dos serviços públicos, especialmente saúde e educação. (CENTRO LATINO AMERICANO DE ADMINISTRAÇÃO PARA O DESENVOLVIMENTO, 1998) Assim, a descentralização apresenta-se como uma tendência em praticamente todos os países, no que diz respeito à tomada de decisão.

A eficiência e a eficácia do gasto público como meta a ser alcançada fazem do planejamento estratégico ou planificação orientada ferramenta de grande importância para países como Chile, Peru e 
Argentina, na medida em que orienta e direciona a tomada de decisões. No Brasil, mecanismos legais no âmbito da administração pública que disponham sobre princípios e normas em relação ao controle de despesas e finanças públicas tornam-se medidas essenciais para o controle dos gastos.

O governo brasileiro tem incorporado métodos utilizados nas organizações privadas para melhorar seus resultados, qualidade e produtividade. O Modelo de Excelência em Gestão Pública se fundamenta no pensamento sistêmico, aprendizado organizacional, cultura da inovação, liderança e constância de propósitos, gestão baseada em processos e informações, visão de futuro, geração de valor, comprometimento das pessoas, foco no cidadão e na sociedade, desenvolvimento de parcerias, responsabilidade social, controle social e gestão participativa. (FERREIRA, 2012) Coloca-se também em destaque aspectos para construção de uma "nova performance do serviço público", quais sejam: aperfeiçoamento do marco legal (minimizando entraves burocráticos e possibilitando a flexibiliza406 ção e autonomia); recuperação da capacidade financeira (melhoria da eficiência e introdução da responsabilidade fiscal); melhoria da capacidade dos órgãos da administração pública; desenvolvimento do capital intelectual (profissionalizando e modernizando e capacitando servidores na administração pública). (MARINI, 2002) 


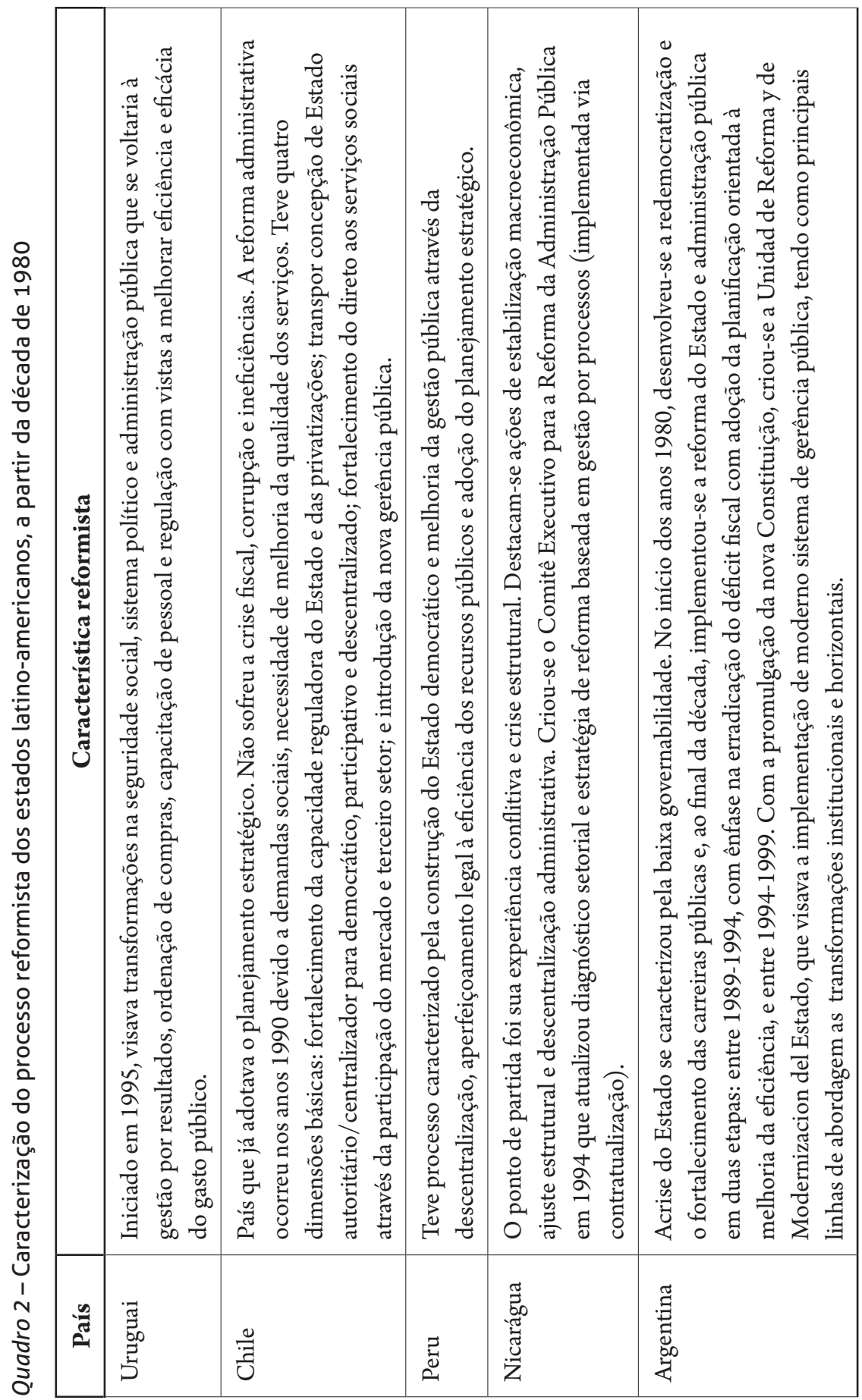

407 


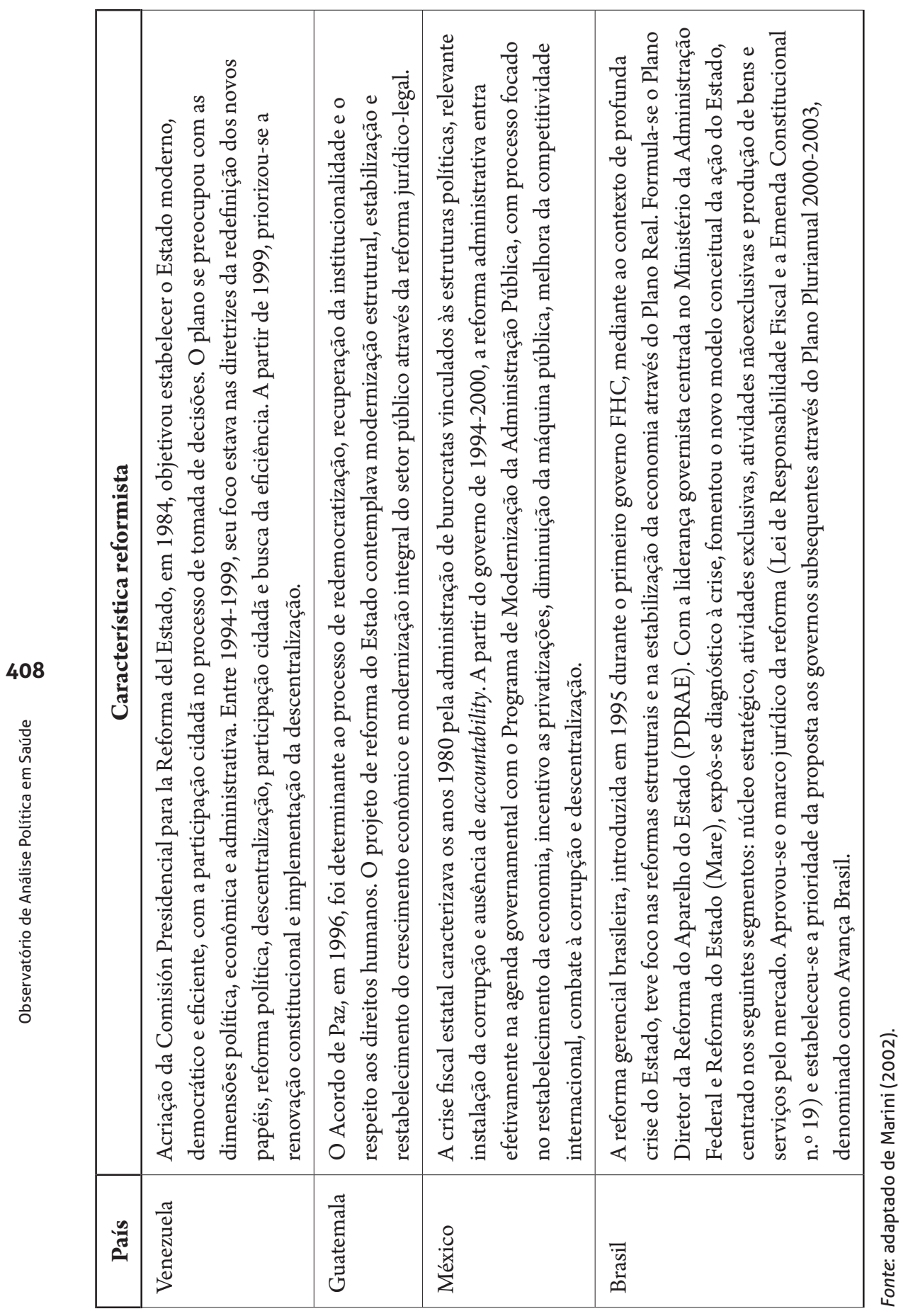


Diante do exposto, observa-se que o debate sobre a "Nova Gestão Pública" origina-se da crise econômica mundial dos anos 1970 e 1980 que provocou recessão, crise fiscal do Estado, déficits da maioria dos governos e crise de governabilidade. Situação que foi marcante na América Latina, também na década seguinte, levando os Estados a adotarem a eficiência como princípio administrativo. (CAPOBIANGO et al, 2013)

No conjunto de países em desenvolvimento, os da América Latina têm se constituído no principal laboratório das reformas gerencialistas nos últimos anos. O Chile foi o cenário inicial de implementação das privatizações de empresas públicas. Na Argentina, a privatização ocorreu de forma mais radical e rápida que no Chile. No contexto brasileiro, a agenda de reformas, influenciada pela ação dos organismos internacionais como o Banco Mundial (DRAIBE, 1993; PINTO 2004), operou a redução e redefinição do Estado, ganhando fôlego as propostas de mudança das formas de gestão, financiamento e provisão de serviços.

\section{Mudanças administrativas no contexto brasileiro}

No caso do Estado brasileiro, historicamente existiram três reformas administrativas. O primeiro marco da administração pública foi o Decreto-Lei n. 579 de 1938, criando o Departamento Administrativo do Serviço Público (DASP), que instituiu a administração burocrática e, posteriormente, o Decreto-Lei n.0200 de 1967, que introduziu a concepção de administração gerencial voltada para resultados, coparticipação do financiamento privado e descentralização para a administração pública indireta. ${ }^{3}$ (BARIANI, 2010; SILVA, 2010) Esses

\footnotetext{
A gestão pública indireta é definida como conjunto de pessoas jurídico-administrativas, que desempenham atividades de gestão delegadas pelo Estado (CARVALHO FILHO, 2012), podendo ser de direito público ou privado, com autonomia administrativo-financeira e destinadas ao exercício de competências públicas descentralizadas. (SALGADO, 2012) Quanto à administração pública direta, compreende-se como um conjunto de órgãos/ agentes públicos integrados à pessoa política estatal (União, Estados, Distrito Federal
} 
dois marcos ocorreram em períodos de ditadura varguista e militar. Para fins deste capítulo, será discutido o terceiro momento reformista que reconfigurou a administração pública do Estado brasileiro após o processo de redemocratização e constituinte de 1988.

A partir da década de 1980, o Brasil seguiu em direção às reformas neoliberais, caracterizadas pelo "novo gerencialismo público". Ancorado na diminuição do tamanho do Estado, enfraquecimento da participação da sociedade civil na administração pública, horizontalização dos processos decisórios às unidades subnacionais (esferas estaduais e municipais), valorização do controle gerencial e cultura organizacional. Esse fenômeno coincidiu com o movimento contra-hegemônico de reforma societal que também exerceu influencias no período constituinte (de 1986 a 1988). (ANDREWS, 2010; PAULA, 2005)

Na década de 1990, enquanto se iniciava a implementação do SUS orientada pelo princípio da descentralização, com as NOB e NOAS, e conforme níveis de capacidade de gestão dos municípios 410 e estados, ocorria a terceira Reforma Administrativa do Estado (RAE). (ANDRADE, 2001) Trata-se do período FHC/1995-2002 que marca a história da administração pública com o Plano Diretor da era, alinhado à Nova Administração Pública.

Para efetivar os ajustes, alterou-se o artigo n. ${ }^{\circ 37}$ da Constituição Federal de 1988 através da Emenda Constitucional n. ${ }^{\circ}$ 19/1998 que incluiu a eficiência como um dos princípios da administração pú-

ou municípios) e subordinados ao Poder Executivo, Legislativo ou Judiciário. (SALGADO, 2012)

4 O modelo gerencialista adota conceitos da administração de empresas, tais como eficiência, transparência, qualidade do serviço prestado. Ele é marcado pelas parcerias entre Estado e sociedade, menor centralização do poder e estruturas hierárquicas, participação popular e criação de novas figuras institucionais. Foi instituído pela Emenda Constitucional n. ${ }^{\circ} 19$, em 1998. Esse modelo de administração pública passa a considerar as atividades estatais como exclusivas (estratégicas) e não exclusivas (de caráter competitivo, como os direitos fundamentais de saúde e educação) do Estado. Estas últimas poderiam ser reguladas ou prestadas pelo Estado, livre a iniciativa privada ou prestadas pelo setor público não estatal. (MATTA; FERREIRA; SILVA, 2014) 
blica.(PEIXOTO NETO; ACCIOLY, 2012) Outra intervenção importante foi a Lei Complementar n. ${ }^{\circ}$ 101/2000 que dispõe sobre a Responsabilidade Fiscal (LRF) por esta direcionar gastos públicosa um percentual máximo pré-determinado em orçamento público dos executivos das três esferas políticas.(ANDREWS; BARIANI, 2010; BRASIL, 2000;)

A RAE considerou que a crise do Estado envolvia três dimensões complexas e inter-relacionadas: a fiscal, o modelo de economia e o modelo burocrático de administração pública. (BRASIL, 1995) A partir do PDRAE, conceberam-se as organizações como pública, privada ou pública nãoestatal. Nesta, o papel do Estado foi reconfigurado em atividades:

a. de núcleo estratégico;

b. de atividades exclusivas;

c. de serviços nãoexclusivos;

d. e de produção de bens e serviços para o mercado. (ANDREWS, 2010; GARCES; SILVEIRA, 2002)

No âmbito das atividades de caráter competitivo estão os serviços sociais (saúde, educação, assistência social) e científicos, que seriam prestados tanto pela iniciativa privada como pelas organizações sociais que integrariam o setor público não-estatal. (PAULA, 2005 p. 38)

Esse processo, denominado de "publicização", permitiu transferir setores estatais para o ente público nãoestatal, denominados como Organizações Sociais, que são “[...] entidades de direito privado que, por iniciativa do Poder Executivo, obtêm autorização legislativa para celebrar contrato de gestão com esse poder”.(BRASIL, 1995, p.60) Assim, começaram a surgir novos atores na arena de implementação de políticas públicas, após os anos 1990, redefinindo papéis assumidos pelo Estado e os entes públicos não estatais, de modo que se constituiu um novo enquadramento institucional nas organizações públicas. De modo que as Organizações Sociais (OS, 
Lei n. ${ }^{\circ}$ 9.637/98) e as Organizações da Sociedade Civil de Interesse Público (OSCIP, Lei n. 9 9.790/99) e Fundações de Apoio (FA, Lei n. $\left.{ }^{\circ} 8.958 / 94\right)$ constituíam novas alternativas de gestão pública indireta. (SANTOS; OLIVEIRA, 2010)

Com a vitória do candidato à presidência da república Luiz Inácio Lula da Silva (Lula) nas eleições de 2002, permanecendo na presidência por dois mandatos (2003-2006 e 2007-2010), e com sucessão nas eleições de 2009 para o governo da presidente Dilma Rousseff (2010-2014), avançou-se na legitimação das alternativas de administração pública indireta.

As Fundações de Apoio foram reiteradas através dos Decretos n.o 5.205/2004 e n. $7.493 / 2010$ ), bem como a Fundação Estatal. Estabeleceu-se a Parceria Público Privada (PPP, Lei n. ${ }^{011.079 / 2004)}$ e criou-se a Empresa Brasileira de Serviços Hospitalares (EBSERH), com a Lei Federal 12.550/2011, para administrar as instituições públicas federais de ensino ou instituições congêneres de serviços de apoio ao ensino, à pesquisa e à extensão, o que inclui hospitais universitários 412 federais e hospitais das três esferas de governo. (BRASIL, 2011b)

Em 2014, estabeleceu-se, por meio da Lei 13.019, o regime jurídico das parcerias voluntárias, envolvendo ou não transferências de recursos financeiros, entre a administração pública e as Organizações da Sociedade Civil (OSC). Elas são pessoas jurídicas de direito privado sem fins lucrativos, com finalidades de interesse público em regime de cooperação, colaboração e fomento. (BRASIL, 2014)Vale destacar que essa lei trata exclusivamente do relacionamento entre a administração pública e as instituições sem fins lucrativos, e institui as regras aplicáveis a essas parcerias. A lei, portanto, padroniza procedimentos no âmbito nacional, em longo prazo, facilitando ainda mais a execução dessas parcerias.

A situação fortalece o direcionamento da reconfiguração da gestão dos serviços à luz de novos parâmetros que se justificam com o discurso de contorno dos entraves burocráticos e redução dos custos, com a finalidade de aperfeiçoar práticas e modernizar administrativamente o Estado através de programas de qualidade e produti- 
vidades típicos do setor privado. Assim, um conjunto de iniciativas foi criado em torno da problemática da gestão dos serviços, em especial à seguridade social, que serão discutidos a seguir, a partir da revisão da produção científica latino-americana sobre gestão hospitalar.

\section{Produção científica latino-americana sobre gestão hospitalar}

Com o objetivo de analisar as tendências da produção científica, procedeu-se uma revisão sistemática na base de dados da Literatura Latino-Americana e do Caribe em Ciências da Saúde (LILACS), sem delimitação de período, nas línguas portuguesa, espanhola e inglesa, disponíveis na íntegra e de acesso gratuito, utilizando um conjunto de descritores. Uma vez selecionados os artigos, foi feita a leitura exaustiva dos resumos, o que permitiu o agrupamento de suas respectivas ideias centrais em quatro dimensões predefinidas conforme a aproximação anterior e que subsidiou o desenvolvimento teórico e crítico sobre a temática da gestão pública hospitalar. $\mathrm{O}$ diagrama apresentado a seguir explicita os passos que compuseram esse processo de revisão sistemática da produção científica. 
Figura 1 - Diagrama da revisão sistemática de literatura

\section{Descritores de busca:}

Administração Pública; Administração em Saúde Pública; Administração de Serviços de Saúde; Administração Hospitalar; Administração Financeira de Hospitais; Administraçăo de Instituições de Saúde; Descentralização; Gestão em saúde; Modernização do Setor Público; Organização e Administração; Parcerias Público-Privadas; Políticas Públicas de Saúde; Reforma dos Serviços de Saúde; Eficiência Organizacional; Institucionalização; Inovação Organizacional; Sistema de Saúde; Atenção a Saúde; Financiamento da Assistência à Saúde; Hospitais Públicos; Hospitais privados; Hospitais universitários; Hospitais Estaduais; Hospitais Municipais; Hospitais; Serviço Hos pitalar de Emergência; Custos Hospitalares; Desenvolvimento Institucional; Seguridade social; Responsabilidade Social; Setor Público; Serviços Terceirizados; Reforma dos Serviços de Saúde; Tomada de Decisão; Acreditaçăo; Sistemas Locais de Saúde: Sistema Único de Saúde; Regionalização; Saúde Pública; Administração de Recursos Humanos; Administração de Recursos Humanos em Saúde; Administração de Recursos Humanos em Hospitais; Pessoal de Saúde; Recursos Humanos; Recursos Humanos em Saúde

Fonte: elaborado pelos autores.

Quanto à internacionalização da temática, destaca-se o maior número de artigosoriundos da Colômbia. Dentre os temas estudados pelos pesquisadores, destacam-se: sistema de informação, gestão de políticas públicas, administração pública, governança cooperativa e descentralizada, indicadores de produtividade financeiros, desafios do acesso nas emergências (BERNAL-ACEVEDO; FOREROCAMACHO, 2011; MOLINA, 2006), modelo de gestão e desenvolvimento organizacional com enfoque na gestão da qualidade, e morbimortalidade hospitalar. (PINZÓN, 2011) Especificamente sobre a atenção hospitalar, destaca-se a temática da autonomia dos hospitais públicos enquanto estratégia à melhoria do desempenho/ administração e qualidade hospitalar (BETANCUR, 2010), a violência institucional e o assédio moral. Sobre os recursos humanos em saúde, foram resultados encontrados: a humanização e liderança nos contextos dos hospitais, avaliação do desenvolvimento organizacional, relações entre as seguradoras/prestadoras com os processos 
de contratação e capital social. (AGUILAR-MEJÍA; QUINTEROÁLVAREZ, 2005; GARCIA-LONDOÑO, 2013; HOYOSHERNÁNDEZ; CARDONA-RAMÍREZ; CORREA-SÁNCHEZ, 2008) Outros países apareceram com menor número de publicações selecionadas, mas não menos importantes. Seguem-se as temáticas segundo países de origem dos estudos:

- Cuba: discussão sobre gestão da saúde pública no sistema de saúde, a história e indicadores de eficiência dos hospitais, a construção sócio-histórica da saúde pública nos períodos democrático, popular, agrário e anti-imperialista. (GALVAN; GARCÍA; MANTILLA, 2009; MORALES, 2011)

- Guatemala: o direito a saúde e realidade social e a relação das epidemias com as unidades hospitalares foram os destaques. (ALVAREZ, 1998; VIEZCA; FERNANDO, 2009)

- México: merecem destaques a administração de serviços de saúde, reformas no setor saúde e responsabilidade social; sobre os hospitais, houve estudo de reflexão histórica. (FRENK; GÓMEZ-DANTÉS, 2010; MICHELI, 2005; TERÁNVARELA, 2011)

- Argentina: o destaque foi a gestão do cuidado às enfermidades crônicas e pesquisa histórica sobre o patrimônio hospitalar. (SIPES, 2008)

- Bolívia: a descentralização da assistência à saúde ao nível local, a consciência social aplicada à saúde, o financiamento e gastos públicos com os serviços da saúde. (CUELLAR, 1987)

- Uruguai: a importância da função normativa da autoridade e a experiência de serviços de hospital-dia.

- Chile: destacaram-se a reforma de saúde, pesquisa histórica e da eficiência da gestão hospitalar, eficácia de instrumentos de diagnóstico e pagamento por desempenho; autogestão no sistema de saúde e a relação da história de Allende com os programas de governo no século XXI. (PAVEZ, 2009; URBINA, 
2011; URBINA; RODRIGUEZ, 2011; SEPÚLVEDAALVAREZ, 2013)

- Peru: foi destaque a utilização de Balanced Scorecard como ferramenta de gestão e análise do valor aplicado na saúde pública. (CONTRERAS-CAMARENA, 2011; CONTRERASCAMARENA;GALARZA-MANYARI, 2011;MURILLO; MENDOZA; FRANCO, 2000)

No que se refere à compreensão sobre administração pública, os estudos abordaram aspectos históricos da reforma administrativa, especificamente a revisão sobre as reformas administrativas e os efeitos no setor saúde no mundo. Nos estudos que analisam o Brasil, aparece a influência da Civil Service Commission sobre o DASP (SOUZA, 1994), crise da administração burocrática a partir de 1930, análise da saúde no governo Vargas (REIS, 1992), entendimento sobre a dimensão social da saúde e enfoque à evolução da administração pública através da institucionalização da avaliação para tomada de decisão. (DENIS, 2010; FOTHERINGHAM et al., 2011; PALMA-SOLÍS, 2006) Aspectos relevantes apareceram em vários estudos e merecem destaque, a exemplo do debate sobre a privatização de serviços no SUS, mercado de planos e seguros de saúde, relação do capitalismo com a saúde pública, assistência hospitalar filantrópica e proposta de programa de controle de infecção hospitalar. (BAHIA, 2008; BONACIM; ARAUJO, 2010)

Chama atenção o interesse e quantidade de estudos sobre as experiências da nova gestão pública indireta, que foram agrupados em três subcategorias:

a. estudos sobre o Estado brasileiro;

b. sobre o setor saúde;

c. sobre a atenção/gestão hospitalar, especificamente.

Quanto ao Estado brasileiro, destacaram-se algumas temáticas como o processo de mudança organizacional e a incorporação de práticas existentes no setor privado nas organizações públicas visando mudanças na gestão. 
Quanto ao setor saúde, destacaram-se temas como: adoção de instrumentos de planejamento para gestão de serviços de saúde, competências gerenciais dos serviços de saúde (VELÁSQUEZ-RESTREPO; RODRÍGUEZ-QUINTERO; JAÉN-POSADA, 2013), tendências de gestão organizacional desenvolvidas por enfermeiras, proposta de descentralização do planejamento em saúde,reforma administrativa das Secretarias Estaduais de Saúde, avaliação de estabelecimentos de saúde sob gestão de OSS (TIBERIO; SOUZA; SARTRI; 2010), situação da rede pública de assistência sanitária e farmacêutica (TREVISAN; JUNQUEIRA, 2010), processo de regionalização da saúde em São Paulo,utilização de sistema de informação em saúde. Chamou atenção a importância do debate sobre os desafios da implantação do SUS e da avaliação econômica como ferramenta à tomada de decisão em saúde.

Quanto à atenção e/ou assistência hospitalar, pode-se destacar: características profissionais do administrador hospitalar (GALVÃO; FEDERIGHI, 2002), avaliação dos serviços de urgência e emergência, gestão do cuidado da enfermagem e gerenciamento de leitos por pacientes, gestão de custos aplicado em hospitais universitários e o impacto dos custos médicos (BONACIM; ARAÚJO, 2010), análise sobre absenteísmo em unidade hospitalar, importância da acreditação e responsabilidade social hospitalar (MANZO; BRITO; CORREA, 2012), ética empresarial, humanização do cuidado e responsabilidade social hospitalar. Nos estudos voltados para a dimensão da terceirização, merecem destaque a associação entre às unidades de produção de serviços e a qualidade da assistência, o papel das empresas hospitalares frente às necessidades do cliente, paciente e mercado e a eficiência como necessidade de administrativa em unidades hospitalares. (ZAMBERLAN; SIQUEIRA, 2005)

A aproximação inicial com os estudos encontrados na literatura sobre gestão hospitalar permitiu identificar algumas lacunas existentes e a necessidade de ampliar o olhar sobre os modelos de gestão na saúde buscando os efeitos produzidos pelas mudanças em curso no sistema de saúde brasileiro. 


\section{Considerações finais}

As diferentes perspectivas de análise apontadas neste capítulo revelam o desafio contemporâneo frente ao entendimento do público no Estado brasileiro, que Cohn (2011) caracteriza como estreitamento embaçado entre público e privado e que perpassa pelo filantrópico, privado sem fins lucrativos e público não estatal. Situações que criam um caráter híbrido no sistema de saúde, ao qual Paim (2014, p.8) se preocupa enquanto interconexão "[...] deletéria e prejudicial aos interesses do setor público da saúde”. Preocupação que tomamos como fenômeno de estudos científicos.

A aproximação à produção científica, permitiu nortear os objetos de estudo definidos pelo eixo temático "Modelos de Gestão Hospitalar”. Nesse sentido, a atenção se volta às unidades hospitalares, indicando-se um conjunto de preocupações como a efetividade, eficiência e eficácia, uso de tecnologias, custos, gestão da qualidade, e aspectos voltados para os trabalhadores da saúde no que tange à sua formação e ao processo de trabalho cotidiano. Sobre a gestão da atenção hospitalar, tem-se como desafios a serem pesquisados o financiamento público das unidades hospitalares, as características dos diferentes modelos de parceria pública na administração dos hospitais públicos, o instigante aspecto da expansão de cobertura à luz das Redes de Atenção da Saúde, a regulação e as características dos contratos de gestão e serviços, a formulação/implantação de novos modelos, a exemplo da Parceria Público Privada e da EBSERH nos hospitais universitários.

Ampliar os estudos sobre a gestão hospitalar e os diferentes modelos de terceirização adotados no Brasil será uma importante contribuição do OAPS no debate sobre a responsabilidade do Estado e o desempenho das organizações públicas de saúde frente às necessidades da população brasileira. 


\section{Referências}

ABRUCIO, F. L. Trajetória recente da gestão pública brasileira: um balanço crítico e a renovação da agenda de reformas. Revista de Administração Pública, Rio de Janeiro, v. 4, p. 67-86, 2007. Edição Especial Comemorativa.

ALVAREZ, R. R. Los hospitales de epidemias. Revista del Colegio de Medicos y Cirurjanos de Guatemala,, Guatemala, v. 8, n. 1-2, p. 32-6, ene./ jun. 1998.

ANDRADE, F. A. G. de. Esculpindo o SUS a golpes de portaria: considerações sobre o processo de formulação das NOBs. Cienciał Saúde Coletiva, Rio de Janeiro, v. 6, n. 2, p. 292-318, 2001.

ANDREWS, C. W. Da década perdida à reforma gerencial: 1980-1998. In: ANDREWS, C. W.; BARIANI, E. Administração pública no Brasil: breve história política. São Paulo: Unicamp, 2010. p. 85-118.

ANDREWS, C. W.; BARIANI, E. As marcas de nascence: a administração pública da Colônia à República Velha. In: ANDREWS, C. W.; BARIANI, E.Administração pública no Brasil: breve história política. São Paulo: Unicamp, 2010. p.13-38.

ARANTES, P. F.; MARICATO, E. O ajuste urbano: as políticas do Banco Mundial e do BID para as cidades. Pós, São Paulo, n. 20, p. 60-75, dez. 2006.

ARAGAO, C.V. de. Burocracia, eficiência e modelos de gestão pública: um ensaio. Revista do Serviço Público, Brasília, DF, ano 48, n. 3, p. 104-132, set./dez. 1997.

AGUILAR-MEJÍA, O.M.; QUINTERO-ÁLVAREZ, M.X. Memoria colectiva y organizaciones. Universitas Psychologica, Bogotá, v. 4, n. 3, p. 285-296, oct./dic. 2005.

BARIANI, E. DASP: entre a norma e o fato. In: ANDREWS, C. W.; BARIANI, E. Administração pública no Brasil: breve história política. São Paulo: Unicamp, 2010. p. 39-62.

BAHIA, L. A privatização no sistema de saúde brasileiro nos anos 2000: tendências e justificação. In: SANTOS, N. R. dos; AMARANTE, P. D. de 
C. Gestao pública e relação público privado na saúde. Rio de Janeiro: Cebes, 2011.p. 115-128.

BAHIA, L. A Démarche do privado e o público no sistema de atenção à saúde no Brasil em tempos de democracia e ajuste fiscal, 1988-2008. In: MATTA, G. C.; LIMA, J. C. F. Estado, sociedade e formação profissinal em saúde: contradições e desafios em 20 anos de SUS. Rio de Janeiro: Ed. FIocruz, 2008. p. 123-185

BERNAL-ACEVEDO, O.; FORERO-CAMACHO, J. C. Sistemas de información en el sector salud en Colombia. Revista Gerencia y Políticas de Salud, Bogotá, v. 10, n. 21, p. 85-100, jul./dic. 2011.

BETANCUR, M.A.L. et al. Dificultades para la atención en los servicios de urgencias: la espera inhumana. Investigación y Educación en Enfermería, Medellín, v. 28, n.1, Marzo 2010.

BONACIM, C. A. G.; ARAUJO, A. M. P. Gestão de custos aplicada a hospitais universitários públicos: a experiência do Hospital das Clínicas da Faculdade de Medicina de Ribeirão Preto da USP. RAP, Rio de Janeiro, v. 44, n. 4, p. 903-931, jul./ago. 2010.

BORGES, A.F.; FREITAS JUNIOR, D.B. de; OLIVEIRA, E.R. de. Estratégia e administração pública: o caso do programa "choque de gestão" do governo do estado de Minas Gerais. Pretexto, Belo Horizonte, v. 9, n. 3, 79-106, jul./set. 2008.

BRAGA NETO, F. C. et al. Atenção hospitalar: evolução histórica e tendências. In: GEOVANELA, L. (Org.). Politicas e sistema de saúde. 2. ed. Rio de Janeiro: Ed. Fiocruz, 2012. p. 577-608.

BRASIL. Câmara da Reforma do Estado. Plano diretor da reforma do aparelho do estado. Brasília, DF, 1995.

BRASIL. Constituição (1988). Constituição da República Federativa do Brasil. Brasília, DF: Senado, 1988.

BRASIL. Decreto no 7.661, de 28 de dezembro de 2011. Aprova o Estatuto Social da Empresa Brasileira de Serviços Hospitalares -EBSERH, e dá outras providências. Diário Oficial [da] Republica Federativa do Brasil. Brasília, DF, 29 dez. 2011 a. 
BRASIL. Lei Complementar n ${ }^{\circ}$ 101.de 4 de maio de 2000. Estabelece normas de finanças públicas voltadas para a responsabilidade na gestão fiscal e dá outras providencias. Diário Oficial [da] Republica Federativa do Brasil. Brasília, DF, 5 maio 2000 Disponível em<http://www.planalto. gov.br/ccivil_03/leis/lcp/lcp101.htm>. acesso em: 4 out. 2014.

BRASIL. Lei n ${ }^{\circ}$ 12.550, de 15 de dezembro de 2011. Autoriza o Poder Executivo a criar a empresa pública denominada Empresa Brasileira de Serviços Hospitalares - EBSERH; acrescenta dispositivos ao DecretoLei no 2.848, de 7 de dezembro de 1940 - Código Penal; e dá outras providências. Diário Oficial [da] Republica Federativa do Brasil Brasília, DF, 16 dez. $2011 \mathrm{~b}$.

BRASIL. Lei 13.019, de 31 de julho de 2014. Estabelece o regime jurídico das parcerias entre a administração pública e as organizações da sociedade civil. Diário Oficial [da] Republica Federativa do Brasil Brasília, DF, 1 ago. 2014. Disponível em: <http://www.planalto.gov.br/ ccivil_03/_ato2011-2014/2014/lei/113019.htm>. Acesso em: 17 out. 2016.

BRASIL. Ministério da Administração Federal e Reforma do Estado / 421 Secretaria da Reforma do Estado. Organizações sociais. Brasília, DF: Secretaria da Reforma do Estado, 1997a.

BRASIL. Ministério da AdministraçãoFederal e Reforma do Estado. A reforma do aparelho do estado e as mudanças constitucionais: síntese \& respostas a duvidas mais comuns. Brasília, DF, 1997b.

BRASIL. Portaria n. 3390 de 30, de dezembro de 2013. Institui a Política Nacional de Atenção Hospitalar (PNHOSP) no âmbito do Sistema Único de Saúde (SUS), estabelecendo-se as diretrizes para a organização do componente hospitalar da Rede de Atenção à Saúde (RAS). Diário Oficial da União. Brasília, DF, 30 dez. 2013.

BRASIL. Reforma do sistema de atenção hospitalar brasileira. Brasília, DF: Ministério da Saúde, 2004.

CARVALHO FILHO, J. S. Manual de Direito Administrativo, São Paulo: Atlas, 2012. 
CAPOBIANGO, R. P. et al. Reformas administrativas no Brasil: uma abordagem teórica e crítica. REGE, São Paulo, v. 20, n.1, p. 61-78, jan./ mar. 2013.

CAPUANO, E. A. Construtos para modelagem de organizações fundamentadas na informação e no conhecimento no serviço público brasileiro. Ciência da Informação, Brasília, DF, v. 37, n. 3, p. 18-37, set./ dez. 2008.

CASTELLS, M. A era da informação: a sociedade em rede. 5. ed. São Paulo: Paz e Terra, 2001.v. 1.

CATELLI, A.; SANTOS, E. S. Mensurando a criação de valor na gestão pública. RAPRio de Janeiro, v. 38, v. 3, p. 423-449, maio/Jun. 2004.

CENTRO LATINO AMERICANO DE ADMINISTRAÇÃO PARA O DESENVOLVIMENTO-CLAD. Uma Nove Gestão Pública para América Latina, [S.1.], 1998. Disponível em: <Centro Latino Americano de Administração para o Desenvolvimento >. Acesso em: 13 dez. 2015 COHN, A. Questionando conceitos: o público e o privado na saúde no século 21. In: SANTOS, N. R. dos; AMARANTE, P. D. de C. Gestão pública e relação público privado na saúde. Rio de Janeiro: Cebes, 2011. p. 244-251.

CONTRERAS-CAMARENA, C. Factores asociados a hospitalizaciones inadecuadas a los servicios de medicina. Sociedad Peruana de Medicina Interna ,Lima, v. 24, n. 4, p. 177-184, 2011.

CONTRERAS-CAMARENA, C.; GALARZA-MANYARI, C.

Hospitalizaciones inadecuadas en emergencias médicas. Sociedad Peruana de Medicina Interna, Lima ,v. 24, n. 1, p. 19-25, 2011.

COSTA, N. do R.; SILVA, P.L.B.; RIBEIRO, J.M. A experiência internacional de reforma do setor saúde: inovações organizacionais e de financiamento. RAP, Rio de janeiro, v. 34, n. 1, p. 209-227, jan./fev. 2000.

CUELLAR, M. J. Bolivia: salud y conciencia nacional. [S.l.]: UNICEF, 1987. 
DENIS, J. L. Institucionalização da avaliação na administração pública. Revista Brasileira de Saúde Materno Infantil, Recife, v. 1, n. 1, p. 229-237, nov. 2010. Suplemento.

DRAIBE, S. M. As politicas sociais e o neoliberalismo: reflexões suscitadas pelas experiências latino-americanas. Revista USP, São Paulo, n. 17, p. 86-101, 1993.

ESCOREL, S.; TEIXEIRA, L. A. História das políticas de saúde no Brasil de 1822 a 1963: do império ao desenvolvimentismo populista. In: GEOVANELA, L. (Org.). Políticas e sistema de saúde. 2. ed. Rio de Janeiro: Ed. Fiocruz, 2012. p.279-322.

ESCOREL, S. História das políticas de saúde no Brasil de 1964 a 1990: do golpe militar à reforma sanitária. In: GEOVANELA, L. (Org). Politicas e sistema de saúde. 2. ed. Rio de Janeiro: Ed. Fiocruz, 2012. p.323-364.

FARIA, C. F. Estado e organizações da sociedade civil no Brasil contemporâneo: construindo uma sinergia positiva? Revista de Sociologia e Política., Curitiba, v. 18, n. 36, p. 187-204,jun. 2010.

FARIA, J. A.; MADEIRA, R. B. Impacto da estrutura organizacional de dois hospitais públicos portugueses na execução dos seus objetivos. Perspectivas em Gestão \& Conhecimento, João Pessoa, p. 106-124, v. 1, n. 1, jan./jun. 2011.

FARAH, M. F. S. Gestão pública e cidadania: iniciativas inovadoras na administração subnacional no Brasil. RAP, Rio de Janeiro, v. 31, n. 4, p. 126-156, jul./ago. 1997.

FARAH, M.F.S. Reformas de políticas sociais no Brasil: experiências recentes de governos subnacionais. Revista de Administração, São Paulo, v. 33, n. 1, p. 51-59, jan./mar. 1998.

FERREIRA, A. R. Modelo de excelência em gestão pública. Revista Eixo, Brasília, DF, v. 1, n. 1, p. 31-43, jan./jun. 2012.

FERREIRA JUNIOR, W.C. Gerenciamento de hospitais estaduais paulistas por meio das organizações sociais de saúde. RAP, Rio de Janeiro, v.37, n. 2, p. 243-64,mar./abr. 2003. 
FERREIRA, C. M. M. Crise e reforma do Estado: uma questão de cidadania e valorização do servidor. RSP, Rio de Janeiro, v.120, n. 3, p. 5-33, set./dez.1996.

FOTHERINGHAM, M.A. et al. La perspectiva de las necesidades, el enfoque de derechos y la autodeterminación: fundamentos actuales para el Trabajo Social. Su visibilidade en un hospital privado de comunidade. Revista del Hospital Italiano de Buenos Aires. Buenos Aires, v. 1, 31, n. 2, Junio 2011.

FLEURY, S.; OUVERNEY, A. M. Política de saúde: uma política social. In: GIOVANELLA, L. et al. (Org.). Políticas e sistema de saúde no Brasil. Rio de Janeiro: Fiocruz, 2012. p. 25-57.

FREDERICO-FERREIRA, M.; SILVA, C. F. R. da. Reformas da gestão na saúde. Desafios que se colocam aos enfermeiros. Revista de Enfermagemreferência, Coimbran. 8, p. 85-93, 2012.

FRENK1, J.; GÓMEZ-DANTÉS, O. Lecciones globales de la reforma mexicana de salud: empoderamiento a través del uso de evidencias. Revista Peruana de Medicina Experimental y Salud Pública.Lima, v. 27, n. 3, p. 412-418, 2010.

GALVÃO, C. R.; FEDERIGHI, W. J. P. O hospital e o administrador hospitalar: um breve resgate histórico. O Mundo da Saúde, São Paulo,v. 6, n. 2, p. 209-215, abr./jun. 2002.

GALVAN, W.T.; GARCÍA, S.F.; MANTILLA, M.R. Breve historia del Hospital de Caridad "Santa Isabel de Cárdenas". Revista Médica Electrónica, Matanzas v.3, n. 6, 2009.

GARCES, A.; SILVEIRA, J.P. Gestão pública orientada para resultados no Brasil. Revista do Serviço Público, Brasília, DF, ano 53, n.4, p. 53-77, out./dez. 2002

GUIMARAES, M. do C. L. et al.Avaliação da capacidade de gestão de organizações sociais: uma proposta metodológica em desenvolvimento. Caderno Saúde Pública, Rio de Janeiro, v. 20, n. 6, p. 1642-1650, nov./dez. 2004.

GARCIA-LONDOÑO, J. D. Alcances y limitaciones teóricas y prácticas del “capital social en salud”. El caso del sistema de salud en Medellín. 
Revista Gerencia y Políticas de Salud, Bogotá, v. 12, n. 24, p. 184-208, enero/junio 2013.

GOHN, M. G. Teorias dos movimentos sociais: paradigmas clássicos e contemporáneos. São Paulo: Loyola, 1997.

HOYOS-HERNÁNDEZ, P. A.; CARDONA-RAMÍREZ, M. A.;

CORREA-SÁNCHEZ, D. Humanizar los contextos de salud, cuestión de liderazgo. Investigación y Educación en Enfermería, Medellín, v. 26, n. 2, p. 218-225, sept. 2008.

OLIVEIRA, F. B. de; SANT'ANNA, A. de S.; VAZ, S.L. Liderança no contexto da nova administração pública: uma análise sob a perspectiva de gestores públicos de Minas Gerais e Rio de Janeiro. RAP, Rio de Janeiro, v. 44, n. 6, p. 1453-1475, nov./dez. 2010.

MARINI, C. O contexto contemporâneo da administração pública na América Latina. Revista do Serviço Público, Brasília, DF, ano 53, n. 4, p. 31-35, out./dez. 2002.

MANZO, B. F.; BRITO, M. J. M.; CORREA, A. dos R.Implicações do processo de Acreditação Hospitalar no cotidiano de profissionais de saúde. Revista da Escola de Enfermagem da USP, São Paulo, v. 46, n. 2, p. 338-394, 2012.

MATTA, I. B. da.; FERREIRA, M. A. M.; SILVA, E. A. Políticas públicas no setor de saúde: mudanças, tendências e desafios sob a perspectiva da administração pública. Revista de Administração Hospitalar e Inovação em Saúde, Belo Horizonte, v. 11, n. 1112-27, jan./mar. 2014.

MICHELI, A. En torno a la evolución de los hospitales. Gaceta Médica de México,México, v. 141, n. 1,p. 57-62. 2005

MOLINA, G. M. et al. Descentralización del sector salud en Colombia: análisis de 91 municipios. Revista Facultad Nacional de Salud Pública, Medellín, v. 24, n. 1, enero/junio 2006.

MORALES, M. del V. et al. La salud pública vista desde el contexto de la localidad palmera. MEDISAN, Santiago de Cuba, v. 15, n. 5, p. 698, 2011. MURILLO, J. P.; MENDOZA, W.; FRANCO, G. ¿Quo vadis Salud Pública? Discurso y práctica de la Salud Pública en el Perú y su auge 
universitário en la década de los noventa. Anales de la Facultad de Medicina, Lima, v. 61, n. 2, p. 146-160, 2000.

NORONHA, J. C de; LIMA, L. D. de; MACHADO, C.V. O Sistema Único de Saúde - SUS. In: GEOVANELA, L. (Org.). Politicas e sistema de saúde.2. ed. Rio de Janeiro: Ed. Fiocruz, 2012. p. 365-394.

OLIVEIRA, J. A. de A.; TEIXEIRA, S. M. F. (Im)previdência social: 60 anos de história da Previdência no Brasil. 2. ed. Petrópolis: Vozes: Rio de Janeiro ABRASCO, 1989.

PAIM, J. S. O que é o SUS. Rio de Janeiro: Ed. Fiocruz, 2009.

PAIM, J. S. Recursos humanos em saúde no Brasil: problemas crônicos e desafios agudos. São Paulo:USP, 1994.

PAIM, J. S. O que fizeram com a saúde dos brasileiros? Estadão, São Paulo, abr. 2014. Disponível em: <http://esportes.estadao.com.br/blogs/ ricardo-guerra/jair/>. Acesso em: 16 abr. 2014.

PAIM, J. S.; TEIXEIRA, C. F. Configuração institucional e gestão do Sistema Único de Saúde: problemas e desafios. Ciência e Saúde Coletiva, Rio de janeiro, v. 12, p. 1819-1829, 2007.

PALMA-SOLÍS; M. A. et al. Infl uencias y hegemonías en la orientación de la investigación de las reformas de salud. Caderno de Saúde Pública, Rio de Janeiro, v. 2, n. 12, p. 2527-2537, dez. 2006.

PAVEZ, F. Experiencias autogestionarias en salud: El legado de Gandulfo em La Hoja Sanitaria y el Policlínico de la Organización Sindical Industrial Workers of the World (1923-1942). Revista Médica de Chile, Santiago, n. 137, p. 426-432, 2009.

PINTO, I. C. M; TEIXEIRA, C. F. Formulação da Política Gestão do Trabalho e Educação na Saúde: o caso da Secretaria Estadual de Saúde da Bahia, Brasil, 2007-2008. Caderno de Saúde Pública, Rio de Janeiro, ano 27, n. 9, p. 1777-1788, set. 2011.

PINTO, I. C. de M. et al. Organização do SUS e diferentes modalidade de gestão e gerenciamento dos serviços e rercursos públicos de saúde. In: PAIM, J. S; ALMEIDA-FILHO, N. (Org.). Saúde coletiva: teoria e prática. Rio de Janeiro: MedBook, 2014. p. 231-244. 
PINTO, I. C. de M. Ascensão e queda de uma questão na agenda

governamental: o caso das organizações sociais da saúde na Bahia. 2004. 237 f. Tese (Doutorado em Administração) - Escola de Administração, Universidade Federal da Bahia, Salvador, 2004.

PIEARANTONI, C. R. Reformas da saúde e recursos humanos: novos desafios x velhos problemas. 2000. $208 \mathrm{f}$. Tese (Doutorado) Universidade Estadual do Rio de Janeiro, Rio de Janeiro, 2000.

PEIXOTO NETO, P. A. de S.; ACCIOLY, N. V da C. C. A supremacia do interesse público sobre o privado: breves reflexões. Revista da Seção Judiciária do Rio de Janeiro, Rio de Janeiro, v. 19, n. 35, p. 35-57, 2012.

PINZÓN, J. F. et al. Costos directos e impacto sobre la morbimortalidad hospitalaria de eventos adversos prevenibles a medicamentos en una institución de tercer nivel de Bogotá. Biomédica, Bogotá, v. 31, n. 3, p. 307-315, 2011.

PAULA, A. P. P. de. Administração pública brasileira entre o gerencialismo e a gestão social. RAE, Rio de Janeiro, v. 45, n. 1, p. 36-49, jan./mar. 2005.

SANTOS, M. A. C. Organizações sociais, serviços públicos e contratos de gestão. Revista Jurídica da Seção Judiciária de Pernambuco, Recife, p. 289321, 2011.

SILVA, L. B. e. A reforma administrativade 1967. In: ANDREWS, C. W.; BARIANI, E. Administração pública no Brasil: breve história política. São Paulo: Unicamp, 2010. p.63-84.

REIS, E. Brazil: the politics of state administration. Rio de Janeiro: UERJ: IMS, 1992.

RESENDE, R. E. M. A regulamentação da emenda constitucional 29: esperança ou decepção para o financiamento da saúde pública? Revista de Direito PGE-GO, Goiânia, v. 26, p. 59-81, 2011.

ROSA, T. O papel do hospital na Rede de Atenção à Saúde. Consensus, Brasília, DF , ano 4, n. 11, p. 12-23, 2014. 
SILVA, L. B. e. A reforma administrativa de 1967. In: ANDREWS, C. W.; BARIANI, E. Administração pública no Brasil: breve história política. São Paulo: Unicamp, 2010. p.63-84.

SALGADO, A. B. S. Manual de administração pública democrática: conceitos e formas de organização. Campinas: Saberes, 2012.

SANTOS, T. B. S.; PINTO, I. C. de M. Novo modelo de gestão para hospitais universitários: construção da linha do tempo da EBSERH na perspectiva do Ciclo da Politica Pública. In: CONGRESSO PLANEJAMENTO E GESTAO EM SAÚDE BRASILEIRO DE POLITICA, 2., 2013, Belo Horizonte. Anais... Belo Horizonte;Abrasco, 2013.

SANTOS, T. B. S. Compreensões sobre a Empresa Brasileira de Serviços Hospitalares: ensaio de aproximação com a problemática sócio-política. In: SILVA, G.T.R. da. Legislação aplicada à EBSERH comentada. Salvador: Sanar, 2014. p.14-19.

SANTOS, J. C.; OLIVEIRA, S. S. A importância da administração pública indireta para a prestação do serviço público. ReFAE, São Paulo, v. 1, n. 2, p. 64-89, 2010.

SEPÚLVEDA-ALVAREZ, C. Allende y la realidad Médico-Social, a 75 años. Cuadernos médico-sociales, Santiago de Chile, v. 53, n. 3, p. 163-171, 2013.

SIPES, C. Patrimonio cultural hospitalário. Buenos Aires: Comisión para la Preservación del Patrimonio Histórico Cultural de la Ciudad de Buenos Aires, 2008.

SOLLA, J.; CHIORO, A. Atenção ambulatorial especializada. In: GIOVANELLA, L. et al. (Org.). Políticas e sistema de saúde no Brasil. Rio de Janeiro: Ed. Fiocruz, 2012.p. 547-576.

SOUZA, L. E. P. F. de. A agenda atual da Reforma Sanitária Brasileira. Physis Revista de Saúde Coletiva, Rio de Janeiro, v. 24, n. 4, p. 1017-1021, 2014.

SOUZA, M. N. Reforma administrativa no Brasil: um debate Interminável. RAP, Rio de Janeiro, jan./mar. 1994. 
TERÁN-VARELA, O. E. et al. La responsabilidad social de las instituciones de salud pública (caso centro de rehabilitación e integración social zona oriente del estado de México). Revista Gerencia y Políticas de Salud, Bogotá, v. 10, v. 21, p. 48-59, Julio/dic. 2011.

TEIXEIRA, C.;PAIM, J. S. A política de saúde no governo Lula e a dialética do menos pior. Saúde em Debate, Rio de Janeiro, v. 29, p. 268283, 2005.

TIBÉRIO, A.A.; SOUZA, E.M.; SARTRI, F.M. Considerações sobre Avaliação de Estabelecimentos de Saúde sob Gestão de OSS: o caso do Hospital Geral do Grajaú. Saúde Sociedade São Paulo, v. 9, n. 3, p. 557$568,2010$.

TREVISAN, L.; JUNQUEIRA, L. A. P. Gestão em Rede do SUS e a Nova Política de Produção de Medicamentos. Saúde e Sociedade, São Paulo, v. 19, n. 3, p. 638-652, 2010.

URBINA, P.B.; RODRIGUEZ, F.Efectos de las políticas sanitarias sobre la contención del gasto sanitario en Chile. Anales de la Facultad de Medicina.Lima, v. 72, n. 3, p. 197-204, 2011.

URBINA, P.B. Análisis de eficiencia hospitalaria en Chile. Anales de la Facultad de Medicina. Lima, v. 72, n. 1, p. 33-38, 2011.

VAITSMAN, J.; MOREIRA, R.; COSTA, N. do R. Entrevista com Jairnilson da Silva Paim: "Um balanço dos 20 anos do Sistema Único de Saúde (SUS)”. Ciência e Saúde Coletiva, Rio de Janeiro, v. 14, n. 3, p. 899 901, 2009.

VIEZCA, S.; FERNANDO, A. Derecho a la salud y la seguridad social: discurso y realidade. Revista del Colegio de Medicos y Cirurjanos de Guatemala, Guatemala,v. 4, n. 1, p. 5-11, jul./dic. 2009.

VELÁSQUEZ-RESTREPO, P. A.; RODRÍGUEZ-QUINTERO, A.K.; JAÉN-POSADA, J.S. Aproximación metodológica a la planificación y a la programación de las salas de cirugía: una revisión de la literatura. Revista Gerencia y Políticas de Salud, Bogotá, v. 12, n. 24, p. 249-266, enero/junio 2013.

ZAMBERLAN, C.; SIQUEIRA, H. C. H. de. A terceirização nos serviços e conseqüências no cuidar em enfermagem. Revista Brasileira de Enfermagem, Brasília, DF, v. 58, n. 6, p. 727-730, 2005. 
Catharina Leite Matos Soares, Ednir Assis Souza , Iracema Viterbo Silva, Liliana Santos, Soraya Almeida Belisário, Tania França, Vinício Oliveira da Silva e Isabela Cardoso de Matos Pinto

\section{TRABALHO E EDUCAÇÃO NA SAÚDE diálogos entre a produção científica e as políticas na saúde}

A problemática relativa ao trabalho e educação na área de saúde se inscreve no Movimento de Reforma Sanitária Brasileira (MRSB) e na criação do Sistema Único de Saúde (SUS). (PINTO et al, 2014) Desde então, as questões referentes a essa área vêm tomando espaço na produção acadêmica (PAIM, 1994; PINTO et al., 2013; SCHRAIBER, 1989) e nas preocupações dos gestores (BRASIL, 2004), tendo em vista os desafios apontados pela implementação do SUS e ao mesmo tempo, a expansão do Sistema de Atenção Médica Supletiva (SAMS).

De fato, já no período da constituição da Comissão Nacional de Reforma Sanitária (CNRS), a área hoje denominada "Trabalho e Educação" trazia ao debate questões centrais como a isonomia salarial entre as mesmas categorias profissionais nos distintos níveis de governo; o estabelecimento urgente e imediato de plano de cargos e salários; a necessidade da formação permanente; admissão através 
de concurso público, estabilidade no emprego; composição multiprofissional das equipes, considerando as necessidades da demanda de atendimento de cada região em consonância com os critérios estabelecidos pelos padrões mínimos de cobertura assistencial; compromissos dos servidores com os usuários; cumprimento da carga horária contratual e incentivo à dedicação exclusiva; direito à greve e sindicalização dos profissionais de saúde; formação dos profissionais de saúde integrada ao sistema de saúde, regionalizado e hierarquizado; inclusão, no currículo de ensino em saúde, do conhecimento das práticas alternativas, incorporação dos agentes populares de saúde, como pessoal remunerado, sob a coordenação do nível local do SUS, para trabalhar em educação para a saúde e cuidados primários. (BRASIL, 1986)

Esse conjunto de problemas apontados na década de 1980 denunciava a concepção utilitarista da força de trabalho até então vigente na organização das práticas de saúde e esteve por muito tempo atrelado ao conceito de Recursos Humanos em Saúde, cuja reflexão, 432 ao longo das décadas de 1980 e 1990, deu subsídios para análises críticas acerca dessa concepção. Esse conjunto de reflexões, junto aos movimentos em prol dos direitos dos trabalhadores, possibilitou a produção de novos sentidos para essa área de conhecimentos e práticas, sendo adotada então a terminologia "Trabalho e Educação na Saúde”, o que coloca os trabalhadores no centro das reflexões e ações no processo de consolidação do SUS. (MACHADO, 2005a)

O presente texto tem como objetivo analisar a problemática do Trabalho e Educação na Saúde no Brasil, tomando como referência a produção científica em diálogo com as políticas relativas à referida área. Pretende ainda apresentar as perspectivas de estudos dessa área como um dos eixos temáticos no âmbito do Observatório de Análise Política em Saúde. 


\section{De recursos humanos a trabalho e educação na saúde: desenvolvimento e bases para ampliação da abordagem}

O debate acerca dos trabalhadores da saúde e as múltiplas dimensões que envolvem as relações destes com os sistemas de saúde são considerados por alguns pesquisadores como parte de uma agenda inconclusa ainda no início do século XXI. (FERLA; POSSA, 2013) Todavia, reconhece-se o desenvolvimento da área, tanto no que tange ao arcabouço teórico conceitual (PINTO et al., 2014) quanto na formulação de políticas de saúde voltadas para a gestão do trabalho e da educação na saúde. (MACHADO, 2005a)

Do ponto de vista conceitual, o termo "Recursos Humanos em Saúde" foi objeto de crítica de pesquisadores brasileiros, considerando a centralidade dos trabalhadores como sujeitos do trabalho em saúde (PINTO et al., 2014), tendo nesse arcabouço inclusive trabalhos seminais que inauguraram o campo da Saúde Coletiva. (DONNÂNGELO, 1975)

Nesse aspecto, vale destacar que a ampliação da abordagem expressa o reconhecimento de uma comunidade científica em relação à necessária articulação entre as práticas de saúde e a formação/educação dos trabalhadores, entendendo que são dimensões imbricadas, envolvidas de reciprocidade. (PEDUZZI et al., 2013)

No que tange às políticas relacionadas aos trabalhadores da saúde, Machado (2005) considera três períodos para o desenvolvimento das mesmas. Um primeiro período que compreende os anos de 1967 a 1974, caracterizado por incentivo à formação profissional com prioridade ao nível superior; expansão de empregos privados, a partir do financiamento público; incremento da contratação de médicos e atendentes de enfermagem, reforçando a bipolaridade "médico/atendentes"; e incentivo à hospitalização/especialização. O segundo, datado entre 1975 e 1986, marcado pelas iniciativas de mudança no sistema, destacando-se o aumento da participação do setor público na oferta de serviços ambulatoriais e hospitalares; aumento 
da formação do pessoal técnico e sua incorporação nas equipes de saúde e aumento do pessoal que atua na rede ambulatorial. O terceiro e último, de 1987 em diante, composto por mudanças estruturais rumo à consolidação do SUS, onde se destacam o processo de descentralização da assistência e, por conseguinte, da força de trabalho que integra os serviços. (MACHADO, 2005)

A descentralização das ações de saúde decorrente da implementação do SUS foi responsável pelo aumento do contingente de trabalhadores no Sistema Público de Saúde (MACHADO, 2009, 2012), além da alteração em suas características, uma vez que, os postos de trabalho prioritariamente concentrados nas esferas federal e estadual até a década de 1980, passaram a se concentrar na esfera municipal. Esse processo, todavia, não foi acompanhado de manutenção dos direitos trabalhistas (MACHADO, 2005), sendo responsável pela emergência de novos arranjos institucionais decorrentes do desenvolvimento do neoliberalismo e também da criação da Lei de Responsabilidade Fiscal (Lei Complementar n.o 101, promulgada 434 em 4 de maio de 2000). Esta, por sua vez, estabeleceu impedimentos jurídico-administrativos para a contratação direta de trabalhadores e o estabelecimento de carreiras na saúde. (JAEGER; CECCIM; MACHADO, 2004)

Esse cenário parece ter se alterado a partir dos anos 2000, particularmente em 2003, com a criação de uma estrutura estatal de âmbito federal para tratar das questões relativas aos trabalhadores de saúde. Essa nova estrutura condensa em um só lugar as políticas e programas relativos tanto ao trabalho quanto à educação na saúde, reconhecendo a necessária articulação entre essas duas áreas de conhecimentos e práticas. Além disso, representa um possível resgate das proposições constitucionais tendo em vista as conquistas históricas dos trabalhadores de forma ampla e em especial dos da saúde. 


\section{Trabalho e educação na saúde: ascensão como política de governo}

No ano de 2003, foi criada a Secretaria de Gestão do Trabalho e da Educação na Saúde (SGTES) no âmbito do Ministério da Saúde (MS). Nos primeiros anos de atividade, nota-se a presença de pautas concebidas no MRSB na agenda dos governantes da época. No primeiro ano, o Conselho Nacional de Saúde (CNS) publicou a resolução CNS n.o 330 de 4 de novembro de 2003, que definiu os princípios e diretrizes para a Norma Operacional Básica de Recursos Humanos (NOB/RH-SUS) para que fossem adotados como Política Nacional de Gestão do Trabalho e da Educação em Saúde. O texto desse documento trazia, entre outras proposições, a adoção de medidas relativas à Gestão do Trabalho, como a instalação da Mesa Nacional de Negociação do SUS; a criação da Câmara de Regulação do Trabalho; a constituição de grupos de trabalho com vistas à elaboração das diretrizes nacionais para a desprecarização do trabalho e do Plano de Carreira, Cargos e Salários. Em relação ao desenvolvimento dos trabalhadores, a NOB-RH apresenta estratégias de educação em serviço, educação permanente e acompanhamento dos trabalhadores nas carreiras, além de abordar a questão da saúde ocupacional. A questão da formação profissional, tanto no nível superior quanto no médio, é apenas tangenciada no documento.

Quanto à Gestão do Trabalho, em 2004, instaurou-se a Comissão Especial para Elaboração de Diretrizes do Plano de Cargos e Carreiras (PCC-SUS), cujo produto inspirou alguns estados no processo de elaboração dos planos estaduais e municipais. No ano seguinte, foram elaboradas as diretrizes para a desprecarização do trabalho no SUS, envolvendo a regulação do trabalho, a criação de Planos de Cargos e Carreiras e do Sistema Nacional de Negociação Permanente do SUS, com a reativação da Mesa Nacional de Negociação Permanente (MNNP-SUS), além de mecanismos para a estruturação e qualificação da gestão do trabalho nas esferas estaduais e municipais. (BRASIL, 2005a) Nessa direção, é possível identificar 
avanços com a publicação das leis n. ${ }^{\circ} 11.350$ e 12.994, respectivamente em 5 de outubro de 2006 e 17 de junho de 2014, referentes à criação da carreira pública para agentes comunitários de saúde e agentes de endemias, nessa ordem.

No que concerne à atenção à saúde, a Estratégia Saúde da Família é reconhecida como principal estratégia para o reordenamento do modelo de atenção à saúde no SUS e sua execução exige respostas estatais no sentido de formar e prover profissionais para esse nível de atenção. Vários trabalhos na literatura científica evidenciam a falta de profissionais como entrave para a expansão dessa estratégia. (CAMPOS; MALIK, 2008; BRASIL, 2004; JUNQUEIRA et al., 2010; MENDONÇA et al., 2010; PERPÉTUO et al., 2009) Embora se reconheça esse problema há certo tempo, políticas estratégicas para seu enfrentamento concreto surgem em 2013, com a formulação do Programa de Valorização da Atenção Básica e posteriormente com o Programa Mais Médicos, quando provimento e fixação de profissionais, particularmente os médicos, tornaram-se prioridade nas Políticas de Trabalho e Educação. (BRASIL, 2013)

$\mathrm{Na}$ área da Educação na Saúde, um marco significativo foi a publicação do documento intitulado "Política Nacional de Formação e Desenvolvimento para o SUS: Caminhos para a Educação Permanente em Saúde" (PNEPS) tendo, à época, os Pólos de Educação Permanente (PEPS) como estratégia fundamental para a sua viabilização. (BRASIL, 2005a)

Com a divulgação do Pacto pela Saúde em 2006, discutiu-se acerca da importância dos PEPS e de sua consolidação no âmbito do SUS. Esse movimento resultou na substituição da Portaria GM/MS n. ${ }^{\circ}$ 198, de 13 de fevereiro de 2004, pela Portaria GM/MS n. ${ }^{0} 1.996$, de 20 de agosto de 2007, a qual propõe a condução regional da PNEPS, por Comissões Permanentes de Integração Ensino-Serviço (CIES). Estas estão vinculadas aos Colegiados de Gestão Regional (CGR), assumindo o nível estadual como protagonista desse processo e responsáveis pelo planejamento do desenvolvimento dos trabalhadores 
do SUS. Tal proposta objetivou fortalecer e subsidiar a sistematização dos processos de regionalização e descentralização do SUS.

Essa nova portaria define as CIES como instâncias intersetoriais e interinstitucionais permanentes que participam da elaboração, da condução e do desenvolvimento da PNEPS, e devem ser conformadas por gestores municipais e estaduais, instituições de ensino superior e técnico que ofertam cursos na área da saúde, trabalhadores do SUS e representantes da sociedade - controle social. Ela também orienta a elaboração e execução do Plano de Ação Regional de Educação Permanente em Saúde.

A proposta contida na PNEPS assume a regionalização da gestão do SUS como base para o desenvolvimento de iniciativas qualificadas para o enfrentamento das carências e necessidades do sistema. Isso porque a regionalização é a diretriz que norteia o processo de descentralização dos serviços de saúde e os processos de negociação e pactuação entre os gestores da rede de saúde.

A reorientação da formação profissional em saúde apresenta um conjunto de iniciativas, tanto de articulação interna ao MS quanto externa, envolvendo o Ministério da Educação (MEC). Como resultado dessa articulação, destaca-se a publicação das novas Diretrizes Curriculares Nacionais (DCN), em 2002; as iniciativas AprenderSUS e VER-SUS (BRASIL, 2004) que dialogam diretamente com o reordenamento da formação profissional e o Programa Nacional de Reorientação da Formação Profissional em Saúde (Pró-Saúde), em duas versões, voltado inicialmente para a formação em Medicina, Enfermagem e Odontologia e, em seguida, para as demais profissões da área da saúde. (BRASIL, 2005b; 2007) Outra iniciativa que merece ser destacada foi a formulação do Programa de Educação pelo Trabalho em Saúde (PET-Saúde) que tem como pressuposto a educação pelo trabalho, articulando o ensino e o serviço de saúde, bem como o ensino, a pesquisa e a extensão na formação dos estudantes dos cursos da saúde. Em 2015, essa proposta é reiterada através do Programa PET-Saúde GraduaSUS. (BRASIL, 2015) Destaca-se ainda, a introdução de tecnologias virtuais para o apoio 
da formação em saúde, que concretamente se observa no Programa Telessaúde, especialmente para integrar as equipes da Estratégia Saúde da Família das regiões do país aos centros universitários de referência. (BRASIL, 2007)

Na perspectiva da Educação Permanente, em 2008, criou-se a Universidade Aberta do SUS (UNA-SUS) para a oferta de processos educativos com vistas à qualificação dos profissionais de saúde com a participação das instituições de ensino superior. A formação de profissionais de nível médio teve seu fortalecimento pelo incremento da Rede de Escolas Técnicas do SUS (RET-SUS) e elaboração de programas formação em larga escala, a exemplo do Projeto de Profissionalização dos Trabalhadores da Área de Enfermagem (Profae) e o Programa de Formação de Profissionais de Nível Médio para a Saúde (Profaps).

Da análise do conjunto de ações implementadas desde a criação da SGTES, pode-se afirmar que as questões mais estruturantes da gestão do trabalho (como a desprecarização, a criação de carrei438 ras públicas e os dispositivos de negociação permanente) que foram priorizadas no momento da emergência da SGTES vêm paulatinamente sendo substituídas pelo desafio do provimento e fixação dos profissionais de saúde na atenção primária, especialmente o profissional médico.

De fato, pode-se observar, atualmente, a importância do Programa Mais Médicos na agenda governamental. Esse programa apresenta como uma das suas estratégias o provimento emergencial de médicos, sem, contudo, reduzir-se a ele. Seu intuito é contribuir com as mudanças na formação médica de modo mais geral. E, por conta disso, propõe-se a alterar as características das residências médicas com a introdução da obrigatoriedade na formação em medicina de família e comunidade; aumentar a acessibilidade da população brasileira aos cursos de medicina, tanto com o aumento de número de vagas nos cursos existentes quanto com a criação de cursos novos; entre outras iniciativas. Acresce-se ainda, o ordenamento da formação especializada que se concretizou em 2015, com a formulação 
do decreto 8.497/2015, que criou o Programa Mais Especialidades, substituído pelo Decreto 8.516, publicado no mesmo ano, porém com alteração do texto original.

\section{A problemática do trabalho e educação na produção científica nacional}

O desenvolvimento das Políticas de Trabalho e Educação na Saúde no Brasil e os desafios colocados para a implementação do SUS, contemplados na agenda dos gestores (BRASIL, 2004), abrem questões de análise que se desdobram em objetos de pesquisa e investigação, de modo que essas questões vêm tomando espaço na produção acadêmica. (PAIM, 1994; PINTO et al., 2013; SCHRAIBER, 1989)

No início da década de 1990, Schraiber e Peduzzi (1993) apontaram um conjunto de categorias analíticas para estudar essa área, naquela época, denominada "Recursos Humanos em Saúde":

a. profissionais de saúde;

b. formação/capacitação de recursos humanos;

c. administração de recursos humanos;

d. política de recursos humanos e,

e. agentes do trabalho em saúde.

Essas categorias abarcavam os problemas citados no relatório da CNRS (FIOCRUZ, 2015) e foram validadas pelo estudo apresentado por Paim (1994). Vinte anos depois, o estudo de Pinto e colaboradores (2013) utilizou as mesmas categorias para analisar a produção científica dessa área entre 1990 e 2010. Embora elas ainda estejam passíveis de utilização, o grande número de estudos enquadrados nas categorias de Formação de Recursos Humanos e Profissionais de Saúde requer uma análise mais aprofundada que possibilite identificar quais das subcategorias identificadas podem avançar no sentido de se tornarem categorias principais. 
Assim sendo, tomando-se essas categorias para produzir um debate acerca da área Trabalho e Educação em saúde é possível, de início, observar o predomínio dos estudos relativos à formação e capacitação e profissionais de saúde seguido dos profissionais de saúde, tanto no trabalho de Schraiber e Peduzzi (1993) quanto no trabalho de Pinto e colaboradores (2013). Uma exploração nas bases de dados de pesquisa, nos últimos quatro anos, permite observar a mesma tendência, apesar de uma alteração quantitativa de estudos acerca dos profissionais de saúde colocar essa categoria a frente de formação e capacitação, no último quadriênio (2011-2014).

\section{Formação e capacitação de recursos humanos}

A preponderância de estudos que tomam como objeto a formação médica (PINTO et al., 2013) vem sendo minimizada pelo aparecimento de outros que versam sobre a formação de outros profissionais de saúde (CARVALHO, A.; CARVALHO, G.; RODRIGUES, 2012; MODESTO et al., 2012), sobretudo os que integram as equipes de trabalho, especialmente em estratégias como o Núcleo de Apoio à Saúde da Família (NASF), mas também pelo destaque que a atenção primária à saúde passa a ter. (ARCANJO, SCHRAIBER, 2012; FRAGA, CARVALHO E GOMES, 2012)

Nesse sentido, ganham relevância os estudos que analisam os efeitos e desafios postos nas variadas propostas, projetos e programas de formação (ALVES, et al., 2013; GONÇALVES, CARVALHO; TRELHA, 2012), bem como aqueles que avaliam a sustentabilidade econômica, política e técnica destes. (BARRETO et al., 2012; GUIMARÃES, 2011) Incluem-se nessa área as escolas de governo, cuja ênfase anteriormente centrada na gênese, definição de papéis e organização (PINTO et al., 2013) dá espaço para questões relativas à validação, defesa e manutenção. (BORGES, et al., 2012)

$\mathrm{Na}$ área de formação e capacitação, a tendência ao estilo reiterativo e tecnicista, com ênfase em treinamentos e capacitações em áreas específicas, convive com as novas abordagens teóricas e metodológicas, notadamente descritas nos relatos de experiências, que 
apontam para a transformação e se constitui transversalmente pela construção participativa de propostas de formação para o fomento, fortalecimento e consolidação do SUS. (GOMES; REGO, 2011; HORA et al., 2013)

A concepção tecnicista de educação, que se limita à transmissão de conhecimentos operacionais para a execução de técnicas sem se preocupar com os fundamentos científicos e com a totalidade social, vem dando lugar à discussão em torno da formação com vistas ao desenvolvimento das potencialidades humanas e passível de integrar elementos como trabalho, ciência e cultura. (AYRES, 2013) Ainda não é possível identificar com clareza o conjunto de abordagens teóricas adotado pelos estudos, no entanto, a pedagogia de Paulo Freire e a abordagem metodológica de Augusto Boal aparecem referenciadas em alguns estudos. (GOLDSCHMIDT, 2012; SILVA, et al., 2012)

Freire defende que o ato de conhecer está intimamente associado à transformação na consciência e na "leitura do mundo". Essa transformação da percepção não se faz mediante um trabalho em nível puramente intelectualista. (FREIRE, 1975) A ação educativa deve incidir também no campo cultural, nas formas de pensar, ver e sentir, para que os novos conhecimentos venham a se integrar aos conhecimentos já existentes, transformando-os em sua totalidade. Trata-se de um processo de conscientização no processo de formação que implica em aprofundamento. Significa ir além da fase espontânea da apreensão da realidade a uma fase crítica, explorar a realidade nas suas estruturas, uma inserção de maneira crítica na história. (JORGE, 1979)

O reflexo desse debate na produção da área aqui analisada mostra certo deslocamento das questões mais gerais (DIAS; LIMA; TEIXEIRA, 2013) para o âmbito das práticas, enfatizando inclusive a percepção tanto dos sujeitos operadores dos processos formativos quanto os sujeitos egressos ou em processos de formação. (BELISÁRIO et al., 2013; CAPOZZOLO et al., 2013)

A análise desenvolvida anteriormente por Pinto e colaboradores (2013) mostra correlações entre as políticas de formação implemen- 
tadas à época e a produção científica refletindo-se em estudos sobre os Projetos UNI e IDA, RET-SUS, novas tecnologias educacionais entre outros objetos. $\mathrm{Na}$ leitura da produção científica dos últimos quatro anos (2011-2014), destaca-se a farta utilização de instrumentos técnicos e políticos nos estudos, com destaque para os projetos políticos pedagógicos das instituições formadoras em interface com as Diretrizes Curriculares Nacionais (DCN) (FREITAS; CALVO; LACERDA, 2012; GONÇALVES; CARVALHO; TRELHA, 2012), provavelmente pelo interesse dos pesquisadores da área com as questões concretas oriundas do processo de implementação das novas diretrizes curriculares.

\section{Profissionais de saúde}

No que tange aos profissionais de saúde, no estudo realizado por Pinto e colaboradores (2013), os trabalhos que tratam de processo de trabalho em saúde lideram a produção, seguidos de competências, perfil e identidade profissional e por último, saúde do tra442 balhador. Sem considerar os dados quantitativos e/ou percentuais acerca da distribuição dessas temáticas nos últimos quatro anos, vale considerar que a produção científica de 2011 a 2014 nessa área continua por abordar objetos dessa natureza.

Os estudos acerca dos processos de trabalho demonstram certa preocupação com as Equipes de Saúde da Família (ESF) (FRAGELLI; SHIMIZU, 2012) e as Equipes de Saúde Bucal(ESB). (ESPOSTI et al., 2012; SOARES et al., 2011) Outros ainda abordam as práticas profissionais de outros atores de Atenção Primária em Saúde (APS). Esse é o caso das práticas profissionais dos nutricionistas nesse nível de atenção (CAMOSSA, TELAROLLI JUNIOR; MACHADO, 2012), dos fisioterapeutas (PORTES et al., 2011), dos psicólogos (ARCANJO; SCHRAIBER, 2012) e dos apoiadores institucionais. (SANTOS FILHO, 2014)

Talvez a regulamentação das profissões de nível médio, que compõem as equipes de saúde na atenção primária, tenha induzido a produção acerca desses profissionais. Nesse sentido, há presença de 
vários trabalhos que tratam do Agente Comunitário de Saúde (ACS) ou do Agente de Combate as Endemias (ACE) ou Auxiliar de Saúde Bucal (ASB)/ Técnico de Saúde Bucal (TSB). (GUIDA et al., 2012; ESPOSTI et al., 2012; PEREIRA: OLIVEIRA, 2013; QUEIROS; LIMA, 2012; ROSA, BONFATI; CARVALHO, 2012)

A área de enfermagem é recorrente nos estudos sobre Trabalho e Educação na Saúde (PINTO et al., 2013; SCHRAIBER; PEDUZZI, 1993), abordando distintos objetos que analisam o trabalho e as especialidades e suas respectivas áreas de atuação no campo da enfermagem. Alguns exemplos são passíveis de expressão tais como a análise da interação entre o enfermeiro e a comunidade no âmbito da atenção básica (SANTANNA, 2013); a carga de trabalho desses profissionais (COELHO, 2011; NEGELISKII; LIANA, 2011) e a capacidade de trabalho (HILLESHEIN; LAUTERT 2012); o stress e adoecimento no trabalho (BRANDÃO; GALVÃO, 2013; GRIEP et al, 2011, SCHMIDT, 2013); a qualidade de vida associada ao trabalho (FERNANDES et al, 2012); o assédio moral e a violência institucional (BARBOSA et al., 2011, FONTES; PELLOSO; CARVALHO, 2011); as práticas dos enfermeiros nos processos de gestão do cuidado, dos serviços e na atenção às vítimas de violência. (BELLUCI; MATSUDA JÚNIOR, 2013;MANDÚ; PEDUZZI ; SILVA, 201; SARAIVA et al., 2012; entre outros)

Observa-se, nos últimos anos, estudos que abordam as práticas em saúde mental. Nesse particular, tocam nas práticas dos profissionais que atuam nos Centros de Atenção Psicossocial (CAPS) e a sobrecarga de trabalho nesses estabelecimentos (CARDOSO et al., 2012) e por outro lado, aborda-se o prazer com o desenvolvimento do trabalho nesse mesmo local. (GLANZNER et al., 2011)

\section{Mercado de trabalho}

Embora o mercado de trabalho seja um tema constitutivo da área Trabalho e Educação nas origens do campo da Saúde Coletiva (DONNÂNGELO, 1975), estudos acerca desse tema permanecem contribuindo pouco na produção científica (PINTO et al, 2013; 
SCHRAIBER, 1993), inclusive quando observada a produção do último quadriênio. No trabalho de Pinto e colaboradores (2013), esse tema trouxe à tona o debate acerca das condições de trabalho e vínculo relacionado principalmente ao desenvolvimento da ESF. Nessa direção, a produção científica dos últimos quatro anos sinaliza para as expectativas dos técnicos de enfermagem (BARBOSA et al., 2011) e enfermeiros (SILVA et al., 2012) acerca da inserção desses profissionais no mercado de trabalho. Identificam-se também estudos sobre a inserção dos odontólogos. (GIATTI; BARRETO, 2011)

A questão do mercado de trabalho, no que se refere à relação entre o quantitativo de profissionais formados e a oferta de postos de trabalho vem sendo abordada por alguns autores, como Dedecca e Trovão (2011); Hirata (2011). Esses autores apontam para a importância e a magnitude da força de trabalho em saúde no mercado de trabalho brasileiro.

Segundo Dedecca e Trovão (2011) para o alcance da qualidade de atendimento e das condições adequadas de trabalho, a política 444 pública de saúde demanda o equacionamento do seu financiamento e maior articulação com a matriz institucional da política social mais geral. Já Hiratta (2011) discute as novas características da precarização social e do trabalho, analisadas nos anos 1990. Para a autora, há novos contornos que se delineiam no processo de globalização e de crise econômica em curso. Nesses, a intensificação do trabalho e a expansão da subcontratação são fenômenos em vigor.

\section{Administração de recursos humanos}

A problemática da precarização emerge nas abordagens sobre a administração de recursos humanos, que, nas últimas duas décadas, centraram-se basicamente na qualificação de pessoal, absorção e utilização de pessoal na rede de serviços de saúde, mesmo considerando as formas de contratação que esse mercado atualmente impõe. (PINTO et al, 2013) No último quadriênio, talvez pelos desdobramentos da implementação da Política de Gestão do Trabalho, o tema análise de desempenho ganha espaço nas pesquisas. (MAEDA et al., 
2011; MORAES; IGUTI, 2013; PIERANTONI, 2011) Há preocupações com a metodologia utilizada na análise de desempenho individual, apontando recomendações para a utilização de metodologias pluridisciplinares para não haver risco de abordagens excessivamente funcionalistas na gestão de pessoas. (MAEDA et al, 2011)

Nesse sentido, Pierantoni e colaboradores (2011) revelam que há poucas opções metodológicas para Avaliação de Desempenho $\mathrm{AD})$ de profissionais e sua possibilidade de aplicação na área de saúde, dado que integra conhecimentos próprios da saúde articulados com conhecimentos da administração pública.Para as autoras, é necessário gerar novas análises e estudos para uma releitura das práticas administrativas utilizadas pelas organizações na avaliação de desempenho, e adaptá-las para atender às especificidades do setor saúde.

A questão da relação entre a oferta de força de trabalho e provisão de postos de trabalho, na administração de Recursos Humanos em Saúde, ganha espaço também com a expansão da atenção primária e as propostas de reorientação do sistema de serviços de saúde (BAPTISTA et al, 2011; MAEDA et al., 2011; MONTEIRO et al., 2011; PEREIRA et al., 2011), incluindo nessa linha as análises do apoio matricial, a exemplo do NASF (TOMASI; RIZZOTO, 2013) e a rotatividade dos profissionais. (SANCHO et al.,2011)

A temática da atenção básica agrega várias discussões como as tendências do gerenciamento das unidades básicas de saúde (ANDRE; CAMPONE; SANTELLE, 2013), as inovações na gestão de pessoas, com adoção de variáveis do contexto para a sua análise (QUEIROZ; ALBUQUERQUE; MALIK, 2013) e as implicações dos contratos de gestão para a gestão por resultados. (DITTERICH; MOYSÉS, 2012) Essas preocupações são complementadas pelo debate sobre a baixa regulação da força de trabalho médica no Brasil, com destaque para a baixa oferta desses profissionais para a Estratégia Saúde da Família, o que contribuiu para a recente flexibilização da carga horária dos médicos (RODRIGUES et al., 2013), com desdobramentos para os demais âmbitos da atenção. (MARTINS;MOLINARO, 2013) 
Essa questão reverbera nas propostas atuais das políticas para provimento e fixação desses profissionais (BRASIL, 2011a, 2013), com ações do Estado para o enfrentamento da carência de médicos, especialmente, em áreas de difícil acesso, visto que um dos dilemas enfrentados pelo setor saúde no mundo é a má distribuição de médicos entre áreas rurais e urbanas, nas capitais e nos municípios. (SILVEIRA; PINHEIRO, 2014) Nesse particular, Carvalho e Souza (2013) abordaram em seu estudo o Programa de Valorização da Atenção Básica (Provab) dentro do contexto atual da Política de Gestão do Trabalho e da Educação na Saúde.

Também compõe a problemática da área a questão do planejamento da força de trabalho em saúde. Nesse sentido, Vianna e colaboradores (2013), ao levantarem o estado atual do conhecimento sobre modelos econométricos de projeção da força de trabalho no Brasil, buscaram identificar o mais apropriado para aplicação no âmbito da APS. Seus achados evidenciaram que há seis métodos de estimativa de recursos humanos distintos, porém em sua maioria, as me446 todologias propõem cálculos preditivos para o dimensionamento de pessoal, com vistas à alocação/realocação imediata de profissionais. Ressalta a impossibilidade de definir o melhor modelo econométrico para a projeção de recursos humanos em saúde na atenção primária, em virtude do pequeno número de estudos nacionais relativos ao tema, nos quais não se obteve homogeneidade, embora se verifique claramente uma maior preocupação com a alocação da força de trabalho em saúde, mormente no âmbito hospitalar.

\section{Os desafios da área e a agenda de pesquisa no âmbito do Observatório de Análise Política em Saúde}

A análise da problemática que envolve o trabalho e a educação na Saúde revela a cronicidade de muitos desafios identificados na década de 1980, persistindo durante as décadas seguintes com o processo de implementação do SUS. O reconhecimento dessas dificul- 
dades instiga a busca por alternativas fundamentadas em estudos que ampliem o diálogo com diferentes áreas do conhecimento, tratando a questão com a complexidade que ela requer.

Nesse sentido, é importante destacar, especificamente, as mudanças que vêm ocorrendo no mundo do trabalho em saúde, a exemplo da multiplicidade de vínculos empregatícios, consequência da diversidade dos formatos de gestão; a "precarização" das condições e das relações de trabalho e a insuficiência dos mecanismos de gestão do trabalho nas organizações de saúde para dar conta da insatisfação dos trabalhadores e da baixa qualidade dos serviços prestados.

O campo do trabalho passa a requerer, portanto, análises que agreguem outras dimensões aos estudos dos problemas organizativos e gerenciais, que analisem as dificuldades enfrentadas pelos gestores do sistema de saúde em relação a aspectos da regulação do trabalho, além da necessidade de compreender como se entrelaçam as políticas de trabalho e educação formuladas em nível macro e as determinações decorrentes da organização e gestão das práticas profissionais no cotidiano do trabalho em saúde.

Ademais, sob a ótica da articulação entre a educação e o trabalho, o cenário das políticas atuais da área revela concentração de ações voltadas para a formação médica e provisão emergencial desses profissionais, bem como para a regulação e a formação deles em detrimento dos outros profissionais de saúde, garantidas por investimentos financeiros, inclusive. Trata-se, todavia, de uma questão mais ampla, tendo em vista a incorporação de profissionais médicos oriundos de outras nacionalidades que carregam outras características na formação, sendo necessário investigar a repercussão das práticas profissionais orientadas por outras lógicas e seus efeitos na APS.

Esse debate desdobra-se em questões mais complexas uma vez que as mudanças produzidas pelo Programa Mais Médicos na formação, pode a longo prazo produzir um outro perfil profissional e, por conseguinte, novas práticas e novas formas de organizar o trabalho e o cuidado aos usuários no SUS. Por outro lado, observa-se o esvaziamento da temática da Educação Permanente quando analisada 
a produção científica dos últimos quatro anos. Talvez esse fenômeno seja decorrente da redução de investimentos federais na qualificação dos profissionais de saúde.

No âmbito do Observatório de Análise Política em Saúde, essas questões fazem parte da agenda de pesquisa, além de outras lacunas identificadas a partir do mapeamento da produção científica nos últimos anos, a exemplo da graduação em Saúde Coletiva e seus desdobramentos em relação ao mercado de trabalho e inserção dos egressos. Nesse sentido, o conjunto de estudos apresentados pelo eixo temático "Políticas de trabalho e educação na saúde" abarca temáticas que contemplam desde estudos históricos acerca da força de trabalho em saúde, passando pela precarização do trabalho e análise dos processos e trabalho, até as políticas contemporâneas de gestão da educação permanente e formação de profissionais de nível médio e superior, o mercado de trabalho na área da saúde e a inserção dos jovens sanitaristas graduados em Saúde Coletiva.

Finalizando, ressalta-se que essa agenda de pesquisa não se pre448 tende estática. Pelo contrário, pretende incorporar sempre que necessários novos objetos, desde que sua relevância contribua para o fortalecimento da área e, por conseguinte, do SUS.

\section{Referências}

ALVES, C. R. L. et al. Mudanças curriculares: principais dificuldades na Implementação do PROMED. Revista Brasileira de Educação Médica,Rio de Janeiro, v. 37, n. 2, p. 157-166, Jun. 2013.

ANDRÉ, A. M.; CIAMPONE, M. H. T.; SANTELLE, O. Tendências de gerenciamento de unidades de saúde e de pessoas. Revista de Saúde Pública, São Paulo, v. 47, n. 1. fev. 2013

ARAÚJO, A. M. F. Mesa estadual de negociação permanente-avanços e desafios na relação governo e servidores. In: CONGRESSO CONSAD DE GESTÃO PÚBLICA, 2, 2009, Brasília, DF. Anais... Brasília, DF: [s.n], 2009. p. $5-15$. 
ARCHANJO, A. M.; SCHRAIBER, L. B. A atuação dos psicólogos em unidades básicas de saúde na cidade de São Paulo. Saúde e Sociedade, São Paulo, v. 21, n. 2, p. 351-363, 2012.

AROUCA, A. S. O dilema preventivista contribuição para a compreensão e crítica da medicina preventiva. 1975. 197 f. Tese (Doutorado em Ciências Médicas) - Faculdade de Ciências Médicas, Universidade Estadual de Campinas. Campinas, 1975.

AYRES, J. R. C. M. et al. Humanidades como disciplina da graduação em Medicina. Revista Brasileira de Educação Médica, Rio de Janeiro, v. 37, n. 3, p. 455-463, set. 2013.

BAPTISTA, P. C. P. et al. A inovação tecnológica como ferramenta para monitoramento da saúde dos trabalhadores de enfermagem. Revista da Escola de Enfermagem da USP, São Paulo, v. 45, p. 1621-1626, dez. 2011. Edição especial.

BARBOSA, R.et al. Violência psicológica na prática profissional da enfermeira. Revista da Escola de Enfermagem da USP, São Paulo, v. 45, n. 1, p. 26-32, mar. 2011.

BARRETO, I. C. H.C. et al. Gestão participativa no SUS e a integração ensino, serviço e comunidade: a experiência da Liga de Saúde da Família, Fortaleza, CE. Saúde e Sociedade, São Paulo, v. 21, n. 1, p. 80-93, 2012. Suplemento.

BELISÁRIO, S. A. et al. Implantação do curso de graduação em saúde coletiva: a visão dos coordenadores. Ciência e Saúde Coletiva, Rio de Janeiro, v. 18, n. 6, p. 1625-1634, Jun. 2013.

BELLUCI JÚNIOR, J. A.; MATSUDA, L. M. Governanca em enfermagem: revisao integrativa da literatura. Revista da Escola de Enfermagem da USP, São Paulo, v. 47, n. 6, p. 1425-1425, dez. 2013.

BORGES, F. T. et al. Escolas Técnicas do SUS (ETSUS) no Brasil: regulação da integração ensino serviço e sustentabilidade administrativa. Ciência e Saúde Coletiva, Rio de Janeiro, v. 17, n. 4, p. 977-987, 2012.

BRANDÃO, D. E. C.; GALVÃO, C. M. O estresse da equipe de enfermagem que atua no período perioperatório: revisão integrativa. Revista Rene, Fortaleza , v. 14, n. 4, p. 836-44, 2013. 
BRASIL. Secretaria Técnica da Comissão Nacional da Reforma Sanitária. Comissão Nacional de Reforma Sanitária. Rio de Janeiro, 1986.

BRASIL. Conselho Nacional de Secretários de Saúde. A estruturação da área de Recursos Humanos nas secretarias estaduais e Distrito Federal. Brasilia, DF, 2004.

BRASIL. Conselho Nacional de Saúde. Resolução no 330, de 4 de novembro de 2003. Aprova as diretrizes para criação, reformulação, estruturação e funcionamento dos Conselhos de Saúde. Diário Oficial da União. Brasília, DF, 4 dez. 2003, n. 236, seção 1, p. 57, col. 1.

CONFERÊNCIA NACIONAL DE SAÚDE. 8.,1986, Brasília, DF. Anais... Brasília: Centro de Documentação do Ministério da Saúde, 1987. BRASIL. Ministério da Saúde. Conselho Nacional de Saúde. Princípios e diretrizes para a gestão do trabalho no SUS (NOB/RH-SUS). 3. ed. Brasília, DF, 2005a.

BRASIL. Portaria Interministerial no 1.369, de 8 de julho de 2013. Dispõe sobre a implementação do Projeto Mais Médicos para o Brasil. Diário Oficial União. Brasília, DF, 2013.

BRASIL. Portaria Interministerial no 2.087, de 1 de setembro de 2011. Institui o Programa de Valorização do Profissional da Atenção Básica. Diário Oficial União. Brasília, DF, 2011a.

BRASIL. Portaria no 2.546, de 27 de outubro de 2011.Redefine e amplia o Programa Telessaúde Brasil, que passa a ser denominado Programa Nacional Telessaúde Brasil Redes (Telessaúde Brasil Redes). Diário Oficial União. Brasília, DF, 2011 b.

BRASIL. Portaria Interministerial MS /MEC no 2.101, de 3 de novembro de 2005.Institui o Programa Nacional de Reorientação da Formação Profissional em Saúde - Pró-Saúde - para os cursos de graduação em Medicina, Enfermagem e Odontologia. Diário Oficial União. Brasília, DF, 4 nov. $2005 b$.

BRASIL. Portaria Interministerial no 3019, de 26 de novembro de 2007. Dispõe sobre o Programa Nacional de Reorientação da Formação Profissional em Saúde - Pró-Saúde - para os cursos de graduação da área da saúde. Diário Oficial União. Brasília, DF, 2007. 
BRASIL. Secretaria de Gestão do Trabalho e da Educação na Saúde. Edital n 13 de 28 de setembro de 2015. Seleção para o Programa de Educação pelo Trabalho para a Saúde PET Saúde/GRADUASUS 20162017. SEGTES. 2015. Diário Oficial União. Brasília, DF, 29 set. 2015

CAMOSSA, A. C. A.; TELAROLLI JUNIOR, R.; MACHADO, M. L. T. O fazer teórico-prático do nutricionista na estratégia saúde da família: representações sociais dos profissionais das equipes. Revista de Nutrição, Campinas, v. 25, n. 1, p. 89-106, jan./ fev. 2012.

CAMPOS, F. E.; MACHADO, M. H.; GIRARDI, S. N. A fixação de profissionais de saúde em regiões de necessidades. Divulgação em Saúde para Debate, Rio de Janeiro, n. 44, p 13-24, maio 2009.

CAMPOS, C. V. A.; MALIK, A. M. Satisfação no trabalho e rotatividade dos médicos do Programa de Saúde da Família. RAP, Rio de Janeiro, n. 42, v. 2, p. 347-368, mar./abr. 2008.

CAPOZZOLO, A. A. et al. Experiência, produção de conhecimento e formação em saúde. Interface, Botucatu, v. 17, n. 45, p. 357-370, Jun. 2013.

CARDOSO, L. et al. Perspectivas atuais sobre a sobrecarga do cuidador em saúde mental. Revista da Escola de Enfermagem da USP, São Paulo, v. 46, n. 2, p. 513-517, abr. 2012.

CARVALHO, A. A. S.; CARVALHO, G. S.; RODRIGUES, V. M. C. P. Valores na educação em saúde e a formação profissional. Trabalho, Educação e Saúde, Rio de Janeiro, v. 10, n. 3, p. 527-540, 2012.

CARVALHO, M. S.; SOUSA, M. F. Como o Brasil tem enfrentado o tema provimento de médicos? Interface, Botucatu, v. 17, n. 47, p. 913-926, dez. 2013.

CECCIM, R. B.; FERLA, A. Educação Permanente em Saúde. In: PEREIRA, I. B. e LIMA, J. C. F. (Org.).Dicionário da educação profissional em saúde.2.ed. Rio de Janeiro: EPSJV, 2008. Disponível em: <http:// www.epsjv.fiocruz.br/dicionario/>. Acesso em: 17 nov. 2015

COELHO, M. C. R. Mesa de negociação permanente do SUS: um espaço político das relações do trabalho em saúde para enfermeiros no município de Vitória no estado de Espírito Santo (2003-2009). 2011. 170 f. Tese 
(Doutorado em Enfermagem) - Escola de Enfermagem Anna Nery, Universidade Federal do Rio de Janeiro, Rio de Janeiro, 2011.

CUNHA, G. T.; CAMPOS, G. W. de S. Apoio matricial e atenção primária em saúde. Saude e Sociedade, São Paulo, v. 20, n. 4, p. 961-970, dez. 2011.

DEDECCA, C. S.; TROVÃO, C. J. B. M. A força de trabalho no complexo da saúde: vantagens e desafios. Ciência e Saúde Coletiva, Rio de Janeiro, v. 18, n. 6, p. 1555-1567, Jun. 2013.

DIAS, H.S.; LIMA, L. D.; TEIXEIRA, M. A trajetória da política nacional de reorientação da formação profissional em saúde no SUS. Ciência e Saúde Coletiva, Rio de Janeiro, v.18, n. 6, p. 1613-1624, Jun. 2013.

DITTERICH, R. G. ; MOYSÉS, S. J. O uso de contratos de gestão e incentivos profissionais no setor público de saúde. Cadernos de Saúde Pública, Rio de Janeiro, v. 28, n. 4, p. 615-625, abr. 2012.

DONNANGELO, M. C. F. Medicina e sociedade: o médico e seu mercado de trabalho. São Paulo: Pioneira, 1975.

452 ESPOSTI, C. D. D.; OLIVEIRA, A. E.; SANTOS NETO, E. T.; ZANDONADE, E. O processo de trabalho do técnico em saúde bucal e suas relações com a equipe de saúde bucal na Região Metropolitana da Grande Vitória, Espírito Santo, Brasil. Saúde e Sociedade, São Paulo, v. 21, n. 2, p. 372-385, 2012.

FARIAS, M. R. de; SAMPAIO, J. J. C. Papel do cirurgião-dentista na equipe de saúde da família, RGO, Porto Alegre, v. 59, n. 1, p. 109-115, jan./mar. 2011.

FERLA, A. A.; POSSA, L. B. Gestão da educação e do trabalho na saúde: enfrentando crises ou enfrentando o problema? Interface, Botucatu, v. 17, n. 47, p. 927-928, dez. 2013.

FERNANDES, J. S. et al. A relação dos aspectos profissionais na qualidade de vida dos enfermeiros das equipes Saúde da Família.Revista da Escola de Enfermagem da USP, São Paulo, v. 46, n. 2, p. 404-412, abr. 2012. 
FIOCRUZ. Comissão Nacional da Reforma Sanitária. Base Arch.

Disponivel em: <http://arch.coc.fiocruz.br/index.php/comissaonacional-de-reforma-sanitaria $>$. Acesso em: 25 nov. 2015.

FONSECA, A. F.; MENDONÇA, M. H. M. A interação entre avaliação e a atuação dos Agentes Comunitários de Saúde: subsídios para pensar sobre o trabalho educativo. Saúde em debate, Rio de Janeiro, v. 38, p. 343357, out. 2014. Edição Especial.

FONTES, K. B.; PELLOSO, S. M.; CARVALHO, M. D. de B. Tendência dos estudos sobre assédio moral e trabalhadores de enfermagem. Revista Gaúcha de Enfermagem, Porto Alegre, v. 32, n. 4, p. 815-822, dez. 2011.

FRAGA, A. B.; CARVALHO, Y. M.; GOMES, I. M. Políticas de formação em educação física e saúde coletiva. Trabalho, Educação e Saúde, Rio de Janeiro, v.10, n. 3, p. 367-386, 2012.

FRAGELLI, T. B. O.; SHIMIZU, H. E. Competências profissionais em Saúde Pública: conceitos, origens, abordagens e aplicações. Revista da Escola de Enfermagem da USP, São Paulo, v. 65, n. 4, p. 667-674, jul./ago. 2012.

FREIRE, P. Pedagogia do oprimido. 3. ed. Rio de Janeiro: Paz e Terra, 1975.

FREITAS, S. F. T.; CALVO, M. C. M.; LACERDA, J.T. Saúde coletiva e novas diretrizes curriculares em odontologia: uma proposta para graduação. Trabalho, Educação e Saúde, v. 10, n. 2, p. 223-234, 2012.

FRIGOTTO, G. Trabalho. In: PEREIRA, I. B; LIMA, J. C. F. (Org.).Dicionário da educação profissional em saúde. 2.ed. Rio de Janeiro: EPSJV, 2008. Disponível em: <http://www.epsjv.fiocruz.br/ dicionario/>. Acesso em: 17 nov. 2015.

GARCÍA, J. C. La educación médica em la América Latina.Washington: OPS, 1972.

GISELLE, G. Avanços e desafios da gestão do trabalho e da educação em saúde no Rio de Janeiro: o papel do Cosems RJ. Educação em Saúde do Conselho Nacional de Secretarias Municipais de Saúde (CONASEMS). 
GIATTI, L.; BARRETO, S. M. Situação no mercado de trabalho e utilização de serviços de saúde no Brasil. Ciência e Saúde Coletiva, Rio de Janeiro, v. 16, n. 9, p. 3817-3827, 2011.

GLANZNER, C. H. et al. O trabalho como fonte de prazer: avaliação da equipe de um Centro de Atenção Psicossocial. Revista da Escola de Enfermagem da USP, São Paulo, v. 45, n. 3, p. 716-721, Jun. 2011.

GOLDSCHMIDT, I. L. O teatro de Augusto Boal e a educação profissional em saúde. Trabalho, Educação e Saúde, Rio de Janeiro, v. 10, n. 1, p. 61-69, 2012.

GOMES, A. P.; REGO, S. Transformação da educação médica: é possível formar um novo médico a partir de mudanças no método de ensinoaprendizagem? Revista Brasileira de Educação Médica, Rio de Janeiro,v. 35, n. 4, p. 557-566, dez. 2011.

GONCALVES, F. G.; CARVALHO, B.G.; TRELHA, C. S. O ensino da Saúde Coletiva na Universidade Estadual de Londrina: da análise documental à percepção dos estudantes. Trabalho, Educação e Saúde, Rio de Janeiro, v. 10, n. 2, p. 301-314, 2012.

GORAYEB, R. B.; BORGES, C. D.; OLIVEIRA, C. M. Psicologia na atenção primária: ações e reflexões em programa de aprimoramento profissional. Psicologia: Ciência e Profissão, Brasília, DF , v. 32, n. 3, p. 674$685,2012$.

GRIEP, R. H. et al. Uso combinado de modelos de estresse no trabalho e a saúde auto-referida na enfermagem. Revista de Saúde Pública, São Paulo, v. 45, n. 1, p. 145-152, fev. 2011.

GUIDA, H. F. S. et al. As relações entre saúde e trabalho dos agentes de combate às endemias da Funasa: a perspectiva dos trabalhadores. Saude e Sociedade, São Paulo, v. 21, n. 4, p. 858-870, 2012.

GUIMARÃES, J. M. X.; JORGE, M. S. B.; ASSIS, M. M. A. (In) satisfação com o trabalho em saúde mental: um estudo em Centros de Atenção Psicossocial. Ciência e Saúde Coletiva, Rio de Janeiro, v. 16, n. 4, p. 2145-2154, abr. 2011.

GUIMARÃES, R. Desafios da pós-graduação em saúde humana no Brasil. Revista de Saúde Pública, São Paulo, v. 4, n. 1, p. 1-13, fev. 2011. 
HILLESHEIN, E. F.; LAUTERT, L. Work capacity, sociodemographic and work characteristics of nurses at a university hospital. Revista LatinoAmericana de Enfermagem, Ribeirão Preto, v. 20, n. 3, p. 520-527, June 2012.

HIRATTA, H. Tendências recentes da precarização social e do. trabalho: Brasil, França, Japão. Caderno CRH, Salvador, v. 24, n. 1, p. 15-22, 2011. Edição especial.

HORA, D. L. et al. Propostas inovadoras na formação do profissional para o Sistema Único de Saúde. Trabalho, Educação e Saúde, Rio de Janeiro, v. 11, n. 3, p. 471-486, dez. 2013.

JAEGER, M. L.; CECCIM, R. B.; MACHADO, M. H. Gestão do trabalho e da educação na saúde. Revista Brasileira de Medicina de Família e Comunidade, Rio de Janeiro, v. 3, p. 86-103, 2004.

JORGE, J. A ideologia de Paulo Freire. São Paulo: Loyola, 1979.

JUNQUEIRA, T.et al. As relações laborais no âmbito da municipalização da gestão em saúde e os dilemas da relação expansão/precarização do trabalho no contexto do SUS Labor relations under decentralized health. Caderno de Saúde Pública, Rio de Janeiro, v. 26, n. 5, p. 918-928, 2010.

MACHADO, M. H. Gestão do Trabalho em Saúde. In: PEREIRA, I. B.; LIMA, J. C. F. (Org.).Dicionário da educação profissional em saúde. 2. ed. Rio de Janeiro: EPSJV, 2008. Disponível em: <http://www.epsjv.fiocruz. br/dicionario/>. Acesso em: 17 nov. 2015.

MACHADO, M. H. Trabalhadores da saúde e sua trajetória na Reforma Sanitária. In: LIMA, N. T. et. al.(Org.). Saúde e democracia: histórias e perspectivas do SUS. Rio de Janeiro: Ed. Fiocruz: 200. p. 257-281.

MACHADO, M. H.; STIEBLER, A. L.;OLIVEIRA, E. dos S. de. Gestão, trabalho e educação em saúde: perspectivas teórico-metodológicas. In: BAPTISTA, T. W. F.; AZEVEDO, S.; MACHADO, C. V. Políticas, planejamento e gestão em saúde: abordagens e métodos de pesquisa. Rio de Janeiro: Ed. Fiocruz, 2015. p. 293-321. v. 1.

MACHADO, M.H. Trabalhadores da Saúde e sua trajetória na reforma sanitária. In: BRAGA, D.G. et al. (Org.). Curso negociação do trabalho no 
sus: caderno de textos. Rio de Janeiro: Fundação Oswaldo Cruz. Escola Nacional de Saúde Pública, 2008.p. 70-89.

MATUSUMOTO, S. et al. Discussão de famílias na estratégia saúde da família: processo de trabalho em construção. Revista da Escola de Enfermagem da USP, São Paulo, v. 45, n. 3, p. 603-610, Jun. 2011.

MAEDA, S. T. et al. Recursos humanos na atenção básica: investimento e força propulsora de produção. Revista da Escola de Enfermagem da USP, São Paulo, v. 45, n. 2, p. 1651-1655, dez. 2011. Edição especial.

MANDÚ, E. N. T.; PEDUZZI, M.; SILVA, A. M. N. Análise da produção científica nacional sobre o trabalho de enfermagem. Revista Enfermagem UERJ, Rio de Janeiro, v. 20, n. 1, p. 118-123, jan./mar. 2012.

MARTINS, M. I. C.; MOLINARO, A. Reestruturação produtiva e seu impacto nas relações de trabalho nos serviços públicos de saúde no Brasil. Ciência e Saúde Coletiva, Rio de Janeiro, v. 18, n. 6, p. 1667-1676, Jun. 2013.

MENDONÇA, M. H.et al. Desafios para gestão do trabalho a partir de experiências exitosas de expansão da Estratégia de Saúde da Família. Ciência e Saúde Coletiva, Rio de Janeiro, v. 15, n. 5, p. 2355-2365, 2010.

MODESTO, M.S.A., et al. Avaliação de curso técnico de agente comunitário de saúde sob a ótica dos egressos. Trabalho, Educação e Saúde, Rio de Janeiro, v. 10, n. 3, p. 387-406, 2012.

MONTEIRO, M. S. et al. Work capacity evaluation among nursing aides. Revista da Escola de Enfermagem da USP, São Paulo,São Paulo, v. 45, n. 5, p. 1177-1182, out. 2011.

MORAES, P. N.; IGUTI, A. M. Avaliação do desempenho do trabalhador como forma peculiar de prescrição do trabalho: uma análise do PMAQAB. Saúde em debate, Rio de Janeiro, v. 37, n. 98, p. 416-426, set. 2013.

NEGELISKII, C.; LAUTERT, L. O enfermeiro no gerenciamento à qualidade em serviço hospitalar de emergência: revisão integrativa da literatura. Revista Gaúcha de Enfermagem, Porto Alegre, v. 32, n. 4, p. 797-806, dez. 2011. 
PAIM, J. S; ALMEIDA FILHO, N. Análise da situação de saúde: o que são necessidades e problemas de saúde? In: PAIM, J. S.; ALMEIDA FILHO, N. Saúde coletiva: teoria e prática. Rio de Janeiro: Medbook, 2014. p. 29-39.

PAIM, J. S. Recursos humanos em saúde no Brasil: problemas crônicos e desafios agudos. São Paulo: Faculdade de Saúde Pública, Universidade de São Paulo, 1994.

PAIM, J. S. Reforma sanitária brasileira: contribuição para a compreensão e crítica. Salvador: EDUFBA; Rio de Janeiro: Ed. Fiocruz, 2008.

PAIM, J. S.; ALMEIDA FILHO, N. Saúde coletiva: uma "nova saúde pública" ou campo aberto a novos paradigmas?Revista de Saúde Pública, São Paulo, v. 32, n. 4, p. 299-316, 1998.

PEDUZZI, M. et al. Educação interprofissional: formação de profissionais de saúde para o trabalho em equipe com foco nos usuários. Revista da Escola de Enfermagem da USP, São Paulo, v. 47, n. 4, p. 977-983, ago. 2013.

PEDUZZI, M.; SCHRAIBER, L. B. Processo de trabalho em saúde. In: PEREIRA, I. B.; LIMA, J. C. F. (Org.). Dicionário da educação profissional em saúde. 2.ed. Rio de Janeiro: EPSJV, 2008. Disponível em: <http:// www.epsjv.fiocruz.br/dicionario/>. Acesso em: 18 nov. 2015.

PEREIRA, I. C.; OLIVEIRA, M. A. C. O trabalho do agente comunitário na promoção da saúde: revisão integrativa da literatura. Revista Brasileira de Enfermagem, Brasília, DF, v. 66, n. 3, p. 412-419, maio/jun. 2013.

PEREIRA, I. M. et al. Dimensionamento informatizado de profissionais de enfermagem: avaliação de um software. Revista da Escola de Enfermagem da USP, São Paulo, v. 45, p. 1600-1605, dez. 2011. Edição especial.

PERPÉTUO, I. H. O. et al. A categoria profissional dos médicos: fatores condicionantes de sua atração e fixação na atenção primária à saúde em Minas Gerais. Belo Horizonte: Observatório de Recursos Humanos em Saúde do Nig.One/UFMG, 2009. 
PIERANTONI, C. R. et al. Gestão do trabalho e da educação em saúde: recursos humanos em duas décadas do SUS. Physis, Rio de Janeiro, v. 18, n. 4, p. 685-704, 2008.

PIERANTONI, C.R.; VARELLA, T.C.; FRANÇA, T. Recursos humanos e gestão do trabalho em saúde: da teoria para a prática. BARROS A. F. R.; SANTANA J. P. ; SANTOS NETO, P. M. (Org.). Observatório de recursos humanos em saúde no Brasil: estudos e análises, v. 2, p. 51-70, 2004.

PIERANTONI, C. R. et al. Avaliação de desempenho: discutindo a tecnologia para o planejamento e gestão de recursos humanos em saúde. Revista da Escola de Enfermagem da USP, São Paulo, v. 45, p. 1627-1631, dez. 2011. Edição especial.

PINTO, I. C. M et al. De recursos humanos a trabalho e educação na saúde: o estado da arte no campo da saúde coletiva. In: PAIM, J.; ALMEIDA FILHO, N.de (Org.). Saúde coletiva: teoria e prática. Rio de Janeiro, MedBook. 2014. p. 611-623.

PINTO, I. C. M. et al. Trabalho e educação em saúde no Brasil: tendências da produção científica entre 1990-2010. Ciência e Saúde coletiva, Rio de Janeiro, v. 18, p. 1525-1534, 2013.

PORTES, L. H. ET AL. Atuação do fisioterapeuta na atenção básica à saúde:uma revisão da literatura brasileira. Revista de APS, Juiz de Fora, v. 14, n. 1, jan.-mar. 2011.

QUEIROZ, A. C. S.; ALBUQUERQUE, L. G.; MALIK, A. M.de Gestão estratégica de pessoas e inovação: estudos de caso no contexto hospitalar. Revista de Administração, São Paulo, v. 48, n. 4, p. 658-670, dez. 2013.

QUEIROS, A. A. L.; LIMA, L. P. A institucionalização do trabalho do agente comunitário de saúde. Trabalho, Educação e Saúde, Rio de Janeiro, v. 10, n. 2, p. 257-281, 2012.

RODRIGUES, P. H. A. et al. Regulação do trabalho médico no Brasil: impactos na Estratégia Saúde da Família. Physis, Rio de Janeiro, v. 23, n. 4, p. 1147-1166, dez . 2013.

ROSA, A. J.; BONFANTI, A. L.; CARVALHO, C. S. O sofrimento psíquico de agentes comunitários de saúde e suas relações com o trabalho. Saúde e Sociedade, São Paulo, v. 21, n. 1, p. 141-152, 2012. 
SANCHO, L. G. et al. Rotatividade na força de trabalho da rede municipal de saúde de Belo Horizonte, Minas Gerais: um estudo de caso. Trabalho, Educação e Saúde, Rio de Janeiro, v. 9, n. 3, p. 431-447, 2011.

SANTANA, L. L. et al. Cargas e desgastes de trabalho vivenciados entre trabalhadores de saúde em um hospital de ensino. Revista Gaúcha de Enfermagem, Porto Alegre, v. 34, n. 1, p. 64-70, mar. 2013.

SANTOS FILHO, S. B. Apoio institucional e análise do trabalho em saúde: dimensões avaliativas e experiências no Sistema Único de Saúde (SUS). Interface, Botucatu, v.18, n. 1, p. 1013-1025, 2014.

SARAIVA, R. J. et al. Qualificação do enfermeiro no cuidado a vítimas de violência doméstica infantil. Cienc. Enferm, n. 18, n. 1, p. 17-27, abr. 2012.

SCHMIDT, D. R. C. Modelo demanda-controle e estresse ocupacional entre profissionais de enfermagem: revisão integrativa. Revista Brasileira de Enfermagem, Brasília, DF, v. 66, n. 5, p. 779-788, set./out. 2013.

SCHRAIBER, L.B.; PEDUZZI, M. Tendências e possibilidades da investigação de recursos humanos em saúde no Brasil. Educación Médica y Salud, Washington, v. 27, n. 3, p. 295-313, 1993.

SCHRAIBER LB. Educação Médica e Capitalismo. São Paulo: Hucitec, 1989. v. 1.

SILVA, T. L. et al. Capacitação do agente comunitário de saúde na prevenção do câncer de colo uterino. Revista Brasileira de Educação Médica, Rio de Janeiro, v. 36, n. 1, p.155-160, mar. 2012. Suplemento.

SILVEIRA, R. P.; PINHEIRO, R. Entendendo a necessidade de médicos no interior da Amazônia - Brasil. Revista Brasileira de Educação Médica, Rio de Janeiro, v. 38, n. 4, p. 451-459, dez.2014.

SOARES, R. J. O. et al. Fatores facilitadores e impeditivos no cuidar de si para docentes de enfermagem. Texto \& Contexto - Enfermagem, Florianópolis, v. 20, n. 4, p. 758-765, dez.2011.

TEIXEIRA, M. Desenhos institucionais e relações de trabalho no setor público de saúde: as Organizações Sociais e as Fundações Estatais de Direito Privado. 124 f. 2015. Tese (Doutorado em Saúde Pública) - Escola Nacional de Saúde Pública Sergio Arouca, 2015. 
TEIXEIRA, M.; OLIVEIRA, R. G.; ARANTES, R. F. Mudanças nas Políticas do Trabalho e da Educação em Saúde no Governo Lula. In: MACHADO, C. V.; BAPTISTA, T. W. de F.; LIMA, L. D. de. (Org.). Políticas de Saúde no Brasil continuidades e mudanças. Rio de Janeiro: Ed. Friocruz, 2012. p. 197-225.v. 1.

TOMASI, A R. P.; RIZZOTTO, M. L. F. Análise da distribuição e composição profissional dos Núcleos de Apoio à Saúde da Família no Paraná. Saúde em debate, Rio de Janeiro, v. 37, n. 98, p. 427-436, set 2013. VIANNA, C. M. M. et al. Modelos econométricos de estimativa da força de trabalho: uma revisão integrativa da literatura. Physis, v.23, n. 3, p. 925-950, 2013. 


\section{NARRATIVAS DE PESOUISADORES SOBRE A MIDIATIZAÇÃO DAS POLÍTICAS DE SAÚDE NO BRASIL}

\section{Introdução}

$\mathrm{O}$ processo de construção de qualquer democracia tem os meios de comunicação de massa - os media ou a mídia -, como atores fundamentais na cena social, haja vista a sua centralidade na vida contemporânea e a sua relação com a cultura e a sociedade, sobre as quais exerce significativa influência, ao tempo em que é por estas influenciada. Como instituições sociais e culturais poderosas, os media são elementos constitutivos da política.

A mídia tem legitimidade delegada por outros campos sociais, por conta da sua característica de mediação. (RODRIGUES, 1999) Portanto, não só repercute como também atua e faz parte do que se passa no espaço público, interagindo com outros campos, que buscam visibilidade na esfera midiática. Como afirma Rodrigues (1999), "o campo dos media, ao mesmo tempo, constitui e é constituído pelo público, instância que é contemporânea da sua própria formação". 
Os estudos da mediação e midiatização da sociedade e da cultura são, portanto, fundamentais para compreender a construção da realidade social, moldada pelas representações embutidas nos enquadramentos midiáticos, que influenciam a definição da agenda pública, estimulam, criticam e, ao mesmo tempo, revelam a disputa de interesses e as relações de poder nos discursos tornados públicos.

Quando se trata da área da saúde, encontra-se uma evidente preferência dos meios de comunicação para explorar esse tema, o qual aparece com grande frequência nos mesmos. Ao abordar o conceito de políticas públicas como uma resposta às demandas da população (DUNN, 1981), considera-se a mídia como ator político fundamental para o debate público, a formação da agenda pública e os processos de formulação, implementação e avaliação das ações realizadas para solucionar problemas da sociedade. As políticas de saúde, por exemplo, quando ganham visibilidade na mídia, podem ou não favorecer o capital político dos seus atores públicos e/ou privados, dependendo das representações construídas pelo enqua462 dramento do conteúdo midiatizado e sua repercussão no contexto cultural e social.

Os estudos sobre a relação mídia e saúde iniciaram no Brasil na década de 1990, quando a relação comunicação e saúde passou a integrar os objetos de pesquisa e de ensino. Nesse capítulo, analisa-se a narrativa de pesquisadores brasileiros a respeito do discurso da mídia sobre a saúde, tomado como objeto de estudo. Para a definição do objeto, considera-se a centralidade da mídia nos modos da vida contemporânea, apontando a sua relação com a cultura e a sociedade, a partir de uma lógica operacional que interfere em outras instituições sociais. Destacam-se os conceitos de mediação e midiatização, por serem fundamentais para compreender como a mídia opera na construção da realidade social. Diante da complexidade que envolve a mídia e seus discursos, interessa saber como os pesquisadores na área da saúde têm se posicionado frente aos meios de comunicação de massa enquanto objeto de pesquisa. Até que ponto compreendem essa complexidade? Como entendem a midiatização das políticas de saúde? 


\section{Mediação e midiatização da cultura e da sociedade}

A mídia é uma manifestação cultural hegemônica da contemporaneidade, segundo Kellner. (2001) Com o uso das tecnologias digitais, os recursos de imagens e sons oferecidos por meios de comunicação, como a televisão e a internet, ampliaram a capacidade dos meios de alcançar uma audiência vasta e de diferentes níveis sociais e educacionais, destinados a diferentes públicos e mercados.

Numa cultura contemporânea dominada pela mídia, os meios dominantes de informação e entretenimento são uma fonte profunda e muitas vezes não percebida de pedagogia cultural: contribuem para nos ensinar como nos comportar e o que pensar e sentir, em que acreditar, o que temer e desejar - e o que não. (KELLNER, 2001, p.10)

Abordagens que consideram as mídias apenas formações tecnológicas ou elementos de conexões entre os participantes de um processo comunicativo linear e previamente estabilizado foram contestadas pela incapacidade de oferecer uma leitura da complexidade que marca as relações entre mídia, sociedade e cultura. Martín-Barbero (2006) utilizou o conceito de mediação como estratégia de superação do modelo informacional, centrado na técnica e de grande influência em todo o mundo, ao destacar as diversas relações de apropriações e ressignificações que perpassam os processos de produção e recepção dos produtos midiáticos. $\mathrm{O}$ autor propõe uma reflexão sobre a mídia em sua articulação com a cultura, a política, a vida cotidiana, a partir das mediações, “[...] lugares dos quais provém as construções que delimitam e configuram a materialidade social e a expressividade cultural da televisão" (MARTÍN-BARBERO, 2006, p. 294), a mídia que hoje alcança quase cem por cento dos lares brasileiros. As mediações envolvem produtores, lógicas produtivas, audiência, expectativa de consumo, matrizes culturais, os meios e as mensagens.

No processo de mediação, a mídia produz o que está na cultura e o público se reconhece nos produtos da indústria cultural sem necessariamente implicar na imposição dos veículos de comunicação a 
uma audiência passiva. A hegemonia, no sentido gramsciano usado por Martín-Barbero (2006), está presente no cotidiano das pessoas e nos usos sociais da mídia. Trata-se da disputa de sentidos reconhecida pelo consenso do público e não relações de poder pela força, pois a cultura hegemônica é feita de cumplicidade e sedução.

O massivo, nesta sociedade, não é um mecanismo isolável, ou um aspecto, mas uma nova forma de sociabilidade. São de massa o sistema educativo, as formas de representação e participação política, a organização das práticas religiosas, os modelos de consumo e os de uso do espaço. Assim, pensar o popular a partir do massivo não significa, ao menos não automaticamente, alienação e manipulação, e sim novas condições de existência e luta, um novo modo de funcionamento da hegemonia. (MARTÍN-BARBERO, 2006, p. 311)

Entretanto, a tecnicidade e a identidade são reconhecidas por Martín-Barbero nas novas matrizes comunicativas da cultura na contemporaneidade, como mediações fundamentais que transformam o lugar da cultura na sociedade. A tecnicidade midiática permite a interação com novos atores, novas formas de participação do cidadão e hibridações literárias, audiovisuais e digitais, num cenário em que as identidades são desterritorializadas. A visualidade eletrônica, como parte da visibilidade cultural, amplia a capacidade de comunicação em torno de uma narrativa audiovisual, que é mais do que uma ferramenta instrumental ou sua manipulação tecnológica. A centralidade da cultura audiovisual tem, principalmente, a cumplicidade das novas gerações. (MOURA, 2009)

O debate sobre a recepção impõe considerar as formas de transgressão e conflito com os sentidos hegemônicos, destacando-se na mediação as estratégias de apropriação, interpretação e resistência, o que implica uma percepção dos meios para além dos seus elementos técnicos. Essa proposta é ainda mais adensada quando Martín-Barbero refina o conceito e aposta nas "mediações comunicativas da cultura", que sintetiza a perspectiva de avaliar não apenas os produtos culturais, 
mas também os campos social e político, reconhecendo, dessa forma, que a comunicação faz a mediação do espectro social mais vasto e das diversas formas de vida na sociedade contemporânea.

Assim como a mediação representa avanços nos estudos da comunicação, pensada enquanto instância de intercâmbio entre os indivíduos e as instituições, o termo midiatização também nos auxilia na compreensão do processo de longa duração da ação social dos meios de comunicação. A mídia como agente de mudança social e cultural é interpretada por Stig Hjarvard (2012) a partir do conceito de midiatização, entendido como uma nova condição social, que vai além do uso de tecnologias e é capaz de submeter outras instituições à sua lógica. $\mathrm{O}$ autor aponta a crescente influência da mídia sobre $\mathrm{o}$ exercício do poder político, na produção e difusão do conhecimento, no debate público e legitimação da ciência e práticas religiosas.

Por midiatização da sociedade, entendemos o processo pelo qual a sociedade, em um grau cada vez maior, está submetida a ou torna-se dependente da mídia e de sua lógica. Esse processo é caracterizado por uma dualidade em que os meios de comunicação passaram a estar integrados às operações de outras instituições sociais ao mesmo tempo em que também adquiriram o status de instituições sociais em pleno direito. Como consequência, a interação social - dentro das respectivas instituições, entre instituições e na sociedade em geral - acontece através dos meios de comunicação. (HJARVARD, 2012, p. 64, grifo do autor)

Para Fausto Neto (2008), a midiatização é um fenômeno no qual a mídia deixa de ser instrumento para ser referência, permitindo novos processos interacionais entre as instituições e os atores sociais. Braga (2006) defende que a midiatização ocorre, tanto na perspectiva microssocial quanto no macrossocial, ao destacar a adaptação e simulação da sociedade à lógica dos meios. Assim, a midiatização ultrapassa a perspectiva técnica e instrumental dos meios, a ponto de ser elaborada a concepção de cultura midiatizada. Nesse aspecto, 
argumenta "que os processos sociais não podem ser entendidos sem a função ativa dos media, uma vez que as ações sociais, os produtos culturais e os programas políticos tornaram-se eles todos mediais". (BASTOS, 2012, p. 70)

A mídia, baseada numa lógica do capital, permeia a vida do cidadão, que faz as suas conexões a partir de condições de acesso e consumo, em que informação e mercado atendem interesses diversos. Sodré (2001, p. 111) define essa nova etapa da organização social de bios midiático, um quarto bios existencial, cujas “[...] práticas sócio-culturais ditas comunicacionais ou midiáticas vêm se instituindo como um campo de ação social correspondente a uma nova forma de vida”. Os discursos no bios midiático são muitos, envolvendo vários atores e a produção de diferentes sentidos. Tomando-se a concepção ampliada de cultura essencialmente semiótica (GEERTZ, 1989), entende-se que os significados de símbolos e contextos publicizados na mídia ajudam a construir as representações partilhadas na sociedade.

A concepção é o 'significado' do símbolo [...] são formulações tangíveis de noções, abstrações da experiência fixada em formas perceptíveis, incorporações concretas de ideias, atitudes, julgamentos, saudades ou crenças. (GEERTZ, 1989, p. 67-68).

Os enquadramentos da mídia mostram que o processo comunicativo envolve diferentes agentes, saberes e partilhas, através de "esquemas de interpretação" (GOFFMAN, 1974), que funcionam como princípios organizadores de interações sociais e auxiliam o indivíduo a se posicionar diante de uma determinada situação.

Mas os enquadramentos não são construídos individualmente, pois podem ser encontrados nos códigos, valores e crenças compartilhados na memória coletiva da sociedade, como afirma Van Gorp (2007). A articulação entre os discursos dos diferentes atores sociais envolvidos no debate público tem na mídia um espaço de disputa entre vários grupos sociais e instituições, para definir a realidade social que vai auxiliar na percepção pública sobre os assuntos. No campo 
da saúde, por exemplo, a luta contra o fumo associada ao discurso científico e suas provas de ameaça à saúde pública, foi fundamental no processo de mudança da moldura individual para um problema de âmbito coletivo, que se tornou um sentido partilhado socialmente e incentivou a implementação de políticas públicas nessa área.

O estudo de Lawrence (2004) sobre o enquadramento da obesidade na cobertura de notícias dos Estados Unidos, de 1985 a 2003, revela que a forma mais convencional de compreender a obesidade é tratá-la como um problema de comportamento individual porque as pessoas relacionam o excesso de peso ao consumo de alimentos calóricos e pouca queima de gordura. Dessa forma, médicos e outros profissionais da saúde insistem continuamente para que as pessoas façam escolhas saudáveis e atividade física para controlar o peso.

Apesar de a obesidade ser um problema grave de saúde pública, a responsabilidade individual limita a ação governamental. Já o enquadramento ambiental coloca o problema da obesidade em um contexto de influências ambientais e opções políticas. Muitos especialistas em saúde pública enquadram a obesidade como sintoma de uma alimentação insalubre, assim como práticas empresariais e governamentais que direcionam comportamentos. A autora conclui que, quanto mais esse discurso se aproxima do polo sistêmico e se distancia do individual, maior a possibilidade de uma ação governamental efetiva na saúde pública. (LAWRENCE, 2004)

Como importante dimensão do contemporâneo, os meios possuem uma centralidade nos processos sociais em função das novas formas de sociabilidade que decorrem da lógica da midiatização, enfraquecendo outras estruturas de mediação, como a família, o trabalho e as conversações interpessoais. A construção social da realidade moldada pela mídia envolve relações de poder, disputas de interesse, aciona capitais econômicos, políticos e sociais, constituindo-se, também, num espaço de luta e negociações entre diferentes atores e instituições.

A centralidade da mídia, segundo Braga (2011), é reforçada, principalmente, pela capacidade da comunicação midiática estar em 
profunda conexão com os espaços não midiáticos, aprofundando sua capilaridade, imbricando-se no social. São características que remetem à necessidade de refletir sobre o papel das mídias nos debates e análises das políticas públicas, especialmente do campo da saúde, que demanda efetiva participação social no exercício da cidadania.

\section{Mídia e agenda pública}

Em uma sociedade marcada pela centralidade da mídia, os veículos de comunicação têm papel relevante na formação da opinião, e por isso, são atores que não podem ser excluídos das análises de políticas públicas. Howlett (2000) e Souza (2006) defendem que a opinião pública tem papel significativo na formação de políticas em estados democráticos, com sua ação ocorrendo de forma direta ou indireta, em função do ciclo da política pública. Essa relação entre opinião pública e política é fortemente percebida no estágio da construção da agenda, pois é nessa etapa que os veículos de comunicação têm grande poder de influenciar ativamente na definição e hierarquização de temáticas e de problemas.

Estudos sobre o agendamento da mídia, cujas bases teóricas estão no trabalho dos pesquisadores americanos McCombs e Shaw (1972), abordam os efeitos dos meios de comunicação de massa sobre o público. Num artigo seminal, os autores afirmam que a mídia pode até nem saber dizer às pessoas o que pensar, mas tem o poder de dizer sobre o que elas devem pensar. Ou seja, as pessoas agendam suas conversas a partir do que a mídia lhes apresenta como a realidade social, destacando o seu poder na construção da agenda pública e, consequentemente, nas políticas públicas que demandam atenção de atores públicos e da sociedade.

Ao explorar a relação da mídia com a política no contexto brasileiro, Lima (2009) afirma que o papel mais importante da mídia está no poder de construir a realidade por meio de suas representações e definir o que é público no mundo contemporâneo. Nesse palco, os 
políticos disputam espaço para dar visibilidade às suas propostas e a própria mídia se consolida como um importante ator político.

Torna-se, assim, mais fácil o exercício pela mídia de algumas das tradicionais funções atribuídas aos partidos, como por exemplo: construção da agenda pública (agendamento); gerar e transmitir informações políticas; fiscalizar as ações de governo; exercer a crítica das políticas públicas; canalizar as demandas da população. (LIMA, 2009, p. 22)

A capacidade da mídia em agendar o debate público vem sendo cada vez mais discutida, diante do declínio de conceitos como objetividade e imparcialidade na produção de conteúdo. Afinal, os meios de comunicação de massa, enquanto empreendimentos corporativos concentrados e controlados por poucas empresas, têm os seus interesses econômicos, políticos, sociais e culturais, conformando-se como um grupo de pressão na defesa dos seus interesses e como espaço para a disputa política e visibilidade na esfera pública. Esse ambiente desperta e canaliza a atenção da audiência para determinadas questões, e não outras. "A cobertura da mídia, porém, não apenas aumenta as percepções e atenção públicas sobre várias questões, mas as constrói, definindo-as como econômicas ou políticas, sociais ou pessoais, radicais ou conservadoras”. (HOWLETT, 2000, p. 175)

Embora a efetiva influência da mídia sobre as políticas públicas ainda seja pouco pesquisada e a maioria dos estudos se concentre na questão do agendamento (PENTEADO; FORTUNATO, 2015), a participação da mídia nos processos tem sido apontada em diferentes análises de políticas públicas. Na etapa de tomada de decisão, o impacto da opinião pública e dos meios de comunicação é relevante, apesar de ser menos expressivo do que na construção da agenda. Mesmo sendo uma influência indireta, uma vez que o número de atores participantes diminui substancialmente em função das barreiras que surgem pela exigência do conhecimento técnico, a influência da mídia apresenta-se mediante os grupos de interesse e partidos 
políticos. Esses atores especificamente buscam apoio público para participar das formulações, por meio da visibilidade das alternativas apresentadas dentro dos espaços midiáticos, ampliando sua representação social.

De forma indireta, a mídia também pode influenciar na tomada de decisão ao atuar na constituição de ambiente de opinião favorável ou contrário a uma alternativa que os governos tenham que adotar. A busca pela visibilidade para obtenção de consenso ou aceitação das opções colocadas em jogo imprime a disputa pelo agendamento e pelos enquadramentos que auxiliem na luta pela legitimidade dessas opções. Ainda que a burocracia tenha um grau de isolamento em relação às pressões da opinião pública, Howlett (2000) aponta que essas barreiras possuem alguma porosidade, em virtude da participação do alto escalão do executivo na implementação das políticas. Assim, apesar dos espaços de controle burocrático, os meios podem atuar na visibilidade ou silenciamento desse processo, acentuando ou atenuando características positivas ou negativas que podem gerar 470 repercussões relevantes no ritmo e dimensão da política. Situação similar ocorre na fase de avaliação, que está cercada de mecanismos e sistemas específicos desenvolvidos e aplicados por especialistas, devidamente regulados por normas que, em geral, fogem ao controle do executivo.

Diversas políticas são defendidas por atores políticos, mesmo em clima de opinião pública hostil. Outras são implementadas por pressão dessa opinião pública. Nesses casos, a visibilidade dos resultados alcançados é condição essencial para a conquista de capital político, o que pode resultar na ampliação ou redução de recursos, com impactos na decisão da continuidade da política. $\mathrm{O}$ aval da opinião pública pode não ser determinante, mas é " [...] uma 'condição de fundo' importante, com base na qual a formação de políticas ocorre e depende." (HOWLETT, 2000, p. 186)

A inclusão de uma demanda social na agenda pública pode implicar em debate ou controvérsia pública na mídia, até que se estabilize enquanto política que propõe a solução de um problema, que 
tem apoio político e da população. Dependendo do enquadramento que vai receber da mídia, os benefícios ou não de tais políticas vão ser percebidos pela população.

Por mais que determinada política alcance resultados positivos do ponto de vista técnico, ela somente poderá ser convertida em capital político para seu realizador se for percebida pela população. Boas políticas com boas avaliações técnicas podem perder sua continuidade caso não obtenham visibilidade positiva e apoio da opinião pública. (PENTEADO; FORTUNATO, 2015, p. 139)

Para Howlett (2000), a relação entre opinião pública e políticas públicas é complexa, não linear e de natureza dialética. Portanto, envolve convencimento, argumentação, persuasão num processo em que tanto a opinião pública afeta as políticas quanto as políticas afetam a opinião pública.

Um óbvio exemplo da dialética opinião-políticas diz respeito ao uso de instrumentos substantivos de políticas baseados em informação, como a propaganda e a educação ou campanhas de conscientização para atingir objetivos governamentais específicos. Os esforços do governo para alterar a opinião e o comportamento do público em questões como beber e dirigir, os riscos das drogas ou do cigarro para a saúde, a necessidade do respeito aos direitos humanos, ou mesmo a promoção de sentimentos de solidariedade nacional ou unidade nacional são conhecidos e documentados nos estudos sobre o tema. (HOWLETT, 2000, p. 183-184)

A visibilidade de determinadas políticas públicas na mídia, desde a sua formulação até os resultados alcançados, além de contribuir para fortalecer ações que poderão solucionar problemas de âmbito coletivo, também amplia o capital político dos atores envolvidos. Aqueles que dispõem de maior poder de decisão têm, consequentemente, mais facilidade de acesso aos meios de comunicação. Nesse 
contexto, discursos hegemônicos tendem a se sobressair enquanto outras vozes são silenciadas nas representações construídas pela sociedade na sua interface com a mídia e a política pública.

Estudos sobre os efeitos do enquadramento na audiência (frame effects) revelam que a maneira de abordar um assunto influencia na opinião dos receptores das mensagens. No campo da psicologia cognitiva, Kahneman e Tversky (1984) mostram como a formulação de problemas pode interferir na escolha das pessoas. Numa proposição imaginária de que os Estados Unidos deveriam anunciar à população ações de combate a uma doença que poderia atingir 600 pessoas, programas foram apresentados para que os participantes da experiência fizessem uma escolha. Em um programa, 200 pessoas poderiam ser salvas e em outro, 400 pessoas poderiam morrer. Apesar das alternativas serem idênticas, $72 \%$ escolheram o primeiro programa, enquanto $28 \%$ preferiram o segundo. A experiência mostrou que o enquadramento de temas influenciou na decisão das pessoas, como um efeito de formulação, sem distorcer ou excluir a 472 informação. A pequena mudança na redação de "vidas salvas" para "vidas perdidas" demonstra a preferência por ganhos e não perdas. (KAHNEMAN; TVERSKY, 1984) Ou seja, por processos subjetivos de percepção de valor e resultados, as pessoas podem escolher a sensação de ganhar em função do seu temor ao risco. Percebe-se a sutileza do enquadramento como instrumento de poder no texto comunicativo, como afirma Porto.

Efeitos de formulação podem ocorrer sem ninguém ter consciência do impacto do enquadramento adotado nas decisões e podem ainda ser explorados para alterar a atratividade relativa das opções. Enquadramentos são, portanto, importantes instrumentos de poder. (PORTO, 2004, p. 79)

No debate sobre a mídia e a proposição de políticas públicas, devemos considerar que a produção de conteúdo, a partir de uma determinada perspectiva, favorável ou não aos atores envolvidos, não 
se trata de uma relação linear da mídia para a audiência. Trata-se de um processo de disputas e relações de poder que envolvem diferentes discursos, de diferentes campos sociais, interessados em defender suas ideias e valores, buscando a repercussão pública de sentidos partilhados socialmente. Sendo assim, a cobertura midiática de políticas de saúde é um elemento revelador do que se passa no espaço social e exige um olhar menos instrumentalizado sobre os meios de comunicação e mais atento aos processos de mediação e midiatização da saúde que emolduram a realidade social. Se, por um lado, essa moldura produz efeitos políticos nem sempre desvinculados de sentidos hegemônicos, por outro, a atuação da mídia como grupo de pressão no jogo político possibilita o exercício da cidadania no debate público e a emergência de temas, situações e novos atores sociais em busca da solução de problemas da sociedade.

\section{Aspectos metodológicos}

Trata-se de pesquisa qualitativa realizada sobre uma base bibliográfica e desenvolvida a partir de recorte em banco de dados estruturado a partir de pesquisas indexadas na Biblioteca Virtual de Saúde (BVS), publicadas no período de 1995 a 2015, com o objetivo de analisar a midiatização da saúde tomada como objeto de pesquisas.

A BVS reúne e disponibiliza, por meio de acesso aberto e gratuito, informações organizadas de 60 bases de dados com produção nacional e internacional sobre ciências da saúde, incluindo áreas como saúde pública, medicina, odontologia, enfermagem, nutrição, psicologia, entre outras. Nessas bases, foram encontrados 63 trabalhos, após busca realizada em 5 de julho de 2015 com os descritores "mídia" e "saúde", incluindo artigos, teses, monografias.

Para esse estudo, elegeu-se os artigos que focaram a abordagem da mídia para temas associados às políticas de saúde, em especial o Sistema Único de Saúde (SUS). Procedeu-se a um recorte dos artigos que tratavam desse tema, a partir da mídia impressa. Assim, dos 44 artigos existentes na base, foram encontrados 14 cujos objetos 
eram relacionados às políticas de saúde. Dentre estes, apenas quatro tiveram como objeto midiático o SUS, nos quais buscou-se identificar a abordagem teórica dos autores para a mídia, ou seja, os posicionamentos epistêmicos, na sua construção narrativa. Este capítulo apresenta a análise das narrativas construídas pelos pesquisadores sobre o SUS na mídia.

A partir de leitura flutuante dos artigos, foram encontrados dois principais posicionamentos epistêmicos dos pesquisadores frente à mídia: a perspectiva crítico-reflexiva e a visão instrumental. Estes foram assim definidos:

a. Perspectiva crítico-reflexiva: os meios são concebidos como fenômenos socioculturais, que também formatam a sociabilidade contemporânea e, por isso, constituem-se em privilegiados espaços de disputa de sentidos e de poder. Está preocupada em entender os modos como a mídia atua sobre as políticas públicas e contribui para a construção de uma ordem discursiva para as mesmas em meio à disputa simbólica no campo social. Fundamenta-se em teorias de perspectivas histórico - estrutural, estruturalista ou pós-estruturalista, abrangendo a teoria crítica, teoria da ação comunicativa, a hermenêutica, a análise de discurso, incluindo autores como Jesús MartínBarbero, Pierre Bourdieu, Michel Foucault, Jürgen Habermas, dentre outros, em que a categoria "poder" ganha relevo. Inclui os estudos sobre produção de sentido, fundamentados em diversas perspectivas da análise do discurso, bem como estudos que discutem a influência da mídia no agendamento do debate público;

b. Perspectiva instrumental: os meios de comunicação são compreendidos como instrumento a serviço de forças políticas e econômicas e não como um campo que reproduz o que se passa no espaço social. Tem sido criticada por diversos autores, pelo seu caráter tecnicista e linear da comunicação, apesar de sua grande influência nos estudos de comunicação. 
Trata-se, segundo Habermas (1980) da "lógica instrumental" de caráter essencialmente técnico, com finalidade de dominar a realidade. Entende que a mídia tem o poder de informar, difundir informações e portanto pode assumir, ocupar o lugar de educador ou de utilidade pública.

\section{Resultados e discussão}

A análise de narrativas dos pesquisadores sobre mídia e saúde e as políticas de saúde relacionadas à construção do SUS, em particular, revela a presença de temas como o poder do discurso midiático e políticas de saúde na mídia.

\section{Estudos sobre SUS}

As narrativas dos pesquisadores sobre o SUS na mídia abordaram facetas distintas do sistema de saúde, tanto as formas como o sistema é mostrado na mídia quanto aspectos específicos da integralidade da atenção à saúde, do modelo assistencial, e da política de provimento de pessoal de saúde, que teve grande repercussão na sociedade brasileira, o Programa Mais Médicos. Dentre os artigos encontrados nessa categoria, dois são estudos descritivos de caráter quali-quantitativos, um qualitativo e outro quantitativo.

\section{Formas de abordagem da mídia}

A análise das abordagens da mídia adotadas pelos pesquisadores em suas narrativas, na categoria SUS, permite-nos discutir as duas perspectivas teóricas dos estudos de mídia apontadas acima, destacando particularidades:

a. a análise crítico-reflexiva da mídia;

b. visão instrumental da mídia.

São vários os autores que fundamentam os estudos críticos-reflexivos sobre a mídia como produtora de sentido, encontrando-se 
os mesmos nos campos e interfaces da análise de discurso na linguística, semiótica e hermenêutica. São importantes nessas análises: o linguista francês Èmile Benveniste; o linguista britânico, Norman Fairclough; a linguista brasileira, Eni Orlandi; os filósofos franceses, Paul Ricoeur e Michel Foucault; o filósofo e sociólogo argentino Eliseu Verón, dentre outros.

A narrativa do artigo "Crise dos serviços de saúde no cotidiano da mídia impressa” (MENEGON, 2008), o primeiro do conjunto que é objeto de estudo deste trabalho, de cunho quali-quantitativo, apresenta uma análise do ponto de vista da Psicologia Social de um corpus de 735 notícias acerca da crise dos serviços de saúde publicadas em jornais de Campo Grande/MS, em 2005, para problematizar "o posicionamento do hospital como lócus privilegiado no cuidado com a saúde e as formas verticais de negociação”. (MENEGON, 2008, p. 32)

O entendimento sobre a mídia, presente neste estudo, é fundamentado em dois autores da área de análise de discurso e comuni476 cação: Fairclough, 1995 e Thompson, 1995, posicionando a mídia no cotidiano das pessoas como coprodutora de sentidos e de subjetividades.

Fairclough é um pesquisador da Universidade de Lancaster, no Reino Unido, reconhecido como um dos fundadores da Análise Crítica do Discurso. Os seus estudos colocam a categoria "poder" na centralidade para a realização da crítica social. Na introdução do seu livro Language and power, Norman Fairclough (1989, p. 1, tradução nossa) afirma :

Este livro é sobre a linguagem e poder, ou, mais precisamente sobre as conexões entre o uso da linguagem e relações desiguais de poder, particularmente na Grã-Bretanha moderna. Eu escrevi isso para duas finalidades principais. A primeira é mais teórica: para ajudar a corrigir uma subestimação generalizada da importância da linguagem na produção, manutenção e alteração das relações sociais de poder. A segunda é mais prática: para ajudar a aumen- 
tar a consciência de como a linguagem contribui para o domínio de algumas pessoas - por outros, porque a consciência é o primeiro passo para a emancipação. ${ }^{1}$

Jonh Thompson é também um autor cujas pesquisas se situam no campo da Teoria Social Crítica, voltadas preferencialmente ao estudo dos meios de comunicação de massa e da cultura e ideologia.

Segundo Costa (1997), em resenha do trabalho citado pela autora, Thompson e Fairclough estariam próximos no que se refere ao entendimento entre linguagem e estrutura social.

[...] Norman Fairclough [...] nos fala da relação dialética entre estrutura social e discurso. $\mathrm{O}$ discurso é moldado pela estrutura social, mas é também socialmente constitutivo. O mesmo se pode dizer, concordando com Thompson, das formas simbólicas em geral, e da ideologia em particular. A ideologia está relacionada, desse modo, a uma determinada estrutura social, mas, por outro lado, é igualmente constitutiva dessa estrutura. (COSTA, 1997, p. 144)

Aproximando-se à perspectiva crítico-reflexiva, a mídia assume para os autores uma atuação relevante de caráter ideológico, na medida em que pode gerar repercussões/valorizações positivas ou negativas (obscurecimentos, depreciações) na produção de sentidos sobre saúde e doença que, por extensão, podem influenciar o processo de avaliação de uma política. Amparada em outros referenciais como Antonia C. Lyons e Mary Jane Spink a pesquisadora Menegon (2008) considera que a mídia pode também reafirmar modelos e

This book is about language and power, or more precisely about connections between language use and unequal relations of power, particularly in modern Britain. I have written it for two main purposes. The first is more theoretical: to help correct a widespread underestimation of the significance of language in the production, maintenance, and change of social relations of power. The second is more practical: to help increase consciousness of how language contributes to the domination of some people - by others, because consciousness is the first step towards emancipation." 
práticas tradicionais e discriminatórias. Contudo, a narrativa não evidencia como a mídia opera e tampouco aprofunda a contextualização das relações (sociais, econômicas e políticas) que permeiam e influenciam a mídia impressa no processo de implementação das políticas de saúde.

Mas, para a autora, a análise das redescrições da situação de crise nos serviços de saúde de Campo Grande/MS, veiculada na mídia impressa, evidencia a ausência dos pressupostos da humanização do cuidado e integralidade da atenção à saúde, preconizados como eixos norteadores para promover a implementação do SUS. Essa ausência se expressa tanto no âmbito dos serviços de saúde (microrrelações) quanto da gestão, no exercício da descentralização de políticas públicas e centralização de recursos como poder, verbas e decisões (macrorrelações), o que na concepção da autora implica na instalação de problemas como não garantia dos direitos à saúde, condições de trabalho inadequadas, e falta de diálogo, de comunicação e de participação popular efetivos.

$478 \quad$ Um segundo estudo na perspectiva crítico-reflexiva de análise da mídia é realizado no ensaio intitulado $A$ comunicação midiática e o sistema único de saúde", datado de 2000, de autoria do jornalista Valdir de Castro Oliveira, docente da Universidade Federal de Minas Gerais (UFMG) e doutor em Ciências da Comunicação. O autor discute a relação entre as redes de comunicação midiática e a constituição simbólica das políticas públicas de saúde representada pelo SUS; para tanto, fundamenta-se em autores como Milton Santos ; Manuel Castells; Pierre Bordieu ; Mikhail Bahktin; e Néstor Garcia Canclini ; todos de inspiração marxista, nos campos da sociologia, da filosofia, da linguagem e da comunicação.

A narrativa focaliza a análise nos modos de interpretação e reconfiguração da mídia sobre o campo da saúde, considerando as relações de poder e o contexto político-comunicacional, repleto de conflito, jogos de interesses e luta política na sociedade. $\mathrm{O}$ autor está preocupado com o modo como questões comunicacionais e informacionais afetam as formas de percepção da população sobre o 
SUS enquanto uma política pública de saúde. (OLIVEIRA, 2000) Sua narrativa assume o pressuposto de que o SUS só efetivará suas proposições ético-políticas se houver um amplo conhecimento por parte da população que lhe permita reconfigurar seu entendimento sobre a saúde pública brasileira.

Nesse sentido, constrói-se uma argumentação sobre a necessária organização de diferentes modalidades comunicacionais e fluxos informacionais (midiáticos e não midiáticos) para o controle social, a gestão, implementação e viabilização do sistema. Critica a divulgação de imagens e informações sobre as mazelas e dificuldades do setor, que levam à construção de uma ordem simbólica pouco reflexiva sobre o SUS, ao tempo em que a construção imagética do setor privado é tolerante e parcimoniosa, não contribuindo para que o público possa compreender que os segmentos são complementares e não antagônicos. Desse modo, a mídia contribui para fragilizar politicamente o SUS naquela conjuntura e fortalecer as instâncias privadas junto à opinião pública.

Dispõe-se no texto a "[...] entender a lógica que preside a construção das mensagens e das imagens produzidas pelas mídias em relação à sociedade e ao SUS” (OLIVEIRA, 2000, p. 72) O autor reafirma a ideia de que nossas formas de perceber o mundo e viver o cotidiano são indissociáveis dos sistemas de comunicação midiática que nos induz "a relacionamentos com as redes comunicacionais geradas ou tornadas possíveis pelo telefone, fax, televisão, cinema, jornais, televisão, satélites de telecomunicações, correio eletrônico, internet" (OLIVEIRA, 2000, p. 73), de modo cada vez mais veloz. É esse novo ambiente simbólico que permite ampliar as nossas bases cognitivas para a interpretação, mas também forjar várias espécies de mimetismo informacional e cognitivo, diz o autor.

Oliveira (2000), em sua narrativa sobre a mídia, afirma que esta aparece de um lugar de poder a construir de modo determinante as relações sociais assimétricas e de sujeitamento social, o que é

[...] obtido graças a um eficiente jogo discursivo, no qual a pedagogização das mensagens midiáticas tende a criar 
a ilusão de transparência e naturalizar as relações sociais, deixando de revelar que o sistema econômico é um espaço organizatório da vida social. Reforça-se, na verdade, o deslocamento do sujeito da enunciação para as zonas sombrias do processo comunicativo, esquecendo que a razão de ser de um discurso não reside na competência propriamente lingüística do locutor e sim no lugar de onde ele é socialmente proferido, reiterando formas autorizadas de discurso, como nos lembra Bordieu (1994). (OLIVEIRA, 2000, p. 73)

O autor critica, portanto, a visão instrumental da mídia, ressaltando que esta é "responsável por reproduzir as relações sociais assimétricas e atribuir sentidos aos mundos, em conformidade com a dinâmica cultural da sociedade contemporânea" (OLIVEIRA, 2000, p.74) e portanto constituindo-se num "[...] campo de forças no qual diferentes atores sociais buscam fazer prevalecer determinados sentidos através de suas práticas discursivas, tornando-o um lócus de tensão permanente" (OLIVEIRA, 2000, p.74). Trata-se da disputa por hegemonia de sentidos, ressalta o autor. Contudo o pesquisador não vê a mídia com um sentido de externalidade à sociedade em que atua, entendendo que a interação dos grupos sociais com a mesma conforma novas formas de sociabilidade e dão concretude às estratégias políticas dos grupos sociais.

Se a mídia é hoje o lugar privilegiado de visibilidade pública e legitimidade das forças atuantes na sociedade, uma melhor compreensão do processo midiático só pode ser obtida se for conjugada com uma análise de outros processos interacionais que ocorrem simultaneamente fora do universo das mídias. (OLIVEIRA, 2000, p.74)

Desse modo, a narrativa do pesquisador conduz a uma visão dinâmica e complexa da mídia na sociedade contemporânea, em que a política sofreu um deslocamento dos partidos para o universo midiático. Na conclusão do estudo, destaca que somente quando 
os movimentos de lutas sociais em defesa do SUS conseguirem entrar na pauta das redes midiáticas é que será possível mudar a imagem do SUS na mídia e "[...] desmontar uma construção discursiva sectariamente corrosiva e conduzida por grupos contrários a ele.” (OLIVEIRA, 2000, p.79)

No terceiro estudo aqui analisado, Taberner e colaboradores (2007), interpreta a mídia de uma perspectiva instrumental, tomando-a como fonte de informação e conhecimento útil para a sociedade, ou seja, como um veículo utilitário para auxiliar na busca por serviços e outras necessidades de informação. $O$ limite dessa visão é acentuar a credibilidade na mídia e pautar as políticas de saúde a partir das "verdades" mostradas em suas narrativas, o que significa ignorar o viés que ela introduz ao noticiar certos fatos e ocultar outros, dar visibilidade a certas vozes em detrimento de outras.

Dessa perspectiva, Taberner e colaboradores (2007), em estudo transversal retrospectivo "A influência da mídia nos atendimentos cardiológicos de urgência: o caso Bussunda”, discute como as repercussões na imprensa não especializada do fato noticioso - a morte 481 por infarto do miocárdio de um importante personagem da mídia nacional, o Bussunda - impactaram no serviço de atendimento de emergência do Instituto do Coração (InCor).

Ao abordar a relação mídia e sistema de saúde, Taberner e colaboradores (2007) não fundamentam seus argumentos em teorias das mídias e da comunicação, mas em autores de áreas biomédicas. O objeto tomado como estudo pelos pesquisadores é a constatação de que a literatura sobre mídia e saúde destaca que a mídia, de um lado valoriza "demasiadamente resultados sem significado médico", e de outro, divulga "tratamentos sem comprovação científica". Com seu estudo esperam trazer uma análise estatística de dados concretos.

A prática sensacionalista da mídia é estudada por diversos autores, tendo como um dos recursos a ampla divulgação de morte de famosos. Nesse caso, Bussunda, o morto famoso, ingressaria assim “[... no mundo do espetáculo e passa a ter sua vida editada e reeditada para usufruto e exemplo de quem permaneceu”. (RONDELLI; 
HESCHMANN, 2000, p. 5) No caso, o usufruto é servir de exemplo para a proteção da saúde, com discurso ideológico fundamentado no efeito medo da morte. Tal interpretação surge no artigo, da seguinte maneira:

O aumento de atendimentos por sintomas cardiológicos pode estar relacionado à identificação da população com o perfil do personagem vítima de um infarto ou com a divulgação em nível nacional dos sintomas da doença coronariana aguda. Os achados de nosso estudo confirmam esta hipótese uma vez que não observamos aumento paralelo do número de internações ou de diagnósticos de infarto do miocárdio, ao contrário dos estudos que analisaram catástrofes como bombardeios e terremotos onde ocorreu aumento real da incidência da doença (maior número de internações) e de óbitos a ela relacionados. (TABERNER et al., 2007, p. 336-337)

Assim, os autores constatam que houve mudança do perfil dos usuários que recorreram ao serviço no período, em menor faixa etária e do sexo masculino, em vez do habitual feminino, sugerindo que isso se deva à identificação desse grupo populacional com o personagem vítima do infarto, um famoso ator da Rede Globo, principal rede da televisão brasileira, que teve sua morte espetacularizada, produzindo esse e outros efeitos, embora o estudo não tenha se voltado para o campo da recepção.

A narrativa de Taberner e colaboradores (2007) reafirma também a tendência alarmista da mídia, uma vez que ao aumento da procura dos serviços não correspondeu o aumento de casos de doença coronariana, como ocorre em outras situações, mas estimulou a procura pelo serviço, pela indução do medo:

A percepção de que a doença coronariana tem um curso clínico silencioso e que pode ter como primeira manifestação um evento fatal, pode ter provocado medo na população geral. Isso levou à grande procura do serviço de emer- 
gência do InCor, assim como provavelmente em todo o país. [...] (TABERNER et al., 2007, p. 337, grifo nosso)

Pode-se perceber nas entrelinhas da narrativa o entendimento da mídia a partir de uma perspectiva instrumental, na medida em que o texto sugere restringir a atuação dos meios de comunicação sobre as políticas de saúde a um mero meio de divulgação de notícias. Dessa forma, os autores não inserem no debate proposto uma contextualização sobre o papel desenvolvido pela indústria da mídia em uma estrutura de mercado, permeada pela disputa de interesses, e a interação com atores diversos, incluindo os atores do campo da saúde.

Os pesquisadores argumentam que a relação mídia e sistema de saúde é pouco explorada, e apontam para a perspectiva da necessidade de uma mídia colaborativa que possa contribuir com as políticas de saúde. Tal visão mostra-se ingênua e evidencia o não entendimento da natureza empresarial e da complexa dinâmica de construção discursiva, que envolve a cobertura midiática face ao seu forte compromisso com determinados setores da sociedade. (HERNANDES, 2006) Nesse sentido, admite-se um papel de utilidade pública para 483 a mídia com respeito às políticas de saúde. Os achados do estudo de Taberner e colaboradores (2007, p. 337) indicam que houve associação entre a divulgação pela mídia dos sinais e sintomas do infarto agudo do miocárdio que levou a óbito personagem da mídia brasileira (Bussunda) e o aumento do quantitativo de atendimentos e alterações do perfil demográfico dos indivíduos que procuram a emergência cardiológica do InCor. A partir dos achados, os pesquisadores recomendam uma relação mais profícua com a mídia.

Exemplos como este salientam a importância da necessidade da otimização da relação entre a mídia e o sistema de saúde, envolvendo jornalistas e médicos. Esta relação, se mais bem explorada, pode permitir o conhecimento do comportamento da população e a elaboração de estratégias adicionais para prevenção cardiovascular. (TABERNER et al., 2007, p. 337, grifo nosso) 
O quarto estudo analisado está associado à perspectiva crítico -reflexiva, pois utiliza a hipótese da agenda setting para demonstrar a participação da mídia no debate público, com base na cobertura midiática do Programa Mais Médicos. Trata-se de narrativas em que os pesquisadores demonstram que o jornalista influencia com seu discurso a veracidade do discurso da mídia, reduzido-o à opinião do jornalista, ignorando a estrutura organizativa em que ele se move, ou seja, jornal enquanto empresa.

Em "Jornais Folha de S. Paulo e Correio Braziliense: o que dizem sobre o programa mais médicos?”, Morais e colaboradores (2014) contextualizam esse programa instituído no Brasil através da Lei n. ${ }^{\circ} 12.871$, de outubro de 2013, frente à necessidade de provimento de médicos no SUS, em diferentes regiões do país. Trata-se de estudo descritivo, de base quali-quantitativa, em que foram analisadas 262 matérias jornalísticas da Folha de S. Paulo e 101 do Correio Braziliense, relacionadas ao referido programa, no período de julho a setembro de 2013.

$484 \quad$ Morais e colaboradores (2014, p. 115) em sua narrativa, destacam que

Desde o anúncio do Programa Mais Médicos, vários foram os debates por diferentes sujeitos sociais e matizes ideológicas, entretanto o confronto mais acirrado se deu entre o representante do governo, e sua base de sustentação no Congresso Nacional e as corporações médicas, sobretudo o Conselho Federal de Medicina.

Salientam ainda que esse debate foi ampliado pela mídia que divulgou as teses favoráveis e desfavoráveis ao Programa.

O Programa Mais Médicos repercutiu nas entidades médicas, no governo, na mídia e sociedade, dando subsídio para jornais publicarem notícias sobre as fases do programa, disputas corporativas e negociações relacionadas a temas abrangentes como educação, política e economia do país. (MORAIS et al., 2014, p.116) 
Ao explicitarem os diversos tipos de matérias analisadas - reportagem (217), opinião (130), charge/imagem (10) e crônica (6) -, Morais e colaboradores (2014, p.116) identificam os distintos posicionamentos dos atores sociais presentes nas notícias, evidenciando

Assim, tomando como referencial de análise o caráter do título das publicações, isto é, o posicionamento favorável ou desfavorável ao Programa Mais Médicos, os pesquisadores observaram que a Folha de S. Paulo apresentou 110 títulos negativos e o Correio Braziliense 50 publicações ditas neutras. Contudo, ao examinar o caráter das notícias

[...] nota-se que 178 (49\%) destas são pessimistas, mostrando que havia jornalistas e leitores contrários ao programa. Percebeu-se que nos dois jornais a maioria das reportagens era escrita pelos mesmos jornalistas, por este motivo as publicações possuíam percepções parecidas. As notícias de cunho 'neutro' representaram 101 (28\%), e as 'otimistas' 83 (23\%), a soma destes possui valor maior que a categorização 'pessimista'. (MORAIS et al, 2014, p. 118)

$\mathrm{O}$ artigo se fundamenta na teoria da notícia de Traquina, 2005, trazendo desse autor a ideia de que uma notícia “[...] tem valor pelos critérios de noticiabilidade que orientam o processo de produção das notícias. (MORAIS et al., 2014, p. 119) Os autores atribuíram valor negativo a muitas publicações, pois para se ter valor notícia, "a publicação deveria conter informações relevantes que incitassem o leitor a ler e comentar”. (MORAIS et al., 2014, p. 119) Assim, atribuíram valor elevado "no Folha de São Paulo, em julho pela instauração da Medida Provisória n ${ }^{\circ} 621$ neste mês” fato que desencadeou “[...] o início dos debates entre a categoria médica e polêmica sobre os motivos além daqueles expostos pelo Ministério da Saúde como justificativa para implantação do Programa”. (MORAIS et al., 2014, p. 117) No estudo, classificou-se $56 \%$ das matérias com valor notícia positivo, no jornal Folha de S. Paulo e no Correio Braziliense. 
Essa abordagem permitiu perceber mais do que a atuação do jornalista e do jornal na mediação do debate público acerca de uma política de saúde, e influenciar a opinião pública a partir do posicionamento do jornalista, assim como do jornal, posto que é evidente que privilegiou um conjunto de atores sociais, atribuindo maior espaço às suas reivindicações e questionamentos, e limitou a discussão sobre os possíveis resultados dessa política para a melhoria da saúde de toda a população.

Os pontos mais discutidos pelos jornalistas eram aqueles que diziam respeito ao posicionamento de médicos representados por seus conselhos profissionais, de modo que a visão de como o programa afetaria a vida dos brasileiros ficou em segundo plano. Outro ponto a se destacar é que a mídia não explicita a complexidade dos fatos, mas sim as opiniões de alguns jornalistas tomam maior relevo. (MORAIS et al., 2014, p. 120, grifo nosso)

Ao tecer uma análise sobre o discurso midiático acerca da crise dos serviços de saúde, especialmente em relação às crises hospitalares, Menegon (2008, p. 39) considera que a mídia impressa reforça e confere visibilidade ao modelo hospitalocêntrico, colocando em posição periférica a "forma ampliada de cuidar da saúde" que inclui práticas de prevenção de doenças e promoção da saúde. A autora reconhece o papel da mídia na circulação de sentidos sobre doença e atenção à saúde, sinalizando que muitos dos sentidos de saúde foram historicamente produzidos em diferentes esferas sociais e ainda contribuem para reafirmar e dar visibilidade ao modelo biomédico-hospitalocêntrico como modelo de atenção à saúde e lócus de prática de saúde privilegiados. Nesse sentido, afirma que

A ruptura com essa associação e a abertura ao diálogo é um grande desafio para que o Sistema Único de Saúde (SUS) se constitua em um sistema público, pautado pelos eixos da integralidade e da humanização na atenção à saúde que, no debate atual, formatam propostas defendidas 
pela Saúde Coletiva e outras áreas que atuam na saúde, entre eles a Psicologia. (MENEGON, 2008, p. 32)

Considera-se incipiente a circulação de novos sentidos de atenção à saúde que são vinculados às propostas de integralidade e humanização do cuidado em saúde. Contudo, esses sentidos ainda se encontram restritos à área da saúde, a despeito de tais propostas serem adotadas enquanto eixos norteadores para promover o avanço do SUS e como estratégias de governabilidade em saúde. (MENEGON, 2008)

[...] observamos que, assim como o jornal dá maior visibilidade às notícias que envolvem procedimentos hospitalares, também para a população em geral, cuidar da saúde está associado ao hospital e à procura de serviços de saúde para sanar doenças já instaladas e cuidados emergenciais. Ou seja, um dos aspectos da lógica da integralidade que inclui a prevenção de doenças e a promoção da saúde, ainda não faz parte do cotidiano da maioria de nossa população [...]. (MENEGON, 2008, p. 37)

Seguindo os critérios de noticiabilidade de Traquina, 2005, isto é, reconhecendo fatores que agregam valor como notícia em saúde, Menegon (2008) aponta em sua narrativa temas relacionados à "emergência e complexidades hospitalares". Nesse aspecto, Morais e colaboradores (2014), em pesquisa que avalia a forma como a mídia circula informações sobre o Programa Mais Médicos para a sociedade, afirma ter encontrado em seu estudo muitas publicações com o valor negativo, pois não apresentavam informações que instigassem o leitor a uma leitura crítica. Para Oliveira (2000, p. 77),

A notícia não circula no espaço público pelo seu valor em si, mas por ser uma mercadoria dotada de valor de troca. Através de sua forma narrativa e de um sistema logotécnico cada vez mais sofisticado, o relato jornalístico seleciona, amplia e hierarquiza os acontecimentos, permitindo 
que o cidadão comum articule seu cotidiano social e nele se reconheça.

Os repertórios utilizados pela mídia impressa para tratar do Programa Mais Médicos incluem "fases do programa, disputas corporativas e negociações relacionadas a temas abrangentes como educação, política e economia do país”, tendo como vozes autorizadas a falar sobre o assunto governo (ministério, prefeitos), entidades médicas, sociedade e mídia. (MORAIS et al., 2014, p. 116) Já para relatar a situação de crise no sistema de saúde, os repertórios retratam situações limite dos serviços hospitalares; mensagens funcionais (orientações e recomendações de autoridades do setor), desvios do SUS (falhas no atendimento, conduta inadequada de profissionais, escândalos etc), medidas de intervenção emergenciais, verticalizadas e autoritárias; e as contradições presentes nas negociações que buscam solucionar a crise, a exemplo da descentralização das políticas públicas e a concentração de verbas e de poder. (MENEGON, 2008; OLIVEIRA, 2000) Assim, ao descrever a dinâmica do posicionamento dos atores sociais envolvidos e/ou afetados na situação, Menegon (2008) explicita as vozes autorizadas a falar sobre a crise dos serviços de saúde: governador, prefeito, gestores da saúde nas esferas federal, estadual e municipal, ministério público, médicos e pacientes - estas últimas vozes quase sempre assumindo posição figurativa/passiva. Chama à atenção a ausência/omissão de vozes das instâncias de participação e controle social nesse contexto.

A esse respeito, Oliveira (2000) lembra o caráter empresarial da mídia nacional, organizada em rede que monopoliza a fala, constitui a agenda pública, exacerba seu papel de ator político e imprime na notícia seu valor de troca. Sendo favorável aos grupos de poder, produzem notícias sobre os desvios do SUS, em detrimento das mudanças substantivas que esse sistema pode produzir na sociedade. Assim, o que é público "[...] aparece como sintoma de ineficiência, desperdício, mau atendimento ou corrupção, como se fosse portador de uma doença crônica, generalizada e sem cura" e o que é privado é "valorado positivamente, juntamente com determinadas ações 
desenvolvidas por entidades públicas não estatais ou não-governamentais". (OLIVEIRA, 2000, p. 76)

Essa mídia, contudo, não costuma mostrar a ocupação de cargos públicos por representantes do setor privado, $\mathrm{e}$

[...] contribui para que as idéias de cidadania e de espaço público sejam restringidas ao plano da oferta de serviços e consumo pelo Estado e pelas empresas privadas e não pela inserção substantiva do cidadão e dos grupos sociais na organização e reorganização do aparato de Estado e da economia. (OLIVEIRA, 2000, p. 77)

\section{Considerações finais}

É evidente que o debate sobre as políticas de saúde no Brasil ocupa uma posição ainda pouco privilegiada na mídia nacional e no imaginário popular. A despeito de o tema saúde ser frequentemente abordado na mídia, são raros os momentos em que o debate sobre políticas de saúde ganha visibilidade nas mesmas. Boa parte da população desconhece o que seja uma política de saúde e as ações de saúde a que tem direito, o que em parte poderia ser revertido se $\mathrm{o}$ espaço dedicado pela mídia à reflexão crítica dessa temática fosse ampliado, alcançando todos os segmentos sociais.

A mídia além de participar da definição da agenda pública e construção do imaginário social, pode influenciar a proposição de temas para a formulação de políticas e também afetar a credibilidade de uma política de saúde. Assim, no escopo da saúde, as informações veiculadas na mídia quase sempre são fundamentadas em elementos factuais, dão visibilidade a descobertas científicas e ao desenvolvimento de tecnologias, a problemas do estado de saúde da população, a falhas do sistema de saúde, pautando temas para a esfera pública. Essas informações, a depender do modo como são apresentadas e circulam, podem contribuir positivamente para potencializar o debate sobre saúde e qualidade de vida, favorecer a prevenção de 
enfermidades, enfatizar a necessidade de maior controle social para a melhoria do sistema; quanto podem reforçar estereótipos sobre determinadas condições e acepções de saúde que se distanciam do conceito ampliado de saúde e da autonomia do sujeito no cuidado em saúde, noções caras à saúde coletiva.

Pondera-se que a análise de narrativas de pesquisadores sobre o tema "SUS na mídia" aponta a presença de formas de abordagens sobre mídia nas perspectivas crítico-reflexiva e instrumental. As narrativas evidenciam os repertórios utilizados pela mídia para retratar o SUS: mensagens funcionais de autoridades do setor saúde, desvios de qualidades do SUS e medidas de intervenção sobre situações-problema.

A literatura aponta entre os problemas dos pesquisadores na análise do jornalismo, a confusão, a mistificação e ingenuidade em torno da discussão do que seja a verdade. Há que se considerar a falta da compreensão não só da mídia como ator social, como também das especificidades da mídia brasileira, e da luta política que se dá nas arenas da Reforma Sanitária Brasileira. Estudos mais contundentes 490 e aprofundados sobre a participação da mídia nas diversas etapas do ciclo de políticas públicas de saúde, associando ambiente político, atores, etapas de implementação e avaliação à cobertura jornalística são necessários para não incorrer em análises mais simplistas que apenas percebem os meios como instrumentos. Essa percepção bloqueia as diversas oportunidades, inclusive fora dos grandes meios de comunicação, que podem ser construídas no âmbito das organizações sociais e profissionais, da comunicação pública, das assessorias de comunicação das instituições de saúde e do SUS e dos próprios meios hegemônicos.

Sabe-se que a mídia, inserida numa estrutura de mercado, está vinculada a interesses diversos, o que já coloca em questionamento a sua neutralidade/imparcialidade na produção de conteúdo. Como integrante do processo de construção social da realidade, deve-se considerar o poder da mídia na definição da agenda pública que, potencializada pelo processo de midiatização da sociedade, torna-se um dos mais importantes atores sociais no exercício do poder po- 
lítico. Assim, torna-se referência nos processos interacionais entre as instituições e os atores sociais, que disputam e negociam na lógica dos meios de comunicação em busca de visibilidade e apoio aos seus interesses. Nesse ambiente, políticas públicas de saúde, como o SUS, ganham visibilidade favorável ou desfavorável, a depender dos discursos que se sobressaem no jogo político e tem repercussão nos sentidos partilhados socialmente. Nesse contexto, o discurso da Saúde Coletiva tem o desafio de ampliar a sua participação na arena política, contribuindo para uma mídia mais plural e democrática, aberta a dar visibilidade às conquistas e desafios que o SUS enfrenta para sua construção e mesmo preservação.

\section{Referências}

BASTOS, M. T. Medium, media, mediação e midiatização: a perspectiva germânica. In: JANOTTI JUNIOR, J.; MATTOS, M. A.; JACKS, N.

(Org.). Mediação \& midiatização. Salvador: EDUFBA; Brasília, DF: Compós, 2012. p. 53-77.

BRAGA, J. L. Midiatização como processo interacional de referência. In: XV ENCONTRO ANUAL DA ASSOCIAÇÃO DOS PROGRAMAS DE PÓS-GRADUAÇÃO EM COMUNICAÇÃO-COMPÓS, 15., 2006, Bauru. Anais... Bauru: Compós, 2006.

BRAGA, J. L. Dispositivos Interacionais. In: ANUAL DA ASSOCIAÇÃO DOS PROGRAMAS DE PÓS-GRADUAÇÃO EM COMUNICAÇÃOCOMPÓS, 20., Porto Alegre, 2011. Anais... Porto Alegre: COMPÓS, 2011.

COSTA, A. F. Thompson, J. B. Ideologia e cultura moderna: teoria social crítica na era dos meios de comunicação de massa. Petrópolis, RJ: Vozes, 1995. Resenha. Cadernos de Linguagem e Sociedade, v. 3, n. 1, 1997. Disponível em: <http://periodicos.unb.br/index.php/les/article/ download/1325/981>. Acesso em: $15 \mathrm{dez} .2015$.

DINES, A. Ministério Público inicia o desmonte do "coronelismo eletrônico”. Observatório da Imprensa. Observatorio da Imprensa, [S.1.], n. 877, nov. 2011. Disponível em: <http://observatoriodaimprensa. 
com.br/interesse-publico/ministerio-publico-inicia-o-desmonte-docoronelismo-eletronico/>. Acesso em: 25 nov. 2015.

DUNN, W. N. Public pozicy analysis: an introduction. Englewood Cliffs, N.J.: Prentice-Hall, 1981.

ENTMAN, R. M. Framing: toward clarification of a fractured paradigm. Journal of Communication, New York, v. 43, n. 4, p. 51-58, 1993.

FAUSTO NETO, A. Fragmentos de uma analítica da midiatização. Matrizes, São Paulo, v. 1 n. 2, 2008. Disponível em: <http://www. matrizes.usp.br/index.php/matrizes/article/view/88>. Acesso em: 12 fev. 2014.

FAIRCLOUGH, N. Language and power. New York: Longman, 1989. GAMSON, W. A.; MODIGLIANI, A. Media discourse and public opinion on nuclear power: a constructionist approach. The American Journal of Sociology, Chicago, v. 95, n. 1, p. 1-37, 1989.

GEERTZ, C. A interpretação das culturas. Rio de Janeiro: LTC, 1989. GOFFMAN, E. Frame analysis: an essay on the organization of experience. New York: Harper, 1974.

HABERMAS, J. Técnica e ciência enquanto ideologia. In: BENJAMIN, W. et al. Textos escolhidos. Tradução de Zeljiko Loparic e Andréa Maria Altino de Campo Loparic. São Paulo: Abril Cultural, 1980. p. 313-343. (Coleção Os pensadores).

HERNANDES, N. A mídia e seus truques: o que jornal, revista, TV, rádio e internet fazem para captar e manter a atenção do público. São Paulo: Contexto, 2006.

HJARVARD, S. Midiatização: teorizando a mídia como agente de mudança social e cultural. Matrizes, São Paulo, ano 5, n. 2 p. 53-91. jan./ jun. 2012.

HOWLETT, M. A Dialética da opinião pública: efeitos recíprocos da política pública e da opinião pública em sociedades democráticas contemporâneas. Opinião Pública, Campinas, v. 6, n. 2, p. 167-186, 2000. KAHNEMAN, D.; TVERSKY, A. Choices, values and frames. American Psychologist, Washington, v. 39, n. 4, p. 341-395, 1984. 
KELLNER, D. A cultura da mídia: estudos culturais: identidade e política entre o moderno e o pós-moderno. Tradução de Ivone Castilho Benedetti, Bauru: EDUSC, 2001.

LAWRENCE, R. G. Framing Obesity: the Evolution of news discourse on a public health issue. Harvard international journal of press/politics, Cambridge, v. 9, n. 3, p. 56-75, 2004.

LIMA, V. A. de. Revisitando as sete teses sobre política e mídia no Brasil. Ensaio Comunicação \& Sociedade, São Paulo, ano 30, n. 51, p. 13-37, jan./ jun. 2009.

MARTÍN-BARBERO, J. Dos meios às mediações: comunicação, cultura e hegemonia. 4. ed. Rio de Janeiro: Editora UFRJ, 2006.

MOURA, M. Jesús Martín-Barbero: as formas mestiças da mídia.

Pesquisa FAPESP, São Paulo n. 163, set. 2009. Disponível em: <http:// revistapesquisa.fapesp.br/2009/09/01/as-formas-mesticas-da-midia/>. Acesso em: 12 fev. 2014.

MARTÍN-BARBERO, J. Tecnicidades, identidades, alteridades: desubicacioines y opacidades de la comunicación em el nuevosiglo: mudanças e opacidades da comunicação no novo século. Diálogos de la comunicación, Lima, n. 64, p. 9-24, 2002.

MARTÍN-BARBERO, J. Entrevista ao Roda Viva. Roda Viva. Rio de Janeiro, 2003. Disponível em: <http:/ / www.rodaviva.fapesp.br/ materia/62/entrevistados/jesus_martinbarbero_2003.htm>.Acesso em: 5 fev. 2015.

MCCOMBS, M.E; SHAW, D. L. The Agenda-Setting Function of Mass Media. The Public Opinion Quarterly, Public Opinion Quarterly, v. 36, n. 2, p. 176-187, 1972.

MENEGON, V. S. M. Crise dos serviços de saúde no cotidiano da mídia impressa. Psicologia \& Sociedade, Belo Horizonte, v. 20, p. 32-40, 2008. Edição especial.

MORAIS, I. et al. Jornais Folha de São Paulo e Correio Braziliense: o que dizem sobre o programa mais médicos?, Revista da Escola de Enfermagem da USP. São Paulo, v. 48, n. 2, p. 112-120, 2014. 
OLIVEIRA, V. C. A Comunicação midiática e o Sistema Único de Saúde. Interface. Comunicação, Saúde, Educação. Botucatu, v. 4, n. 7, p. 71-80, 2000 .

PENTEADO, C. C.; FORTUNATO, I. Mídia e políticas públicas: possíveis campos exploratórios. Revista Brasileira de Ciências Sociais, São Paulo, v. 30 n. 87, fev. 2015.

PORTO, M. P. Enquadramentos da mídia e política. In: RUBIM, A.

A. (Org.). Comunicação e política: conceitos e abordagens. Salvador: EDUFBA, 2004. p. 73-104.

RODRIGUES, A. D. Experiência, modernidade e campo dos media. Lisboa, 1999. Disponível em: <http://bocc.ubi.pt/pag/rodrigues-adrianoexpcampmedia.htm>. Acesso em: 3 mar. 2015.

RONDELLI, E; HESCHMANN, M. A mídia e a construção do biográfico. O sensacionalismo da morte em cena. Tempo Social, São Paulo, v. 12, n. 1, p. 201-218, maio 2000.

SODRÉ, M. Comunicação, um novo sistema de pensamento? In: NETO, A. F.; PRADO, J. L.A.; PORTO, S.D. (Org.). Campo da comunicação: caracterização, problematizações e perspectivas. João Pessoa: Ed. Universitária daUFPB, 2001.

SOUZA, C. Políticas públicas: uma revisão da literatura. Sociologias, Porto Alegre, ano 8, n. 16, p. 20-45, jul./dez. 2006.

TABERNER, J. S. et al. A influência da mídia nos atendimentos cardiológicos de urgência: o caso Bussunda. Revista da Associação Médica Brasileira, São Paulo, v. 53, n. 4, p. 335-337, 2007.

TRAQUINA, N. Teorias do jornalismo: a tribo jornalística: uma comunidade interpretativa transnacional. Florianópolis: Insular; 2005. v. 2.

VAN GORP, B. The constructionist approach to framing: bringing culture back. Journal of Communication, New York, v. 57, n. 1, p. 60-78, 2007. 


\section{SOBRE OS AUTORES}

\section{Alyne Alvarez Silva}

Psicóloga e mestre em Psicologia pela Universidade Federal do Pará (UFPA). Doutora em Psicologia Social pela Pontifícia Universidade Católica de São Paulo (PUC-SP).É membro da Secretaria Executiva da Rede Nacional Internúcleos da Luta Antimanicomial (Renila). Pesquisadora do eixo temático "Acompanhamento de iniciativas do Poder Legislativo federal em saúde”.

\section{Ana de Oliveira Barbosa}

Mestre em Saúde Comunitária pelo Instituto de Saúde Coletiva da Universidade Federal da Bahia (ISC/UFBA), nutricionista da Secretaria Municipal de Saúde de Salvador e membro do grupo de pesquisa Comunicação e Educação em Saúde do ISC/UFBA.

\section{Ana Luiza Queiroz Vilasbôas}

Médica, doutora em Saúde Pública pelo Instituto de Saúde Coletiva da Universidade Federal da Bahia (ISC/UFBA). Professora adjunta III do ISC, pesquisadora do Programa Integrado de Pesquisa e Cooperação Técnica em Formação e Avaliação da Atenção Básica (GRAB) do ISC/UFBA, membro do Conselho Gestor do Observatório de Análise Política em Saúde. anav@ufba.br 


\section{Ana Maria Costa}

Medica sanitarista, doutora em Ciências da Saúde pela Universidade de Brasília (UnB), professora da Escola Superior de Ciências da Saúde do Distrito Federal (ESCS).

\section{Ana Maria Freire de Lima Almeida}

Dentista. Mestranda em Saúde Comunitária, pelo Instituto de Saúde Coletiva da Universidade Federal da Bahia (ISC/UFBA). anamariafsl@gmail.com

\section{Andrea Montalvão}

Graduada em Serviço Social pela Universidade Federal de Pernambuco (UFPE) (1998). Mestre em Saúde Coletiva pelo Instituto de Saúde Coletiva da Universidade Federal da Bahia (ISC/UFBA) (2016). Assistente Social do Hospital Geral de Palmas (HGP).

\section{Antonio Marcos Pereira brotas}

Doutor em Cultura e Sociedade e mestre em Comunicação e Cultura Contemporâneas pela Universidade Federal da Bahia (UFBA), professor universitário, jornalista profissional e assessor de comunicação da Fundação Oswaldo Cruz - Bahia (Fiocruz). Atua e pesquisa em divulgação científica, jornalismo científico e comunicação e saúde.

\section{Bethania de Araújo Almeida}

Graduação em Ciências Sociais, mestrado em Sociologia e doutorado em Saúde Pública pela Universidade Federal da Bahia (UFBA). Em 2012, realizou parte do curso de doutorado na Science Policy Research Unit (SPRU), Universidade de Sussex (Inglaterra). Analista de Gestão em Saúde na Fundação Oswaldo Cruz (Fiocruz). Pesquisadora colaboradora no Instituto Nacional de Ciência e Tecnologia de Gestão da Inovação em Doenças Negligenciadas (INCT-IDN) e no Programa de Economia, Tecnologia e Inovação em Saúde do Instituto de Saúde Coletiva (PECS) do ISC/UFBA. 


\section{Carla Silva Soares}

Psicóloga, doutora em Saúde Pública pela Universidade Federal da Bahia (UFBA), mestre em Saúde Comunitária pelo Programa de Pós-Graduação em Saúde Coletiva do Instituto de Saúde Coletiva (PPGSC/ISC/UFBA), pesquisadora do eixo temático "Análise de políticas de saúde voltadas para a infância”.

\section{Carmen Fontes Teixeira}

Médica (1978). Mestre em Saúde Comunitária (1981). Doutora em Saúde Pública pelo Instituto de Saúde Coletiva da Universidade Federal da Bahia (ISC/UFBA) (1996). Professora titular do Instituto de Humanidades, Artes e Ciências Prof. Milton Santos (IHAC/UFBA). Docente do Programa de Pós-Graduação do ISC e do Programa de Pós-Graduação Estudos Interdisciplinares sobre a Universidade (IHAC). Pesquisadora do Observatório de Análise Política em Saúde e coordenadora executiva do Centro de Documentação Virtual (CDV). carment@ufba.br

\section{Carolina Rodrigues Araújo}

Cirurgiã-dentista (UFBA), pesquisadora do Observatório de Análise Política em Saúde - eixo "Infância".

\section{Catharina Leite Matos Soares}

Professora adjunta do Instituto de Saúde Coletiva da Universidade Federal da Bahia (ISC/UFBA). Doutora em Saúde Pública pela mesma instituição, na área de concentração em Planificação e Gestão de Serviços e Sistemas de Saúde. catharinamatos@gmail.com

\section{Cristiane Abdon Nunes}

Assistente social, mestre em Saúde Comunitária e doutora em Saúde Pública. Coordenadora da Residência Multiprofissional em Saúde da Família, professora adjunta do Instituto de Saúde Coletiva da Universidade Federal da Bahia (ISC/UFBA) com atuação na 
área de Políticas, Planejamento e Gestão em Saúde. Pesquisadora do Programa Integrado de Pesquisa e Cooperação Técnica em Formação e Avaliação da Atenção Básica (GRAB) do ISC/UFBA. abdoncris@gmail.com

\section{Daniel Adolpho Daltin Assis}

Graduado em Direito pela Pontifícia Universidade Católica de São Paulo (PUC-SP). Mestrado em Adolescência e Conflitualidade pela Universidade Bandeirante de São Paulo (Uniban). Especialização em Gestão de Redes de Atenção à Saúde pela Fundação Oswaldo Cruz (Fiocruz). Advogado popular em direitos humanos. Servidor público do Ministério da Saúde. Pesquisador do eixo temático "Acompanhamento de iniciativas do poder legislativo federal em saúde”.

\section{Denise Nogueira Cruz}

498 Dentista sanitarista. Doutora em Saúde Pública pelo Instituto de Saúde Coletiva da Universidade Federal da Bahia (ISC/UFBA), professora e pesquisadora do Departamento de Odontologia Social e Pediátrica da Faculdade de Odontologia da UFBA.dncruz@ufba.br

\section{Ediná Alves Costa}

Doutora em Saúde Pública pela Universidade de São Paulo (USP). Mestre em Saúde Comunitária pela Universidade Federal da Bahia (UFBA). Professora associada do Instituto de Saúde Coletiva (ISC/UFBA). Coordenadora do Programa Integrado de Pesquisa e Cooperação Técnica em Vigilância Sanitária e do Centro Colaborador em Vigilância Sanitária no ISC/UFBA. Pesquisadora do eixo temático "Políticas de medicamentos, assistência farmacêutica e vigilância sanitária”. 


\section{EdNir Assis Souza}

Graduação e mestrado em Enfermagem. Doutoranda em Saúde Pública pelo PPGSC - Instituto de Saúde Coletiva da Universidade Federal da Bahia (UFBA). Professora da Escola de Enfermagem da UFBA. Pesquisadora do eixo temático "Trabalho e educação na saúde".

\section{Erik Asley F. Abade}

Mestre em Saúde Comunitária pelo Instituto de Saúde Coletiva da Universidade Federal da Bahia (ISC/UFBA). Doutorando em Saúde Pública pelo PPGSC - Instituto de Saúde Coletiva da Universidade Federal da Bahia (UFBA). Enfermeiro da Estratégia Saúde da Família, em Salvador/BA.

\section{Erick Soares Lisboa}

Farmacêutico pela Universidade Federal da Bahia (UFBA). Mestre em Saúde Comunitária pelo Instituto de Saúde Coletiva (ISC/ UFBA). Doutorando em Saúde Pública pelo PPGSC do ISC 499 UFBA. Membro do Programa Integrado de Economia, Tecnologia e Inovação em Saúde (PECS) do ISC/UFBA. Pesquisador do eixo temático "Acompanhamento das decisões judiciais relativas à saúde".

\section{Erika Aragão}

Graduação e mestrado em Economia pela Faculdade de Economia da Universidade Federal da Bahia (UFBA). Doutorado em Saúde Coletiva pela mesma instituição. Pós-doutorado na Science Policy Research Unit (SPRU), Universidade de Sussex (Inglaterra). Professora adjunta e pesquisadora do Programa de Economia, Tecnologia e Inovação em Saúde do Instituto de Saúde Coletiva da UFBA. Pesquisadora no Instituto Nacional de Ciência e Tecnologia de Gestão da Inovação em Doenças Negligenciadas (INCT-IDN) e colaboradora do Instituto Nacional de Ciência, Inovação e Tecnologias em Saúde (INCT-Citecs). 


\section{Fabiana da Cunha Saddi}

Doutora em Sociologia, mestre em Ciência Política e bacharel em Economia pela Universidade de São Paulo (USP). Pós-doutora em Política e Política de Saúde pela Universidade de Oxford. Pesquisadora de pós-doutorado e professora na Universidade Federal de Goiás (UFG). Pesquisadora do eixo temático "Acompanhamento de iniciativas do Poder Legislativo federal em saúde.

\section{GABriela LAMEgo}

Doutora em Saúde Pública e mestre em Saúde Comunitária pelo Instituto de Saúde Coletiva da Universidade Federal da Bahia (ISC/ UFBA), professora adjunta da Universidade Federal do Sul da Bahia (UFSB) e membro do grupo de pesquisa de Comunicação e Educação em Saúde (ISC/UFBA).

\section{Gisélia Santana Souza}

Doutora em Saúde Pública pelo Instituto de Saúde Coletiva da Universidade Federal da Bahia (ISC/UFBA). Mestre em Saúde Comunitária pela UFBA. Professora adjunta da Faculdade de Farmácia da UFBA. Pesquisadora do eixo temático "Políticas de medicamentos, assistência farmacêutica e vigilância sanitária”.

\section{Iracema Viterbo Silva}

Mestre em Saúde Comunitária pela Universidade Federal da Bahia (UFBA), doutora em Saúde Pública pela mesma instituição, sanitarista da Secretaria de Saúde do Estado da Bahia (Sesab), pesquisadora do eixo temático "Trabalho e educação na Saúde”.

\section{Isabela Cardoso de Matos Pinto}

Mestre em Saúde Comunitária pela Universidade Federal da Bahia (UFBA), doutora em Administração pela mesma instituição, professora adjunta do Instituto de Saúde Coletiva (ISC/UFBA), coor- 
denadora do Grupo de Trabalho "Trabalho e educação na Saúde" da Associação Brasileira de Saúde Coletiva (Abrasco), membro do Conselho Gestor do Observatório de Análise Política em Saúde, coordenadora e pesquisadora dos eixos temáticos "Trabalho e educação na saúde" e "Modelos de gestão hospitalar no SUS".

\section{Izamara Damasceno Cathanheide}

Farmacêutica, especialista em Assistência Farmacêutica, mestre em Saúde Coletiva, MBA em Economia e Avaliação de Tecnologias em Saúde. Consultora técnica do Departamento de Gestão e Incorporação de Tecnologias em Saúde do Ministério da Saúde. izamaradc@gmail.com

\section{Jairnilson Silva Paim}

Médico, mestre em Medicina Interna (1976) e doutor em Saúde Pública (2008), pela Universidade Federal da Bahia (UFBA). Professor titular em Política de Saúde do Instituto de Saúde Coletiva (ISC/UFBA. Pesquisador 1-B do Conselho Nacional de Desenvolvimento Científico e Tecnológico (CNPq). Coordenador geral do Observatório de Análise Política em Saúde. jairnil@ufba.br

\section{Jamacy Costa Souza}

Nutricionista pela Universidade Federal do Rio de Janeiro (UFRJ) (1995). Mestre em Nutrição Humana Aplicada pela Universidade de São Paulo (USP) (1999). Doutor em Saúde Coletiva pela Universidade Federal da Bahia (UFBA) (2013). Fez estágio de doutorado no Centre Européen de Sociologie et Science Politique - Paris. Professor da Escola de Nutrição da UFBA e membro do Grupo de Estudos e Pesquisa em Alimentação para Coletividades (Gepac).jamacy@ufba.br 


\section{Jamilli Silva Santos}

Enfermeira. Mestre em Saúde Coletiva pelo Progama de PósGraduação em Saúde Coletiva do Instituto de Saúde Coletiva (PPGSC/ISC/UFBA). Membro do grupo de pesquisa "Análise do processo de Reforma Sanitária Brasileira 2006-2017”.

\section{Jane Mary Guimarães}

Licenciada em Ciências pela Universidade Federal da Bahia (UFBA), mestre em Ciências da Educação pela Universidade Lusófona de Humanidades e Tecnologias e doutora em Saúde Pública pelo Instituto de Saúde Coletiva (ISC/UFBA). Pesquisadora do Programa Economia, Tecnologia e Inovação em Saúde (PECS) do ISC/UFBA. Pesquisadora do Instituto Nacional de Ciência, Inovação e Tecnologias em Saúde (INCT-Citecs) e do Programa Integrado de Estudos em Saúde Coletiva (Piesc).

Josele de Farias Rodrigues Santa Bárbara

Graduada em Enfermagem pela Universidade Estadual de Feira de Santana (UEFS) (2002). Mestre em Saúde Coletiva também pela UEFS (2006). Doutoranda em Saúde Pública pelo Instituto de Saúde Coletiva da Universidade Federal da Bahia (ISC/UFBA). Professora assistente da Universidade Federal do Recôncavo da Bahia (UFRB).

\section{Kleize Araújo de Oliveira Souza}

Enfermeira. Doutoranda em Saúde Pública pelo Instituto de Saúde Coletiva da Universidade Federal da Bahia (ISC/UFBA). Mestre em Saúde Coletiva pela Universidade Estadual de Feira de Santana (UEFS). Especialista em Neonatologia pela Universidade do Estado da Bahia (UNEB). Professora assistente do curso de Enfermagem da UEFS. 


\section{LAIANA Behy SANTOS}

Psicóloga, mestranda em Saúde Comunitária pela Universidade Federal da Bahia (UFBA), pesquisadora do Observatório de Análise Política em Saúde, eixo "Infância".

\section{LIDIANE F. GoNÇALVES}

Graduada em Ciências Sociais pela Universidade Federal de Goiás (UFG) (2004), especializada em Políticas Públicas também pela UFG. Bacharel em Direito pela Universidade Católica de Goiás (2003). Mestre em Saúde da Mulher e da Criança no Instituto Fernandes Figueira da Fundação Oswaldo Cruz (Fiocruz) (2015). Pesquisadora do eixo temático "Acompanhamento de iniciativas do Poder Legislativo federal em saúde”.

\section{Ligia Maria Vieira da Silva}

Mestre em Saúde Comunitária pelo Instituto de Saúde Coletiva da Universidade Federal da Bahia (ISC/UFBA). Doutora em Saúde 503 Pública pela Universidade de São Paulo (USP). Professora associada do Instituto de Saúde Coletiva. Membro do Conselho Gestor do Observatório de Análise Política em Saúde. Pesquisadora do eixo temático "Análise sócio-histórica de políticas de saúde".

\section{LiLiana SANTOS}

Mestre em Psicologia pela Universidade Federal do Paraná (UFPR), doutora em Saúde Pública pela Universidade Federal da Bahia (UFBA), professora adjunta do Instituto de Saúde Coletiva. Pesquisadora do eixo temático "Trabalho e educação na saúde".

\section{Liz Duque Magno}

Mestre em Saúde Comunitária pelo Programa de Pós-Graduação em Saúde Coletiva do Instituto de Saúde Coletiva (PPGSC/ ISC/UFBA). Pesquisadora do eixo temático "Análise da Reforma Sanitária”. 


\section{Luis Eugênio Portela Fernandes de Souza}

Médico. Mestre em Saúde Comunitária pela Universidade Federal da Bahia (UFBA) (1996) e doutor em Saúde Pública pela Universidade de Montreal (2001). Professor adjunto de Política de Saúde e coordenador do Programa de Economia, Tecnologia e Inovação em Saúde do Instituto de Saúde Coletiva da UFBA. luiseugenio@ufba.br.

\section{Márcia Cristina Rocha Costa}

Doutora em Cultura e Sociedade pela Universidade Federal da Bahia (UFBA) e professora do curso de Comunicação Social - Jornalismo da Universidade Federal do Recôncavo da Bahia (UFRB). marcia -rocha@uol.com.br

\section{Marcos Vinícius Ribeiro de Araújo}

Doutor em Saúde Coletiva (2015) e mestre em Saúde Comunitária (2011) pelo Instituto de Saúde Coletiva da Universidade Federal da Bahia (ISC/UFBA). Docente do Departamento de Fonoaudiologia do Instituto de Ciências da Saúde da UFBA.marvinribeiro@yahoo.com

\section{maria Cristina de Camargo Fonseca}

Enfermeira graduada pela Pontifícia Universidade Católica do Paraná (PUC-PR), licenciada em Enfermagem pela PUC-PR. Especialista em Enfermagem Obstétrica pela Universidade Estadual de Santa Cruz (UESC)/Universidade Federal de São Paulo (Unifesp), mestre em Saúde Comunitária pelo Instituto de Saúde Coletiva da Universidade Federal da Bahia (ISC/UFBA), professora assistente da Universidade Estadual de Feira de Santana (UEFS), enfermeira da Secretaria de Saúde do Estado da Bahia (SESAB). Doutoranda em Saúde Pública pelo ISC/UFBA e pesquisadora do Programa de Economia, Tecnologia e Inovação em Saúde (PECS) do ISC/UFBA. 


\section{Maria Guadalupe Medina}

Médica, mestre em Saúde Comunitária e doutora em Saúde Pública, docente do Programa de Pós-Graduação em Saúde Coletiva e da Residência Multiprofissional em Saúde da Família do Instituto de Saúde Coletiva da Universidade Federal da Bahia (ISC/UFBA). Membro da Rede de Pesquisa em Atenção Primária e do Grupo de Trabalho de Avaliação da Associação Brasileira de Saúde Coletiva (Abrasco).medina@ufba.br

\section{Maria Ligia Rangel-S}

Médica, sanitarista, especialista em Tisiopneumologia Sanitária pela Universidade de São Paulo (USP) e Escola Nacional de Saúde Pública Sérgio Arouca (ENSP-Fiocruz), Mestre em Saúde Comunitária pela Universidade Federal da Bahia (UFBA) e doutora em Saúde Pública pela UFBA. Professora associada do Instituo de Saúde Coletiva (ISC) da UFBA. Coordenadora do grupo de pesquisa Comunicação e Educação em Saúde do ISC/UFBA. lirangel@ufba.br

\section{Mariluce Karla Bonfim De Souza}

Doutora em Saúde Pública pelo Instituto de Saúde Coletiva da Universidade Federal da Bahia (ISC/UFBA). Professora adjunta do ISC. Pesquisadora do eixo temático "Políticas de medicamentos, assistência farmacêutica e vigilância sanitária”.

\section{Marta Caires de Sousa}

Odontóloga, mestre em Saúde Comunitária pela Universidade Federal da Bahia (UFBA), pesquisadora do Observatório de Análise Política em Saúde. 


\section{Monique Azevedo Esperidião}

Psicóloga, doutora em Saúde Pública pela Universidade Federal da Bahia (UFBA), professora adjunta do Instituto de Saúde Coletiva (ISC/UFBA).moniqueesper@yahoo.com.br.

\section{Nília Maria de Brito lima Prado}

Professora da Universidade Federal da Bahia (UFBA), Instituto Multidisciplinar em Saúde/Campus Anísio Teixeira (IMS/UFBA). Farmacêutica graduada pela UFBA, especialista em Gestão em Saúde pela Fundação Oswaldo Cruz (Fiocruz), doutoranda em Saúde Pública pelo Instituto de Saúde Coletiva (ISC/UFBA), pesquisadora do Programa Integrado de Pesquisa e Cooperação Técnica em Formação e Avaliação da Atenção Básica (GRAB) do ISC/UFBA.

\section{Patrícia Sodré Araújo}

Mestre em Saúde Comunitária e doutoranda em Saúde Pública pelo Instituto de Saúde Coletiva da Universidade Federal da Bahia (ISC/ UFBA). Professora assistente da Universidade do Estado da Bahia (UNEB).

\section{Paulo frazão}

Doutor em Saúde Pública pela Universidade de São Paulo (USP). Livre docente pela USP. Professor titular da Faculdade de Saúde Pública (FSP/USP). Pesquisador 2 do Conselho Nacional de Desenvolvimento Científico e Tecnológico (CNPq) e consultor do Ministério da Saúde. Coordenador de projetos do Centro Colaborador do Ministério da Saúde em Vigilância em Saúde Bucal da FSP-USP.pafrazao@usp.br 


\section{Rafael Damasceno de BARros}

Enfermeiro. Especialista em Gestão de Serviços de Saúde pela Escola Nacional de Saúde Pública Sérgio Arouca (ENSP-Fiocruz). Mestrando em Saúde Comunitária pelo Instituto de Saúde Coletiva da Universidade Federal da Bahia (UFBA). Professor substituto da Escola de Enfermagem da UFBA.

\section{Raquel Abrantes Pêgo}

Socióloga, doutora em Ciências Sociais pelo El Colegio de Michoacán, México. Professora visitante no Departamento de Saúde Coletiva da Universidade de Brasília (UNB). Pesquisadora do eixo temático "Acompanhamento de iniciativas do Poder Legislativo federal em saúde”.

\section{Raquel Malheiros Teixeira M. da Paz}

Psicóloga, mestre em Saúde Comunitária pela Universidade Federal da Bahia (UFBA), pesquisadora do Observatório de Análise Política em Saúde, eixo "Infância”.

\section{Rosana Aquino}

Médica epidemiologista, mestre em Saúde Comunitária e doutora em Saúde Pública, docente do Programa de Pós-Graduação em Saúde Coletiva e da Residência Multiprofissional em Saúde da Família do Instituto de Saúde Coletiva da Universidade Federal da Bahia (ISC/UFBA) e pesquisadora do Programa Integrado de Pesquisa e Cooperação Técnica em Formação e Avaliação da Atenção Básica (GRAB) do ISC/UFBA. Bolsista de Produtividade em Pesquisa do Conselho Nacional de Desenvolvimento Científico e Tecnológico CNPq - Nível 2. Membro da Rede de Pesquisa em Atenção Primária à Saúde e da Comissão de Epidemiologia da Associação Brasileira de Saúde Coletiva (Abrasco). aquino@ufba.br. 


\section{SANDRA Garrido De Barros}

Doutora em Saúde Pública pelo Instituto de Saúde Coletiva da Universidade Federal da Bahia (ISC/UFBA). Professora adjunta da Faculdade de Odontologia da UFBA.

\section{Sebastião Loureiro}

Professor emérito da Universidade Federal da Bahia (UFBA). Graduação em Medicina pela UFBA, mestrado em Tropical Public Health pela University of London e doutorado em Epidemiologia pela University of Texas System. Atualmente é vice-coordenador do Instituto Nacional de Ciência, Inovação e Tecnologias em Saúde (INCT-Citecs) e vice-coordenador do Programa de Economia, Tecnologia e Inovação em Saúde (PECS) da UFBA. Ao longo de sua carreira, presidiu várias organizações da área e saúde pública no Brasil, como a Associação Brasileira de Saúde Coletiva (Abrasco) (1985-1987). Também atuou na Organização Mundial de Saúde (OMS), entre os anos de 2007 e 2008, como coordenador do projeto "Institutional arrangements and efficiency of the Tuberculosis control program in the decentralization context in Brazil”.

\section{Silvânia Sales de Oliveira}

Mestre em Saúde Coletiva pela Universidade Estadual de Feira de Santana (UEFS) e doutoranda em Saúde Pública pelo Instituto de Saúde Coletiva da Universidade Federal da Bahia (ISC/UFBA). Graduada em Enfermagem pela UEFS. Professora auxiliar da UEFS. Pesquisadora do eixo temático "Modelos de gestão hospitalar no SUS".

\section{Silvana Lima Vieira}

Enfermeira (2004), especialista em Administração Hospitalar em Serviços de Saúde pela Escola de Administração da Universidade Federal da Bahia (UFBA) (2007), mestre em Enfermagem (2011) e doutoranda da Escola de Enfermagem da UFBA. Pesquisadora do eixo temático "Modelos de gestão hospitalar no SUS". 


\section{Sônia Cristina Lima Chaves}

Professora associada da Faculdade de Odontologia da Universidade Federal da Bahia (UFBA), professora do quadro permanente da pós-graduação e pesquisadora em Política, Planejamento, Gestão e Avaliação de Saúde do Instituto de Saúde Coletiva (ISC/UFBA). Graduada em Odontologia pela UFBA (1993), mestre em Saúde Comunitária (2000) e doutora em Saúde Pública (2005) pelo ISC/UFBA. Atuou na Secretaria Municipal de Saúde da Prefeitura Municipal de Salvador. Principais linhas de pesquisa: análise sociológica de políticas, avaliação de serviços e saúde bucal coletiva. Coordenadora do eixo temático "Análise de políticas de saúde bucal no Brasil”.schaves@ufba.br

\section{Soraya Almeida Belisário}

Médica, mestre em Saúde Pública pela Escola Nacional de Saúde Pública (ENSP) (1993) e doutorado em Saúde Coletiva pela Universidade Estadual de Campinas (Unicamo) (2002). Professora associada da Universidade Federal de Minas Gerais (UFG). Pesquisadora do eixo temático "Trabalho e educação na saúde”.

\section{Tania Cristina França da Silva}

Estatística. Doutora em Saúde Coletiva pela Universidade Estadual do Rio de Janeiro (UERJ) (2007) e mestre em Saúde Pública pela Escola Nacional de Saúde Pública Sergio Arouca (ESNP-Fiocruz) (2001). Professora adjunta do Instituto de Medicina Social da UERJ. Docente do programa de pós-graduação da instituição. Coordenadora de Pesquisa da Estação de Trabalho IMS/UERJ da Rede Observatório de Recursos Humanos em Saúde. Pesquisadora do eixo temático "Trabalho e educação na Saúde”. 


\section{Tatiane de Oliveira Silva Alencar}

Farmacêutica. Mestre em Saúde Coletiva pela Universidade Estadual de Feira de Santana (UEFS). Doutora em Saúde Pública pelo Instituto de Saúde Coletiva da Universidade Federal da Bahia (ISC/ UFBA). Professora assistente do curso de Farmácia da UEFS.

\section{Thadeu Borges Souza Santos}

Enfermeiro pela Universidade Estadual do Sudoeste da Bahia (UESB), mestre em Enfermagem pela Universidade Federal da Bahia (UFBA). Doutorando em Saúde Coletiva pela Instituto de Saúde Coletiva (ISC/UFBA). Professor assistente da Universidade do Estado da Bahia (UNEB). Pesquisador do eixo temático "Modelos de gestão hospitalar no SUS”.

\section{Thais Regis Aranha Rossi}

Professora da Universidade do Estado da Bahia (UNEB). Mestre em Saúde Comunitária e doutora em Saúde Pública pelo Instituto de Saúde Coletiva da Universidade Federal da Bahia (ISC/UFBA). thais.aranha@gmail.com

\section{Vinício Oliveira da Silva}

Enfermeiro, graduado em Saúde Coletiva pelo Instituto de Saúde Coletiva da Universidade Federal da Bahia (ISC/UFBA), mestre em Saúde Coletiva pelo ISC, doutorando em Saúde Coletiva pelo ISC. Pesquisador do eixo temático “Trabalho e educação na saúde”.

\section{YARA OYRam Ramos Lima}

Doutora em Saúde Pública pelo Instituto de Saúde Coletiva da Universidade Federal da Bahia (ISC-UFBA). Mestre em Saúde Comunitária pelo ISC-UFBA. Pesquisadora do eixo temático "Políticas de medicamentos, assistência farmacêutica e vigilância sanitária”. 


\begin{tabular}{|c|c|}
\hline & COLOFÃO \\
\hline Formato & $16 \times 23 \mathrm{~cm}$ \\
\hline Tipologia & $\begin{array}{l}\text { Arno Pro } \\
\text { Aller }\end{array}$ \\
\hline Papel & $\begin{array}{l}\text { Alcalino } 75 \mathrm{~g} / \mathrm{m}^{2} \text { (miolo) } \\
\text { Cartão Supremo } 300 \mathrm{~g} / \mathrm{m}^{2} \text { (capa) }\end{array}$ \\
\hline Impressão & EDUFBA \\
\hline Capa e Acabamento & Cian \\
\hline Tiragem & 500 \\
\hline
\end{tabular}

